University of San Diego

Digital USD

1999-05-01

\title{
Towards a New Theory of Personal Teaching Efficacy: The Development and Testing of a New Model and Scale Using Teachers and Student Teachers Participating in a Reflective Practitioner Model Practicum
}

Jan Shields EdD

University of San Diego

Follow this and additional works at: https://digital.sandiego.edu/dissertations

Part of the Leadership Studies Commons

\section{Digital USD Citation}

Shields, Jan EdD, "Towards a New Theory of Personal Teaching Efficacy: The Development and Testing of a New Model and Scale Using Teachers and Student Teachers Participating in a Reflective Practitioner Model Practicum" (1999). Dissertations. 659.

https://digital.sandiego.edu/dissertations/659

This Dissertation: Open Access is brought to you for free and open access by the Theses and Dissertations at Digital USD. It has been accepted for inclusion in Dissertations by an authorized administrator of Digital USD. For more information, please contact digital@sandiego.edu. 
TOWARDS A NEW THEORY OF PERSONAL TEACHING EFFICACY: THE DEVELOPMENT AND TESTING OF A NEW MODEL AND SCALE USING TEACHERS AND STUDENT TEACHERS PARTICIPATING IN A REFLECTIVE PRACTITIONER MODEL PRACTICUM

\author{
A Dissertation \\ Presented to the \\ Faculty of \\ University of San Diego
}

In Partial Fulfillment

of the requirements for the Degree

Doctorate of

Education

by

Jan Shields

May, 1999 


\section{ACKNOWLEDGEMENTS}

I would like to gratefully thank the members of my committee: Dr. Ed Kujawa from University of San Diego for his forthright direction, Dr. John Chamley from San Diego State University for his careful reading of the early drafts of the dissertation proposal and for his caring support, and Bobbi Hansen for her last-hour help in the final structuring of the dissertation.

Kind thoughts go to Dr. Gordon McIntosh from the University of Alberta who expedited the gathering of data for this research. I value our professional friendship. I am sorry his other academic pursuits did not allow him to sit as an external advisor. Many thanks to Warren Wilde, Randy Wimmer, Betty Skogen, and all the university facilitators and seminar leaders at the University of Alberta for making the gathering of data such as smooth process. Their help and patience is much appreciated.

Special thanks go to my "study group," Roger Mestinsek and Debbie Wright, for becoming my family through the eight month residency and for making statistics fun. To Scott McAlpine go unfathomable appreciation for the many hours he dedicated to helping me with the statistical analyses and in discussing the findings and implications.

And finally, as always, thanks to my husband Tom, who made it possible for me to embark on this endeavor, and whose gentle urging over the past four years assured that I would finish. Your faith in me was my support and my motivation. 


\section{ABSTRACT \\ Towards a New Theory of Personal Teaching Efficacy: \\ The Develooment and Testing of a New Model and Scale}

Research shows that teachers' sense of efficacy is a central mediator of teacher effectiveness and is related to student achievement. Generally, the results have been interpreted using a two-factor model of teacher efficacy. However, most researchers consider teachers' sense of efficacy to be a multidimensional construct with many underlying factors. This study introduces a new theory of personal teaching efficacy which proposes that personal teaching efficacy is best explained from a volitional perspective.

The first purpose of the study was to reconceptualize the personal teaching efficacy construct and develop a model and scale. As a result of factor analysis techniques, a seven-factor model of personal teaching efficacy and a 31-item personal teaching efficacy scale with high reliability were developed.

The second purpose was to test the personal teaching efficacy model and scale for their utility in measuring and explaining changes in the personal teaching efficacy of teachers and student teachers participating in the final elementary student teaching experience offered through the University of Alberta. Using t-tests, the study found that both teachers and student teachers showed gains in overall personal teaching efficacy and on most of the seven factors. Further testing of the data using the ANOVA technique found some differences among teacher groups and student teacher groups. 
TABLE OF CONTENTS

PAGE

ACKNOWLEDGMENTS $\quad$ iii

ABSTRACT iv

CHAPTER

I INTRODUCTION 1

$\begin{array}{ll}\text { Overview } & 1\end{array}$

Background of the Problem 2

Teaching in the 1990s 2

Problems with the Current Conceptualization 11 and Measurement of Teachers' Sense of Efficacy

$\begin{array}{ll}\text { Statement of the Problem } & 16\end{array}$

$\begin{array}{ll}\text { Purposes of the Study } & 17\end{array}$

$\begin{array}{ll}\text { Delineation of the Theoretical Problem } & 17\end{array}$

Delineation of the Research Problem 18

Importance of the Study 20

Scope and Delimitations of the Study 21

Limitations of the Study $\quad 22$

$\begin{array}{ll}\text { Dissertation Outline } & 23\end{array}$

II. REVIEW OF THE LITERATURE I 26

Overview 26

Theory and Research Underlying $\quad 27$

Personal Teaching Efficacy

Introduction: Teachers' Belief Systems $\quad 27$ 
CHAPTER

II. REVIEW OF THE LITERATURE I (continued)

Definitions of Teacher Efficacy 29

Three Models of Teacher Efficacy 32

$\begin{array}{ll}\text { Measuring Teacher Efficacy } & 37\end{array}$

Teacher Efficacy Research and Findings $\quad 40$

Concerns with Current Conceptualizations and Measurements of Teacher Efficacy

Reconceptualizations of the Underlying Factors 61

$\begin{array}{ll}\text { Conclusion } & 67\end{array}$

Theory and Research Underlying Self-Efficacy 68

$\begin{array}{ll}\text { Introduction } & 68\end{array}$

$\begin{array}{ll}\text { Social Cognitive Theory } & 68\end{array}$

$\begin{array}{ll}\text { Self-Efficacy Defined } & 71\end{array}$

$\begin{array}{ll}\text { Measurements of Self-Efficacy } & 81\end{array}$

Effects of Self-Efficacy on Behavior $\quad 84$

Types of Efficacy Judgments $\quad 85$

$\begin{array}{ll}\text { Conclusion } & 100\end{array}$

Constructs and Theories Related to Self-Efficacy 100

$\begin{array}{ll}\text { Introduction } & 100\end{array}$

Causal Attributions of the Contingencies 101

Between Actions and Outcomes

$\begin{array}{ll}\text { Motivational Perspectives } & 107\end{array}$

$\begin{array}{ll}\text { Comparing Bandura's Self-Efficacy } & 115\end{array}$

Construct and the Related Constructs

Conceptions of Ability 
II. REVIEW OF THE LITERATURE I (continued)

Conceptions of the Environment 126

$\begin{array}{ll}\text { Conclusion } & 134\end{array}$

III. REVIEW OF THE LITERATURE II

$\begin{array}{ll}\text { Overview } & 135\end{array}$

Theory and Research Underlying Volition 136

Introduction $\quad 136$

An Overview of the Theory of Volition 136

Volitional Control Capabilities 141

Implications of a Volitional Psychology 145

Perspective for Self-Efficacy Theory

$\begin{array}{ll}\text { Conclusion } & 164\end{array}$

Constructs and Theories Related to Volition 165

$\begin{array}{ll}\text { Resiliency } & 165\end{array}$

Emotional Intelligence $\quad 166$

Other Theories Related to Volition, Resilience 169 and Emotional Intelligence

$\begin{array}{ll}\text { Conclusion } & 173\end{array}$

The Context of Teaching and Learning to Teach 173

$\begin{array}{ll}\text { Introduction } & 173\end{array}$

Contextual Conditions of Schools $\quad 174$

The Contexts of Teacher Education 194

$\begin{array}{ll}\text { Conclusion } & 213\end{array}$ 
CHAPTER

III REVIEW OF THE LITERATURE II (continued)

Teacher as a Reflective Practitioner $\quad 215$

$\begin{array}{ll}\text { Introduction } & 215\end{array}$

An Historical Overview 216

Theoretical Foundations For Reflective Practice 217

The Teacher as Reflective Practitioner 223

Types of Teacher Reflection $\quad 231$

The Role of Reflection in Teacher Thinking 233

Reflective Practice in Teacher Education 236

$\begin{array}{ll}\text { Conclusion } & 244\end{array}$

Conclusion to the Review of the Literature 245

IV TOWARDS A NEW CONCEPTUALIZATION OF TEACHERS' SENSE OF EFFICACY

$\begin{array}{ll}\text { Rationale } & 246\end{array}$

The Contribution fo Social Cognitive Theory to a 247

New Conceptual Analysis of Teachers'

Sense of Efficacy

The Development of a New Model and Scale of 256

Personal Teaching Efficacy

A Tentative Model of Personal Teaching Efficacy 256

Developing a New Personal Teaching 260 Efficacy Scale

Part 1 of the Personal Teaching Efficacy 262

Scale: Teacher Performance Efficacy

Part 2 of the Personal Teaching Efficacy 265

Scale: Teacher Control Efficacy

$\begin{array}{ll}\text { The Pilot Study } & 267\end{array}$ 
Preliminary Results from the Factor Analyses of

Teacher and Student Teacher Data Using the

Personal Teaching Efficacy Scale

Preliminary Factor Analyses

272

The Contribution of Volitional Theory and Other

Related Constructs to the Conceptual Analysis

of Personal Teaching Efficacy

Personal Teaching Efficacy from a

Volitional Perspective

291

Definitions of Proposed Factors Underlying

The Teaching Performance Aspect of

Personal Teaching Efficacy

Definitions of Proposed Factors Underlying

299

The Teacher Volitional Aspect of

Personal Teaching Efficacy

A Reexamination of the FactorAnalyses Results

Using the New Model of Personal Teaching Efficacy

300

Factor Analyses Using Matched-Cases Data 302

Modifications to the Personal Teaching 308

Efficacy Scale

Results of Factor Analyses of the Modified 31-Item

Scale Using Matched Cases

General Overview

The Factor Solution of the Teacher Pretest

The Factor Solution of the Teacher Posttest

Factor Stability from Teacher Pretest to

Teacher Posttest Factor Analyses 
IV TOWARDS A NEW CONCEPTUALIZATION OF TEACHERS'

SENSE OF EFFICACY (continued)

The Factor Solution of the Student Teacher Pretest

The Factor Solution of the Student. Teacher Posttest

Factor Stability from Student Teacher Pretest to Student Teacher Posttest Factor Analyses

Stability of the Student Teacher Posttest Factor Solution Compared to the Teacher Pretest and Posttest Factor Solutions

Conclusion

V METHODS

Overview

The Study Population

Study Sample of Each Group: Teachers

The Setting

The Geographical Area

The Structure and Organization of the Practicum

Research Methodology

Research Design 356

The Instrument: The Personal Teaching 357 Efficacy Scale

Data Collection

Independent and Dependent Variables 
V METHODS (continued)

Definitions of the Terms Used in the Practicum 364

Operational Definitions: Dependent Variables 366

Operational Definitions: Independent Variables $\quad 370$

Study Questions, Hypotheses, and Methods 371

of Interpreting Data

Questions and Hypotheses Related to Specific

Limitations of the Study Design

Threats to Internal Validity

Threats to External Validity

The School-Practicum Context

Demographic Data

The Teacher Sample

The Student Teacher Sample

Research Question 1: Changes in Personal

Changes in the Personal Teaching Efficacy of the Teacher Sample

Changes in the Personal Teaching Efficacy of the Student Teacher Sample

Research Question Two: The Effect of Personal

Characteristics on Changes in Personal

Teaching Efficacy 
The Effect of Personal Characteristics on Changes in Personal Teaching Efficacy of the Teacher Sample

The Effect of Personal Characteristics on Changes in Personal Teaching Efficacy of the Student Teacher Sample

Conclusion

Overview of the Study 466

Review of the Theory and Research Underlying 467 the Study

Discussions Related to the Reconceptualization of Personal Teaching Efficacy

474

Review of the Theoretical Aspect of the Study 475

The Importance of the Theoretical Study 478

The Effectiveness of the Scale in Delineating the Hypothesized Factors Underlying Personal Teaching Efficacy

Discussion Related to the Empirical Study

Using the New Personal Teaching Efficacy

Model and Scale

Summary of Findings

Conclusions Related to the Empirical Study

Overview of the Study's Main Conclusions

Recommendations for Further Study and Research

Recommendations Related to the Revision of 

(continued)

Recommendations Related to the Contexts of

\section{LIST OF TABLES}

1 Summary of Self-Regulatory Processes Identified by

2 Quality Teaching Competencies And Related Knowledge, Skills, and Attributes

3 Six Elements of Effective Teaching

4 Comparative Rankings of Teaching Problem Seriousness By Preservice and Beginning Teachers

5 Descriptive Statistics for the Teacher Sample of the Pilot Study: Demographic Variables of Age and Teaching Experience

6 Descriptive Statistics for the Teacher Sample of the Pilot Study: Demographic Variables of Gender and Past Practicum Experience

$7 \quad$ Number of Teachers and Student Teachers Completing The Pretest and Posttest Administrations of the Personal Teaching Efficacy Scale for the Appropriateness of Factor Analysis of Personal Teaching Efficacy Variables Using Teacher Pretest Data 
9 Number of Factors Extracted from Teacher and Student Teacher Pretest and Posttest Data from Various Forms of the Personal Teaching Efficacy Scale

All Cases Data: Eigenvalues and Percentages of Variance Across Four Administrations of the 46-Item Personal Teaching Efficacy Scale

11 Statistical Tests for the Appropriateness of Factor Analysis of Personal Teaching Variables Using Matched Cases and the 46-Item Personal Teaching Efficacy Scale

12 Factor Eigenvalues and Percentages of Variance Across Four Administrations of the 46-Item Personal Teaching Efficacy Scale Using Matched Cases

13 Hypothesized Factors and Factor Loadings on the 31-Item Personal Teaching Efficacy Scale

14 Statistical Tests for the Appropriateness of Factor Analysis of Personal Teaching Variables using Matched Cases and the Modified 31-Item Personal Teaching Efficacy Scale

15 Range of Communalities of the Variables from Factor Analyses of Teacher and Student Teacher Pretest and Posttest Data Using the Modified 31-Item Scale

16 Factor Eigenvalues and Percentages of Variance Across Four Administrations of the 31-Item Personal Teaching Efficacy Scale Using Matched Cases

17 Teacher Pretest Factors and Factor Loadings for the 31-Item Personal Teaching Efficacy Scale Using Oblimin Rotation

18 Factor Correlation Matrix for a Ten-Factor Solution of the Teacher Pretest Using the 31-Item Scale and an Oblimin Rotation

19 Teacher Posttest Factors and Factor Loadings for the 31-Item Personal Teaching Efficacy Scale Using Oblimin Rotation

20 Factor Correlation Matrix for an Eight-Factor Solution of the Teacher Posttest Using the 31-Item Scale and an Oblimin Rotation 
21 Student Teacher Pretest Factors and Factor Loadings for the 31-Item Personal Traching Efficacy Scale Using Oblimin Rotation

22 Factor Correlation Matrix for a Nine-Factor Solution of the Student Teacher Pretest Using the 31-Item Scale and an Oblimin Rotation

23 Student Teacher Posttest Factors and Factor Loadings for the 31-Item Scale Using Oblimin Rotation

Factor Correlation Matrix for a Nine-Factor Solution of the Student Teacher Posttest Using the 31-Item Scale and an Oblimin Rotation

26 Independent and Dependent Variables Used in Statistical Analyses of the Teacher Sample

27 Independent and Dependent Variables Used in Statistical Analyses of the Student Teacher Sample

Descriptive Statistics for the Teacher Sample: Demographic Variables of Age and Teaching Experience

29 Descriptive Statistics for the Teacher Sample: Gender

30 Descriptive Statistics for the Teacher Sample: Past Practicum Experience

31 Teachers' Perceptions of Their Practicum Experience and Its Value

32 Results from t-tests: Change in Mean Teacher Responses From Pretest to Posttest By Context Variables

33 Descriptive Statistics for the Student Teacher Sample: Demographic Variables of Gender

34 Descriptive Statistics for the Student Teacher Sample: Demographic Variables of Age and Teaching Experience Experience and Its Value 
36 Descriptive Statistics for the Composite Scores of the Teaching Sample on the Pretest and Posttest 31-Item Personal Teaching Efficacy Scale

37 Results of t-tests for Grouped Variables Using Data from the Teacher Sample

38 Item Statements Representing Indices for Five Underlying Factors of Personal Teaching Efficacy in the Teacher Sample Posttest Factor Indices Used in the Analysis of the Teacher Sample

Results from t-tests: Change in the Mean Teacher Responses from Pretest to Posttest By Variable

404

Descriptive Statistics for the Composite Scores of the Student Teaching Sample on the Pretest and Posttest 31-Item Personal Teaching Efficacy Scale

Results of t-tests for Grouped Variables Using Data from the Student Teacher Sample

Item Statements of Indices Represnting Five Underlying Factors of Personal Teaching Efficacy in the Student Teacher Sample

44 Descriptive Statistics for Each of the Pretest and Posttest Factor-Indices Used in the Analysis of the Student Teacher Sample

45 Results from t-tests: Change in Mean Student Teacher Responses from Pretest to Posttest By Variable

46 Analysis of Variance Table: The Main effects of Four Independent Variables on Teacher Gain Scores for the 31-Item Personal Teaching Efficacy Scale

47 Analysis of Variance Table: The Main Effects of Four Independent Variables on Teacher Gain Scores for Group Relations Efficacy Index of Age Group and Previous Practicum Participation on Teacher Gain Scores for the Instruction Efficacy Index 
49 Two-way ANOVA Table: The Main and Interaction Effects of Teaching Experience and Previous Practicum Participation on Teacher Gain Scores for the Instruction Efficacy Index

Two-way ANOVA Table: The Main and Interaction Effects of Teaching Experience and Previous Practicum Participation on Teacher Gain Scores for the Action Efficacy Index

51 Two-way ANOVA Table: The Main and Interaction Effects of Age Group and Previous Practicum Participation on Teacher Gain Scores for the Action Efficacy Index

52 Analysis of Variance Table: The Main Effects of Three Independent Variables on Student Teacher Gain Scores for the 31-Item Personal Teaching Efficacy Scale

53 Two-Way Analysis of Variance: The Main and Interaction Effects for Gender and Previous Work with Children on Student Teacher Personal Teaching Efficacy Gain Scores

54 Two-Way Analysis of Variance: The Main and Interaction Effects for Age Group and Previous Work with Children on Student Teacher Personal Teaching Efficacy Gain Scores

55 Analysis of Variance Table: The Main Effects of Three Independent Variables on Student Teacher Gains Scores for the Teaching Operations Efficacy Index

Two-Way Analysis of Variance: The Main and Interaction Effects for Gender and Previous Work with Children on Student Teacher Teaching Operations Efficacy Gain Scores 
LIST OF FIGURES

$\begin{array}{lll}\text { FIGURE PAGE } & \text { PAT }\end{array}$

1 Denham-Michael Model of Teacher Efficacy 34

$2 \quad$ Ashton and Webb's Model of Teachers' Sense of Efficacy 36

3 Tri-Reciprocal Causation 70

$4 \quad$ The Practicum Environment 175

5 The Practicum Surround: A Mesosystem of Microsystems 175

6 The Proposed Model of Personal Teaching Efficacy 258

$7 \quad$ New Model of Personal Teaching Efficacy 292

$8 \quad$ Interaction Effects of Age Group and Previous 437

9 Interaction Effects of Teaching Experience and Previous Practicum Experience on Teachers' Change in Instruction Efficacy

10 Interaction Effects of Teaching Experience and Previous Practicum Experience on Teachers' Change in Action Efficacy

11 Interaction Effects of Age Group and Previous Practicum Experience on Teachers' Change in Action Efficacy

12 Interaction Effects of Age Group and Previous Work with Children on Student Teachers' Change in Action Efficacy 


\section{APPENDICES}

\section{APPENDIX}
A Personal Teaching Efficacy Scale: Teacher Pretest
B Personal Teaching Efficacy Scale: Student Teacher Pretest
C Teacher Pretest Factors Using 46-Item Scale and A Varimax Rotation
D Teacher Posttest Factors Using 46-Item Scale and A Varimax Rotation
E Student Teacher Pretest Factors Using 46-Item Scale and A Varimax Rotation
F Student Teacher Posttest Factors Using 46-Item Scale and A Varimax Rotation 


\section{CHAPTER 1}

\section{INTRODUCTION}

\section{Overview}

Research shows that teachers' sense of efficacy is a central mediator of teacher effectiveness. It has been found to positively correlate with student achievement (Ashton \& Webb, 1986) and to contribute to high student selfesteem (Borton, 1991) and more positive student attitudes towards school (Miskel et al., 1983, cited in Ross, 1994a).

Teachers' sense of efficacy is also correlated with aspects of teacher behavior considered important for student learning. For example, teachers' sense of efficacy positively correlates with teachers' feelings of organizational commitment (Kushman, 1992), with their ability to keep students on task and motivated (Ashton \& Webb, 1986), and with their willingness to try harder when faced with obstacles (Ashton \& Webb, 1986). Ashton and Webb (1986) found that high-efficacy teachers are more likely to maintain a focus on academics, choose more challenging learning activities, and set warm and secure classroom climates. In addition, high-efficacy teachers are also less likely than low-efficacy teachers to display anger or feel threatened when students misbehave (Barfield \& Burlingame, 1974) and more likely to praise low-ability students, criticize them less, and persist with them longer in failure situations (Gibson \& Dembo, 1984). 
Given the wide-ranging effects of teachers' sense of efficacy, it is important that the educational environment support the development and maintenance of teachers' sense of efficacy. Further, educational researchers and theorists need to continue to expand their understanding of how and under what conditions a teacher's sense of efficacy is developed and sustained and to develop more effective ways to measure teachers' sense of efficacy.

\section{Background of the Problem}

The present educational milieu is fraught with conditions that make it increasingly difficult for teachers to develop and sustain strong, resilient selfpercepts of efficacy. In addition, the important work of finding how, and under what conditions, teachers' sense of efficacy is influenced is confounded by a number of theoretical and research problems.

\section{Teaching in the 1990s}

Research shows that teachers' sense of efficacy can be both positively and negatively influenced by the contexts in which teachers teach. Following Bronfenbrenner's (1977) model of ecological human development, Ashton and Webb (1986) posited that teachers' actions and their sense of efficacy are affected not only by classroom and school contexts, but also by public opinion, societal conditions, and legislative and school board decisions.

\section{Public Opinion}

In a controversial book about the state of education in Canada, Lewington and Orpwood (1993) suggested that the "dissonant voices in education-some raising the alarm, others growing cynical-signal an erosion of public trust and respect for those traditionally responsible for schools: the politicians, the policy makers and the teachers" (p. 1). This claim is supported 
by a survey done by Gallup Canada in 1992 which indicated that $56 \%$ of Canadians surveyed were dissatisfied with the education system (Lewington \& Orpwood, 1993). Similarly, the Annual Phi Delta Kappa/Gallup Poll of 1992 showed only $18 \%$ of taxpayers in the United States gave public schools in the nation a rating of A or B, a decline of $10 \%$ from the ratings of 1986 (Elam, Rose, \& Gallup, 1994).

This decline in positive regard for teachers is part of a continuing trend of negative perceptions of schools which perhaps began with the Equality of Educational Opportunity study conducted by Coleman and his colleagues (1966, cited in Mackenzie, 1983). The Coleman study concluded that schools had little impact on student achievement in comparison to the influence of family background. Unfortunately, the paucity of positive recognition of teachers' efforts from the public, and more specifically from parents, not only negatively affects teachers' feelings of satisfaction (Rosenholtz, 1989), but also results in what Ashton and Webb (1986) refer to as status panic, or perceived low status in the community, which acts to further undermine teachers' sense of efficacy (Ashton \& Webb, 1986). This is confirmed by the 1984 and 1989 Gallup Polls, which revealed that many teachers leaving the profession cite low professional standing and related low salaries as reasons for doing so (cited in Kottkamp, 1990).

Those teachers who remain in the profession are left to grapple not only with public dissatisfaction, but also with changing conditions within schools. Many of these changes have resulted, directly or indirectly, from economic, social, and cultural changes in American and Canadian societies as they, in turn, struggle for a place within the global community of the 1990 s. 


\section{Changing Conditions in Schools and}

\section{School Communities}

Increased immigration of non-English-speaking families, disruptions in the stability of family life as a result of both parents needing to work or as a side effect of single-parent or blended family arrangements, and the increasing numbers of children with special needs, many of them completing the bulk of their education in regular classrooms, not only reflect changes in societal conditions and values, but also represent underlying reasons for the increased economic, social, educational, and psychological diversity of students in schools and classrooms. Not only does such diversity make teachers' work more unpredictable and uncertain, but the wide variance in student ability, described as "the most significant characteristic affecting a teacher's sense of efficacy" (Moore \& Esselman, 1994, p. 3), also ensures that teachers will have difficulty meeting the needs of all their students and will feel less efficacious and more dissatisfied as a result.

Ashton and Webb's (1986) study of teachers in two middle schools also found an interrelationship between teachers' sense of efficacy and the feeling of efficacy of their students: As the number of children with language or learning challenges increased, teachers' sense of efficacy became more vulnerable. This conclusion is also indirectly confirmed by the 1985 Metropolitan Life Poll (1995a, cited in Kottkamp, 1990) which showed that of those teachers satisfied enough to remain in the teaching profession, $23 \%$ remained because they found it rewarding to see students grow, while $55 \%$ of teachers leaving teaching for another profession did so because of worsethan-expected numbers of special needs children.

The diversity of student ability is only one factor making teachers' work more difficult. Social and cultural conditions, including the decline in public respect for teachers, have also contributed to an increase in student 
disrespect for authority. Langdon's 1997 poll of teachers' attitudes towards public education reported that $58 \%$ of teachers cited behavior that disrupts class as an important problem in schools where they teach. While this percentage was up by only $1 \%$ since 1989 , it reflected an $11 \%$ increase from the $47 \%$ of teachers who reported disruptive behavior as characteristic of their schools in 1984 (Langdon, 1997). Additionally, 50\% of teachers in the 1997 poll cited talking back or disobeying teachers as an important problem where they teach--an increase of $5 \%$ since 1989 and $7 \%$ since 1984 (Langdon, 1997).

Many teachers in 1997 also perceived parents to be unsupportive: 50\% of teachers felt parents would take their children's side when teachers reported they had misbehaved or disrupted others, compared to $41 \%$ of teachers who thought the parents would take the teacher's or school's side (Langdon, 1997). This is balanced somewhat by perceptions of $53 \%$ of teachers who thought parents would take the teachers' side when their children were not working hard enough on their schoolwork, compared to $40 \%$ of teachers who believed parents would take their children's side (Langdon, 1997).

The diversity in student ability and increased student recalcitrance not only contribute to declines in teachers' sense of efficacy (Smylie, 1988, cited in Ross, 1994a) and job satisfaction (Goodlad, 1984), but also limit teachers' opportunities to build successful relationships with students and to receive positive recognition from colleagues, principals, and parents--also potent variables for teacher satisfaction (Rosenholtz, 1989). Indeed, the 1985 Metropolitan Life Poll (1995a, cited in Kottkamp, 1990) showed that $40 \%$ of teachers who remained in the profession did so because of the opportunity to develop positive relationships with their students.

Rosenholtz (1989) reported that over 30\% of any cohort of teacher education graduates do not make it past the second year of teaching, while 
another $20 \%$ to $30 \%$ leave by the end of the fifth or sixth year. Student problems are often among the reasons teachers give for leaving the profession. For example, discipline problems and unmotivated, uninterested students were two of the top four reasons cited by teachers in 1984 for leaving the profession, while in 1989 , lack of pupil interest, truancy, and lack of pupil discipline continued to make the top four list of reasons for leaving the profession (Gallup Poll, 1984, 1989, cited in Kottkamp, 1990). Similarly, according to polls on teacher attitudes towards schools conducted in 1984, 1989, and 1997, practicing teachers ranked failure to complete school and homework assignments as the number one problem in the schools where they teach, with disrupting class, talking back or disobeying teachers, and truancy or being absent from schools ranking second, third, and fourth, respectively (Langdon, 1997).

\section{Increased Legislative and}

\section{School Board Demands}

In addition to social, economic, and cultural changes, which are a contributory factor in the increasing numbers of students with learning and behavioral problems, concerns arising from these changes have also resulted in the tendency to use schools to "solve critical social problems" (Goodlad, 1984, p. 196). This, in turn, has resulted in not only an increase in the breadth and depth of the curriculum taught, but also an increase in the managerial responsibilities assumed by teachers. For example, teachers are asked to include multicultural content in their coursework, to develop students' social skills (through cooperative learning, character education, etc.), and to increase the authenticity of the work they ask children to do. Additionally, they are urged to increase opportunities for students to use computer technology and develop computer skills to access information and complete assignments. Teachers are also expected to effectively deal with special needs 
children in their classrooms, to plan for their learning, to consult with specialists, and to plan the activities of teacher assistants. Finally, teachers in Alberta and other provinces and states are mandated to work more closely with parents, particularly through school councils, and to take a more active role in school governance and in the development and implementation of new curriculum.

Demands such as these on Alberta teachers led the Alberta Teachers' Association (ATA; 1993) to publish a document, Trying to Teach, outlining concerns of teachers. The document concluded that "schools and teachers [are] pushed to their limits and, in some cases, beyond" (p. 22). One ATA Local group suggested that "teachers feel suffocated, frustrated, angry and stressed to the point of collapse" (p. 22). To further exacerbate the situation, less than a year after the ATA document was published, the Alberta government, in response to public concern over the high cost of education and its contribution to rising provincial debt, announced that it would reduce government spending on public education by $12.4 \%$ from 1994 to 1997 (Government of Alberta, January 18, 1994). For many schools this has meant larger classes and a reduction in the number of teacher assistants to help with special needs children. The effects of these budgetary reductions on teachers' time and work have been further aggravated by structural, procedural, and policy changes in Alberta education: Schools in Alberta are now legislated to form school councils, composed not only of parent and community representatives, but also of teachers, and to use these councils as the main forum for school-based decision making. In addition, schools and school districts must write 3-year plans and hold themselves accountable for implementing them by identifying and reporting the outcomes of key performance indicators, including, but not limited to, the academic performance of their students. 
While many of these reforms have potential to increase teachers' feelings of efficacy, Rosenholtz (1987, cited in Ross, 1994a) points out that statewide schemes to improve schooling are more likely to negatively affect most teachers' positive sense of efficacy--the exception being a small group of teachers whose activities were already similar to those being introduced.

As teachers try to fulfil their roles within this turbulent context, their positive sense of themselves as teachers becomes increasingly vulnerable (Bruner, 1990, cited in Moore \& Esselman, 1994) and their commitment to their work with children wanes. In addition, a number of factors endemic to schools, which serve as barriers to teachers' development of positive perceptions of efficacy, conspire to further exacerbate the potential negative effect of this unsettled societal and educational context.

\section{Life Within Schools}

Isolation. Much has been written about the isolation that characterizes teachers' daily life (Lortie, 1975; Goodlad, 1984; Sarason, 1993). Confined to the classroom, regimented by a timetable that offers few opportunities to work and talk with their colleagues, and constrained by "norms of noninterference" (Lipsky, 1980, cited in Ashton \& Webb, 1986, p. 46) which create a cultural barrier against asking for help from or offering help to colleagues, teachers face many of the challenges of teaching alone. Unfortunately, when there is little feeling of community within the school, say Forber and Miller (1981, cited in Dembo \& Gibson, 1985), teachers not only feel isolated, but also perceive themselves as inconsequential. In addition, Goodlad and his colleagues (1990, cited in Fullan \& Steigelbauer, 1991) contend: "The social, intellectual, and professional isolation, so well described by Dan Lortie, begins in teacher education" (p. 299).

The assault of isolation on teachers' sense of efficacy follows a predictable path: Left alone to confront the uncertainties and ambiguities that 
characterize teaching (Lortie, 1975), lacking opportunities for social comparison needed to develop realistic self-standards from which to judge their own capabilities (Bandura, 1986), and hiding feelings of self-doubt from discovery by judgmental colleagues, teachers feel vulnerable and unsure of their competence (Ashton \& Webb, 1986). Such feelings lower teachers' sense of efficacy and the ongoing lack of support from and connection with other teachers ensures that feelings of efficacy remain low.

However, despite our understanding that teachers have strong social needs (Holland, 1973, and Super, 1970, cited in Ashton \& Webb, 1986, p. 19), that collegial relations are the norm in successful schools (Little, 1982), and that there is a positive relationship between collegiality and teachers' sense of efficacy (Ross, 1994a), schools have made few attempts to reduce isolation. Uncertainty and Unpredictability

The knowledge base of teaching. Teaching is also "characterized by an almost total absence of truths, unimpeachably 'correct' answers to the most important issues: why students behave as they do, the nature of learning and cognitive growth, the best way to structure a lesson" (Kagan, 1992, p. 73). This relative lack of a straightforward knowledge base for teaching, along with the multiple demands of teaching, force teachers to make tentative decisions based on incomplete and uncertain information. In addition, the diversity among children ensures that the relationship between instruction and student learning will always be uncertain (Lieberman \& Miller, 1978)--what works for one student almost surely will not work for another.

Student teachers also suffer from the unpredictability of incomplete and uncertain knowledge. Armed with only a shaky knowledge of the curriculum, a relatively untested pedagogy, and a limited understanding of the knowledge, skills, and interests of their students, they must nonetheless make and execute their lesson plans. When they begin to understand the diversity 
of children in their classes, they often feel even more overwhelmed.

Teachers' sense of control. Teachers who are capable of executing courses of actions and who can control many of the aspects of the environment that impinge on their work will feel efficacious. Unfortunately, teachers do not always feel capable or in control of the many diverse situations with which they are confronted.

The multiple demands of teaching force teachers to make rapid-fire decisions, with little time to gather complete information or to consider the best way to proceed. In addition, a mandated curriculum, an inviolate teaching schedule, and the use of standardized tests and state- or provincial-level examinations take away many of the discretionary decisions so important to teacher satisfaction and feelings of efficacy. Further, increasing numbers of special needs students with learning and behavioral problems press the limits of teachers' competency and increase their feelings of inefficacy.

Student teachers' feelings of not having control over teaching and the teaching environment are exacerbated by the context of student teaching. Student teachers report that they have little or no status and, therefore, have little or no influence over their practicum experience. In addition, because they share classrooms and pupils with their cooperating teachers, many student teachers feel compelled not only to hold back their own beliefs and opinions, deferring to those of their cooperating teacher, but also to adopt the teaching behaviors of their cooperating teachers (MacKinnon, 1989). This sense of not being in control, accompanied by uncertain teaching capability, tends to inhibit the risk-taking behaviors necessary for further development of capabilities and feelings of efficacy.

Conclusion

Both societal factors and long-standing conditions endemic to school life conspire to make teachers' work more difficult, unpredictable, and uncertain 
(Lortie, 1975). They also increase the likelihood that, in the face of intractable problems, teachers will be unable or unwilling to persevere in their commitment to serve children and, thus, will either compromise their high standards (Sizer, 1984) or choose to leave the profession.

\section{Problems With the Current Conceptualization and Measurement of Teachers' Sense of Efficacy}

A large body of research findings exists as a result of studying how teachers' sense of efficacy affects, and is affected by, a variety of contextual factors including the following: school conditions; student behavior and achievement; conditions for teaching and learning; and relationships between teachers and others within the mesosystem of the school, including students, other teachers, administrators, support workers, and parents. While the research clearly points to the importance of teachers' sense of efficacy to effective teaching and learning, problems with the current conceptualization and measurement of teachers' sense of efficacy not only limit researchers' understanding of what is actually being measured, but more importantly, constrain the capacity of school leaders and teacher educators to support the development and maintenance of teachers' and student teachers' strong, resilient sense of efficacy.

Definitions and Measurements of Teachers' Sense of Efficacy

While teachers' sense of efficacy is defined in various ways, the most common theoretical explanations and definitions are based on Bandura's (1986) self-efficacy theory. Bandura posits that one's willingness and capability to act are influenced by both self-efficacy expectancies and response-outcome expectancies, with self-efficacy expectancies clearly having the most influence. 
Self-efficacy theory is one of a number of theories concerned with people's sense of their capability to "exercise control over events that affect their lives" (Bandura, 1986, p. 391) and "to predict performance in many domains" (Skinner, 1992, p. 40). Other related theories include locus of control theory (Rotter, 1966), attribution theory (Weiner et al., 1971, cited in Stipek \& Weisz, 1981), perceived personal control theory (Skinner, 1992), achievement motivation theory (Atkinson, 1957, cited in Schunk, 1996), and learned helplessness theory (Seligman, 1991), to name a few. Of late, researchers like Bandura (1986) and Skinner (1992) have called for an integration of these related constructs to expand understanding of human agency, particularly in complex, dynamic, and socially mediated situations.

Recent definitions of teachers' sense of efficacy have been influenced predominantly by self-efficacy theory. For example, teacher efficacy, as defined by Gibson and Dembo (1984) and others (Ashton \& Webb, 1986; Guskey \& Passaro, 1993; Woolfolk \& Hoy, 1990), has been construed as a domain-specific type of self-efficacy. However, not all researchers using self-efficacy theory explain teachers' sense of efficacy in the same way. In addition, many researchers use other theories related to self-efficacy in order to define the teacher efficacy construct. This has resulted in a number of current definitions of teachers' sense of efficacy, each with a different scale for its measurement.

These multiple definitions of what efficacy for teaching means and the many resultant instruments used to measure teachers' sense of efficacy have left researchers and research consumers wary of research findings. They question whether or not teachers' sense of efficacy has actually been measured (Ross, 1994a) and, if not, what is having the effect on the dependent variables under study. 
The most prevalent definition of and measurement for teacher efficacy was developed by Gibson and Dembo (1984) using self-efficacy theory. They developed a 16-item scale to measure two underlying factors of teacher efficacy: personal teaching efficacy, defined as the "belief that one has the skills and abilities to bring about student learning" (p. 573), and teaching efficacy, defined as the "belief that any teacher's ability to bring about change is significantly limited by factors external to the teacher such as home environment, family background, and parental influences" (p. 574). However, the two-factor structure and the substantive meaning assigned to the factors have been subject to scrutiny.

The personal teaching efficacy factor. Some researchers have found or hypothesized additional factors. For example, Woolfolk and Hoy's (1990) factor analysis of the Gibson and Dembo (1984) items revealed three factors rather than two, with items from the Gibson and Dembo subscale of personal teaching efficacy loading on two factors. Woolfolk and Hoy interpret these two factors as two ends of a continuum representing teachers' sense of responsibility. Alternately, Ashton and Webb (1986) propose that personal teaching efficacy is made up of a sense of teaching efficacy integrated with generalized beliefs about one's personal self-efficacy.

Other researchers posit alternative factors related to personal teaching efficacy based on one of the related theories. For example, Midley, Feldlaufer, and Eccles (1989, cited in Woolfolk \& Hoy, 1990) base their theory of personal teaching efficacy on Seligman's (1991) learned optimism and propose two factors of personal teaching efficacy representing two ends of a continuum of teacher optimism. Alternately, Fuller, Rapoport, and Dornbusch (1982) presume a performance efficacy factor, defined as "perceived efficacy in performing one's own work tasks, independent of social interaction with 
other staff members of the school organization" (p. 9), rather than a personal teaching efficacy factor.

The teaching efficacy factor. Researchers also question the meaning assigned to Gibson and Dembo's teaching efficacy factor. Woolfolk and Hoy (1990) suggest that the factor does not represent outcome expectancies, as Gibson and Dembo (1984) have posited, but rather efficacy expectancies related to teachers' potential to perform. Guskey and Passaro (1993) question the general nature of the teaching efficacy factor, reporting that research evidence does not support a personal-general distinction between the two factors; the distinction appears more related to external and internal locus of control.

Kushner (1993) posits that, despite the wide use of both the Gibson and Dembo (1984) Teacher Efficacy Scale and Woolfolk and Hoy's (1990) modified version, the model does not fit the data very well. He proposes that items on both scales be either revised or eliminated. Further, Smylie (1990) suggests that the "possibility that teachers possess different senses of efficacy that operate in different ways in relation to different dimensions of their work has yet to be adequately explored" (p. 62). However, the Gibson and Dembo (1984) scale items represent a limited number of dimensions of teachers' work.

Finally, almost all researchers, including Gibson and Dembo (1984), consider teachers' sense of efficacy to be a multidimensional construct and recommend continued exploration for and delineation of additional underlying factors. For example, Guskey and Passaro (1993) point to the need for a further conceptualization and detailed exploration of the construct of teacher efficacy, along with the development of "more sophisticated measures of teacher efficacy" (p. 12). 


\section{The Collection and Analysis of Data From}

\section{Gibson and Dembo's Teacher Efficacy Scale}

Researchers and research consumers also report a number of limitations in the way data from the administration of Gibson and Dembo's (1984) Teacher Efficacy Scale are typically collected and analyzed: For example, the prevalent analyses and interpretations of teacher efficacy use correlational statistics which do not establish cause and effect patterns and, therefore, are only minimally useful in increasing understanding of how to develop and maintain strong feelings of teacher efficacy among teachers (Ross, 1994a). In addition, one-time measurements of teacher efficacy do not reveal whether or not changes in teacher efficacy occur across contexts, situations, and over time and, therefore, limit our knowledge of conditions that support and undermine teachers' self-percepts of efficacy (Ross, 1994).

Of particular importance is the fact that there is no accepted way of organizing the data for reporting teacher efficacy. Some researchers report scores for each of the two factors. Others aggregate the data from the two subscales. However, using the composite scores of the two factors not only increases chances for misinterpretations of the results, but also increases the likelihood that important relationships among variables and subtle differences in teachers' beliefs will be missed (Ross, 1994a). In fact, researchers who use disaggregate data have found important within-teacher differences between personal teaching efficacy and teaching efficacy, as well as differences in the reciprocal relationship of each factor with other teaching-related variables (Greenwood, Olejnik, \& Parkay, 1990; Hoy \& Woolfolk, 1993; Ross, 1994a).

Conclusion

The teacher efficacy construct needs to be reexamined, and a more detailed conceptual understanding of teachers' sense of efficacy, which 
overcomes the limitations of the present two-factor model of teacher efficacy, should be sought. This will require not only resolving the problems associated with the interpretation of the teaching efficacy factor, but also expanding understanding of the elements of teachers' thoughts, feelings, and behavior that differentiate highly efficacious teachers from those with a low sense of efficacy.

\section{Statement of the Problem}

A high sense of efficacy for teaching has been established as an important underlying condition for teaching effectiveness and student learning. In addition, research suggests that teachers' sense of efficacy can be enhanced or undermined by the various contexts in which teachers' work is nested. Similarly, student teachers' capabilities to develop effective teaching practices are also influenced by their sense of efficacy for teaching and the conditions in which they learn and practice.

However, what constitutes teachers' sense of efficacy is only partly understood. For example, not only is Gibson and Dembo's (1984) two-factor model of teacher efficacy believed to underrepresent the multidimensional nature of teaching, but the interpretations of the factors, particularly the factor representing general teaching efficacy, have been questioned. In addition, the various definitions and measurements of teachers' sense of efficacy currently in use undermine the applicability of research findings related to the construct.

Furthermore, while many current societal, school, and classroom conditions are believed to have a negative effect on teachers' effectiveness and sense of efficacy, there is no firm sense of what contextual elements 
protect teachers' sense of efficacy and what conditions support the development of strong, resilient self-percepts of efficacy for teaching.

\section{Purposes of the Study}

A new conceptual analysis of the efficacy construct as it applies to teachers and student teachers is needed in order to better understand the underlying factors of personal teaching efficacy and to more fully measure teachers' and student teachers' sense of personal teaching efficacy. This study was organized to address these two needs through the following two purposes:

Purpose 1

To reconceptualize the personal teaching efficacy construct and to develop a model and scale based on the reconceptualization.

\section{Purpose 2}

To test the utility of the model and scale for understanding and measuring changes in personal teaching efficacy, using a sample of teachers and student teachers participating in a reflective practitioner model practicum at the University of Alberta.

\section{Delineation of the Theoretical Problem}

The central question of the theoretical study was related to designing a new model and constructing a new measure of personal teaching efficacy. The question asked: What underlying factors contribute to teachers' sense of their own personal efficacy for teaching? In order to answer this question, this study was organized around the following objectives:

Objective 1

To review the literature related to social cognition theory in order to fully understand teacher agency and efficacious behavior. 
Objective 2

To develop a new model of personal teaching efficacy that was research-based, resolved the problems with the Gibson and Dembo (1984) model, and, when possible, integrated the various conceptualizations of teachers' sense of efficacy.

Objective 3

To develop a scale to measure personal teaching efficacy which not only reflected the theoretical model, but also more adequately represented the complexity of the teaching role and more fully delineated the role-specific tasks and competencies of teachers.

\section{Objective 4}

To conduct a pilot study of the new Personal Teaching Efficacy Scale. The pilot study would provide data for exploratory factor analyses and information for the modification of the scale prior to the study.

\section{Objective 5}

To conduct exploratory factor analyses of data collected from the two sample groups of teachers and student teachers in the study. The factor

analyses of the teacher and student teacher data would confirm the model and the scale or provide information for modifications to one or the other, or both.

\section{Delineation of the Research Problem}

The central questions of the research study were related to the testing of the new personal teaching efficacy model and scale for its utility in delineating differences in self-percepts of personal teaching efficacy among teachers and student teachers and in measuring changes in their personal teaching efficacy over the term of a student teaching experience. 


\section{General Questions}

1. Will teachers' and student teachers' self-percepts of personal teaching efficacy change after participation in a reflective practitioner model practicum?

2. On what underlying factors will changes in teachers' and student teachers' self-percepts of personal teaching efficacy occur?

The general study questions focused on teacher and student-teacher changes in personal teaching efficacy from pretest to posttest and looked at three levels of change: change at the individual-variable level, change at the full-scale level, and change at the factor level. The operational definitions and null hypotheses used to test these questions are delineated in chapter 4.

Additional study questions focused on differences in the degree of change in the personal teaching efficacy of teachers and student teachers due to various demographic variables. The demographic variables of teachers included gender, age group, years of teaching experience, and previous practicum experience; while the demographic variables for student teachers included gender, age group, and previous work with children. Mean gain scores at the full-scale level and the factor level were used.

Questions Related to the

\section{Teacher Sample}

1. Are changes in the personal teaching efficacy of teachers participating in a reflective practitioner model practicum affected by their gender?

2. Are changes in the personal teaching efficacy of teachers participating in a reflective practitioner model practicum affected by their age?

3. Are changes in the personal teaching efficacy of teachers participating in a reflective practitioner model practicum affected by the amount of teaching experience they have? 
4. Are changes in the personal teaching efficacy of teachers participating in a reflective practitioner model practicum affected by whether or not they have participated in other practicum experiences?

Questions Related to the Student Teacher Sample

1. Are changes in the personal teaching efficacy of student teachers participating in a reflective practitioner model practicum affected by their gender?

2. Are changes in the personal teaching efficacy of student teachers participating in a reflective practitioner model practicum affected by their age?

3. Are changes in the personal teaching efficacy of student teachers participating in a reflective practitioner model practicum affected by the amount of their previous work with children?

The operational definitions related to these questions and the operational hypotheses to test them are outlined in chapter 4.

Importance of the Study

This study contributes to the conversation on teachers' sense of efficacy. It offers a new perspective that focuses on personal teaching efficacy, while at the same time it provides an alternate interpretation of the meaning underlying Gibson and Dembo's (1984) teaching efficacy factor. The new perspective expands the theoretical and research base to include new aspects of self-efficacy theory (Bandura \& Wood, 1989) and introduces a new volitional perspective of teachers' s sense of efficacy which takes into account other related theories such as Skinner's (1992) personal control theory. 
A new model of personal teaching efficacy is also proposed that conceptualizes teachers' sense of efficacy for teaching as a self-schema, composed not only of teachers' perceptions of their teaching capabilities, but also of their volitional capabilities and predispositions. The model posits seven underlying factors of personal teaching efficacy and more fully delineates the thoughts, feelings, and behaviors that affect self-percepts of personal teaching efficacy.

This study also contributes to the research on teachers' sense of efficacy. In testing the new Personal Teaching Efficacy Scale, the study examines the changes in personal teaching efficacy of teachers and student teachers after participation in a reflective practitioner model practicum. While changes in the personal teaching efficacy of student teachers have been studied (for example, Housego, 1992), this study is unique in two respects: First, it studies changes in student teachers' sense of personal teaching efficacy as a result of a particular kind of practicum--a reflective practitioner model practicum. Second, it examines changes in the personal teaching efficacy of teacher participants.

Scope and Delimitations of the Study

The theoretical and empirical aspects of this study are affected by the following two delimitations:

1. The population of interest. This study is limited to teachers and student teachers participating in the elementary practice teaching experience offered by one university. It does not include the university facilitators, practicum associates, or seminar leaders who were also part of the practice teaching experience. Further, the study does not include nonparticipating teachers and administrators within participating schools. Finally, teachers and student 
teachers participating in other practice teaching experiences in secondary education or at other universities are also not included.

2. Participants in the study. The data used in the theoretical and empirical aspects of the study were collected from only those teachers and student teachers participating in a reflective practitioner model practicum at the University of Alberta.

The research aspect of the study was affected by an additional two delimitations:

3. The context of the study. Changes in personal teaching efficacy were measured only under the conditions created by the implementation of a reflective practitioner model practicum as delineated by the University of Alberta. The effects on personal teaching efficacy of other types of practica or of school conditions alone are not addressed.

4. Changes in personal teaching efficacy. This study is limited to measuring teachers' and student teachers' perceptions of personal teaching efficacy and the changes that occur in these self-percepts after participation in a reflective practitioner model practicum experience. It does not relate personal teaching efficacy or changes in personal teaching efficacy to student achievement.

\section{Limitations of the Study}

The theoretical aspect of the study was limited by the fact that there were only two opportunities to collect data for factor analyses; thus, there was no opportunity to revise the scale and readminister it. In addition to this limitation to the theoretical aspect, the following posed constraints on the empirical aspect of the study: 
1. Time limitations. The 12-week period of the practicum necessitates a short time interval between pretest and posttest administrations of the Personal Teaching Efficacy Scale. The 12-week interval may be too short for significant changes in personal teaching efficacy beliefs to take place, particularly the self-perceptions of personal teaching efficacy of teachers acting as school facilitators.

2. Control of the treatment variables. The practicum context is organized across many school sites. Each individual within the program is likely to have a different experience depending upon the characteristics of the people involved, the way the program principles have been interpreted and adapted to each school site, and the skills of the particular school and university facilitators who are organizing the student teaching experience. The researcher was unable to control for these variabilities.

3. Generalizability of study findings. Subjects in the study were selfselected and, therefore, do not represent a truly random sample. Thus, only tentative generalizations of the findings to the two populations of interest can be made.

In addition, because the populations of interest are teachers and student teachers participating in the elementary practice teaching experience offered by one university, generalizations to the larger populations of all teachers and all student teachers cannot be made.

\section{Dissertation Outline}

Fulfilling the two purposes of this dissertation required a modification in the usual dissertation format. These modifications include an additional chapter to complete the review of literature and an additional chapter to outline the theory underlying a new model of personal teaching efficacy and 
to report the results of factor analyses of data derived from the administration of the new Personal Teaching Efficacy Scale.

\section{Reviews of the Literature}

The next two chapters provide a review of the literature relevant to the development of a new perspective on personal teaching efficacy and to the study of change in teachers' and student teachers' sense of personal teaching efficacy.

Chapter 2 reviews the theory and research related to teacher efficacy, self-efficacy, and other related constructs. This review provided the initial background for a tentative new model of personal teaching efficacy and for the development of the Personal Teaching Efficacy Scale used in this study.

Theories and research related to volition and its related constructs are introduced in chapter 3. This review of the literature was conducted after initial factor analyses of the study data in an attempt to explain the derived factors. It led to the development of the new volitional perspective of personal teaching efficacy. Chapter 3 ends with a review of the literature related to the school context and reflection. This review prepared for the interpretation of findings derived from the empirical aspect of the study.

\section{The Development of a New Model}

and Scale of Personal Teaching Efficacy

Chapter 4 outlines the steps taken in the design a new model and scale of personal teaching efficacy. The chapter begins with a summary of the literature related to self-efficacy and other related constructs used in the development of the initial theory and model of personal teaching efficacy. A tentative new model is proposed and a new scale of personal teaching efficacy is introduced. The results of test statistics and factor analyses are then discussed and the necessity to return to the literature is explained. Chapter 4 then summarizes the volitional literature and shows how it was used to derive a 
new conceptualization of personal teaching efficacy from a volitional perspective. Results from previous factor analyses are then reinterpreted using the new model, followed by reports of new factor analyses using a modified scale.

Methods and Results, Analyses, and Findings

Chapter 5 describes the methods and statistics used for examining changes in teachers' and students teachers' personal teaching efficacy and provides information on the statistical tests used. It introduces the independent variables and outlines the operational definitions and null hypotheses which shape the study.

Chapter 6 reports the findings from analyses of data collected from teachers and student teachers using the Personal Teaching Efficacy Scale. Recommendations and Conclusions

Chapter 7 outlines several recommendations and conclusions related to both the theoretical and the empirical aspects of the study. 


\section{CHAPTER 2}

\section{REVIEW OF THE LITERATURE I}

\section{Overview}

The purposes of this study were to develop a new scale and model of personal teaching efficacy and to test the new model and scale through a study of teachers and student teachers participating in a reflective practitioner model practicum. These two purposes required a review of the literature across a number of areas of study related to teachers' and student teachers' sense of efficacy, teachers' work, and the conditions of teaching and learning to teach.

Chapter 2 focuses on theory and research required for a reconceptualization of self-percepts of personal teaching efficacy and provides the background of theory and research used to develop the initial new model and scale of personal teaching efficacy. It begins with a review of the literature on teacher efficacy. Since the current conceptualization of teacher efficacy and the reconceptualization of personal teaching efficacy presented in this dissertation are based, in part, on Bandura's (1986) selfefficacy theory, the chapter then outlines the social cognitive theory and research, with a focus on self-efficacy and other related constructs. 
Theory and Research Underlying Personal Teaching Efficacy

\section{Introduction: Teachers' Belief Systems}

Teachers' sense of efficacy is one of many sets of beliefs that guide teachers' decision making and action in the educational arena. Pintrich (1990, cited in Pajares, 1992) affirms that the study of teachers' beliefs, including efficacy beliefs, will be the most valuable of all studies informing teacher education. According to Dewey (1933) "belief is crucial to action because it covers all the matters of which we have no sure knowledge and yet which we are sufficiently confident of to act upon. ..." (p. 6, cited in Pajares, 1992). As Brown and Cooney (1982, cited in Pajares, 1992) posit, beliefs underlie our dispositions for action.

One set of beliefs are "pre- or in service teachers' implicit assumptions about students, classrooms, and subject matter taught" (Kagan, 1992, p. 66). These teaching assumptions influence, and are influenced by, teaching expectations and one's self-beliefs of teaching efficacy, which in turn, collectively mediate teachers' behavior and experience (Chester \& Beaudin, 1996). In addition, we know that teachers' high expectations have a positive impact on student performance (Bamburg \& Andrews, 1989, cited in Bamburg, 1994) and that teachers' expectations for student achievement are associated with self-beliefs of efficacy (Woolfolk \& Hoy, 1990).

Further, Fletcher (1990, cited in Ross, 1994a) found that differences in teachers' perceived efficacy predicted differences in beliefs about student learning. That is, teachers with higher perceived efficacy were more likely to believe that student ability was malleable, while teachers with lower perceived efficacy tended to see student ability as fixed. Similarly, Ashton and Webb (1986) consider teachers' beliefs about ability to have much in common with one's sense that teaching can make a difference. Woolfolk and Hoy (1990) note 
that beliefs that one is relatively powerless to overcome deficits in student ability and home background (low teaching efficacy) are also associated with a more bureaucratic orientation to teaching, that is, beliefs that one's actions are controlled by the norms and rules of the school or district.

Teachers expectations and beliefs also influence how teachers treat their students. For example, Chaikin, Sigler, and Derlega (1974, cited in Bamburg, 1994) found that when teachers believe their students are bright, they smile at, interact with, and lean towards them more often than do teachers who believe their students are slow. Such positive interactive patterns, referred to as immediacy (Schaller \& De Wine, 1993), are known to foster interpersonal relationships (Richmond, Gorham, \& McCroskey, 1987, cited in Schaller \& De Wine, 1993) and have been found to be positively related to student learning and cognitive development (Christophel, 1990, cited in Schaller \& De Wine, 1993). Interpersonal relationships also enhance students' positive attitudes towards course content and predict teachers' positive sense of efficacy (Schaller \& De Wine, 1993).

Teachers also hold beliefs about the purpose of teaching which, in turn, can affect their teaching actions. For example, research suggests that most beginning teachers believe that the job of teaching is one of transmitting and dispensing information (Brookhart \& Freeman, 1992, cited in Pajares, 1992). Alternately, research shows that fledgling teachers place exaggerated emphasis on the importance of affective variables, while underestimating the importance of cognitive and academic variables (Weinstein, 1988, cited in Pajares, 1992).

New teachers' sense of efficacy also affects their teaching beliefs. For example, research shows that teachers who begin their careers with high teacher efficacy are more likely to see teaching as fostering student development, while low-efficacy teachers are more likely to see covering the 
curriculum as the main purpose of teaching (Pajares, 1992). If, as Bandura (1986) suggests, beliefs underlie important action decisions, including defining tasks and selecting the cognitive tools which will be used to interpret, plan, and make decisions regarding tasks; then beginning teachers' belief patterns will have a significant effect on their teaching and student learning. Interestingly, preservice teachers also tend to believe that the most effective teacher attributes are also the ones that they possess (Pajares, 1992). This may serve to protect their feelings of efficacy against the inevitable failures and setbacks common to learning new tasks (Heckhausen, 1991).

In keeping with Pajares (1992), who emphasizes the need to take all belief substructures into account when assessing their effect on behavior, this study not only focuses on perceptions of teaching capabilities, but also finds a place for more general beliefs related to teaching within its proposed selfschema of personal teaching efficacy.

\section{Definitions of Teacher Efficacy}

Perhaps the earliest references to efficacy are White's effectance motivation (1959, cited in Schunk, 1996, p. 328) and Heider's naive analysis of action (Schunk, 1994, p. 80). White suggests that effectance motivation leads humans to interact with the environment and try to master it. Mastering effective interactions then produces feelings of competence or efficacy which are highly satisfying and which lead to further interactions and mastery efforts (reported in Stipek \& Weisz, 1981, p. 127).

From a slightly different perspective, Heider (1958) identifies two forces affecting efficacy: an effective personal force consisting of personal power (one's abilities) and motivation (intention and exertion) and an effective environmental force (Schunk, 1994, p. 80). According to Heider, one's abilities are referenced in terms of the environment, and when the interaction of 
power and environment produces a positive "can factor," the motivational "try factor" affects outcomes. Heider's "can factor" is usually considered synonymous with self-percepts of efficacy.

Early attempts to apply the construct of efficacy tended to be broad and unspecific. For example, Barfield and Burlingame (1974) defined efficacy as a global "personality trait that enables one to deal effectively with the world" (p. 10, cited in Guskey \& Passaro, 1993, p. 4). Similarly, one of the first attempts to measure teacher efficacy, the Rand studies, did so using only two general items.

The Rand studies. As part of a wide-scale evaluation of 100 projects funded by Title III grants through the Federal Elementary and Secondary Educational Act, two Rand Corporation studies (Armor et al., 1976, cited in Gibson \& Dembo, 1984; Berman \& McLaughlin, 1977) used two items on a long postproject questionnaire to assess the self-perceptions of efficacy of teachers who had participated in innovative change projects. When these two items, which reflected teachers' perceptions of their capability to effect student learning under aversive conditions, were used as independent variables, Berman and McLaughlin (1977) found that a teachers' sense of efficacy was positively related to the percentage of project goals achieved and the degree of teacher change. Armor and his colleagues (1976, cited in Gibson \& Dembo, 1984), who were also involved in the Rand studies, found that the more teachers felt efficacious, the more their students improved in reading.

The first Rand item refers generally to one's teaching capabilities and is classroom focused:

If I really try hard, I can get through to even the most difficult or unmotivated students. (cited in Gibson \& Dembo, 1984, p. 573) This item has been interpreted as a measure of 'individuals' assessment of their own teaching competence" (Ashton \& Webb, 1986, p. 4 ) or as a "belief 
that one has the skills and abilities to bring about student learning" (Gibson \& Dembo, 1984, p. 573). It is also cunsidered to parallel Bandura's (1986) concept of self-efficacy.

The second Rand item, usually paralleled with Bandura's (1986) response-outcome expectancies, refers to a teacher's capabilities to influence students in relation to other outside factors, specifically parents, the family, and the home environment:

When it comes right down to it, a teacher really can't do much because most of a student's motivation and performance depends on his or her home environment. (cited in Gibson \& Dembo, 1984, p. 574)

This item is usually interpreted as a general measure of "teachers' expectations that teaching can have an effect on student performance" (Ashton \& Webb, 1986, p. 4) or the "belief that any teacher's ability to bring about change is significantly limited by factors external to the teacher such as home environment, family background, and parental influences" (Gibson \& Dembo, 1984, p. 574).

Some researchers relate these two Rand aspects of efficacy, at least in part, to Rotter's (1966) locus of control, which distinguishes beliefs about the means for accomplishing tasks and goals as either internally or externally situated (see Smylie, 1990).

Commonly used definitions. Since the publication of the Rand studies, many definitions of efficacy have been formulated by educational researchers. In a review of the teacher efficacy literature, Smylie (1990) reiterates a number of these current definitions of teacher efficacy: First, Huberman (1989) defines efficacy as "teachers' perceptions of their effectiveness with students" (cited in Smylie, 1990, p. 56). Interestingly, Huberman posits that teachers determine their efficacy by also assessing 
certain dispositional qualities related to their work with children such as "their decisiveness, prudence, and indulgence" (cited in Smylie, 1990, p. 56).

On the other hand, Guskey (1987) sees sense of efficacy and sense of responsibility as synonymous, differing only in the timing of their appraisals. One's sense of efficacy is appraised before prospective action, while one's sense of responsibility is appraised retrospectively. Thus, Smylie (1990) interprets Guskey's definition of efficacy as teachers' “sense of responsibility for student learning" (p. 56). Alternately, Rosenholtz (1989) defines efficacy as sense of “certainty . . . [of] teachers' knowledge about their own practice (awareness of what they actually do in the classroom), the effects of those practices on students, and the technology of teaching (those practices that are believed to achieve certain intended outcomes with students)" (cited in Smylie, 1990, p. 56). Similarly, Pigge and Marso (1993) define teachers' sense of efficacy as "the extent to which teachers believe that they have the capacity to affect pupil performance" (p. 3).

Other researchers have developed more explicit theoretical models of teacher efficacy which not only build on the two Rand items, but also utilize Bandura's self-efficacy theory.

\section{Three Models of Teacher Efficacy}

Recent models of teacher efficacy (Ashton \& Webb, 1986; Denham \& Michael, 1981; Gibson \& Dembo, 1984) continue to conceptualize the construct in terms of the two Rand items. That is, they see teacher efficacy as a combination of "beliefs about the relative influence that teachers in general have over student learning and development and beliefs that teachers have about their own ability to influence learning and development" (Smylie, 1990, p. 55, emphasis in the original). However, these two factors of teacher 
efficacy are now further explained in terms of Bandura's (1986) self-efficacy theory.

Bandura's model of self-efficacy. Bandura (1986) conceptualizes motivation as a combination of two expectancies: perceptions of self-efficacy, defined as "judgments of capabilities to organize and execute course of action required to attain designated types of performances" (p. 391), and responseoutcome expectancies, defined as "judgments of the likely consequences [such] behavior will produce" (p. 391). While most action can be explained by these two expectancies, according to Bandura, self-efficacy is the more potent explanatory construct.

Denham and Michael's (1981), Gibson and Dembo's ( 1984), and Ashton and Webb's (1986) conceptions of teacher efficacy as a two-factor construct parallel Bandura's (1986) constructs of self-efficacy and response-outcome expectancies.

The Denham-Michael Model of Teacher Efficacy

Denham and Michael (1981) offer the following definition of teacher efficacy:

Teacher sense of efficacy is defined as an intervening variable composed of a cognitive component and an affective component. The cognitive aspect has two parts: [1] a sense of the likelihood that the ideal or normative teacher can bring about positive change in the student; and [2] an assessment of the teacher's own ability to bring about such changes. The affective aspect of teacher sense of efficacy is the pride or shame associated with the sense of efficacy. (pp. 39-40).

The Denham-Michael model (see Figure 1) also construes teachers' sense of efficacy as having dimensions of magnitude, generality, and strength. In addition, they see teachers' sense of efficacy as mediating and being mediated by four antecedent conditions, as well as by teacher behaviors and student 
Figure 1

Denham-Michael Model of Teachers'

Sense of Efficacy ${ }^{a}$

EMPIRICALLY DEFINED ANTECEDENT CONDITIONS

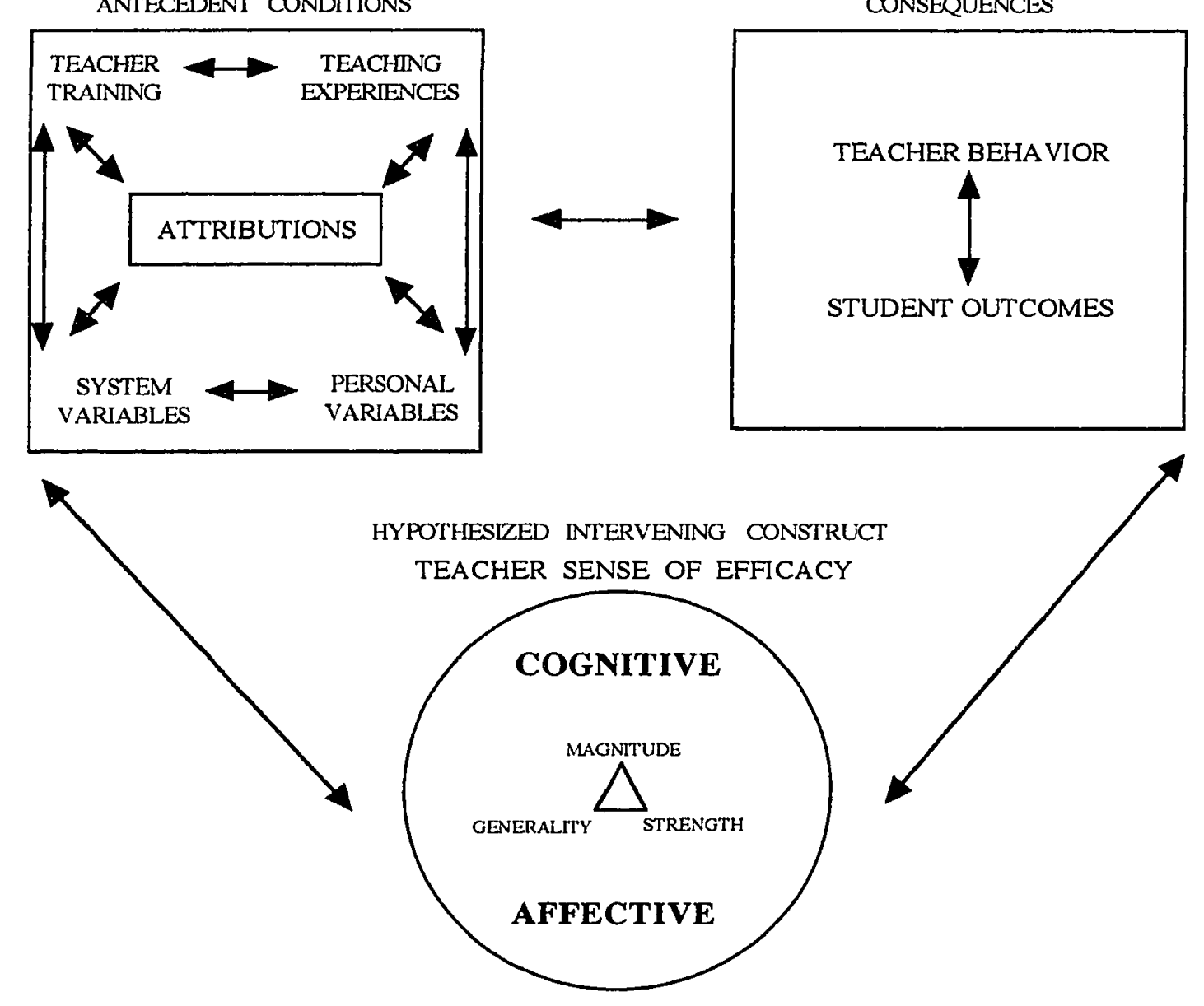

MEASURABLE

CONSEQUENCES

a from Denham \& Michael (1983). 
outcomes. This is reflective of Bandura's (1986) process of triadic reciprocal causation. Further, the two cognitive aspects of efficacy appear to align not only with the two Rand items, but also with Bandura's self-efficacy and response-outcome expectancies.

Three aspects of the model should be noted: First, the first cognitive aspect is expressed in normative terms (that is, whether the ideal teacher can bring across positive change). Second, the affective aspects of the model are similar to the conceptions of self-pride in success and self-blame in failure outlined by other expectancy theorists (Stipek \& Weisz, 1981). Third, the model gives important emphasis to the mediating role of contextual factors in developing and maintaining teachers' sense of efficacy. The Ashton-Webb Concept of Teacher Efficacy

Ashton and Webb (1986) also suggest a two-factor model of teacher efficacy based on the Rand items. They define one factor, a sense of personal teaching efficacy, as “individuals' assessments of their own teaching competence" (p. 4 ) and a second factor, a sense of teaching efficacy, as "teachers' expectations that teaching can have an effect on student performance" (p. 4). Note that while Denham and Michael (1981) express the teaching efficacy component in normative terms (the ideal teacher), Ashton and Webb express teaching efficacy in general terms (all teachers).

Ashton and Webb (1986) conceptualize teachers' sense of efficacy as "hierarchically organized" (p. 4), reciprocal relationships among one's generalized beliefs about response-outcome contingencies and one's perceived self-efficacy, personal teaching efficacy, and teaching efficacy (see Figure 2). They posit, however, that teacher behavior is best predicted by general personal efficacy (self-efficacy) and personal teaching efficacy "acting in concert" (Fritz, Miller-Heyl, Kreutzer, \& McPhee, 1995, p. 200). 
Figure 2

Ashton and Webb's Model of Teachers' Sense of Efficacy ${ }^{\mathrm{a}}$

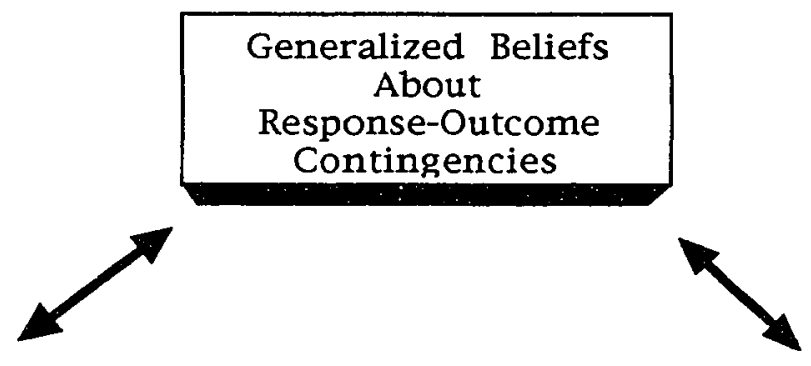

Sense of Teaching Efficacy

Specific Beliefs About Teachers'

Ability to Motivate Students

(Rand Efficacy 1)

Generalized Beliefs About Perceived Self-Efficacy

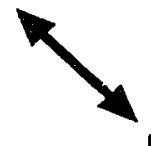

Personal $\frac{\text { Sense of }}{\text { Teaching }}$

Specific Beliefs About One's Personal

Competence in Motivating Students

(Rand Efficacy 2)

a from Ashton \& Webb, 1986, p. 5. 
Ashton and Webb (1986) see the teaching milieu as a "nested arrangement of structures" (Ashton \& Webb, 1986, p. 13; also see

Bronfenbrenner, 1977), or “surrounds" (Guba \& Lincoln, 1989, p. 8), consisting of various overlapping "communities" that directly and indirectly affect teachers' actions and their perceptions of teacher efficacy. However, while they use an "ecological framework" (p. 13) to emphasize the important effect contextual variables have on teacher efficacy, they do not formally represent this framework as part of their model.

\section{Gibson and Dembo's Teacher Efficacy}

Gibson and Dembo (1984) have tested, validated, and adopted a two-factor model of teacher efficacy. They conceptualize a personal and general sense of teaching efficacy as underlying teacher efficacy and, like Ashton and Webb (1986), parallel the two factors to self-efficacy and outcome expectancies. They define personal teaching efficacy as the "belief that one has the skills and abilities to bring about student learning" (Gibson \& Dembo, 1984, p. 573) and teaching efficacy as the "belief that any teacher's ability to bring about change is significantly limited by factors external to the teacher such as home environment, family background, and parental influences" (p. 574).

While Gibson and Dembo (1984) account for home and family environment as a factor influencing student achievement in their teaching efficacy factor, their model does not make specific reference to other contextual factors which would affect teachers' self-percepts of efficacy.

\section{Measuring Teacher Efficacy}

There have been a number of scales designed to measure teacher efficacy since the two-item Rand measure for teacher efficacy was used: For example, Brogdon (1973, cited in Woolfolk \& Hoy, 1990) designed a 10-item scale for teachers using modified items from a political efficacy scale. As well, 
Midgley, Feldlaufer, and Eccles (1983, cited in Woolfolk \& Hoy, 1990) devised a short five-item scale that included the two Rand items, two items from Brookover, Beady, Flood, Schweitzer, and Wisenbaker (1979, cited in Woolfolk \& Hoy, 1990). and one item from Ashton, Olejnik, Crocker, and McAuliffe (1982, cited in Woolfolk \& Hoy, 1990). Ross (1994a) also cites three "more extensive instruments . . . based on teachers' willingness to take responsibility for student successes and failures" developed by Rose and Medway (1981), Guskey (1988), and Vitali (1993).

In keeping with Bandura's conjecture that efficacy beliefs are situation- and domain-specific, Riggs and Enochs (1990, cited in Ross, 1994a) created a 25-item scale for elementary school science teachers, which has been further adapted for chemistry and other more specific science teaching areas (Rubeck \& Enochs, 1991, cited in Ross, 1994a).

In addition, Coladarci and Breton (1991) modified the Gibson and Dembo (1984) scale for resource room teachers. As a result of a confirmatory factor analysis, they found that the modified items loaded similarly to the Gibson and Dembo items on two factors accounting for $28 \%$ of the total variance, with personal teaching efficacy accounting for $17 \%$ and teaching efficacy accounting for $11 \%$.

The Gibson and Dembo Teacher Efficacy Scale

The most used teacher efficacy scale was designed by Gibson and Dembo, using the preliminary work of Gibson and Brown (1982, cited in Dembo \& Gibson, 1985), who developed 53 items based on teacher interviews and the research literature related to efficacy. The Gibson and Dembo (1984) version was first scaled down to 30 items. Items were eliminated because of "poor variability" or because they did not "load clearly on one of the substantial factors" (p. 571). The scale was tested using 208 elementary school teachers who were asked to respond to each item using a 6-point Likert scale. Data from 
the 16 items were subjected to factor analysis and two "substantial" (p. 573) factors were identified using Catell's scree test. There was a low and inverse correlation $(\underline{r}=-.19)$ between these two factors, confirming their independence. Items with factor loadings equal to or less than .45 were omitted from the scale, and a second factor analysis of the remaining 16 items was conducted.

This second analysis confirmed the two-factor model of teacher efficacy, with Factor 1 accounting for $18.2 \%$ of the total variance and Factor 2 accounting for $10.6 \%$ and with the "remaining factors account[ing] for less than $6 \%$ of the total variance" (Gibson \& Dembo, 1984, p. 573). An analysis of the internal consistency reliability "yielded Cronbach's alpha coefficients of .78 for the Personal Teaching Efficacy factor, .75 for the Teaching Efficacy factor, and .79 for the total 16 items" (Gibson \& Dembo, 1984, p. 574).

Dembo and Gibson conclude that teacher efficacy represents two dimensions of Bandura's self-efficacy model (self-efficacy and responseoutcome expectancies) but that other self-efficacy dimensions, such as generality, magnitude, and strength, should be explored.

The Woolfolk and Hoy Scale

A second scale introduced by Woolfolk and Hoy (1990) utilized 15 of the 16 items from the Gibson and Dembo study, the 2 Rand items, and 4 new items related to the adequacy of preservice preparation. Data were collected from 182 liberal arts majors completing teacher preparation courses. A two-factor confirmatory factor analysis using a varimax rotation revealed two factors similar to the Gibson and Dembo (1984) factors and accounting for $29 \%$ of the total variance. Despite a further exploratory analysis which revealed three factors, Woolfolk and Hoy continue to conceptualize a two-factor model of teacher efficacy. 
Woolfolk and Hoy's modification of the Gibson and Dembo scale for use with preservice teachers was validated by Kushner (1993) in a large study of 359 students majoring in education (197 in summer term and 162 in fall term).

\section{Teacher Efficacy Research and Findings}

The Gibson and Dembo scale and the Rand items, as well as many other teacher efficacy scales--some modifications of the Gibson and Dembo scale-have been used to research teacher efficacy and the variables which influence or are influenced by it. This section gives an indication of the breadth and diversity of that research.

Relationship Between Teachers' Sense of Efficacy and Other Attributes

Teacher efficacy, as well as the underlying factors, teaching efficacy and personal teaching efficacy, have been found to be positively correlated with other personal aptitudes and attributes. For example, in a recent review of the teacher efficacy literature, Ross (1994a) cites studies showing teacher efficacy to be positively associated with internal locus of control (Ashton, Webb, \& Dodd, 1983) and with high professional esteem (Ashton \& Webb, 1986); Ross (1994a) also cites studies that found teaching efficacy to be positively correlate with teacher reasoning (Anderson, Green, \& Loewen, 1988), with self-concept (Lucus, Ginns, Tulip, \& Watters, 1993), and with thinking styles (Cancro, 1992).

Less stable personal feelings of stress have also been found to be negatively correlated with both teachers' sense of efficacy and an internal locus of control (Parkey, Greenwood, Olejnik, \& Proller, 1988, cited in Pigge \& Marso, 1993). 
Research Results Showing Within-Person Differences in

Teaching Efficacy and Personal Teaching Efficacy

Research shows that teaching efficacy and personal teaching efficacy are independent aspects of the construct of teacher efficacy. In addition, Gibson and Dembo (1984) and Moore and Esselman (1992) found that personal teaching efficacy and teaching efficacy appear to be highly but inversely related. However, Hoy and Woolfolk (1993) point out that many studies use an aggregate teacher efficacy score which combines teaching efficacy and personal teaching efficacy scores, and as a result, the relative independence of the two factors is not acknowledged and many subtle, and often divergent, relationships between the independent variables and each of the two factors are missed.

In a large study of 1,802 teachers, Moore and Esselman (1992) analyze the effects of several organizational variables on both teaching efficacy and personal teaching efficacy. They found that while greater influence in school-based decision making was significantly related to high self-percepts of personal teaching efficacy, greater staff collegiality was significantly related to high teaching efficacy.

In similar fashion, a study of preservice teachers at different stages of their training conducted by Gibson and Brown (1982, cited in Dembo \& Gibson, 1985 ) revealed that prospective teachers with the least amount of training had low self-percepts of personal teaching efficacy but high self-percepts of teaching efficacy. In addition, while personal teaching efficacy continued to grow as a result of course work and experience (declining only as a result of the practicum experience), teaching efficacy slowly declined as they gained more experience. This was also confirmed by a study conducted by Hoy and Woolfolk (1993). 
The variable effect of the two factors and their interrelated patterns is also supported by research conducted by Greenwood, Olejnik, and Parkay (1990). They suggest that teachers can have any of four patterns of teacher efficacy beliefs made from various combinations of personal teaching efficacy and general teaching efficacy:

Pattern 1 low personal teaching efficacy, low teaching efficacy "I can't; teachers can't"

Pattern 2 low personal teaching efficacy, high teaching efficacy "I can't; teachers can"

Pattern 3 high personal teaching efficacy, high teaching efficacy "I can; teachers can"

Pattern 4 high personal teaching efficacy, low teaching efficacy "I can; teachers can't"

In a study of 321 teachers in nine low-stress and nine high-stress schools which used the two Rand items to measure teacher efficacy and the Wilson Stress Profile for Teachers to measure stress, Greenwood et al. found that Pattern 1 teachers had significantly higher stress scores than Pattern 2 or Pattern 3 teachers on three subscales: student behavior, psychological and emotional symptoms, and stress management. In addition, Pattern 3 teachers were significantly more likely to attribute both student successes and failures to their own ability or effort than were Pattern 1 teachers.

However, as Hoy and Woolfolk (1993) suggest, not all researchers report separate findings for personal teaching efficacy and teaching efficacy. Thus, the review of the research that follows will sometimes report only findings related to teacher efficacy. 
Research Related to Preservice

Teachers' Sense of Efficacy

Given the presumed importance of strong self-percepts of teacher efficacy to effective teaching and student achievement, educational researchers are also interested in what effect teacher education has on prospective teachers' sense of efficacy.

In a study of student teachers enrolled in a teacher education program at the University of British Columbia, Housego (1992) found that student teachers showed significant increases in personal teaching efficacy in the third and fourth terms of the final professional preparation component of the University of British Columbia's teacher education program. However, thirdand fourth-term scores for teaching efficacy were significantly lower than baseline or first-year scores. A study of Korean teachers, conducted by Gorrell and Hwang (1995), also showed preservice teachers increased their selfpercepts of personal teaching efficacy, but not their teaching efficacy, over a 4-year training period. In a similar study, Allan and Wright (1992, cited in Pigge \& Marso, 1993) found significant gains in five of the the nine personal teaching efficacy items of the Gibson and Dembo scale from the beginning to the end of student teaching.

Evans and Tribble (1986) found that preservice elementary and female teachers had stronger perceptions of teaching efficacy than their preservice secondary and male counterparts. Housego (1992) also found significant differences in male and female efficacy scores: Mean teacher efficacy scores were significantly different for males and females in Terms 2, 3, and 4, while personal teaching efficacy subscores of males and females significantly differed in Term 2. Housego also found significant differences in teaching efficacy between primary- (Grades 1 to 3) and intermediate-level (Grades 4 to 6) student teachers. 
Differences in self-percepts of personal teaching efficacy also make a difference in preservice teachers' decisions related to teaching. A study by Czerniak and Schriver-Waldon (1991, cited in Ross, 1994a) indicates that preservice teachers with high personal teaching efficacy were more likely to choose instructional strategies for their ability to increase student learning, while student teachers with low personal teaching efficacy chose methods believed to reduce noise and confusion.

Research Related to Changes in Teacher Efficacy

Research findings suggest that self-percepts of teaching efficacy are not static but rather change over different contexts and situations, as well as over time. Research indicates that self-percepts of efficacy for teaching change during preservice training and over the career span. In addition, preservice teachers' sense of efficacy differs from that of experienced teachers.

Changes in preservice teachers' sense of efficacy. Preservice teachers have been found to begin their teacher education with high confidence in the ability of teaching to overcome adverse home conditions (teaching efficacy), but this confidence declines after the first year of study (Saklofske, Michayluk, \& Randhawa, 1988, cited in Ross, 1994a). Alternately, preservice teachers' personal teaching efficacy is believed to increase every year of their training (Housego, 1992; Hoy \& Woolfolk, 1993) and to continue to increase into the first few years of teaching (Hoy \& Woolfolk, 1993).

Preservice and experienced teachers. Dembo and Gibson (1985) found that preservice teachers had higher confidence in the ability of teaching to overcome adverse home conditions (teaching efficacy) than experienced teachers. However, item analysis of the data collected for preservice and practising teachers notes a difference in self-percept of efficacy for different skills: Student teachers report higher personal teaching efficacy for 
motivating students than experienced teachers, while experienced teachers feel more efficacious planning and evaluating lessons than preservice teachers (Benz, Bradley, Alderman, \& Flowers, 1992, cited in Ross, 1994a).

In a variation of this theme, Pigge and Marso (1993) found no significant mean differences between teachers grouped into four career stages: preservice, early career, midcareer, and late career. However, an itemby-item analysis revealed significant differences among teacher groups on three of the nine personal teaching items and two of the seven teaching efficacy items. For example, preservice teachers were less sure than early career and midcareer teachers that they could redirect disruptive students and find better ways to help students get a better grade. However, they believed more strongly that good teaching could make a difference than did teachers in the early and midcareer groups. They also believed less strongly than midcareer teachers that their efforts could make a difference but more strongly believed that hours in class could make a difference.

Evans and Tribble (1986) also found that preservice teachers' concerns differed from those of beginning teachers: While both groups were concerned about student motivation, preservice teachers emphasized problems with teaching subject matter, and beginning teachers stressed problems with discipline, assessment of student work, and relationships with parents.

As an interesting aside, a recent international study of student teachers in several countries conducted by Gorrell, Hazareesingh, Carlson, and Sjoblom (1993, cited in Gorrell \& Hwang, 1995) found American preservice teachers had consistently more positive teaching efficacy beliefs than practising teachers in Sweden and Sri Lanka.

Practising teachers. The first year of teaching sees a definite change in teacher efficacy beliefs and attitudes towards teaching (Bullough, 1989, cited in Chester \& Beaudin, 1996). Hogben and Petty (1979, cited in Chester, 1991) 
posit that the first few weeks of a new teaching career can profoundly affect beginning teachers' attitudes. In addition, first-year teachers often reevaluate their professional knowledge downward over the course of the year (Gaede (1987, cited in Chester, 1991).

Similarly to preservice research, Hoy and Woolfolk (1993) found differences in the growth or decline of experienced teachers' efficacy beliefs depending on the factor being analyzed: In their study, general teaching efficacy of experienced teachers declined over time, while personal teaching efficacy increased for the first 5 years. Ross (1994a) posits that this decline in general teaching efficacy could be the result of increased awareness of student variability and the realization that this variability could affect teachers' ability to influence all children. Alternately, Ross (1994) suggests that beliefs that some children cannot be influenced may be a way to protect self-percepts of teaching efficacy: If no one can influence these children (the basis of teaching efficacy), then one does not have to lower one's selfpercepts of personal teaching efficacy.

Teachers' sense of efficacy may also decline as a result of change in context. In a study of 173 newly hired teachers, a third of whom had no previous teaching experience, Chester (1991) found that a new school differentially affected experienced and beginning teachers. When background characteristics were not controlled for, he found a significant decline in mean self-efficacy scores over the first year in a new school for older and younger experienced teachers and older novice teachers but not for younger novice teachers. This is confirmed by Chester's later study (Chester \& Beaudin, 1996) using the Gibson and Dembo (1984) scale. 
The Effects of Organizational

Variables on Teacher Efficacy

In the tradition of social cognitive theory discussed later in this chapter, self-beliefs of teacher efficacy are believed to be influenced by environmental factors. In fact, as previously stated, one subfactor of teacher efficacy, teaching efficacy, is concerned with perceptions of the effect of parent, family, and home environment on teachers' capability to influence student achievement. In addition, at least one conceptualization of teacher efficacy includes an untested factor called organization efficacy (Fuller Wood, Rapoport, \& Dornbusch, 1982), or perceptions of one's capabilities to influence others at different levels within the school. However, most researchers consider organizational variables to be antecedent conditions which can affect teachers' sense of efficacy both negatively and positively.

In one study of organizational variables and teacher efficacy, Smylie (1988, cited in Smylie, 1990) found positive but statistically nonsignificant relationships between teaching efficacy and school characteristics of goal clarity, supervisor feedback, and collegial interaction. However, in their previously mentioned study of the effect of six organizational variables on teacher efficacy, Hoy and Woolfolk (1993) found that organizational variables had significant differential effects on personal teaching efficacy and general teaching efficacy. Using a short 5-item form of the Woolfolk and Hoy (1990) teacher efficacy scale, a 39-item Organizational Health Inventory, and several demographic items, they surveyed 179 elementary teachers randomly selected from 37 schools in New Jersey. Hoy and Woolfolk (1993) found that principal influence, academic emphasis, as well as teaching experience, teacher educational level, and gender, correlated significantly and positively with personal teaching efficacy. Alternately, only academic emphasis and institutional integrity (described as the school's ability to cope with its 
environment in a way that maintains the educational integrity of its programs) correlated significantly and positively with general teaching efficacy, while teaching experience correlated negatively.

Subsequent multiple regression and hierarchical multiple regression analyses led Hoy and Woolfolk (1993) to conclude that only two aspects of the organization, principal influence and academic emphasis, made unique contributions to predicting personal teaching efficacy, and only institutional integrity made a unique contribution to predicting general teaching efficacy.

The positive effect of strong principal leadership on a general teacher attitude of efficacy has also been found by Brookover and Lezotte $(1977$, cited in Hoy \& Woolfolk, 1993). Further, high-efficacy teachers have also been found to be more likely than low-efficacy teachers to view school and central office administrators as supportive and helpful (Miller, 1989, cited in Miller, 1991).

Research findings related to the effect of having enough resources on teachers' sense of efficacy are mixed. Resource support had no independent or interaction effect on teachers' sense of efficacy in the Hoy and Woolfolk (1993) study. However, Chester (1991) found that changes in self-efficacy for older experienced or novice teachers were

substantially higher than the baseline values for their age when they are placed in schools with high levels of resources and considerably lower when they are placed in schools with low levels of resources. For young teachers, the effect reverses. (p. 249)

Professional interactions. Various kinds of professional interactions have be studied for their effect on teachers' sense of efficacy. Two of the most mentioned are collegial or collaborative interactions with other teachers and supervisory interactions. 
In addition to Smylie's study, Rosenholtz (1989, cited in Smylie, 1990) also found positive relationships between teaching efficacy and opportunities for feedback and to collaborate with other teachers about instruction (also see Ashton \& Webb, 1986). Similarly, Ashton and Webb (1986) found a positive relationship between teaching efficacy and participation in school decision making, while Cavers (1988) found that personal teaching efficacy correlated positively with horizontal communication, that is, communication between and among teachers. In a related study using a modified 14-item Gibson and Dembo scale, Chester and Beaudin (1996) found that all teachers (regardless of age or experience) who saw their new school as highly collaborative reported higher values of teacher efficacy. Interestingly, research done by Poole and his colleagues shows teachers with high teaching efficacy were more likely to implement curriculum guides if they collaborated more with others (Poole \& Okeafor, 1989, cited in Ross, 1992), while teachers with high personal teaching efficacy were more likely to implement them if they collaborated less (Poole, Okeafor, \& Sloan, 1989, cited in Ross, 1992).

Finally, from a staff development perspective, McDaniel and DibellaMcCarthy (1989, cited in Miller, 1991) found that coaching, case study problem solving, and collaboration with support personnel can contribute to growth in efficacy. In addition, Ross (1992) found that the combined effect of teacher efficacy and the two underlying factors of personal teaching efficacy and teaching efficacy, along with using a teaching coach and having a coaching network, correlated positively with student achievement. Personal teaching efficacy and the reported use of a coach predicted student improvements in achievement, while mean student achievement was negatively correlated with reliance on administrator help. These studies are confirmed by Little's (1982) study of teachers working together to change their instructional practices. 
She found that professional and collegial relations focused on teaching increased a "can do" attitude among school staff.

Teacher supervision. One subfactor of teacher efficacy, teaching efficacy, has been found to positively correlate with supervision practices: Teaching efficacy was found to be a significant predictor of the valence of superintendent appraisals (Trentham et al., 1985, cited in Ross, 1994a), principal appraisals ( Riggs \& Enochs, 1990, cited in Ross, 1994a), and student teacher appraisals by university faculty (Saklofske et al., 1988, cited in Ross, 1994a). In addition, Coladarci and Breton's (1991) study of 580 resource room teachers in Maine using a modified Gibson and Dembo scale showed that the perceived utility of supervision was significantly related to the teacher efficacy.

School and grade level. Ross (1994a) reports many studies that indicate differences in the level of efficacy of elementary and secondary students. Elementary teachers have been found to have higher efficacy for teaching than high school teachers (Guskey, 1982, cited in Ross, 1994a; also see Greenwood et al., 1990) and than middle school teachers (Midgley, Feldlaufer, \& Eccles, 1988, cited in Ross, 1994a). Teachers of Grade 3 students were also found to have higher teaching efficacy than those in Grade 6 (Anderson et al., 1988, cited in Ross, 1994). Bandura (1993) posits that this may be the result of a "quadratic relationship between grade and efficacy" (cited in Ross, 1994, p. 13). According to Bandura, low-efficacy teachers of kindergarten children are influenced by the relative unpreparedness of children to know how to be a good student. As students learn the routines and master tasks in kindergarten and Grade 1, teachers' sense of efficacy increases, but as academic demands increase and deficits in student learning become more pronounced, efficacy can again decrease. 
There is also some research that suggests that the amount of success schools experience in influencing students also affects self-efficacy for teaching. For example, Brookover and his colleagues found that teachers in high-achieving school had a higher sense of efficacy (Brookover \& Lezotte, 1979, cited in Gibson \& Dembo, 1984), spent more time in instruction, and demonstrated greater concern for and commitment to their students (Brookover, 1978, cited in Gibson \& Dembo, 1984). Smylie (1988) also found that school context had a significant indirect influence on efficacy through a measure of teachers' certainty about what constitutes effective teaching (cited in Smylie, 1990). Perhaps, a concerted effort based on similar beliefs first influences teacher efficacy, which then affects student achievement, which then creates a school marked by high achievement. Schools with high teaching efficacy then affect both teacher efficacy and student achievement. For example, high-efficacy schools have been shown to have math achievement scores 3 months higher than those of schools with low teaching efficacy (Smylie, 1990).

Some research suggests that schools organized for specific purposes also affect teachers' sense of efficacy. For example, Moore and Esselman's (1992) study of 1,802 teachers, using school-level factor scores of teacher efficacy as the unit of analysis, revealed that teachers in magnet schools reported a lower sense of teacher efficacy than teachers in regular schools. In an earlier study, Ashton and Webb (1986) found that teachers in schools organized for multiage classrooms and a focus on team teaching had higher teacher efficacy than teachers in more traditional schools.

Classroom effects on teacher efficacy. Both Smylie (1988, cited in Smylie, 1990) and Guskey (1987) found a positive and statistically significant relationship between teaching efficacy and classroom context variables, particularly the achievement levels of students. In addition, Raudenbusch, 
Rowen, and Cheong (1992) found that when teachers felt prepared to teach a particular subject or students in a particular ability group, they had higher self-percepts of teaching efficacy. Ashton, Webb, and Doda (1983, cited in Ross, 1994a) reaffirm the large impact of student ability on teaching efficacy, while Newman, Rutter, and Smith (1989, cited in Ross, 1994a) found that the orderly behavior of students was also a strong predictor of teacher efficacy. Cavers (1988) also found that student behavior positively correlated with personal teaching efficacy. In addition, interactions with students have been found to have a potent effect on teachers' self-percepts of efficacy regarding classroom management and planning of curriculum and lessons (Bullough, 1989, cited in Chester, 1991).

Teachers with higher teacher efficacy are also known to think about and deal with low-achieving students differently than do teachers with lower teacher efficacy. Soodak and Powell (1993) found that regular educators with high personal teaching efficacy thought a regular classroom placement more appropriate for the education of special needs students than did teachers with low personal teaching efficacy. In addition, while teachers with both high personal teaching efficacy and high teaching efficacy found regular classroom placements appropriate, they differed significantly from teachers with high personal teaching efficacy but low teaching efficacy.

In related research, Gibson (1981, cited in Miller, 1991) found that highefficacy teachers referred fewer students, while Riffle (1985, cited in Miller, 1991) found that teachers' efficacy beliefs for educating lowability students influenced their rate of referral. Supporting this finding, Miller (1987, cited in Miller, 1991) found that high-efficacy teachers referred difficult students to Special Education services only as a last resort. Similarly, Podell and Soodak (1993, cited in Ross, 1994a) found that high-efficacy teachers were more willing to develop in-class programs for special needs students rather than 
referring them. Ross (1994a) suggests that a strong sense of efficacy appears to be "an enabling factor increasing teachers' acceptance of difficult instructional challenges" (p. 23). Finally, teachers in resource rooms were shown to have higher teacher efficacy when they were satisfied with their classroom assignment (Coladarci \& Breton, 1991).

Relationship Between Sense of Teacher Efficacy

and Student Achievement

Teachers with a strong sense of efficacy believe they are capable of positively influencing student achievement and are proud of their successes (Ashton \& Webb, 1986). Studies also show that teaching efficacy (one factor of teacher efficacy) is positively related to student achievement (Ashton \& Webb, 1986; McLaughlin \& Marsh, 1978)). Alternately, teachers with low perceptions of efficacy tended to avoid challenging activities, to reduce their effort or give up in the face of difficulty, and to doubt their ability to affect student achievement (Ashton \& Webb, 1986).

Teachers with strong perceptions of teacher efficacy also differed from low-efficacy teachers in the attributions they hold regarding student success and failure: Teachers who scored high on either teaching efficacy or personal teacher efficacy using the two Rand items placed significantly greater importance on student ability and the program of study as factors influencing student performance than their colleagues who reported low personal teaching efficacy (Hall, Hines, Bacon, \& Koulianos, 1992). Teachers with high personal teacher efficacy found teacher influence to be of significantly greater importance in explaining academic failure than did teachers with low personal teaching efficacy. Alternately, teachers with low teaching efficacy attributed significantly greater importance to home influence as an explanation for student success than did teachers with high teaching efficacy. 
From a different perspective, Hall, Hines, Bacon, and Koulianos (1992) found that teachers with high teaching and personal teaching efficacy believed their ability was an important aspect of student success, while Brookhart and Loadman (1993, cited in Ross, 1994a) found that teachers with high personal teaching efficacy attributed not only student success, but also student failure, to their own actions.

Relationship Between Teacher Efficacy and Students' Achievement in Particular Subject Areas

Of particular interest is the differential relationship between each of the factors of teacher efficacy and student achievement in particular subject areas. Ashton and Webb (1986) report a strong correlation between high teaching efficacy and higher student cognitive outcomes and student achievement in math. Alternately, Rose and Medway (1981, cited in Ross, 1994a) found that personal teaching efficacy also predicted math instruction practices. In addition, personal teaching efficacy was positively related to student achievement in reading, language arts, and social studies (Ashton \& Webb, 1986).

Using the two Rand items, Armor et al. (1976, cited in Ross, 1994a) found that teacher efficacy predicted large and consistent gains in reading achievement after Grade 6, while Rosenholtz (1989, cited in Ross, 1994a) found similar predictive effects for gains in Grade 4 reading achievement. This relationship, however, was not found in Grade 2. Finally, Berman and McLaughlin (1977) found significant positive relationships between gains in minority students' reading scores on standardized tests and levels of teacher efficacy (again using the Rand items to measure efficacy). In addition, high levels of school collegiality were also significantly and positively related to higher reading scores (Moore \& Esselman, 1992). 
From a teacher perspective, Rubeck and Enochs (1991, cited in Ross, 1994a) found that high personal teaching efficacy for chemistry was strongly correlated with beliefs that the effort to teach chemistry was worthwhile. Relationship Between Sense of Teacher Efficacy and Teacher Instruction and Management Behavior

Research indicates a relationship between teachers' classroom decision making and behavior and perceptions of teacher efficacy.

As a result of interviews with Grade 1 to 3 teachers, Miller (1987, cited in Miller, 1991) found that high-efficacy teachers believed that good teaching makes a difference regardless of external obstacles. In addition, while both low- and high-efficacy teachers gave themselves high ratings for ability to teach and their success with low-ability students, high-efficacy teachers could be differentiated from low-efficacy teachers in their ability to articulate more teaching strategies and to identify specific strategies for low-ability students, as well as in their use of more positive and professional language, in their perceptions of low-ability students as wanting and able to learn, and in their sense of responsibility for difficult learners and their willingness to persist with them.

Effects of teacher efficacy on instruction. High self-percepts of teaching efficacy were associated with the tendency to use new curricula (Guskey, 1988, cited in Ross, 1994; Poole, Okeafor, \& Sloan, 1989, cited in Kagan, 1992) and to make changes in practices (Berman \& McLaughlin, 1977; Smylie, 1988, cited in Kagan, 1992). Stein and Wang (1988, cited in Ross, 1994a) posit that changes to teaching practices precede changes in teaching efficacy.

Teachers with a strong sense of teacher efficacy tend to spend more time out of school in planning (Miller, 1989, cited in Miller, 1991) and tend to choose more challenging learning activities, to maintain focus on academics, and to try harder when faced with obstacles (Ashton \& Webb, 1986). They also 
praised low-ability students more, criticized them less, and persisted with them longer in failure situations (Gibson \& Dembo, 1984) than low-efficacy teachers. Teachers high in teaching efficacy also promoted student autonomy (Midgley et al., 1988, cited in Ross, 1994a) and were more successful keeping students on-task (Ashton et al., 1983, cited in Ross, 1994a).

High-efficacy teachers also spent more time in whole-group instruction than their low-efficacy counterparts (Gibson \& Dembo, 1984) and were more likely to communicate high expectations for students (Ashton \& Webb, 1986; Gibson \& Dembo, 1984). However, when they did use small-group instruction, high-efficacy teachers were more able to keep other students actively engaged than their low-efficacy counterparts (Gibson \& Dembo, 1984). In contrast to Gibson and Dembo's (1984) findings, Ross's (1994a) review of the literature suggests that teachers with high teaching efficacy tend to use powerful teaching strategies that are more difficult to implement than wholegroup instruction, including small-group techniques (Tracs \& Gibson, 1986, cited in Ross, 1994a), cooperative learning (Dutton, 1990), and activity-based methods (Riggs \& Enochs, 1990, cited in Ross, 1994a). High efficacy also correlates with self-reported use of effective teaching strategies for gifted and talented children (Starko \& Schack, 1990, cited in Ross, 1994a) and for mildly handicapped children in mainstream classrooms (Bender \& Ukeje, 1989, cited in Ross, 1994a).

Elementary teachers with a high sense of teacher efficacy were found to be more effective in leading students to a correct answer, to have higher rates of on-task student behaviors, to spend more time monitoring and checking seat work, and to spend less time in small group instruction than teachers with low teacher efficacy (Gibson \& Dembo, 1984).

On the other hand, junior high school teachers with high teacher efficacy tend to maintain high academic standards and on-task behavior, 
transmit clear expectations to students, and give high priority to academic instruction (Ashton \& Webb, 1986).

Effects of teacher efficacy on classroom management. High personal teaching efficacy was positively related to setting warm and secure classroom climates which supported students' initiatives and needs (Ashton \& Webb, 1986). In addition, high-efficacy teachers were also reported less likely to display anger or feel threatened when students misbehaved (Barfield \& Burlingame, 1974). Low-efficacy teachers were found to be more likely to rely on positional rather than relationship power, and they tended to sort and classify students by ability and to ignore low achievers (Ashton \& Webb, 1986). On the other hand, high-efficacy teachers were more likely to trust low achievers and to establish encouraging relationships with them (Ashton \& Webb, 1986). In addition, teachers high in teaching efficacy responded actively rather than passively to classroom management problems (Korevaar, 1990 , cited in Ross, 1994a), felt more confident in their capability to use classroom management techniques, and rated management problems as less severe (Payne, Ford, \& Wisenbaker, 1992, cited in Ross, 1994a).

Low-efficacy teachers are often more concerned with control issues related to discipline and classroom management (Barfield \& Burlingame, 1975) but are less likely to display "withitness" than are high-efficacy teachers (Gibson \& Dembo, 1984). In general, low-efficacy teachers spend more energy coping with the environment than their do high-efficacy colleagues.

In a study of 182 liberal arts majors in teacher preparation programs, Woolfolk and Hoy (1990) found that teaching efficacy was negatively correlated with a custodial orientation, $(\underline{r}=-.50, \underline{p}<.01)$, which is one dimension of pupil control ideology, and with bureaucratic orientation $(\underline{r}=-$ $.42, \mathfrak{p}<.01$ ). This suggests that as individuals' teaching efficacy increases, they become more humanistic in their pupil control ideology and less bureaucratic 
in their orientation. This is also confirmed in a study conducted by Ashton and Webb (1986). In a related study, Woolfolk, Rosoff, and Hoy (1990) also found that the higher the personal teaching efficacy of teachers, the less custodial they were in their approach to classroom management. In addition, teachers who were highly custodial were found to see rewards and incentives as necessary ways to control student behavior.

However, interaction effects in the Woolfolk and Hoy (1990) study reveal interesting control patterns: For example, prospective teachers with high teaching efficacy and high personal teaching efficacy were also highly humanistic in their pupil control ideology, while prospective teachers with low teaching efficacy but high personal teaching efficacy were more custodial. In addition, prospective teachers with low teaching efficacy and high personal teaching efficacy were the most bureaucratically oriented. Barfield and Burlingame's (1974) study of teacher efficacy and pupil control ideology also found that teachers in elementary schools were more humanistic than junior high school teachers. No differences were found in pupil control ideology between elementary and senior high school teachers. Teachers in low-socioeconomic-status (SES) schools were also found to be more custodial than teachers in middle- and high-SES schools.

High school teachers with high personal teaching efficacy were found to be more likely than high school teachers with low personal teaching efficacy to maintain secure, accepting classroom environments which encourage student initiative and support the needs of individual students (Ashton \& Webb, 1986). Secondary teachers with high personal teaching efficacy were also more relaxed and friendly and handled misbehavior in more positive ways than high school teachers with low personal teaching efficacy (Ashton \& Webb, 1986). Secondary teachers with low teacher efficacy tended to define the classroom in terms of conflict and control and tended to 
use punishment, coercion, and public embarrassment to control the class (Ashton \& Webb, 1986, cited in Woolfolk, Rosoff, \& Hoy, 1990).

Relationship between teacher efficacy and student affect. High teacher efficacy has been found to enhance students' motivation (Ashton \& Webb, 1986), improve student self-direction (Rose \& Medway, 1981, cited in Ross, 1994a), and increase their feelings of self-esteem (Borton, 1991). High teacher efficacy has also been known to contribute to more positive student attitudes towards school (Miskel et al., 1983, cited in Ross, 1994a).

Parent involvement. Hoover-Dempsey et al. (1987, 1992, cited in Ross, 1994a) found that teachers who were confident in their abilities (high personal teaching efficacy) were more likely to involve parents in school conferences, in volunteering, and in home monitoring.

This relatively brief review of the teacher efficacy literature suggests the teachers' perceptions of their efficacy have widespread effects on schooling. However, as the next section enumerates, there are some limitations to this research.

\section{Concerns With Current Conceptualizations and}

Measurements of Teacher Efficacy

The research literature proposes several deficiencies in the conceptualization and measurement of teacher efficacy which may limit the validity and, therefore, the usefulness of research findings:

1. The variety of definitions of teacher efficacy and the various scales used to measure teacher efficacy leave researchers and research consumers uncertain about what has been actually measured (Ross, 1994a).

2. Similarly, concerns have been raised related to the items on the scale and the proposed meaning underlying the two factors (Ross, 1994a).

Ross (1994a) suggests that items on the Gibson and Dembo scale "overlap 
with locus of control, confuse efficacy with outcome expectancy, are susceptible to response bias, ... and are too general to meet Bandura's definition of self-efficacy as a situation specific construct" (p. 6). Kushner (1993) posits that, despite the wide use of both Gibson and Dembo's (1984) Teacher Efficacy Scale and Woolfolk and Hoy's (1990; also see Guskey \& Passaro, 1993) modified version, the model does not fit the data very well and proposes that items on both scales be either revised or eliminated.

3. Most conclusions about teacher efficacy are the result of analyses and interpretations of correlational data. Such methods make it difficult to establish cause-and-effect patterns which would be helpful to know in order to develop and maintain strong feelings of teacher efficacy among teachers (Ross, 1994).

4. By conducting one-time measurements of teacher efficacy, researchers treat teacher efficacy as a global trait rather than as a contextually sensitive state (Ross, 1994a). Such a perspective limits our understanding of changes in teacher efficacy that can occur across contexts, across situations, and over time (Ross, 1994a).

5. The aggregation of data from the two subscales not only increases chances for misinterpretations of the results, but also increases the likelihood that important relationships among variables and subtle differences in teachers' beliefs will be missed (Ross, 1994a).

For example, using the composite score of both factors in data analysis can miss important within-teacher differences between personal teaching efficacy and teaching efficacy, as well as differences in the reciprocal relationship of each factor with other teaching-related variables (Greenwood, Olejnik, \& Parkay, 1990; Hoy \& Woolfolk, 1993; Ross, 1994a).

While these five limitations all create potential problems for the interpretation and use of teacher efficacy research, this study is most 
concerned with those limitations related to the development of the teacher efficacy model. The following section discusses these shortcomings in depth.

\section{Reconceptualizations of the Underlying Factors}

A major concern with the Gibson-Dembo model has been the substantive meaning attached to each of the two subscales, particularly teaching efficacy. Studies conducted by Woolfolk and Hoy (1990) and Guskey and Passaro (1993) have sought to better understand what each factor is measuring.

\section{Redefining Personal Teaching Efficacy}

Using Bandura's definition of self-efficacy as the foundation, Woolfolk and Hoy (1990) define personal teaching efficacy as "the teacher's judgments of his or her personal ability to execute particular courses of action" (p. 82) and consider it to be similar to the related Rand item and to Gibson and Dembo's definition of personal teaching efficacy. However, when they conducted an exploratory factor analysis of data collected using a modified Gibson and Dembo (1984) teacher efficacy scale, a three- rather than a two-factor solution emerged, which, on analysis, served to clarify the substantive content of personal teaching efficacy. Woolfolk and Hoy (1990) found that while items loading on teaching efficacy (Factor 2) "remained virtually the same" (p. 86), items loading on personal teaching efficacy became two moderately but negatively correlated factors $(\underline{r}=-.42)$.

Woolfolk and Hoy consider these two new factors to follow Guskey's (1981, cited in Woolfolk \& Hoy, 1990) conception of personal teaching efficacy as "teachers' sense of personal responsibility for positive student outcomes (Factor 3) and responsibility for negative student outcomes (Factor 1)" (p. 86). Because the two factors represent a continuum of teachers' sense of responsibility, with responsibility for student successes on one end of the continuum and responsibility for student failures on the other, Woolfolk and 
Hoy conclude that Factors 1 and 3 are really dimensions of the one factor and not two separate factors. Thus, they continue to use Gibson and Dembo's (1984) two-factor model.

\section{Redefining Teaching Efficacy}

The first impetus to redefine teaching efficacy was the result of a dissatisfaction with the explanation of teaching efficacy as outcome expectancies. Bandura (1986) defines these expectancies as the perceived consequences or rewards that accrue as a result of one's actions or performance. After a discussion with Bandura in June of 1988, Woolfolk and Hoy (1990) concluded that "the question of whether teachers can override the effects of adverse background influences (Rand Item 1) is an efficacy expectation, not an outcome expectation, because it involves the potential to perform" (p. 82) rather than expectancies of possible consequences. This further suggests that items loading on teaching efficacy may more accurately indicate perceptions of one's capability to exercise control over the environment.

Thus, Woolfolk and Hoy (1990) redefine teaching efficacy as an efficacy expectancy, concerned with teachers' capabilities to exercise control over the environment and with their potential to perform. Maintaining the focus on teachers or teaching in the general sense, they see teaching efficacy as "the power of the school to overcome home and background factors" (p. 86) or as a "general belief in the power of teaching to reach difficult children" (Hoy \& Woolfolk, 1993, p. 357). To emphasize the general nature of this factor they have relabelled it as "general teaching efficacy" (p. 357).

Woolfolk and Hoy make a significant contribution to our understanding of the second factor of teacher efficacy and offer a new interpretation of its substantive meaning. However, the focus of general teaching efficacy on teachers in general, which is also maintained by Gibson and Dembo (1984), has 
been subject to scrutiny by other researchers.

A recent "systematic replication" (Van Wagenen, 1991, p. 60) by Guskey and Passaro (1993) of the factor analyses conducted by Woolfolk and Hoy (1990) and Gibson and Dembo (1984) suggests that the current conceptualization of teacher efficacy may need to be further revised. Guskey and Passaro (1993) used the 16 items from Gibson and Dembo's (1984) construct validation, 3 new items from the Woolfolk and Hoy (1990) measure, and the 2 Rand items in order to make a new scale. They then reworded a random selection of these 21 items to reflect each of four dimensions: 5 of the items represented a personalinternal dimension ("I can influence"); 5 items represented a personalexternal dimension ("I can't influence"); 5 items, a teaching-internal dimension ("teachers can influence"); and 6 items, a teaching-external dimension ("teachers can't influence"). For example, note the changes made to the following Gibson and Dembo items. The first Gibson and Dembo sample item reads as follows:

When the grades of my students improve, it is usually because I found more effective teaching approaches.

In the Guskey and Passaro (1993) scale, this item is changed from a personalinternal dimension to represent a teaching-internal dimension as follows:

When the grades of students improve, it is usually because their teachers found more effective teaching approaches. The second Gibson and Dembo sample item reads as follows:

When a student is having difficulty with an assignment, I am usually able to adjust it to his/her level.

Guskey and Passaro (1993) change this item from a personal-internal dimension to the personal-external dimension as follows:

When a student is having difficulty with an assignment, I often have trouble adjusting it to his/her level. 
Using data collected from the administration of this modified scale to 283 experienced teachers and 59 preservice teachers, Guskey and Passaro (1993) conducted a principal components confirmatory factor analysis for a twofactor solution. The two factors had eigenvalues of 4.43 and 2.30 , respectively, and accounted for $32 \%$ of the variance $(\underline{r}=.237)$ in explaining teacher efficacy. However, the 11 items which loaded on Factor 1 were all negative and external, while the remaining 10 items loading on Factor 2 were positive and internal.

In addition, both personal ("I") and general teaching ("teachers") items could be found in both factors. Thus, the first modified sample item, noted above, continued to load on personal teaching efficacy (Guskey and Passaro's internal factor), despite the change from the personal to the general perspective. However, the second sample item, which had been modified from a personal-internal perspective to a personal-external perspective, now loaded on teaching efficacy rather than personal teaching efficacy. Another interesting change in factor loading occurred with the following Gibson and Dembo item:

The influences of a student's home experience can be overcome by good teaching.

This unchanged item had loaded negatively on the teaching efficacy factor in the Gibson and Dembo study, but now loaded positively on Guskey and Passaro's internal (or personal teaching efficacy) factor.

Guskey and Passaro (1993) conclude that there is "no evidence to indicate the distinction between these two dimensions related to a personal teaching efficacy versus a teaching efficacy difference" (p. 9). They also question the accuracy of explaining personal teaching efficacy and teaching efficacy in terms of Bandura's (1986) self-efficacy and outcome expectancies. However, they are quick to point out that a simple internal-external locus does 
not adequately explain the new loadings either and suggest that perhaps one of the new factors captures perceptions of personal power within the classroom, while the other captures perceptions of the power of outside variables (specifically home, family, and parents) to have an impact on teaching and learning situations.

Thus, despite Guskey and Passaro's (1993) denouncement of a teaching efficacy factor, they continue to maintain the general focus of the second factor. Their interpretation of the meaning underlying this second factor is also limited by the fact that it suggests only a one-way influence of outside variables on teaching and learning and does not account for the individual's perceptions of his or her ability to reciprocally influence the environment.

A third study conducted by Midgley, Feldlaufer, and Eccles (1989, cited in Woolfolk \& Hoy, 1990) moves away from a general teaching efficacy factor altogether to posit a personal factor with two dimensions. Analysis of data collected using a five-item scale (two of which were the Rand items) resulted in defining efficacy as a personal dimension with a teacher's sense of optimism "in affecting student achievement" (p. 83) on one end of the continuum and his or her sense of futility on the other. This seems to be an overly simplistic conceptualization of efficacy for such a complex task as teaching.

Another approach to delineating the underlying factors of teacher efficacy has been proposed by Fuller, Wood, Rapoport, and Dornbusch (1982). They conceive teachers' sense of efficacy as having a performance component and an organizational component. The performance efficacy component, while similar to personal teaching efficacy, differs from the Rand items and other definitions of personal teaching efficacy by focusing more specifically on teaching competencies, with little reference to their effect on student achievement. They define performance efficacy as "perceived 
efficacy in performing one's own work tasks, independent of social interaction with other staff members of the school organization" (p. 9). Their second component, organization efficacy, "refers to an organizational actor feeling efficacious in gaining valued outcomes by influencing another person in a different level of the organization" (p. 9). While this factor adds a new inschool-influence dimension to the model of teacher efficacy, Fuller and his colleagues fail to account for the influence of external factors, such as parents, family, and home environment, on a teacher's sense of efficacy.

The advantage of this two-factor conceptualization of teacher efficacy is that it grounds teacher efficacy within an occupational framework (work tasks) and within the context of the school. Unfortunately, the narrow focus of the organizational factor, which is definitionally limited to teacher influence at other levels of the organization, does not account for other important interactional aspects of the teaching role or for the many other inschool and external-context variables known to affect teacher performance.

Despite their individual limitations, these four conceptualizations of teacher efficacy do point to possible next steps in the reconceptualization of teachers' sense of efficacy. For one thing, they appear to support the commonsensical notion that, in addition to perceptions of what teachers in general can or cannot accomplish in a given context, teachers also have perceptions of their own capacity to bring about change in light of constraining factors external to them, including, but not necessarily limited to, home environment, family background, and parental influence. Teacher Efficacy as a Multidimensional Construct

The call to reconceptualize teacher efficacy is not limited to the above researchers. In fact, despite several theoretical and/or experimental validations of the two teacher efficacy factors (Ashton \& Webb, 1986; Gibson \& Dembo, 1984; Denham \& Michael, 1981; Woolfolk \& Hoy, 1990; Guskey \& Passaro, 
1993), almost all researchers and theorists reviewed called for continued exploration and delineation of the factors and refinement of the scales used. For example, Dembo and Gibson (1984) conclude that teacher efficacy is a multidimensional construct and that the moderate correlation of the two factors indicates the importance of continuing to study teacher efficacy as a multivariate construct. Smylie (1990) suggests that "we remain confronted with an evidential problem and a problem of reaching a common understanding of what teacher efficacy means" (p. 64). He emphasizes that the "possibility that teachers possess different senses of efficacy that operate in different ways in relation to different dimensions of their work has yet to be adequately explored" (p. 62). Alternately, Good and Tom (1985) urge researchers to distinguish between teacher efficacy and teachers' expectations and to study how situations affect teacher efficacy (cited in Guskey \& Passaro, 1993). Fuller, Wood, Rapoport, and Dornbusch (1982) also urge researchers to investigate the specific organizational variables that influence perceived efficacy. Finally, Guskey and Passaro (1993) point to the need for further conceptualization and detailed exploration of the construct of teacher efficacy and the development of "more sophisticated measures of teacher efficacy" (p. 12).

\section{Conclusion}

The theory and research underlying teacher efficacy raised a number of issues related to the model and measurement of teacher efficacy which pointed to need for a reconceptualization of teachers' sense of efficacy. Because most theories used Bandura's self-efficacy theory as a foundation, I turned to social cognitive theory and, in particular, the theory and research on self-efficacy and other related constructs. A review of the literature on social cognition and self-efficacy follows next. 


\section{Introduction}

This section reviews the theoretical and research literature on selfefficacy from a social cognitive perspective. It begins with an overview of social cognitive theory and then focuses on the self-efficacy construct. An expanded definition of self-efficacy is given, followed by discussions on the measurement of self-efficacy and its effects on various aspects of self-referent thought and action. The chapter ends with a description and discussion of a number of types of self-efficacy, with particular focus on those that inform an understanding of teachers' sense of efficacy.

\section{Social Cognitive Theory}

Social cognitive theory separates itself from other psychological theories underlying human functioning not only by its supposition that cognitive processes play a significant and ongoing role in determining one's actions, but also by its recognition that the effects of a person's behavior along with environmental factors also play an important role. While psychodynamic theorists view behavior as motivated by "various needs, drives, impulses, and instincts" (Bandura, 1986, p. 2) and behaviorists consider the cognitive activity that leads to behavior to be primarily influenced by external stimuli, social cognitive theorists believe that cognition gives human beings a "vast potentiality" (p. 21) of responses to the environment.

\section{Cognitive Capabilities}

It is the plasticity of the human mind, and the highly evolved neural system that underlies it, which gives humans their potential for varying their responses to the environment. The plasticity of the human mind provides the necessary conditions for the development of a number of basic cognitive 
capabilities which mediate between internal and external stimuli and human action, and this allows human action to transcend their direct influence.

Bandura (1986) identifies five such basic cognitive capabilities: a symbolizing capability, which allows people to "process and transform transient experience into internal models that serve as guides to action" ( $p$. 18); a forethought capability, which allows people to "motivate themselves and guide their actions anticipatorily" (p. 19); a vicarious capability or "the capacity to learn from observation [and, thus,] acquire rules for generating and regulating behavioral patterns without . . tedious trial and error (p. 19); a self-regulatory capability, which allows people to determine "internal standards and evaluative reactions to their own behavior" (p. 20); and, finally, a self-reflective capability, which allows humans to "analyze their experiences and to think about their own thought processes" (p. 21). Information derived from the use of these five sets of cognitive capabilities is utilized in the formation of self-percepts of efficacy. However, Bandura (1986) does not presume that cognitive processes are the sole determinants of either behavior or perceptions of self-efficacy.

\section{Triadic Reciprocal Causation}

A second major supposition of social cognitive theory is that "behavior, cognitive and other personal factors, and environmental influences all operate interactively as determinants of each other" (Bandura, 1986, p. 23) in a process of triadic reciprocal causation (see Figure 3 ). Within the school context, this means that both students and teachers (or student teachers) not only influence and are influenced by their own thoughts and behavior, but also influence and are influenced by the behavior of others and the social and structural context of the workplace and the larger society. Thus, judgments of self-efficacy are also influenced by the three determinants and tend to vary depending upon the particular circumstances in which they are made. 
Bandura (1986), however, is quick to point out that the reciprocal influence among the three groups of determinants does not necessarily imply "simultaneity of influence" (p. 25) or a symmetrical pattern of influence. Simultaneity of influence cannot be guaranteed because it is only through action that potential influencers are actualized and as "influences are altered by the reciprocal effect ... counter influences undergo reciprocal adjustments during the ongoing sequence of interactions" (p. 30). Similarly, a symmetrical pattern of influence is also not necessarily present. Depending on individuals, circumstances, or activities, one set of determinants may dominate thought and action; for example, when a person is drowning, environmental determinants command central influence.

Thus, the determinants which influence an individual's percepts of self-efficacy, and the resultant self-efficacy beliefs themselves, can change over time and vary under different circumstances. This makes self-efficacy perceptions both domain-specific and situation-specific. That is, one's selfpercepts of efficacy will change depending upon the particular competencies being utilized and the particular situation requiring their use. In addition, the reciprocal influence of the three groups of determinants over time makes it possible for self-percepts of efficacy to be strengthened or weakened as a result of adjustments in one's behavior.

\section{Self-Efficacy Defined}

Although references to individual efficacy can be found as early as the 1950s (White, 1959, cited in Fuller, Wood, Rapoport, \& Dornbusch, 1982), selfefficacy as a psychological construct is best attributed to Albert Bandura (1977, 1986) and his work in social learning theory, now referred to as social cognitive theory. 
According to Bandura (1986), it is primarily as a self-regulatory mechanism of self-referent thought that self-percepts of efficacy influence human action. People use their cognitive capabilities to process a wide variety of information and form perceptions about their "capabilities to exercise control over events that affect their lives" (Bandura, 1992, p. 3) or to "produce and to regulate events in their lives" (Bandura, 1982, p. 122). These perceptions of self-efficacy then regulate human functioning through cognitive, motivational, affective, and selection processes.

Bandura's (1986) research supports perceived self-efficacy as a central mediator between thought and action. While perceptions of self-efficacy are part of a complex, multidimensional, and multidirectional self-regulatory system, Bandura (1986) has been successful in isolating the self-efficacy mechanism from other self-regulatory processes and in analyzing the dynamic interplay among self-referent thought, action, and affect. He has also been able to effect positive changes in individuals' perceptions of selfefficacy using methods such as enactive and vicarious learning.

Formal definition. Bandura (1986) defines self-efficacy as “people's judgments of their capabilities to organize and execute courses of action required to attain designated types of performances" (p. 391). He is careful to point out that efficacy beliefs are not beliefs about what one knows or even about what cognitive, social, or behavioral subskills one has, but beliefs about what one is able to do with one's knowledge and subskills.

\section{Self-Efficacy Appraisals}

Appraisals about what one is able to do with the knowledge and skills one possesses will vary depending upon the courses of action required by a particular activity or depending upon the particular situation in which a person is required to act. For Bandura (1982, 1986), an assessment of selfefficacy is "not a global self-evaluation but instead, is quite tied to particular 
task demands and characteristics of a given situation" (Berry \& West, 1993, p. 17, emphasis mine). Appraisals of efficaciousness are more likely to be made when either the required tasks or the environmental conditions, or both, are uncertain, ambiguous, unfamiliar, or stressful (Berry \& West, 1993, p. 353). When one acts in routine circumstances, one does not always make conscious assessments of one's efficaciousness.

Current self-efficacy appraisals are also influenced by the level, generality, strength (Bandura, 1986, p. 396), and magnitude (Locke, Frederick, Lee, \& Bobko, 1984 , p. 245 ) of preexisting self-perceptions of efficacy. The level of one's efficacy beliefs refers to how efficacious one feels at different levels of task difficulty or complexity. Some people feel highly efficacious performing only simple tasks; others maintain high self-percepts of efficacy even for very difficult and highly complex tasks. Generality refers to one's belief that one will be efficacious in new situations, as well as across a range of contexts, while strength refers to the durability of positive self-perceptions when faced with contrary information. Bandura (1986) suggests that "weak self-percepts of efficacy are easily negated by disconfirming experiences, whereas people who have a strong belief in their own competence will persevere in their coping efforts despite mounting difficulties" (p. 396). Strength of self-efficacy in a particular domain of functioning is often measured by having people indicate the degree of their confidence in being able to perform a number of specific tasks within the domain and calculating the average score (Berry \& West, 1993, p. 355). Finally, the magnitude of one's perceived self-efficacy refers to the number of courses of action that one believes can be mobilized with success. When a set of behaviors within a domain of functioning are ordered hierarchically by difficulty and complexity, magnitude and level are synonymous. 
Sexton and Tuckman (1991) suggest that preexisting perceptions of selfefficacy form a generalized belief in one's efficacy in a particular domain. In a study of mathematics self-efficacy, they distinguish between general mathematics efficacy, defined as general beliefs in one's mathematical ability that derive from past math accomplishments, and situational math selfefficacy, defined as confidence in one's ability to solve a particular set of problems (p. 727). They found that prior to an experience with new math problems and even after the first trial, research subjects made choices about the level of difficulty of the math task they would undertake based on their general efficacy beliefs. These general beliefs then influenced their situational math efficacy. Situational self-efficacy and immediate past performance influenced the level of persistence in solving math problems after the first trial. However, by the third trial, subjects were making decisions about the level of task difficulty and the level of persistence based on immediate past performance rather than either general or situational selfbeliefs of math efficacy. Sexton and Tuckman (1991) conclude that, while performing new tasks, "participants very quickly developed a behavioral pattern that became the source from which their choice of future behavior and persistence were developed" (p. 735).

\section{Developing Perceptions of Self-Efficacy}

The use of feedback from past performances to inform one's future actions supports Bandura's (1986) conclusion that the strongest influence on the development of self-efficacy beliefs are "enactive attainments" (p. 399), or successful performances. Other information also contributes to the formation of self-efficacy beliefs: the pattern of one's past successes and failures; social comparisons of others of less, equal, or greater capability; vicarious experiences, especially those which demonstrate others coping well in the face of difficulty; and finally, an individual's "somatic arousal" (p. 399). An 
appraisal of one's feelings and the physiological responses they evoke, along with an inferential analysis of the situation, provides data about one's relative vulnerability for failure within a particular situation and, thus, contributes to self-percepts of efficacy. Following the theory of reciprocal triadic causation, these contributors would not only influence the formation of current perceptions of self-efficacy, but would also be influenced by each other and by preexisting efficacy beliefs.

Bandura (1986) further suggests that a past performance or completed course of action may or may not alter perceptions of self-efficacy depending upon a person's retrospective appraisal of the amount of effort he or she has expended, the degree of task difficulty, the amount of external support provided, and the particular circumstances which surrounded the actions. Information from these appraisals is used along with preexisting perceptions of self-efficacy to self-evaluate performance, weighting it according to one's self-standards.

Thus, one's actions in a particular setting are, at least partly, affected by one's previous actions and past ability to mobilize requisite knowledge and skills. They are also determined by past outcomes of one's actions. In addition, a person's actions will be determined by perceptions about the present requirements of the situation, by judgments about one's capabilities to mobilize previously acquired knowledge and skills in order to act, and by perceptions about the possible outcomes these actions may create.

Bandura conceptualizes the perceptions which affect performance as a combination of two expectancies: self-efficacy expectancies and responseoutcome expectancies. Self-efficacy expectancies are "judgments of one's capabilities" (Bandura, 1986, p. 391) or "convictions that one can successfully perform the behavior required to produce a given outcome" (Tipton \& Worthington, 1984 , p. 545). Alternatively, outcome expectancies are 
"judgments of the likely consequences" of one's behavior (Bandura, 1986, p. 391 ) or "beliefs that a given behavior will lead to a given outcome" (Tipton \& Worthington, 1984, p. 545). While Bandura (1986) emphasizes that empirical research shows self-efficacy to be a better predictor of future performance than outcome expectancies alone, he does concede that behavior is best predicted by considering both. Indeed, Bandura (1982) suggests that "for activities in which outcomes are either inherent to the actions or are tightly linked by social codes, expected outcomes cannot be disembodied from the very performance judgments on which they are conditional" (p. 140).

Distinguishing Self-Efficacy Expectancies

From Response-Outcome Expectancies

Bandura (1986), nonetheless, clearly delineates between self-efficacy and response-outcome expectancies: He relates self-efficacy expectancies to performance attainments and response-outcome expectancies to consequences or rewards. Thus, one's efficacy expectancies are concerned with whether or not one has the capabilities to successfully complete what one has set out to do, while one's outcome expectancies are concerned with the consequences accrued from completing or not completing a particular course of action. Bandura posits that incomplete acts should not be construed as consequences: If one is high jumping and knocks the bar down, the failed jump is an incomplete act or interrupted performance attainment and not the outcome ( $\mathrm{p}$. 396). However, incomplete acts do produce their "own divergent collection of social, physical, and self-evaluative outcomes" (p. 392).

Unfortunately, not all researchers make the same distinction between self-efficacy and response-outcome expectancies, nor do all researchers use the same terms or use them in the same way.

Alternate meanings of the term "outcome." Some researchers use the term "outcome" to refer to the successful completion of a task (performance 
attainment). For example, some theories related to personal agency (e.g., attribution theory, perceived personal control theory, achievement motivation theory, learned helplessness theory) refer to the success or failure of completed tasks or performance attainments as achievement outcomes (Schunk, 1996). Achievement outcome expectancies, or one's expectations of success or failure in completing a particular task, parallel Bandura's (1986) conceptualization of self-efficacy expectancies and his construal of selfpercepts of efficacy as dependent on perceptions of one's capabilities "to attain designated types of performances" (p. 391). This is because success or failure (achievement outcomes) is not only "highly contingent on quality of performance" (Bandura, 1992. p. 19) but inseparable from it.

Other researchers use "outcome expectancy" to refer to the general effectiveness of a given course of action rather than the consequences or rewards accrued from the performance attainment. For example, Maddux, Sherer, and Rogers (1982) define outcome expectancy as "the belief that a given behavior will or will not lead to given outcome" (p. 208), which they operationalize as beliefs about the effectiveness of "the 'broken record' technique used in assertiveness training" (p. 209). They define the selfefficacy expectancy as “one's beliefs that one is or is not capable of performing a behavior or set of behaviors" (p. 208) and operationalize it as beliefs about the difficulty in using the technique.

The effect of these beliefs on reported "intentions to use the 'brokenrecord' technique" (Maddux, Sherer, \& Rogers, 1982, p. 209) was tested using 95 students attending introductory psychology classes. The expectancies were induced vicariously through written descriptions of the broken record technique, and a " $3 \times 3$ factorial design with three levels of outcome expectancy (high, low, and no information) and three levels of self-efficacy expectancy (high, low, and no information)" (p. 209) was used. Univariate 
analysis of variance revealed that information about the effectiveness of the technique (outcome expectancy) significantly influenced students' intention to use the technique, $\mathrm{E}(2,87)=12.32, \underline{\mathrm{p}}<.0001$ (p. 210). However, information about the difficulty in using the technique (self-efficacy expectancy) did not, although there was "a trend in the predicted direction" (p. 210).

While the results of this study are interesting, the definition of outcome expectancy used by Maddux, Sherer, and Rogers (1982) clearly does not jibe with Bandura's definition of response-outcome expectancies as rewards or consequences. In fact, because information about the general effectiveness of particular courses of action is accrued through vicarious experiences of others (Bandura, 1986), reading about the effectiveness of the broken record technique would provide information about one's own capability to use the technique. Bandura would consider this type of information to be one of many sources of diverse information that contribute to the formation of selfefficacy beliefs and expectancies.

Outcome expectancies in organizations. The definitional problems related to distinguishing self-efficacy expectancies from outcome expectancies become particularly problematic in social and organizational situations where the goals of one's actions include influencing others or changing the environment. For example, a teacher's goal to get students to work quietly (performance attainment) depends not only on the teacher successfully executing the appropriate courses of action, but also on the compliance of students. If students do not comply, does this represent the teacher's failed act or the consequences of his or her actions? Stated another way: Are the expectancies for student compliance part of a teacher's self-efficacy expectancies or his or her outcome expectancies?

Research by Bandura and others (Bandura \& Jourden, 1991; Bandura \& Wood, 1989; Wood \& Bandura, 1989a, 1989b) on managerial decision making in a 
simulated organizational environment suggests that influencing others and changing the environment represent another set of capabilities and courses of action for which one can form self-efficacy expectancies. Effective managerial performance involved not only deploying employees to perform particular subfunctions in the organization, but also discovering and mastering "a complex set of decision rules on how best to guide and motivate their supervisees" (Bandura \& Wood, 1989, p. 808) in order to "mobilize [their] concerted efforts" (p. 805). Successful performance attainments depended on whether or not managers were able to "get the group they were managing to perform" (p. 808). Thus, the actions of others in organizational settings appear to be inextricably linked not only to assessments of one's performance attainments, but also to one's self-efficacy expectancies.

Separating the types of expectancies. One way to sort out this ongoing confusion between the two types of expectancies might be to keep in mind the effects of triadic reciprocal causation (Bandura, 1986) among cognitions, behavior, and the environment. As previously mentioned, social cognitive theory stresses that one's actions are the result of a complex reciprocal influence relationship in which cognitive self-regulatory processes such as self-efficacy influence, and are influenced by, one's behavior and the environment. Bandura (1986) also emphasizes that efficacy beliefs are not just about what one knows or what cognitive, social, or behavioral subskills one has, but, more importantly, they are about what one is able to do given one's knowledge and subskills. Therefore, expectancies about what one is able to do inevitably require integrating information not only about the effectiveness of one's past actions but also about the current situation or context in which one is preparing to act. This suggests that self-efficacy expectancies might better be construed as expectancies about one's potential to act effectively (see Woolfolk \& Hoy, 1990), given the potentialities of the environment (Wood \& 
Bandura, 1989b) and the vast potentiality of responses to the environment made possible by the mind's plasticity. Any information related to these potentialities would be the basis of self-efficacy expectancies, not outcome expectancies.

Heckhausen (1991) identifies four types of expectancies which he believes influence one's decision to act and which clarify the differences and relationships between behavior and the environment and between outcomes and consequences. According to Heckhausen the first expectancy, situationoutcome expectancy, "indicates the subjective probability with which the current situation will lead to a future outcome state without action" (p. 415) or "where the situation would lead by itself, i.e., without being acted on" (p. 176). The second expectancy, action-outcome expectancy, is defined as "the subjective probability that one's action will modify a given situation" (p. 415) or expectations about "how one can influence events" (p. 176). This expectancy appears to be a precursor to Wood and Bandura's (1989b) conceptualization of the social environment as a "potentiality that is actualized through appropriate action" (p. 374). The third, action-by-situation-outcome expectancy, refers to "the subjective probability that external and variable circumstances will heighten or lessen the action-outcome expectancy" (p. 415). Both action-outcome and action-by-situation-outcome expectancies speak to the potential to act and are, thus, closely related to Bandura's (1986) self-efficacy expectancies. Action-by-situation-outcome expectancy, however, best reflects the reciprocal causation principle underlying Bandura's (1986) self-efficacy theory and more clearly delineates the importance of both personal effectiveness and situational conditions in the development of expectancies. The fourth expectancy identified by Heckhausen (1991), outcome-consequence expectancy, "denotes the degree to which an outcome is instrumental in bringing about a consequence with a specific incentive 
value" (p. 415) or "the instrumentality of the attained action outcome for subsequent consequences" (p. 176). Outcome-consequence expectancy parallels Bandura's (1986) response-outcome expectancies. The delineation of these four types of expectancies has strong potential value in helping us understand how various sources of information contribute to the development of percepts of self-efficacy.

\section{Measurements of Self-Efficacy}

Researchers who attempt to measure self-efficacy typically favor one of three types of instruments: task-specific measures, domain-specific measures, or global or "omnibus" measures (Bandura, 1982, p. 124). Each type can be differentiated from the others by the degree of specificity of the behavior being studied or by the use for which the instrument has been constructed.

Task-specific and domain-specific measures tend to mirror Bandura's (1986) microanalytic methodology (p. 422) in which perceptions of selfefficacy are measured for specific tasks "varying in difficulty, complexity, stressfulness, or in some other dimension depending on the particular domain of functioning being explored" (p. 422). Thus, microanalytic measures often attempt to measure one or more of the dimensions of self-efficacy perceptions: level, generality, strength, and magnitude.

Task-specific measures are most often used to analyze the congruence between perceived self-efficacy and actual performance on individual tasks and serve to "garner more precision regarding the accuracy of efficacyperformance relationships" (Berry \& West, 1993, p. 358; see also Bandura, 1986, p. 422).

While domain-specific scales also tend to measure perceptions of one's efficaciousness in performing specific tasks, they are often designed to assess self-percepts of efficacy across a number of different tasks required in a 
particular domain of functioning. They yield a more general self-efficacy score for a particular domain by aggregating the self-efficacy values of individual items. Their purpose is to describe the domain-specific efficacy levels of individuals or groups at a particular moment in time and they may tap the "self-schema" of efficacy proposed by Wood and Bandura (1989a, p. 413). According to Berry and West (1993), domain-specific measures of selfefficacy "are based on subscales within multidimensional questionnaires that assess a variety of efficacy-related beliefs and capabilities" (p. 358). Such subscales are often derived from factor analyses of data gathered from the administration of the instrument.

Finally, omnibus tests purport to measure self-percepts of efficacy that either "generalize across various contexts and behavioral domains" (Wang \& Richarde, 1988, p. 534) or reflect a "global disposition" (Bandura, 1982, p. 124). Items on omnibus tests tend to be nonspecific. For example, Tipton and Worthington's (1984) General Self-Efficacy (GSE) scale, which purported to measure "people's expectations concerning their competency for performance across a broad range of activities which are challenging and require effort and perseverance" (p. 545), contained items like the following:

I am a very determined person.

I can succeed at most any endeavor to which I set my mind.

Sometimes things just don't seem worth the effort. (p. 546) According to Tipton and Worthington the purpose of the GSE scale is to measure perceptions of one's general capability to cope.

There is at least some support for the supposition that efficacy beliefs are generalized across similar behavior domains or situations. For example, Wang and Richarde (1988) report studies that show cognitive modelling in dealing with a particular phobia enhanced self-efficacy towards other threats and that coping behavior and self-efficacy enhanced in one situation also 
transferred to other situations (Wang \& Richarde, 1987, cited in Wang \& Richarde, 1988, p. 534; also see Bandura, 1986).

Despite Bandura's contention that global measures of self-efficacy are of dubious value in predicting behavior, Tipton and Worthington (1984) suggest that self-efficacy perceptions related to a specific performance would account for the greater part of the variance when the situation is clearly defined and familiar to the individual, whereas GSE [General Self-Efficacy] would account for more of the variance when the situation is ambiguous and less familiar to the individual. (p. 548) They found their GSE scale useful in predicting certain kinds of behavior: They report that, when given a specific physical task or when asked to complete a long-term self-improvement project, participants with high GSE scores "expended more effort, persevered longer, and/or changed more than participants with low GSE scores" (p. 547). In the self-improvement project study they also found a significant linear relationship between scores on a goal attainment scale (GAS) and scores on the GSE scale, $\underline{r}(30)=.37, p<.05$ (p. $547)$.

The conceptualization of general self-percepts of efficacy and specific self-percepts of efficacy as separate constructs is also supported by the findings of one study completed by Wang and Richarde (1988). In an experiment in which the control and experimental groups completed tasks of long division and 20-digit serial recall, they found that "the GSE scale did not relate statistically to the task-specific ratings of self-efficacy or the performance measures in either group" (p. 537), and they propose that GSE may be a general measure of a person's willingness to persevere, especially on tasks requiring a high level of motivation.

Many teacher efficacy scales (Gibson \& Dembo, 1984; Woolfolk \& Hoy, 1990) attempt to measure self-perceptions of efficacy through items that could 
be categorized loosely as domain-specific or field-specific. That is, items reflect teachers' perceptions of their capabilities to execute a number of courses of action required within the domain of functioning, or field, called teaching. However, because item statements reflect typical scenarios encountered in teaching and are not tied to specific "lived" situations, they may measure more general self-percepts than those measured using Bandura's (1986) microanalytic techniques.

\section{Effects of Self-Efficacy on Behavior}

Strong beliefs of self-efficacy have been related to the setting of challenging goals (Wood \& Bandura, 1989a; Locke, Frederick, Lee, \& Bobko, 1984) which enhance and sustain motivation, and to the degree and perseverance of effort (Bandura, 1986, 1992). A person with strong selfefficacy believes in his or her ability to cope with or exercise control over potentially threatening situations (Bandura, 1986) and the feelings of anxiety which accompany them (Bandura, 1992). Thus, the stronger a person's perceived coping self-efficacy, the more likely he or she is to take risks (Bandura, 1989).

Alternatively, perceptions of low self-efficacy negatively affect motivation (Bandura \& Abrams, 1986, cited in Bandura, 1992) and give rise to feelings of anxiety, despondency, or depression in difficult or risky situations (Bandura, 1991, cited in Bandura, 1992): When people believe their goals are beyond their capabilities or are unrealistic, they tend to become apathetic (Bandura \& Abrams, 1986, cited in Bandura, 1992) or to disengage (Skinner, 1992), further reducing their chances for success. However, when individuals must mobilize courses of action without the necessary resources or under conditions of physical or social constraint, their perceptions of self-efficacy will often exceed their actual performances. 
Wood and Bandura (1989b) found that the stronger the subjects'

perceived self-efficacy in a simulated organizational setting, the more challenging were the organizational goals they set for themselves and the more systematically they used analytic strategies to discover managerial rules. High-set goals and systematic analytic thinking, in turn, "enhanced the strength of self-percepts of efficacy and the level of organizational performance" (p. 371).

\section{Types of Efficacy Judgments}

According to self-efficacy theory, judgments about one's capabilities to execute courses of action imply task-, situation-, or domain-specificity. For example, Bandura (1982) often refers to self-percepts of efficacy as being specifically related to a "particular domain of psychological functioning" ( $p$. 124) and identifies learning efficacy (p. 128), physical efficacy (p. 131), selfregulatory efficacy (p. 129), and thought control efficacy (Bandura, 1989, p. 420) as some examples. According to Bandura (1986), because self-efficacy beliefs are domain-specific, a person can hold positive self-perceptions of efficacy in one domain of functioning while holding negative selfperceptions of efficacy in another.

In addition to identifying domain-specific self-percepts of efficacy, some researchers specify judgments of self-efficacy which are more taskspecific. For example, Sexton and Tuckman (1991) make reference to both perceptions of general math self-efficacy (general beliefs in one's mathematical ability that derive from past mathematical accomplishments) and perceptions of situational math self-efficacy (confidence in one's ability to solve a particular set of word problems), while Schwarzer, Dunkel-Schetter, Weiner, and Woo (1992) refer to "cognitions about one's capability to support 
others and to make a difference with this support" (p. 69) as perceived helpspecific self-efficacy.

Researchers have also identified several other types of efficacy, such as operative efficacy (Bandura, 1986), coping efficacy (Bandura, 1986; McCarthy \& Newcomb, 1992; Skinner, 1992), self-regulatory efficacy (Bandura, 1992), occupational efficacy (Bandura, 1992, p. 31) and managerial efficacy (Bandura \& Wood, 1989; Wood \& Bandura, 1989a, 1989b). Because these types of efficacy are pertinent to the development of a model of personal teaching efficacy, they will be dealt with in more detail in the discussion that follows.

Operative Efficacy

Bandura (1986) has identified self-percepts of efficacy arising from judgments of one's capabilities to be effective in particular tasks or situations over time. He suggests that to function competently one must not only possess the necessary cognitive, social, and behavioral subskills and be able to marshal them to perform required courses of action, but also have the "generative capability [to] improvise [these] multiple subskills to manage ever changing circumstances, most of which contain ambiguous, unpredictable, and often stressful elements" (Bandura, 1986, p. 391). Bandura refers to this generative capability as operative efficacy (p. 391).

Perceptions of any type of efficacy may vary, of course, depending on whether one is required to perform under optimal conditions or in situations fraught with constraints or threats. This variance is often the result of either the level or the strength of one's perceived self-efficacy to execute particular courses of actions. In the first instance, one may feel capable to successfully solve mathematical problems as long as they are not too difficult (level of selfefficacy). In the second, one is able to maintain positive feelings of efficacy despite the obstacles and constraints in the environment and the resultant setbacks that occur (strength of efficacy). The strength of one's self-beliefs 
of efficacy provides the resilience to maintain one's sense of efficacy and to stay task-oriented over time and across constantly changing situations.

\section{Coping Efficacy}

The capability to maintain one's sense of efficacy in the face of challenges or difficulties also calls into play perception of one's specific capabilities to deal with or be effective in difficult situations. These have been generally referred to as coping capabilities and possessing them results in self-percepts of coping efficacy (Bandura, 1986; McCarthy \& Newcomb, 1992; Skinner, 1992).

Through a complex process of factor analyses, McCarthy and Newcomb (1992) were able to confirm two categories of perceived coping efficacy: perceived behavioral coping ability (p. 40), defined as "beliefs about one's ability to have an impact on the environment to accomplish one's goals" ( $p$. 56), and perceived cognitive control ability (p. 40), defined as "beliefs in one's ability to regulate cognitions in response to challenges associated with accomplishing desired goals" (p. 56).

Each type of coping ability depends on the use of different strategies, and the amount each coping ability is used to cope varies depending on the environment and the person. In general, the problem-focused strategies of behavioral coping ability tend to be used more in work situations (Folkman \& Lazarus, 1980, cited in McCarthy \& Newcomb, 1992, pp. 40-41) or when making major lifestyle changes. They involve strategies such as "informationseeking, cognitive problem-solving, inhibition of action and direct action" (McCarthy \& Newcomb, 1992, p. 40). On the other hand, cognitive coping strategies tend to be used more often when individuals feel relatively helpless to bring about changes themselves or "have little control over their environment" (p. 57). According to McCarthy and Newcomb, they include cognitive strategies such as "thought management, self-reward, and 
distractive thoughts" (p. 57) or "emotion-focused ... behaviors [such] as avoidance, intellectualization, isolation, suppression, and magical thinking" (p. 40).

McCarthy and Newcomb see perceived behavioral coping ability as a perception of general ability because

many of the specific challenges following a major lifestyle change are unanticipated at the time of the decision ... [and are] accompanied by multiple changes in how the individual interacts with his/her social and physical environment. (p. 42)

While perceived behavioral coping ability and perceived cognitive control ability appear similar to Bandura's (1989) perceived coping efficacy and perceived cognitive control efficacy or thought control efficacy, respectively, there are important differences.

First, Bandura's (1989) definition of perceived coping efficacy as selfperceptions of capabilities to "exercise control over potential threats" (p. 419) is more narrowly focused than perceived behavioral coping ability. Behavioral coping ability, as defined by McCarthy and Newcomb (1992), appears more related to process-oriented self-regulatory behavior, which will be discussed next.

Second, while perceived cognitive coping ability and cognitive control efficacy or thought control efficacy, defined as "perceived efficacy to control distressing cognitions" (Bandura, 1989, p. 420), both focus on the regulation of thought, Bandura (1989) considers cognitive control efficacy to be mediated by perceived coping efficacy, not distinct from it.

Third, Bandura's conceptualization of both perceived coping efficacy and cognitive control efficacy clarifies the relationship between perceived coping capabilities and "people's appraisals of external threats and their 
affective reactions to them. These relationships are less clear in McCarthy and Newcomb's conceptualization.

The relationship between perceived coping capabilities and appraisals of environmental conditions. Bandura (1992) considers "threat to be a relational property concerning the match between perceived coping capabilities and potentially hurtful aspects in the environment" (p. 24). Therefore, like perceptions of thought control efficacy, assessments of environmental threat are mediated by perceptions of coping efficacy "which in a large part, determine the subjective perilousness of environmental events" (p. 25).

The relationship between perceived coping efficacy and thoughts and feelings. Bandura (1992) suggests that people who feel highly efficacious to cope "do not conjure up apprehensive cognitions and, hence, are not perturbed by them" (p. 25). It is when one cannot manage threatening circumstances or is unsure of one's coping capabilities that perturbing thoughts occur and give rise to feelings of anxiety, despondency, or apathy. Such thoughts include attentional focus on coping incapabilities and "magnifying the severity of possible threats" (p. 25). Cervone and Peake (1986, cited in Bandura, 1992) found that "dwelling on formidable aspects [of a task] weakened people's belief in their efficacy, but focusing on doable aspects raised self-judgments of capabilities" (p. 7). However, cognitive focus has no effect "on motivation when perceived-self-efficacy is partialed out" (Bandura, 1992, p. 7).

Bandura (1992) also notes that response-outcome expectancies associated with the inability to exercise control over threatening events determines both the nature of the affective response and the thought control strategies needed to subdue these feelings. For example, when one believes coping inability will result in self-injury, the psychosomatic response is heart-rate acceleration, 
rise in blood pressure, and "increased catecholamine secretion" (Bandura et al., 1982, 1985, cited in Bandura, 1992, p. 25). Redirection of stressful thoughts is the basic thought control strategy required to quell anxious thoughts and remain task-focused. However, when the response-outcome expectancies associated with coping inability are loss of valued rewards, the affective response is despondency and then depression, and the main thought control strategy needed is "control over ruminative thought" (p. 30).

Bandura (1989) notes that "it is not the sheer frequency of disturbing cognitions, but the perceived inability to turn them off that is the major source of stress" (p. 420) and ongoing depression. The inadequate control of one's thoughts can result in an ongoing negative mood which negatively affects one's self-percepts of efficacy. However, because mood and feelings of efficacy influence each other bidirectionally, an increase in one's perceived efficacy has some power to change one's mood in a positive direction.

McCarthy and Newcomb (1992) suggest that while "individuals may have similar perceptions concerning their respective abilities to accomplish their jobs or to effect major lifestyle changes ... they nevertheless vary greatly in their perceived ability to cope with the behavioral or cognitive challenges associated with accomplishing the desired behaviors" (p. 41). Coping capabilities are needed whenever obstacles or constraints in the environment tax one's capabilities for self-directed action or increase one's vulnerability to failure or whenever dangerous or debilitating effects are the consequences of failure.

The foundation underlying effective coping is one's capability for selfregulation, that is, one's ability to manage and direct one's thoughts, feelings, and behavior. Self-percepts of efficacy for coping are also part of a larger constellation of beliefs about one's self-regulatory efficacy which will be discussed next. 
Self-Regulatory Efficacy

The theory and research related to self-regulation differ not so much in substantive content as in perspective. Theorists and researchers working from a more general perspective of social cognitive theory tend to emphasize the structure of the self-regulatory system and to focus on the internal selfregulatory processes which influence action and performance (see Figure 3 ). On the other hand, theorists and researchers working from the more specific perspective of learning tend to emphasize the use of self-regulatory processes which affect learning and focus on cognitive, motivational, and behavioral strategies that enhance or impede learning and the completion of learningrelated tasks (for example, see Schunk, 1994; Zimmerman, 1994). Both perspectives stress the importance of control over internal cognitive and noncognitive processes and the resultant positive effect of strategic selfregulation when confronting environmental distractions, difficulties, and obstacles.

Self-regulation from the perspective of social cognitive theory. Social cognitive theory posits that underlying people's management and direction of their own behavior is a complex, multidimensional, and multidirectional selfregulatory system made up of a number of cognitive, motivational, affective, and selection processes (Bandura, 1992). See Table 1 for a list of Bandura's self-regulatory processes. According to Bandura (1986) perceptions of selfefficacy are not only part of this self-regulatory system, but are also the central mediator of the dynamic interplay among the self-regulatory processes and between self-referent thought and action.

Self-regulatory processes act as instating conditions which affect the processing of efficacy information (Bandura, 1992) and, thus, they also influence people's capabilities to act or perform effectively. For example, conceptions of ability and beliefs about the controllability of the environment 
Table 1

Summary of Self-Regulatory Processes Identified by Bandura ${ }^{a}$

as Biased by Self-Efficacy Beliefs

Self-Regulatory

Process

Description

Cognitive Processes

Thinking Processes

Goal-setting

"forethought embodying cognized goals" (p. 414)

Anticipatory Scenarios

self-talk and imaging about future events

Predictive Rule Formation

"predict[ing] the occurrence of events and creating the means of exercising control over those that affect daily lives" (p. 414); requires analytic thinking and aids in effective decision making

Belief Systems

Conceptions of Ability

one sees ability as an acquirable skill or a fixed capacity

Conceptions of Environment one sees the environment as controllable or uncontrollable

Bandura, A. (1989, October). Perceived self-efficacy in the exercise of personal agency. The Psychologist Bulletin of the British Psychological Society $2,411-424$. 
Table 1 Continued

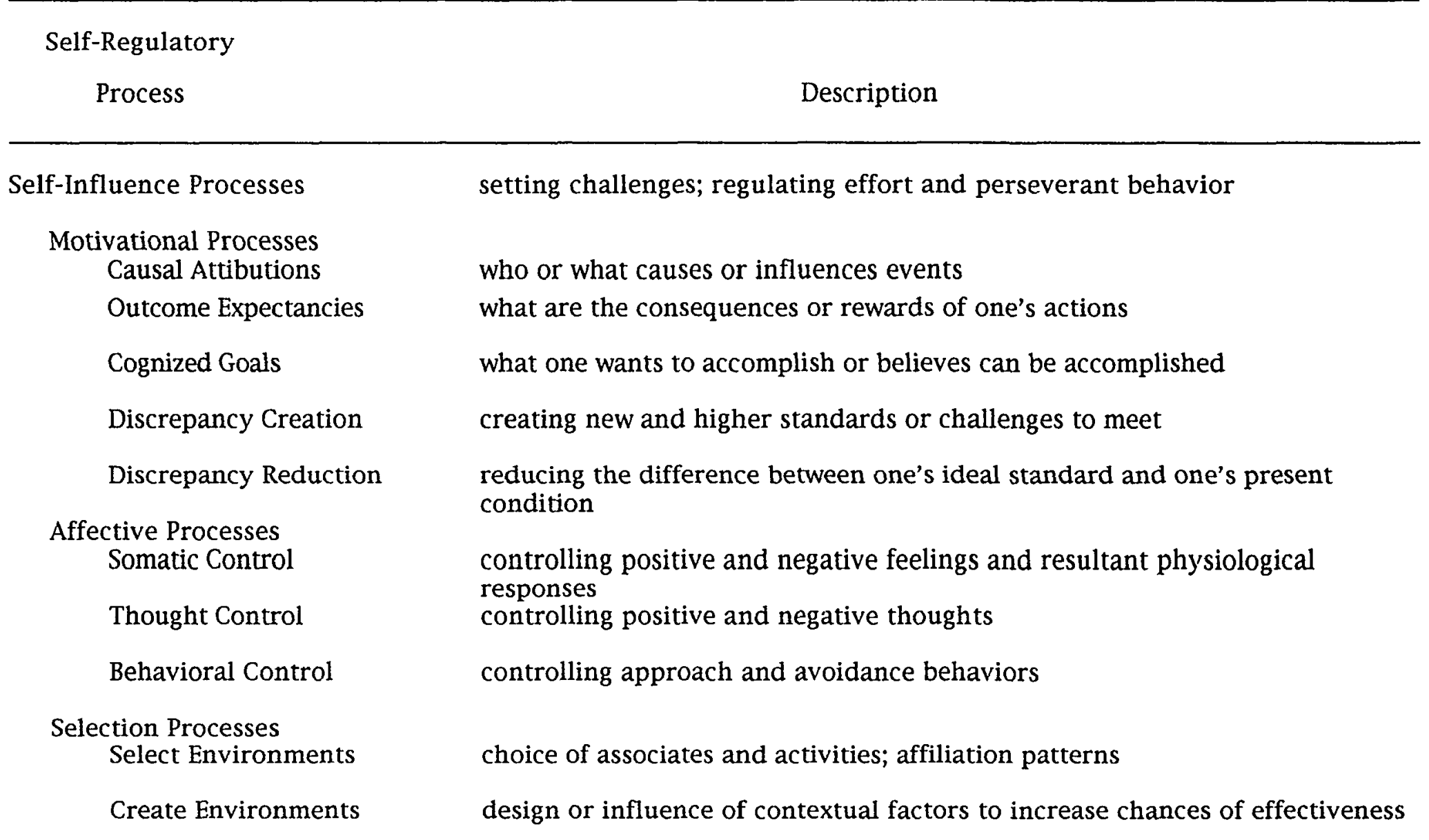


(cognitive self-regulatory processes) have been shown to influence selfpercepts of managerial efficacy (Wood \& Bandura, 1989a, 1989b), which, in turn, influence their managerial effectiveness.

The self-regulatory processes are also mediated by self-percepts of efficacy. For example, research shows that a person with a strong sense of efficacy sets higher goals (cognitive self-regulatory process) and is more committed to them than a person with low self-efficacy (Bandura, 1989). In addition, while causal attributions (motivational self-regulatory process) and self-percepts of efficacy have been found to influence each other bidirectionally, "the effects of causal attributions on performance attainments are mediated through self-efficacy rather than operate directly on performance" (Bandura, 1989, p. 416).

Perceptions of one's capabilities to control one's thoughts, feelings, and behaviors, referred to as self-regulatory efficacy (Bandura, 1986), mediate and are mediated by both the conscious and unconscious self-direction of the selfregulatory processes. In addition, perceptions of one's self-regulatory efficacy are an important component of efficacy-related self-appraisals.

Self-control of one's thoughts, feelings, and behavior becomes increasingly important in the face of obstacles and aversive conditions where they often make the difference in whether or not one performs well or attains one's goals. Under these conditions, one's self-regulatory efficacy informs one's self-percepts of coping efficacy.

Self-regulation from a learning perspective. In practice, theory and research on self-regulation emphasize one's capability to direct one's thoughts, feelings, and actions in ways that support the completion of tasks and the attainment of goals. For example, as a result of their research on student learning, Schunk (1994) defines self-regulation as "the process whereby students activate and sustain cognitions, behaviors, and affects that 
are systematically oriented toward the attainment of goals" (p. 75), and Zimmerman (1994) refers to self-regulation as "the degree that individuals are metacognitively, motivationally, and behaviorally active participants in their own learning" (p. 3). Self-regulatory activity includes having a purpose or a goal, employing goal-directed actions, monitoring behavior, and adjusting behavior to ensure success (Schunk, 1996). Self-regulatory competence refers to the ability to "systematically adapt [self-regulatory] strategies to changes in personal and situational conditions" (p. 348).

Zimmerman (1994) reorganizes Bandura's self-regulatory processes into three task-oriented categories related to active participation: First, productoriented self-regulatory processes, such as self-goals, percepts of selfefficacy, values, and attributions, influence self-motivation and choice to participate (also see Bandura, 1992; Woods \& Bandura, 1989a, 1989b). Second, process-oriented self-regulatory processes, such as metacognition and strategy use, support successful learning and performance. Finally, environmentally focused processes, such as help-seeking and organizing or restructuring the environment, ensure that environmental conditions support learning and performance.

Researchers (Bandura, 1992; Corno, 1993, 1994; Corno \& Kanfer, 1993; Graham \& Harris, 1994; Heckhausen, 1991; Schunk, 1994; Zimmerman, 1994) contend that people employ strategies to actively direct these self-regulatory processes, which, in turn, enhance their learning and performance and increase their chances of successfully attaining their goals. For example, Schunk (1994) indicates that the product-oriented strategy of goal setting and the related process-oriented strategy of evaluating goal progress are important determinants for effective self-regulation of task-oriented behavior. One's goals then influence both adaptive strategy use (also see Corno \& Kanfer, 1993) and one's sense of efficacy depending on their 
"proximity, specificity, difficulty level" (Schunk, 1994, p. 89) and whether they are learning-oriented or performance-oriented.

A number of specific self-regulatory strategies have been identified through the research on learning: Garcia and Pintrich (1994) introduce cognitive strategies such as "rehearsal, elaboration, and organization" (p. 140), while Zimmerman (1994) identifies self-monitoring or self-observation strategies (also see Bandura, 1986). Zimmerman also suggests that there are "volitional strategies for sustaining one's attention and managing one's cognitive and situational resources" (p. 18; also see Corno, 1993, 1994; Corno \& Kanfer, 1993), as well as for controlling one's emotions, which, for Zimmerman, also involves additional relaxation and stress-reducing strategies. Finally, Schunk (1994) points to environmental strategies for "establishing a productive work environment and using resources effectively" (p. 75), along with time planning and time management strategies.

Graham and Harris (1994) emphasize that "the use of personal, behavioral, and environmental strategies is regulated by an enactive feedback loop ... [ [which] involves learning from the consequences of one's actions. ... [and] enables one regulative process to influence another" (p. 205). This conceptualization of the "reciprocal interactions among behaviors, environmental events, and covert processes" ( $p$ 205) is supported by Bandura's (1986) theory of triadic reciprocal causation.

The researchers discussed to this point do not specifically refer to the use of self-regulatory processes and strategies as "coping." However, Skinner (1992), whose research from the perspective of personal control theory also focuses on school-based learning, emphasizes the affect self-regulatory processes such as patterns of causal attributions have on students' ability to cope in the face of difficult learning tasks. 
The role of self-regulation in the formation of efficacy beliefs. Selfregulation has been described in three ways: (a) as a system of cognitive, motivational, affective, and selection processes that act as instating conditions of self-efficacy appraisals; (b) as a global process of activating and sustaining cognitions, behaviors, and affects that are systematically oriented towards active participation or the attainment of goals; and (c) as a number of cognitive and noncognitive strategies which enhance learning, performance, and goal-directed action.

These processes and strategies can enhance or impede effective action whether one is consciously aware of their impact or not. However, as soon as one consciously considers one's capability to direct the use of these processes and strategies to enhance performance or chances for goal attainment, they become subject to efficacy-related appraisals. Such appraisals of one's selfregulatory capabilities include self-percepts of control over cognitions, affect, and behavior, as well as self-percepts of one's capabilities to enact and sustain strategies or to learn new strategies when necessary. Thus, self-percepts of self-regulatory efficacy are the result of considering a wide range of cognitive, affective, and behavioral capabilities that can be brought to bear to manage and direct one's behavior. Good use of these capabilities enables people to respond enactively and proactively to life events rather than be limited to simple stimulus-response reactions.

Occupational and Managerial Efficacy

Of particular import to the research on personal teaching efficacy are self-percepts of personal efficacy having to do with one's capabilities to fulfill role demands (Bandura, 1982), which have been referred to generally as occupational efficacy (Bandura, 1992, p. 31) or, more specifically, as managerial efficacy (Bandura \& Wood, 1989; Wood \& Bandura, 1989a, 1989b). 
Self-percepts of occupational efficacy can influence precareer decisions related to career choice, in that people who believe strongly in their capabilities consider more career options (Bandura, 1992). Occupational efficacy and decisions related to precareer choices can also be negatively affected by "biased cultural practices, stereotypic modelling of gender roles, and dissuading opportunity structures" (Hackett \& Betz, 1981, cited in Bandura, 1992, p. 31).

Perceptions of in-service occupational efficacy and managerial efficacy are the result of self-appraisals of one's capability to be effective in particular "dynamic organizational environments" (Wood \& Bandura, 1989a, p. 407) and, therefore, are self-appraisals of one's “capabilities to mobilize the motivation, cognitive resources, and courses of action needed to meet given situational demands" (p. 408) over the long term. Self-percepts of occupational and managerial efficacy are closely related to self-percepts of operative efficacy because the fulfillment of role demands requires the use and assessment of one's capabilities over time and across a number of tasks, domains of functioning, and situations or events particular to a specific occupational role and a specific organization.

Self-schema of efficacy to fulfill role demands. The multidimensional nature of role demands, the distal nature of higher order occupational goals, and the complexity, unpredictability, and stressfulness often inherent in socially mediated organizational environments also suggest that self-precepts of occupational or managerial efficacy are the result of an integration of selfbeliefs and self-percepts of capabilities for a number of discrete domains of functioning and a variety of situational conditions. Wood and Bandura (1989a) characterize this integration as a "self-schema" (p. 413) of efficacy.

Wood and Bandura (1989b) found that managers in a simulated organizational environment formed self-schemas of efficacy for managing 
based on an integration of self-beliefs and self-perceptions of efficacy for a number of organizational tasks and self-regulatory capabilities.

Organizational tasks included the following: deploying employees to complete activities, applying rules to predict and influence the collective effort, and "match[ing] motivational factors to employee attributes in order to achieve good collective outcomes" (p. 377). These tasks required managers to continually improvise the use of their capabilities to execute the specific courses of actions required by particular and continuously varying circumstances (operative efficacy). Self-perceptions of cognitive and selfregulatory capabilities were also integrated into managers' self-schemas of efficacy, for example, their capabilities to develop new competencies; their capabilities to learn and master the rules underlying the mobilization of the collective effort; and their capabilities to cope, especially in situations requiring them to overcome obstacles and adverse conditions in pursuit of their organizational goals. Wood and Bandura (1989a, 1989b) found that these self-percepts of operative, self-regulatory, and coping efficacy were initially biased by belief systems related to conceptions of ability and the controllability of the environment, which also become integrated in one's self-schema of organizational efficacy.

The development of self-schemas of efficacy requires the same attention to "diverse sources of efficacy information" (Bandura, 1992, p. 32) as in the formation of discrete self-efficacy beliefs, and the same use of a wide array of cognitive, motivational, affective, and selection processes to select, interpret, and integrate “efficacy-relevant' information (Bandura, 1992, p. 32) and self-beliefs. However, self-schemas of efficacy do not develop at once, but rather, they are developed over time as a result of participating in and learning from organizational experiences (Wood \& Bandura, 1989a). It is through the process of developing a positive self-schema of efficacy that 
individuals strengthen their perceptions of self-efficacy, giving them the resiliency needed for long-term effective action in a dynamic organization. According to Bandura (1992), this "robust sense of personal efficacy [is necessary] to sustain the perseverant effort needed to succeed" (p. 22).

\section{Conclusion}

The review of the literature on social cognitive theory and self-efficacy clarified the place and structure of self-efficacy within the system of selfreferent thought. The next section of this review of literature looks at the constructs related to self-efficacy with an eye for integrating them into a new model of personal teaching efficacy. The section also includes a discussion of beliefs related to conceptions of ability and of the environment which play a role in a self-schema of personal teaching efficacy.

\section{Constructs and Theories Related To Self-Efficacy}

\section{Introduction}

Bandura (1986) is only one of many social cognitive psychologists who study "the interactive relation between thought and action as their sector of interest [and, thus,] examine how conceptions, beliefs, self-percepts, and intentions shape and direct behavior" (p. 25). In addition to Bandura's selfefficacy theory, a number of other specific theories, developed from different perspectives, have arisen out of this interest: for example, the theories of locus of control, attribution, perceived personal control, achievement motivation, personal causation, and learned helplessness. Despite the divergence in perspectives and labels, "the [common] basic phenomenon being addressed centers on people's sense of personal efficacy to exercise control over events that affect their lives" (Bandura ,1986, p. 391). 
This section introduces these related theories under two themes: causal attributions and motivation. After the theories have been introduced and discussed, they are compared to each other and to Bandura's self-efficacy theory according to differences in classification, differences in conceptions of the internal mechanisms that translate internal means into action, and differences in conceptions of competence. The chapter ends with an introduction to alternate conceptions of ability and of the environment and a discussion of the role they play in shaping and directing behavior. .

\section{Causal Attributions of the Contingencies}

Between Actions and Outcomes

Common to all the theories related to self-efficacy is the delineation of the contingencies between action and outcomes and the explication of the effects these causal attributions have on actions and outcomes. While the theories all consider the general interrelationship between causal attributions and behavior, three theories specifically explore the types of causes (means) that people assign to outcomes and delineate how these perceived causes affect actions and outcomes (ends). Locus of Control Theory

As the name implies, locus of control theory is interested in where the control over rewards or outcomes is perceived to be situated. When a person believes that the reward or outcome is "contingent upon his own behavior or his own relatively permanent characteristics" (Rotter, 1966, p. 1) the person is said to have an internal locus of control. Alternately, a person with an external locus of control believes that the reward is relatively independent of his or her own behavior and, therefore, "typically perceived as the result of luck, chance, fate, as under the control of powerful others, or as unpredictable because of the great complexity of forces surrounding him" (p. 1). 
Rotter (1966) suggests that "generalized expectancies in combination with specific expectancies act to determine choice behavior along with the value of potential reinforcements" (p. 2). His review of the research on locus of control showed that people who attribute outcomes to internal characteristics (skill) not only increase their expectations of rewards after positive reinforcement, but are also more likely to persevere in the face of failure, to generalize expectancies from one task to another, and to "exhibit perceptual behavior that will enable them to cope with potentially threatening situations than are subjects who feel chance or other noncontrollable forces determine whether or not their behavior will be successful" (p. 8). For Rotter, it is the belief that one possesses the internal means to attain rewards or outcomes which positively influences what one chooses to do, how one chooses to do it, and whether or not outcomes are possible.

\section{Attribution Theory}

Locus of causality. The attribution of the contingencies between action and outcomes as either internal or external is called "locus of causality" in Weiner's attribution theory (Schunk, 1994). Locus of causality represents personal or internal characteristics like ability, effort (Weiner et al., 1971, cited in Stipek \& Weisz, 1981), mood, fatigue, illness, personality, and physical appearance (Freize, 1980, cited in Schunk, 1996) and external factors like task difficulty, luck (Weiner et al., 1971, cited in Stipek \& Weisz, 1981), and other people (Freize, 1980, cited in Schunk, 1996), including powerful others (Rotter, 1966).

Stable and unstable causes. However, locus is only one dimension of causality in attribution theory. Stability and control of causes represent the other two dimensions. Causes believed to be invariant or unchangeable are said to be stable: "Intelligence or task difficulty are examples of causes usually 
considered to be stable, whereas mood or effort are more often (but not always) considered unstable" (Stipek \& Weisz, 1981, p. 120). In general, unstable causes are believed to be more controllable than stable ones. Thus, ability and task difficulty are often thought to be uncontrollable while effort is usually believed to be controllable. For internal causes, the differentiating condition for controllability and uncontrollability seems to be whether or not a cause is perceived to be subject to self-regulation (Weiner, 1994). Most stable causes are considered outside the realm of self-regulation. For example, it has been generally believed that one cannot change or control one's innate intelligence or ability. However, some causes like mood, fatigue, and illness are viewed as unstable, but because they are not considered subject to regulation they are also believed to be uncontrollable.

Attribution theory also posits that the categorization of causes to particular dimensions is subjective; for example, ability may be considered a stable and uncontrollable contingency for most adults, but an unstable and, therefore, influenceable contingency for children (Schunk, 1994). Alternately, some people might consider luck to be a relatively stable quality for them but an unstable quality for others (Schunk, 1994).

Attributions are formed from previous experiences and applied to new situations using behavioral cues that relate to specific attributed causes. For example, in learning situations, one makes ability attributions when one achieves success often, easily, or "early in the course of learning" (Schunk, 1996, p. 306).

From an examination of attributional research, Schunk (1996) concluded that attributing outcomes to stable causes such as ability or task difficulty influences expectations for success. Such attributions are common among children and, in many cases, the influence of stable causes is a positive one. For example, when children consider tasks to be easy and ability to be 
high, these stable causes create expectancies for success that are also high. Unfortunately, children who perceive themselves to have low ability may approach both easy and challenging tasks with low expectations for success. They are likely to approach tasks in a "lackadaisical fashion" and to not put forth the effort required to succeed (p. 307).

Controllable and uncontrollable causes. Expectations of success and the resultant behaviors are also affected by the controllability dimension of attribution theory. Students who perceive causes to be uncontrollable tend to "hold low expectations for success and display low motivation to succeed" (Licht \& Kistner, 1986, cited in Schunk, 1996, p. 307). In contrast, perceiving causes as controllable promotes "choosing to engage in academic tasks, effort and persistence at difficult tasks, and achievement" (p. 307).

Perceiving internal causes as controllable or uncontrollable is also an important component in the evaluation of failures. In a recent experiment, Farwell and Weiner (1993, cited in Weiner, 1994) asked subjects to evaluate students, some of whom had failed due to lack of ability, others, due to lack of effort. Persons who failed due to inability were evaluated less negatively than persons who failed due to lack of effort (Weiner, 1994). An earlier experiment by Karasawa (1991, cited in Weiner, 1994) also found failure from lack of effort to be more negatively evaluated than failure due to both lack of ability and illness.

Attribution theory refines the conceptualization of the contingencies between actions and outcomes by going beyond the internal-external locus. While Rotter believes it is the internality of means which directs behavior and affects outcomes, attribution theorists consider the stability and control dimensions also to be potent forces influencing behavior and outcomes. The addition of the dimensions of stability and control of causes to explain how and 
why people act the way they do provides for a more complete understanding of behavior than the locus of causality alone.

Perceived Personal Control Theory

Perceived personal control theory is organized around three sets of generalized beliefs which can be related to the stability and control dimensions outlined in Weiner's attribution theory, albeit from a different perspective.

One set of beliefs, called strategy beliefs, are means-ends beliefs or "generalized expectancies about the extent to which categories of potential causes [means] are effective in producing desired outcomes [ends]" (Skinner, 1992, p. 93). Beliefs in this category include both internal and external means similar to those listed by Rotter and Weiner.

The next set of beliefs, called "capacity beliefs, or generalized expectancies about the extent to which the self possesses or has access to those potential means" (Skinner, 1992, p. 93), reflect the internal-external locus, labelled locus of control in Rotter's theory and locus of causality in Weiner's theory. Here, the focus is on internal means. Capacity beliefs are also similar to Weiner's dimension of control and to Bandura's self-efficacy expectancies, if personal capabilities are considered a type of means.

Strategy beliefs and capacity beliefs focus on means, while the third set of beliefs, called control beliefs, move from a focus on means to a focus on outcomes. Control beliefs are "generalized expectancies about the extent to which the self can produce outcomes irrespective of the means involved" (Skinner, 1992, p. 93). While control beliefs are not the same as Weiner's control dimension, which focuses on means, they do appear to be similar to Bandura's outcome expectancies.

According to Skinner (1992), individuals use all three sets of beliefs in their appraisals of personal control. For example, people may attribute success 
to ability (strategy beliefs) but they may also believe that they do not possess the necessary ability (capacity beliefs) required to complete certain tasks. The combined effect of the two beliefs would be to undermine one's perceived control and disrupt the effective deployment of one's effort. However, individuals who believe they have the ability (capacity beliefs) may still believe that they cannot effect a particular outcome (control beliefs). Thus, control beliefs seem to take into account external means, especially those which enhance or thwart one's exercise of person control. Nonetheless, in most instances, positive capacity beliefs strengthen one's control beliefs.

In a study of 246 schoolchildren aged 8 to 15, Skinner and her colleagues found that "children with high effort and ability beliefs were more likely, in the face of challenge, to strategize and persevere, and less likely to attempt to get others to solve their problems for them" (reported in Skinner, 1992, p. 102). Alternately, children who reacted impulsively or with confusion, blamed others, or avoided challenging tasks, attributed outcomes to unknown causes and to external means such as luck and powerful others.

The distinction Skinner makes between strategy beliefs and capacity beliefs further refines our understanding of attributions by pointing out that it is not only one's beliefs that certain causes effect certain outcomes, but also beliefs about one's capacity to possess or have access to these causes, which then influence choice behavior and engagement. Skinner also shows how different patterns of attributional causes (for example, high ability and high effort) influence not only decisions to engage in learning tasks, but also the effectiveness of that engagement. 


\section{Motivational Perspectives}

Another way in which one can analyze the theories related to Bandura's self-efficacy is to examine their perspectives on why people choose certain activities over others and what cognitive mechanisms govern people's engagement in these activities. In other words, what motivates people to action.

Locus of control. As noted previously, locus of control theory purports that the major determinant of motivation is locus of control: When people believe that the rewards and consequences of their behavior are due to their own behavior or personal characteristics (internal locus of control) they not only choose to participate in certain activities, but they also engage in activities with persistent effort.

Attribution theory. On the other hand, attribution theory relates motivation more to perceptions of the stability and controllability of causes than to locus of causality. People choose activities and engage with perseverant effort if they believe that they can influence or control the causes that will bring them the outcomes they desire.

Perceived personal control theory. Perceived personal control theorists hold beliefs similar to those of attribution theorists. However, they also posit that a basic need for competence underlies motivated behavior.

The first link between the need for competence and motivation was made by White (1959), who labelled the motivation for "effective-competent-interaction with the environment" (cited in Schunk, 1996, p. 328) as effectance motivation. According to White, effectance motivation leads humans to interact with the environment and try to master it. Mastering effective interactions then produces feelings of competence or efficacy that are highly satisfying and that lead to further interactions and mastery efforts (reported in Stipek \& Weisz, 1981, p. 127). 
Building on this basic schema, Skinner (1992) posits that "individual differences in perceived control . . . reflect variations in the extent to which individuals have experienced themselves as competent to produce desired and prevent undesired outcomes" (p. 93). She also suggests that the more competent individuals believe they are and, thus, the more control they believe they have, the more likely they are to engage in the activities at hand and not disengage or become disaffected. However, obstacles and adverse conditions can threaten this relationship between perceived competence and engagement. When obstacles or threats are perceived to be optimal, or within one's capacity to control, they are viewed as challenges, and individuals enthusiastically engage in the activities required to overcome them. Such engagement is characterized by perseverant, attentional effort; feelings of happiness, curiosity, and interest; and an "orientation toward the goal of understanding how to be effective" (p. 93).

On the other hand, when obstacles or threats are found to be uncontrollable and no amount of effort can overcome them, individuals begin to feel less and less competent in the interaction and eventually disengage. This can be a positive and temporary condition which gives individuals time to review their strengths and weaknesses and to learn new skills. However, the more chaotic the environment, the more chance there is that individuals will not reengage even when conditions present a manageable challenge. Such disaffection is characterized by avoidant, passive, or resistant behavior; negative emotions like boredom, anger, anxiety, and fear; and an orientation away from understanding how to be effective "toward trying to appear effective" (Skinner, 1992, p. 93, emphasis in the original).

The theory underlying perceived personal control expands our understanding of how the need for competence and self-percepts of 
competence affect one's motivation, as well as the processes of engagement, disengagement, and disaffection.

Achievement Motivation

A construct closely related to effectance motivation is the achievement motive, defined by Schunk (1996) as "the striving to perform difficult tasks as well as possible" (p. 292). Both motives are strengthened by successful interactions with the environment; however, the achievement motive tends to be linked with motivation for learning because much of the research has been conducted with children in school-based learning situations. Although the motive was first identified by Murray in 1938, it is Atkinson (1957, cited in Schunk, 1996) who is credited with developing the first theory of achievement motivation.

Achievement motivation theory. According to Atkinson, achievement motivation is a stable disposition or characteristic trait that holds across many domains of personal experience. While effectance motivation is energized by an innate need for competence and "aims for a feeling of efficacy" (White, cited in Harter, 1978, p. 36), achievement motivation derives from positive beliefs in one's ability (competence) and past successful experiences and aims for continuing achievements. Success acts as a signal of achievement and competence and reinforces the desire to approach achievement situations. Failure, on the other hand, becomes a signal of nonachievement and incompetence and reinforces the desire to avoid failure in the future. The strength of the achievement motive is, thus, theoretically calculated as the difference between the strength of one's desire to approach achievement situations and the strength of one's desire to avoid failure (reported in Schunk, 1996).

The achievement motive works to influence choice behavior: When one has "a strong hope for success and a low fear of failure" (Schunk, 1996, p. 293), 
one chooses to engage in achievement activities, while having weak hopes of success and a strong fear of failure leads to avoidance of achievement activities. Results from Atkinson's research show that students with high achievement motivation "voluntarily approach achievement situations ... and select tasks of intermediate difficulty" to ensure success (reported in Stipek \& Weisz, 1981, p. 117). In addition, achievement motivation has been shown to affect the quality of one's engagement behaviors: Atkinson found that students with high achievement motivation "perform tasks with greater intensity [and] persist in the face of failure" (reported in Stipek \& Weisz, 1981, p. 117).

Eccles's model of achievement motivation. A more recent model of achievement motivation was also researched in learning situations but conceptualizes the achievement motive to be domain-specific and task-specific rather than a characteristic trait (Eccles, 1983, reported in Schunk, 1996). In Eccles's model, achievement motivation is the result of perceived personal chances to do well. One's current chances to be successful are based on perceptions of the current task and one's task-specific self-concept, both of which are gleaned, in part, from the student's interpretation of past achievement outcomes (Schunk, 1996). Research using Eccles's model shows that when students have positive perceptions of the current task and a positive task-specific self-concept they are more likely to engage in the learning task and to persist (Schunk, 1996).

Fear of Success Theory

A corollary construct to the desire for success and the desire to avoid failure as outlined in achievement motivation theory is the desire to avoid success. Horner (1972) posits that, although some individuals are sure of their ability to achieve, they fear that adverse consequences will be associated with achievement outcomes (cited in Schunk, 1996). Research on the fear of 
success construct showed that some females in nontraditional roles felt anxiety with the possibility of success. It is possible that fear of success is more likely to be found in individuals who have not internalized their own incentive system of self-rewards and self-standards but find themselves in situations where significant others disapprove of their achievement activities (see Harter, 1978, pp. 53-54). The combination of intentions which are not selfreinforced and the strong disapproval of others creates anxiety about the achievement. Using the achievement motivation formula, fear of success works in a similar way to the desire to avoid failure by disrupting the achievement motivation response and not only inhibiting the behavior required to ensure successful attainments, but also stalling the development of new competencies.

\section{Self-Worth Theory}

Another theory related to achievement motivation theory is the selfworth theory of motivation posited by Beery and Covington (1976, cited in Schunk, 1996). This theory reiterates the positive cycle of interactionsuccess-satisfaction-further action proposed by effectance motivation. However, the satisfaction from successful interactions focuses on feelings of self-worth rather than feelings of efficacy. Beery and Covington postulate that, when outcome expectancies are based on perceptions of ability, success brings feelings of satisfaction and worthiness, while failure brings feelings of unworthiness (Schunk, 1996). As in achievement motivation theory, when individuals find success difficult to attain, they act to avoid failure and, thus, preserve their feelings of self-worth. Some people may choose to pursue easy goals or escape from achievement situations to avoid failure. Others may choose to cheat or blame failure on the lack of effort. 
Personal Causation Theory

A final theory related to achievement motivation is De Charm's (1968) theory of personal causation (cited in Schunk, 1996). While research shows that "children take more responsibility for their successes than their failures" (Freize \& Weiner, 1971, reported in Stipek \& Weisz, 1981, p. 116), De Charm believes not only that taking responsibility for both successes and failures strengthens students' achievement motive, but also that students can and should be trained how. The training includes learning goal-setting and self-motivation strategies which are specific self-regulatory processes. By learning to regulate their cognitive and motivational processes, students are able to become and remain task-focused rather than ego-focused.

Nichols (1983, 1984, cited in Schunk, 1996) reported differences in the value placed on learning and performing activities between task-involved (task-focused) and ego-involved (ego-focused) students. Task-involved students saw learning and performing activities as valuable in themselves, while ego-involved students valued learning and performance activities as "means of avoiding looking incapable" (p. 300). Research has also shown that students who were task-focused had strong beliefs in their capabilities to learn and, thus, chose challenging tasks and persevered when they faced difficulties (Dweck, 1986, reported in Schunk, 1994). On the other hand, students who were ego-focused felt unsure of their capabilities and, as a result, avoided difficult tasks and gave up easily (Dweck, 1986, reported in Schunk, 1994).

Theories based on the achievement motive posit that it is the combined effect of the desire to succeed and the desire to avoid failure or negative consequences which motivates people and influences choice behavior and engagement. When there is little chance for failure or other negative consequences, achievements tend to increase feelings of competence and 
satisfaction, to ensure the continued use of task-focused behaviors, and to reinforce an ongoing motive to achieve.

\section{Learned Helplessness}

The cumulative effect of successful experiences is increased confidence in one's capability to interact effectively and take control of the events that affect one's life. Similarly, learned helplessness theory shows how failure experiences can initiate a cyclic effect where each successive failure undermines confidence in and creates doubts about one's competence to interact effectively with life's experiences. As the failures mount, motivation to interact and to take control of one's life decreases, and one is likely to become increasingly passive and nonassertive. Unfortunately, such givingup behaviors only increase one's chances for new failures.

When Seligman (1991) first identified the learned helplessness construct in 1975, he believed it to be a generalized psychological trait characterized by passiveness and nonassertiveness. During experiments with dogs in 1965, Maier and Seligman became "convinced that only inescapable events produced giving up. ... Clearly animals can learn their actions are futile, and when they do, they no longer initiate action, they become passive" (Seligman, 1991, p. 23). Maier and Seligman concluded that when life experiences lead people to believe that outcomes are uncontrollable, they literally learn to feel helpless and act accordingly (reported in Schunk, 1994).

In a later reformulated model, Seligman and others clarify how learned helplessness develops by identifying the dimensions of attributional thinking which underlie it (Abramson, Seligman, \& Teasdale, 1978, cited in Schunk, 1996). Seligman is interested in how people's attributions for success and failure become habits of explanation which reinforce feelings of control or helplessness. He proposes that people whose habits of explanation are optimistic explain successes and failures differently than people whose habits 
of explanation are pessimistic: Learned helplessness is the result of pessimistic habits of explanation. Seligman (1991) identifies three dimensions of attributional self-talk which influence the development of both learned helplessness and what he calls learned optimism. The first two, permanence and personalization, are build on Weiner's attribution theory, while the third, pervasiveness, is a dimension unique to Seligman's theory.

The permanence dimension. In explaining this dimension, Seligman builds on Weiner's conceptualization of the stability dimension underlying attributions. Seligman (1991) suggests that "pessimists" habitually attribute failure experiences to permanent causes like personal traits or abilities and success experiences to unstable causes like fatigue, luck, or lack of effort. They also interpret present failures as a strong indication of future failures but consider present success to be temporary. The self-talk of "optimists" is reversed: Optimists believe successes are the result of internal stable causes, and failures, the result of unstable ones. They also believe that successful experiences foreshadow future success, but failure experiences are not a portent of future failures.

The personalization dimension. On the surface, the personalization dimension is similar to the locus of causality and control dimensions outlined in attribution theory; however, Seligman (1991) considers external attributions for failures to hold positive value in maintaining optimism. He believes that optimists maintain their optimism by attributing successes to themselves and failures to other people and circumstances; alternately, pessimists hold themselves to blame for their failures and believe their successes are the result of external or uncontrollable causes. Because failures undermine confidence and optimism for the future, Seligman believes that one can protect oneself from the debilitating effects of doubt and preserve one's feelings of optimism by considering them to be outside one's control. 
The pervasiveness dimension. The explanatory style of the pervasiveness dimension is to attribute success or failure to either universal or specific conditions. For example, pessimists tend to interpret failure experiences as the result of universal external conditions ("All teachers are unfair") or to generalized internal causes ("I'm dumb"). Optimists, on the other hand, tend to be more specific: "Professor Seligman is unfair" or "I'm dumb at math" (Seligman, 1990, p. 50). Attributions are reversed for both optimists and pessimists in explanations for success.

Explanations related to the permanence and pervasiveness dimensions can give us feelings of either hope or hopelessness and "control what [we] do: how long [we] are helpless and across how many situations" (Seligman, 1990, p. 50, emphasis in the original).

Seligman (1991) believes that failure makes us all feel temporarily helpless, but it is our explanations for failure that make us permanently so. The theory of learned helplessness points out the cumulative effect of failure and negative self-talk on motivation and other self-regulatory processes (Schunk, 1994). By reacting to the challenges of life by giving up, helpless people exemplify the achievement motivation gone awry.

\section{Comparing Bandura's Self-Efficacy Construct and the Related Constructs}

While the constructs discussed above are all types of self-referent thought, they clearly represent different perspectives and different conceptualizations. However, there are a number of ways in which they can be compared and contrasted. 
Classification Differences

Among the Constructs

The self-efficacy construct and the constructs related to it can be grouped according to certain common characteristics.

Beliefs versus traits. The constructs can be separated and grouped according to whether they are perceptual beliefs or dispositional traits: Rotter (1977) and Weiner's (1994) causal attributions, Skinner's (1992) perceived personal control, and Bandura's (1986) self-efficacy are all types of perceptual beliefs that influence action. On the other hand, Seligman's (1991) learned helplessness and learned optimism, De Charm's (1968, cited in Schunk, 1996) personal causation, and Atkinson's (1957, cited in Schunk, 1996) achievement motivation, as well as the related constructs of self-worth and fear of failure, are more dispositional in nature.

General versus specific. The constructs can also be grouped according to whether they are general or specific. With the exception of Eccles's revision of achievement motivation, the other theories related to self-efficacy focus on generalized beliefs or present their central constructs as innate or enduring psychological traits that hold across tasks, situations, and often, domains.

On the other hand, Bandura considers self-efficacy beliefs to be taskand situation-specific. Bandura's (1986) conceptualization is predicated on the concept of triadic reciprocal causation, which presumes a reciprocal interaction between personal, behavioral, and environmental determinants. For Bandura, the formation of percepts of self-efficacy is dependent upon information from all three sets of determinants.

However, situational self-appraisals of efficacy made in particular circumstances also use preexisting self-efficacy beliefs as one source of information on which to make current judgments (Bandura, 1986). Preexisting 
self-efficacy beliefs are based on the pattern of past successes and failures and can be appraised not only on the dimension of strength, but also on the dimensions of level and generality. These last two dimensions give preexisting self-efficacy beliefs some generalizability; that is, they represent a range of courses of action which one feels efficacious performing and a composite of previous self-percepts of efficacy across a number of similar tasks and situations. Skinner's capacity beliefs, which include appraising one's possession of various subskills and internal means, seem most similar to Bandura's generalized self-percepts of efficacy.

Contributions of the Theories

to Conceptions of Effort

The conception of effort as the primary characteristic of active engagement and as an important intermediary force underlying successful performance attainments and outcomes is common to all theories, including self-efficacy theory. However, various theories have different perspectives that help to refine our understanding of the effects that attributions of effort and the deployment of effort have on perceptions, actions, and outcomes.

For example, attribution theory shows effort is an inner resource that is amenable to change and influence and, therefore, can be directed to ensure performance and goal attainments. Further, self-efficacy theory explicates the reciprocal relationship among effort, self-percepts of efficacy, and outcomes. For example, Wood and Bandura (1989a) point out that too much effort, especially on easy tasks, can diminish one's self-percepts of efficacy, while too little effort can make success or rewards unattainable even when one has the requisite ability (Bandura, 1986). Other theorists posit a similar relationship between effort and personal causation, for example, the achievement motive and learned helplessness or learned optimism. Similarly, Harter's (1978) research shows that when a challenging task requires too 
much effort, the amount of satisfaction or pleasure one has in its successful completion is reduced. This suggests that some tasks may not be chosen at all if there appears to be a diminishing return on one's intrinsic gratification.

Skinner's research on perceived personal control shows that attributions of both ability and effort provide the best assurance of active engagement and the accomplishment of desired outcomes. Wood and Bandura (1989a, 1989b) found this to be especially true in organizational contexts where effective performance attainments require a considerable investment of effort not only in deploying resources and influencing others to reach organizational goals, but also in learning how best to do so.

Differences Among the Constructs in the Mechanisms Translating Internal Means Into Action and Outcomes

All theories, including Bandura's self-efficacy theory, regard the personal possession of causes or means (e.g., ability, effort) as important to effective action and acquiring desired outcomes. However, the cognitive mechanisms by which one's perceptions of means and causes are translated into action and outcomes differ among theories.

Rotter, Weiner, and Seligman presume a direct link between causal attributions and human agency, while the theories of achievement motivation, perceived personal control, personal causation, and self-efficacy propose a cognitive mediator between internal means and action.

For example, Bandura (1986) considers perceptions of self-efficacy to be separate from attributional beliefs about internal means. He postulates that the focus of self-appraisals of efficacy should be not on the means one possesses but on what one is able to do with these means. In self-efficacy theory, perceptions of the self's possession of the internal means outlined by Rotter, Weiner, and Skinner are used as only one source of information in 
making appraisals of one's capabilities to execute the courses of action required for specific performances (self-efficacy).

Bandura (1989) also believes that "the effects of causal attributions on performance attainments are mediated through self-efficacy beliefs rather than operating directly on performance" (p. 416). For example, persons with strong self-beliefs of efficacy are likely to attribute failure to lack of effort rather than lack of ability. The causal attributions of ability and low effort then cause them to increase their effort and persistence in similar future activities which they value.

However, causal attributions can also have an intervening effect on self-efficacy: When persons accomplish difficult tasks with little perceived effort, their perceptions of self-efficacy are likely to be strengthened (Bandura, 1986).

Self-beliefs of efficacy also bias "the effects of outcome expectancies on performance motivation" (Bandura, 1989, p. 416) and enhance the predictiveness of outcome expectancies in determining future performance. This is particularly true when there is a high contingency between actions and outcomes, that is, when the quality of one's performance closely determines success or reward. However, when "extraneous factors also affect outcomes . . . [or when] expected outcomes are independent of perceived selfefficacy" (p. 417), self-efficacy beliefs will only partly govern outcome expectancies.

Like causal attributions, outcome expectancies also influence perceptions of self-efficacy. When outcomes are expected to be difficult or impossible to obtain, these expectancies can have a debilitating effect on selfefficacy. Self-efficacy will be maintained, however, if one believes that no one could have attained the desired outcomes (Bandura, 1986). 
The bidirectional influence between self-efficacy and causal

attributions and outcome expectancies, proposed by self-efficacy theory, suggests that the influence of internal factors on actions and outcomes is a complex one. Skinner also iterates a complex causal relationship between causal attributions, actions, and outcomes by positing that the basic need for competence and positive self-percepts of control are mediating factors of engagement. The basic need for competence motivates interactions with the environment and underlies the development of perceptions of competence. Perceived competence then governs ongoing choice behavior and engagement.

Alternately, achievement motivation theorists see the achievement motive as the mediating mechanism between causal attributions and action and outcomes, while personal causation theorists believe that one can take a proactive role in determining one's outcomes through self-regulation as a mediating mechanism. De Charm and the personal causation theorists believe that the cognitive process of goal-setting and other self-motivational processes in the self-regulatory system can help one to develop and reinforce the achievement motive.

Differences Among the Theories

in Conceptions of Competence

All theories place instrumental value on one's feelings of competence. However, the meaning of competence is not always clearly delineated within and across theories. Analyzing the different ways the various theories use the terms ability, capability, and capacity in relation to competence is one way to differentiate among theories and their conceptions of competence.

Locus of control and attribution theories appear to equate competence with ability. In these theories, ability, construed as an innate capacity and as 
particular discrete skills, is considered to be one of the internal means which play a role in achieving outcomes.

Alternately, perceived control theory sees competence as a basic need, and, as in effectance motivation, one gains feelings of competence through effective interactions with the world. Skinner's (1992) capacity beliefs are beliefs about one's internal means, one of which is ability. However, for Skinner, one's control beliefs--one's perceptions of personal control over outcomes--are the focus of competence appraisals, with capacity beliefs still playing a role in influencing choice behavior and engagement. Interestingly, Skinner sees control beliefs as existing separately from means. Both Skinner's perceptions of control and Bandura's perceptions of capability are informed by the specific task, situation, or event. In addition, both theories take past experiences into account in appraising competence.

Seligman (1991) is interested in the effect that beliefs about control have on personal agency, as well as in the way individuals talk to themselves to reinforce these beliefs. He equates feelings of competence with learned optimism, which is gained from successful attempts to control the events that affect one's life or from attributing success and failure in ways that preserve one's optimism. Alternately, learned helplessness is synonymous with permanent and pervasive feelings of incompetence which come from a series of failures and self-explanations which undermine one's feelings of confidence and competence. As with Skinner's (1992) perceived personal control theory, when individuals suffer from feelings of incompetence, they are likely to disengage from the task or situation. If feelings of futility prevail, individuals then disaffect completely, often feeling despondent and depressed (Bandura, 1992; Seligman, 1991; Skinner, 1992).

In contrast to the other theorists, the achievement motivation theorists focus less on competence per se and more on the development of 
predispositions for interaction with situations (achievement situations) that develop competence (Schunk, 1996). The achievement motivation theorists propose that feelings of competence influence and are influenced by the achievement motive.

Bandura's self-efficacy theory also contrasts with the other theories by clearly separating ability from capability. For Bandura (1986), the discrete cognitive, social, and behavioral subskills which make up one's ability are necessary but insufficient to efficacious behavior. To be efficacious--and competent--one must also be able to marshal these subskills into effective performances. Capability, thus, implies not only possession of ability, but most importantly, effective execution of courses of action using one's ability.

While Bandura does not specifically distinguish between capability and competence, the distinction between the two can be inferred from selfefficacy theory: Beliefs about one's competence are not formulated from the one-time competent performance but, rather, develop as one gains a history of competent performances across similar tasks, situations, and events. Therefore, competence beliefs are generalized perceptions of capability or efficacy.

Self-efficacy theory suggests two types of efficacy beliefs upon which perceptions of one's competence can be formed. The first type is one's selfperceptions of operative efficacy, or perceptions of one's capabilities to "continuously improvise multiple subskills to manage ever-changing circumstances" (Bandura, 1986, p. 396). Thus, one's competence depends on being able to adjust one's performance (improvise) as circumstances change. For example, a competent golfer can finesse a shot to get out of trouble, or a teacher can adjust his or her explanatory techniques for more complex or difficult material. 
Other efficacy beliefs upon which perceptions of one's competence can be formed are preexisting self-efficacy beliefs. As previously stated, these beliefs are a composite of previous perceptions of self-efficacy across a range of similar tasks and situations varying in difficulty or complexity. Past efficacious performances build a strong sense of personal efficacy or feelings of competence for future performances.

While the theories differ in their conceptions of competence, beliefs about one's ability are foundational to them all. In addition, one's beliefs about the nature of ability can have an effect not only on the causal attributions one makes, but also on one's perceptions of capability, control, and efficacy.

\section{Conceptions of Ability}

Ability is often equated with innate intelligence or talent and is usually considered to be an internal, stable, and largely uncontrollable cause, to use Weiner's terminology.

Recent research and theory, however, see ability and the more specific denotations of intelligence and talent as malleable and changeable (for example, see Sternberg, 1985). Thus, in considering the effects of ability on self-percepts of efficacy, performance, and outcomes, it is important to consider not only the effects of causal attributions of ability, but also the effects of different conceptions of ability (Wood \& Bandura, 1989a). Ability as a Fixed Quality

Despite the close relationship between ability and competence, research findings from other theories related to self-efficacy theory, such as locus of control, attribution, and perceived control theories, suggest that ability is still widely considered to be a relatively fixed, innate quality or trait. With that in mind, Weiner (1994) posits that, because one is generally considered to be 
responsible only for those causes that are "subject to self-regulation" (p. 165), failure due to lack of effort should receive high punishment because it is within one's influence, while failure due to lack of ability (perceived to be fixed and, therefore, uncontrollable) would receive little or no punishment. Weiner's (1994) recent studies of the "effects of causal attributions on observer evaluation" (p. 164) not only confirm this hypothesis, but also indicate that the conception of ability as fixed is still widely held.

Weiner also suggests that the conception of ability as fixed differentially affects people who perceive themselves to have high ability and those who perceive themselves to have low ability: People with perceived high ability have strong expectations of success and are highly motivated to engage in tasks (cited in Schunk, 1996). On the other hand, people with perceived low ability have low expectations of success and low motivation (Schunk, 1996), and, as Wood and Bandura (1989a) point out, weak self-beliefs of efficacy and low outcome expectancies.

Results from a study of managers in a simulated environment show similar effects. Wood and Bandura (1989b) found that managers who saw ability as fixed were "beset by increasing doubts of their managerial efficacy as they encountered problems" (p. 373). As a result, they became "more and more erratic in decisional activities, they lowered their organizational aspirations, and they achieved progressively less" (p. 373). For people who see ability as fixed, each performance is viewed as evidence of their basic capacity (Wood \& Bandura, 1989a, p. 410), and the high effort required to learn and meet challenges in organizational situations "poses an evaluative threat because it is indicative of low ability" (Wood \& Bandura, 1989b, p. 373).

Ability as an Acquirable Condition

Alternately, when ability is conceived as an acquirable condition, not only is effort viewed as a valued means of improving or increasing one's 
ability, but the attainment of effective performances and desired outcomes is also considered to be the result of effort and ability working together. Results from the simulated organizational experiment show that people who believe ability is an acquired condition focus on improving their managerial performances and tend to "judge [their] capabilities in terms of personal improvement" (Wood \& Bandura, 1989b, p. 372). By setting an "inquiring learning goal" (p. 372), they not only "seek challenges that provide opportunities to expand their knowledge and competencies" (p. 372), but also view successes and failures as opportunities for learning. This perspective protects their self-beliefs of efficacy from the "diverse effects of substandard performance" (Wood \& Bandura, 1989a, p. 408) and develops “a robust sense of personal efficacy [which sustains] the productive attentional focus and perseverance effort needed to succeed" (Wood \& Bandura, 1989a, p. 413).

Wood and Bandura (1989a, 1989b) found that while subjects began the organizational simulation with similar perceptions of self-efficacy and previous organizational attainments, their beliefs about ability biased how they cognitively processed their initial poor performance, which then affected the ongoing processing of information and either positively or negatively influenced self-percepts of managerial efficacy and performance attainments.

Different conceptions of ability also affect broader, more global perceptions of the self. Self-worth theory, for example, connects achievement due to ability with feelings of self-worth. This leads to the conclusion that if ability is believed to be fixed, then attributions of low ability would have a negative and relatively permanent effect on one's sense of self-worth.

In addition to conceptions of ability, conceptions of the environment are also an important aspect of at least two of the constructs being discussed, self-efficacy and perceived personal control. The theories underlying these 
constructs presume that one's perceptions of the environment affect, and are affected by, one's perceived efficacy (Bandura, 1986) or one's perceived personal control (Skinner, 1992).

\section{Conceptions of the Environment}

Conceptions of the environment form another belief system which has an influence on human agency and on individual perceptions of efficacy and personal control.

While it is necessary for a person to believe that "as a result of effort and perseverance he or she can realize desired performances" (Reid \& Ziegler, 1981 , p. 135 ), it is equally important to believe that "the environment will respond to reasonable effort" (Coleman, 1966, cited in Gozali, Cleary, Walster, \& Gozali, 1973, p. 10). Heider (1958), an early proponent of causal attribution, conceptualizes this interrelationship between person and environment as two forces which work with or in opposition to each other to influence the attainment of outcomes (cited in Schunk, 1996). According to Heider, the positive potentiality for reaching one's outcomes depends on two factors derived from these forces. The first is the "can factor," which is made up of an effective environment force and one aspect of an effective personal force, designated as power or ability (Schunk, 1996, p. 341). The second is the "try factor," which is represented by a second aspect of an effective personal force, referred to as motivation, or intentions and exertion (Schunk, 1996, p. 341). Similarly, Bandura and Wood (1989), delineate two factors underlying the exercise of control over organizational change. They are "personal efficacy to effect changes by creative use of capabilities and the enlistment of effort [and] the changeableness or controllability of the environment" (p. 805). 
Thus, according to these researchers, the characteristics of

environmental conditions and one's valuative perceptions of them play an important role in determining performance and outcome attainments through their influence on both the "can" factor and the "try" factor. Bandura (1989) posits that the environment's real and perceived controllability can also either enhance one's perceived power "to control the events that affect one's life" (p. 415) or contribute to one's feelings of powerlessness.

A review of the literature on self-efficacy theory and other related constructs suggests that conceptions of environmental controllability are derived from two general factors: the environment's potential for change and the environment's potential to empower. The Environment's Potential for Change

Coleman (1966) alludes to two conditions of changeableness when he suggests that effort is thwarted by environments that are "random or immovable" (cited in Gozali et al., 1973, p. 10). Environments can be considered random when they are inconsistent and unpredictable, characteristics of what Skinner (1992) calls a "chaotic" environment (p. 93). Alternately, environments can be considered immovable when they are difficult or impossible for people to change.

Randomness of the environment. Skinner (1992) addresses the relative randomness of environments in relation to perceived personal control. Representing environments on a continuum from highly structured to chaotic, she suggests that the number and quality of experiences of personal control one has will vary depending upon "the amount and quality of structure" (p. 93) of the social context. According to Skinner (1992), highly structured social contexts are "consistent and predictable ... [with] high contingencies between actions and outcomes" (p. 93) and, therefore, provide reliable information about which actions have the most potential for attaining 
outcomes. Chaotic contexts, on the other hand, are inconsistent and unpredictable and have unclear contingencies between actions and outcomes.

The highly complex and dynamic nature of the forces at work within organizations increases their potential for chaos: Increases in the number of and interrelationships among the relevant factors that determine effective action make predicting which actions will achieve which outcomes more difficult (Wood \& Bandura, 1989b) and, thus, require complex decision making (Bandura \& Wood, 1989). According to Wood and Bandura (1989b), "these predictive factors are usually related probablistically, rather than invariably, to future events" (p. 370), which blurs the contingencies between actions and outcomes and increases the uncertainty of decision-making results. The complex rules that govern contingencies can eventually be learned through trial and error as one carries out organizational activities (Bandura \& Wood, 1989). However, the feedback or information "concerning the adequacy of decisions is often delayed, multidimensional, and tainted by biases" (Wood \& Bandura, 1989b, p. 369), reinforcing perceptions that the environment is inconsistent, unpredictable, and volatile. In organizations where "working through others and coordinating, monitoring, and managing collective efforts is required" (Bandura \& Jourden, 1991, p. 941), these conditions are further exacerbated not only by the fact that people are all different, but also by the fact that they vary in their capacity for and responsiveness to change attempts.

Immovability of the environment. A second condition of the changeableness of the environment is its relative immovability. This can be likened to Weiner's dimension of stability. Following Weiner's logic, when the systemic, structural, or cultural aspects of a social context or organization are (or are perceived to be) inherent or stable, it will be (or will be perceived to be) relatively immovable. Further, stable environments will be more or less 
positive depending on whether or not the stable conditions enhance or constrain actions and outcomes.

Eccles, Bandura, and Skinner each consider the effects of one or more of the relatively stable systemic, structural, or cultural aspects of social contexts or organizations. For example, Eccles's (1983, cited in Schunk, 1996) model of achievement motivation cites cultural conditions as one of the antecedents of task-specific self-concept. Eccles includes the sex-role structure, the economic system, and what he calls the "socializers," or influential people within the environment, as examples of aspects of the cultural milieu that can have an indirect effect on actions and outcomes, through their more direct influence on task-specific self-concept (cited in Schunk, 1996, p. 297).

Bandura (1989) reports the effect of endemic cultural conditions such as "biased cultural practices, stereotypic modelling of gender roles, and dissuading opportunity structures" on "occupational efficacy" (p. 422). He suggests that "when contingencies are discriminately structured so that no level of competence can produce desired effects" (p. 417) self-percepts of organizational efficacy are adversely affected. More generally, Bandura (1986, 1989) also points out that the system, structure, or culture of a social context or organization can also constrain choice behavior, which, in turn, limits the development of interests and competencies that assist individuals in gaining control over the environment.

Finally, Bandura (1989) found that when organizations were viewed as not easily changeable, people "quickly lost faith in their decision-making capabilities even when performance standards were within easy reach" ( $p$. 415). However, when organizations were viewed as controllable people set "increasingly challenging goals and used good analytic thinking for discovering effective managerial rules" (pp. 415-416). These positive effects were mediated by perceptions of self-efficacy. 
From Seligman's (1991) point of view, perceived environmental controllability is learned through the effects of effort. Seligman postulates that underlying learned helplessness are perceptions that negative conditions are permanent and pervasive, much like environments characterized to be immovable. Such negative perceptions lead people to believe that effort will never produce the desired outcomes, and they give up trying, becoming passive and nonassertive.

In addition, Skinner (1992) reports that the "the links established between perceived control and high levels of performance and psychological functioning are largely mediated by engagement and disaffection" (p. 93). In a review of two studies of elementary school children (Wellborn \& Connell, 1986, cited in Skinner, 1992), Skinner showed that engagement was "undermined by beliefs in the effectiveness of non-action means" (p. 93 ), that is, environmental conditions unamenable to change such as powerful others or random conditions in which luck is the only known contingency.

The structure and culture underlying social contexts and organizations also determine one's personal autonomy through the effects on one's opportunities to exercise personal efficacy. In a study of 365 college students in 10 classrooms across four Midwestern institutions, Garcia and Pintrich (1991) found that self-determination, or autonomy, may have an indirect effect on performance through its direct effect on intrinsic goal orientation, task value, and self-efficacy, with self-efficacy "most strongly related to performance" (p. 6).

Self-worth is also affected by similar perceptions. In their study of the differential effects of teaching environments on college students, Schonwetter, Perry, and Struthers (1992) found that students who felt they could influence the conditions under which they learned or were evaluated 
"felt more pride" in their learning accomplishments than students with low perceived control" (p. 236).

The Environment's Potential to Empower

As Heider (1958, cited in Schunk, 1996) suggests, the environment can work either with or against individuals in their attempts to attain desired performances and outcomes or goals. More specifically, the environment works against individuals through its constraints, its lack of amenability to change, and its provision of levels of challenge that are either too low or too high. Alternately, the environment works with individuals through its amenability to change and through its provision of optimal levels of challenge and environmental support.

Environmental constraints. Bandura (1989) suggests the environment will work in conjunction with an individual's actions and, therefore, be more controllable depending upon "the level of system constraints, the opportunity structure to exercise personal efficacy, and the ease of access to those opportunity structures" (p. 415).

The degree to which the environment provides human, material, and time resources determines the level of environmental constraint. In general, the less these resources are available to a person, the greater the real and perceived constraints. For example, Bandura and Wood (1989) point to time constraints as one of the factors that impede effective decision making.

Environment's amenability to change. It is often one's subjective appraisal of the environment's amenability to change which influences selfpercepts of efficacy and subsequent performance (Bandura \& Wood, 1989). In a simulated organizational situation which was the same for all subjects, Bandura and Wood (1989) found that subjects who were told that employees were neither easily changeable nor responsive to guidance and that "fractional changes" would not produce improvements in overall 
organizational performance displayed "a low sense of self-efficacy regardless of whether they were performing under easy or difficult performance standards" (pp. 808-809). On the other hand, subjects who were told that employees were responsive to guidance and easily changeable and that fractional changes could produce improvements retained stronger selfpercepts of efficacy even after many failures, "adopted more challenging goals, displayed better analytic thinking, and achieved higher production levels than those assigned to the low controllability conditions" (pp. 810-811).

Bandura and Wood (1989) also found that "approaching a collective endeavor as relatively uninfluenceable instills a sense of personal inability to effect change that, in turn, makes group accomplishment difficult to realize" (p. 811). Believing the environment to be changeable helped to maintain "a resilient belief in one's ability to mobilize the efforts of others in joint endeavors [which promoted] organizational attainments, as well as individual accomplishments" (p. 812).

In a study of self-efficacy for six specific but unrelated tasks, Wang and Richarde (1988) found that the General Self-Efficacy (GSE) scale was inversely related to both Internal-External $(I-E)$ scores $(\underline{r}=-.24, \underline{p}<.05)$ and Helplessness scores $(\underline{r}=-.23, \underline{p}<.05 ;$ p. 536). A high GSE score indicated high general selfefficacy, while low scores on the I-E and Helplessness scales indicated high perceptions of internal and personal control, respectively.

Level of challenge. Another condition of the environment which constrains individuals' actions to attain outcomes is the level of challenge. According to Skinner (1992) "understimulating or overwhelming" levels of challenge negatively affect perceptions of personal control (p. 93). In two studies of college students, Earle and Lituchy (1991, cited in Berry \& West, 1993) found that good performances under difficult goal conditions produced higher levels of self-efficacy than effective performance under easy goal conditions. 
The understimulation resulting from easy goal conditions may have been a factor in this difference. However, while optimal challenges may enhance self-percepts of efficacy, overwhelming challenges will undermine selfpercepts of efficacy (Bandura, 1989) and of personal control (Skinner, 1992). When challenges become too difficult, the resultant effects on self-efficacy and perceived personal control lead to disengagement and, possibly, disaffection (Bandura, 1989; Skinner, 1992).

Environmental support. The second factor related to the environment's potential to empower is the social supportiveness of the environment.

Bandura (1992) postulates that social support systems can help people maintain feelings of efficacy by reducing the adverse effects of coping with negative life events, while lack of a social support can enhance feelings of inefficacy. Unfortunately, self-percepts of inefficacy then act to "curtail the cultivation of the very interpersonal relationships that can provide satisfactions and buffer the effects of daily stressors" (Bandura, 1989, p. 422).

Environments can also provide support by helping people to develop their capabilities, one of which is the capability to cope with many constraints. Bandura (1992) considers the development of one's knowledge and subskills as the foundation not only for effective performance, but also for the creation of strong self-efficacy beliefs. When environments offer few opportunities to practice and receive advice (Skinner, 1992) or to see models of effective performance, perseverance, and coping (Bandura, 1992), they can have a debilitating effect on one's development. According to Skinner (1992), support for the development of capabilities through "opportunities for practice, help, support and advice" (p. 93) is another characteristic of structured environments. In contrast, chaotic environments provide little support and few opportunities to develop one's capabilities. 
The four aspects of environmental controllability overlap considerably: Environments which are difficult to change will most often be constraining. Alternately, random environments can also be seen as difficult to change because of their unpredictability. Supportive environments can reduce the effects of constraints by sustaining people in otherwise adverse conditions or by helping them to develop the necessary capabilities to overcome obstacles. Thus, while it is useful to separate the factors underlying environmental controllability for analysis and discussion, in real life they overlap to produce multiple, combined effects on self-percepts, actions, and outcomes.

\section{Conclusion}

The review of the literature on other constructs related to self-efficacy offered an alternate and broader perspective for a new conceptualization of personal teaching efficacy. In addition, the summary of ideas related to the role of beliefs about ability and the controllability of the environment informed possible interpretations of Gibson and Dembo's (1984) teaching efficacy factor. Along with the review of the literature on teacher efficacy and self-efficacy, this section provided a starting point from which to develop a new theory and model of personal teaching efficacy. 


\section{CHAPTER 3}

\section{REVIEW OF THE LITERATURE II}

\section{Overview}

Chapter 3 begins with a review of the literature on volition and other related constructs. This review was conducted after initial factor analyses of the study data and provides a new volitional perspective for the conceptualization of personal teaching efficacy.

Chapter 3 then reviews the literature related to contexts of teaching and learning to teach and to reflective practice. This section provides a more complete understanding of the contextual conditions which influence teachers' and student teachers' feelings of efficacy as they engage in teaching and learning to teach. In addition, the review provides an overview of the essential elements of a reflective practitioner model of teaching and learning to teach. Thus, this section sets the stage for the interpretation of the findings derived from the empirical aspect of the study. 
Theory and Research Underlying Volition

\section{Introduction}

Looking at human agency from the perspective of volitional theory and research clarifies the role the self-regulatory system plays in human action. It construes individual differences in volitional aptitudes and capabilities as important determinants of differences in the successful completion of tasks and goals, particularly in complex, dynamic environments and for tasks and goals requiring ongoing action over the long term. Since organizations like schools are also characterized by complex, dynamic environments, and occupational roles such as teaching require one to fulfill tasks and goals over the long term, volitional theory seems particularly salient to this study.

This section begins with an overview of volitional theory, followed by an outline of the volitional control strategies. The implications of a volitional psychology perspective for self-efficacy theory are then discussed, and six main conclusions related to the relationship between self-efficacy and volition are explicated.

\section{An Overview of the Theory on Volition}

Volitional theorists (Corno 1993, 1994; Corno \& Kanfer, 1993;

Heckhausen, 1991) divide the constructs and processes more traditionally considered to be part of motivation into two distinct categories: motivation and volition. Motivational processes are believed to "set the stage for action" (Corno \& Kanfer, 1993, p. 305), while volitional processes are concerned with the implementation and attainment of goals. According to Heckhausen (1991), motivation and volition are separated by a boundary which he calls "intention formation" and defines as "an act of inner consensus to transform an action goal into an intention" (p. 11). He sees intention formation as a virtual 
"Rubicon" (p. 175) after which the direction of one's determination and will (volition) is set. Thus, an action goal can be considered to be a decision about whether or not to act, while intention formation is a decision about what actions to take, "at what opportunity, and in what manner" (p. 10). These "behavioral intentions" are usually formed "only for those goal intentions whose execution and implementation are difficult or imperilled" (Heckhausen, 1991, p. 184).

Similarly, Corno and Kanfer (1993) argue that while one's motivation helps to direct attention and mobilize effort by affecting decision making and choice around goals, it is one's volition that transforms goals or intentions into action and determines one's "initiative and persistence when there are obstacles" (p. 301). Simply stated, "motivation denotes commitment and volition denotes follow-through" (Corno, 1994, p. 230). They see motivation and volition as part of the larger self-regulatory system concerned with selfreferent thought and self-directed action. Each is made up of a distinct but related set of constructs and processes which address "different work conditions and different information processing demands" (p. 304).

The motivational mind-set and processes. The task of the motivational processes is to support the development of goal intentions. Thus the motivational mind-set and processes are largely "reality-oriented" (Heckhausen, 1991, p. 11) and focus on solving problems related to the elaboration of "value and expectancy features" (p. 11) of an action goal. They are concerned with the "receiving and processing of information" (p. 176) from many sources in order to make both an "assessment of direct and indirect consequences in terms of the likelihood of their occurrence and a comparison of alternate goals and courses of action" (p. 11). Personal sources of information include "individual differences in preferences, beliefs, expectancies, perceptions of outcome value, and patterns of attribution" 
(Corno \& Kanfer, 1993, p. 303) as well as "individual differences in goalorientation, self-efficacy judgments regarding performance, self-worth, and individual conceptions of possible selves" (p. 303). In addition, the "incentive conditions of the situation which may consist of perceived opportunities for achieving a goal" (Heckhausen, 1991, p. 10) are also taken into account.

The volitional mind-set and processes. The volitional mind-set and processes, on the other hand, support behavioral intentions related to the implementation and completion of action. Heckhausen (1991) considers action to be made up of all "activities which pursue the same goal idea" (p. 12). The volitional mind-set and processes are considered to be "actualization-oriented" (Heckhausen, 1991, p. 11) or "implementation-oriented" (p. 176) and are mainly concerned with "plans of action and behavioral intentions that focus attention and assure selective receptivity of information" (p. 176). In addition, following Kuhl's work (1986, cited in Corno, 1993), Corno considers one function of volition to be "metamotivational" because it serves to direct and control "intellectual, emotional, and behavioral energy toward ... goals that are subjectively difficult to enact" (p. 16).

After an intention is formed, volition involves "first, the planned preparation for the actualization of the intention to act, particularly with respect to seeking and utilizing suitable opportunities and the preparation of appropriate steps for implementation" (Heckhausen, 1991, p. 11) and second, the shielding of this particular intention against competing ones.

\section{Defining Volition}

Heckhausen and Kuhl (1985) define volition as "a psychological state characterized by thoughts about the implementation of goals into action [and] a predisposition to use available resources to manage the maintenance of intentions" (pp. 151, 153, cited in Corno, 1994, p. 231). Volition is also viewed as "akin to buckling down when we need to" (Corno \& Kanfer, 1993, p. 301) or as a 
"tendency to maintain focus and effort toward goals despite potential distractions" (Corno, 1994, p. 229).

Most volitional theorists and researchers conceptualize volition in terms of both volitional styles (or dispositional tendencies) and volitional control processes (Corno, 1993, 1994; Corno \& Kanfer, 1993; Heckhausen \& Kuhl, 1985, cited in Corno, 1994; Schunk, 1994). For example, Schunk (1994) posits that underlying volition is an action control function made up of "potentially modifiable skills or strategies" (p. 376) and a volitional style function made up of "stable, individual differences in volition [that are] less amenable to change" (p. 377). Similarly, Corno (1994) sees volition as "skills of self-management and dispositions toward self-responsibility" (p. 248).

Because people differ in their personal volitional styles and in their knowledge of and skill in using volitional processes, they also differ in their capability to protect their intentions and direct and sustain their effort (Corno \& Kanfer, 1993; Schunk, 1994; Zimmerman, 1994).

\section{Volitional Styles}

Messick (1985) defines personal style as the "self-consistent regularities in the manner or form of human activities" (p. 34, cited in Corno, 1993, p. 20) and sees these dispositional tendencies as "key variables in the organization and control of attention, impulse, thought, and behavior" (Messick, 1989, pp. 1, 3 , cited in Corno, 1993, p. 20). Dispositional tendencies are posited to affect both motivation and volition through their effect on goal choice (motivational process) and on the choice of volitional control strategies.

People with strong capabilities for self-direction (one aspect of volitional control) can be distinguished by certain dispositional characteristics. Zimmerman (1994) characterizes self-directed people as "selfstarters [who are] confident, strategic, and resourceful in overcoming problems [and] self-reactive to task performance outcomes" (p. 5). They are 
also noted for their acceptance of personal responsibility for their actions and for their "persistence, resourcefulness, and self-reliance" (p. 4). Alternately, he describes "underachievers" as "tend[ing] to give up more easily," and as being "more impulsive," "more self-critical," and "less efficacious" than achievers (p. 5).

Corno and Kanfer (1993) suggest that "the collective evolution of certain aspects of personal character long prized in many cultures: nonintellectual attributes such as patience and duty, responsibility, and determination" (p. 309) is at least partly the result of one's volitional activity over time. As these attributes develop they also become part of one's volitional style and work to enhance volitional behavior for the attainment of goals.

Using data collected from the administration of the Action Control Scale, Kuhl (1985, cited in Corno \& Kanfer, 1993) has also identified two dispositional factors related to volition, action orientation and state orientation. Action orientation has been shown to be clearly and positively correlated with selfcontrol ( $\underline{r}=.33$ to .37 ; Klinger \& Murphy, in press, cited in Corno \& Kanfer, 1993$, p. 315$)$ and negatively correlated $(\underline{r}=-.55$ and $\underline{r}=-.48)$ with "vulnerability to stress and general cognitive failure," respectively (Kanfer, Dugdale, \& McDonald, in press, cited in Corno \& Kanfer, 1993, p. 315). In addition, high levels of action orientation have been found to have a positive influence on performance during difficult or complex tasks (Kuhl, 1984, cited in Corno \& Kanfer, 1993).

Action-oriented people have a propensity to develop action schemas (visualized enactment of goals) and a propensity for goal-related action (Corno $\&$ Kanfer, 1993, p. 314). They tend to be task-focused and to concentrate on developing plans and strategies for the implementation of goals. This is confirmed by Kuhl"s $(1983,1984$, cited in Heckhausen, 1991) study of elementary school children. Kuhl found the children's determination to 
participate in 22 after-school activities was positively correlated with the actual time they spent participating and concluded that "action-oriented individuals are much more likely to implement their plans than state-oriented subjects" (Heckhausen, 1991, p. 173). On the other hand, state-oriented people are characterized by a disinclination to visualize taking action and a proneness "to ruminate about emotional states and past difficulties" (Corno \& Kanfer, 1993 , p. 314). They tend to be self- or ego-focused rather than taskfocused.

From a slightly different perspective, Bullock and Lutkenhaus (1988, cited in Corno \& Kanfer, 1993) conclude from their developmental study of preschool children that having a sense of oneself as an agent (which is also the basis for action orientation) is a necessary prerequisite for volitional competence. That is, "implicit representations of the self engaging in relevant actions become triggers for self-regulatory activity" (Corno \& Kanfer, 1993, p. 316 , emphasis in the original).

\section{Volitional Control Capabilities}

In addition to certain dispositional tendencies or styles, volition is also affected by one's capabilities to protect one's goals and behavioral intentions through self-regulation. These self-directed capabilities have been categorized in a variety of ways.

For example, in addition to volitional style, Corno and Kanfer (1993) propose two categories of volitional control processes adapted from the work of Heckhausen and Kuhl (1989, cited in Corno, 1994). They are action control processes and goal-related cognitions. Action Control Processes

Action control processes refer to the knowledge and strategies used to manage internal (cognitive and noncognitive) and external (environment 
and people) resources for goal attainment. Pressley, Goodchild, Fleet, Zajchowski, and Evans (1989) delineate the internal, covert processes of action control as strategies that engage the mind and the external, overt processes as strategies that set the environment (cited in Corno \& Kanfer, 1993). Corno and Kanfer, however, categorize the action control processes into three subcategories: metacognitive control strategies, emotion and motivation control strategies, and environmental control strategies (p. 311).

Metacognitive control strategies. Metacognitive control strategies are used to manage "cognitive activities that regulate information around goals" (Corno, 1994, p. 311) and include strategies such as metacognitive monitoring and attention control. Metacognitive control strategies help one to perform to the specification of the task.

When teachers keep tabs on how many times a student acts out, when they reflect on their lessons and make "immediate mental notes on what to do differently," or when they develop strategies for coping with failure, they are using metacognitive control strategies (Corno \& Kanfer, 1993, p. 312).

Emotion and motivation control strategies. Emotion and motivation control strategies differ from metacognitive control strategies in terms of their focus of control. While metacognitive control focuses on cognitive processes such as selective attention and information processing, emotion and motivation control focus on the affective domain.

Emotion control strategies are used to manage thoughts and feelings that could get in the way of effective action. They include strategies such as using inner speech, visualization, or controlled breathing to keep one focused on the task rather than on self-vulnerabilities (Corno, 1994). When teachers "wait 5 seconds before speaking" when they are angry or when they imagine the satisfaction they would feel if they were made teacher of the year, they are employing emotion control strategies (Corno \& Kanfer, 1993, p. 312). 
Motivation control strategies manage thoughts and feelings to "enhance or strengthen the motivational basis of intentions" (Corno \& Kanfer, 1993, p. 311). They include ways to keep one focused like redesigning tasks to make them more interesting or establishing one's own contingencies for task completion. Using one's thoughts and feelings to mobilize effort and increase persistence is also a motivational strategy (Corno \& Kanfer, 1993). When teachers "berate [themselves] mentally for handling something wrong," plan improved teaching techniques, or read in the literature with an eye for analyzing and changing their own work, they are using motivation control strategies (Corno \& Kanfer, 1993, p. 312). Forming intermediate-level or proximal goals on the way to higher level and more distal goals is another type of motivation control strategy that falls in the arena of volition. As Heckhausen (1991) points out,

The level of goal representation at a given time depends on the prevailing demands. It can relocate itself at a high level if the activity's path is unimpeded. However, action will come under the control of approximate intermediate goals if the current activity runs into trouble and demands total attention. (p. 185)

Motivation control strategies help one to stay on task, continue in the face of obstacles, renew commitments to one's goals, and keep distal goals in sight. Environmental control strategies. Finally, environmental control strategies manage environmental factors to enhance the use of the internal control strategies. Environmental factors include the physical space, the situation, and the people in the situation. Thus, embellishing teaching, establishing classroom rules, rearranging classrooms, getting assistance from others, and getting students to change their behavior are all examples of environmental control strategies that teachers might use (Corno \& Kanfer, 1993, p. 312). Environmental control strategies help one design, redesign, or 
change elements in the environment so that they will better support one's intentions and goals.

In keeping with the idea that one has internal and external resources that can be used or manipulated to enhance performance and goal attainment, Corno (1994) alternately refers to resource management strategies rather than to action control processes.

\section{Goal-Related Cognitions}

Goal-related cognitions, the second broad category of volitional processes, form the basis for the adaptive use of action control strategies. Goal-related cognitions assure volitional control by focusing on "strategic self-regulation" and the "well-timed application" of action control processes (Corno \& Kanfer, 1993, p. 305). The emphasis is not so much on effort expenditure per se, but on how the deployment of effort is managed. This mirrors Heckhausen's (1991) model of action control which sees the volitional process of intention formation as being concerned with what actions to take, "at what opportunity, and in what manner" (p. 10).

A new conception of effort. In addition, Corno (1994) suggests that considering action control as resource management represents a new perspective on the concept of effort. Rather than using Weiner's perspective of effort as an internal attributional component, the resource management perspective is that effort is

a function of person-situation interaction, and occurs when available external and internal resources combine. Effort is not trying in the absence of resources; it is the striving to enlist all available resources [internal and external] to pursue goals. (Corno, 1994, p. 232) Implicit in Corno's reconceptualization of effort as resource management is that the enhancement of current resources and the development of new ones are ways in which one can strive to attain one's goals. When teachers 
rearrange their classrooms, for example, they are, in effect, striving to make the learning environment more supportive of their goal of student learning. In addition, when teachers learn and implement new strategies for teaching or managing their classrooms, they are, in essence, changing themselves to make themselves a more useful resource.

\section{Implications of a Volitional Psychology Perspective for Self-Efficacy Theory}

Dividing the processes underlying self-directed action into the two arenas of motivation and volition holds promise for a better understanding of human action, especially goal-directed action in difficult, complex, or longterm situations. Volitional theory and research have already begun to answer questions about why some people perform more competently than others with similar task- or role-related skills and about how and why some people continue to persevere in the face of obstacles and others do not. These questions are also central to the study of self-efficacy, especially to those areas of study related to self-percepts of occupational efficacy like personal teaching efficacy.

While the terminology and perspective of current volitional psychology are relatively new, volitional aptitudes and control processes are either directly referred to or implied in much of the research literature related to effective performance and to the formation of self-percepts of efficacy. From these studies, several conclusions can be drawn.

Conclusion 1: Volitional control processes work in tandem with task- or role-specific capabilities.

Volitional psychology emphasizes the importance of strategic selfregulation through volitional control processes for the successful performance of task- or role-related courses of action. (See Table 2 in chapter 
2 for a list of self-regulatory processes.) These volitional control processes, often referred to as self-regulatory strategies in the current literature, have been posited to enhance or augment one's task- or role-specific capabilities. For example, the Labor Secretary's Commission of Achieving Necessary Skills (SCANS, 1991, cited in Corno \& Kanfer, 1993) emphasizes volitional processes related to self-management and responsibility as one of three broad areas (basic skills and thinking skills are the other two) which support the acquisition and use of competencies.

Volitional processes are considered to support performance competencies by acting as mediators that "energize the maintenance and enactment of intended actions" (Kuhl, 1985, p. 90, cited in Corno \& Kanfer, 1993, p. 14) and, as a result, enhance chances for high performance attainments. For example, McIntyre (1991, cited in Corno \& Kanfer, 1993) found moderate but significant correlations between student GPA and selfreported self-regulatory and motivational characteristics. Similarly, Willingham (1985) found students with high productive follow-through, defined as "a pattern of persistent and successful effort over time," (p. 8, cited in Corno, 1994 , p. 235 ) were "over-represented by $20 \%$ to $30 \%$ in several categories of success" (Corno, 1994, p. 236), although productive followthrough did not correlate with students' GPA in Willingham's study.

Kuhl and Kraska (1989, cited in Corno, 1993) suggest that because volitional strategies affect the way one's resources are expended, differences in volitional strategy knowledge may affect performance. This has been confirmed by at least two studies on student learning. Pintrich, Smith, Garcia, and McKeachie (in press, cited in Pintrich, Marx, and Boyle, 1993) found a positive correlation between cognitive and metacognitive strategy use and actual learning performance. In related research, Schunk and Rice (1987, cited in Corno, 1994) show that deliberate strategy training, including 
information on the value of strategy use, can also improve student performance.

Thus, volitional theory and research, by focusing on humans in action, emphasize that people use both task- or role-related capabilities and volitional control capabilities to successfully complete tasks and reach their goals.

For example, one may have the capability to drive a golf ball 250 yards, straight at any target. While this is an important task-related skill to be a successful golfer, one's golfing performance and goal attainment of a low score depend on one's ability not only to repeat this course of action time after time, but also to do so when it is windy, or when one is nervous or frustrated, or when the stakes for winning are high. In addition, when the drive does not go off as planned, a successful golfer must also be able to get back on track, recover with the next shot, and thereby get "up and down" in regulation. Thus, golf-specific capabilities are enhanced by capabilities to direct the use of these golf-specific behaviors (metacognitive control), control thoughts and feelings (emotion and motivation control), and adaptively manage the use of external resources such as golf clubs or the position of one's lie (environmental control).

If these volitional control capabilities influence one's capabilities to golf, it seems likely that they may also be taken into account, along with more specific task-related capabilities, in assessments of one's golfing efficacy. It is also probable that volitional control capabilities used in teaching will be taken into account in assessments of personal teaching efficacy.

Conclusion 2: Self-percepts of efficacy consciously or unconsciously include assessments of volitional control capabilities

That perceptions of self-efficacy include appraisals of volitional control capabilities is inferred in Bandura's conceptualization of self-efficacy as the 
marshalling of cognitive, affective, and behavioral subskills to complete courses of action. In addition, research has uncovered a correlation between certain volitional control capabilities and self-percepts of efficacy. For example, studies show that self-percepts of efficacy are moderately but positively correlated with cognitive and metacognitive strategy use during learning (Zimmerman \& Martinez-Pons, 1990, cited in Corno, 1994; also see Pintrich, Marx, \& Boyle, 1993). In addition, Finn and Cox (1992, cited in Corno, 1994) found that active participation correlated significantly with math and reading achievement.

Some research suggests that volitional strategy use is mediated by perceptions of self-efficacy: Bouffard-Bouchard, Parent, and Larivee (1991) found a significant main effect for self-efficacy (operationalized as the number of problems students indicated they could do and how certain they were that they could do them) on monitoring of work time and on persistence, both of which are acknowledged aspects of volitional control.

However, in related research, Schunk and Rice (1987, cited in Corno, 1994) posit that volitional control strategies also reciprocally influence selfefficacy. They found that strategy training, including information on the value of strategy use, not only improved performance, but also increased perceptions of self-efficacy. Similarly, Locke, Frederick, Lee, and Bobko (1984) found that the strategies one used (which were affected by training), along with one's ability and posttraining performance, affected the level and strength of self-efficacy (operationalized as the number of uses students indicated they could give for common objects and how certain they were that they could).

The role volitional control plays in performance and goal attainment is particularly salient in the face of distractions, obstacles, and other conditions that obstruct or impair one's action plans or "during the pursuit of difficult or 
long-term goals when effective volitional control over action can enhance learning and performance as well as sustain goal striving" (Corno \& Kanfer, 1993 , p. 305). How one handles these challenges are central issues for selfefficacy for coping (McCarthy \& Newcomb, 1992) and for volitional theory (Heckhausen, 1991). Bandura (1989) identifies "capabilities to exercise control over potential threats" (p. 419), or coping efficacy, and capabilities to control distressing cognitions, or thought control efficacy, as two instrumental processes underlying the coping mechanism. He delineates these two coping capabilities as types of self-regulatory processes and strategies. For Bandura (1992), perceptions of coping efficacy determine the "subjective perilousness of environmental events" (Bandura, 1992, p. 25) in the first place, as well as mediate perceptions of thought control efficacy: "controllability is the key organizing principal regarding the nature of stress effects" (Bandura, 1989, p. 420). As people "gain increasing ability to predict and manage potential threats, they develop a robust self-assurance that serves them well in mastering subsequent challenges" (Bandura, 1982, p. 126).

From a more general perspective, McCarthy and Newcomb (1992) posit a behavioral coping ability which allows one to "have an impact on the environment" (p. 56) and a cognitive control ability which allows one to "regulate cognitions in response to challenges associated with accomplishing desired goals" (p. 56). These abilities are appraised to form self-percepts of behavioral coping efficacy and thought control efficacy, respectively. While not identifying behavioral coping as specifically self-regulatory, McCarthy and Newcomb do consider behavioral coping to be a general ability that can be applied to deal with the multiple and often unplanned new interactions with the environment that occur when one makes major life changes.

These two perspectives on coping both construe successful coping behavior as a proactive (and, therefore, volitional) response to aversive 
situations. Similarly, Skinner (1992) conceptualizes coping as the proactive regulation of one's engagement (involvement with ongoing activities) under conditions of psychological distress. According to Skinner, if an "event involving loss of control" (p. 101) is perceived as a threat to ongoing competence, the distress reaction which follows will push the individual into coping behavior. A positive coping response, which includes metacognitive, emotion, and motivation control aspects of volitional control, involves the energizing of "a number of self-regulatory processes" (p. 101) which assure active rather than passive behavior, positive rather than negative emotions, and an orientation towards rather than away from the activity. For Skinner, how one copes is the result of one's perceived control, which includes one's strategy, capacity, and control beliefs. Strategy beliefs are beliefs about which means (e.g., ability, effort, powerful others, luck) affect performance and goal attainments, capacity beliefs are beliefs about one's own access to these means, and control beliefs are general expectancies about the extent to which the self can produce desired outcomes, regardless of the means used. While Skinner's capacity beliefs most closely conform to Bandura's conceptualization of self-percepts of efficacy, control beliefs also play a role.

The above research suggests a reciprocal influence relationship between volitional control and self-percepts of efficacy. However, the research also suggests that action control--resource management--strategies and the ability to use them strategically are capabilities that not only can be learned and developed, but also can "serve as one type of cues people have learned to use as indicators of personal efficacy" (Bandura, 1982, p. 127). Conclusion 3: Volitional goals also affect self-percepts of efficacy.

Volitional theory emphasizes the role of self-direction in meaningful action. Action becomes meaningful when it is based on goals to which the 
individual has committed and for which he or she has formed intentions for action (Heckhausen, 1991). Self-percepts of efficacy play a role in both initial commitment (motivation) and follow-through (volition). As Bandura (1986) points out, motivation to pursue a task or challenge arise from internalized goals, needs, and aspirations, all dependent on the self-efficacy mechanism. In addition, research shows that the level of goals set, a preaction motivational task, is significantly related to the level of perceived self-efficacy (Locke, Frederick, Lee, \& Bobko, 1984).

Specific proximal goals. However, goals also play a role in sustaining feelings of efficacy, especially during long-term action, through the use of motivation control strategies to reenergize goal commitments and intentions. One such strategy is the use of specific, proximal goals. Specific, proximal goals positively affect one's self-directed action and situation- and taskspecific assessments of self-efficacy by providing information about one's progress towards more distal goals (Bandura, 1986). Proximal goals framed in terms of discrete action (what volitional psychologists would call behavioral intentions) have also been found to enhance feelings of competence (Schunk, 1991, cited in Meece, 1994) and to influence initial self-percepts of efficacy (Stock \& Cervone, 1990). For example, in pursuit of long-term goals such as mathematical competency, Bandura and Schunk (1981, cited in Berry \& West, 1993) found that children given proximal goals had significantly higher math self-efficacy than children given distal goals or no goals at all.

Similarly, Schunk and Rice (1989, cited in Corno, 1994) found that students with process as well as product goals had higher self-percepts of efficacy than groups with only general goals or with no goals. Process goals are similar to the proximal goals discussed above, as well as to Kuhl's (1985, cited in Corno \& Kanfer, 1993) action schemas and Bandura's (1982) selfregulatory processes of cognized goals and anticipatory scenarios. Because the 
propensity to form action schemas is known to differ among individuals and because action schemas also trigger additional strategies for protecting one's intentions (Kuhl, 1985, cited in Corno \& Kanfer, 1993), it makes sense that one's propensity and capability to form them will also affect differences in self-efficacy.

In addition, because organizational goals are often distal in nature or conceptualized at a high level of abstraction or generality (Bandura \& Wood, 1989), efficacious action in organizational settings may require the setting of proximal goals which will then mediate and be mediated by self-percepts of efficacy.

Learning or mastery goals. Having a learning or mastery goal where the emphasis is on building competence (Graham \& Golan, 1991, cited in Meece, 1994), rather than a performance goal which emphasizes success, can also protect self-efficacy during long-term action or in the execution of difficult tasks: Learning-oriented people are more likely to view setbacks or failure as a source of information for forming revised behavioral intentions rather than a source of information for making negative self-evaluations (Meece, 1994). In addition, according to Schunk (1994), "students who adopt a learning goal are apt to experience a sense of self-efficacy for skill improvement and engage in activities which they believe enhance learning (p. 89). Thus, if one has faith in one's ability to learn, a learning orientation protects one's sense of self-efficacy by providing incremental performance attainments and by focusing on improvements in performance for a sense of efficacy (Wood \& Bandura, 1989a). In addition, the continually renewed or revised intentions which result from a learning orientation help one to stay on-task (Schunk, 1989, cited in Schunk, 1994) and promote the tendency to use deep processing (Graham \& Golan, 1991, cited in Meece, 1994) and problem-solving strategies (Eliot \& Dweck, 1988, cited in Meece, 1994). Time on task and the strategic use 
of volitional capabilities assure increasing proficiency (Bandura, 1986). Increasing proficiency then enhances beliefs that one can continue to augment or make generative use of one's capabilities and, thus, continue to respond effectively even in the face of new obstacles and setbacks.

A self-efficacious learning orientation also fosters a task-diagnostic focus for learning from one's mistakes (Bandura \& Wood, 1989). A taskdiagnostic focus supports the learning of the predictive rules necessary for one to successfully pursue goals in complex and dynamic organizational settings. In addition, Bandura and Wood found that managers with high selfpercepts of efficacy who focused on learning from their mistakes saw belowstandard performance as a motivator to reduce the discrepancy between selfperceptions of efficacy and actual performance.

In professions like teaching, where developing competence occurs on the job and where it often takes 2 to 3 years to reach high levels of expertise (Garmston, 1998), a learning-oriented use of volitional control strategies and a task-diagnostic focus for learning from one's mistakes may be essential to effective teaching and the development and maintenance of self-percepts of personal teaching efficacy.

Conclusion 4: Strategic use of volitional control strategies increases feelings of control and these feelings enhance self-efficacy.

Feelings of self-control. Goal-related cognitions during the volitional phases of action reinforce the adaptive use of volitional control strategies (Corno \& Kanfer, 1993). This capability to respond flexibly to task and situation demands while keeping goals in mind also reinforces intentionality and self-control (Schunk \& Rice, 1987, cited in Corno, 1994). Intentionality and self-control, in turn, foster feelings of being in control, an essential aspect of self-percepts of competence (Skinner, 1992). Zimmerman, Bandura, 
and Martinez-Pons (1992, cited in Garcia \& Pintrich, 1994) found students capable of strategic self-regulation perceived themselves to have greater selfefficacy for concentrating in the face of distractions than students who did not possess self-regulatory ability. Additionally, positive self-percepts of one's capabilities for self-direction have an effect on maintaining effective action and on getting back on course when one's intentions are interrupted. This is confirmed by Condiotte and Lichtenstein (1981, cited in Bandura, 1982), who found that measurements of perceived self-regulatory efficacy predicted not only relapses in quitting smoking but also individual differences in how participants would respond to the relapse.

Perceptions of environmental controllability. As the theory and research on coping suggest, strategic use of volitional control capabilities, and self-percepts of efficacy for their use, enhances not only feelings of selfcontrol, but also perceptions of environmental controllability. While the social context plays a critical role in creating experiences of control (Skinner, 1992), one's perceptions of environmental controllability are not objective observations but rather the combined result of perceptions of environmental factors and assessments of one's capability to deal with them (Bandura, 1989). Heckhausen (1991) refers to the combined result of these two perceptions as action-by-situation expectancies. Action-by-situation expectancies are "the subjective probability that one's actions will modify a given situation" (p. 415) or the probability that one will be able to influence events (p. 176) combined with the "subjective probability that external and variable circumstances will heighten or lessen one's ability to act" (p. 415). These combined expectancies are also very similar to Skinner's (1992) control beliefs and to BouffardBoucher and Pinard's (1988, cited in Bouffard-Boucher, Parent, \& Larivee, 1991) description of self-efficacy as "the result of the interaction between the individual's estimation of the demands and conditions of a particular task, the 
resources they believe they possess, and especially their ability to use them in precisely this situation" (p. 154).

Volitional psychology's emphasis on the strategic use of volitional control strategies places the capacity of individuals to be proactive in their engagement with challenging or hostile environments at the center of effective action. Thus, complex, dynamic, or uncertain environments can be perceived as being more or less controllable if, despite aversive conditions, one believes that (a) one has adequate task-related and volitional capabilities for the demands of the situation and the actions required for goal attainment, (b) one has the self-capabilities to bring the situation under control or to create conditions that support one's action goals and behavioral intentions, or (c) one can learn new capabilities for effective action and environmental control.

For example, in teaching situations, it is not so important that teachers feel parents influence their children and that this influence is often strong and negative, but that they believe they have the capabilities to neutralize this effect through their teaching of and interactions with students, or that they have the capabilities to enlist parental support. Alternatively, the aversive conditions of the present context are not so important for feelings of controllability as perceptions of one's capabilities to deal with them or to change them. When teachers plan ways to prevent off-task or unruly behavior or when they rearrange their classrooms or set up routines for the class to follow, they are acting on this second set of perceptions. Finally, when teachers feel they can learn new techniques and strategies or form new understandings of how children learn and when they follow through with their acquired knowledge and skills, situations of being unable to "get through" to students or to help them learn do not present themselves as 
uncontrollable. As was outlined previously, these are all volitional control strategies of resource management.

Conclusion 5: The deployment of effort is the

foundational capability underlying volitional control.

According to Heckhausen (1991), volitional issues are "phenomena of action initiation, of perseverance, and of overcoming obstacles to action" ( $p$. 163), that is, issues of effort deployment. Thus, volitional theorists and researchers see capabilities for self-regulation and environmental control, as well as the ability to implement and protect one's intentions, as functions of one's capability to direct and sustain effort in the pursuit of goals (Corno \& Kanfer, 1993). By emphasizing the strategic expenditure of effort, or as Corno (1994) suggests, effort "mindfully not blindly invested" (p. 232), volitional theory also conceptualizes the deployment of effort as a capability that can be learned or developed. Because the quality and quantity of deployed effort vary among individuals, self-percepts of one's capability to direct and sustain effort may also contribute separately to feelings of self-efficacy. In fact, this has already been demonstrated in relation to self-regulatory and coping efficacy which depends on perceptions of capabilities to strategically use one's effort to overcome aversive conditions.

As previously stated, effort has been traditionally conceptualized as the strength and duration of one's trying and, more recently, as a personsituation interaction referred to as resource management. Both concepts of effort have been discussed in relation to self-efficacy.

Effort, as the capability to focus energy and time, is related to selfefficacy. Strength of effort and persistence (duration of effort) have both been found to be related to self-efficacy. However, most researchers conceptualize effort as a causal attribution mediated through self-efficacy or view self-efficacy as influencing effort rather than the other way around. 
For example, Collins (1984, cited in Corno, 1994) found that subjects rely heavily on judgments of their efficacy in regulating their expenditure of effort. Self-efficacy has also been found to account for $12 \%$ of the variance in persistence (Multon et al., 1991, cited in Berry \& West, 1993) and to be significantly related to persistence on boring or difficult tasks (Pintrich \& DeGroot, 1990, cited in Berry \& West, 1993). Bandura (1986) found that perceived self-efficacy predicts persistence in task completion (also see Bouffard-Bouchard, Parent, \& Larivee, 1991), as well as how much and how long effort will be expended in the face of obstacles and aversive situations. Alternately, Sexton and Tuckman (1988, cited in Tuckman \& Sexton, 1989) found immediate past performance, rather than self-percepts of efficacy, to be the major determinant of persistence; however, Feltz (1982, cited in BouffardBouchard, Parent, \& Larivee, 1991) posits that self-percepts of efficacy are more highly related to past performance than to future performance in the first place.

On the other hand, attributions of effort have also been found to influence perceptions of self-efficacy. For example, Schunk (1982, cited in Garcia \& Pintrich, 1994) notes that effort feedback for successes has a positive effect on a sense of goal progress, on motivation, and on efficacy for further learning. Such effort feedback reinforces the importance of self-control through one's own effort in attaining success. Skinner (1992) found that children who not only saw effort as an effective means for achieving goals, but who also believed they had the capacity to exert effort, had the highest levels of engagement and the strongest beliefs in their ability to control their school successes and failures.

Alternately, children who believed that success was the result of “nonaction causes" (Skinner, 1992, p. 96 ), such as ability, powerful others, and luck, and who also believed they did not have access to these means had 
the lowest levels of engagement and consistently undermined their achievement efforts.

Beliefs about both ability and effort affect performance and selfpercepts of efficacy. Skinner and Wellborn (1991, cited in Skinner, 1992) found that while "children with high effort and ability beliefs were more likely to strategize and persevere and less likely to attempt to get others to solve their problems for them" (p. 102), it was the combined strategy and capacity scores for effort that were the "highest unique predictors for both strategizing and perseverance" (p. 102). Further, in failure situations where ability is perceived to be fixed rather than an acquirable skill and failure is believed to be due to lack of ability rather than lack of effort, Weiner and Kukla (1979, cited in Tuckman \& Sexton, 1989) found that people have low motivation to achieve. Thus, ability perceived as an acquirable skill can actually enhance beliefs in the "efficacy of effort" (Skinner, 1992, p. 102) and, thus, positively influence the propensity for active engagement, the adaptive use of analytic strategies, the desire for self-development, and the development of highly resilient self-percepts of efficacy in the face of repeated failures and setbacks (Bandura \& Wood, 1989).

Effort, as the capability to manage internal and external resources, is also related to self-efficacy. Corno's (1994) conceptualization of effort as resource management focuses on the mindful use of all available resources to protect one's intentions and assure continuing action towards one's goals. Effort as resource management takes into consideration how well one is able to deploy one's effort to utilize both personal and environmental resources.

Thus, it emphasizes the proactive use of self-capabilities not only to act in the environment, but also to act on the environment. Zimmerman and Martinez-Pons (1988, cited in Garcia \& Pintrich, 1994) found that students with high capabilities for self-regulation were significantly more likely to 
organize and restructure their place of study and to seek help than regular students. In addition, research suggests that effort as resource management can be directed and managed and, therefore, learned. Training in environmental control as well as in self-control strategies has been found to be an effective intervention for people trying to change debilitating behaviors such as overeating and excessive alcohol consumption (Meichenbaum, 1977, cited in Corno \& Kanfer, 1993).

Actions on the environment also make a difference to one's eventual success by aligning aspects of the environment in ways that support performance and goal attainments. A 12-year follow-up study of 405 adult males who were overcoming drug addiction, conducted by Simpson, Joe, Lehman, and Sells (1986, cited in McCarthy \& Newcomb, 1992), found that the ability to manage social variables (avoiding old friends and making new ones, strengthening family ties, and improving one's work habits) was a significant determiner of long-term continued abstinence. McCarthy and Newcomb (1992) posit that perceptions of one's capabilities to proactively influence oneself and the environment, referred to as perceived behavioral coping efficacy, underlie effective action in work settings and during large-scale lifestyle changes. Similarly, Bandura and Wood (1989) found that in the face of obstacles and setbacks, managers who believed they were capable of effectively using and influencing the environment to meet their goals had strong and resilient self-percepts of efficacy.

These findings support the importance of effort in volitional control of oneself and the environment. As Bandura (1982) points out, people who do not believe they can exercise control undermine their own efforts, especially in coping situations. While not expressed in self-efficacy terms, these findings suggest that when people believe they can direct and sustain their effort, they 
may also have stronger self-efficacy for volition, especially in the face of difficulty or failure.

Conclusion 6: Dispositional aspects of volition

play a role in volitional control.

One aspect of volition theory of interest to self-efficacy is the proposed influence of dispositional components on volition. It speaks to the commonsense notion that stable individual qualities can also enhance or impede one's capability to act. Because perceptions of capabilities for action are known to underlie self-efficacy judgments, it seems likely that dispositions which influence action would also play at least an indirect role in perceptions of self-efficacy.

One source of dispositional differences among individuals is underlying values and beliefs. Beliefs in ability and environmental controllability have already been shown to influence self-regulatory processes (Bandura \& Wood, 1989). Bandura (1989) notes that the successful operation of self-regulation processes can be enhanced or undermined by belief systems related to ability and environment controllability. In addition, Clark (1993, cited in Corno, 1994) posits that valuing learning and believing in the importance of strategic or mindful effort investment underlie volitional behavior in children and that these values and beliefs are adopted from home and the general sociocultural context.

Some dispositional characteristics are known to influence volitional control; for example, the ability to delay gratification (impulse control) is an individual differences attribute found in children as young as 5 years of age (Miskel \& Miskel, 1983, cited in Corno \& Kanfer, 1993) which influences volitional control. Garner and Alexander (1989, cited in Corno \& Kanfer, 1993) found that when early informal learning experiences do not require the use of delayed gratification (as well as motivation and concentration) the 
development of volitional control is retarded. Similarly, Sockett (1988, cited in Corno, 1994) posits that personal qualities of determination, carefulness, conscientiousness, self-restraint, and endurance also influence personal capability and found these qualities not only "central to the development of moral agency" (p. 195, cited in Corno \& Kanfer, 1993, p. 333), but also "predictive of educational outcomes and related opportunities, such as college admission and employability" (Corno, 1993, p. 17).

Alternately Snow (1989, cited in Corno, 1993) suggests that volitional control skills and strategies may underlie measurable dimensions of personality related to action. This is confirmed by Kuhl and Kraska's (1989, cited in Corno, 1993) study of German children in Grades 1 to 4. Kuhl and Kraska found volitional strategy knowledge to be positively related to "personality indicators" of school success such as "attentiveness in class, frequency of finishing homework, and independence" (p. 19). Additionally, according to Corno (1993), increased ability to mange both task and personal resources leads to the developmental acquisition of volitional dispositions of responsibility and dependability.

Researchers have also identified dispositional patterns which influence action. For example, Cronbach and Snow (1977, cited in Corno \& Kanfer, 1993) propose a type of learner called a "constructively motivated striver"; Eisenberger (1992, cited in Corno \& Kanfer, 1993) proposes a dispositional pattern of behavior called "learned industriousness"; Seligman (1991) proposes both "learned helplessness" and "learned optimism"; and Kuhl (1985, cited in Corno \& Kanfer, 1993) proposes "action orientation." Corno and Kanfer (1993) also note that an action orientation has "convergent validity" (p. 314) with a number of other volitional aspects such as the tendency to form images of one's self in a future or desired state (possible selves) and the tendency to plan one's actions (future time perspective). 
Action orientation is related to self-schemas of efficacy. Action orientation has particular salience in the study of self-efficacy because the propensity to act (agency) is known to be mediated by self-percepts of efficacy (Bandura, 1986). However, the disposition for action orientation is better conceptualized as a self-schema because self-schemas "incorporate . . a large network of self-related beliefs that can be situation specific but can also have some intra-individual consistency over time and situations" (Garcia \& Pintrich, 1994, p. 132). An action orientation is also a network of self-related beliefs which affect thoughts, feelings, and behavior in a particular situation and over time and situations.

Action-oriented people are distinguished from state-oriented people by their strong capabilities for action control--including strong capabilities to control their thoughts in ways that support continuing action--particularly in the face of obstacles, difficulties, or failures or during long-term action. Using terminology common to self-efficacy theory, they have highly developed multiple capabilities for self-regulation, coping, and thought control. In their study of managers in a simulated organizational setting, Bandura and Wood (1989) found that strong self-percepts of managerial efficacy were the result of a self-schema of efficacy consisting of self-regulatory factors such as beliefs about ability and the controllability of the environment, coping and thought control capabilities, and strong performance capabilities. Action orientation seems to be the result of a similar self-schema and is best recognized under dynamic conditions fraught with uncertainties or distractions, obstacles, and failures.

The multiple capabilities of an action orientation are indirectly confirmed by Heckhausen's (1991) study requiring subjects to solve problems in logical transformation and to think aloud while doing so. Heckhausen found that "action-oriented subjects confronted their failures with increased 
action control" (p. 433) and focused their thinking on "self-instruction, how they could improve their efficacy, and a predominance of success certainty" (p. 433). That is, action-oriented individuals use volitional control strategies which parallel the self-regulatory, coping, and thought control capabilities of Bandura and Wood's (1989) self-schema of efficacy. In contrast, state-oriented subjects worried about their lack of ability and their inefficaciousness, felt pessimistic about their chances for success, and "abandoned their goals" (pp. 433-434).

It also seems likely that the predisposition for an action-oriented response to difficulties may reciprocally influence one's self-schema of efficacy. First, by increasing one's propensity to continue to act, an action orientation increases the possibility for performance and goal attainments, and a record of success as a result of persistent volitional control then increases the strength and resiliency of feelings of self-efficacy (Bandura \& Wood, 1989). As Bandura (1986) points out, performance mastery is the strongest cue for positive self-perceptions of efficacy.

Second, an action orientation is characterized by a higher frequency of "mastery-oriented" thoughts than a state orientation (Heckhausen, 1991, p. 434). As stated previously, a mastery orientation is known to positively influence and protect self-efficacy. Heckhausen found that action-oriented people were most noticeably different from state-oriented people in the frequency of thoughts related to "confidence in one's ability, expectancy of success, and enjoyment of the activity" (p. 434).

Third, as Beckmann and Heckhausen (1988, cited in Heckhausen, 1991) discovered, focusing on a future task results in putting aside the negative selfevaluation that occurs after failure in favor of preparation for further action. They conclude that "constriction of retrospective evaluation induced by the announcement of a new task also prevented subjects from fixating on self- 
evaluative thought" (p. 188). In addition, Heckhausen (1991) suggests that, during long-term activities, this "evaluation of a previous action frequently involves an achieved or partially achieved intermediate goal on the way to a more distant or supraordinate goal. What finally terminates retrospective evaluation are typical behavioral intentions for future approaches to the same or similar action" (p. 188). Thus, an action orientation serves to protect selfpercepts of efficacy not only by interrupting ruminations about one's poor performance and possible incompetence, but also by focusing on future actions to recoup one's chances for success and, thus, weakening present selfcriticism.

Of the 11 pairs of success/failure thoughts identified by Heckhausen (1991) that differentiate action- and state-oriented people, the following have been directly related to positive or negative self-percepts of efficacy: positive or negative self-evaluation, confidence or doubts in abilities, and perceptions of low or high task difficulty (Bandura, 1986). Others, like enjoyment or dislike of the activity, self-forgetfulness or focus on task irrelevancies, relaxation or nervousness, the need for achievement or the abandonment of standards, and the anticipation of success or failure, may be indirectly related to self-efficacy. They can also be viewed as "value-added" affective responses to activities and tasks that positively affect the propensity for continuing action and increase the resiliency of positive feelings of efficacy. These value-added, largely affective responses are discussed in the next section of this review of the literature.

\section{Conclusion}

This review of theory and research on volition serves as a starting point for a new conceptualization of personal teaching efficacy from a volitional perspective. The next section, on other constructs similar to volition, places 
the concepts underlying volitional theory in the mainstream of effectiveness literature.

Constructs and Theories Related to Volition

\section{Resiliency}

One construct which focuses on the importance of volitional control and value-added affective responses is that of resiliency. Henderson and Milstein (1996) define resilience as the "capacity to spring back, rebound, successfully adapt in the face of adversity and develop social, academic, and vocational competence despite exposure to severe stress or simply to the stress that is inherent in today's world" (p. 7). Masten (1989) similarly defines resiliency as the "capacity to return to better functioning when adversity abates" (p. 270, emphasis mine).

According to Masten (1989), all individuals have "vulnerabilities, resources, and protective factors" (p. 269) which affect their capability to be effective. Vulnerabilities amplify the "effect of challenges, stressors, or risk factors" (p. 269) and potentially reduce effectiveness, while one's resources can be either assets or liabilities for effective performance and successful adaptation. However, protective factors always support individuals' resilience by indirectly "reducing the effect of vulnerabilities, challenges, or risks to development" (p. 270). Henderson and Milstein (1996) describe protective factors as both "individual and environmental characteristics [that] mitigate the negative impact of stressful situations and conditions" (p. 5). Masten (1989) points out that whether they are innate or learned, "internal or transactional, specific or general" (p. 270), protective factors not only mitigate risk, but also serve to maintain competent functioning and to enhance individuals' ability to rebound. Protective factors also support performance and goal attainments 
by limiting the chances that risk factors will occur in the first place, by lessening the effect of challenges, or by "increasing the availability of compensatory resources" (Masten, 1989, p. 282).

Henderson and Milstein (1996) identify 12 internal protective factors or "characteristics that facilitate resiliency" (p. 9). Some of these factors are volitional capabilities such as self-motivation, assertiveness, impulse control, good decision making, problem solving, and "capacity for and connection to learning" (p. 9). Others are more related to volitional dispositions, including sociability and flexibility and having a positive future view and a sense of humor.

\section{Emotional Intelligence}

A second construct related to both resilience and volition--and receiving wide attention in education circles--is Daniel Goleman's (1995) emotional intelligence. Goleman emphasizes the role that emotions play in "shaping our decisions and our actions" and characterizes them as "impulses to act, the instant plans for handling life that evolution has instilled in us" ( $p$. $6)$.

The central place of emotions in human action and in the brain's physiology has led Goleman (1995) to consider humans to have two minds, one which operates largely from the neocortex of the brain and one that operates primarily in the limbic system. These two minds give rise to two functionally and substantively different intelligences, referred to as "rational and emotional" (p. 28). According to Goleman (1995), emotions arise in the limbic system but are largely governed by the prefrontal lobes, "the seat of planning and organizing actions toward a goal, including emotional ones" (p. 25). From a volitional point of view, the limbic system and the prefrontal lobes would also play a major role in directing volitional processes and making use of 
internal resiliency factors. This is partly confirmed by studies conducted by Norman and Shallice (1985, cited in Corno \& Kanfer, 1993), who found that patients with frontal lobe damage had low volitional control.

Goleman (1995) points out that the idea of an emotional intelligence is so new that no one yet knows how much variability in individual differences can be attributed to it. The data that do exist suggest emotional intelligence can be "as powerful and at times more powerful than I.Q" (Goleman, 1995, p. 34). For example, Goleman posits that "at best, I.Q contributes about $20 \%$ to the factors that determine life success" (p. 34). At the heart of Goleman's theory of emotional intelligence is the following thesis:

Emotional life is a domain that, as surely as math and reading, can be handled with greater or lesser skill, and requires its unique set of competencies, and how adept a person is at those is crucial to understanding why one person thrives in life while another of equal intellect dead-ends: emotional aptitude is a meta-ability, determining how well we can use whatever skills we have, including raw intellect. (p. 36).

Goleman's thesis is similar to Corno's (1994) conceptualization of volitional control capabilities as a set of competencies separate from task- or role-related competencies (also see Corno \& Kanfer, 1993; Schunk, 1996) and Heckhausen's (1991) view of volition as a metalevel capacity for directing action.

Resonating with Corno and Kanfer's (1993) concept of a situated volitional aptitude, Goleman also sees emotional intelligence as a "master aptitude" (p. 95) which give individuals an "added edge in the workplace" (p. 36). In addition, he posits that people with strong emotional intelligence create their own conditions which allow them to be not only highly productive, but also more effective in and satisfied with their lives. De Charm's (1968, cited in Schunk, 1996) concept of personal causation is similar 
to this aspect of emotional intelligence. Goleman adds that "people who cannot marshal some control over their emotional life fight inner battles that sabotage their ability for focused work and clear thought" (p. 36).

Following Salovey and Mayer (1990, cited in Goleman, 1995), Goleman outlines five key domains of emotional intelligence: knowing and managing one's emotions, self-motivation, empathy, and handling relationships.

Knowing and managing one's emotions allows one to "soothe oneself, to shake off rampant anxiety, gloom, or irritability" (Goleman, 1995, p. 43) and "to withstand the emotional storms that the buffeting of Fortune brings" ( $p$. 56). This capability parallels Bandura's (1982) thought control efficacy and volitional theorists' emotion control strategies (Corno \& Kanfer, 1993). Being able to motivate oneself emphasizes the emotional self-control needed for "marshalling emotions in the service of a goal" (Goleman, 1995, p. 43). Goleman suggests that the volitional capability of focusing one's attention is a necessary requirement not only for self-motivation, but also for "mastery and for creativity" (p. 43).

The last two domains of emotional intelligence, knowing the emotions of others (empathy) and handling relationships, relate to Howard Gardner's (1993) interpersonal intelligence. According to Goleman (1995), these capabilities "undergird popularity, leaderships, and interpersonal effectiveness" (p. 43) and lead to development of further capabilities for connecting with others and for social analysis, described as "being able to detect and have insights about people's feelings, motives, and concerns. . . . [which] can lead to an easy intimacy or sense of rapport" (p. 118). In addition, interpersonal intelligence includes capabilities for "organizing and coordinating the efforts of a network of people" (p. 118) and for negotiating solutions to prevent or resolve conflicts, which strongly resemble Bandura 
and Wood's (1989) managerial capabilities and the environmental control strategies of Corno and Kanfer (1993).

The five domains of emotional intelligence are volitional in nature and emphasize the importance of being in touch with and having control over the processes of the limbic brain in order to maximize our work and enhance our life chances. As Goleman (1995) purports: “To the degree that our emotions get in the way of or enhance our ability to think and plan, to pursue training for a distant goal, to solve problems and the like, they define the limits of our capacity to use our innate mental abilities and so determine how we do in life" (p. 80).

\section{Other Theories Related to Volition,}

\section{Resilience, and Emotional Intelligence}

\section{Playing the Inner Game}

In a pop-psychology book called The Inner Game of Golf, Gallwey (1981) also indirectly relates golfing effectiveness to the capabilities associated with volitional control, resiliency, and emotional intelligence. His thesis is that, by producing fear and tension, self-doubts undermine one's effectiveness and result in the loss of command of one's resources.

Gallwey (1981) suggests that people can respond to the loss of command of their resources in three ways. First, some people respond by giving in. According to Gallwey, when people give in they are in "unconscious mode," which first leads to decreased effort, decreased motivation, and decreased concentration. These states of inhibited action then lead to underachievement. In volitional terms, the unconscious mode inhibits the use of emotion control, motivation control, and metacognitive control strategies and undermines behavioral intentions and action goals. 
Alternately, some people choose to resist the loss of command of their resources and go into what Gallwey (1981) refers to as "trying mode." However, for Gallwey, trying is not a positive response to the loss of command of resources, but rather, reflects an overcompensation for people's mistrust of their capabilities. This mistrust interferes significantly with the expression of individuals' potential for performance and goal attainment by creating overtightness and mental tension and conflict. In volitional terms, trying conjures up negative self-talk which adversely affects people's capability to focus and to perform and, thus, to fulfill their behavioral intentions and goals.

The third response to the loss of command of our resources is "awareness mode," which Gallwey (1981) believes is the best response, not only for golfers, but for professionals in every field. A response from awareness mode results in the development of innate potentialities and skills through experiential learning. In this sense, awareness promotes resilience by adding capabilities.

One learns through experience by being aware of the variables that affect performance and then adjusting one's behavior until these variables are accounted for. Awareness depends on relaxed concentration. Under conditions of relaxed concentration, people are capable of switching their attention and placing it where it is needed to enhance awareness. In addition, relaxed concentration predisposes individuals to be interested in what they are doing, which makes them more responsive to the experience and increases awareness of the subtleties underlying the activity or the environment. Interest also helps people to sustain their effort in making contact with what they are focusing on, while reducing the actual amount of effort they need to hold their attention. Finally, relaxed concentration produces a sense of "oneness" with the activity which allows people to give themselves totally to what they are doing. 
Gallwey (1981) suggests that people are able to enter into a state of relaxed concentration when they trust their potential to be effective and when they have the individual desire or will to learn to be successful.

Trusting their potential allows people to count on what is reliable and let go of what is unreliable. Will, of course, is the layman's term for volition. According to Gallwey, will has both direction and strength. Will helps to clarify goals and to direct attention to the relevant components of effective action. These represent volitional control processes of motivation control and metacognitive control. The strength of people's will determines the quality of their concentration (another metacognitive capability) and gives them the energy to overcome inner and outer obstacles and to make an effort to trust and be aware (Gallwey, 1981, p. 83). People strengthen their will through exercise, that is, by practicing the volitional actions which will supports. Gallwey (1981) posits that will is undermined when people make goals only for an external result. Because no one can fully control external results, people need internal goals to gain control of their effort, as well as external goals to direct their effort.

\section{Habits for Effectiveness}

Another conceptualization of human action related to volition is espoused by Steven Covey (1990) in his Seven Habits of Highly Effective People. His work reflects the close relationship that volition, as a function of will, has to its conceptual beginnings in philosophy. Of the seven habits Covey outlines, four can be most closely paralleled with volitional control: Three habits are associated with what Covey refers to as "private victory," and one, referred to as "sharpening the saw," can be paralleled with continuous learning and improvement.

Using a social cognitive framework, Covey (1990) suggests that between the stimulus and the response lies a moment of personal choice which 
provides all human beings with an opportunity to choose their response, despite their "conditioning and conditions" (p. 67). That is, the moment of personal choice allows individuals to rise above their feelings, moods, and thoughts, as well as above environmental conditions, and act from principle. The basis of choice is the "habit of proactivity" (Covey, 1990, p. 69), characterized not only as taking of initiative, but also as responding from self using the human "endowments" (p. 70) of self-awareness, imagination, conscience, and independent will. Covey points out that, by taking initiative, people recognize it is their responsibility to decide how to respond and to make things happen, rather than responding reactively or allowing themselves to be buffeted by external events.

In addition, by choosing their response, individuals are able to create their own circumstances (Covey, 1990, p. 75) and to take responsibility for their actions, for their learning, and for who they become. An effective response requires individuals to narrow their focus to concentrate on those aspects which they can influence. Because people have more opportunities to affect themselves than anybody else, Covey suggests that their major work is improving and changing themselves rather than other people or problems in the environment. However, by continually working on their ability to respond, to be "response-able" (p. 75), they also increase their circle of influence.

Finally, Covey (1990) emphasizes that, while we are free to choose our actions, we are not equally free to choose the consequences of our actions. However, a proactive approach helps us to think preventively, which results in "feeding opportunities and starving problems" (p. 154). When mistakes or failures do occur, we can continue to proactively develop our ability to respond by instantly acknowledging our mistakes and by correcting and learning from them and then moving on. 


\section{Conclusion}

The four perspectives outlined in this section of the review of the literature present ways to maintain effectiveness. Chapter 3 now reviews the literature related to teaching and learning to teach, as well as the theory and research related to reflective practice.

The Contexts of Teaching and Learning to Teach

\section{Introduction}

A teachers' sense of efficacy does not result directly from the acquisition of knowledge and skills. Rather, it is developed and sustained as teachers use their knowledge and skills while interacting with others within the context of their ongoing work. From an ecological environment perspective, teaching occurs within a "nested arrangement of structures" (Bronfenbrenner, 1977, p. 514) or “surrounds" (Guba \& Lincoln, 1989, p. 8) which include not only the classroom and school, but also "the overarching patterns of culture or subculture" (Bronfenbrenner, 1977, p. 515) and "other specific structures ... that impinge upon or encompass the immediate settings in which the person is found" (p. 515). Bronfenbrenner refers to these as the macrosystem and exosystem, respectively.

In similarity with Bandura's (1986) conceptualization of triadic reciprocal causation, which suggests that the environment in which one is situated affects, and is affected by, one's courses of action, Bronfenbrenner (1977) considers the relationship between the person and these nested environments as a process of "progressive mutual accommodation" (p. 514) occurring over time. Thus teachers' and student teachers' real and perceived efficacy is influenced directly by conditions in their classrooms and schools, and indirectly by other factors such as societal trends, public opinion, 
government decisions related to education, the school neighborhood, and the parents of their students.

Chapter 1 delineated major factors endemic to the 1990 s and to public schools which can undermine teachers' work and their sense of personal teaching efficacy. They represent Bronfenbrenner's (1977) exosystem and macrosystem. This section of the review of the literature focuses on specific contextual conditions of schools and the contextual milieu of student teaching that are known to influence teachers' effectiveness and self-percepts of personal teaching efficacy. These represent what Bronfenbrenner refers to individually as microsystems, or "the complex of relations between the developing person and environment in the immediate setting containing the person" (p. 514), and collectively as a mesosystem or "a system of microsystems" (p. 515). Figures 4 and 5 depict the school and the student teachers' practicum environment from this ecological perspective.

The section begins with a discussion of the context of schools, emphasizing the importance of collaboration, teacher decision making, and school culture in developing and sustaining teacher engagement, commitment, and effectiveness. The discussion then focuses on the context of teacher education, looking first at the socialization of student teachers and then moving to an overview of the more specific context of practice teaching. Four recommendations for improving practice teaching and a description of three models which incorporate some or all of the recommendations follow. The section concludes with a summary of the concepts related to school context and teacher education which are most relevant to this study.

\section{Contextual Conditions of Schools}

The school and the classrooms nested within it represent the main contexts of teaching and learning. As such, the way in which schools are 
Figure 4

\section{The Practicum Environment ${ }^{a}$}

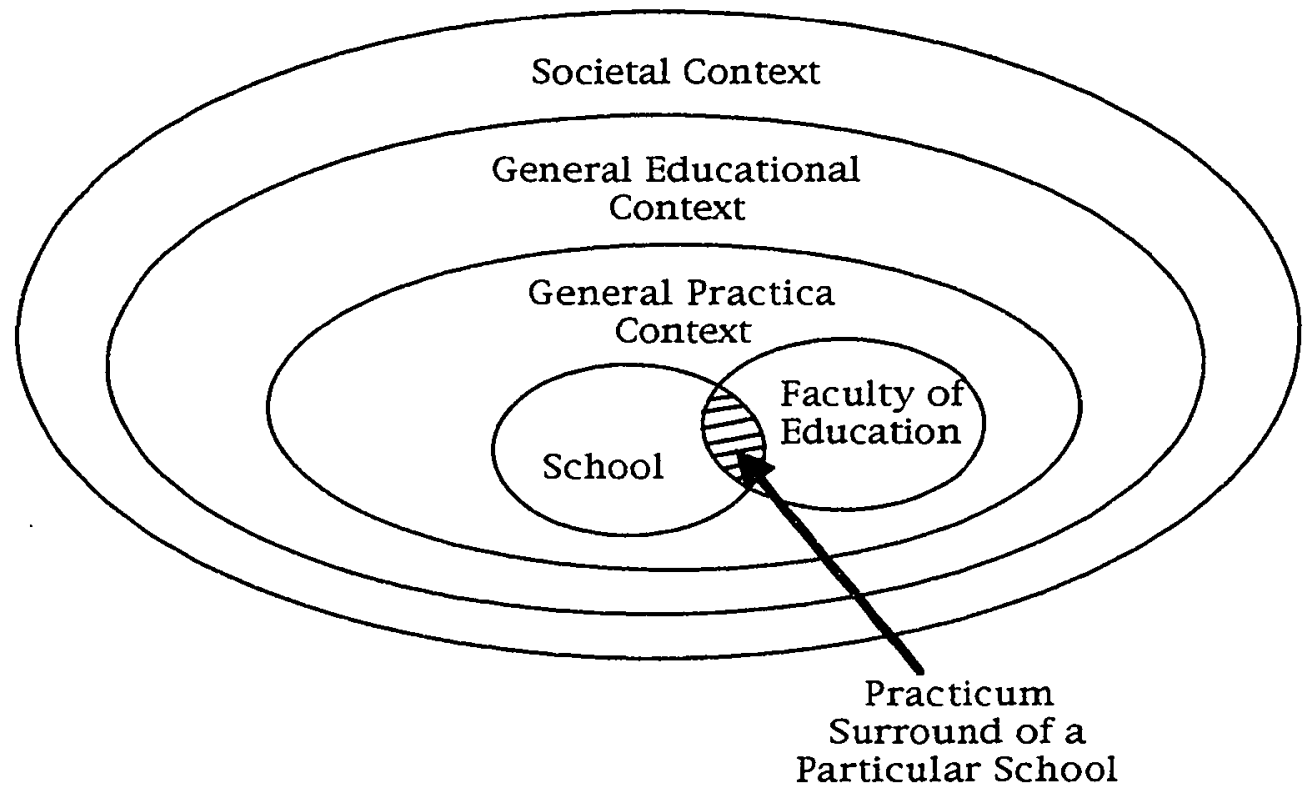

Figure 5

The Practicum Surround: A Mesosystem of Microsystems ${ }^{a}$

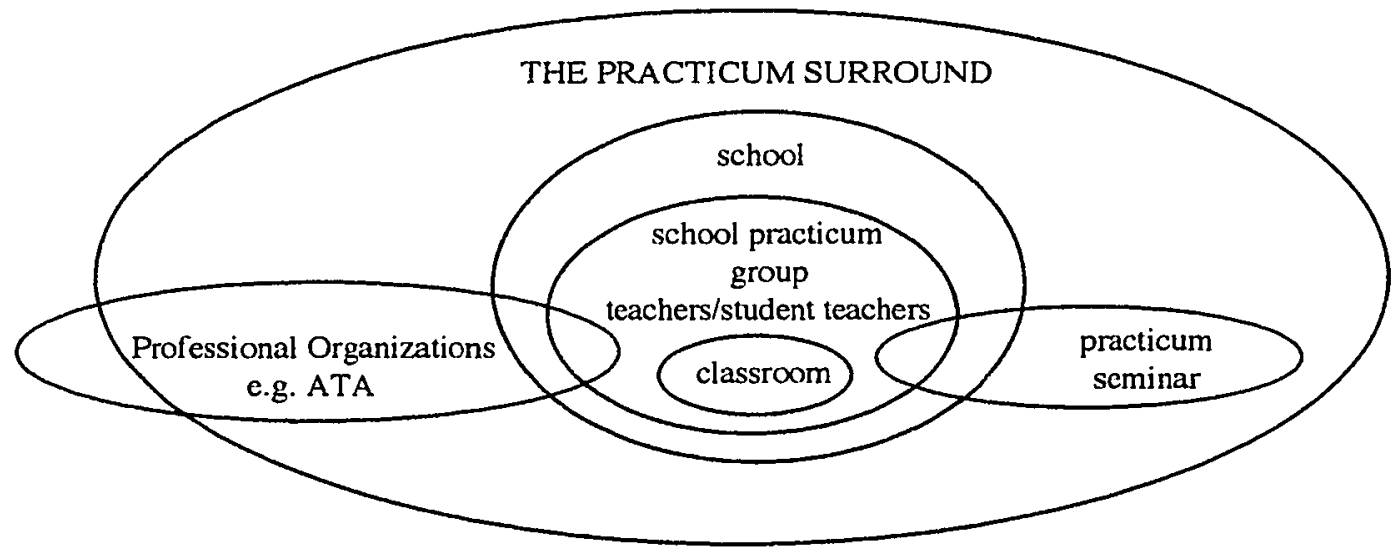

a Adapted from Bronfenbrenner (1977) and Guba \& Lincoln (1989) 
organized and the ways in which they deploy their resources of time, space, materials, and people can enhance or constrain teacher effectiveness and student achievement. With this in mind, current research on the effect of school context on teaching and learning seeks to answer questions about how schools should be restructured and resources redeployed to improve the quality of teaching and learning.

For example, research on the contextual resource of time shows that when teachers feel that they do not have enough time to do their job or that their work demands are unrealistic, they feel overwhelmed and powerless (ATA, 1993). Similarly, not having the material resources needed to complete their tasks as teachers is found to be negatively related to teachers' sense of efficacy (Fuller, Wood, Rapoport, \& Dornbusch, 1982). However, of particular interest to this study is the role the school organization and other contextual factors play in enhancing or constraining teacher engagement, commitment, and effectiveness, as well as teachers' sense of efficacy.

Contextual Factors Contributing to

Teacher Commitment and Engagement

Rosenholtz (1989) posited that teachers with strong commitment to their work are highly motivated to perform well. They can be distinguished from their low-motivation colleagues by their regular attendance at school, by their satisfaction with teaching, and by their desire to remain in the profession.

In addition to the psychic rewards teachers receive from successful relations with students and positive recognition from parents, colleagues, and principals, Rosenholtz's (1989) research showed that teacher commitment is enhanced when teachers control the terms of their work, when they perceive their work as meaningful and important, and when they have opportunities to grow and develop. Similarly, Kushman (1992) found that teachers with high 
organizational commitment perceived their schools as "providing a professionally rich and satisfying place to work" (p. 27).

According to Rosenholtz (1989), "teachers who are repeatedly thwarted in their quest for psychic rewards, professional discretion, opportunities for growth and development, and a sense of performance efficacy also dysfunctionally define their work" (p. 426). For example, some thwarted teachers overemphasize befriending students or maintaining control over them rather than defining their work in terms of student learning and achievement. Others shift their focus away from teaching and get their professional fulfillment from involvement in teacher associations or from developing teacher friendships rather than professional relationships.

Kushman (1992) defined two types of teacher commitment: organizational commitment, which refers to "a sense of teacher loyalty to the school workplace and an identification with its values and goals" (p. 6), and commitment to student learning, or teachers' "dedication to helping students learn regardless of their academic difficulties or social background" (p. 6). In his quantitative study of 750 teachers from 63 elementary and middle schools, Kushman found that $63 \%$ of the variance in teachers' organizational commitment was due to the student behavioral and motivational climate of the school, while $19 \%$ of the variance was explained by teacher decision-making power. Organizational commitment tended to be stronger in advantaged schools than in disadvantaged ones and in schools characterized by high student attendance, low student suspension or expulsion rates, and high student gains in reading and language arts. Kushman's (1992) quantitative study also showed teachers' organizational commitment positively correlated with their sense of job satisfaction (.811) and personal efficacy (.403), as well as with their expectations that students would complete high school (.427) or college (.559). Alternately, only teachers' ratings of behavior climate 
predicted their commitment to student learning, and teachers' sense of personal efficacy was the only related personal attribute to correlate positively (.528) with commitment to student learning.

Kushman's (1992) follow-up case studies of three schools emphasize that both teachers' work and their workplace influence organizational commitment. An integrating factor for Hillsdale school's high organizational commitment was its structural organization around collaborative teacher relationships. Teachers at Hillsdale worked together in an open space rather than the "egg carton classrooms" (Kushman, 1992, p. 25) found at the other two schools. Teacher work at Hillsdale was characterized by "dynamic and changing jobs" (p. 26) and collaborative teamwork and leadership which served to enhance teachers' willingness to put in extra effort and to sustain their sense of control over their work.

Together, Kushman's (1992) and Rosenholtz's (1989) studies outlined six aspects of teachers' work and workplace that affect teacher engagement: (a) psychic rewards from interactions with students and recognition from colleagues, principals, and parents; (b) performance efficacy; (c) social support; (d) opportunities to develop and grow; (e) professional discretion in determining teaching activities; and (f) student learning and behavior. Combined, these work and workplace components contribute to teachers' feelings that their work is meaningful and important.

The studies also point to the importance of viewing teaching as a collective rather than an individual enterprise. Such a perspective not only values collegial relations and collaborative work, but also supports the maintenance of teachers' sense of control over their work through opportunities to develop and grow and to have a real say in the decisions which set the course of the school and affect their work with children. 
Collaboration as a Means for Increasing

Teacher Engagement, Commitment, and Efficacy

Collaboration is believed to have widespread direct and indirect effects on the aspects of work and the workplace that affect teacher engagement and, therefore, on school and teacher effectiveness and student behavior and learning. Reyes's (1990) study of schools with high levels of participation (HLP schools) revealed that interactions among colleagues positively affect teachers' engagement with their work, especially within collegial models of teachers' roles such as team teaching, job sharing, and self-managing teams. Teachers' with high levels of engagement also had a strong sense of commitment to the school and a will to work hard to make their schools effective.

Psychic rewards. In addition, according to Kushman (1992), teachers who work collaboratively to solve problems also derive psychic rewards from their interactions with other teachers, which then increases their willingness to be highly engaged and makes them less dependent on student achievement for their "sense of job satisfaction and professional fulfilment" (p. 27). Rosenholtz (1989) found that collaborative work actually reduced teachers' staff-room griping about students and parents, while Coladarci and Breton (1991) have shown that teachers' sense of job satisfaction positively relates to high levels of teacher efficacy.

Performance efficacy. Collaboration is also espoused as the solution to the endemic isolation of teachers (Rosenholtz, 1985, cited in Cavers, 1988) and its negative effect on performance efficacy. Lortie (1975) suggested that isolation feeds teachers' self-doubt about their performance capabilities, which then undermines their teaching effectiveness. However, Lieberman and Miller (1978) pointed out that, if isolation is reduced by developing personal rather than instructional relationships with other teachers, teachers 
will still experience a lack of confidence and feelings of vulnerability. Further, Rosenholtz (1989, cited in Kagan, 1992) warned that the longer teachers remain isolated, the more uncertain they are likely to become about their practice and the more likely they will be to actively avoid substantive interaction with one another, further perpetuating their isolation and their self-doubt. In contrast, establishing relationships with other teachers has been shown to positively correlate with teachers' sense of efficacy (Rosenholtz, 1989, cited in Ross, 1994a). In fact, Raudenbush, Rowan, and Cheong (1992) suggested that the predisposition to collaborate may actually be an attribute of efficacious teachers.

In addition to reducing uncertainty and increasing teachers' sense of efficacy, collaborative relationships are also known to encourage teachers to see themselves as having a positive influence on their schools and to view their organizations positively (Moore \& Esselman, 1992).

Supportive relationships. Collaboration is also touted as a factor in ameliorating the negative effects of difficult or aversive conditions. For example, some teachers in Kushman's (1992) study reported that collegiality, collaboration, and teamwork not only added variety and challenge to their work, but also provided a daily source of social support which counterbalanced teachers' feelings of job stress and reduced the chances that daily stresses would lead to teacher burnout. In addition, support from colleagues was positively related to teacher growth and success (Kagan, 1992, cited in Guyton, 1994). Further, Hall, Burley, Villeme, and Brockmeier (1992, cited in Ross, 1994a) found that in schools reporting lower stress, teachers had a higher sense of efficacy, while the research of Brissie, Hoover-Demsey, and Brassier (1988, cited in Ross, 1994a) pointed to the negative relationship between personal teaching efficacy and teacher burnout. 
Teachers' engagement and commitment to their work are also related to support from administrators. In fact, lack of support from administrators is cited as the most frequent reason teachers leave the profession or change school districts (National Center for Educational Statistics, 1994, cited in Chester \& Beaudin, 1996). Ross (1994a) also cited studies that show teacher efficacy to be positively related to school leaders who are responsive to teacher concerns and who emphasize the accomplishments of teachers and their importance to the school endeavor, while Hoy and Woolfolk (1993) found teacher efficacy to be positively associated with teachers' perceptions that principals make efforts on their behalf.

Supervision and mentorship practices. Other examples of collegial and administrative support are supervision and mentorship practices.

Supervisory relationships provide a vehicle for collegial and administrative recognition (Rosenholtz, 1989). However, Dreeban's (1979, cited in Rosenholtz, 1989) research found that principals rarely provided for adequate teacher supervision, with $33 \%$ of tenured teachers and $19 \%$ of probationary teachers in his study reporting they were not observed even once by their principals. Hardest hit by the lack of regular observation and feedback are probationary teachers: Chester (1991,1992, cited in Chester \& Beaudin, 1996) found that first-year teachers suffer from feelings of uncertainty, anxiety, and neglect when they do not receive regular feedback about their work. In addition, because positive feedback on teaching performance is known to increase teacher efficacy (Rosenholtz, 1989, cited in Ross, 1994a), lack of feedback may actually retard the development of feelings of efficacy.

One way to increase feedback to teachers is to set up mentoring relationships. While the goal of mentoring is to provide support and feedback to fledgling or struggling teachers, Crow and Matthews (1998) also pointed to 
several benefits to the mentor: Helping a new teacher or working with a struggling one is often a way for longtime teachers to gain renewed enthusiasm and satisfaction with teaching. Mentors also gain opportunities to acquire new knowledge and skills, to make their own intuitive understanding of teaching more explicit, and to become part of a developing network of both mentor and mentee teachers.

In addition, the regular communication about practice which is characteristic of mentorships provides the "rich professional dialogue" (p. 186) espoused by Goodlad (1984) as the necessary condition for teacher effectiveness and teacher growth.

Developing and growing. Collaboration not only supports the development of new ideas, but it also helps to generate enthusiasm and sustain momentum when learning new skills (Rosenholtz, 1986, cited in Cavers, 1988). In addition, as Johnson and Johnson (1987) pointed out, cooperative efforts are a necessary aspect of teacher learning because developing procedural knowledge requires feedback on one's performance. In a meta-analysis of 133 studies of adult learning, they found that in addition to promoting stronger feelings of self-esteem, more positive interpersonal relationships, and greater social support, cooperative adult learning also resulted in higher learning achievement than did competitive or individualistic learning.

Data from Kushman's (1992) case studies of teacher engagement in three schools identified a sense of job renewal, defined as "the extent to which the teaching job itself provides for positive change and professional growth" (p. 26), as a positive side effect of collaboration and as counterbalance to job stress. In related research, Rosenholtz (1989) reported that teachers cite lack of opportunities to use new teaching strategies as a reason for the absenteeism and attrition. On the other hand, she noted that the "act itself of developing and pursuing an alternative and more successful course of action draws 
attention to teachers' efficacy, to their sense of actually making things happen with their own instructional repertoires" (p. 432), and, therefore, reinforces teacher satisfaction and efficacy.

In addition, opportunities to collaborate with others have been found to positively influence the quality of the first year of teaching (Chester, 1991, 1992, cited in Chester \& Beaudin, 1996). For example, Driscoll and Kulman (1989, cited in Guyton, 1989) reported that first-year teachers who experienced a proactive and interactive socialization to their schools were not unduly influenced by many of the negative factors associated with first-year teaching. Further, Ashton and Webb (1986) suggested that collaborative settings help new teachers sustain their initial humanistic orientation towards students.

Collaboration also has a positive effect on the capacity of in-service training to positively affect teachers' sense of efficacy. Ross (1994b) found that in-service programs that simultaneously build collaboration among teachers while introducing new ideas are more likely to affect changes in efficacy. Similarly, Dutton (1990, cited in Ross, 1994a) reported that group sharing and problem solving during training in cooperative learning techniques were associated with participant teachers' increased feelings of efficacy, while Ross's (1992) research demonstrated that participation in peer coaching had a positive effect on general teaching efficacy.

Student learning and behavior. Collaborative school relations have also been correlated with student learning and behavior. Kushman (1992) noted that schoolwide coordination of discipline, for example, was a differentiating factor among the three schools in his case studies' research. Teachers at the two less collaborative schools saw their children as unmotivated or unprepared to learn due to negative home and community factors and were, thus, "more fatalistic about students' willingness to learn and less systematic 
in their efforts to engage students and discipline errant behavior" (p. 33). In contrast, teachers at the highly collaborative Hillsdale school worked together to create a "20-page written discipline plan with a clear declaration of the teacher's right to teach and the student's right to learn" (p. 32), which kept them proactive in their efforts to resolve discipline problems. Fletcher (1991, cited in Ross, 1994a) also reported that teacher efficacy is higher in schools perceived to have well-behaving students, while Rosenholtz (1989, cited in Ross, 1994) suggested that teacher efficacy is positively affected by collaborative efforts for schoolwide coordination of student behavior.

In addition, when students are better behaved, they are also perceived to be more engaged in their learning, a factor that positively correlates with teachers' sense of efficacy (Raudenbush, Rowan, \& Cheong, 1992). Raudenbush and his colleagues also found that high student engagement sharply reduced the dependence on student achievement as a variable influencing teachers' sense of efficacy.

Moore and Esselman's (1994) research revealed that "historically belownorm achievement" (p. 13) in reading and mathematics can have a negative effect on school instructional climate, delineated as positive school atmosphere, lack of impediments to effective instruction, and collegiality. They also found a relationship between student achievement and teachers' sense of efficacy but concluded that contextual variables such as "minimization of perceived barriers to effective teaching, enhancing teacher authority to make instructional and curricular decisions, and creating a positive school atmosphere in which to work ... [had] greater explanatory power for efficacy" (p. 13). 


\section{The Effect of Decision Making on}

\section{Teacher Engagement and Effectiveness}

The effects of teachers' participation in decision making are widespread. Teacher decision making is widely held to be a determinant of effective school organizations (Levine \& Stark, 1982), school health (Louis \& Smith, 1990), and teachers' organizational commitment (Kushman, 1992). Kushman found that schools with high teacher organizational commitment are highly collaborative, characterized by "dynamics of felt responsibility, joint problem solving, public decision making and accountability" (p. 30).

Decision making is also considered an aspect of teacher power (Moore \& Esselman, 1994) and a key determinant of teachers' loyalty and job satisfaction (Bacharach, Bamberger, Conley, \& Bauer, 1990). In addition, opportunities to participate in decision making with colleagues, Rosenholtz (1989) proposed, help first-year teachers to broaden their knowledge of instructional strategies and curricular approaches. Finally, studies have shown that involving teachers' in school decision making positively affects teachers' sense of efficacy (Ross, 1994a), and perceptions of control over instructionally-related policies significantly reduce the dependency of teachers' feelings of efficacy on student achievement (Raudenbush, Rowan, \& Cheong, 1992).

When decisions are made far away from the classroom and imposed from above, teachers may experience feelings of powerlessness and a sense of eroding professionalism (ATA, 1993). Further, Bacharach, Bauer, and Conley (1986, cited in Bacharach, Bamberger, Conley, \& Bauer, 1990) found that lack of decision-making opportunities was related to teacher stress and burnout.

Decisions related to teaching are often divided into two types--those at the microsystem level and those at the macrosystem level (see Bronfenbrenner, 1977). For example, Bacharach and Aiken (1976, cited in Bacharach, Bamberger, Conley, \& Bauer, 1990) identified macrosystem 
decisions as those related to teachers' influence on organization-level decisions and microsystem decisions as those related to teachers' influence on work- or task-level decisions. Similarly, Mohrman et al. (1978, cited in Bacharach et al., 1990) delineated teacher decisions as either technical (microsystem level) or managerial (macrosystem level). Finally, in addition to distinguishing between organizational and personal decisions, Bacharach et al. (1990) also delineated two additional types: strategic decisions and operating decisions.

The Mohrman study (1978, cited in Bacharach et al., 1990) found not only that teachers made more technical decisions than managerial decisions, but that they also placed greater value on opportunities to make technical decisions than on opportunities to make managerial decisions. However, in a study of 1,531 teachers in 842 elementary and 689 secondary schools, Bacharach and his colleagues (1990) demonstrated that the types of decisions teachers make, and desire to make, may vary according to contextual variables; for example, elementary teachers desired to make more organizationalstrategic decisions, while secondary teachers wanted more opportunities to make organizational-operational and personal-operational decisions.

Current studies of teacher decision making clearly emphasize the importance of collaborative or participative decisions. In fact, most definitions of collaboration include joint decision making or problem solving as a necessary aspect of collaborative endeavors. For example, West (1990) defined collaboration as "an interactive planning, decision-making, and problem-solving process involving two or more team members (p. 29, cited in Idol \& West, 1991, p. 72). Similarly, Schaffer and Bryant (1983) defined collaboration as "shared decision making in governance, planning, delivery and evaluation of programs" (p. 3, cited in Idol \& West, 1991, p. 72), while Olson (1986) defined collaboration as "interactive processes based on joint problem 
solving and a set of commonly held beliefs, norms, and practices" (p. 12, cited in Idol \& West, 1991, p. 72).

\section{School Cultures That Develop and Maintain}

\section{Teachers' Engagement and Effectiveness}

The quest to find the principles underlying effective school organization and culture began in response to the Coleman (1966, cited in Mackenzie, 1983) studies, with what we now refer to as "effective schools research" (see Purkey \& Smith, 1983, cited in Cavers, 1988). Effective schools were defined as those with high student achievement on norm-referenced tests, and the effective schools research showed that student achievement gains were affected by teacher, school, and community characteristics (Schneider, 1986, cited in Moore \& Esselman, 1994).

For example, effective schools were characterized as orderly and businesslike, with good vertical and horizontal communication and effective time use (Cavers, 1988). In a study of elementary schools in three school districts that were undergoing changes to improve the academic achievement of students and create more successful inner schools, Levine and Stark (1982) found that schools that were making gains in student reading had the following characteristics: high levels of parent involvement, careful curriculum alignment, easy access to appropriate resources, minimal recording keeping, and high levels of grade-level decision making, with student progress across classrooms as part of the decision-making process.

Teachers in high-achieving schools spend more time on instruction and are more committed to and concerned about student achievement (Brookover et al., cited in Gibson \& Dembo, 1984). High-achieving schools also have a positive effect on teachers' sense of efficacy (Raudenbush, Rowan, \& Cheong, 1992; Smylie, 1988, cited in Ross, 1994a). In a study of 114 teachers in three school districts, Guskey (1987) found that student performance outcomes at the 
group level were significantly related to self-percepts of personal efficacy. In contrast, Raudenbush, Rowan, and Cheong's (1990) study of 263 teachers in 14 schools showed that assignment to "low-track classes presents challenges to teachers that make it difficult for them to maintain elevated perceptions of self-efficacy" (p. 32). High student engagement also had a positive effect on teachers' sense of efficacy in this study.

As a result of effective schools research, the context of schools continues to be examined as an important factor affecting teacher effectiveness and student achievement, and research related to school context has widened in perspective.

A culture of professionalism. King and Longquist (1992, cited in Chester \& Beaudin, 1996) considered schools from the perspective of professionalism and defined a professional culture as one in which teachers take ownership of schoolwide and systemwide planning. Similarly, Little (1982) identified teacher commitment as contributing to the development of a professional work culture, while Reyes (1990) pointed to the effect a positive school culture has on teachers' engagement with their work.

According to Kruse and Louis (1995, cited in Sullivan, 1996a), opportunities for reflective dialogue, shared norms and values, deprivatization of practice, and a collective focus on student learning are critical elements underlying professional cultures. Further, professional collaboration supports the development of a richer technical language, an extensive sharing of knowledge, and an increased capability for complex problem solving, which in turn assure improvement in school achievement. In addition, professional collaboration encourages greater risk taking; increased interdependence; dispersed leadership; more continuous efforts to improve the school; and increased willingness to discuss failures, mistakes, and disagreements (Peterson \& Brietzke, 1994, cited in Sullivan, 1996b). 
Healthy schools. Researchers have also viewed schools from the perspective of organizational health--a condition of high-achieving schools (Hoy, Tarter, \& Bliss, 1990, cited in Hoy \& Woolfolk, 1993). According to Hoy and Forsyth (1986, cited in Hoy \& Woolfolk, 1993), organizational health is concerned with factors which facilitate or impede positive interpersonal relationships. Healthy schools are distinguished by their warmth, collegiality, and high expectations, which, in turn, influence student achievement (Brookover et al., 1978, cited in Hoy \& Woolfolk, 1993).

The metaphor of school health also emphasizes that organizations can grow, develop, and survive, or atrophy and die, depending on how well they are able to integrate their functions, adapt to change, and meet their goals (Hoy \& Woolfolk, 1993). Accordingly, Hoy and Woolfolk (1993) identified six dimensions of organizational health which support integration, adaptation, and goal attainment: emphasis on academics, resource support, strong principal influence, high morale, considerate staff relationships, and institutional integrity. Little (1982) identified an additional four practices critical to school adaptability: regular, ongoing, and increasingly concrete and precise talk about teaching practice; collegial planning and preparation of teaching materials; frequent observation of other teachers accompanied by useful feedback; and teachers teaching each other.

Teachers' quality of work life. From a slightly different perspective, Louis and Smith (1990) looked at the dimensions of teachers' quality of work life (TQWL). They identified five of seven TQWL dimensions that were founded on collegial communication: respect for relevant adults, participation in decision making, frequent and stimulating professional interactions, goal congruence, and a high sense of collective efficacy. The remaining two TQWL dimensions are availability of resources and opportunities to use one's knowledge and skills. Louis and Smith (1990) also identified three categories 
of school change that may increase TQWL: social-cultural changes which strengthen teachers' collegial relationships and their sense of vitality, administrative-political changes which alter decision-making structures and enhance teacher influence, and technical-instructional changes which focus on restructuring the curriculum and classroom grouping and activities.

Restructuring schools. Professionalization is a priority of the current reform agenda (Fullan, 1993, cited in Walker \& Cousins, 1994), with school and teacher flexibility as a key component. However, any change activity towards school reform can have a negative effect on teacher efficacy (Rosenholtz, 1987, cited in Ross, 1994a). For example, Huberman's (1989) research demonstrated that teachers who did not become involved in major reforms during their career fared better than those who did:

Teachers who steered clear of reforms or other multiple-classroom innovations but who invested consistently in classroom-level experiments--what they called "tinkering' . . . were more likely to be satisfied later on in their career than most others, and far more satisfied than their peers who had been heavily involved in schoolwide or districtwide projects. ... heavy involvement in schoolwide innovation was a fairly strong predictor of disenchantment after 20-25 years of teaching. (pp. 50-51)

Norms of collegiality may shield teachers from some of the negative effects of schoolwide reform, with interactions among colleagues paving the way for organizational change by opening up traditional beliefs and values to challenge (Cousins, 1994, cited in Walker \& Cousins, 1994). Collegiality has been shown to provide the foundation for effective schoolwide reform (Chester \& Beaudin, 1996; Fullan \& Steigelbauer, 1991; Goodlad, 1984) and to be a strong indicator that implementations of change will be successful (Fullan, 1982, cited in Cavers, 1988). 
In a qualitative study of one school with 320 students and 14 teachers, Simpson (1990) found that a culture of change was supported by teacher feelings of empowerment and by opportunities for sharing and collegiality, which were built into the structure of the school day: DeKeyser Elementary used planning retreats involving the whole staff, regular Tuesday meetings, and staff meetings focused on teacher concerns to instill a feeling of collegiality and to ensure that change agendas were kept on track. Similarly, Little (1982) found that schools organized to ensure regular teacher interaction and teacher participation in decision making were able to implement innovations and curriculum at higher levels than schools not organized collegially.

Schools with high levels of participation. Reyes (1990) looked at school context from the perspective of teacher participation and identified what he called high-level participation (HLP) schools. He described HLP schools as having flat organizational structures, decentralized decision making, and strong systemic arrangements for teacher skill building, goal setting, and feedback about school progress. Reyes' research reported that administrators in the HLP school are highly involved and focus on involving and rewarding teachers and encouraging them to reflect on their own work and to take a proactive approach to solve problems of practice. In a similar vein, Cox and Wood (1980, cited in Scott \& Smith, 1987) found a strong relationship between teacher feelings of alienation and schools with rigid organizational hierarchies that discourage teacher participation in decision making. Finally, Reyes (1990) characterized teachers in HLP schools as highly committed not only to their students, but also to school-level effectiveness.

High-consensus schools. Similarly, Rosenholtz (1989, cited in Kagan, 1992) differentiated between high- and low-consensus schools. In highconsensus schools, teachers work together to define goals, decide on teaching 
processes, and solve classroom problems. As teachers work together, they develop a common technical language that helps to reduce their feelings of uncertainty about what constitutes effective teaching. In another study, high consensus on how to make schools effective also predicted high individual teacher efficacy (Newmann et al., 1989, cited in Ross, 1994a).

According to Rosenholtz (1989), "in instructionally successful schools . . . teaching is considered a collective rather than an individual enterprise; requests and offers of assistance among colleagues are frequent; and reasoned intentions, informed choices, and collective actions set the conditions under which teachers improve instructionally" (p. 430). These conditions of joint work and decision making were also found to be positively related to teachers' sense of efficacy (Miskel, McDonald, \& Bloom, 1983, cited in Ross, 1994a).

Collaborative schools. The research cited here suggests that collaborative schools are synonymous with school effectiveness. Smith and Scott (1990, cited in Idol \& West, 1991) posit that a central characteristic of collaborative schools is a focus on what happens at the school level. Collegial interactions among teachers and administrators and organizational practices and structures that encourage joint work and decision making provide a schoolwide focus aimed at school improvement. This definitely moves away from the "egg carton" classroom and the endemic isolation that have both characterized teachers' work.

Collaborative cultures are created when principals provide opportunities for task-related interaction among teachers and between teachers and administrators (Rosenholtz, 1986, cited in Cavers, 1988). Ross's (1994a) survey of educational research revealed that teacher effectiveness is higher in schools with heightened teacher collaboration, while high levels of school-level organizational effectiveness are found to be significantly related to good vertical and horizontal communication within the school (Miskel et al., 
1983, cited in Cavers, 1988). As teachers work together, the natural result is better communication and stronger consensus on academic goals and expectations (Kushman, 1992). Further, when teachers are aware of expectations, particularly the expectations of teachers in the grades above and below them, they have a higher sense of teacher efficacy (Hoover-Demsey et al., 1992, cited in Ross, 1994a).

However, collaborative schools still do not represent the norm, and teachers do not always have the skills and dispositions required for effective collaborative work. For example, Duke, Showers, and Imber (1980, cited in Ashton \& Webb, 1986) pointed out that many teachers perceive collaborative decision making as a threat to their autonomy, and many doubt that their participation will make a difference. Fuller and his colleagues (1982) suggested that, while collaborative work and participative decision making may increase what they refer to as teachers' "organizational efficacy" (p. 9), working with others also has the potential to diminish teachers' perceptions of control over their own classrooms when group decisions impinge on classroom practice.

In a qualitative study of six teachers, Wilson and Coolican (1996) found a positive relationship between teachers' sense of self-empowerment and their willingness to establish professional relationships with colleagues and to collaborate with and learn from them. However, they concluded that willingness may not be enough: Teachers may also need to have similar ways of approaching their joint work to develop effective collaborative relationships. Effective collaborative work is also built on a strong foundation of trust and a strong sense of community (Friend \& Cook, 1990), rarely present at the beginning of collaborative endeavors. As Idol and West (1991) point out, changing schools to make them more collaborative will require high-quality staff development, changes in policy and school organization, and deep 
changes in the values and beliefs currently underlying professional behavior.

\section{The Contexts of Teacher Education}

Most teacher education programs are organized around professional course work and varying lengths of practice teaching experience in the schools. From this combination of theory and practice, student teachers are proposed to learn to teach. However, Lanier and Little (1986) posit that the research on teacher education in the United States is "ambivalent about the capacity of such programs to build substantive competence or to serve as a route to personal self-confidence, professional prestige or other rewards" ( $p$. 543).

In part, this uncertainty results from the contradictory perspectives held by student teachers, teachers, and teacher educators about the value of both teacher education course work and practice teaching experiences.

Perceptions of education course work. Student teachers criticize educational courses as being too theoretical, too repetitive, and lacking in intellectual content (Zahorik, 1988). They describe courses, especially education foundation courses, as "boring, useless, as a waste of time, and merely empty words" (Su, 1992, p. 245). Given these perspectives, it is no wonder that "the knowledge, skills, and dispositions introduced to students in the education methods and foundation courses have little influence on their subsequent actions, even during initial training" ( $\mathrm{Su}, 1992, \mathrm{p} .245$ ). Cooperating teachers also questioned the value of teacher education courses, particularly educational foundation courses ( $\mathrm{Su}, 1992$ ). A minor consolation is the finding that student teachers at least found informal interactions with faculty an important opportunity to learn (Su, 1992). 
Perceptions of practice teaching. In contrast to their opinion of course work and despite the fact that practice teaching can have negative as well as positive consequences (Zeichner, 1980, cited in Richardson-Koehler, 1988), student teachers consider their practice teaching experience to be the most important (Zahorik, 1988) and valued (Walker, 1992) part of their preparation. In addition, most student teachers report wanting more rather than less time spent on practice teaching (Nixon \& Bumberger, 1984, cited in Grommet \& Ratzlaff, 1986). Not surprisingly, long after their practice teaching is completed, teachers also consider their student teaching as the most influential aspect of their teacher education program (Davies \& Amershek, 1969, cited in Richardson-Koehler, 1988).

Teacher educators are more ambivalent about the value of the practice teaching experience. On the one hand, they acknowledge the importance of practice teaching (Lortie, 1975) and its potential to change student teachers' attitudes and perspectives on teaching (Horowitz, 1968, cited in Su, 1992). In addition, practice teaching is acknowledged as potentially the "single most powerful intervention in a teacher's professional preparation" (Turnkey et al., 1982, p. 47, cited in Grommet \& Ratzlaff, 1986, p. 41) and as having a potent effect on student teachers as they move towards becoming teachers (Campbell \& Whitehall, 1983, cited in Grommet \& Ratzlaff, 1986).

On the other hand, teacher educators worry that student teaching produces conservatism (Lanier \& Little, 1986) and that the overemphasis on practice will move student teachers away from reflective inquiry and towards the unquestioned adoption of the cooperating teacher's techniques (Dewey, 1904, cited in Zahorik, 1988). Eighty years after Dewey, a national research project, the Study of the Education of Educators (SEE), validated this concern. It concluded that, for the most part, student teachers are deliberately socialized to be passive models who uncritically adopt their cooperating teachers' methods 
and style (Su, 1989, cited in Su, 1992). Similarly, Richardson-Koehler (1988) posited that cooperating teachers' practical rather than theoretical orientation to teaching risks student teachers' learning of the underlying principles of teaching.

In addition to these contradictory perspectives on the value of teacher education, the complex nature of teaching and the diversity of variables that affect teachers' learning and practice also conspire to make the effects of teacher education on student teachers unpredictable.

\section{Socialization of Student Teachers}

Socialization can be defined as "the processes by which persons acquire the knowledge, skills, and dispositions that make them more or less able members of their society" (Brim, 1966, p. 3, cited in Crow \& Matthews, 1998, p. 17). The socialization process also has at least some effect on teachers' attitudes and beliefs. However, Fullan and Steigelbauer (1991) pointed out, "personal beliefs are a critical part of teacher education that has been neglected both in the design of programs and in research on how teachers develop" (p. 297).

It is known that the attitudes and beliefs with which teachers approach the teaching role have a powerful effect on their actual performance as teachers (Oestrich, 1974, cited in Clifton \& Covert, 1980). According to Pajares (1992), research findings also "suggest a strong relationship between teachers' educational beliefs and their planning, instructional decisions, and classroom practices (p. 326).

Entering beliefs of student teachers. The personal beliefs and perspectives of student teachers also have a powerful influence on how they will go about teaching in the future (Fullan \& Steigelbauer, 1991). However, attempts to influence student teachers' attitudes and beliefs are fraught with difficulty. For one thing, unlike students of other professions such as 
medicine or law, students of teaching have already completed what Lortie (1975) describes as an "apprenticeship of observations" through their 12 years spent in public schools. Thus, student teachers have already developed many of their attitudes and beliefs about teaching before entering teacher education and these attitudes and beliefs serve as "filters" for processing program content (Hollingsworth, 1989, cited in Fullan \& Steigelbauer, 1991, p. 296) and for determining what is important to learn. These preconceived attitudes and beliefs dilute the influence their teacher education course work has on their socialization into the profession. In fact, Kennedy (1991) found that most student teachers complete their preservice program with their entering beliefs intact.

Practice teaching effects on student teacher beliefs. Research also suggests that any socialization effects of teacher education course work on student teachers' practice are temporary (Lanier \& Little, 1986). Once student teachers enter their practice teaching, the cooperating teacher influences their socialization more than the university supervisor (Emmons, 1983, cited in Hoover, O'Shea, \& Carroll, 1988). In addition, knowledge and skills learned in course work are often rejected in favor of the knowledge and skills learned in practice teaching. For example, Richardson-Koehler (1988) found that after 2 weeks in the school placement, only $15 \%$ of the methods student teachers used were taken from methods classes, with $80 \%$ of methods used adopted from their cooperating teachers and $5 \%$ devised by student teachers themselves. By the end of the practicum, student teachers continued to use only $15 \%$ of the methods taught in methods classes. However, there was a balance between those they devised and those they adopted from cooperating teachers ( $40 \%$ for each), with an additional 5\% taken from suggestions from others.

In addition to the weak effect of course work on student teachers' practice, attempts to liberalize student teachers' attitudes and beliefs are often 
"washed out" (Zeichner \& Tabachnick, 1981, cited in Boydell, 1986) by their practice teaching experiences: Research suggests that by the end of their student teaching experience, student teachers have become "more authoritarian, rigid, impersonal, restrictive, arbitrary, bureaucratic, and custodial" (Glassberg \& Sprinthall, 1980, p. 31, cited in Boydell, 1986, p. 117) and have left behind the innovative practices and progressive attitudes they developed in their preservice training (Etherbridge, 1987, cited in Guyton, 1994). Relatedly, as student teachers continue in their practice teaching, they often change their perspective of student teaching from one of service to one of survival (Gibson, 1976, cited in Boydell, 1986).

According to Su (1989), much of the inability of teacher education to affect student teachers is the result of the conservatism of the teaching culture and its strong resistance to change. If teacher education is to counter the negative effects of this conservative milieu on student teachers' learning of the craft of teaching, then, according to Zeichner and Tabachnick (1981, cited in Boydell, 1986), teacher education institutions will have to reform their own teaching and restructure their program, especially the student teaching component.

The Context of Practice Teaching

The triad. The practice teaching component varies from program to program in the number of teaching experiences and in the length of time spent in the schools. The supervisory structure, however, is relatively stable across programs: Typically student teachers are supervised by their cooperating teachers and by a member of the teacher education faculty, with the relationship of the three being referred to as the "triad." For example, in a national survey of teacher education in England and Wales, Stone and Morris (1972, cited in Boydell, 1986) found that all teacher education institutions appointed a faculty supervisor who typically visited the student teacher once 
every 7 days, while two thirds of the institutions used two faculty supervisors per student, with visits from one or the other every 5 days. The average length of each faculty supervisor visit was $1 \mathrm{hr} 38 \mathrm{~min}$.

Despite the small number of persons in the triad, the roles of university supervisor and cooperating teacher are often ambiguous and overlapping (Grommet \& Ratzlaff, 1986, cited in Richardson-Koehler, 1988), and there is little evidence of triad members "working closely together on common goals intended to produce appropriate teacher behavior (McIntyre, 1984, p. 42, cited in Grommet \& Ratzlaff, 1986, p. 41).

In addition, several studies suggest that student teaching suffers because of the lack of clearly stated performance standards (Hoover, O'Shea, \& Carroll, 1988, cited in Walker, 1992). According to Griffin (1983), "attention to the particulars of research-derived or craft knowledge was conspicuous by its absence" (p. 18, cited in Boydell, 1986, p. 117). In order to better define program intentions, McCutcheon, Schmidt, and Bolder (1991, cited in Walker, 1992) have called for further research on what constitutes successful teaching performance.

In a summary of three studies which they initiated in 1981, Applegate and Lasley (1986) concluded that there was widespread need for better communication among the triad members and speculated that good communication may be exacerbated by time constraints, by the "difficulty interfacing different contexts" (p. 25), by lack of "formal structures in both universities and schools that support preservice teachers and university faculty in their interactions with classroom teachers" (p. 25), and by lack of commitment by the institutions to the field experience.

In addition to the research on the triad relationships, the roles of cooperating teachers, university faculty, and student teachers are the most often explored (Hersom, Birch, Gaskell, Horowitz, \& Plante, 1981). 
The Cooperating Teacher

Cooperating teachers are acknowledged as the key facilitators in the practice teaching process and the most valued by student teachers ( $\mathrm{Su}, 1992$ ), influencing their attitudes (Dutton, 1982, cited in Zahorik, 1988) and their classroom practice ( Zahorik, 1988). For example, a questionnaire survey of 500 randomly selected student teachers from England and Wales revealed that three quarters of student teachers found their cooperating teachers were of more help than their university supervisors (Yates, 1982, cited in Boydell, 1986). In addition, Emmons (1983) found that cooperating teachers have a strong influence on student teachers' practice, "even to the extent of negating what the students have learned from their college courses" (pp. 14-15, cited in Boydell, 1986, p. 116).

Roles and functions of cooperating teachers. In a comparative study of the roles and expectations of triad members from the 1970s to the mid-1980s, Grommet and Ratzlaff (1986) found several cooperating teacher functions that have withstood the test of time and context. They include providing basic information and necessary resource materials to the student teacher, involving student teachers in planning and evaluating learning, conferencing with student teachers, and evaluating their progress, usually in collaboration with the university supervisor. Similarly, Sparks and Brodier (1987, cited in Walker, 1992) cited sharing expertise, acting as a role model, and talking with and advising student teachers as the three main tasks usually assigned to cooperating teachers. Grommet and Ratzlaff also noted a number of trends that appeared to be developing in the 1980s: There were increasing expectations that cooperating teachers become more directly involved in teaching student teachers and that they provide more opportunities for student teachers to study how learning occurs, encourage more experimental 
behavior, and help student teachers to develop a sense of professional responsibility.

Preparation of cooperating teachers. Because there is almost no attempt to screen cooperating teachers ( $\mathrm{Su}, 1992)$, many come to the practice teaching experience poorly informed about the content and the requirements of teacher education programs and unable to model a wide variety of effective teaching strategies (Hollingsworth, 1988, cited in Walker, 1992). A study of 139 elementary preservice teachers conducted by Wood and Eicher (1989) emphasized the importance of selecting teachers who not only are effective role models, but who are also able to provide honest, open, and constructive feedback (cited in Walker, 1992).

However, despite the fact that cooperating teachers are acknowledged to have a great deal of influence on student teachers (Dispoto, 1980, cited in Walker, 1992; Joyce, 1973, cited in Richardson-Koehler, 1988), they are often not trained (Su, 1992) or are trained poorly for student teacher supervision (Guyton, 1989, cited in Walker, 1992). As a result, many cooperating teachers provide little or no feedback to student teachers on the effectiveness of their teaching (Mcintyre \& Killion, 1986, cited in Walker, 1992). Further, Richardson-Koehler (1988) found that even when feedback was given, cooperating teachers' lack of ability or willingness to reflect on their classroom practice or the practice of their student teachers contributed to the poor quality of the feedback given and to the confusion and frustration of student teachers.

As a way to rectify this situation, Richardson-Koehler (1988) stressed the need for cooperating teachers to receive training to observe and analyze teaching in order to give better feedback. Killion, McIntyre, and Wheeler (1987, cited in Wilson, 1994) found that trained cooperating teachers provided more positive and constructive criticism to student teachers. They also 
involved student teachers earlier in classroom teaching and gave them more planning and clerical responsibilities by the end of the practice teaching experience. In addition, Copeland (1977, cited in Housego, 1987) found that when cooperating teachers have been prepared for their role, student teachers are more likely to take the risks needed to acquire or test their teaching skills.

\section{The University Supervisor}

Given the low status of the faculty supervisor role within the university (Benne, 1976, cited in Hoover, O'Shea, \& Carroll, 1988), it is not surprising that faculty supervisors often adopt their role reluctantly and perceive little value in the experience. For example, Zahorik (1988) found that of the $30 \%$ of university supervisors who gave high ratings to their work with student teachers none were tenure-tracked, while the $30 \%$ who gave supervision of student teachers a low rating were all full professors. In addition, the low status of the university supervisor role also contributes to the lack of longterm involvement by qualified personnel (Benne, 1976, cited in Hoover, O'Shea, \& Carroll, 1988), which is turn affects the quality of the role.

Roles and functions of the university supervisor. Some researchers opine that the role of faculty supervisor is unnecessary to the practice teaching experience (Bowman, 1979, cited in Zahorik, 1988). For example, Morris (1974, cited in Boydell, 1986) found no significant difference between student teachers who were supervised and those who were not.

However, other researchers see the university supervisor role as an important complement to that of the cooperating teacher (Becher \& Ade, 1982, cited in Zahorik, 1988). Through a series of observations and interviews of triad members, Zimpher, de Voss, and Nott (1980, cited in Zahorik, 1988) found that the university supervisor fulfills many important functions in the practice teaching experience: setting goals and expectations, working with 
principals, phasing the student teacher into the practice teaching role, serving as a personal confidant to the student teacher, and offering constructive criticism to the student teacher. Koehler (1984, cited in Zahorik, 1988) added orienting the school to the practice teaching experience, reducing conflict within the triad, and serving as a liaison between the university and school to the list. However, Housego's (1987) study of 17 elementary and 10 secondary interns noted that prospective teachers tend to view their faculty supervisors more as "resource persons, evaluators, liaison persons, and sources of support rather than as people whose responsibility it is to ensure that classroom practice was carried on at a high professional level" (Housego, 1987, p. 251).

Contextual constraints to fulfilling the university supervisor role. The role of university supervisors is also constrained by the dual context in which they perform. Contrary to both cooperating teachers and student teachers who fulfill their roles and responsibilities within the school, the university supervisor must move back and forth between the university and the school and fulfill obligations in both milieus. This makes it more difficult for the university supervisor to spend enough time at the school to "strongly affect the feedback process by working with individual dyads" and to build the trust of both the cooperating teacher and student teacher (Richardson-Koehler, 1988, p. 33). In addition, the short time university supervisors are able to spend in schools tends to reduce their function to a social rather than a technical one (Morris, 1980, cited in Boydell, 1986).

A second constraining contextual factor is the value placed on the university supervisor role by student teachers. Supervisors do have influence on practice teaching and student teachers through their expertise and their power to reward and punish (Martin, Isherwood, \& Rapagna, 1978, cited in Boydell, 1986). In fact, student teachers perceive their supervisors as more 
concerned with evaluation than helping them teach (Yates, 1982, cited in Boydell, 1986) but less able to judge their teaching because they haven't seen enough of it (Yates, 1982, cited in Boydell, 1986). This leads them to mistrust university supervisors' assessments of their practice, which further diminishes the effectiveness of the university supervisor role (Shipman, 1966, cited in Boydell, 1986). In addition, Blumberg's (1974) study of 50 taped interviews between student teachers and faculty supervisors found that typical postconferences were characterized by distancing, avoidance, and ritualism, with less than $1 \%$ of talk directed to asking questions or to finding ways to resolve student teachers' problems.

The differences in perspectives of the university supervisor and cooperating teacher also constrain the university supervisor's effectiveness. For one thing, “teachers' norms related to learning from experience, individualism, and egalitarianism strongly affected the feedback (or lack thereof) provided to student teachers by their cooperating teachers" (Richardson-Koehler, 1988, p. 33). Richardson-Koehler (1988) found that university supervisors could not override these norms with a more preferred model emphasizing a rigorous analysis of teaching. Indeed, the belief that teaching is best learned in practice by serving as an apprentice to a good teacher implied a passive university supervisor (Stones, 1984, cited in Boydell, 1986). Further, an ethno-methodological study of six triads conducted by Terrell, Tregaskis, and Boydell (1985, cited in Boydell, 1986) revealed that, despite their wishes for a different kind of supervisory relationship, supervisors consciously avoid saying or doing anything that would hurt their relationship with the cooperating teacher. This "feel-good" relationship, however, was bought at the expense of substantive professional dialogue.

The differences in norms between teachers and university supervisors no doubt account for the finding of Griffin and his colleagues (1983, cited in 
Hoover, O'Shea, \& Carroll, 1988) that the university supervisors and cooperating teachers in their study did not often articulate or agree on the policies and processes of student teaching. In addition, Morrow and Lane (1983, cited in Boydell, 1986) found that while student teachers and cooperating teachers agreed on the problems of the student teacher, the supervisors' views were often different (Morrow \& Lane, 1983, cited in Boydell, 1986; Emmons, 1983, cited in Hoover, O’Shea, \& Carroll, 1988).

The cumulative effect of these contextual constraints is that university supervisors not only feel they do not contribute much to the practice teaching process (Koehler, 1984, cited in Richardson-Koehler, 1988), but they also often feel left out.

\section{The Student Teacher}

Student teachers are in a relatively marginal position within the practice teaching situation (Clifton, 1979, cited in Housego, 1987): For example, student teachers are not only required to share classrooms and pupils who are not their own (MacKinnon, 1989), but they also have little or no choice over the school or class in which they will practice; nor are they able to choose their university supervisors or cooperating teachers. Some cooperating teachers consider having a student teacher as a mutually beneficial experience; others try to at least take care of their student teachers to the best of their ability; and still others take advantage of their student teachers, considering them handy helpers rather than prospective teachers who need help to learn their craft (Su, 1989, cited in Su, 1992). Unfortunately, regardless of the cooperating teacher's perspective, student teachers are expected to fit in and become proficient at the craft of teaching.

In addition, despite the fact that student teachers' success depends more on the environment in which they practice than on their training (Copeland, 1979, cited in Boydell, 1986), Zahorik (1988) found that no student teaching 
experience was the same even when there were conscious attempts to make the patterns and procedures uniform. This suggests that some student teachers may be more advantaged than others as they strive to successfully complete their practice teaching.

Interactions with others. Student teachers worry about their relationships with both cooperating teachers and university supervisors; Housego (1987) found that, in addition to organization, management, and teaching strategies, the greatest number of critical incidents student teachers reported were related to interpersonal relationships with their supervisors.

However, while they report that they learn the most from their cooperating teachers (Johnston, 1984, cited in Grimmet \& Ratzlaff, 1986), student teachers often fail to recognize their cooperating teachers' strong training role--and the training role of university supervisors--which may result in a lack of substantive professional talk (Housego, 1987). In fact, interactions between cooperating teacher and student teacher are often relatively shallow exchanges, characterized by a conscious effort to avoid conflict (Olson, 1982, cited in Housego, 1987) and to maintain satisfying social relationships (Terrell, Tregaskis, \& Boydell, 1985, cited in Boydell, 1986). Interestingly, Griffin (1983) suggested that the more unclear the expectations for practice, the more likely the "void will be filled by frequent, intense demonstrations of personal regard" (cited in Boydell, 1986, p. 118). The research of Zimpher, de Voss, and Nott (1980, cited in Boydell, 1986) revealed that most student teachers are unwilling to do anything except satisfy their cooperating teachers. Similarly, many student teachers in MacKinnon's (1989) study reported feeling compelled to withhold their own attitudes and beliefs in favor of conforming to wishes of their cooperating teachers.

Student teachers also tend to interact very little with other teachers in the school (Freibus, 1977, cited in Boydell, 1986). Research has shown that 
neither student teachers nor cooperating teachers place much currency on observing other teachers in the school (Zimpher, de Voss, \& Nott, 1980, cited in Boydell, 1986), and given the nature of schools, student teachers spend as little time with other teachers in the school as the teachers do themselves (Su, 1992).

In addition, there is little evidence that student teachers develop a strong peer culture or feeling of community ( $\mathrm{Su}, 1992)$ : Student teachers interact very little with each other, and when they do, the bulk of their conversations focuses on technical matters rather than philosophical issues and concerns. Therefore, student teachers have a relatively weak influence on each other's educational values and beliefs (Su, 1992).

Finally, student teachers' interactions with their pupils are central to their practicum experience. Most report that they look to their pupils to determine their degree of success and failure (Freibus, 1977, cited in Boydell, 1986) and feel that pupils have a greater influence on them than faculty or teachers or their peers, relatives, or friends ( $\mathrm{Su}, 1992)$.

Much of the research on the triad roles took place within what is referred to as an apprenticeship model of student teaching. However, as Stone (1984, cited in Zahorik, 1988) points out, the apprenticeship model is inadequate not only because all cooperating teachers cannot be uniformly excellent, but also because, even if they were, the student teacher's apprenticeship to one teacher reduces his or her opportunities to observe a wide variety of practices. The apprenticeship model also has an inadequate structure which presumes that student teachers can learn to teach through induction.

\section{Calls for Reform}

At the end of a major review of 29 teacher training institutions and a survey of 2,947 student teachers and 1,217 faculty, Su (1992) concluded that student teaching is "the least controlled, organized, and cared about 
component in teacher socialization" (p. 249). There have been a number of recommendations to rectify this situation and to deal with some of the limitations of the practice teaching component.

Recommendation 1: More Clearly

Articulate the Intentions of Practice Teaching

In addition to Su's (1992) recommendation that the foundation courses be restructured and their purpose rethought, Clifton and Covert (1977, cited in Clifton \& Covert, 1980) have suggested that student teachers will develop more positive attitudes when academic studies and practice teaching experiences become more congruent. Similarly, Applegate and Lasley (1986) have called for an extended articulation of specific curricular and experiential intentions of the practice teaching component. They suggested that curricular goals should be translated into concrete activities that not only are meaningful for student teachers, but also fit in with cooperating teachers' classroom goals. Recommendation 2: Extend the Partnership

Between Teacher Education and Schools

Most researchers concur that the preservice education of teachers is no longer the exclusive domain of colleges and universities (Zimpher, 1988, cited in Kirchhoff, 1989), but rather, should move towards a more collaborative approach (Rowell, 1988, cited in Kirchhoff, 1989). Su (1992) posited that stronger partnerships between teacher educators and school personnel need to be forged. These new partnerships should be built on a foundation of communication and support structures within the universities and in schools (Applegate \& Lasley, 1986) and with the goal of establishing strong communication links among student teachers, faculty, faculty advisors, schools, and teachers (Su, 1992). Further, Richardson-Koehler (1988) endorsed collective participation among triad members and coordinated efforts to develop essential helping skills and attitudes. 
Recommendation 3: Change the Structure

of the Practice Teaching Experience

Make practice teaching school-based. Teacher educators have also called for changes to the structure of the practice teaching component. For example, Richardson-Koehler (1988) recommended the establishment of a school improvement context for student teacher supervision, a move away from the class-based apprenticeship model. The Study of the Education of Educators (SEE) found that a large percentage of student teachers would prefer a more school-based model. However, while $86 \%$ of student teachers reported a preference for becoming members of the whole school during their practice teaching experience, only 59\% saw this happening (Su, 1992).

Make practice teaching more logical and developmental. In relation to the practice teaching experience, Wilson's (1994) study of preservice elementary teachers showed that field experiences that are clearly defined and are logically sequenced with a pattern of slow introduction into the clinical sites provide the most positive experiences for preservice teachers. Clear expectations and logical, developmental sequencing are also prominent variables for increasing student teachers' feelings of self-efficacy. Increase the amount of concrete and specific feedback. Some researchers have pointed to the need for increased concrete and specific feedback to student teachers, noting that many cooperating teachers provide little or none (McIntyre \& Killion, 1986, cited in Walker, 1992). For example, Volkman, Scheffler, and Dana (1992) provided a graduate assistant to a small group of student teachers to give them regular feedback. They found that increases in the self-percepts of teacher efficacy of student teachers with a grad assistant were significantly greater than the increases in feelings of efficacy of student teachers with no grad assistant. 
Make practice teaching more collaborative. An increase in collaborative activities is also often recommended as a structural change to the practice teaching component. Wildman and Niles (1987) contended that "a collaborative work environment provides a condition for learning that can accommodate the cognitive and emotional 'side effects' of complex learning" (pp. 7-8). In addition, collaborative groups are known to expand the levels of expertise available by providing intellectual provocation and new ideas (Little, 1982). Yinger (1988) has described collaboration as "dwelling together" on a topic (cited in Sparks, 1994, p. 15), while Howey (1988) has suggested that colleagues reflecting together on classroom practices "could be viewed as the hallmark of both professionalism and professional development" (p. 30, cited in Germyn, 1992, p.49). According to Richardson-Koehler (1988) collective participation should be characterized by common goals, self-direction rather than hierarchical control, emphasis on the welfare of all members of the supervisory triad, and most importantly, consensual decision making where everyone who is affected is part of the decision-making process.

Make practice teaching more reflective. Given the unpredictable and complex nature of teaching and learning, reflection may be a necessary requirement of effective teachers (Wellington, 1991, cited in Volkman, Scheffler, \& Dana, 1992). According to Smyth (1984) "adults learn in situations where they are provided with an opportunity for continuous guided reflection based on 'lived experiences'" (p. 27, cited in Boydell, 1986, p. 123). In addition, high-level reflective activity holds some promise for diminishing the centrality of survival concerns (Zeichner \& Teitelbaum, 1982, cited in Zahorik, 1988). Bidley and Lasley (1991, cited in Volkman, Scheffler, \& Dana, 1992) have suggested that student teachers who reflect on their practice are decisive and self-assured, while Nolan and Hillkirk (1991) found that when reflection is used as part of the coaching and supervisory processes, student teachers 
develop greater feelings of self-efficacy (cited in Volkman, Scheffler, \& Dana, 1992). The concurrent seminar (Zeichner \& Liston, 1987) and the dialogue journal (Staton, 1984, cited in Bolin, 1988) are two components believed to increase student teacher reflectivity and help student teachers see their experiences from different perspectives. Both can be easily incorporated into the practice teaching experience.

Recommendation 4:

Restructure the Triad Roles

There is also a call to restructure the triad roles. For example, Howey (1988, cited in Kirchhoff, 1989) has suggested that the teacher role itself be augmented to include preparation of preservice teachers, while Bowman (1979, cited in Boydell, 1986) has called for an enhancement of the role of cooperating teacher. For example, Swanson (1995) noted the establishment of a site director for teacher education as one way to enhance the teacher's role, while also increasing communication and collaboration. However, if cooperating teachers are going to play an expanded role in practice teaching, they should also be trained to do so, especially in the analysis of teaching and supervisory techniques (Carter, 1987, cited in Richardson-Koehler, 1988).

Alternately, Zeichner and Liston (1987) focused on strengthening the role of the university advisor as a mediator of student teachers' reflection on and critical analysis of their practice and the schools and classrooms in which they teach. Similarly, Richardson-Koehler (1988) called for the effort of university supervisors to be directed to helping local school districts and principals create the context, skills, and incentives necessary for "norms" of improvement, reflective teaching, and critical analysis. On the other hand, Blumber (1977, cited in Zahorik, 1988) emphasized the university supervisors' role as interpersonal mediators rather than subject or methods specialists. 
Organize student teachers into cohort groups. In addition to a schoolbased practice teaching experience, Richardson-Koehler (1988) has suggested that student teachers be clustered into small groups at each school, and $\mathrm{Su}$ (1992) has proposed that student teachers be organized into cohort groups, with regular time and space created for collective reflection and sustained contact. Further, Wilson (1994) found that small teams of two or three student teachers promoted reciprocal professional development.

New Models for Practice Teaching

The PAR model. In response to the recommendation for better communication and collaborative work, Kirchhoff (1989) proposed a model of collaborative student teaching supervision through the Peer Assistance and Review (PAR) program. Along with two university supervisors, two PAR teachers, who had been fully released from their teaching duties, observed and supervised nine student teachers and co-presented a student teaching seminar. Kirchhoff (1989) found that adding the two PAR teachers benefited student teachers and positively affected the attitudes and perceptions of college supervisors and cooperating teachers, largely through the increased understanding of each other's viewpoints and roles that was a by-product of their collaborative work.

Strong university/school partnerships. In a study of three university/school partnerships in south Maine, West Virginia, and Ontario, Canada, Swanson (1995) found that the partnerships were designed to "enhance connection between theory and practice, training and socialization in a culture of inquiry, collaborative practice, reflection, and careful placement of students in schools that model 'best practices'” (p. 37). As a side benefit, the partnerships provided supportive working environments that "set aside time for teachers to plan and work together, foster participation in 
professional networks ... and develop cooperative and collaborative cultures within schools and universities" (p. 37).

Reflective practitioner model. Perhaps the model that best encompasses the range and spirit of the reform ideas is the Reflective Practitioner Model Practicum at the University of Wisconsin (Zeichner \& Liston, 1987). The model has five components: The first component is a 15 -week student teaching experience. This component differs from other student teaching experiences in its length and in its focus on all aspects of the teaching role, including aspects that occur outside the classroom like working with parents and school staff. The second component is inquiry-oriented and designed to increase student teachers' understanding of school and classroom cultures and to encourage them to reflect on "the relationship between these educational contexts and the surrounding social, economic, and political milieux" (Zeichner \& Liston, 1987 , p. 30). The third component, a seminar which runs concurrently with a 15-week student teaching experience, provides student teachers with an opportunity for collaborative inquiry and collective reflection on classroom practice. The fourth and fifth components of journal writing and supervisory conferences add a reflective element to the supervisory process and provide student teachers with a more facilitative supervision which many prefer (Housego, 1987). The model is described more fully in the review of the literature on reflection.

\section{Conclusion}

The review of the literature related to the school and practice teaching contexts is strongly weighted towards teacher collaboration and decision making as necessary factors for teacher engagement, commitment, and effectiveness. The power of collaboration lies not only in its potential to provide a warm, supportive teaching environment of shared values and 
norms, but also in its potential to provide conditions that enhance the amount and quality of professional talk. When teachers converse regularly about their practice and work together to solve the problems of practice, the effect is increased professionalism, improved teaching practices, higher student achievement, and greater school-level effectiveness. However, the important criterion for teacher talk is that it be about practice.

Decision making influences teacher engagement, commitment, and effectiveness largely through the sense of control and discretion it gives teachers. Regardless of whether decisions are at the school or classroom level, or are made individually or collectively, the important criterion, here, is that the emphasis be on decisions that directly impact or are related to teachers' work. Collaborative decision making has particular power because it “deprivatizes" (Kruse \& Louis, 1995, cited in Sullivan, 1996a) teaching practice and focuses on working together to plan for teaching and learning and to resolve teaching and learning problems. When teaching and learning problems are considered and resolved collectively, the focus centers on teaching as problematic, rather than the teacher. This creates a problemsolving orientation where progress made to resolve problems, rather than the success or failure of individual teaching performances or student achievement. provides the information for teachers' sense of efficacy.

If structured according to the four recommendations outlined in the review of the contexts of teacher education, teacher participation in the education of student teachers can provide increased opportunities for teachers to work together and converse regularly about their practice. In addition, working together to help student teachers solve the problems of practice helps to expand teachers' perspectives of teaching and learning and provides teachers with opportunities for collective decision making. 
Student teachers also benefit from a collaborative model of practice teaching which has implemented the four recommendations. A stronger partnership between teacher education and the schools could resolve many of the existing communication problems and provide a structure for the establishment of common goals and program intentions. In addition, when teams of teachers are working with cohorts of student teachers, student teachers are more likely to be socialized into the profession in a collaborative culture of inquiry. They will have more opportunities to hear different perspectives on teaching, to see a wide variety of teaching practices, and to get feedback from more than one teacher.

The collaborative model also gives the university supervisor a venue in which to influence the practice teaching process. As part of a practice teaching team, the university supervisor has an opportunity to enhance the training role of both teachers and university personnel and to encourage a more rigorous analysis of teaching practice through concrete, specific feedback and substantive professional talk among all three triad members.

The review of the literature on the contexts of schools and teacher education also recommends that teachers and student teachers spend more time reflecting on their practice with a view for improvement or change. The teacher as reflective practitioner is the subject of the next section of this review of the literature.

The Teacher as Reflective Practitioner

\section{Introduction}

The reflective practitioner model of teaching holds promise for the preservice and in-service development of teaching expertise and effectiveness. This section provides a survey of current thinking on 
reflective practice. It begins with an historical overview of conceptions of good teaching and outlines two theories of reflective practice foundational to current thinking on reflection. Discussions of the teacher as a reflective practitioner, the types of reflection, and the role of reflection in teacher thinking follow. The section then provides an overview of reflective practice in teacher education and concludes with a summary of concepts particularly relevant to this study.

\section{An Historical Overview}

Conceptualizations of what makes a good teacher and how good teachers are made have changed over time. Simmons and Schuette (1988) delineate these changing perspectives as four "historical paradigm shifts" (p. 19), with shifts in the definition of an effective teacher moving over the years from "teacher as an effective person(ality)" (p. 19) prior to the 1960 s, to "teacher as a skilled performer" (p. 19) in the 1960s and early 1970s, to "teacher as instructional decision-maker" (p. 19) in the late 1970s and early 1980s, and finally, to "teacher as a reflective practitioner" (p. 20), currently in vogue.

These shifts have been useful in promoting understanding of what constitutes effective teaching and how teachers develop expertise. For example, recognizing that there were things that teachers could learn to increase their effectiveness was an important move away from the belief that good teachers are "born not made" (Simmons \& Schuette, 1988, p. 19). However, the drawback of the teacher-as-skilled-performer paradigm is the assumption that learning to teach can be equated with learning a set of "prescriptive rules" (p. 19) widely applicable in almost all teaching situations, a view easily refuted by real-life practice. The teacher-as-instructionaldecision-maker paradigm also moved the conceptualization of teaching forward by giving importance to the dynamic nature of teaching contexts: the 
teacher not only must know what to teach and how to teach it, but also must be able to decide what knowledge and strategies should be used and when to use them. Unfortunately, the teacher-as-instructional-decision-maker paradigm lacked a clear perspective on how teachers honed decision-making and other teaching skills to become experts. The teacher-as-reflective-practitioner paradigm is considered to fill this gap.

\section{Theoretical Foundations for Reflective Practice}

While there are a number of theorists and researchers who are making valuable contributions to our understanding of reflection and its effect on teaching and on teacher development from preservice to retirement, many of their conceptions begin with the work of Donald Schon (1983) and John Dewey (1916, 1966).

\section{Donald Schon and}

\section{the Reflective Practitioner}

Schon's (1983) perspective of reflective practice begins with an understanding of professional occupations as highly complex and of professional situations as "inherently unstable" (p. 15) and characterized by uncertainty, disorder, and indeterminacy" (pp. 15-16). However, according to Schon, the epistemology of practice in most professions is based on a technical-rational approach that relies on a "specialized, firmly bound, scientific, and standardized" (p. 25) knowledge base and a rational process of problem solving. The technical-rational approach, however, does not account for "dynamic ... complex systems of changing problems that interact with each other" (Schon, 1983, p. 16), nor does it account for processes like "making sense of uncertainty, performing artistically, setting problems, and choosing among competing professional paradigms" (p. 20). 
Schon (1983) decries that these phenomena, so "central to professional competence" (p. 19), are ignored and that artistic ways of coping with these phenomena are excluded from definitions of rigorous professional knowledge (p. 42). He calls for a new "epistemology of practice implicit in the artistic, intuitive processes which some practitioners do bring to situations of uncertainty, instability, uniqueness, and value conflict" (p. 49). This new epistemology would first honor the "tacit knowing-in-action" (p. 49) or "know-how" (p. 50) which guides practice and would acknowledge the importance of experience in developing a "repertoire of examples, images, understandings, and actions" (p. 138) which practitioners use to make "sense of a situation" (p. 138). According to Schon, a new epistemology of practice would then focus on how this repertoire of practice is developed and what part it plays in developing professional artistry. That is, it would focus on what Schon refers to as reflection-in-action.

Problematic and "messy" (p. 16) situations of professional practice require not only knowing-in-action, but also thinking about what one is doing while evolving a way of doing it. The practitioner who reflects-in-action is, thus, "a researcher in the practice context" (p. 68): He or she "focuses interactively on the outcomes of action, the action itself, and the intuitive knowing implicit in the action" (p. 56) and, therefore, does not separate means from ends, thinking from doing, or inquiry from implementation.

Responding to problematic situations. Much of knowing-in-action is undergirded by a tacit theory-in-action which remains undisturbed unless the results of one's actions are surprising or unsuccessful. Practitioners usually respond to this puzzling development--their knowing-in-action isn't working--in one of two ways.

Practitioners can choose not to find anything worth reflecting upon and seek to "preserve the constancy of their knowledge" (p. 69) through 
"selective inattention, junk categories, and situational control" (p. 69). That is, they can ignore data that do not fit their theory, explain away phenomena by junking it into a category like "personality" or "politics" (p. 44), or mold the situation to fit their available applied knowledge. For practitioners who respond in this way "uncertainty is a threat; its admission is a sign of weakness" (p. 69). Unfortunately, such narrow and rigid responses may also lead to "boredom or burn-out" (p. 61) for practitioners and result in negative consequences for others involved.

Alternately, practitioners can choose to respond to aspects of the situation which fall outside their normal expectations with feelings of "surprise, puzzlement, or confusion" (Schon, 1983, p. 68). This is a positive response which can activate reflective thinking. At first, practitioners may respond by reapplying their current theory more carefully, in what Schon (1983) refers to as an "action response" (p. 57). However, if that fails to explain the puzzle or resolve the problem, they then stop and think in order to "surface and criticize [their] initial understanding of the phenomenon, construct a new description of it, and then test the description by an on-thespot experiment" (p. 63). This reflective inquiry is shaped by "two critically important processes" (p. 269): When faced with a unique situation, reflective practitioners first draw on their repertoires of practice to frame the situation, and second, they use the frame to form hypotheses which can be tested "by experimental actions which also function as moves for shaping the situation and as probes for exploring it" (p. 269).

The reconsideration of the theory underlying their practice and the onthe-spot experiment that follows are called a "theory response" (p. 58), rather than an action response. A theory response shifts practitioners from a "success orientation" (p. 58) where positive and negative results are signs of success or failure, to a "theory orientation" (p. 58) where positive and 
negative results are used as information for understanding what is happening in a particular situation.

Reflection as a design process. Schon (1983) further posits that, in "all occupations engaged in converting actual to preferred situations" (p. 78), the ongoing process of reflection-in-action is a design process which he describes as "a conversation with the materials of the situation" (p. 78). This reflective conversation is really a series of moves by the practitioner and responses or countermoves from the situation. The practitioner reflects on the situation, forms an appreciation of what it is about, and then makes a move. The situation "talks back" (p. 79) by revealing the anticipated and unanticipated consequences of the designer's move. According to Schon (1983), "each move is a local experiment which contributes to the global experiment of reframing the problem" (p. 94). Thus, design is a reflective process of "spinning out a web of moves, consequences, implications, appreciations, and further moves" (p. 95), and reflective practitioners are defined by their willingness "to step into the problematic situation, to impose a frame on it, to follow the implications of the discipline thus established, and yet to remain open to the situation's back-talk" (p. 269).

Developing artistry. The "art of practice" (p. 17) requires "problem setting" (p. 40), the use of analytic skills to understand situations, and an "active synthetic skill of designing a desirable future and inventing ways of bringing it about" (p. 16). As the reflective practitioner develops "artistry" (p. 130), that is, a practical expertise, he or she becomes

like a chess master who develops a feeling for the constraints and potentials of certain configurations of pieces on the board . . . [and thus] does not need to play out all the trees of moves which might follow from his [or her] initial reframing of the problem. (p. 104) 
While Schon is not an educator, his conception of the professional as a reflective practitioner is salient to teacher development and practice. Teacher educators have found it particularly useful in reframing their own conception of how individuals learn to teach and develop artistry. John Dewey and Experience and Thinking

Dewey $(1913,1966)$ describes "thought or reflection [as the] discernment of the relation between what we try to do and what happens as a consequence" (pp. 144-145). These represent the two parts of an experience, one of which is active and referred to as "trying" (p. 139), and one of which is passive and represents "undergoing" (p. 139). It is the combination of these two elements which creates a meaningful experience, and it is thinking that "makes it possible to act with an end in view" (p. 146).

Like Schon, Dewey (1966) accords the reflective process to an active agent who is affected by the outcomes of present events in his or her environment and seeks "to influence the direction present occurrences take" (p. 124) or "to take some steps which will influence future happenings" (p. 124). However, Dewey emphasizes the importance of two dispositional qualities or personal conditions which support the willingness to reflect. First, to be an active participant, one must have an "interest" (p. 128), or stake, in what happens. Second, an active participant also needs the "discipline" (p. 129) to "persist and endure in a planned course of action in spite of difficulties and contrary solicitations" (p. 128). Dewey equates discipline with will, or volition, which he describes as having two aspects: "One has to do with the foresight of results, the other with the depth of hold the foreseen outcome has on the person" (p. 128). For Dewey, "the primary difference between strong and feeble volition is intellectual, consisting in the degree of firmness and fullness with which consequences are thought out" (p. 128). 
Thus, thinking, and particularly thinking about ends, is foundational to meaningful action. In fact, Dewey defines "mind" as the "ability to respond to present stimuli on the basis of anticipation of future possible consequences, and with a view of controlling the kind of consequences that are to take place" (pp. 130-131). He further suggests that anything that is a factor in constraining or supporting one's aims becomes "an object of study--that is, of inquiry and reflection" (p. 134) and "to learn from experience is to make a backward and forward connection between what we do to things and what we enjoy or suffer from things in consequence" (p. 140).

The reflective experience. The opposites of reflective experience are "routine and capricious behavior" (p. 146). Routine behavior ignores the connections between intent and outcomes and "accepts what has been customary as a full measure of possibility" (p. 146). Alternately, capricious behavior ignores the connection between personal action and "the energies of the environment" (p. 146) and says "things are to be just as I happen to like them at this instant" (p. 146). Because both disregard the effects present actions have on future consequences, they also obscure the role a thinking participant can play in shaping events and their outcomes.

There are two ways to learn from experience: One is through trial and error, and one is through reflection. Trial and error is relatively thoughtless in that "we see that a certain way of acting and a certain consequence are connected, but we do not see how they are" (Dewey, 1960, p. 145, emphasis in the original). However, when we consciously look for the "details of the connection" (p. 145) and analyze them "so as to bind cause and effect, activity and consequence" (p. 145), we not only make our thoughts explicit, but we also make thinking a reflective experience.

In accordance with Schon (1983), Dewey (1966) posits that the reflective experience occurs "when things are uncertain or doubtful or problematic" (p. 
148). In uncertain situations, Dewey suggests that active participants enact a five-step reflective process:

1. Participants respond to a previously unexperienced effect of their actions with "perplexity, confusion, doubt" (p. 150).

2. They enter into "conjectural anticipation" (p. 150) in which they explore the tendency of the elements of the situation "to effect certain consequences" (p. 150).

3. They make "a careful survey (examination, inspection, exploration, analysis) of all attainable considerations which will define and clarify the problem at hand" (p. 150).

4. They form "tentative hypotheses" (p. 150) about actions and consequences.

5. They commit to a "projected hypothesis as a plan of action" (p. 150). Dewey notes that it is the careful survey of all attainable considerations (3) and the construction of tentative hypotheses (4) that separate a reflective experience from a trial-and-error experience. In addition, the commitment to a plan of action makes reflection a proactive, future-oriented response to situations where both interest and discipline play a vital role.

\section{The Teacher as Reflective Practitioner}

Currently, teacher educators view reflection as a way to overcome the continuing effects of the teacher-as-skilled-performer paradigm, which they believe oversimplifies teaching practice (van Manen, 1977; Zeichner, 1986), ignores the effects of the student and the context on teaching (Yinger, 1990), and underestimates the role teacher decision making and judgment play in the mobilization of competencies for effective and appropriate teacher action (see Eisner, 1988; Shulman, 1987). As Yinger (1990) points out, "the intelligence of practice is based on an ability to fit tool and method to specific needs of 
specific people and places. The essence of practice is work-in-place" (p. 83).

However, when practice as work-in-place is applied to teaching, questions inevitably arise about what constitutes this work and what role responsibilities teachers ought to fulfill. These questions are, perhaps, best addressed by van Manen (1977) through his conceptualization of the practical. He suggests that we can link the practical world of teaching with the three main traditions of social science: the empirical-analytic tradition, the hermeneutic-phenomenological tradition, and the critical-dialectic tradition. The Empirical-Analytic Tradition

The empirical-analytic tradition is based on "professional faith in an authoritative science of education" (Walker, 1975a, p. 265, cited in van Manen, 1977 , p. 209). Educational problems in this tradition are "technicalinstrumental" (p. 225) problems that can be solved through the application of empirical research. The empirical-analytic tradition mirrors the technicalrational epistemology of practice referred to by Schon (1983). It could also be interpreted as directly paralleling the teacher-as-skilled-professional paradigm (Simmons \& Schuette, 1988) with its emphasis on skills as "trainable techniques, procedures, ways of accomplishing things" (van Manen, 1977, p. 211).

However, van Manen (1977) cites Schwab's (1973) conception of "practical action [as consisting of] deliberative and eclectic procedures" ( $p$. 206, emphasis mine), which supports Schon's premise that reflection on technical matters is necessary to learn the artistry of practice. While van Manen (1977) concedes that effective practitioners do reflect on the technical aspects of their practice, he warns that because the focus of empiricalanalytic deliberation is on economy, efficiency, and effectiveness and on effective control over outcomes, it is too narrow to adequately address educational experience. Within teacher education, as well as within schools, 
the focus on technical skills underemphasizes other capabilities and dispositions which are of great importance for successful teaching but are also more difficult to teach for and to measure. Van Manen (1977) cautions that when the interpretation of the educational experience is reduced to "aggregates of distinct, separable perceptions, conceptions, and skills" (p. 216), it can lead to a view of education as "a technical production process, with inputs, treatments, and outputs" (van Manen, 1991, p. 513), where the curriculum is perceived to be the treatment. Similarly, Tom (1984) posits that a purely technical perspective on teacher education and educational practice reinforces underlying assumptions of teaching as a direct "one way flow of influence" (p. 54) from teacher to student and as a stable natural phenomenon with "enduring regularities" (p. 54).

Van Manen (1995) suggests that the hermeneutic-phenomenological and the critical-dialectic traditions offer necessary perspectives for delineating an epistemology of reflective educational practice and for expanding the instrumental view of knowledge and practice of the empiricalanalytic tradition.

The Hermeneutic-Phenomenological Tradition

Van Manen (1977) defines hermeneutics as "the science of interpretation or as the phenomenology of social understanding" (p. 213) and posits that

from the perspective of hermeneutics there is no such thing as stimuli, responses, or measurable behaviors; instead there are encounters, lifeworlds, and meanings, which invite investigation. The focus is on actions not behaviors. (p. 214)

The practical in this tradition sees education as "motivated by a caring interest in the growth and welfare of children" (van Manen, 1995, p. 33). It is concerned with "communicative understanding of educational expressions, 
educational actions, and educational experiences" (van Manen. 1977, p. 213). In addition, the hermeneutic-phenomenological tradition delineates problems of teaching as "situations, predicaments, possibilities and difficulties [which] constitute 'problems of meaning' that cannot be 'solved' and done away with once and for all" (van Manen, 1991, p. 515). Teachers, nonetheless, must constantly negotiate and work in tension with these problems of meaning.

Within teacher education programs, the focus of hermeneuticphenomenological deliberation is on the nature and the quality of the educational experience. The hermeneutic-phenomenological tradition emphasizes the "lived experience" of classrooms and teachers' roles in creating a positive lifeworld. Thus, an interpretive understanding of the practical requires empathy, "the capacity to grasp the inner realities of the human world" (van Manen, 1977, p. 214), along with reflective considerations of alternate "ways of being in the world ... [and of] the actions of teachers, not only as educators, but also as adults who share a lived reality with children" (Grimmet et al,, 1990, p. 29).

While the empirical-analytic tradition informs the technical aspects of practice and the hermeneutic-phenomenological tradition informs the human and social aspects, van Manen (1977) suggests that a third perspective, the critical-dialectic tradition, is needed to deal "with the theoretical-practical problem of systematically distorted patterns of communication that reside in the historical structures of everyday institutions" (p. 220).

\section{The Critical-Dialectic Tradition}

The critical-dialectic tradition is based on the conception that there is "no such thing as a neutral educational process" (Schaull, 1970, p. 15, cited in van Manen, 1977, p. 221). Educational problems in this tradition are associated with the practical as "a distortion-free model of consensus-seeking community" (p. 222). Reflection becomes a process of "conscientization" 
(Freire, 1970, cited in van Manen, 1977, p. 222), described by van Manen as a process by which individuals, "as knowing subjects rather than recipients, achieve a deepening awareness both of the sociocultural reality that shapes their lives and their capacity to transform it" (p. 222). Reflective considerations focus on the aims of self-determination, liberation, and emancipatory, practical action.

Teacher education from the critical-dialectic perspective includes activities which seek to engage prospective teachers in reflection as a dialectical process of reconstructing experience by "recasting situations" (Grimmet et al., 1990, p. 27) from different perspectives, surfacing and scrutinizing one's views of the self-as-teacher, and rethinking taken-forgranted assumptions about teaching and problematic issues. Such reflection makes practice problematic and, thus, open for reconsideration and change. Other Perspectives on the Teacher

\section{as a Reflective Practitioner}

Current perspectives on the teacher as reflective practitioner resonate with one or more of the theoretical foundations laid down by Dewey, Schon, and van Manen.

Teacher reflection as developmental. Coming from a more or less technical perspective, Reagan (1993) considers reflection to be a three-stage developmental process that coincides with teacher development. According to Reagan, at the beginning of their practice, teachers first reflect on technical knowledge and its "effective application" (p. 190) in classroom settings. After

they have developed some technical skill, teachers then begin to reflect on the assumptions that underlie classroom practice and judge them according to “educational criteria" (p. 190). While this second level increases teachers' independent decision making, it does not directly address the social-relational aspects of teaching of the hermeneutic-phenomenological perspective and, 
thus, is more an extension of the empirical-analytic perspective. However, it does move teachers towards a "conscience of craft" (Green, 1985, cited in Reagan, 1993, p. 194) in which "the expert or the novice in any craft adopts the standards of that craft as his or her own" (p. 194). With its focus on questions of "moral, ethical, and other types of normative criteria" (p. 190), Reagan's (1993) final level of development, critical reflection, moves away from the empirical-analytic tradition to more closely align with van Manen's (1977) critical-dialectic perspective.

Three modes of reflection. More closely aligning with van Manen's conception of the practical, Grimmet, MacKinnon, Erickson, and Riecken (1990) suggest three modes of reflective practice: a technical process that directs the act of teaching, a deliberative process which informs practice, and a dialectical process which helps educators apprehend and transform experience. They suggest that each process represents a different perspective on education with separate sources of knowledge, modes of knowing, and ways of using knowledge in the reflective process.

According to Grimmet et al. (1990), when the "mode of reflective knowing" (p. 35) is technical, teachers utilize external authorities, such as theory and research, as sources of information to direct their practice. Knowledge is viewed as a set of rules that must be learned, and reflection is concerned with how best to replicate what authorities say is the most effective way to teach.

The deliberative mode of reflection also relies on external authority as a source of information but mediates that information through a particular teaching context in order to make choices between alternative practices. Knowledge is now viewed as a repertoire of strategies or a set of "rules of thumb" that can be applied in the appropriate situation to benefit student learning. 
In contrast to the technical and deliberative modes, the dialectical mode of reflection uses the context, mediated through other teachers and one's self, as its main source of knowledge.

Such knowledge is emergent, and reflection on practice is a reconstruction of experience, which is intended to expand the number of perspectives with which a situation can be viewed, to increase appreciation for the complexity underiying practice, and to expose the inherent tensions embedded in the cooperative practice of teaching. When Fenstermacher (1982) suggests that "instead of being a source of rules for guiding practice, research results might serve either as evidence for testing the beliefs of practitioners or as a schemata for helping practitioners see classroom events in new ways" (cited in Tom, 1984, p. 74), he is alluding to both the deliberative and the dialectical processes of reflection as outlined by Grimmet and his colleagues.

Grimmet and his colleagues (1990) clearly move away from an empirical-analytic tradition with their dialectical mode of reflection, which encompasses both the critical-dialectic and the hermeneuticphenomenological traditions. Following the critical-dialectic tradition, the dialectical mode of reflection requires practitioners to make explicit the norms and values that undergird their teaching and to carefully scrutinize their taken-for-granted assumptions about teaching to prevent them from becoming "distorted and constrained by the structural forces in education systems" (p. 32).

Following the hermeneutic-phenomenological tradition, the dialectical mode of reflection also includes reconstructing self-as-teacher and examining one's place in the lifeworld of children. Grimmet et al. (1990) cite Hultgren's (1987) phenomenological study of student teachers' lived experiences as an example of research in this area. Similarly, Court (1989) proposes self- 
reflection as a way for teachers to sensitize themselves to the thoughts and feelings of their students. By recalling their own experiences with school or adult authority figures, teachers learn to take children's feelings and perspectives seriously, which in turn motivates them to develop positive and empathetic relationships with the children they teach, to create warm and trustworthy classroom environments, and to attend to children's social and emotional needs, as well as their academic ones.

Reflecting on teaching as a moral and ethical enterprise. Perhaps the theoretical perspective which resonates most closely with van Manen's (1977, 1991, 1997) perspective on reflective practice is that of Linda Valli. Valli (1990) emphasizes the moral and ethical nature of all aspects of teaching and suggests that teachers should ask not "how to do something, but rather, if it is worthwhile, if is good, and for whom it is good" (p. 42). To that end, she outlines three approaches to reflection: a deliberative approach, a critical approach, and a relational approach.

The deliberative approach views the technical aspects of teaching within a moral framework which emphasizes rightness of conduct and asks questions related to the value and desirability of educational ends. The critical approach follows the political philosophy of neo-Marxism with its beliefs in the inherent injustice and repressiveness of the dominant social class. Teachers following this approach attempt to view schooling from the perspectives of those who benefit from it least and, thus, expose hegemonic biases towards race, class, and gender. Such critical reflection then turns to questions of how to give more power to those who are marginalized in the educational context. Finally, Valli's (1990) relational approach mirrors van Manen's (1991, 1995) concern for the human, interactional aspects of teaching and emphasizes reflection for the development of caring relations and communities. 
Teaching as pedagogical tact. The human and therefore normative aspects of teaching are also central to van Manen's $(1991,1995)$ conception of teaching practice. He suggests that, in addition to reflection-in-action, which requires teachers to stop and think, however briefly, teaching necessitates the development of what he refers to as a "pedagogical tact" (p. 520). Pedagogical tact requires an orientation of responsiveness to each pedagogical moment and a "pedagogical understanding in being attentive to young people, through what we notice about them, in the way that we listen to them" (p. 520). This tactful orientation is characterized by "moral intuitiveness" (p. 521) and guided by a sense that an adult has a responsibility to "do something pedagogically right in his or her relation with some child or children" (p. 510).

Pedagogical tact also requires what van Manen (1991) refers to as "pedagogical fitness" or "cognitive and emotional and moral and sympathetic and physical preparedness" to work with children (p. 534). We learn tact through "the tacit or intuitive nature of our bodily skill [which] is learned in subtle ways by attuning ourselves to the concrete particulars of situations" (p. 534) and through reflection on our conscious efforts to act thoughtfully.

\section{Types of Teacher Reflection}

The levels of reflection outlined above emphasize the complexity underlying learning to teach and the role that reflection might play in ongoing teacher development. Other examinations of reflective practice make a more pragmatic contribution by outlining when and how reflection is used. Space and Time of the

\section{Reflective Process}

Following Schon (1983), most educational theorists and researchers refer to two types of reflective thinking: reflection-in-action and reflection- 
on-action. Reflection-in-action is considered to occur in the live moments of teaching and to increase teachers' ability to respond flexibly to in-themoment contextual changes. Van Manen (1991) refers to reflection-in-action as active or interactive reflection which "permits[one] to make decisions virtually on the spur of the moment" (p. 512), while Killion and Todnem (1991) suggest that such reflection-in-action involves becoming "aware of the metacognitive process one is experiencing" (p. 15). On the other hand, reflection-on-action, or "recollective reflection" (van Manen, 1991, p. 512), occurs after an action is completed when one has more time "to make sense of past experience and thus gain new or deeper insights" (p. 512) into one's experiences with children.

Killion and Todnem (1991) also offer a third type of reflection, which they refer to as reflection-for-action, which parallels van Manen's (1991) "anticipatory reflection" (p. 512) and resonates with Dewey's (1966) conception of mind as responding not only to present stimuli, but also with a view to controlling consequences. The purpose of reflection-for-action is to "guide future action" (Killion \& Todnem, 1991, p. 15) and to help teachers "approach situations and people in an organized, decision-making, prepared way" (van Manen, 1991, p. 512).

Finally, Killion and Todnem (1991) see reflection as a process that encompasses all time designations, past, present, and future, simultaneously. This conception of reflection reiterates Schon's (1983) and Dewey's (1966) emphasis on the reflective process as embedded in meaningful action and as always goal-focused and, therefore, future-oriented. In fact, in his first book, Schon (1983) did not distinguish clearly between reflection-in-action and reflection-on-action, but rather, distinguished between situations as having either a short time frame or a long one. For example, in teaching, one class or a whole semester of classes could be referred to as a situation. Thus, how the 
situation is framed determines whether or not one sees oneself reflecting in or reflecting on action.

Reflection in Education as a Design Process

Other educational researchers and theorists prefer Schon's conception of reflection as a design process. For example, Noordhoff and Kleinfeld (1990) propose that educators adopt Schon's conception of reflection as a design process because it is clearly action-oriented and focuses on transforming present situations into preferred ones. For them, teaching as design evokes an "image of inventing and constructing, with intents, purposes, and goals informing both mental organization and physical activity" (Noordoff \& Kleinfeld, 1990, p. 168). This image of teaching seems particularly useful in educational roles and contexts and as a framework for developing prospective teachers.

Yinger (1990), on the other hand, emphasizes Schon's idea of reflection as a conversation with the situation. Although this is Schon's definition of design, Yinger sees the metaphor of conversation as more accurately describing the improvisational nature of reflection by design: Individuals must be in the situation and with people in order to participate, and although they can be well-prepared for a conversation--they have the language of practice and know what they are trying to accomplish--they do not know exactly how the conversation will go and, therefore, must improvise the use of their knowledge. The metaphor of conversation, thus, emphasizes both preparedness and responsiveness.

\section{The Role of Reflection in \\ Teacher Thinking}

The recognition that schools are complex and dynamic social contexts, with increasing diversity among children, has led educational researchers 
and theorists to a focus on the improvisational nature of teaching and on the cognitive aspects that support teachers' abilities to be responsive and flexible in the face of changing conditions.

\section{Reflection and Cognitive Complexity}

Paraphrasing Piaget's concept of cognitive schemata, Reiman and Thies-Sprinthall (1993) suggest that "humans behave in accord with the level of complexity of their mental structures" (p. 179) and posit that, given the complex nature of teaching, teachers must possess highly developed cognitive capabilities or be able to develop them. That teachers are able to increase the level of complexity of their thinking is supported by Simmons and Schuette (1988): Summarizing Ropo's (1987) studies, they point out that “in comparison with novices, experts' thinking was more hierarchically complex, specific, responsive to contextual factors, inclusive, and characterized by interrelated abstract principles and concrete situations" (pp. 19-20).

Reflective teachers are also generally described as having a wider array of cognitive capabilities than nonreflective teachers. Reagan (1993) posits that this is because reflective thinking requires "schemata, or organized networks of facts, concepts, generalizations and experiences" ( $p$. 190) about teaching. Simmons and Schuette (1988) characterize reflective teachers as having metacognitive and analytic capabilities, as well as capabilities for problem solving and for making "intuitive, creative interpretations and judgments" (p. 20). Similarly, Zeichner and Liston (1987) cite teacher capabilities of "keen observation and reasoned analysis" (p. 24).

To test the role reflection might play in teachers' cognitive development, Reiman and Thies-Sprinthall (1993) devised and implemented a mentor teacher training program based on guided reflection. The guided reflection framework established five conditions believed to positively affect psychological growth: placing teachers in complex new helping roles, 
encouraging continuous guided reflections, balancing experience and reflection, blending personal support and challenge, and providing time for psychological growth to occur (p. 180). Pretest-posttest data from the Hunt Paragraph Completion Test and the Rest Defining Issues Test showed that mentor teachers trained using the guided reflection approach made positive gains over a 6-month period in cognitive complexity and interpersonal maturity $(\mathrm{p}<.15)$ and in moral reasoning $(\mathrm{p}<.10)$. The pretest-posttest differences, however, were greater for teachers with low to moderate pretest scores than for teachers with high pretest scores. Reiman and ThiesSprinthall (1993) conclude that guided reflection may be a "crucial key ... for developmental growth" (p. 184).

Reflection and Decision Making

Decision making is another cognitive capability that may be improved through reflection. Decision making has been touted as a "basic teaching skill" (Shavelson, 1977 , p. 144 , cited in Court, 1989, p. 265) that all teachers must learn in order to teach effectively. This is supported by the National Commission for Excellence in Teacher Education (1985), who concluded that teachers do not "simply follow directions in a teacher's manual . . . [but, instead, must] continually make complex decisions about the curriculum, the students, and instruction" (pp. 1-2, cited in Cornbleth, 1986, p. 11). Teachers also make decisions related to educational outcomes (Reagan, 1993).

Court (1989) proposes that the conception of teacher decision making as a learnable skill has, unfortunately, also led to the belief that it can be easily taught by giving step-by-step instructions. However, she points out that decision making is not a discrete cognitive skill but, rather, a complexity of cognitive capabilities applied to a judgment of value. Thus, teachers cannot learn decision making through direct instruction. Instead they must use their practical knowledge and experience as a basis for choosing what to do, given 
the available choices of courses of action and the particular situation and students involved. Therefore, Court (1989) suggests that teachers can develop their decision-making capabilities only through "the analysis of the reflection of the decisions they have made, the knowledge, beliefs, and values that underlie them, and the ramifications they have had in the classroom" (Court, 1989, p. 266, emphasis mine).

\section{Reflective Practice in Teacher Education}

Educating teachers who are able and willing to reflect on their practice holds promise as a way to prepare prospective teachers for career-long learning. Wong, Kember, Chung, and Yan (1995) posit that "reflective learning is of particular relevance to the education of professionals, as it encourages students to integrate theory with practice, appreciate the world on their own behalf, and turn every experience into a new potential learning experience" (p. 48). In addition, a reflective practitioner model of teacher education promises to overcome the perceived negative influence of apprenticeship models, characterized as "socializing [student teachers] into existing school practices without affording them the opportunity to examine reflectively how schools operate or understand the social aspects of school" (Wedman \& Martin, 1991. p. 35). Thus, the capability to reflect allows teachers to continue to develop not only their technical proficiency, but also their capabilities to respond positively to students' personal, social, and academic differences and their willingness and capability to effect change in their classrooms and schools.

With such high hopes for reflection as a way to develop teaching expertise or "artistry" (Schon, 1983, p. 130) and to effect school change, many teacher educators are seeking ways to develop the reflective capabilities of 
prospective teachers and to refocus their programs on the teacher as a reflective practitioner.

Focus on Technical Proficiency.

The RITE program. Freiberg and Waxman (1990) see reflection-inaction and reflection-on-action (Schon, 1983) to be integral to the development of technical teaching skills. Their Reflection and the Acquisition of Technical Teaching Skills (RITE) program is designed around the belief that such reflection requires the development of systematic observation and selfassessment skills. They found that students who had opportunities to observe and reflect on teaching began to understand how teaching behaviors "differentially influence" (p. 121) student behavior. In addition, students who were trained in the use of fixed-category observation systems such as Flanders Interaction Analysis System, low-inference self-assessment measure (LISAM), and Stallings Observation System showed greater use of interactive instruction and academic statements and less use of organizing statements. In addition, fewer student teachers in the training group were off-task than student teachers in a control group who did not receive the training.

The analyzed apprenticeship. In a similar attempt to influence prospective teachers' developing technical expertise, Noordoff and Kleinfeld (1990) applied Schon's three-stage reflective design process to an "analyzed apprenticeship" (p. 169) model of student teaching. The analyzed apprenticeship took place over 6 weeks and involved three phases of reflective action.

In Phases 1 and 2, student teachers observed teachers in their classrooms and corrected student papers, maintained student records, prepared material for teaching, and taught portions of lessons. As they fulfilled their participant-observer roles, student teachers were also given opportunities not only to "name and frame" situations and issues they encountered (Stage 1), but 
also to practice sorting images, selecting strategies, and spinning out consequences (Stage 2). In Phase 3, student teachers taught a 3- to 5-day miniunit. After reflecting on the effects of their teaching, student teachers provided a written analysis that included considerations of how they might redesign their practice as a result of their teaching experience. This third stage parallels the third stage of Schon's (1983) reflective design process.

Systematic reflection. Wildman, Niles, Magliaro, and McLaughlin (1990) focused on how to extend in-service teachers' capabilities for reflection (defined as their ability to look at their practice thoughtfully) and their positive attitudes towards self-analytic inquiry. However, they conjectured that the complexity and uncertainty of schools, along with the constraints of time, would make developing and sustaining reflective practice difficult. The solution, say Wildman and his colleagues, is to institute a systematic process of reflection which first moves teachers from analytic descriptions of teaching issues to reflective responses to them. From this beginning point, reflective activities moved from simple to complex, neutral to personal, and individual to collaborative.

Wildman et al. (1990) found that the quality of the collaborative reflection process varied according to the nature of the teacher-partner relationships and was often constrained by time, lack of administrative support, and feelings of personal vulnerability. Despite these constraints, participating teachers felt that the opportunities to reflect helped them to "slow down and think" (p. 153), to put covering the curriculum in perspective, and to see their teaching as well as the way their school solved problems in a new light. From this study, Wildman et al. (1990) concluded that systematic reflection encourages a self-analytic approach to teaching and a positive attitude towards inquiry which can be learned through a carefully designed set of developmental experiences. 
While the merit of these programs cannot be disputed, Tom (1984) and Zeichner and Liston (1987) warn that too much emphasis on the technical dimension of teaching may result in simplistic and incomplete solutions to the problems of practice. Zeichner (1986) points out that effective teachers ought to consider the moral and political issues inherent in practice as well as the instrumental ones (also see van Manen, 1977, 1991, 1995). Other teacher education programs have responded to this call to move beyond the technicalanalytic level.

Focus on Relationships With Children

Explicit dialogue approach. A research study conducted by Pugach and Johnson (1990) focused on developing positive teacher responses to children through their Peer Collaboration Project. Collaborative reflection was encouraged through the use of what Pugach and Johnson refer to as an "explicit dialogue technique" (p. 189), described as a "structured, interactive process ... in which teachers rehearse specific reflective, strategic thinking patterns in a structured dialogue with their colleagues" (p. 189). The Peer Collaboration Project was based on the thesis that "complex and more reflective patterns of thinking are fostered in socially interactive situations" (Pugach \& Johnson, 1990, p. 186).

During the second year of the project, the 48 participating elementary and junior high school teachers were assessed using the Kornblau TeacherPupil Survey. Results showed that teachers had significantly increased the range of cognitive behaviors they found tolerable.

In Year 3 of the program, the effect of the Peer Collaboration Project was again assessed for its effect on teaching thinking and practice, using pretest-posttest data collected from 78 participating elementary teachers: First, data from the Kornblau Teacher-Pupil Survey replicated findings from the previous year that peer collaboration and the explicit dialogue technique 
significantly increased the range of cognitive competence for which intervention teachers were tolerant. Second, data from the Classroom Problem Questionnaire showed that intervention teachers became more confident in their teaching. Third, data from the Classroom Questionnaire showed teachers in the intervention group became more positive towards students, while the comparison group of 77 teachers became less positive. Finally, data from the administration of the Gibson and Dembo (1984) Teacher Efficacy Scale found that self-percepts of teacher efficacy increased for both intervention teachers and control group teachers.

Developing an Integrated Program of

Teacher Education: University of Wisconsin's

Reflective Practitioner Model

Teacher educators in the University of Wisconsin elementary student teaching program remodelled their program to

emphasize the preparation of teachers who are both willing and able to reflect on the origins, purposes, and consequences of their actions, as well as on the material and ideological constraints and encouragements embedded in the classroom, school and societal contexts in which they work. (Zeichner \& Liston, 1987, p. 23)

Zeichner and Liston (1987) suggest that the program planners hoped that these new goals would also enhance student teachers' development of "pedagogical habits and skills necessary for self-directed growth [and their ability] to participate as full partners in the making of educational policies" (p. 23).

Program components. At the heart of these pedagogical habits and skills was the capability to reflect meaningfully on one's actions. Thus, the University of Wisconsin program integrated five major components believed to encourage reflective practice. 
The first component was a 15-week student teaching experience. This component differed from other student teaching experiences in its length and in its focus on all aspects of the teaching role, including those aspects which occur outside the classroom, such as working with parents and school staff. In addition, there was a strong emphasis on developing the teacher role of "userdeveloper of curriculum--one who is both aware of critical choice points in curriculum development and who is skilled in curriculum development" (Zeichner \& Liston, 1987, p. 30).

Second, the student teaching experience was augmented with an inquiry component designed "to promote student teachers' understanding of the contemporary cultures of their classrooms and schools, of the relationship between these educational contexts and the surrounding social, economic, and political milieux" (Zeichner \& Liston, 1987, p. 30). Student teachers were first required to observe outside their student teaching classrooms at least three times in order to compare teaching approaches at the same grade level, to discern differences in approaches to the same subject area, and to analyze "theories-in-use evident in particular kinds of classrooms" (Zeichner \& Liston, 1987 , p. 31 ). In addition, student teachers were requested to complete either an action research project, an ethnographic study, or a curriculum analysis project.

A third component was a seminar which ran concurrently with a 15week student teaching experience. The seminar offered an opportunity for collaborative inquiry and was intended to extend student teachers' thinking about classroom practice and to help students become "critical consumers of educational research" (Zeichner \& Liston, 1987, p. 35).

Journal writing and supervisory conferences based on clinical supervision, the fourth and fifth components, were integral parts of the supervisory process. Throughout the student teaching experience, student 
teachers kept a record of their activities and thoughts about their teaching. Supervisors read and responded to these journals on a regular basis. In addition, formal observation of students teachers were followed by a supervisory conference. While the supervisory conferences followed a model of "clinical supervision" (Goldhammer, Anderson, \& Krajewski, 1980, cited in Zeichner \& Liston, 1987, p. 33) with its "emphasis on the 'rational analysis' of classroom instruction" (p. 33), they also included opportunities to raise questions and to discuss not only the technical dimensions of teaching, but also the educational and ethical aspects.

Research on the program. Despite the obvious careful planning underlying the University of Wisconsin program, the positive effects of this reflective practitioner model for elementary student teaching have been weak.

For example, research on the program found that student teachers finished the program with the same perspectives as they had started with: Students who entered with a technical perspective of teaching left with a technical perspective; those who entered with a moral-craft perspective also left with one (Tabachnick \& Zeichner, 1984, cited in Zeichner \& Liston, 1987). Similarly, students who had a humanistic pupil control orientation and those who had a custodial view when they entered also left the program with those views intact (Zeichner \& Grant, 1981, cited in Zeichner \& Liston, 1987). Further, while student teachers in the program were "encouraged to alter curricula to provide for cultural differences and to recognize and rectify the injustices connected to these differences" (Zeichner \& Liston, 1987, p. 37), no evidence was found that they did so.

Research findings on the effect of program components were mixed. While reflective discourse between supervisors and student teachers was noted only $19.6 \%$ of the time (Zeichner \& Liston, 1985, cited in Zeichner \& Liston, 
1987), the seminar was found to successfully provide and encourage reflective communication among students and the seminar leader in most seminar groups (Koskela, 1985, cited in Zeichner \& Liston, 1987). Alternately, the seminar did not positively influence collaboration to resolve issues among students in the seminar.

Zeichner and Liston (1987) concluded that, while it was difficult to overcome many of the factors that constrained the implementation of the reflective practitioner model, many opportunities still remain for faculty to reinforce or change aspects of the program in the future and, thus, to make it a more potent agent in the development of reflective practitioners.

Findings from a similar program. Wedman and Martin's (1991) research of a teacher education program with similar components (teaching, conferences, seminars, action research, and journal writing) reported similar results. Using data collected from the Teacher Belief Inventory, classroom scenarios problems, and student teachers' essays on their philosophical orientation, these researchers found that student teacher beliefs did not change significantly over the 9 weeks of student teaching. In addition, the research showed that student teachers recorded more routine than reflective thought units in their journals and that their problem solving was based mainly on routine thinking. In addition, student teachers became less flexible in their curriculum modifications and less willing to adjust class time for low achievers--findings similar to those found in research of apprenticeship models of student teaching.

However, students' perceptions of many of the program components were positive. Eighteen of the 23 students found that the conference contributed most to their reflective growth and to their understanding of teaching complexity. In addition, they reported that "reflectivity allowed 
student teachers to evaluate and improve their teaching practices independently" (Wedman \& Martin, 1991, p. 39).

\section{Conclusion}

The review of the literature on reflection outlines many important aspects of teaching and learning to teach that are, or can be, supported by reflective processes. First, it characterizes ongoing learning as a necessary requirement of effective teaching: Schon (1983) refers to learning-inpractice as a "theory orientation" (p. 58) that involves using the positive and negative results of teaching as information about the task and the situation and as a starting point in reflective inquiry.

Second, reflection theory and research emphasize the important role reflective thinking plays in learning to teach and in teaching effectively: Reflective thinking is placed as the foundation for developing not only the technical-rational aspects of teaching, but also the hermeneutic-

phenomenological and critical-dialectic aspects. Reflective thinking is needed to teach with skill and artistry (Schon, 1983), to improvise one's knowledge and skills in the moment (Yinger, 1990), to respond to children in a caring way (van Manen, 1995), and to create positive and supportive learning communities (Valli, 1990). Reflective thinking is also needed to expand the number of perspectives one is able to take on teaching situations and events, on one's teaching actions, and on the possible consequences of both (Grimmet et al., 1990).

Third, this review emphasizes, in Dewey's (1966) terms, the importance not only of responding to present stimuli, but also of doing so with a view to control consequences: The theory and research emphasize the proactive and deliberative role that teachers can have in creating a preferred future. 
(Noordhoff \& Kleinfeld, 1990) and the importance of holding distal goals to which one is committed (Dewey, 1966).

Finally, the review of the literature on reflection emphasizes the importance of community in the educative process. Not only does a caring community support students' learning, but it also supports the continuing process of learning to teach and fosters reflective inquiry (Pugach \& Johnson, 1990).

Conclusion to the Review of the Literature

Chapters 2 and 3 have outlined the foundational theory and research required to reconceptualize personal teaching efficacy, as well as necessary school and student teaching conditions supportive of changes in teachers' sense of efficacy.

Chapter 4 outlines the applicable theoretical background and steps taken for the development of a new model and scale of personal teaching efficacy. 


\section{CHAPTER 4 \\ TOWARDS A NEW CONCEPTUALIZATION \\ OF TEACHERS' SENSE OF EFFICACY}

\section{Rationale}

As was pointed out in the introductory chapter of this dissertation, a review of the theory and research underlying teacher efficacy revealed a need to reconceptualize what it means for teachers to feel efficacious. For instance, many researchers (Ashton \& Webb, 1986; Guskey \& Passaro, 1993; Gibson \& Dembo, 1984; Woolfolk \& Hoy, 1990) saw teacher efficacy as highly complex and, therefore, posited it to be a multidimensional construct. In contrast, the model and scale in prevalent use (Gibson \& Dembo, 1984) limit teachers' sense of efficacy to two factors, and according to Kushner (1993), the scale does not fit the data well.

However, the most compelling reason to reconceptualize teachers' sense of efficacy for teaching arose from the disagreement among researchers about the substantive meaning of Gibson and Dembo's (1984) second factor, teaching efficacy. In concert with definitions offered by the RAND studies (see McLaughlin \& Marsh, 1978), by Denham and Michael (1981), and by Ashton and Webb (1986), Gibson and Dembo have proposed that the teaching 
efficacy factor not only represents teachers' perceptions of the efficacy of teachers in general, but is also similar to the response-outcome expectancies discussed in Bandura's (1986) self-efficacy theory. Other researchers have proposed alternate explanations. For example, after their replication study, Guskey and Passaro (1990) posited that the two factors may represent internalexternal locus of control rather than personal and general teaching efficacy, while Woolfolk and Hoy's (1993) studies of the construct led them to conclude that the teaching efficacy factor represents individual teachers' perceptions of their potential to act and, therefore, is related more to efficacy expectancies than to response-outcome expectancies.

In an attempt to resolve these differences, I began a review of the literature on social cognitive theory, turning first to Bandura's (1986) theory underlying self-efficacy and then to the theories underlying other constructs purported to be related to self-efficacy.

\section{The Contribution of Social Cognitive Theory to a New Conceptual Analysis of Teachers' Sense of Efficacy}

Bandura's (1986) social cognitive theory clarified the place and structure of self-percepts of efficacy within the larger system of self-referent thought and provided a conceptual understanding of the role of selfperceptions as mediators between thought and action. The review of this theory and, particularly, the theory and research related to self-efficacy revealed a number of ideas that could be used in a conceptual analysis of teachers' sense of efficacy. 
Self-Efficacy

Bandura (1986) sees self-efficacy perceptions as important mediators between thought and action that arise from assessments of one's capabilities for particular tasks. Also foundational to his self-efficacy theory is the concept of triadic reciprocal causation, which stipulates a reciprocal influence relationship among one's perceptions, one's past and present behaviors, and the particular situation or event. Thus, according to Bandura, self-percepts of efficacy will vary in level, generality, strength, and magnitude, depending not only on one's behavior, but also on the particular situation and the particular domain of functioning.

In comparing Gibson and Dembo's (1984) model to Bandura's (1986) conception of self-efficacy, I found that the personal teaching efficacy factor, defined as the "belief that one has the skills and abilities to bring about student learning" (p. 573), was similar to Bandura's (1984) conception of selfefficacy, defined as "people's judgments of their capabilities to organize and execute course of action required to attain designated types of performances" (p. 391). In addition, a review of the research showed that teachers' sense of efficacy changed for different tasks and across different situations (for example, see Ross, 1994), which fit well with Bandura's concept of self-efficacy as task- and situation-specific. However, the relationship between the Gibson and Dembo's second factor, teaching efficacy, and Bandura's responseoutcome expectancies was less clear.

\section{Response-Outcome Expectancies}

Bandura (1986) clearly differentiates efficacy expectancies from response-outcome expectancies, which he describes as one's perceptions of the resultant consequences and rewards of one's actions, whether completed or uncompleted. He posits that while self-efficacy theory accounts for response-outcome expectancies as one aspect of preaction thought, self- 
efficacy expectancies are more influential in determining one's decision to act and one's subsequent performance. On the surface, Gibson and Dembo's (1984) definition of teaching efficacy as the "belief that any teacher's ability to bring about change is significantly limited by factors external to the teacher such as home environment, family background, and parental influences" (p. 574) appeared somewhat similar to Bandura's conceptions of self-efficacy in its focus on teachers' change capabilities; however, teaching efficacy did not appear to represent rewards and consequences of behavior as delineated in Bandura's definition of response-outcome expectancies.

Bandura (1986) does suggests that, when there is a high contingency between action and outcomes, not only will the impact of self-efficacy and response-outcome expectancies be more equal, but differentiating between the two expectancies will also be more difficult. Given the high contingency between teachers' actions and students' responses, it seemed likely that teachers' outcome expectancies would also be difficult to distinguish from their efficacy expectancies. In addition, because home environment, family background, and parental influence act as confounding variables affecting student responses, it also seemed likely that teachers' perceptions of these influences would have an effect on their sense of efficacy. Unfortunately, even with this broadened perspective, teaching efficacy still did not fit Bandura's definition of response-outcome expectancies.

To further confuse matters, a review of other related research (Maddux, Sherer, \& Rogers, 1982; Schunk, 1996) revealed that many researchers did not use the term "outcomes" as precisely or in the same way as Bandura, adding to the difficulty of discerning the difference between perceptions of possible outcomes and perceptions of efficacy. However, the review of the literature on self-efficacy did point to possible types of efficacy that might underlie teachers' sense of efficacy. 
Types of Self-Efficacy Related to Teaching

The review showed that self-percepts of efficacy have already been identified for a number of tasks, situations, and domains of functioning, some closely related to teaching. For example, operative efficacy, defined by Bandura (1986) as "the generative capability [to] improvise multiple subskills to manage ever changing circumstances, most of which contain ambiguous, unpredictable, and often stress elements" (p. 391), seems particularly salient. Teaching can easily be characterized as a generative task in a dynamic environment. In addition, because teaching is so often fraught with ambiguous, unpredictable, and stressful elements, teachers may also need to possess a sense of coping efficacy--described by Bandura (1989) as selfperceptions of capabilities to "exercise control over potential threats" (p. 419)-or what McCarthy and Newcomb (1992) call behavioral coping ability, which is a more general capability to respond effectively to multiple and unanticipated events or situations. In turn, a sense of efficacy for coping is dependent on the effective use of various self-regulatory capabilities, including capabilities to control one's thoughts, feelings, and behaviors. Assessments of one's capabilities in these areas gives rise to self-percepts of self-regulatory efficacy (Bandura, 1986), which also require thought control efficacy (Bandura, 1986) or what McCarthy and Newcomb (1992) refer to as perceived cognitive control ability.

These various efficacy perceptions appear salient to teachers' sense of efficacy for teaching. In fact, Gibson and Dembo's (1984) teaching efficacy factor appears to be a negative image of coping efficacy. There is a similarity between their definition of teaching efficacy as teachers' perceptions that their "ability to bring about change is significantly limited by factors external to the teacher" (p. 574) and Bandura's (1989) positively stated definition of coping efficacy as self-perceptions of capabilities to "exercise 
control over potential threats" (p. 419). However, while some items in Gibson and Dembo's scale could be construed as related to coping, other types of selfefficacy perceptions related to teaching were either underrepresented in Gibson and Dembo's (1984) two-factor model or not represented at all.

At this stage of my study I felt confident that Gibson and Dembo's (1984) conception of personal teaching efficacy represented teachers' perceptions of their capabilities to enact courses of action related to teaching and, therefore, was highly similar to Bandura's (1986) self-efficacy construct. In addition, there was some evidence that Gibson and Dembo's teaching efficacy factor might better be considered as a type of coping efficacy. However, the roles played by outcome expectancies and other types of efficacy perceptions in influencing teachers' sense of efficacy for teaching were still unclear. Therefore, I began a study of the theory and research of other constructs related to self-efficacy.

\section{Other Constructs Related to Self-Efficacy}

Social cognitive theory provided a conceptual structure for understanding the theories of other psychological constructs purported to mediate between thought and action and postulated to be part of the motivational system, for example, locus of control theory, attribution theory, personal control theory, personal causation theory, achievement motivation theory, and learned helplessness and learned optimism theories.

Mediators between thought and action. These theories are similar to self-efficacy theory and to each other in their identification of a psychological construct that is theoretically situated between thought and action. However, the theories differ in the types of mediator they propose: For example, locus of control and attribution theorists posit that perceived locus of control mediates between thought and action. In the other theories, the mediator is one of the following: self-percepts of efficacy, perceived personal 
control, perceived personal causation, the achievement motive, or the predispositions of learned helplessness or learned optimism. In addition to presuming a mediator between thought and action, these theories also distinguish between internal and external means.

Internal means. All the theories studied concede the presence of internal means that are appraised prior to or during action. For example, locus of control and attribution theorists refer to personal or internal characteristics, such as ability and effort, which affect one's actions and their outcomes. Attribution theory presumes that these internal characteristics include not only ability and effort, but also mood, fatigue, illness, personality, and physical appearance. In addition, Weiner and his colleagues (1971, cited in Stipek \& Weisz, 1981) posit that perceptions of the stability and controllability of these internal means affect performance and outcomes. Skinner's (1992) personal control theory adds a similar set of perceptions called control beliefs, which are defined as "generalized expectancies about the extent to which the self can produce outcomes irrespective of the means involved" (p. 93).

Of particular note is that these theories construe both ability and effort as internal means. The most common assertion by the theorists was that ability is a fixed means and, therefore, not subject to personal control, while effort is changeable and, therefore, controllable. The importance placed on effort for completing actions and attaining outcomes suggests that the deployment of effort is a type of capability. A reanalysis of the items loading on teaching efficacy in Gibson and Dembo's validation showed that, in addition to representing views of external circumstances (home, family), many of the items referred to teacher effort. For example, one item reads: "Even if I try really hard, I will not be able to make a difference with some children." While it is likely that Gibson and Dembo (1984) saw responses to this item as a 
measure of how teachers perceived the constraints of outside forces, it is also probable that teachers might respond in terms of their perceived capability (or willingness) to "try really hard," that is, in terms of their capability to deploy effort.

External means: the role of the environment. While external means are also considered in all theories, the role environment plays in enhancing or constraining action differs across theories. Attribution theorists tend to see person and environment in duality: Control over causes is either external or internal. When individuals perceive the causes of outcomes to be external, they feel little power over results. When the causes of outcomes are perceived as internal, individuals believe they have "the power to produce a desired or intended result" (Funk \& Wagnalls Standard Dictionary, 1983, p. 246), which is the common definition for efficacy.

The power to produce a desired or intended result is also the focus of the theories of personal control, personal causation, learned helplessness and learned optimism, and, from the perspective of self-capabilities, self-efficacy. However, these theories propose a two-way relationship between person and environment, suggesting that an interaction between perceptions of one's capabilities and perceptions of the controllability of the environment or its amenability to change will have an influence on one's actions and the resultant outcomes. They further posit that when individuals have a strong sense that they possess the necessary internal means, the perceived threat of aversive situations and difficult tasks is minimized.

Thus, with the possible exception of the achievement motive, all of the mediating constructs focus on a sense of control. In self-efficacy theory, individuals' perceptions of their capabilities to perform or execute courses of action give them a sense of control. Alternately, in perceived personal control theory, it is perceived control over outcomes gained through engagement with 
the environment that gives a sense of control. Similarly, personal causation theory suggests that individuals with feelings of proactive agency have a sense of control. On the other hand, the importance of individuals' perceptions of the environment's amenability to influence is the focus of learned optimism.

While the differences in perspectives and labels often obscure the relationships among constructs and the differences in research subjects make generalizations across age groups and domains of functioning highly suspect, some researchers (Bandura \& Wood, 1989; Schunk, 1996; Skinner, 1992) have already begun work to consolidate these theories to better understand "the power of perceived control to predict performance in many domains" (Skinner, 1992, p. 40). This work points to usefulness of taking a broader view of efficacious behavior as the power to control events and situations through internal and external means.

By applying this broader view of efficacy to teachers' sense of efficacy, I posited that both factors in Gibson and Dembo's (1984) teacher efficacy could be conceptualized from a personal perspective. Personal teaching efficacy would continue to be delineated by individual teachers' perceptions of their teaching capabilities, while the conception of teaching efficacy would shift from a focus on teachers' perceptions of the constraints of external forces to a focus on teachers' self-percepts of their own sense of control over external factors.

Thus, two aspects of teachers' sense of their own efficacy were emerging. One aspect, self-percepts of teachers' capability to teach effectively, aligned with Gibson and Dembo's (1984) personal teaching efficacy. The second aspect seemed to be related to either a sense of coping or a sense of control, or both. Therefore, to further inform my conceptual analysis of teachers' sense of efficacy for teaching, I turned to Bandura's 
conception of occupational efficacy and Wood and Bandura's (1989) work on managerial efficacy.

\section{Occupation Efficacy}

As previously stated, Bandura's (1986) self-efficacy theory posits that one may hold self-percepts of efficacy for a domain of activity; occupations and the occupational role represent one such domain. Wood and Bandura (1989) have explored the occupational role of manager in relation to selfpercepts of efficacy. From their research, they conclude that, to fulfill most occupational roles, individuals must complete multiple, ongoing tasks that lead to both proximal and distal goals. In addition, they must do so within dynamic and often unpredictable socially mediated environments, which further require ongoing interactions with people and generative responses to changing situations and circumstances.

Thus, to fulfill ongoing role demands and organizational goals in an occupational setting, individuals need positive perceptions not only of their capabilities for a wide variety of tasks (including their work with others), but also of their capabilities to improvise the use of their knowledge and skills and to "activate and sustain cognitions, behaviors and affects" (Schunk, 1994, p. 75) which will serve them over the long term. Bandura and Wood (1989) suggest that these capabilities were enhanced when managers saw ability as a malleable state, that is, when they were confident they could learn the predictive rules that operated with the ever-changing circumstances of the organization. As a result of the interplay of various types of efficacy, as well as beliefs about ability and the controllability of the environment, Bandura and Wood conceptualize managerial efficacy as a self-schema of all these selfperceptions that are developed and maintained over time.

Similarly, the role of teacher also requires a complex array of capabilities to perform a wide variety of tasks within the classroom and within 
the school, district, and community. This wide range of capabilities includes not only the effective use of discrete knowledge and skills related to teaching, but also the capability to improvise their use. Further, teachers also need to be able to "activate and sustain [the] cognitions, behaviors and affects" (Schunk, 1994, p. 75) to fulfill ongoing role demands and organizational goals across many contexts and situations. In other words, they must also have capabilities to cope, particularly when situations are not optimal and maintaining a sense of efficacy in the face of obstacles, setbacks, and failures is difficult. Finally, teachers must believe that, through their own efforts, they can have an impact on people, situations, and events within the classroom and the larger context or that they can learn to do so.

Bandura and Wood's (1989) study of managers revealed the complex interrelationship of factors that determined self-percepts of efficacy within an occupational setting and introduced the idea of a self-schema of efficacy, composed of self-beliefs and different types of self-percepts of efficacy. As a result I began to reconceptualize teachers' sense of efficacy as a self-schema of efficacy for teaching which would include teachers' self-percepts not only of their teaching skills and ability, but also of their capabilities to cope with and influence environmental conditions in the classroom and school and at home.

The Development of a New Model and Scale of Personal Teaching Efficacy

\section{A Tentative Model of \\ Personal Teaching Efficacy}

As a result of the review of the literature on social cognitive theory, I began to reconceptualize teachers' sense of efficacy, focusing on teachers' 
perceptions of their own capabilities to teach effectively. I reasoned that teachers' assessments of their own effectiveness--personal teaching efficacy-would take into account not only their teaching skills and ability, but also other capabilities required by the occupation of teaching, including their capabilities to cope with and influence environmental conditions in the classroom and school and at home. In fact, many researchers suggest that it is only in the face of obstacles, difficulties, or aversive conditions that people use self-percepts of their potential for performance or goal attainments in deciding whether or not to act (Bandura, 1986; Corno \& Kanfer, 1993; Skinner, 1992). Furthermore, the dynamic, socially mediated nature of the context of teaching suggests that teachers will often be faced with complex and sometimes aversive conditions that could impede their capability to teach effectively. These conditions will require teachers not only to make assessments about their potential to act effectively and to improvise their responses, but also to call on additional capabilities in order to either influence circumstances or find a way to act. Therefore, I hypothesized that the factors underlying personal teaching efficacy could be classified as either teaching performance efficacy (Gibson and Dembo's personal teaching efficacy) or teacher control efficacy (see Figure 6). Teaching Performance Efficacy

In keeping with Gibson and Dembo's (1984) personal teaching efficacy factor and Bandura's (1986) theoretical definition of self-efficacy, teaching performance efficacy was proposed to represent individual teachers' perceptions of their capabilities to "execute courses of action" (Bandura, 1986, p. 391) required to fulfill their teaching role. Two factors were hypothesized to delineate a sense of teaching performance efficacy: (a) an instructional efficacy factor encompassing the capabilities required for effective instruction and successful student learning and (b) a classroom management 
Figure 6

First Proposed Model of Personal Teaching Efficacy

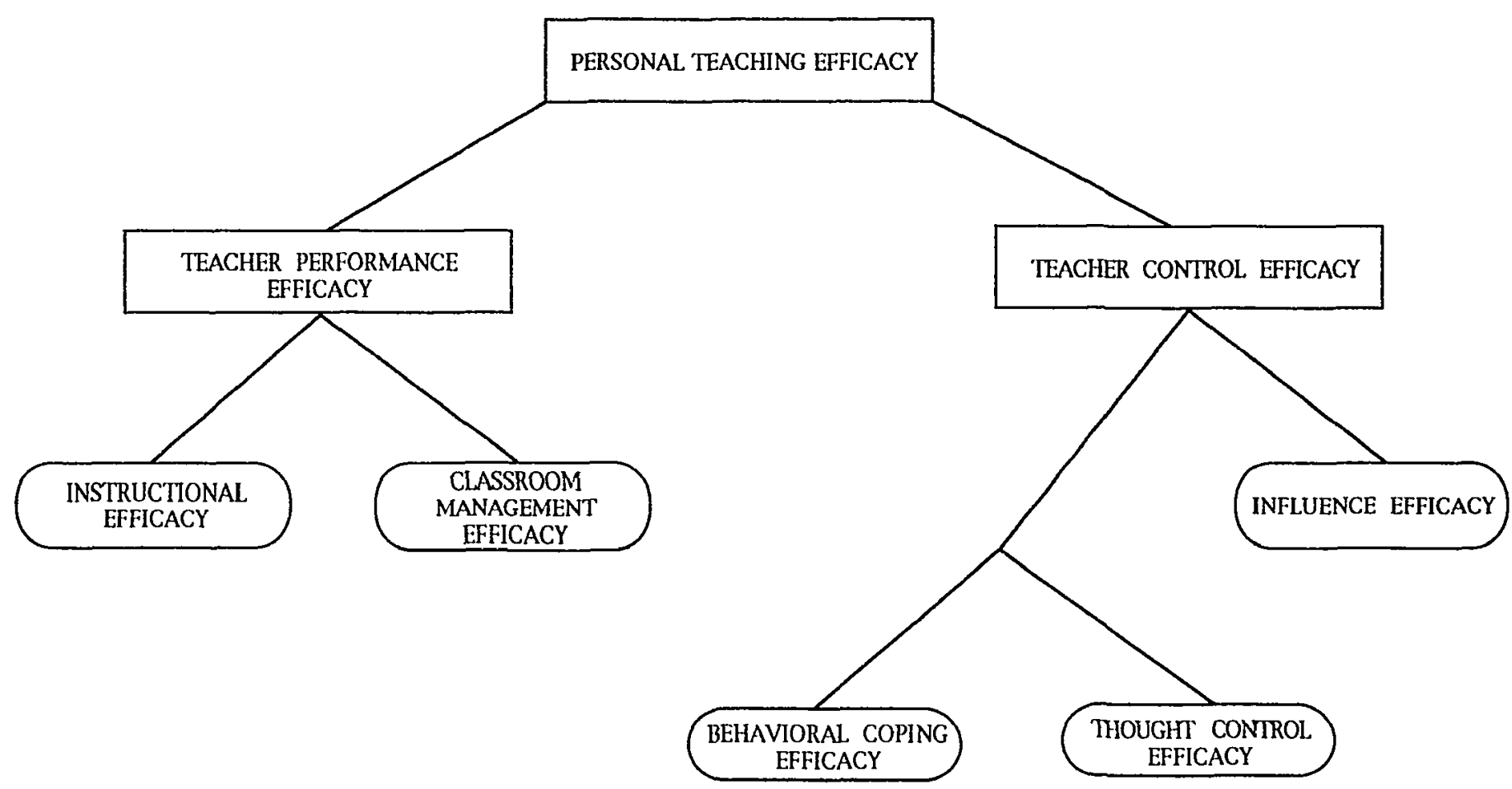


efficacy factor encompassing capabilities required for setting a classroom environment conducive to learning and for effectively managing and disciplining students.

\section{Teacher Control Efficacy}

Teacher control efficacy was hypothesized to represent individual teachers' perceptions of their potential to act effectively given the present circumstances within the classroom and school, as well as circumstances outside the school such as parents, family background, and home environment. While this moves substantively away from Gibson and Dembo's teaching efficacy factor, a close analysis of the items loading on this factor could be interpreted to represent individual teachers' sense of their capabilities to influence students even in the face of external impediments. In addition, it relates to Bandura's (1989) conception of coping efficacy and McCarthy and Newcomb's (1992) conception of perceived behavioral control, as well as Skinner's (1992) conception of perceived personal control and various other researchers' conception of self-regulation (for example, see Schunk, 1994, 1996; Zimmerman, 1994).

Three factors were hypothesized to delineate teacher control efficacy. In keeping with Wood and Bandura's (1989a, 1989b) research on managerial efficacy, one factor, influence efficacy, represented individual teachers' perceptions of their capabilities--or, perhaps, capacity-to influence circumstances (people, places, things) within and outside the school. Influence efficacy included individual teachers' perceptions of their potential to influence and change people and events, based on perceptions of the environment, perceptions of their personal capabilities, and the interaction effect of these perceptions.

The other two factors delineating teacher control efficacy were the two aspects of coping efficacy outlined by McCarthy and Newcomb (1992), thought 
control efficacy (also see Bandura, 1986) and behavioral coping efficacy. Thought control efficacy was related to teachers' perceptions of their capabilities to control their thoughts and feelings in the face of obstacles and distressing situations. On the other hand, behavioral coping efficacy related to teachers' perceptions of their capabilities to expend effort to increase their effectiveness. Teachers' efforts to learn how to manage student behavior and enhance student learning were part of this factor. Wood and Bandura (1989a, 1989b) infer behavioral coping when they refer to learning the predictive rules that underlie compiex, socially mediated organizations; however, construing effort as a capability--and therefore as information for the development of self-percepts of efficacy--moves away from self-efficacy theory. Bandura (1986) usually conceives effort as a by-product of positive self-percepts of efficacy. In contrast, I reasoned that the active response to tasks, situations, and events that characterizes effective teachers is the result of positive assessments of their potential to act, based on strong self-percepts of their capabilities to expend effort.

With a model in mind, I was ready to design a new Personal Teaching Efficacy Scale.

\section{Developing a New Personal Teaching Efficacy Scale}

In order to prepare items for a new Personal Teaching Efficacy Scale, a number of decisions had to be made related to the syntax and content of the items. I used the two Rand items (McLaughlin \& Marsh, 1978) and items from the Gibson and Dembo (1984) and Woolfolk and Hoy (1990) scales as a starting point and guide. These are referred to as the "combined scales" in the discussion that follows. In addition, I referenced teacher efficacy theory, selfefficacy theory, and the theory of other constructs related to self-efficacy to revise items from the combined scales and to build new items. The following 
discussion outlines the first set of key decisions made in developing a new scale.

Decision 1: To Incorporate Items From the

Combined Scales Into the New Personal Teaching

Efficacy Scale, With All Items Stated in the Personal (I)

In addition to new items, most items from the combined scales were incorporated into the new scale. However, the proposed new model focused on teachers' perceptions of their own personal teaching efficacy, and in order for the scale to be representative of the new model, all scale items would necessarily be in the first person, "I." Therefore, items from the combined scales were rewritten to reflect a personal ("I") perspective; some were also revised to clearly reflect only one idea.

Decision 2: To Expand the Number of Items to

Represent the Full Range of Teachers' Role-Specific Capabilities

Smylie (1990) proposes the "possibility that teachers possess different senses of efficacy that operate in different ways in relation to different dimensions of their work" (p. 62). However, after a perusal of the items in the combined scales, I concluded that the items did not represent the full range of teachers' role-specific tasks, duties, and responsibilities; nor did they provide "adequate coverage of the semantic space" (Marradi, 1981, p. 25). Therefore, I expanded the number and type of role-specific tasks, duties, and responsibilities accounted for by the items to more adequately represent the teaching role.

\section{Decision 3: To Retain Items From the Combined}

\section{Scales Related to Coping and to Add Additional Items}

Given my new interpretation of Gibson and Dembo's teaching efficacy factor as representing individual teachers' sense of their potential to act 
given the circumstances in the classroom and school and at home, I retained items from the combined scales related to coping and added additional items, including items related to Bandura's (1989) and McCarthy and Newcomb's (1992) conception of thought control efficacy, to better reflect the coping response.

The scale items were organized into two main parts: Part 1 contained items purported to relate to teaching performance efficacy, while Part 2 contained items purported to relate to teacher control efficacy.

\section{Part 1 of the Personal Teaching Efficacy Scale: Teaching Performance Efficacy}

The items in Part 1 each represented tasks and activities common to teaching. Teachers and student teachers were asked to first consider their current teaching assignments and activities over the past week. They were then asked to respond to the 20 statements related to various teaching tasks by assessing their present confidence in their ability to perform each, using a 5point Likert scale ranging from "not confident at all" to "completely confident." I reasoned that a profile of a teacher's responses to the 20 items would also provide evidence of the magnitude (Locke, Frederick, Lee, \& Bobko, 1984) of his or her sense of teaching performance efficacy.

The items in Part 1 taken from the combined scales were modified so that they represented the personal ("I") perspective and contained only one main idea. The construction of additional items was guided by my own teaching experience and by three sources from the literature: Alberta Education's (1996) list of 11 "quality teaching" competencies and related knowledge, skills, and attributes (see Table 2); Hudgins' (1988, cited in Cone \& Hudgins, 1989) six elements of effective teaching (see Table 3); and Evans and 
Table 2

\section{Quality Teaching Competencies and}

\section{Knowledge, Skills, and Atributes ${ }^{a}$}

1. Teachers' application of pedagogical knowledge and skills is based on their ongoing analysis of contextual variables.

2. Teachers understand the legislated, moral, and ethical frameworks within which they work.

3. Teachers understand the subject disciplines they teach.

4. Teachers know there are many approaches to teaching and learning.

5. Teachers engage in a range of planning activities.

6. Teachers create and maintain environments that are conducive to student learning.

7. Teachers translate curriculum content and objectives into meaningful learning activities.

8. Teachers apply a variety of technologies to meet students' learning needs.

9. Teachers gather and use information about students' learning needs and progress.

10. Teachers establish and maintain partnerships among school, home, and community, and within their own schools.

11. Teachers are career-long learners.

a from Alberta Education (1996). 
Table 3

Six Elements of Effective Teaching ${ }^{2}$

Element

Description

Classroom Climate

Questioning

Set Induction

Stimulus Variation

Reinforcement

Closure
The learning environment: physical arrangement, psychological climate, enthusiasm, task orientation, classroom management, discipline.

The level and type of inquiry: explicit or implied, used to ascertain mastery of objectives/tasks/ applications. Includes responses posed by students.

The preparation of the student's anticipatory set or activities that precede a learning task to set expectations and spark motivation; introductory remarks.

The use of a variety of instructional materials (media) and techniques; changing stimuli to achieve higher attention levels and lessen learner boredom. Variety.

The act performed to bring about heightened involvement by the learner through positive verbal and nonverbal reinforcement and enthusiasm. Acknowledgement of responses.

The summation of important points in the lesson. Reassurance that intended objectives were achieved; reemphasis of highlights of the lesson; elicitation of feedback from students. Completion of the lesson. Methods of evaluation.

a from Hudgins (1988, cited in Cone \& Hudgins, 1989). 
Tribble's (1986) list of teaching problems (see Table 4). The use of Evans and Tribble's list of teaching problems helped to assure that the difficult aspects of teaching were represented on the scale. All items began with one of the following sentence stems: "I can . ..," "I am able ...," or "I know. . . ."

Of the 20 items in Part 1 of the scale, 15 were hypothesized to load on the instructional efficacy factor: 7 items focused on students at the class or group level, 4 items focused on individual students, 3 focused on generic teaching skill items, and 1 item focused on encouraging parent support. The last 5 items of Part 1 were hypothesized to load on the classroom management efficacy factor: 3 of the items related to group management, 1 item was related to one specific student, and 1 item was a generic classroom management skill.

\section{Part 2 of the Personal Teaching Efficacy Scale:}

\section{Control Efficacy}

Items in Part 2 represented teachers' possible cognitive, affective, and behavioral responses to a variety of common teaching activities and situations. In the second part of the scale, teachers and student teachers were again asked to consider their current situation and, then, to assess the degree of their agreement with each of the item statements using a 5-point Likert scale, which ranged from "do not agree at all" to "always agree." Because many student teachers would not yet have encountered some of the teaching situations referred to in the scale, the student teacher form of the scale asked them to respond with their current beliefs about the ways things were in schools. Both teachers and student teachers had an opportunity to write "NA" if the item was not applicable to them. Items with "NA" responses were not used in subsequent factor analyses. 
Table 4

Comparative Rankings of Teaching-Problem Seriousness

by Preservice and Beginning Teachers ${ }^{a}$

\begin{tabular}{lcc}
\hline \multicolumn{1}{c}{ Problems } & $\begin{array}{c}\text { Beginning } \\
\text { teachers' } \\
\text { rank }^{\mathrm{a}}\end{array}$ & $\begin{array}{c}\text { Preservice } \\
\text { teachers' } \\
\text { rank }^{\mathrm{b}}\end{array}$ \\
\hline Classroom discipline & 1.0 & 8.0 \\
Motivating students & 2.0 & 1.0 \\
Dealing with problems of individual learners & 3.0 & 5.0 \\
Assessing students' work & 4.5 & 11.5 \\
Relations with parents & 4.5 & 11.5 \\
Organization of class work & 6.5 & 4.0 \\
Insufficient materials and supplies & 6.5 & 13.0 \\
Dealing with problems of individual students & 8.0 & 2.0 \\
Heavy teaching load; inadequate preparation time & 9.0 & 18.0 \\
Relations with colleagues & 10.0 & 14.0 \\
Planning lessons and school days & 11.0 & 10.0 \\
Effective use of different teaching methods & 12.0 & 7.0 \\
Knowledge of subject matter & 16.0 & 3.0 \\
Awareness of school policies and rules & 13.0 & -- \\
Determining learning level of students & 14.0 & -- \\
Burden of clerical work & 16.0 & - \\
Relations with administrators & 16.0 & -- \\
Inadequate school equipment & 18.0 & -- \\
Opportunity for personal growth & -- & 6.0 \\
Adequate salary & -- & 9.0 \\
Community recognition as a professional & -- & 15.0 \\
Being accepted by students & -- & 16.0 \\
Opportunity to improve the system & -- & 17.0 \\
\hline
\end{tabular}

a from Evans, E. D., \& Tribble, M. (1986). 
Sentence stems in Part 2 did not follow a consistent pattern. However, items reflected possible thoughts, feelings, and behaviors of teachers. Respective examples are as follows: "It is worth the effort to try to get through to all students" (Item 21), "I worry that I am not an effective teacher" (Item 28), and "I take opportunities to work with other teachers and staff in order to help my students learn" (Item 48).

Of the 34 items in Part 2, 11 were hypothesized to load on behavioral coping efficacy, 8 were hypothesized to load on thought control efficacy, and 15 on influence efficacy. The items hypothesized to load on behavioral coping efficacy were related to teachers' effort expenditure and to their propensity to improve or learn in order to be more effective. These items often suggested a proactive deployment of effort or a belief in the efficacy of effort, in keeping with McCarthy and Newcomb's (1992) concept of behavioral coping and Skinner's (1992) concept of personal control. The items representing thought control efficacy were related to risk-taking, resilience in the face of obstacles or aversive situations, and self-focused or negative thoughts. Finally, the items hypothesized to load on influence efficacy were related to making a difference and to teachers' ability to influence either contextual conditions or student learning and behavior.

\section{The Pilot Study}

A small pilot study was conducted to establish the face and content validity of the scale and to get a sense of how well the data fit the tentative model. A group of teachers ( $\underline{n}=45)$ currently teaching in Grande Prairie, Alberta, completed the 54-item Personal Teaching Efficacy Scale and were asked to offer suggestions for rewording items and to comment on how well the items described teachers' work. 


\section{Demographic Data}

Tables 5 and 6 outline the age, years of teaching experience, gender, and past practicum experience of the pilot sample. While small, the sample is fairly representative of the population of elementary teachers in Alberta, Canada: Teachers' ages ranged from 24 to 54 and their years of teaching experience, from 2 to 30 years. In addition, the unequal number of males (33.3\%) and females (66.6\%) reflects a similar unequal distribution of males and females in elementary schools in Alberta.

Information From Teachers and

the Descriptive Statistics

Verbal comments from several teachers in the pilot study confirmed that the scale items accurately reflected the thoughts, feelings, and behaviors of teachers.

In addition, input provided by the pilot teachers and an examination of the descriptive statistics generated from the pilot scale data led to changes in the scale: Four items were revised to be more specific, three items were eliminated, and two new items were added. Fifty-three items made up the final draft of the scale.

The descriptive statistics also revealed that the teachers' responses were negatively skewed: $79 \%$ of mean teacher responses to all items of the scale were between 3.5 and 4.5 on a 5-point Likert scale, suggesting a nonnormal distribution. While nonnormal distributions can create Type I and Type II errors when some statistical tests are used (Glass \& Hopkins, 1984), given the penchant of large sample data to approach the mean, I anticipated that the larger samples of teachers and student teachers in the main study would yield a more normal distribution of responses. 
Table 5

Descriptive Statistics for Teacher Sample of the Pilot Study:

Demographic Variables of Age and Teaching Experience

\begin{tabular}{ccccc}
\hline Variable & $\begin{array}{c}\text { Mean } \\
\text { (in Years) }\end{array}$ & $\begin{array}{c}\text { Median } \\
\text { (in Years) }\end{array}$ & $\begin{array}{c}\text { Mode } \\
\text { (in Years) }\end{array}$ & $\mathbf{n}$ \\
\hline $\begin{array}{c}\text { Age } \\
\text { Teaching } \\
\text { Experience }\end{array}$ & 37.4 & 41.5 & 42 & 42 \\
\hline
\end{tabular}

Table 6

Descriptive Statistics for Teacher Sample of the Pilot Studv:

Demographic Variables of Gender and Past Practicum Experience

\begin{tabular}{llcl}
\hline Variables & Response & Frequency & $\%$ \\
\hline Gender & Male & 15 & 33.3 \\
& Female & 30 & 66.6 \\
& Missing & 0 & \\
Past Practicum & $\underline{n}$ & 45 & 100.0 \\
Experience & & & \\
& "Yes" & 35 & 77.8 \\
& "No" & 10 & 22.2 \\
& Missing & 0 & 100.0 \\
\hline
\end{tabular}


Factor Analysis of the

Pilot Study Data

I conducted factor analyses of the two parts of the scale and the full scale using principal components extraction methods and both varimax (orthogonal) and oblimin (oblique) rotations (see Norusis, 1990a). Factor analyses of Part 2 and the full scale yielded a warning that the matrix was illconditioned: An ill-conditioned matrix is the result of some eigenvalues of the scaled, uncentered cross-products matrix being much larger than others (Norusis, 1990a). This was later corrected in the factor analyses of the large study.

The factor analyses yielded 6 factors for Part 1 of the scale, 9 factors for Part 2 of the scale, and 13 factors for the full scale, revealing personal teaching efficacy as a much more complex phenomenon than my hypothesized 5-factor model. While factors representing instructional efficacy, classroom management efficacy, influence efficacy, and thought control efficacy were somewhat discernible using the full scale, many of the items hypothesized to load together, in fact, did not.

Small sample size. One reason for the large number of factors and their lack of fit with the model was hypothesized to be the effect of using a small sample. For example, Kass and Tinsley (1979, cited in Tinsley \& Tinsley, 1987) suggest that an adequate sample size for factor analysis should represent 5 to 10 respondents for every item of the scale. Using Kass and Tinsley's estimates, a valid factor analysis of the 54-item Personal Teaching Efficacy Scale would require between 270 and 540 respondents.

Alternately, Arrindell and van der Ende (1985, cited in Tinsley \& Tinsley, 1987) found that as few as 1.3 respondents per item on a 76-item scale and 3.5 respondents per item on a 20 -item scale were adequate to yield stable factors, if the number of factors can be estimated. Using Arrindell and van 
der Ende's estimates, a 54-item scale would require from 70 to 189 respondents in order to conduct valid factor analyses. I anticipated that the final samples of teachers and student teachers would each be greater than 70 and might approach 189 respondents; hence, I put off further factor analyses until the data from the main study could be used.

Relationship of items to the construct of personal teaching efficacy. A second explanation for why the factors did not conform to the hypothesized model might be that the items themselves did not represent the personal teaching efficacy construct. A careful perusal of the items in the scale revealed that seven of the items (previously hypothesized to load on either behavioral control efficacy or influence efficacy) were more likely indicators of school context conditions, rather than indicators of personal teaching efficacy. These items were left in the scale, but were omitted from subsequent analyses of personal teaching efficacy items and factor analyses.

Statistical tests confirming the appropriateness of the pilot data for factor analysis. The Bartlett Test of Sphericity, the Anti-Image Correlation Matrix (AIC), and the Reproduced Correlation Matrix (REPR) could not be calculated from the pilot data of the full scale. However, the Kaiser-MeyerOlkin Measure of Sampling Adequacy (KMO) yielded a final statistic of .71721 for the full scale, which Kaiser (1974, cited in Norusis, 1990a) describes as signalling "middling" appropriateness for factor analysis (p. 317). The small sample size was determined to be at least one cause of the Bartlett test's, the AIC test's, and the REPR test's failure to compute, while the KMO statistic suggested that further factor analyses using larger samples could be valid. Therefore, the scale, with revisions, was retained for further study. Final Personal Teaching Efficacy Scale

The revised Personal Teaching Efficacy Scale contained 53 items (see Appendix A). However, because 7 of the items had been identified as context 
variables, the total number of items used to measure the personal teaching efficacy of teachers and student teachers in the main study was initially 46.

\author{
Preliminary Results From the Factor Analyses \\ of Teacher and Student Teacher Data \\ Using the Personal Teaching Efficacy Scale
}

The 53-item revised scale was administered to teachers and student teachers at the beginning and end of the final elementary student teaching experience of the University of Alberta's Bachelor of Education program. Columns 3 and 4 of Table 7 show the total number of teachers and student teachers who completed the pretest and posttest of the Personal Teaching Efficacy Scale.

\title{
Preliminary Factor Analyses
}

After data entry, I conducted exploratory factor analyses of the teachers' and student teachers' pretest and posttest data using principal components extraction methods and both varimax and oblimin rotations. The seven items previously designated as context variables were not included as items in the analyses. I used the default settings of the SPSS program for this and all subsequent factor analyses. SPSS uses a default setting of 1.0000 for initial communalities and an eigenvalue of greater than 1.000 to determine the number of factors that will be extracted (Norusis, 1990). While the Kaiser criterion (i.e., eigenvalues greater than 1.000) was designed for use in alpha factor analysis, Tinsley and Tinsley (1987) note that "it may [also] be helpful in establishing the lower bound [of factors] when used with other factor extraction methods" (p. 420). 
Table 7

Number of Teachers and Student Teachers Completing

the Pretest and Posttest Administration of

the Personal Teaching Efficacy Scale

\begin{tabular}{|c|c|c|c|c|}
\hline \multirow[b]{2}{*}{ Respondents } & \multicolumn{4}{|c|}{$\begin{array}{l}\text { Number of Participant Cases and } \\
\text { Percentage of the Population of Interest }\end{array}$} \\
\hline & $\begin{array}{l}\text { Population } \\
\text { Cases }\end{array}$ & $\begin{array}{l}\text { Pretest } \\
\text { Cases }\end{array}$ & $\begin{array}{l}\text { Posttest } \\
\text { Cases }\end{array}$ & $\begin{array}{l}\text { Matched } \\
\text { Cases }\end{array}$ \\
\hline Teachers & 467 & $\begin{array}{l}105 \\
22.5\end{array}$ & $\begin{array}{l}93 \\
19.9\end{array}$ & $\begin{array}{l}86 \\
18.4\end{array}$ \\
\hline Student Teachers & 236 & $\begin{array}{l}165 \\
69.9\end{array}$ & $\begin{array}{l}102 \\
43.2\end{array}$ & $\begin{array}{l}94 \\
39.8\end{array}$ \\
\hline
\end{tabular}




\section{Test Statistics}

When data from all respondents (cases) were used, the test statistics confirm the appropriateness of using factor analysis (see Table 8): Table 8 shows that the KMO statistic indicates "middling" appropriateness of the data for factor analysis (Kaiser, 1974, cited in Norusis, 1990a, p. 317) for each of the four administrations of the scale. In addition, the Bartlett value is large, with a low significance level, and the proportion of large coefficients on the AIC is low, both indicating that the factor model can be used (Norusis, 1990). Finally, the number of residuals on the REPR is small (see Table 8), indicating that the model fits the data and factor analysis is appropriate (Norusis, 1990a).

\section{Factor Loadings}

The number of factors extracted varied across the four factor analyses of teacher pretest data, teacher posttest data, student teacher pretest data, and student teacher posttest data (see Table 9 and the column headed All Cases--46 items).

Eigenvalues. Table 10 displays the eigenvalues and percentages of the total variance attributed to factors extracted from each of the four sets of data. An eigenvalue represents the total variance explained by a factor (Norusis 1990a). As Table 10 shows, the cumulative percentage of total variance accounted for by the factors ranges from $69.8 \%$ to $74.3 \%$ across the four data sets.

Of special note is the comparatively high eigenvalues and percentages of total variance allocated to Factor 1 in all four factor analyses. These high eigenvalues were present after extraction and, again, after rotation. In all four data sets, the rotated factor could be identified as the instruction efficacy factor. Kim and Mueller (1985) point out that "in initial factoring [before rotation], the magnitude of descending values of eigenvalues tells us 
Table 8

All Teacher and Student Teacher Cases: Statistical Tests for the

Appropriateness of Factor Analysis of 46 Personal Teaching Efficacy

Variables Using Pretest and Posttest Data

\begin{tabular}{|c|c|c|c|c|}
\hline Test & $\begin{array}{c}\text { Teacher } \\
\text { Pretest } \\
\text { Statistic }\end{array}$ & $\begin{array}{l}\text { Teacher } \\
\text { Posttest } \\
\text { Statistic }\end{array}$ & $\begin{array}{c}\text { Student Teacher } \\
\text { Pretest } \\
\text { Statistic }\end{array}$ & $\begin{array}{c}\text { Student Teacher } \\
\text { Posttest } \\
\text { Statistic }\end{array}$ \\
\hline $\begin{array}{l}\text { Kaiser-Meyer-Olkin Measure of } \\
\text { Sampling Adequacy (KMO) }\end{array}$ & .74149 & .72453 & .72413 & .72540 \\
\hline Bartlett Test of Sphericity & 2190.4559 & 2350.6369 & 2103.9811 & 2156.3173 \\
\hline Significance $=$ & .00000 & .00000 & .00000 & .00000 \\
\hline $\begin{array}{c}\text { Anti-Image Correlation Matrix (AIC) } \\
\text { Off-Diagonal Elements }>0.09\end{array}$ & 122 & 64 & 186 & 74 \\
\hline & $5.9 \%$ & $3.1 \%$ & $9.0 \%$ & $3.6 \%$ \\
\hline $\begin{array}{r}\text { Reproduced Correlation Matrix (REPR) } \\
\text { Residuals (Above Diagonal) }>0.05\end{array}$ & $\begin{array}{l}246 \\
23.0 \%\end{array}$ & $\begin{array}{l}217 \\
20.0 \%\end{array}$ & $\begin{array}{l}256 \\
24.0 \%\end{array}$ & $\begin{array}{l}243 \\
23.0 \%\end{array}$ \\
\hline
\end{tabular}


Table 9

Number of Factors Extracted From Teacher and

Student Teacher Pretest and Posttest Data from

Various Forms of the Personal Teaching Efficacy Scale

\begin{tabular}{lccc}
\hline & \multicolumn{3}{c}{ Number of Factors } \\
\cline { 2 - 4 } $\begin{array}{c}\text { Scale } \\
\text { Administration }\end{array}$ & All Cases & \multicolumn{2}{c}{ Matched Cases } \\
\cline { 2 - 4 } & 46 items & 46 items & 31 items \\
Teacher Pretest & 13 & 13 & 10 \\
Teacher Posttest & 13 & 14 & 9 \\
Student Teacher Pretest & 14 & 11 & 9 \\
Student Teacher Posttest & 14 & & \\
\hline
\end{tabular}


Table 10

All Cases Data: Eigenvalues and Percentages of Variance Accounted for by the Factors

Across Four Administrations of the 46-Item Personal Teaching Efficacy Scale

\begin{tabular}{|c|c|c|c|c|c|c|c|c|}
\hline & \multicolumn{2}{|c|}{$\begin{array}{l}\text { Teacher } \\
\text { Pretest }\end{array}$} & \multicolumn{2}{|c|}{$\begin{array}{l}\text { Teacher } \\
\text { Posttest }\end{array}$} & \multicolumn{2}{|c|}{$\begin{array}{l}\text { Student } \\
\text { Teacher } \\
\text { Pretest }\end{array}$} & \multicolumn{2}{|c|}{$\begin{array}{l}\text { Student } \\
\text { Teacher } \\
\text { Posttest }\end{array}$} \\
\hline Factor & Eigenvalue & $\begin{array}{c}\% \\
\text { Variance }\end{array}$ & Eigenvalue & $\begin{array}{c}\% \\
\text { Variance }\end{array}$ & Eigenvalue & $\begin{array}{c}\% \\
\text { Variance }\end{array}$ & Eigenvalue & $\begin{array}{c}\% \\
\text { Variance }\end{array}$ \\
\hline 1 & 12.12625 & 26.4 & 13.95498 & 30.3 & 9.95182 & 21.6 & 12.63120 & 27.5 \\
\hline 2 & 2.80669 & 6.1 & 2.97479 & 6.5 & 3.85504 & 8.4 & 4.17851 & 9.1 \\
\hline 3 & 2.51586 & 5.5 & 2.53937 & 5.5 & 2.38195 & 5.2 & 2.75468 & 6.0 \\
\hline 4 & 2.23505 & 4.9 & 2.03340 & 4.4 & 1.095136 & 4.2 & 2.25902 & 4.9 \\
\hline 5 & 2.16138 & 4.7 & 1.92411 & 4.2 & 1.82915 & 4.0 & 1.96621 & 4.3 \\
\hline 6 & 1.76315 & 3.8 & 1.79838 & 3.9 & 1.69644 & 3.7 & 1.74030 & 3.8 \\
\hline 7 & 1.56739 & 3.4 & 1.65997 & 3.6 & 1.62993 & 3.5 & 1.55163 & 3.4 \\
\hline
\end{tabular}


something about the relative importance of each factor" (p. 77). This suggests that the instruction efficacy factor is highly important to personal teaching efficacy, which is not surprising. However, high eigenvalues are also known to occur when there are more items loading on one factor than on others. In addition, Marradi (1981) points out that several items with similar syntactic structure "maximize the probability of their clustering together" (p. 31).

Number of factors. The number of factors derived from the factor analyses of the pretests and posttests of teachers and student teachers remained large (see Table 9), despite the removal of the seven "context" items and the use of sample sizes much larger than the pilot study sample. However, while the number of factors did not fit the hypothesized model of five factors, four hypothesized factors were discernible in the factor loadings across two or more of the factor analyses.

As stated previously, the instructional efficacy factor was present in all four factor analyses and was the most stable factor; however, the number and type of items loading on this factor changed somewhat across tests. The classroom management efficacy factor was also clearly discernible in all factor analyses except the teacher posttest. However, the items loading on the classroom management efficacy factor also changed from factor analysis to factor analysis. Next, the thought control efficacy factor was also discernible, but items hypothesized to load on this factor often formed additional factors and loaded with items that were difficult to explain as part of thought control. Finally, the influence efficacy factor was somewhat present in the teacher pretest and posttest but contained only one of the hypothesized variables (the influence of the home environment). The substantive meaning underlying the remaining nine factors was not immediately discernible. Appendices $B$ through $\mathrm{E}$ show the factor loadings for the teacher pretest, teacher posttest, 
student teacher pretest, and student teacher posttest, respectively, using the 46-item scale and data from all respondents.

\section{A Return to the Literature}

The results of the preliminary factor analyses strongly suggested a need for a further conceptual analysis of personal teaching efficacy. To that end, I put aside further factor analyses and interpretation and began another review of the literature. A continued focus on self-referent thought led me to volitional theory and other constructs related to volition and provided a new perspective on personal teaching efficacy.

The Contribution of Volitional Theory and Other Related Theories to the Conceptual Analysis of Personal Teaching Efficacy

Volitional theory, and the theories related to it, introduced a new perspective from which to complete the conceptual analysis of personal teaching efficacy. Together they clarified what it means to be efficacious in organizational settings such as teaching, promoting my understanding of the teaching role and of the ways that self-percepts of personal teaching efficacy are formed and maintained over the long term.

\section{Volitional Theory}

In volitional theory, motivational concerns are the subject of preaction thought and volitional concerns are the subject of in-action thought: As Corno (1994) points out, "motivation denotes commitment and volition denotes follow through" (p. 230). Self-efficacy has typically been conceptualized from a motivational perspective. From this perspective, self-percepts of personal teaching efficacy, particularly those based on one's teaching performance capabilities, inform motivational decisions about whether or not to act, with 
self-appraisals of efficacy influencing how much effort is applied to teaching tasks and for how long.

However, the ongoing and long-term nature of the teaching role and its multiple teaching goals put motivational concerns about whether or not to act rarely in question; rather, volitional concerns about what one will do, when one will do it, and in what situations become more predominant. In addition, volitional theory emphasizes that doing something well requires more than task-related capabilities and proposes that volitional capabilities and volitional dispositions also play a necessary role. Volitional control, a by-product of volitional capabilities and dispositions, is especially important when difficult or complex tasks require time and extended effort to complete, when situations are fraught with obstacles or danger, and when goals are imperilled. The socially mediated context of teaching, the diverse complex of teachers' tasks, the cumulative acquisition of knowledge and skills that characterize student learning, and the distal nature of student achievement goals all suggest that teachers will require volitional capabilities and dispositions to enhance and augment their role-specific capabilities and to "energize the maintenance and enactment of intended actions" (Kuhl, 1985, p. 90, cited in Corno \& Kanfer, 1993, p. 14) required by the teaching role.

Therefore, a volitionally focused appraisal of personal teaching efficacy answers the question "Will I be able to follow through on my commitment to teach effectively?" This question is typically asked in-action and most often in the face of difficulties, obstacles, aversive situations, or failure. While self-appraisals of one's teaching performance capabilities are necessary to answer this question, they are not sufficient. The answer will also be shaped by beliefs about the potentialities of the environment (Bandura \& Wood, 1989), given one's capabilities, and by one's volitional capabilities, goals, and dispositional tendencies. 
Action-by-Situation-Outcome Expectancies

Heckhausen (1991) proposes two types of outcome expectancies that are shaped by beliefs about one's capabilities and the potentialities of the environment and that are a good fit with a volitional perspective of the teaching role. The first, action-outcome expectancies, are expectancies related to the probability that one can complete a performance or influence a situation; they focus on the relationship between one's capabilities and one's desired ends. This set of expectancies acknowledges the close relationship between performance and outcomes. Because there is a close relationship between teachers' actions (performance) and student responses (outcomes), action-outcome expectancies work well to describe the efficacy expectancies held by teachers. The second set of expectancies proposed by Heckhausen (1991), action-by-situation-outcome expectancies, refer to the probability that the particular situation will enhance or constrain one's capabilities to perform or influence. These expectancies focus on the reciprocal influence relationship between actions and contexts.

These two expectancies take into account the concept of triadic reciprocal causation that is foundational to an understanding of Bandura's conceptualization of self-efficacy. In addition, they reflect Bandura's (1986) contention that contrary to constructs like self-worth and self-esteem, selfefficacy is not a "global disposition" (p. 124), but rather, a state influenced by the demands of specific tasks, situations, or events. Further, these two expectancies seem particularly useful in describing changes in teachers' sense of efficacy. For example, teachers may believe they have the capabilities to teach mathematics to students in Grade 3 (action-outcome expectancies); however, they may also believe that they are incapable of doing so to 40 Grade 3 students, on Friday afternoons, with no textbook (action-bysituation-outcome expectancies). 
Volitional Capabilities and

Feelings of Control

Volitional theory provides a way to integrate the diverse constructs that act as mediators of effective action. First, a volitional control perspective emphasizes the importance of feelings of personal control (Skinner, 1992) and self-percepts of personal causation (De Charm, 1968, cited in Schunk, 1996). Skinner (1992) notes that personal control in the face of obstacles or aversive conditions is characterized by a positive coping response which is actionoriented--not only towards engagement with the situation, but also with an "orientation toward the goal of understanding how to be effective" (p. 93). Further, capabilities for the adaptive use of volitional control strategies reinforce a sense of personal causation (Corno, 1993). In addition, the forming of behavioral intentions--the initiatory action that separates motivation from volition--supports a proactive response to tasks or situations (Skinner, 1992), or what Covey (1990) refers to as finding a way to be "response-able" (p. 75). In turn, this proactive response allows individuals to make a difference. For example, within a teaching milieu, Volkman, Scheffler, and Dana (1992) point out that teachers who are decisive, flexible, and thoughtful (aspects of volitional control) are known to function more effectively in today's classrooms than teachers who function by rote.

From a slightly different view, Covey's (1990) perspective on effective habits not only reaffirms human beings' genetic capability for selfdetermination and for a "vast potentiality" (Bandura, 1986, p. 21) of responses to the environment, but it also expands understanding of what it means to be efficacious: Efficacy is more than using the capabilities one has to perform well, more than "hanging in" in the face of adversity, and more than being able to rebound well. For Covey (1990), truly efficacious people put the responsibility for being and feeling efficacious on themselves by recognizing 
that the opportunity to choose how to respond is inherent in every situation-regardless of the conditions--and by then choosing to be proactive and finding a way to be "response-able" (p. 75). When individuals are "responseable," they find ways to act from principle, to become their best selves, and to make a difference.

Covey's perspective resonates with De Charm's (1968, cited in Schunk, 1996) construct of personal causation and seems to be particularly applicable to the work of teaching. For example, while curriculum requirements are mandated, many of the decisions that teachers make about how to teach and interact with students are made autonomously with little interference from forces outside the classroom. Teachers must take responsibility for fulfilling their role, for acting in a principled manner, and for learning new ways to enhance student learning and sense of self-worth--in other words, they must take responsibility for making a difference.

Goleman (1995) suggests that the "master aptitude" (p. 95) that gives individuals an "added edge in the workplace" (p. 36) is the capability to manage emotions and influence the feelings of others. His theory of emotional intelligence puts selected volitional capabilities within a framework of self-understanding and empathy for others. For example, managing one's emotions and self-motivation require understanding of one's emotional self, while handling relationships requires understanding others through empathy. These capabilities parallel volitional capabilities, as well as types of self-efficacy: Managing one's emotions corresponds to emotion control strategies (Corno \& Kanfer, 1993) and thought control efficacy (Bandura, 1992); self-motivation corresponds to motivation control strategies (Corno \& Kanfer, 1993) and aspects of self-regulatory efficacy (Bandura, 1992); and handling relationships, one of the environmental control strategies (Corno \& 
Kanfer, 1993), corresponds to one set of the skills underlying managerial efficacy (Wood \& Bandura, 1989a, 1989b).

Of particular salience to teaching is the capability to handle relationships. Teachers' work with students, colleagues, administrators, and parents requires good communication and relationship abilities. In addition, the ability to organize and coordinate "the efforts of a network of people" (Goleman, 1995, p. 118), which is also one of Gardner's (1993) interpersonal capabilities, can be directly compared to teachers' management of the class. These classroom management capabilities underlie effective teaching, despite the fact that the development of these capabilities is often noticeably absent from teacher preparation programs (Schaller \& De Wine, 1993).

Deployment of effort. Underlying the capable use of volitional control processes is one's capability--and willingness--to deploy effort, particularly in the face of distractions, obstacles, and impending failure. The thoughtful deployment of one's effort is delineated by Corno (1993) as internal and external resource management capabilities such as proactive problem solving, the effective management of stress, and the adaptive use of environmental resources. When effective teachers work proactively to create a preferred for future for their students and their classroom community (Noordhoff \& Kleinfeld, 1990), they employ external resource management strategies; alternately, when teachers manage their emotions in times of stress, they employ internal resource management strategies.

From a similar point of view, Gallwey (1981) suggests that feelings of self-doubt lead to the loss of command of one's resources and that there are ineffective and effective ways to deploy one's effort in these moments of inefficacy. Responding in what he calls "unconscious mode," or giving in, mirrors Skinner's (1992) description of people with perceptions of low personal control. That is, individuals who give in begin to disengage, 
decreasing their effort and becoming less able to concentrate and less motivated to regain the command of their resources. In the face of seemingly intractable conditions, teachers can also respond in unconscious mode by backing off from the challenges of teaching and working from an ethic of "getting by," thus reinforcing beliefs that they cannot make a difference.

However, in the spirit of volitional theory, Gallwey (1981) suggests that moving into "awareness mode" or "learning mode" is the best way to recover command of one's resources and, inferentially, one's feelings of efficacy. Setting internal goals for experiential learning helps people to gain control of their effort, while external goals direct effort. Again, Gallwey's perspective resonates with perceived personal control, emphasizing an orientation towards learning to be effective that is characteristic of high engagement. Gallwey also stresses volitional capabilities of relaxed concentration and mindful effort and volitional dispositions of interest and responsiveness to the environment as ways to gain control of one's resources. It seems likely that highly efficacious teachers will also have the will and the ability, as well as the need, to remain responsive to their students and to the situations of teaching and learning in order to more efficaciously direct their effort on their students' behalf.

Volitional Goals

In occupations such as teaching where competence is developed over time and through practice, feelings of efficacy are tied to one's capability to protect one's intentions over the long term (Heckhausen, 1991), accomplished by setting learning or mastery goals, as well as process or task goals.

Learning as a volitional goal. The theory on volition also picks up the recurring theme of ongoing learning as a requisite for effectiveness that was posited by Gallwey (1981) and introduced in the initial review of the literature on self-efficacy and in a subsequent review on reflection. In relation to 
teaching, Schon (1983) suggests that the artistry of teaching requires ongoing learning through reflective inquiry. He refers to learning-in-practice as a "theory orientation" (p. 58) that involves using the positive and negative results of teaching as information about the task and the situation and as a starting point for setting ongoing learning and mastery goals. In keeping with self-efficacy theory, when these short-term learning or mastery goals are attained, they enhance teachers' self-percepts of efficacy in the same way as performance attainments. In addition, these proximal goals also tend to focus on progress towards distal goals rather than on the setbacks or failures and, therefore, help teachers to maintain strong, resilient self-percepts of efficacy over time.

Other types of volitional goals. Other proximal goals, called task or process goals, are also volitional in nature and characteristic of teaching. Because student progress is a long-term venture, teachers must set proximal goals, or "goals-in-action," not only to be effective, but also to feel efficacious. For example, students must first learn to identify letters and then words before they can learn to read; similarly, students must learn to hold a pencil, control their hand-eye movements, and form letters before they can begin to print or write. Thus, teachers form proximal goals for the development of initial and intermediate student knowledge and skills related to reading and writing to hold themselves on course and provide evidence of progress as they work towards more distal goals of teaching reading and writing. Relatedly, teacher thinking, planning, and decision making, which are "a large part of the psychological context of teaching" (Clark \& Peterson,1986, p. 255, cited in Bolin, 1988, p. 48), can be characterized as the development of process goals and are similar to Heckhausen's (1991) action schemas and Bandura's (1992) anticipatory scenarios. Thus, volitional goals, whether they are learningoriented or process-oriented, task-related or process-related, not only 
moderate long-term action, but also protect one's intentions in the face of distractions and obstacles and maintain one's sense of efficacy. Volitional Dispositions

The application of volitional capabilities and continued effort over time results in the formation of habits, values, and predispositions to act in certain ways that can also be argued to play a role in one's real and perceived volitional control and, hence, in one's self-assessments of efficacy.

For example, habits of attentiveness, conscientiousness, and selfrestraint reinforce perceptions of personal causation, which in turn, influence one's determination and willingness to take responsibility for one's actions. As a corollary, when one believes that one can influence the events that affect one's life (an alternate description of self-percepts of efficacy), one is more likely to view external and internal means as resources and to take the initiative to use them or modify and change them so they can be utilized. The application to teaching is easy to see. When teachers attend in-service events, draft a new unit, or rearrange their classrooms, they are taking the initiative to use or modify the internal and external means available to them. Effective teachers do these things conscientiously.

Volitional theory also counts one's values as dispositional forces governing an action orientation. For example, volitional action towards goals has been found to be positively influenced by placing value on learning (Clark, 1993, cited in Corno, 1994) or on achievement--the achievement motive (Cherniss, 1998, p. 27). In teaching, altruistic values, such as wanting to make a difference in children's lives, may also positively influence volition.

Dispositional tendencies such as finding interest in one's tasks have been identified as an emotional condition of perceived personal control (Skinner, 1992), while other dispositional tendencies such as selfforgetfulness, relaxation, and enjoyment are identified as emotional 
characteristics of an action orientation (Heckhausen, 1991). The dispositional tendency to anticipate success rather than failure (one of the aspects of learned optimism) is also known to reinforce action-oriented behavior (Heckhausen, 1991). Thus, dispositional tendencies enhance the possibility of successful performance and goal attainments by determining the way individuals approach and engage in tasks, situations, or events.

Resiliency Factors

Volitional capabilities and dispositions make another contribution to efficacious behavior. They serve as protective factors which reduce the potential that individuals' own vulnerabilities, along with the challenges and risks in the environment, will negatively influence their effectiveness and feeling of efficacy. These protective factors are posited to underlie individuals' ability to rebound after exposure to stress, returning them "to better functioning when adversity abates" (Masten, 1989, p. 270) and allowing them to maintain high levels of self-efficacy despite setbacks and failures.

Beliefs that enhance resiliency. In addition to volitional capabilities and dispositions, beliefs also moderate volitional behavior over the long term, play a role in forming an action orientation, and serve as protective factors. For example, when individuals believe that ability is malleable or that the environment is subject to their control, the deployment of their effort is considered to be an important vehicle for assuring performance and goal attainments. When setbacks occur, these individuals search for new solutions or new paths, trusting that they will find ways to enhance their abilities or to influence the environment. In contrast, when ability is believed to be fixed or the environment is believed to be unamenable to change, effort is considered wasted and people tend to give up at the first sign of problems. Thus, one's conceptions of ability and the controllability of the environment, along with 
beliefs in the efficacy of mindful effort, may also influence feelings of selfefficacy, largely through their effect on one's volition.

The Volitional Capabilities of

High-Efficacy Teachers

Teachers with strong volitional capabilities have a propensity to "find a way" to be effective and to fulfill their behavioral intentions and long-term goals. This is an additional value-added element of personal teaching efficacy that helps to separate highly efficacious teachers from those who are less efficacious. For example, highly efficacious teachers tend to focus less on "if" they can act, and more on "how" they can act. They also focus less on aversive circumstances and obstacles to their goals and more on how they can effectively act in spite of them. Highly efficacious teachers also tend to focus less on what can't be done and more on those aspects of the task that are doable. Similarly, they focus less on what they can't do and more on what they can learn to do. Highly efficacious teachers also focus less on what has happened in the past and more on what they will do next, and they focus less on situations as they are and more on what situations can become through their own effort.

Teachers with strong volitional capabilities and dispositions also have a high sense of their capability to impact the context of teaching and student's lives and the predispositions to manage their thoughts and feelings, to trust their capabilities in new or dynamic situations, and to follow through even in the face of distractions, obstacles, or failure, all of which ensure effective action and goal attainment. In other words, in addition to having teaching performance capabilities, highly efficacious teachers are also action-oriented (Heckhausen, 1991). 
Personal Teaching Efficacy From a Volitional Perspective

The review of the literature on volitional theory and other theories related to it significantly changed my perspective on what constitutes personal teaching efficacy. However, despite this change and in keeping with the foundational research on teacher efficacy (see Ashton \& Webb, 1986; Gibson \& Dembo, 1984; Guskey \& Pasarro, 1993; McLaughlin \& Marsh, 1978; Woolfolk \& Hoy, 1990) and my previous model, I again theorized that teachers' sense of efficacy could be organized according to two distinct aspects (see Figure 7).

These two aspects, represented in double boxes in Figure 7, are teaching performance and teaching volition. In keeping with Wood and Bandura's (1989a, 1989b) research on managerial efficacy in a simulated organization and with my first model, I continue to conceptualize personal teaching efficacy as a self-schema of efficacy for teaching. From my new perspective, a self-schema of efficacy is represented as the integrated effect of efficacy perceptions of one's performance and volition capabilities, along with dispositional tendencies and teaching beliefs, which develop as a result of work in "dynamic organizational environments" (Wood \& Bandura, 1989a, p. 407). The emphasis of this self-schema is that, in addition to being situationspecific, personal teaching efficacy develops across time as the cumulative result of participating in and learning from teaching experiences and successful (or failed) attempts to "mobilize the motivation, cognitive resources, and courses of action needed to meet situational demands" (p. 408) over the long term.

A self-schema approach to personal teaching efficacy also suggests that positive self-schemas of personal teaching efficacy do not represent a stable product, but rather, represent an amorphous process with developmental 
Figure 7

\section{New Model of Personal Teaching Efficacy}

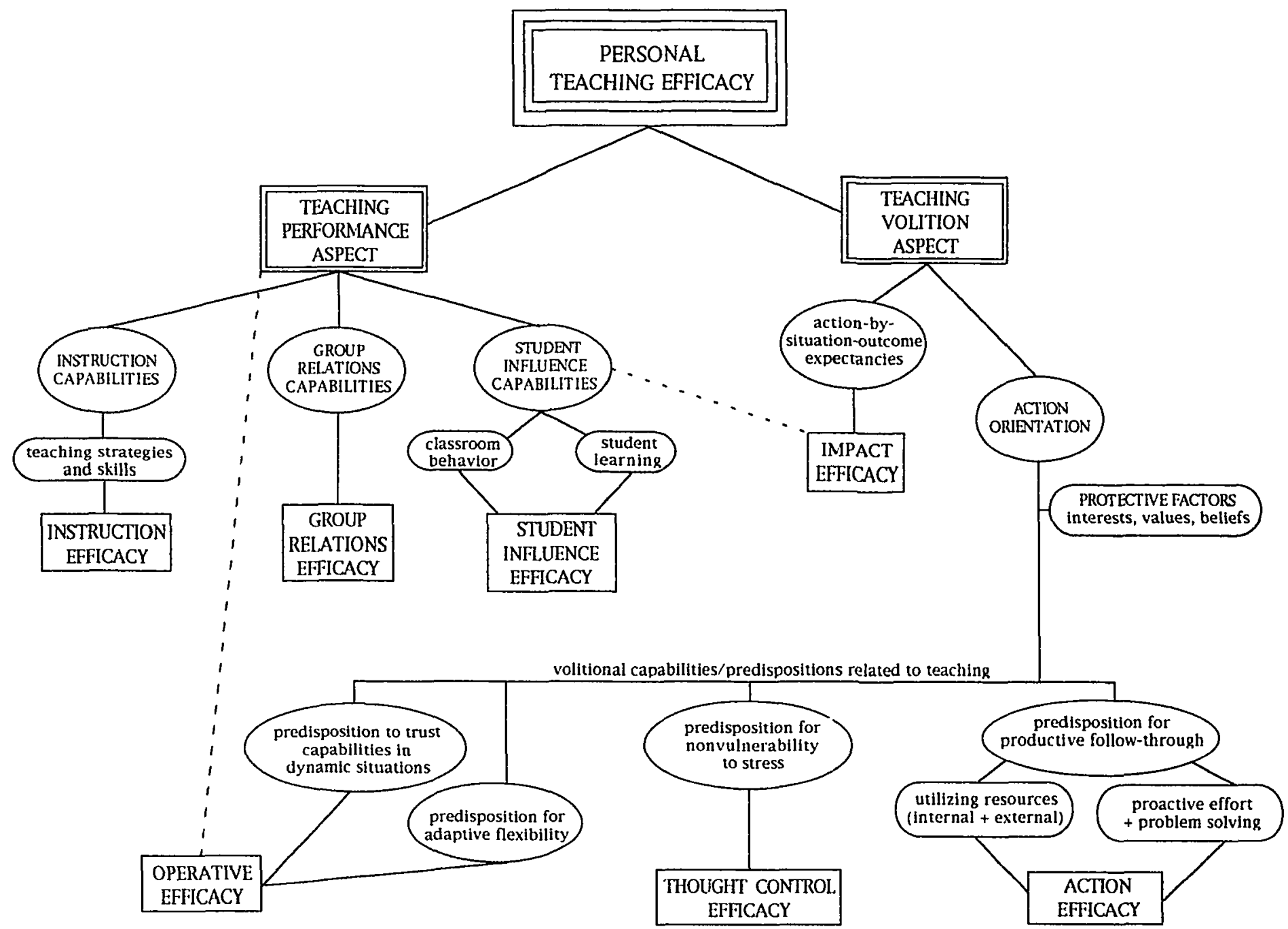


differences among individuals and across experiences. If this is so, then providing contexts and experiences that support and enhance the development of teachers' self-schemas of personal teaching efficacy is an important consideration when designing teacher education programs and building school organizations and school cultures. The Teaching Performance Aspect of

\section{Personal Teaching Efficacy}

The teaching performance aspect, retained from my first model, remains similar to the personal teaching efficacy factor proposed in the foundational literature and in my first model. Self-appraisals of the aspect of personal teaching efficacy related to teaching performance ask the question "Do I have the capabilities of an effective teacher?" The answer to this question would require an assessment of three types of teaching performance capabilities: instruction capabilities, group relations capabilities, and student influence capabilities. These are represented in Figure 7 inside three ellipses that connect to the general category of teaching performance.

Instruction capabilities. Instruction capabilities refer to teaching strategies and skills that support student learning. Positive perceptions of these capabilities would result in feelings of instruction efficacy. Figure 7 represents this type of efficacy in a rectangular box under instruction capabilities.

Group relations capabilities. Group relations capabilities are those aspects of classroom management related to the organization of conditions for positive group interaction, with learning in mind, and to the ability to organize and coordinate "the efforts of a network of people" (Goleman, 1993, p. 118). They are also similar to the influence skills proposed as necessary for managers in Wood and Bandura's (1989) study. Positive perceptions of these 
capabilities would result in feelings of group relations efficacy (represented in a rectangular box under group relations capabilities in Figure 7).

Student influence capabilities. This set of capabilities was embedded under classroom management efficacy in my previous model; however, factor analyses of the data from the teacher and student teacher pretests and posttests suggested that it could be a unique factor. Capabilities to manage the classroom behavior and influence the learning of individual students make up this group of capabilities. Positive perceptions of these capabilities would result in feelings of student influence efficacy (note the rectangle under student influence capabilities in Figure 7).

The Volitional Aspect of

\section{Personal Teaching Efficacy}

The volitional aspect of my new model of personal teaching efficacy moves away from the foundational research on teacher efficacy, which construes the second factor as representing response-outcome expectancies of teachers in general (Gibson \& Dembo, 1984). Alternately, it is somewhat similar to my first model, which proposed a second aspect of personal teaching efficacy related to individual teachers' sense of control over the contextual and situational aspects of teaching, including their own response to situations (control efficacy). However, the volitional aspect of this model was framed from the perspective of volitional theory, and self-appraisals of this aspect of personal teaching efficacy answer the question "Will I be able to follow through on my commitment to teach effectively?" This question is typically asked in-action rather than before action and most often in the face of difficulties, obstacles, aversive situations, or failure. The answer requires a survey of one's action-by-situation expectancies and one's predispositions to act effectively, which I refer to as an action orientation (see Heckhausen, 1991). 
Action-by-Situation Expectancies

Action-by-situation-outcome expectancies, which are similar in nature to Heckhausen's (1991), are defined as the probability that one can influence a situation given the enhancing or constraining factors within it. Positive perceptions of one's capabilities to influence people and events within a situation's enhancing or constraining factors would result in positive feelings of impact efficacy (see the rectangular box under action-by-situation-outcome expectancies on the volitional side of Figure 7). Teachers' with positive selfpercepts of impact efficacy focus on the environment's potential to increase the chance that their actions will be effective, rather than on environmental limitations to effective teaching action and goals. Thus, impact efficacy is a positive and personal corollary of Gibson and Dembo's (1984) teaching efficacy.

Action Orientation

While similar to having a sense of control, action orientation focuses on teachers' capabilities to protect their teaching intentions and, as Corno (1993) suggests, to direct and control "intellectual, emotional and behavioral energy toward. ... goals that are subjectively difficult to enact" (p. 16). While an action orientation requires volitional control and the use of volitional processes and strategies, I found it more useful to consider it in terms of four broad predispositions that result from these capabilities: the predisposition to trust one's capabilities in dynamic situations, the predisposition for adaptive flexibility, the predisposition for nonvulnerability to stress, and the predisposition for productive follow-through (note their representation in ellipses in Figure 7).

The predisposition to trust one's capabilities in dynamic situations and the predisposition for adaptive flexibility. Confidence in one's predisposition to trust one's knowledge and skills and to adapt them to fit new or changing 
situations results in feelings of operative efficacy (see Figure 7). Teachers with high operative efficacy are comfortable in ambiguous situations where outcomes are uncertain and trust that their capabilities and effort will see them through. Thus, the definition of operative efficacy in this model is similar to Bandura's (1986) definition of it as perceptions of one's "generative capability [to] improvise multiple subskills to manage changing circumstances, most of which contain ambiguous, unpredictable, and often stressful elements" (p. 391). Because operative efficacy is dependent on "multiple subskills," a broken line, leading from operative efficacy to the three sets of teaching performance capabilities, has been added to the model.

The predisposition for nonvulnerability to stress. The predisposition for invulnerability to stress is the effect of having strong capabilities for emotion control (Corno \& Kanfer, 1993). When teachers are confident that they will bounce back after difficulties and when they can control their feelings of tension and of being overwhelmed by teaching situations, they are predisposed for nonvulnerability to stress and will have positive feelings of thought control efficacy (represented in the rectangular box below this predisposition in Figure 7).

This factor has been retained from my first model of personal teaching efficacy, but it is now framed in volitional terms. Thought control efficacy includes emotion control strategies such as positive self-talk, as well as capabilities to control thoughts and emotions that impede effective action.

The predisposition for productive follow-through. The volitional capabilities underlying the predisposition for productive follow-through serve to protect teachers' intentions and goals over the long term and in the face of distractions, obstacles, failure, or aversive situations. Underlying this predisposition are three related predispositional activities. 
Proactive problem solving. The predisposition for proactive problem solving is similar to Schon's (1983) "active response" (p. 57) to situations that fall outside normal expectations. In situations such as these, the teacher tends to respond to the situation by reapplying what he or she already knows in a more careful way, being alert to the aspects that return the situation to within the normal range of expectations. In addition, a predisposition for proactive problem solving characterizes an active agent who desires "to influence the direction presence occurrences take" (Dewey, 1966, p. 124), and it resonates with what Dewey (1966) calls "mind" and defines as "anticipation of future possible consequences . . . with a view of controlling the kind of consequences that take place" (pp. 130-131).

Proactive effort: utilizing_internal and external resources. A volitional perspective on human action considers the strategic deployment of effort as an important capability underlying successful performance and goal attainments that can vary among individuals. It also identifies the deployment of effort with the utilization--or creation--of internal and external resources. Applied to personal teaching efficacy, it suggests that teacher effort is not only an effect of high self-percepts of personal teaching efficacy, but also an integral component of teachers' real and perceived efficaciousness.

The predisposition to utilize--or create--internal (personal) and external resources resonates with Schon's (1983) "theory response" (p. 57). Schon suggests that, when situations that fall outside a teacher's normal expectations have not been explained by an active response, the theory response moves a teacher to a "theory orientation" (p. 58) which uses negative and positive results from the situation as information for learning how to improve or change the situation. This component of action efficacy supports the idea that learning is a necessary part of teaching and takes into account 
teachers' use of the "active synthetic skill of designing a desirable future and inventing ways of bringing it about" (Schon, 1983, p. 16).

Teachers' confidence in their capabilities to utilize internal and external resources and in their capabilities for proactive effort and problem solving would result in feelings of action efficacy (see Figure 7).

Resiliency protective factors. In addition to the three factors related to an action orientation, I propose that efficacious teachers also have various beliefs and propensities for approaching their work that serve as resiliencyprotection factors that "facilitate resiliency" (Henderson \& Milstein, 1996, p. 8) and, thus, help to sustain an action orientation.

Resiliency-protection factors reinforce teachers' willingness and capability to act effectively. For example, teachers' beliefs that children can learn and that their own efforts make a difference in that learning support their willingness and capability to continue to act effectively. Similarly, teachers' interest in and enjoyment of their teaching tasks not only protect their intentions to act, but also add resiliency to their sense of personal teaching efficacy.

Previous factor analyses indicate that the resiliency-protection factors tend not to load together but, rather, to load on factors with similar content.

\section{Definitions of Proposed Factors Underlying \\ the Teaching Performance Aspect \\ of Personal Teaching Efficacy}

The teaching performance aspect of personal teaching efficacy focuses on role-specific capabilities that define teaching and that, to a large extent, can be successfully taught in teacher education programs or learned through modelling and experience. 


\section{Instructional Efficacy}

Instructional efficacy is defined as teachers' perceptions of their capabilities to mobilize the discrete subskills required to teach and organize for learning.

\section{Group Relations Efficacy}

Group relations efficacy is defined as teachers' perceptions of their capabilities to organize conditions for positive classroom-level interactions, with learning in mind.

\section{Student Influence Efficacy}

Student influence efficacy is defined as teachers' perceptions of their capabilities to influence students' classroom behavior and students' ability to learn.

\section{Definitions of Proposed Factors Underlying the Teacher Volition Aspect \\ of Personal Teaching Efficacy}

In agreement with van Manen (1977), the volitional aspect of teaching highlights the capabilities and dispositions that are of great importance for successful teaching but are also more difficult to teach for and to measure. Impact Efficacy

Impact efficacy is defined generally as teachers' beliefs that they can make a difference in students' lives despite contextual variables. Specifically, impact efficacy refers to teachers' perceptions of their capabilities to be an active force in and on the environment and requires an appraisal of one's capabilities in light of the current situation and external or variable circumstances. 
Thought Control Efficacy

Thought control efficacy is defined as teachers' capabilities to direct their thoughts and feelings in ways that reduce their vulnerability to stress and, therefore, allow them to remain effective in aversive conditions. Action Efficacy

Action efficacy is defined as teachers' self-percepts of their propensity for "productive follow through" (Willingham, 1985, p. 8, cited in Corno, 1994, p. 235), which involves mindful expenditure of effort, proactive problem solving, and utilization and creation of internal and external resources.

\section{Operative Efficacy}

Operative efficacy is defined as teachers' predispositions for adaptive flexibility and for trusting in one's capabilities to respond effectively to complex or changing situations.

Resiliency-Protection Factors

Resiliency-protection factors are defined as teachers' interests, values, and beliefs that influence the way teachers approach their work and "facilitate resiliency" (Henderson \& Milstein, 1996, p. 9) in the face of aversive situations or circumstances.

A Reexamination of the Factor Analyses Results Using the New Model of Personal Teaching Efficacy

The new model of personal teaching efficacy now had 7 factors; however, the previous factor analyses had yielded 11 to 14 factors, depending on the sample and when the scale was administered. Despite this discrepancy, I felt the new model more adequately conceptualized the factors that underlie differences in personal teaching efficacy among teachers, particularly volitional differences, which had not been previously accounted for. 
I also found that the new model did increase my ability to attach substantive meaning to more factors than had the previous model. For example, an action efficacy factor was clearly discernible in at least one of the factors derived from each of the four scales and a student influence factor could be discerned in two factors using the student teacher data. In addition, by identifying items within a factor as representing resiliency-protection factors, I was able to clarify the factor's possible substantive meaning more easily.

However, while my understanding of personal teaching efficacy and my ability to broadly interpret the factors had increased, three problems still remained:

1. Items loading on factors did not remain stable across teacher and student teacher pretest and posttest administrations of the 46 -item scale. This lack of stability makes reliable factor-level comparisons of teachers' and student teachers' pretest and posttest perceptions of personal teaching efficacy virtually impossible.

2. A seven-factor model still fell short of clearly differentiating among all factors.

While factor analyses of the 46-item scale had yielded a statistically parsimonious solution, Kim and Mueller (1985) point out that "for a large sample with many variables, the number of factors retained tends to be much larger than the number of factors the researcher is willing to accept" (p. 42). In addition, from a practical standpoint, the large number of factors make identifying aspects of teachers' perceptions of personal teaching efficacy overly complex.

3. The large number of variables in the scale appeared to have produced several "minor factors whose identification is not the primary concern but 
whose presence affects the identification of major common factors" (Kim \& Mueller, 1985, p. 7).

In an attempt to reduce the number of factors and produce a substantively parsimonious solution of stable, interpretable factors, while at the same time maintaining a robust factor solution, I first narrowed the number of respondents to include only those who had completed both the pretest and the posttest.

\section{Factor Analyses Using \\ Matched-Cases Data}

I reasoned that the stability of factors and, perhaps, a reduction in the number of factors might be attained if the same respondents were used for pretest and posttest factor analyses (see Table 7 for the number of matched cases found). Thus, I conducted factor analyses of teacher and student teacher pretest and posttest data for matched cases only, using principal components extraction methods and both varimax and oblimin rotations (default SPSS settings for initial communalities and for determining the number of factors were again employed). Matched cases were determined by matching case identification numbers of pretest and posttest respondents. Listwise deletion of cases is the default for factor analysis in the SPSS program, which assures "only cases with valid values on all variables are used" (Norusis, 1990a, p. 339).

\section{Test Statistics}

When teacher and student teacher pretest and posttest data from matched cases were used, all test statistics, with the exception of the KMO statistics for the teacher and student teacher pretests, confirmed the appropriateness of using factor analysis (see Table 11): The teacher pretest KMO statistic using matched cases suggested only "mediocre" appropriateness of the data for factor analysis, while the student teacher pretest KMO statistic 
Table 11

Statistical Tests for the Appropriateness of Factor Analysis of Personal Teaching Efficacy

Variables Using Matched Cases and the 46-Item Personal Teaching Efficacy Scale

\begin{tabular}{|c|c|c|c|c|}
\hline \multirow[b]{2}{*}{ Test } & \multicolumn{4}{|c|}{ Matched Cases } \\
\hline & $\begin{array}{l}\text { Teacher } \\
\text { Pretest } \\
\text { Statistic }\end{array}$ & $\begin{array}{l}\text { Teacher } \\
\text { Posttest } \\
\text { Statistic }\end{array}$ & $\begin{array}{c}\text { Student Teacher } \\
\text { Pretest } \\
\text { Statistic }\end{array}$ & $\begin{array}{c}\text { Student Teacher } \\
\text { Posttest } \\
\text { Statistic }\end{array}$ \\
\hline $\begin{array}{l}\text { Kaiser-Meyer-Olkin Measure of } \\
\text { Sampling Adequacy (KMO) }\end{array}$ & .66087 & .70133 & .33411 & .70330 \\
\hline Bartlett Test of Sphericity & 2000.0929 & 2223.4180 & 1597.5072 & 2055.0832 \\
\hline Significance $=$ & .00000 & .00000 & .00000 & .00000 \\
\hline $\begin{array}{c}\text { Anti-Image Correlation Matrix (AIC) } \\
\text { Off-Diagonal Elements }>0.09\end{array}$ & $\begin{array}{l}64 \\
3.1 \%\end{array}$ & $\begin{array}{l}42 \\
2.0 \%\end{array}$ & $\begin{array}{l}18 \\
.9 \%\end{array}$ & $\begin{array}{l}60 \\
2.9 \%\end{array}$ \\
\hline $\begin{array}{l}\text { Reproduced Correlation Matrix (REPR) } \\
\text { Residuals (Above Diagonal) }>0.05\end{array}$ & $\begin{array}{l}242 \\
23.0 \%\end{array}$ & $\begin{array}{l}236 \\
22.0 \%\end{array}$ & $\begin{array}{l}245 \\
23.0 \%\end{array}$ & $\begin{array}{l}232 \\
22.0 \%\end{array}$ \\
\hline
\end{tabular}


characterized the use of factor analysis as "unacceptable" (Kaiser, 1974, cited in Norusis, 1990a, p. 317).

\section{Number of Factors}

Using the pretest and posttest data of matched teacher and student teacher cases resulted in a reduction in the number of factors for the teacher and student teacher posttests only (see Table 9). Factor analysis of posttest data of matched teacher cases yielded 12 factors (the teacher pretest had yielded 13 factors), while factor analysis of posttest data of matched student teacher cases yielded 11 factors (the student teacher pretest had yielded 14).

\section{Eigenvalues}

Table 12 shows the eigenvalues and percentage of total variance explained by each factor when using pretest and posttest data from matched cases of teachers and student teachers. The cumulative percentage of total variance accounted for by the factors ranges from $73.3 \%$ to $75.0 \%$ across the four data sets, which is slightly higher than the percentages of total variance using all respondents. The eigenvalues and percentages of total variance allocated to Factor 1 continued to remain high in all four factor analyses. Interpretation of Underlying

\section{Meaning of Factors}

The items loading on many of the factors continued to be relatively unstable for both teacher and student teacher data. However, factors had become somewhat more identifiable, and items loading on some factors were somewhat more consistent from pretest to posttest.

Factor analyses of teacher pretest and posttest data. When the factors produced by an oblimin (oblique) rotation were used, the items representing the impact efficacy factor remained the same from the teacher pretest to posttest. In addition, the instruction efficacy factor was relatively stable, with six items remaining constant from teacher pretest to teacher posttest. I was 


\begin{tabular}{|c|c|c|c|c|c|c|c|c|}
\hline $\begin{array}{l}\text { Table } 12 \\
\text { Factor } E \\
\text { of the } 4\end{array}$ & $\begin{array}{l}\text { zalues and Per } \\
\text { n Personal Te }\end{array}$ & $\begin{array}{l}\text { entages of } \\
\text { ching Effica }\end{array}$ & $\begin{array}{l}\text { ariance Acros } \\
\text { y Scale Using }\end{array}$ & Four Admi & istrations & & & 305 \\
\hline \multirow[b]{3}{*}{ Factor } & \multicolumn{8}{|c|}{ Matched Cases } \\
\hline & \multicolumn{2}{|c|}{$\begin{array}{l}\text { Teacher } \\
\text { Pretest }\end{array}$} & \multicolumn{4}{|c|}{$\begin{array}{l}\text { Student } \\
\text { Teacher } \\
\text { Pretest }\end{array}$} & \multicolumn{2}{|c|}{$\begin{array}{l}\text { Student } \\
\text { Teacher } \\
\text { Posttest }\end{array}$} \\
\hline & Eigenvalue & $\begin{array}{c}\% \\
\text { Variance }\end{array}$ & Eigenvalue & $\begin{array}{c}\% \\
\text { Variance }\end{array}$ & Eigenvalue & $\begin{array}{c}\% \\
\text { Variance }\end{array}$ & Eigenvalue & $\begin{array}{c}\% \\
\text { Variance }\end{array}$ \\
\hline 1 & 12.47338 & 27.1 & 14.21383 & 30.9 & 10.04017 & 21.8 & 12.56016 & 27.3 \\
\hline 2 & 2.90380 & 6.3 & 3.01192 & 6.5 & 4.07855 & 8.9 & 4.33637 & 9.4 \\
\hline 3 & 2.69518 & 5.9 & 2.48681 & 5.4 & 2.64930 & 5.8 & 2.86893 & 6.2 \\
\hline 4 & 2.25072 & 4.9 & 2.16271 & 4.7 & 2.35387 & 5.1 & 2.29099 & 5.0 \\
\hline 5 & 2.24297 & 4.9 & 1.95213 & 4.2 & 2.09301 & 4.6 & 2.02021 & 4.4 \\
\hline 6 & 1.94516 & 4.2 & 1.78004 & 3.9 & 2.04547 & 4.4 & 1.74452 & 3.8 \\
\hline 7 & 1.65464 & 3.6 & 1.75116 & 3.8 & 1.92383 & 4.2 & 1.59591 & 3.5 \\
\hline 8 & 1.50437 & 3.3 & 1.46270 & 3.2 & 1.64993 & 3.6 & 1.51568 & 3.3 \\
\hline
\end{tabular}


Table 12 (continued)

Factor Eigenvalues and Percentages of Variance Across Four Administrations

of the 46-Item Personal Teaching Efficacy Scale Using Matched Cases

\begin{tabular}{|c|c|c|c|c|c|c|c|c|}
\hline & \multicolumn{8}{|c|}{ Matched Cases } \\
\hline & \multicolumn{2}{|c|}{$\begin{array}{l}\text { Teacher } \\
\text { Pretest }\end{array}$} & \multicolumn{2}{|c|}{$\begin{array}{l}\text { Teacher } \\
\text { Posttest }\end{array}$} & \multicolumn{2}{|c|}{$\begin{array}{c}\text { Student } \\
\text { Teacher } \\
\text { Pretest }\end{array}$} & \multicolumn{2}{|c|}{$\begin{array}{l}\text { Student } \\
\text { Teacher } \\
\text { Posttest }\end{array}$} \\
\hline Factor & Eigenvalue & $\begin{array}{c}\% \\
\text { Variance }\end{array}$ & Eigenvalue & $\begin{array}{c}\% \\
\text { Variance }\end{array}$ & Eigenvalue & $\begin{array}{c}\% \\
\text { Variance }\end{array}$ & Eigenvalue & $\begin{array}{c}\% \\
\text { Variance }\end{array}$ \\
\hline 9 & 1.42991 & 3.1 & 1.32468 & 2.9 & 1.52858 & 3.3 & 1.27803 & 2.8 \\
\hline 10 & 1.35599 & 2.9 & 1.24871 & 2.7. & 1.40039 & 3.0 & 1.19719 & 2.6 \\
\hline 11 & 1.31903 & 2.9 & 1.19257 & 2.6 & 1.35147 & 2.9 & 1.16346 & 2.5 \\
\hline 12 & 1.10779 & 2.4 & 1.14474 & 2.5 & 1.22222 & 2.7 & 1.01412 & 2.2 \\
\hline 13 & 1.07095 & 2.3 & $N / A^{a}$ & & 1.13316 & 2.5 & N/A & \\
\hline 14 & N/A & & $\mathrm{N} / \mathrm{A}$ & & 1.03663 & 2.3 & $\mathrm{~N} / \mathrm{A}$ & \\
\hline $\begin{array}{l}\text { Cumulative \% } \\
\text { of Variance }\end{array}$ & & 73.8 & & 73.3 & & 75.0 & & 73.0 \\
\hline
\end{tabular}

a N/A Not Applicable; No more factors were derived from the solution 
also able to label each of the remaining factors derived from the teacher pretest and posttest data as representing one of the hypothesized factors in the proposed model; however, the result was two or more factors representing the same hypothesized factor, with little or no stability in item loadings on these particular factors from pretest to posttest.

Factor analyses of student teacher pretest and posttest data. The factors produced by an oblimin rotation showed little stability from student teacher pretest to posttest, with the exception of the factor representing thought control efficacy. Four of the five items loading on this factor remained the same from student teacher pretest to posttest.

Alternately, only two items loading on the instruction efficacy factor remained the same from the student teacher pretest to posttest. Interestingly, however, four of the six items loading on the pretest instruction efficacy factor and seven of nine items loading on the posttest instruction efficacy factor were the same as those loading on the instruction efficacy factor of the teacher posttest.

\section{Conclusions}

As a result of factor analyses of the matched-cases data from teacher and student teacher pretests and posttests, I concluded that, while the factors produced in factor analyses were identifiable with the hypothesized factors, the new model was not detailed enough to distinguish subtle differences among factors of the same type. For example, I could identify two or three factors that all appeared to represent thought control efficacy, but, in most cases, I was unable to clearly distinguish one thought control efficacy factor from another. 
Modifications to the

\section{Personal Teaching Efficacy Scale}

Knowing that a scale with many variables tends to produce many factors, my next step was to reexamine the scale items with an eye for reducing the length of the scale, while at the same time maintaining adequate "semantic space" (Marradi, 1981) and assuring representation of the new model's proposed factors. I reasoned that if items were eliminated, not only would the number of factors be reduced, but factor stability would also improve.

To ensure that retained items represented the new model of personal teaching efficacy, I first categorized each of the 46 items under one of the seven hypothesized factors. I then used the following criteria to determine if an item should be retained or eliminated:

1. If eliminating an item reduced the number of items hypothesized to load on a particular factor to fewer than three, the item should not be eliminated (see Kim \& Mueller, 1985).

For example, because only two items were hypothesized to load on the impact efficacy factor, neither item could be eliminated.

2. If two highly correlated items appeared to address the same capability or predisposition, one could be eliminated. However, if a highly correlated item contributed to the breadth or depth of the meaning underlying a particular factor, it should be retained.

Spearman correlations were used to determine highly correlated items. These items were then examined for similarity of content. As an example of the application of this criterion, Item 13 was found to have a significant correlation $(>.5000$ correlation, $\mathfrak{D}<.001)$ with six other items. Item 13 reads as follows: 
I can plan instruction for students in my class who are at various levels of ability or stages of learning.

Item 13 was retained, and four of the six correlated items were eliminated. One eliminated item reads as follows:

I am able to plan effectively to meet the learning objectives of the subjects I teach.

Because Item 13 adequately represented the planning aspect of teaching capabilities, this item could be removed from the scale. However, the two items that were retained, while similar to Item 13 , appeared to address unique aspects of teaching capability. The retained items read as follows:

I am able to deal with the diversity of learners in my classroom.

I am able to get even the most unmotivated students to actively

participate in their own learning.

These items represent teachers' capabilities to manage students at various levels of ability (or willingness) to learn, as does Item 13; however, the first item broadens the meaning of instruction efficacy, while the second was hypothesized to load on student influence efficacy. Therefore, both items were retained.

3. The number of items representing each factor should be approximately the same. Since the first factor represented instruction efficacy and there were more items representing this factor than any other, this criterion was applied in an effort to reduce the magnitude of the eigenvalue of the first factor.

As a result of this criterion, six items hypothesized to represent the instruction efficacy factor were eliminated from the scale, representing $40 \%$ of the total number of eliminated items. 
Overview of the Modified

Personal Teaching Efficacy Scale

The analysis of item content and intercorrelations resulted in 15 items being eliminated from the scale. Table 13 lists the 31 remaining items, categorized according to the hypothesized factors.

As Table 13 displays, the hypothesized impact efficacy factor was represented by 2 modified-scale items; the student influence efficacy, operative efficacy, and thought control efficacy factors were represented by 3 items; the group management efficacy factor by 4 items; and the instruction efficacy factor by 6 items. Seven items were hypothesized to load on the action efficacy factor, with 2 items representing proactive problem solving and 5 items representing the utilization of internal and external resources.

Items representing action efficacy. One of the two items representing proactive problem solving focuses on teachers' determination to resolve teaching problems, while the other focuses on teachers' propensity to seek the help of other teachers and staff. The remaining five items were hypothesized to represent two aspects of the utilization of internal and external resources: Three items represented teachers' perceptions of their capability to access resources to support their teaching, which included an appraisal of their ability to acquire new skills (an internal resource), to encourage parents to support their children's learning, and to access needed material resources. The other two items focused on teachers' predispositions to learn, either by reflecting on their teaching or by directly setting out to develop new skills. Thus, while the action efficacy items were somewhat overrepresented in the modified scale, I reasoned that they were needed to represent the full nature of action efficacy. Further, if all items did not load together, I conjectured that they would load according to the subcategories of action efficacy. 
Table 13

Hypothesized Factors and Factor Loadings on the

31-Item Personal Teaching_Efficacy Scale

Factor Item

Number

Item Statement

Instruction 6 I know how to organize a classroom for various types of

Efficacy learning and activities.

12 I know how to create interesting learning activities for students to do.

13 I can plan instruction for students in my class who are at various levels of ability or stages of learning.

15 I am able to acquire new skills that are necessary to teach effectively in particular circumstances.

17 I am able to accurately evaluate my students' progress.

18 I know my subject matter well and am able to organize it for successful learning.

Group 7 I am able to develop a rapport with the students in my Management Efficacy

8 I am able to implement routines for an orderly classroom.

10 I can create an atmosphere so that students enjoy being in my classes.

19 I am able to manage most problems in my classroom.

Student 2 I can quickly redirect a disruptive student.

Influence 3 I am able to get even the most unmotivated students to

Efficacy actively participate in their own learning.

37 I can help most students to learn regardless of their ability.

Operative 20 I am able to deal with the diversity of learners in my Efficacy classroom.

22 I am not afraid to try new ways of doing things in the classroom, even if they might not work.

27 If a lesson is not going the way I would like, I find it difficult to change my plans mid-stream. 
Table 13 (continued)

Hypothesized Factors and Factor Loadings on the

31-Item Personal Teaching Efficacy Scale

\begin{tabular}{|c|c|c|}
\hline Factor & $\begin{array}{l}\text { Item } \\
\text { Number }\end{array}$ & Item Statement \\
\hline $\begin{array}{l}\text { Impact } \\
\text { Efficacy }\end{array}$ & 23 & $\begin{array}{l}\text { No matter how hard I try, I will not be able to make a } \\
\text { difference with some students. } \\
\text { The students' home environment has more influence on } \\
\text { their ability to achieve than I do as their teacher. }\end{array}$ \\
\hline \multirow[t]{4}{*}{$\begin{array}{l}\text { Action } \\
\text { Efficacy }\end{array}$} & $16^{\mathrm{a}}$ & $\begin{array}{l}\text { I know how to encourage parents to support their } \\
\text { children's learning. }\end{array}$ \\
\hline & $24^{a}$ & $\begin{array}{l}\text { When a particular lesson has gone badly, I spend time } \\
\text { considering how I might improve it for the next time. } \\
\text { When I am confronted with a particularly difficult } \\
\text { teaching problem, I am determined to resolve it no matter } \\
\text { how much work or time it takes. }\end{array}$ \\
\hline & 33 & $\begin{array}{l}\text { When things are not going well in my classroom, I set out } \\
\text { to learn new knowledge and skills that will improve the } \\
\text { situation. }\end{array}$ \\
\hline & $\begin{array}{l}46^{\mathrm{a}} \\
48\end{array}$ & $\begin{array}{l}\text { I know how to get the resources I need to teach effectively. } \\
\text { I take advantage of opportunities to work with other } \\
\text { teachers and staff in order to help my students learn. }\end{array}$ \\
\hline $\begin{array}{l}\text { Thought } \\
\text { Control }\end{array}$ & 26 & $\begin{array}{l}\text { I know that I will bounce back after a particularly } \\
\text { difficult day. }\end{array}$ \\
\hline Efficacy & $\begin{array}{l}42 \\
43\end{array}$ & $\begin{array}{l}\text { I am often overwhelmed by the diversity of students in my } \\
\text { classroom. } \\
\text { I find it difficult to control feelings of tension or } \\
\text { fearfulness that sometimes occur in a teaching situation. }\end{array}$ \\
\hline $\begin{array}{l}\text { Resiliency } \\
\text { Protection }\end{array}$ & $\begin{array}{l}21 \\
25\end{array}$ & $\begin{array}{l}\text { It is worth the effort to try to get through to all students. } \\
\text { I enjoy the challenge of trying to resolve instructional } \\
\text { problems in my classroom. }\end{array}$ \\
\hline Factors $b$ & 29 & $\begin{array}{l}\text { Resolving discipline problems in my classroom is an } \\
\text { enjoyable challenge. } \\
\text { I know that the effort I put into teaching will have } \\
\text { positive results. }\end{array}$ \\
\hline
\end{tabular}

a Given their syntactic structure, it was also hypothesized that these items might load on one of the three factors related to teaching performance.

b Previous factor analyses suggest that these items will not load together, but rather load with other factors and contribute uniquely to their meaning. 
Results of Factor Analyses of the Modified 31-Item Scale Using Matched Cases

\section{General Overview}

As the last stage of the model- and scale-development process, I conducted further tests and factor analyses. As the following section demonstrates, test statistics remained positive for factor analysis; additionally, the factor solutions were more parsimonious, and the new model of personal teaching efficacy more effectively explained factors derived from factor analyses.

\section{Factor Analysis Procedure}

Factor analyses of the 31-item modified Personal Teaching Efficacy Scale were conducted using matched-cases data from teacher and student teacher pretests and posttests. Principal components extraction methods were used, and both varimax and oblimin rotations conducted.

Factor solutions derived from the oblimin method were used in all interpretations of the factors. While the varimax (orthogonal) method is most commonly used, an orthogonal rotation presumes that the factors produced are uncorrelated. Alternately, the oblimin (oblique) method allows for factors to be correlated, acknowledging that "it is unlikely that influences in nature are uncorrelated" (Norusis, 1990a, p. 334). While, in most cases, the factor solutions of varimax and oblimin were highly similar, factor loadings using oblimin rotations were stronger, and the order of factor loadings assisted in the interpretation of factor meanings.

\section{Test Statistics}

Overall, tests conducted using the modified 31-item scale confirmed the appropriateness of factor analysis (see Table 14). Of particular note are the Kaiser-Meyer-Olkin statistics derived from the teacher and student teacher 
Table 14

Statistical Tests for the Appropriateness of Factor Analysis of

Personal Teaching Efficacy Variables Using Matched Cases and

the Modified 31-Item Personal Teaching Efficacy Scale

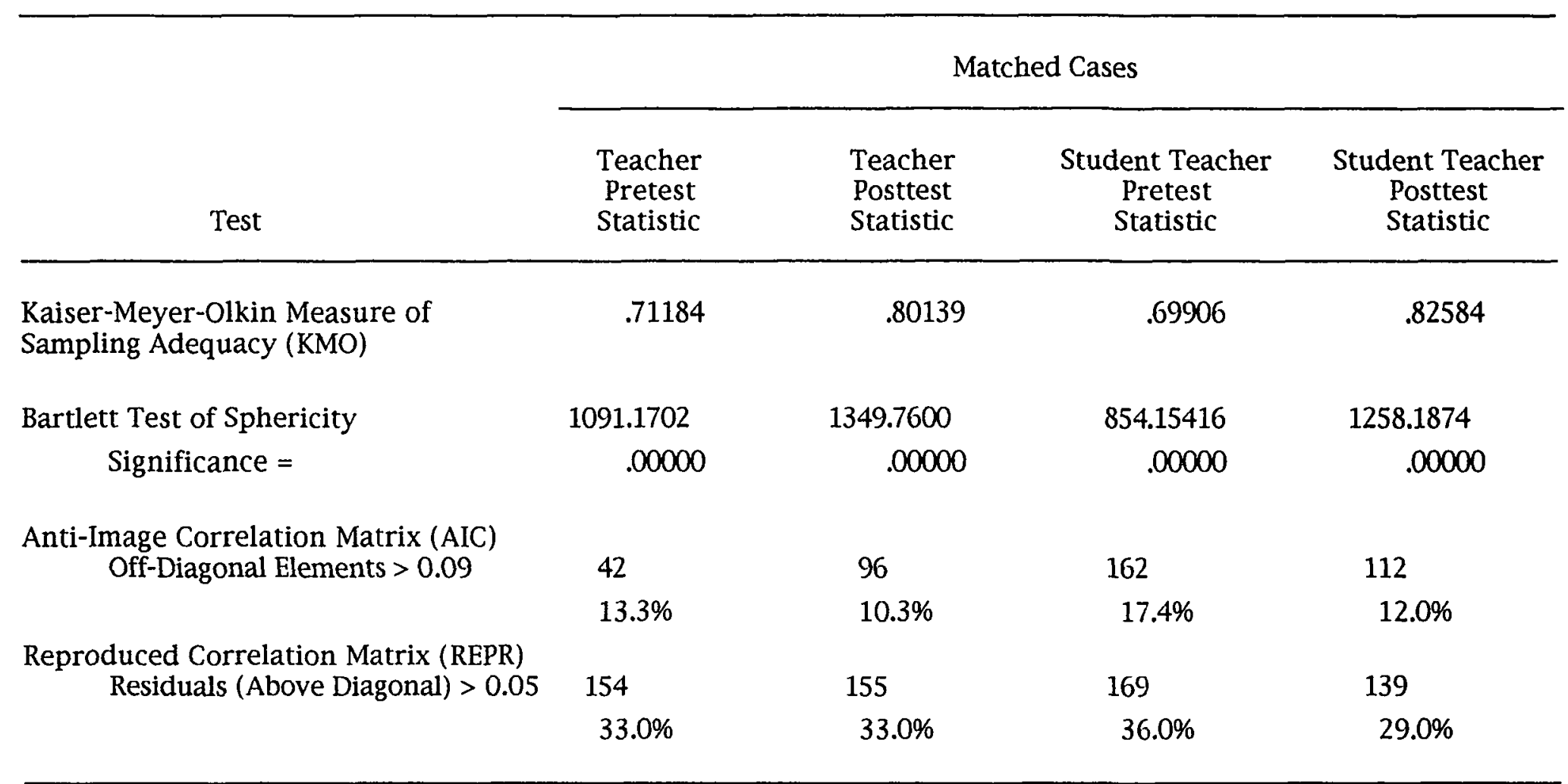


posttests; both yielded a KMO measure of over .800 , indicating "meritorious" appropriateness of the variables for factor analysis (Kaiser, 1974, cited in Norusis, 1990a, p. 317). Alternately, the KMO measure of the student teacher pretest data was only .69906 , suggesting mediocre appropriateness of the variables for factor analysis.

\section{Robustness of Communalities}

of the Variables

In addition to the test statistics discussed above, the communalities of the variables also provide information on the quality of the factor solution. The communality of a variable gives the "proportion of variance explained by the common factors" (Norusis, 1990a, p. 321) or, as Tinsley and Tinsley (1987) describe it, the communality value represents the "proportion of the total variance of a variable that is common variance" (p. 417). Variables with strong communalities are "another indication of the strength of the linear association among variables" (p. 318). When a good factor solution has been found, the variables have high communality values.

An examination of communalities of the variables of the four data sets indicates that the proportion of variance explained by the common factors is strong and, therefore, that a good factor solution has been found (see Table 15).

\section{Factor Loadings}

Factor analysis procedures using the modified 31-item scale and matched-cases data yielded fewer factors than previous factor analyses (see Table 9 for a comparison with other factor analyses). Both the student teacher pretest and posttest data yielded 9 factors. However, the teacher pretest data yielded 10 factors and the teacher posttest data yielded 8 factors. These differences in the number of factors not only indicate that the factors are still 
Table 15

Range of Communalities of the Variables From Factor Analvses of Teacher and Student Teacher Pretest and Posttest Data Using the Modified 31-Item Scale

\begin{tabular}{lccc} 
& & \multicolumn{2}{c}{ Range of Communality } \\
$\begin{array}{c}\text { Test } \\
\text { Administration }\end{array}$ & $\begin{array}{c}\text { Number of } \\
\text { Factors }\end{array}$ & $\begin{array}{c}\text { High } \\
\text { Communality }\end{array}$ & $\begin{array}{c}\text { Low } \\
\text { Communality }\end{array}$ \\
\cline { 3 - 4 } Teacher Pretest & 10 & .84875 & .57498 \\
$\begin{array}{c}\text { Teacher Posttest } \\
\begin{array}{c}\text { Student Teacher } \\
\text { Pretest }\end{array}\end{array}$ & 8 & .77752 & .51333 \\
$\begin{array}{c}\text { Student Teacher } \\
\text { Posttest }\end{array}$ & 9 & .79478 & .55916 \\
& 9 & & .51823 \\
\hline
\end{tabular}


unstable, but also suggest that student teachers and teachers may view the teaching role differently.

Eigenvalues and Percentage

of Total Variance

Table 16 outlines the eigenvalues and percentages of total variance explained by each factor when using pretest and posttest matched-cases data from the 31-item scale. While the eigenvalues for Factor 1 continued to be high across all four data sets, they were somewhat smaller than comparative eigenvalues derived from previous factor analyses. However, the percentages of total variance accounted for by the first factor increased slightly from comparative percentages derived from previous factor analyses and remained much higher than those accounted for by any of the other factors.

Factors from the modified scale accounted for over two thirds of the cumulative total variance, with percentages ranging from a low of $65.7 \%$ to a high of $71.6 \%$. While these cumulative percentages of total variance were somewhat lower than those derived from previous factor analyses, they were much higher than the cumulative total variance percentage of the Gibson and Dembo (1984) two-factor scale. Their scale accounted for $34.8 \%$ of the cumulative total variance, with Factor 1 accounting for $18.2 \%$ of the total variance, Factor 2 accounting for $10.6 \%$, and the "remaining factors account [ing] for less than $6 \%$ of the total variance" (Gibson \& Dembo, 1984, p. $573)$.

Alternately, each of Gibson and Dembo's (1984) two primary factors accounted for relatively high percentages of total variance. This was not the case in the factor solutions derived from the modified scale data: In all four factor analyses, the percentage of total variance dropped sharply from the first to the second factor, and the percentage continued to be under $10 \%$ for all other factors across the four data sets (see Table 15). This raises the question 
Table 16

Factor Eigenvalues and Percentages of Variance Across Four Administrations

of the 31-Item Personal Teaching Efficacy Scale

\begin{tabular}{|c|c|c|c|c|c|c|c|c|}
\hline & \multicolumn{2}{|c|}{$\begin{array}{l}\text { Teacher } \\
\text { Pretest }\end{array}$} & \multicolumn{2}{|c|}{$\begin{array}{l}\text { Teacher } \\
\text { Posttest }\end{array}$} & \multicolumn{2}{|c|}{$\begin{array}{l}\text { Student } \\
\text { Teacher } \\
\text { Pretest }\end{array}$} & \multicolumn{2}{|c|}{$\begin{array}{l}\text { Student } \\
\text { Teacher } \\
\text { Posttest }\end{array}$} \\
\hline Factor & Eigenvalue & $\begin{array}{c}\% \\
\text { Variance }\end{array}$ & Eigenvalue & $\begin{array}{c}\% \\
\text { Variance }\end{array}$ & Eigenvalue & $\begin{array}{c}\% \\
\text { Variance }\end{array}$ & Eigenvalue & $\begin{array}{c}\% \\
\text { Variance }\end{array}$ \\
\hline 1 & 8.46345 & 27.3 & 9.69599 & 31.3 & 6.77623 & 21.9 & 9.69262 & 31.3 \\
\hline 2 & 2.17783 & 7.0 & 2.34908 & 7.6 & 2.78145 & 9.0 & 2.26428 & 7.3 \\
\hline 3 & 1.95158 & 6.3 & 2.26946 & 7.3 & 2.19349 & 7.1 & 2.22023 & 7.2 \\
\hline 4 & 1.76253 & 5.7 & 1.83986 & 5.9 & 1.75295 & 5.7 & 1.73812 & 5.6 \\
\hline 5 & 1.68766 & 5.4 & 1.51315 & 4.9 & 1.60361 & 5.2 & 1.52052 & 4.9 \\
\hline 6 & 1.49788 & 4.8 & 1.40553 & 4.5 & 1.57323 & 5.1 & 1.23625 & 4.0 \\
\hline 7 & 1.33569 & 4.3 & 1.17321 & 3.8 & 1.29921 & 4.2 & 1.14205 & 3.7 \\
\hline 8 & 1.18455 & 3.8 & 1.00712 & 3.5 & 1.27719 & 4.1 & 1.08987 & 3.5 \\
\hline 9 & 1.13480 & 3.7 & N/A & & 1.11606 & 3.6 & 1.04364 & 3.4 \\
\hline 10 & 1.01124 & 3.3 & $\mathrm{~N} / \mathrm{A}$ & & N/A & & & \\
\hline $\begin{array}{l}\text { Cumulative } \% \\
\text { of Variance }\end{array}$ & & 71.6 & & 68.8 & & 65.7 & & 70.8 \\
\hline
\end{tabular}


of whether or not the factor solution produced an overextraction of factors, with the "extra factors [being] difficult to interpret and unreliable from analysis to analysis" (Tinsley \& Tinsley, 1987, p. 420). While this presented a concern to me, I followed Tinsley and Tinsley's advice:

Underestimation of the number of factors is usually a more serious problem than overextraction of factors. .. . Underextraction of factors means that factors are left undiscovered, thereby restricting the discovery of new constructs and inhibiting theory development. (p. 420)

Since the purpose of this study was to inform understanding of self-percepts of personal teaching efficacy, to err on the side of overextraction of factors seemed advisable.

\section{The Factor Solution of the Teacher Pretest}

Factor analyses of the teacher pretest yielded a 10-factor solution, with moderately strong factor loadings (see Table 17). The factor correlation matrix shows small correlations among factors, confirming that the factor structure represents separate factors (see Table 18 ).

Four of the seven factors of the hypothesized model of personal teaching efficacy were each represented by one factor of the factor solution: the instruction efficacy factor, impact efficacy factor, group relations efficacy factor, and thought control efficacy factor. Six factors remained to be explained. The final three hypothesized factors-action efficacy factor, student influence factor, and operative efficacy factor--were found to represent one or more of the six factors that remained, suggesting that the model was not complex enough to explain subtle within-factor differences. 
Table 17

Teacher Pretest Factors and Factor Loadings for the 31-Item

Personal Teaching Efficacy Scale Using Oblimin Rotation

\begin{tabular}{|c|c|c|}
\hline $\begin{array}{l}\text { Factor } \\
\text { Loading }\end{array}$ & $\begin{array}{l}\text { Item } \\
\text { Number }\end{array}$ & Factor and Item Statement \\
\hline .84061 & 13 & $\begin{array}{l}\text { Factor } 1 \\
\text { I can plan instruction for students in my class who are at various } \\
\text { levels of ability or stages of learning. }\end{array}$ \\
\hline $\begin{array}{l}.75803 \\
.71553 \\
.67372\end{array}$ & $\begin{array}{l}12 \\
20 \\
3\end{array}$ & $\begin{array}{l}\text { I know how to create interesting learning activities for students to do. } \\
\text { I am able to deal with the diversity of learners in my classroom. } \\
\text { I am able to get even the most unmotivated students to actively } \\
\text { participate in their own learning. }\end{array}$ \\
\hline .65968 & 6 & $\begin{array}{l}\text { I know how to organize a classroom for various types of learning and } \\
\text { activities. }\end{array}$ \\
\hline .63996 & 15 & $\begin{array}{l}\text { I am able to acquire new skills that are necessary to teach effectively in } \\
\text { particular circumstances. }\end{array}$ \\
\hline .49040 & 17 & I am able to accurately evaluate my students' progress. \\
\hline .83831 & $23^{a}$ & $\begin{array}{l}\text { Factor } 2 \\
\text { No matter how hard I try, I will not be able to make a difference with } \\
\text { some students. }\end{array}$ \\
\hline .73297 & $39 a$ & $\begin{array}{l}\text { The students' home environment has more influence on their ability to } \\
\text { achieve than I do as their teacher. }\end{array}$ \\
\hline $\begin{array}{l}.78670 \\
.71725\end{array}$ & $\begin{array}{l}37 \\
31\end{array}$ & $\begin{array}{l}\text { Factor } 3 \\
\text { I can help most students to learn regardless of their ability. } \\
\text { When I am confronted with a particularly difficult teaching problem, I } \\
\text { am determined to resolve it no matter how much work or time it takes. }\end{array}$ \\
\hline $\begin{array}{l}.77805 \\
.77035 \\
.74588 \\
.63311 \\
.53602\end{array}$ & $\begin{array}{l}10 \\
7 \\
8 \\
19 \\
26\end{array}$ & $\begin{array}{l}\text { Factor } 4 \\
\text { I can create an atmosphere so that students enjoy being in my classes. } \\
\text { I am able to develop a rapport with the students in my class(es). } \\
\text { I am able to implement routines for an orderly classroom. } \\
\text { I am able to manage most problems in my classroom. } \\
\text { I know that I will bounce back after a particularly difficult day. }\end{array}$ \\
\hline-.79097 & 22 & $\begin{array}{l}\text { Factor } 5 \\
\text { I am not afraid to try new ways of doing things in the classroom, even } \\
\text { if they might not work. }\end{array}$ \\
\hline-.53977 & 21 & It is worth the effort to try to get through to all students. \\
\hline
\end{tabular}

a Item responses were recoded prior to statistical analysis. 
Table 17 (continued)

Teacher Pretest Factors and Factor Loadings for the 31-Item

Personal Teaching Efficacy Scale Using Oblimin Rotation

\begin{tabular}{|c|c|c|}
\hline $\begin{array}{l}\text { Factor } \\
\text { Loading }\end{array}$ & $\begin{array}{l}\text { Item } \\
\text { Number }\end{array}$ & Factor and Item Statements \\
\hline & & Factor 6 \\
\hline-.88736 & $43^{a}$ & $\begin{array}{l}\text { I find it difficult to control feelings of tension or fearfulness that } \\
\text { sometimes occur in a teaching situation. }\end{array}$ \\
\hline $\begin{array}{l}-.65006 \\
-.51577\end{array}$ & $\begin{array}{l}42^{\mathrm{a}} \\
18\end{array}$ & $\begin{array}{l}\text { I am often overwhelmed by the diversity of students in my classroom. } \\
\text { I know my subject matter well and am able to organize it for } \\
\text { successful learning. }\end{array}$ \\
\hline .78204 & 24 & $\begin{array}{l}\text { Factor } 7 \\
\text { When a particular lesson has gone badly, I spend time considering } \\
\text { how I might improve it for the next time. }\end{array}$ \\
\hline .70580 & 25 & $\begin{array}{l}\text { I enjoy the challenge of trying to resolve instructional problems in my } \\
\text { classroom. }\end{array}$ \\
\hline .63763 & 33 & $\begin{array}{l}\text { When things are not going well in my classroom, I set out to learn } \\
\text { new knowledge and skills that will improve the situation. }\end{array}$ \\
\hline-.79450 & 29 & $\begin{array}{l}\text { Factor } 8 \\
\text { Resolving discipline problems in my classroom is an enjoyable } \\
\text { challenge. }\end{array}$ \\
\hline-.68149 & 2 & I can quickly redirect a disruptive student. \\
\hline-.84144 & 48 & $\begin{array}{l}\text { Factor } 9 \\
\text { I take advantage of opportunities to work with other teachers and staff } \\
\text { in order to help my students learn. }\end{array}$ \\
\hline-.69655 & 46 & I know how to get the resources I need to teach effectively. \\
\hline .82199 & $27^{\mathrm{a}}$ & $\begin{array}{l}\qquad \text { Factor } 10 \\
\text { If a lesson is not going the way I would like, I find it difficult to } \\
\text { change my plans mid-stream. }\end{array}$ \\
\hline .48612 & 34 & I know that the effort I put into teaching will have positive results. \\
\hline
\end{tabular}

a Item responses were recoded prior to statistical analysis. 
Table 18

Factor Correlation Matrix for a 10-Factor Solution of the Teacher Pretest

Using the 31-Item Scale and an Oblimin Rotation

\begin{tabular}{lllllllllllll}
\hline FACTOR & 1 & 2 & 3 & 4 & 5 & 6 & 7 & 8 & 9 & 10 \\
\hline
\end{tabular}

\begin{tabular}{|c|c|c|c|c|c|c|c|c|c|}
\hline 1 & 1.00000 & & & & & & & & \\
\hline 2 & -.07071 & 1.00000 & & & & & & & \\
\hline 3 & .19412 & -.03318 & 1.00000 & & & & & & \\
\hline 4 & .27332 & -.06646 & .18236 & 1.00000 & & & & & \\
\hline 5 & -.06868 & -.11647 & -.03026 & -.00342 & 1.00000 & & & & \\
\hline 6 & -.20685 & .04563 & -.17726 & -.20782 & .08021 & 1.00000 & & & \\
\hline 7 & .18332 & -.06830 & .16260 & .10529 & -.03945 & -.06392 & 1.00000 & & \\
\hline 8 & -.20786 & .00729 & -.18383 & -.14326 & .05349 & .19966 & -.10638 & 1.00000 & \\
\hline 9 & -.18267 & -.0087 & -.16463 & -.18503 & -.01195 & .12829 & -.17470 & .16940 & 1.00000 \\
\hline 10 & .13515 & .05139 & .02319 & .03755 & .00126 & -.07528 & -.00416 & -.05736 & -.05283 \\
\hline
\end{tabular}


Instruction Efficacy Factor

Factor 1 can be clearly interpreted as representing instruction efficacy. Four of the seven items were items hypothesized to load on instruction efficacy; however, the remaining items, while hypothesized to load on other factors, could also be interpreted to represent instruction. More specifically, knowing how to deal with diverse learners, being able to motivate students, and being able to acquire new skills for teaching effectively are highly related to self-percepts of one's teaching capabilities.

Impact Efficacy Factor

The two items loading on impact efficacy were those hypothesized. Responses to these negative statements had been recoded prior to factor analysis and, thus, represent teachers' perceptions of their capabilities and the positive potential of the environment for their actions to make a difference.

Group Relations Efficacy Factor

Factor 4 clearly represents the group relations efficacy, with four of the five items loading on it representing the hypothesized items. The fifth item, "I know I will bounce back after a particularly difficult day," was hypothesized to load on the thought control efficacy factor. However, this item had loaded with the items representing group relations efficacy in previous factor analyses. Since the ability to "bounce back" is also characterized as an aspect of resiliency, perhaps teachers may have responded to this item as a needed resiliency-protection factor for dealing with the ups and downs of classroom life.

Thought Control Efficacy Factor

Thought control efficacy is clearly represented by the first two items loading on Factor 6; however, at first glance, the third item seems completely unrelated. In fact, knowing your subject well and being able to organize it for 
successful learning is so obviously an instruction efficacy capability that one wonders how and why it could have loaded here. I reasoned that teachers' perception of their preparedness to teach helps them feel in control of the teaching task and, therefore, reduces negative emotional responses to the teaching situation. However, the factor loading of this errant item $(-.51577)$ was much lower than the factor loading of Item $1(-.88736)$, suggesting that it is not strongly related to the factor meaning and more probably represents error variance.

\section{Action Efficacy Factor}

Two factors could be interpreted as representing the action efficacy factor: Factors 9 and 7. The two items loading on Factor 9 represent the use of the external resources, with one item relating to a predisposition to work with other teachers and one item relating to the capability to get resources.

The three items loading on Factor 7 represent predispositions to develop and utilize internal resources by becoming more effective: Two of the items refer to teachers' conscious efforts to improve, while the third item is a resiliency-protection factor related to enjoying the challenge of resolving instruction problems. I reasoned that action efficacy may be a higher order aspect of personal teaching efficacy with its own underlying factors.

\section{Student Influence Factor}

The hypothesized student influence aspect of personal teaching efficacy could also be found in two factors derived from the teacher pretest data. The two items loading on Factor 8 represented teachers' capabilities to effectively discipline students and their predisposition to do so, which are central aspects of teaching and, of course, student influence.

The items loading on Factor 3 were less easily interpreted as representing student influence efficacy. The first item, "I can help most students learn regardless of their ability," was hypothesized to load on student 
influence. However, the other two items related to determination to resolve difficult teaching problems and capabilities to encourage parents to support their children's learning had been hypothesized to load on action efficacy: The first was hypothesized to represent proactive effort and problem solving and the second, the capability to utilize external resources--in this case parents. Thus, while Factor 3 had a student-learning focus, it appeared to be more representative of teachers' predispositions and capabilities for proactive effort, with learning in mind.

Operative Efficacy Factor

Two factors could also be generally identified as operative efficacy: Factors 5 and 10. The first item of Factor 5 represented the teachers' predisposition to trust their capabilities in dynamic situations, while the first item of Factor 10 represented teachers' predisposition for adaptive flexibility. The second item loading on each factor was hypothesized as a resiliencyprotection factor. The factor loading of the second item in each case was much lower than that of the first item (see Table 17), indicating that the two items of each factor were not strongly correlated with each other.

Relationship of the Factor Structure

to the Hypothesized Model

The factor structure derived from the factor analysis of teacher pretest data moderately confirmed the hypothesized model of personal teaching efficacy. All factors hypothesized to underlie personal teaching efficacy were present, but the operative efficacy factor and the student influence factor were less clearly interpretable than the other five. Unfortunately, as the following discussion shows, the factor structure did not remain stable across the other three data sets, but rather, changed significantly. 
The Factor Solution of the Teacher Posttest

Factor analyses of the teacher posttest yielded an eight-factor solution, with moderately strong factor loadings (see Table 19). The factor correlation matrix shows small correlations among factors, confirming that the factor structure represents separate factors (see Table 20). However, the factor solution, while interpretable using the hypothesized model, presented a very different perspective of personal teaching efficacy than the factor solution derived from the teacher pretest data.

For example, the first factor now represented action efficacy, and factors representing a focus on instruction efficacy and student influence had all but disappeared.

\section{Action Efficacy Factor}

Four of the seven hypothesized action efficacy items loaded together on Factor 1, with the item representing proactive effort--determination to resolve difficult teaching problems--now loading as hypothesized. In addition, the two items related to a predisposition to develop internal (personal) resources loaded with the item hypothesized to represent a predisposition to utilized external resources, not separately as they had when using teacher pretest data. This factor could be easily interpreted as representing action efficacy and, thus, strongly confirms the hypothesized factor. One of the remaining two items loading on the action efficacy factor had been hypothesized as a resiliency-protection factor, while the other had been hypothesized as representing student influence efficacy. With their respective emphasis on the positive effect of effort and teachers' assured belief that they can help students learn, they fit reasonably well with action efficacy.

Three of the items hypothesized to load on action efficacy, however, did not do so. They were hypothesized to represent teachers' capabilities to access or develop internal and external resources. The items could be distinguished 
Table 19

Teacher Posttest Factors and Factor Loadings for the 31-Item

Personal Teaching Efficacy Scale Using an Oblimin Rotation

Factor Item

Loading Number

Factor Item Statement

\begin{tabular}{lll}
.83223 & 48 & $\begin{array}{l}\text { Factor 1 } \\
\text { I take advantage of opportunities to work with other teachers and } \\
\text { staff in order to help my students learn. }\end{array}$ \\
$\begin{array}{l}\text { When things are not going well in my classroom, I set out to } \\
\text { learn new knowledge and skills that will improve the situation. }\end{array}$ \\
$\begin{array}{l}\text { When a particular lesson has gone badly, I spend time } \\
.67948\end{array}$ & 24 & $\begin{array}{l}\text { When } \\
\text { considering how I might improve it for the next time. } \\
\text { I know that the effort I put into teaching will have positive results. } \\
\text { When I am confronted with a particularly difficult teaching } \\
\text { problem, I am determined to resolve it no matter how much } \\
\text { work or time it takes. } \\
\text { I can help most students to learn regardless of their ability. }\end{array}$ \\
\hline
\end{tabular}

Factor 2

$.82330 \quad 23^{a} \quad$ No matter how hard I try, I will not be able to make a difference with some students.

$.62016 \quad 16 \quad$ I know how to encourage parents to support their children's learning.

$.59492 \quad 3 \quad$ I am able to get even the most unmotivated students to actively participate in their own learning.

$.5611139 \mathrm{a} \quad$ The students' home environment has more influence on their ability to achieve than I do as their teacher.

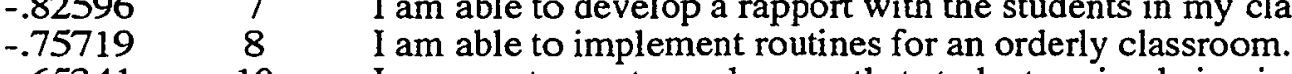

-.65341 $10 \quad$ I can create an atmosphere so that students enjoy being in my classes.

-.62637 $19 \quad$ I am able to manage most problems in my classroom.

$-.54109 \quad 12 \quad I$ know how to create interesting learning activities for students to do.

$-.49113 \quad 18 \quad$ I know my subject matter well and am able to organize it for successful learning.

a Item responses were recoded prior to factor analysis.

continued on the next page 
Table 19 (continued)

Teacher Posttest Factors and Factor Loadings for the 31-Item

Personal Teaching Efficacy Scale Using an Oblimin Rotation

\begin{tabular}{|c|c|c|}
\hline .77066 & 22 & $\begin{array}{l}\text { Factor } 4 \\
\text { I am not afraid to try new ways of doing things in the } \\
\text { classroom, even if they might not work. }\end{array}$ \\
\hline .70735 & 21 & It is worth the effort to try to get through to all students. \\
\hline .66054 & 6 & $\begin{array}{l}\text { I know how to organize a classroom for various types of } \\
\text { learning and activities. }\end{array}$ \\
\hline .61944 & 15 & 1 am able to acquire new skills that are necessary to teach \\
\hline \multirow[t]{2}{*}{.54173} & 46 & $\begin{array}{l}\text { effectively in particular circumstances. } \\
\text { I know how to get the resources I need to teach effectively. }\end{array}$ \\
\hline & & Factor 5 \\
\hline-.81995 & $43^{\mathrm{a}}$ & $\begin{array}{l}\text { I find it difficult to control feelings of tension or fearfulness that } \\
\text { sometimes occur in a teaching situation. }\end{array}$ \\
\hline-80136 & $42^{\mathrm{a}}$ & \multirow{2}{*}{$\begin{array}{l}\text { I am often overwhelmed by the diversity of students in my } \\
\text { classroom. } \\
\text { I know that I will bounce back after a particularly difficult day. } \\
\text { I am able to deal with the diversity of learners in my classroom. }\end{array}$} \\
\hline $\begin{array}{l}-.65812 \\
-.57124\end{array}$ & $\begin{array}{l}26 \\
20\end{array}$ & \\
\hline .82023 & $27^{a}$ & $\begin{array}{l}\qquad \text { Factor } 6 \\
\text { If a lesson is not going the way I would like, I find it difficult to } \\
\text { change my plans mid-stream. }\end{array}$ \\
\hline .81088 & 29 & \multirow{2}{*}{$\begin{array}{l}\text { Factor } 7 \\
\text { Resolving discipline problems in my classroom is an enjoyable } \\
\text { challenge. } \\
\text { I enjoy the challenge of trying to resolve instructional problems } \\
\text { in my classroom. }\end{array}$} \\
\hline \multirow[t]{2}{*}{.48565} & 25 & \\
\hline & & Factor 8 \\
\hline $\begin{array}{l}.78457 \\
.62839\end{array}$ & $\begin{array}{c}2 \\
13\end{array}$ & $\begin{array}{l}\text { I can quickly redirect a disruptive student. } \\
\text { I can plan instruction for students in my class who are at various } \\
\text { levels of ability or stages of learning. }\end{array}$ \\
\hline .61017 & 17 & I am able to accurately evaluate my students' progress. \\
\hline
\end{tabular}

a Item responses were recoded prior to factor analysis. 
Table 20

Factor Correlation Matrix for an Eight-Factor Solution of the Teacher Posttest

Using the 31-Item Scale and an Oblimin Rotation

$\begin{array}{llllllll}\text { FACTOR } 1 & \text { FACTOR } 2 & \text { FACTOR } 3 & \text { FACTOR } 4 & \text { FACTOR } 5 & \text { FACTOR } 6 & \text { FACTOR } 7 & \text { FACTOR } 8\end{array}$

\begin{tabular}{|c|c|c|c|c|c|c|c|c|}
\hline FACTOR 1 & 1.00000 & & & & & & & \\
\hline FACTOR 2 & .07083 & 1.00000 & & & & & & \\
\hline FACTOR 3 & -.24702 & -.03183 & 1.00000 & & & & & \\
\hline FACTOR 4 & .28168 & .08861 & -.22842 & 1.00000 & & & & \\
\hline FACTOR 5 & -.26565 & -.12065 & .25443 & -.28688 & 1.00000 & & & \\
\hline FACTOR 6 & -.06214 & -.02215 & -.05709 & .02072 & -.02504 & 1.00000 & & \\
\hline FACTOR 7 & .11239 & .03728 & -.01352 & 19917 & -.11170 & .03610 & 1.00000 & \\
\hline FACTOR 8 & .19664 & .14627 & -.22712 & .24032 & -.22887 & .15827 & .09049 & 1.00000 \\
\hline
\end{tabular}


semantically from the others by their sentence stems, which began "I am able to" or "I know how to." Alternately, the items that did load on the action efficacy factor were more action-oriented, with sentence stems like "I set out to," "I am determined to," and "I take advantage of opportunities." Instruction Efficacy and Student Influence Factors

In general, the items hypothesized to represent both instruction efficacy and student influence efficacy had been subsumed across the other factors. For example, two of the instruction efficacy items loaded with group relations efficacy items, while one of the student influence efficacy items loaded on the action efficacy factor and the other loaded with the impact efficacy items.

Interestingly, one student influence item, related to capabilities to redirect a disruptive student, and two instruction efficacy items--one related to capabilities to plan for instruction and the other, to capabilities to accurately evaluate student progress--loaded together on Factor 8. Together they covered three major tasks of teaching and, therefore, appeared to represent teachers' perceptions of their general teaching performance capabilities.

In contrast to these changes in the factor solution from pretest to posttest, the group relations efficacy factor, thought control efficacy factor, and impact efficacy factor remained moderately stable.

\section{Group Relations Efficacy Factor}

Four of the items loading on the group relations efficacy factor using teacher pretest data remained the same using teacher posttest data. These items loaded on Factor 3. As stated previously, they also represented the four items hypothesized to load on group relations efficacy. However, two items, representing instruction efficacy in the hypothesized model and when using teacher pretest data, now loaded on the group relations efficacy factor. One 
item, related to capabilities to create interesting learning activities, fit relatively well as a group relations efficacy item. However, the other, which was related to knowing subject matter and organizing it for successful learning, fit less well. While the semantic aspect of "am able to organize [subject matter] for successful learning" may have influenced the loading of this item, its relatively low factor loading (-.49113) suggests that the item is not strongly representative of the factor meaning.

Thought Control Efficacy Factor

The three items loading on the thought control efficacy factor were hypothesized to do so. In addition, two of these items had previously loaded on the thought control efficacy factor, using teacher pretest data. The fourth item was related to capabilities to deal with a diversity of learners. While seemingly unrelated to thought control efficacy, this item does have a similar subject as the item loading second on the thought control efficacy factor: "I am often overwhelmed by the diversity of students in my classroom."

\section{Impact Efficacy}

Factor 2, again designated as impact efficacy, was represented by the hypothesized items. These items had also loaded on impact efficacy using teacher pretest data. However, the factor had now expanded to four items: The additional two items were related to capabilities to motivate students and to encourage parents to support their children's learning. They fit well with impact efficacy, which captures teachers' predisposition to see contextual conditions as amenable to influence.

The remaining three factors, while less clearly interpretable, did appear to remain within the spirit of the hypothesized personal teaching efficacy model. 


\section{Resiliency-Protection Factors}

Although not expected to do so, two items representing resiliencyprotection factors loaded together on Factor 7. These items related to teachers' predisposition to enjoy the challenges of teaching, specifically challenges related to resolving instructional and discipline problems. However, loading together, they appeared to represent an aspect of action efficacy: the predisposition for proactive problem solving.

Operative Efficacy

Two of the hypothesized operative efficacy items again loaded on separate factors, as they had done in the factor solution derived using teacher pretest data. The item related to changing plans mid-stream, representing teachers' predisposition for adaptive flexibility, loaded alone. Alternately, the item representing teachers' predisposition to trust their capabilities in dynamic situations loaded with five other items. One item hypothesized as a resiliency-protection factor had loaded with this operative efficacy item in the previous factor solution. Two of the three remaining items had been hypothesized to load on the action efficacy factor and one had been hypothesized to load on the instruction efficacy factor. While these additional items could be perceived from the perspective of operative efficacy, there was clearly some other meaning which was unifying them.

\section{Relationship of the Factor Structure}

to the Hypothesized Model

The factor solution derived from teacher posttest data also moderately supported the hypothesized model of personal teaching efficacy. While the three performance aspects of the model were accounted for by only one factor, three of the four factors of the volitional aspect were easily interpretable. As with the factor solution using teacher pretest data, representation of operative efficacy remained weak. 


\section{Factor Stability From Teacher Pretest}

\section{to Teacher Posttest Factor Analyses}

Of all the factors hypothesized to represent personal teaching efficacy, the group relations efficacy factor remained the most stable from teacher pretest to posttest, with the four items hypothesized to load on this factor doing so. As well, items representing the thought control efficacy and impact efficacy factors remained reasonably stable from teacher pretest to posttest factor solutions. Both items hypothesized to load on impact efficacy did so in both factor solutions, as did two of the three items hypothesized to load on thought control efficacy.

Of particular interest is the first factor of the teacher pretest and posttest factor solutions. The percentages of total variance accounted for by Factor 1 were $27.3 \%$ using teacher pretest data and $31.3 \%$ using teacher posttest data, indicating that Factor 1 explained the largest percentage of total variance of any factor in each of the factor solutions. However, in the teacher pretest factor solution, the first factor represented instruction efficacy; while in the teacher posttest, the first factor represented action efficacy. Thus, a shift in teachers' perceptions of what is of central importance in determining personal teaching efficacy appears to have occurred.

\section{The Factor Solution of the}

\section{Student Teacher Pretest}

Factor analyses of the student teacher pretest yielded a nine-factor solution, with moderately strong factor loadings (see Table 21). The factor correlation matrix shows small correlations among factors, confirming that the factor structure represents separate factors (see Table 22). However, at first glance, the factor solution appeared to have little resemblance to either the hypothesized model of personal teaching efficacy or the teacher pretest 
Table 21

Student Teacher Pretest Factors and Factor Loadings

for the 31-Item Personal Teaching Efficacy Scale Using an Oblimin Rotation

\begin{tabular}{|c|c|c|}
\hline $\begin{array}{l}\text { Factor } \\
\text { Loading }\end{array}$ & $\begin{array}{l}\text { Item } \\
\text { Number }\end{array}$ & Factor and Item Statement \\
\hline $\begin{array}{l}.81587 \\
.77827 \\
.65333 \\
.58072\end{array}$ & $\begin{array}{l}2 \\
19 \\
20 \\
15\end{array}$ & $\begin{array}{l}\text { Factor } 1 \\
\text { I can quickly redirect a disruptive student. } \\
\text { I am able to manage most problems in my classroom. } \\
\text { I am able to deal with the diversity of learners in my classroom. } \\
\text { I am able to acquire new skills that are necessary to teach } \\
\text { effectively in particular circumstances. }\end{array}$ \\
\hline .56363 & 3 & $\begin{array}{l}\text { I am able to get even the most unmotivated students to actively } \\
\text { participate in their own learning. }\end{array}$ \\
\hline $\begin{array}{l}.77687 \\
.72697\end{array}$ & $\begin{array}{l}21 \\
37\end{array}$ & $\begin{array}{l}\text { Factor } 2 \\
\text { It is worth the effort to try to get through to all students. } \\
\text { I can help most students to learn regardless of their ability. }\end{array}$ \\
\hline $\begin{array}{l}.75567 \\
.71168\end{array}$ & $\begin{array}{l}46 \\
12\end{array}$ & $\begin{array}{l}\text { Factor } 3 \\
\text { I know how to get the resources I need to teach effectively. } \\
\text { I know how to create interesting learning activities for students to } \\
\text { do. }\end{array}$ \\
\hline .56028 & 18 & $\begin{array}{l}\text { I know my subject matter well and am able to organize it for } \\
\text { successful learning. }\end{array}$ \\
\hline .55029 & 26 & I know that I will bounce back after a particularly difficult day. \\
\hline-.75131 & 16 & $\begin{array}{l}\text { Factor } 4 \\
\text { I know how to encourage parents to support their children's } \\
\text { learning. }\end{array}$ \\
\hline $\begin{array}{l}-.62612 \\
-.60463\end{array}$ & $\begin{array}{l}17 \\
31\end{array}$ & $\begin{array}{l}\text { I am able to accurately evaluate my students' progress. } \\
\text { When I am confronted with a particularly difficult teaching problem, } \\
\text { I am determined to resolve it no matter how much work or time it } \\
\text { takes. }\end{array}$ \\
\hline-.54276 & $39 \mathrm{a}$ & $\begin{array}{l}\text { The students' home environment has more influence on their ability } \\
\text { to achieve than I do as their teacher. }\end{array}$ \\
\hline-.54233 & 13 & $\begin{array}{l}\text { I can plan instruction for students in my class who are at various } \\
\text { levels of ability or stages of learning. }\end{array}$ \\
\hline-.47929 & 22 & $\begin{array}{l}\text { I am not afraid to try new ways of doing things in the classroom, } \\
\text { even if they might not work. }\end{array}$ \\
\hline
\end{tabular}

a Item responses were recorded prior to factor analyses

Continued on the next page 
Table 21 (continued)

Student Teacher Pretest Factors and Factor Loadings

for the 31-Item Personal Teaching Efficacy Scale Using an Oblimin Rotation

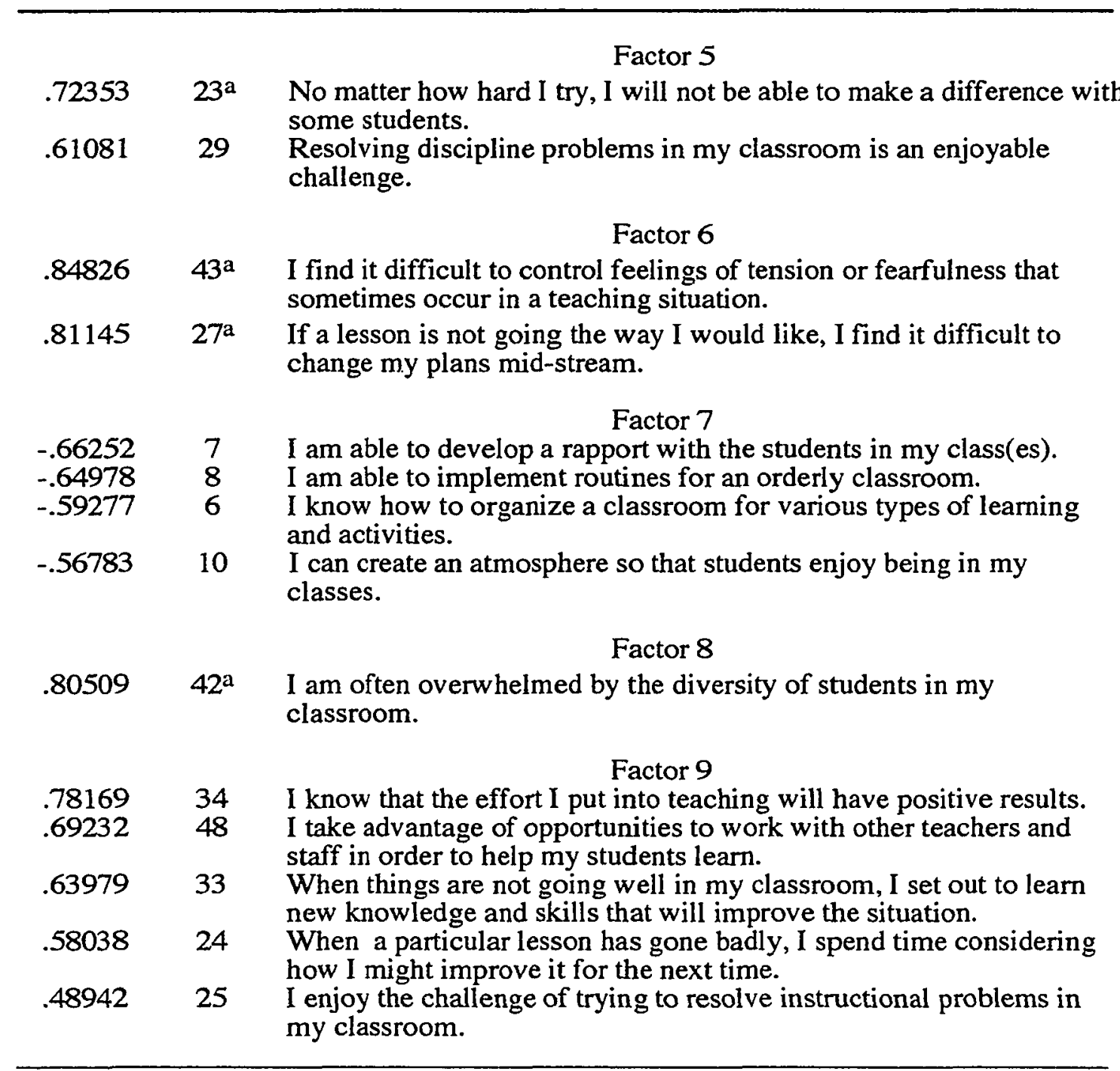

a Item responses were recorded prior to factor analyses 
Table 22

Factor Correlation Matrix for a Nine-Factor Solution of the Student Teacher Pretest

Using the 31-Item Scale and an Oblimin Rotation

\begin{tabular}{cccccccccc}
\hline FACTOR & 1 & 2 & 3 & 4 & 5 & 6 & 7 & 8 & 9 \\
\hline 1 & 1.00000 & & & & & & & & \\
2 & .07569 & 1.00000 & & & & & & & \\
3 & .10659 & .09476 & 1.00000 & & & & & & \\
4 & -.19752 & -.21707 & -.08507 & 1.00000 & & & & & \\
5 & .08881 & .04801 & .02497 & -.03849 & 1.00000 & & & \\
6 & .12591 & .15255 & .10909 & -.17820 & -.04381 & 1.00000 & & \\
7 & -.22863 & -.01200 & -.12665 & .14585 & -.01826 & -.09746 & 1.00000 & & \\
8 & .08864 & .06451 & .05053 & -.01445 & .03921 & .03176 & -.04704 & 1.00000 & \\
9 & .15775 & .21957 & .05761 & -.19877 & .01169 & .05839 & .01476 & .12264 & 1.0000 \\
\hline
\end{tabular}


and posttest factor solutions. On closer examination, Factors 7 and 9 of the student teacher pretest factor solution could be interpreted as representing group relations efficacy and action efficacy, respectively.

\section{Group Relations Efficacy}

Four items loaded on Factor 7 , three of which had been hypothesized to represent group relations efficacy. The fourth item, "I know how to organize a classroom for various types of learning and activities," had been hypothesized to load on the instruction efficacy factor, but its focus on creating a positive atmosphere for learning fits reasonably well with the other items related to group relations efficacy.

\section{Action Efficacy}

Three of the five items loading on Factor 9 had been hypothesized to load on action efficacy, with the remaining two items hypothesized as resiliency-protection factors. The first factor loading was a resiliencyprotection factor: "I know that the effort I put into teaching will have positive results." Given that one aspect of action efficacy focuses on proactive effort, this resiliency-protection factor was highly representative of action efficacy. The second resiliency-protection item, which loaded last, espoused enjoyment in resolving instructional problems, and thus, was aligned with the proactive problem-solving aspect of action efficacy.

While Factors 7 and 9 closely represented two of the hypothesized factors of personal teaching efficacy, the remaining seven factors did not. However, several could be interpreted within the broad frame of the model.

\section{Teaching Performance}

While there were no definitive factors representing instruction efficacy and student influence efficacy, Factors 1 and 3 appeared to represent the more general aspect of teaching performance. In addition, an integrative 
interpretation (Tinsley \& Tinsley, 1987) of the factor loadings did suggest possible interpretations of the two factors.

For example, taken together, the items loading on Factor 1 could be interpreted to represent student teachers' perceptions of their capabilities to overcome common teaching problems, including disruptive or unmotivated students and the diversity of learners. In addition, the item "I am able to acquire new skills that are necessary to teach effectively in particular circumstances," which was hypothesized to load on the action efficacy factor, fits well as a capability needed to effectively deal with the changing nature of these common teaching problems.

Factor 3 could also be interpreted as related to the teaching performance aspect, representing student teachers' perceptions of their capabilities to organize or access "technical" resources. For example, three of the four items loading on Factor 3 related to capabilities to access material resources, develop interesting learning activities, and organize subject matter. The fourth item, "I know that I will bounce back after a particularly difficult day," had been hypothesized to represent thought control efficacy, but it fit reasonably well with the other items if "bouncing back" was considered an internal resource.

Thought Control Efficacy

The remaining two items related to thought control did not load together in the factor solution using student teacher pretest data. One item, "I am often overwhelmed by the diversity of students in my classroom," loaded alone on Factor 8. The other item dealing with perceptions of capability to control feelings of tension or fearfulness loaded with an operative efficacy item related to the capability to change plans mid-stream, and thus, could be interpreted as student teachers' perceptions of their capabilities for selfcontrol. 
Impact Efficacy

Similarly, the two hypothesized impact efficacy items loaded on separate factors in the factor solution using student teacher pretest data. Neither factor was clearly interpretable. Interestingly, the item related to being able to make a difference with some students loaded with the item which espoused resolving discipline problems as an enjoyable challenge. Thus, this factor seems to reflect the high level of concern student teachers have about being able to keep control of the students in their classes.

The other impact efficacy item, "The students' home environment has more influence on their ability to achieve than I do as their teacher," loaded with five other items; two were hypothesized to represent instruction efficacy, two to represent action efficacy, and one to represent operative efficacy. I could not find a meaning for the factor which integrated the items together. Relationship of the Factor Structure

to the Hypothesized Model

The factor analysis of the student teacher pretest data did not produce a factor solution that was fully representative of either the hypothesized model of personal teaching efficacy or the factor solutions derived from teacher pretest and posttest data. In fact, only two of the nine factors--the group relations efficacy and the action efficacy factors--could be clearly interpreted using the model.

As the student teachers in this study had not had much classroom teaching experience, perhaps the factor solution represented their unclear conceptualizations of the teaching role. Alternately, student teachers with little classroom teaching experience may also have different concerns about their capabilities for teaching effectiveness which make their perceptions of what constitutes personal teaching efficacy different from those of practicing teachers. If this is so, as student teachers gain experience, their responses 
should move towards increased similarity with teacher responses. Thus, the posttest factor solution, using student teacher data, should resemble the factor solutions of the teacher pretest and posttest, as well as the proposed model of personal teaching efficacy.

\section{Factor Solution of the}

\section{Student Teacher Posttest}

Factor analyses of the student teacher posttest also yielded a nine-factor solution, with moderately strong factor loadings (see Table 23). The factor correlation matrix shows small correlations among almost all factors, with the exception of the correlation between Factor 5 and Factor 1, which is -.33089 (see Table 24). This relatively high correlation suggests that these two factors represent elements of the same thing. Possible reasons for this strong correlation will be discussed next in terms of factor meanings. Teaching Performance

The hypothesized model delineates three factors related to teaching performance: an instruction efficacy factor, a group relations efficacy factor, and a student influence factor. The student teacher posttest factor solution also has three factors related to teaching performance.

Student influence. Factor 9 can be clearly interpreted as representing student influence. Two of the three items loading on this factor--redirecting a disruptive student and getting unmotivated students to actively participate-were hypothesized as student influence items. The third item, hypothesized as a resiliency-protection factor, deals with enjoying the challenge of resolving discipline problems. Thus, this factor focuses more on the student behavior aspect of student influence, rather than on the student learning aspect.

Instruction efficacy. Three of the four items loading on Factor 5 were hypothesized to load on instruction efficacy. The other item, which loads first, 
Table 23

Student Teacher Posttest Factors and Factor Loadings

Using the 31-Item Scale and an Oblimin Rotation

$\begin{array}{ll}\text { Factor } & \text { Item } \\ \text { Loading } & \text { Number } \quad \text { Factor and Item Statement }\end{array}$

\begin{tabular}{|c|c|c|}
\hline .81793 & 16 & $\begin{array}{l}\text { Factor } 1 \\
\text { I know how to encourage parents to support their children's } \\
\text { learning. }\end{array}$ \\
\hline $\begin{array}{l}.79979 \\
.69968 \\
.67580 \\
.65647 \\
.64655 \\
.51306\end{array}$ & $\begin{array}{l}17 \\
19 \\
8 \\
10 \\
20 \\
15\end{array}$ & $\begin{array}{l}\text { I am able to accurately evaluate my students' progress. } \\
\text { I am able to manage most problems in my classroom. } \\
\text { I am able to implement routines for an orderly classroom. } \\
\text { I can create an atmosphere so that students enjoy being in my classes. } \\
\text { I am able to deal with the diversity of learners in my classroom. } \\
\text { I am able to acquire new skills that are necessary to teach effectively } \\
\text { in particular circumstances. }\end{array}$ \\
\hline
\end{tabular}

Factor 2

$.84209 \quad 43^{a} \quad$ I find it difficult to control feelings of tension or fearfulness that sometimes occur in a teaching situation.

$.71548 \quad 42^{\mathrm{a}} \quad$ I am often overwhelmed by the diversity of students in my classroom.

$.59801 \quad 27 \mathrm{a}$ If a lesson is not going the way I would like, I find it difficult to

$.53543 \quad 26 \quad$ I know that I will bounce back after a particularly difficult day.

-.85058 33 When things are not going well in my classroom, I set out to learn

$\begin{array}{lll}-.78492 & \text { new knowledge and skills that will improve the situation. } \\ \text { I take advantage of opportunities to work with other teachers and }\end{array}$

$\begin{array}{lll}-.68701 & 37 \quad \text { staff in order to help my students learn. } \\ \text { I can help most students to learn regardless of their ability. }\end{array}$

-.61599 13 I can plan instruction for students in my class who are at various levels of ability or stages of learning.

Factor 4

$.7516439^{a}$ The students' home environment has more influence on their ability to achieve than I do as their teacher.

a Item responses were recoded prior to factor analysis

Continued on the next page 
Table 23 (continued)

Student Teacher Posttest Factors and Factor Loadings

Using the 31-Item Scale and an Oblimin Rotation

Factor Item

Loading Number

Factor and Item Statement

\section{Factor 5}

$-.76407 \quad 46 \quad$ I know how to get the resources I need to teach effectively.

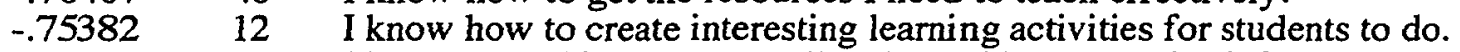

$-.72273 \quad 18 \quad$ I know my subject matter well and am able to organize it for

-603826 I know how to organize a classroom for various types of learning and activities.

\section{Factor 6}

$85042 \quad 23^{a} \quad$ No matter how hard I try, I will not be able to make a difference with some students.

.585027 I am able to develop a rapport with the students in my class(es).

34 I know that the effort I put into teaching will have positive results.

$.66650 \quad 21 \quad$ It is worth the effort to try to get through to all students.

.6422024 When a particular lesson has gone badly, I spend time considering how I might improve it for the next time.

.5862525 I enjoy the challenge of trying to resolve instructional problems in my classroom.

\section{Factor 8}

$.82331 \quad 22$ I am not afraid to try new ways of doing things in the classroom, even if they might not work.

$.52083 \quad 31$ When I am confronted with a particularly difficult teaching problem, I am determined to resolve it no matter how much work or time it takes.

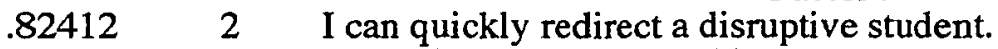

.6781129 Resolving discipline problems in my classroom is an enjoyable

$62641 \quad 3 \quad$ I am able to get even the most unmotivated students to actively participate in their own learning.

a Item responses were recoded prior to factor analysis 


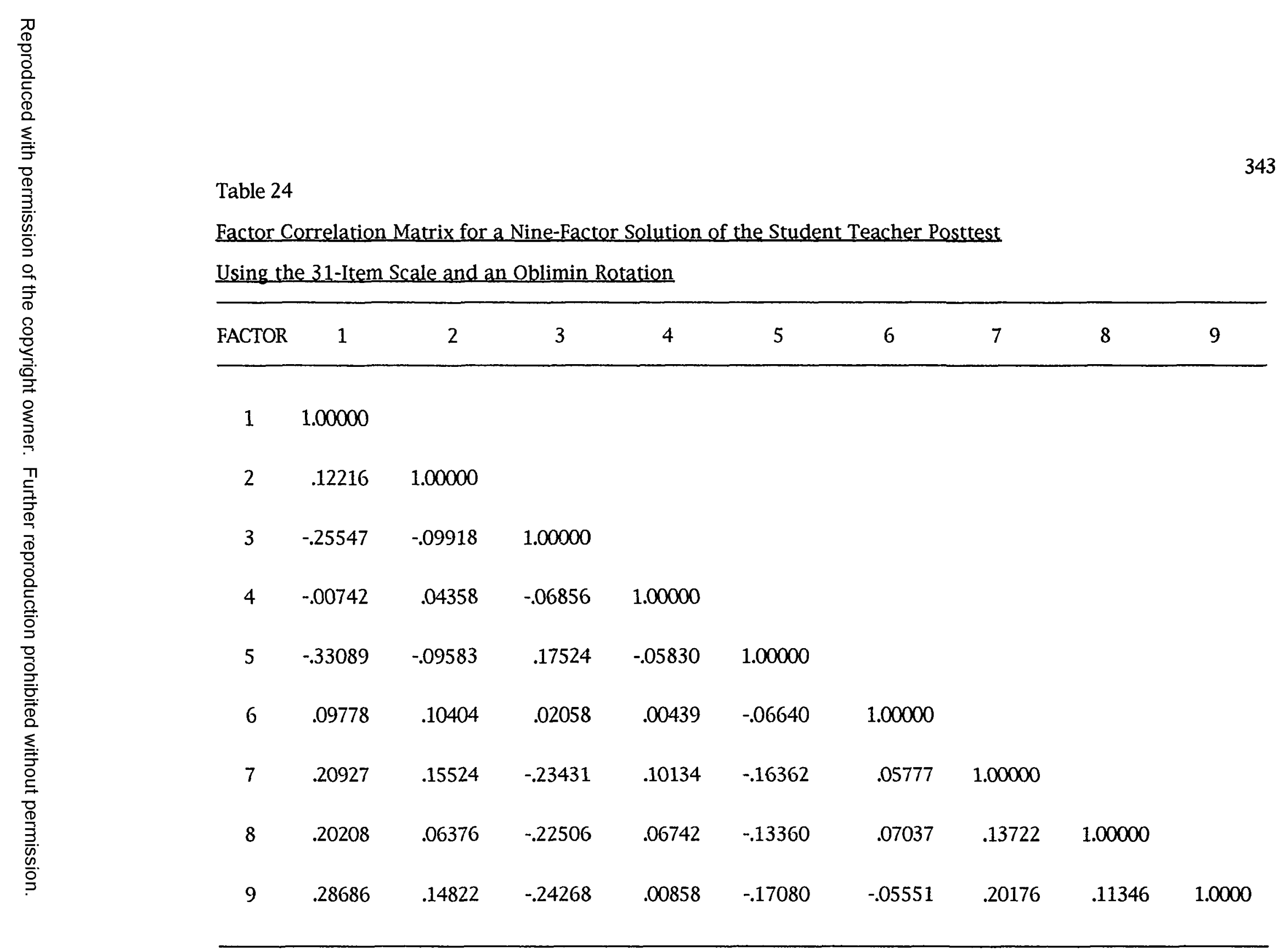


was hypothesized as an action efficacy item and relates to teachers' perceptions of their capability to get the resources needed to teach effectively. As accessing resources is an important part of teachers' work, it fits well with instruction efficacy.

Group relations efficacy. Three items hypothesized to represent group relations efficacy loaded on Factor 1. However, of the remaining four items, two items were hypothesized to load on action efficacy, one item on instruction efficacy, and one item on operative efficacy. These additional items influenced the underlying meaning of the factor such that a clear interpretation of Factor 1 as group relations efficacy could not be made.

Reinterpreting the meaning of Factors 1 and 5. It is clear that Factors 1 and 5 are representative of teaching performance. In addition, the strong, negative correlation between Factor 5 and Factor 1 (-.33089) suggests that these two factors represent different aspects of the same thing. A closer examination of the items loading on Factor 5 reveals that they are representative of the planning and organizing elements of teaching. Alternately, items on Factor 1 are more representative of the active, operational elements of teaching, with developing conditions for positive group relations as one aspect of these operations. Other elements, which are part of Factor 1, include encouraging parents to support their children's learning (the first factor loading), accurately evaluating student progress (loading second), and dealing with diverse learners (loading sixth). They, along with the final item, which relates to teachers' capabilities to acquire new skills for particular circumstances, are "on-the-ground" capabilities. In contrast to Factors 1 and 5, which deviate from the proposed factor structure, three factors of the factor solution using student teacher posttest data do represent the hypothesized model. 


\section{Thought Control Efficacy Factor}

Three of the four items loading on Factor 2 were hypothesized to represent thought control efficacy. The fourth item (loading third), related to capabilities to change plans mid-stream, can also be interpreted as related to thought control. However, when this item is included with the other thought control items, the meaning of the factor seems more related to self-control. Action Efficacy Factor

The first two items loading on Factor 3 had been hypothesized as action efficacy items. The other two items, "I can help most students to learn regardless of their ability" and "I can plan instruction for students in my class who are at various levels of ability or stages of learning," were hypothesized as student influence efficacy and instruction efficacy items, respectively. However, when these items load with the two hypothesized action efficacy items, they can be easily interpreted as aspects of proactive problem solving and, thus, fit well with the other two items.

Impact Efficacy Factor

The two items hypothesized to represent impact efficacy loaded separately on Factors 4 and 6 . The item related to teachers' influence in comparison with home influence loaded alone. However, the item related to being able to make a difference with some students loaded with a hypothesized group relations item, "I am able to develop a rapport with the students in my class(es)." Taken together these two items appear to represent another, more relational aspect of student influence.

\section{Resiliency-Protection Factors}

Interestingly, three of the four items hypothesized as resiliencyprotection factors loaded together with the hypothesized action efficacy item, "When a particular lesson has gone badly, I spend time considering how I might improve it for the next time." Given that two of the resiliency- 
protection items espouse the efficacy of effort, this factor may be representing the proactive-effort aspect of action efficacy.

\section{Qperative Efficacy Factor}

The first item loading on Factor 8 had been hypothesized to represent operative efficacy; however, the second, and final, item had been hypothesized to load on action efficacy. While it may be possible to find an integrative meaning underlying the factor, the large difference in factor loadings (.82331 and .52083 , respectively) suggests that this factor may be "a residual or error factor" (Tinsley \& Tinsley, 1987, p. 423).

\section{Relationship of the Factor Structure}

to the Hypothesized Model

The factor solution produced using student teacher posttest data accounted for four of the seven hypothesized factors, with the thought control efficacy, action efficacy, and student influence factors being most strongly represented in the posttest factor solution. In addition, the thought control efficacy factor gains two items hypothesized to represent thought control efficacy. However, although the impact efficacy factor was somewhat present, only one of the two hypothesized items, loading alone, represented it.

Alternately, while two factors of the factor solution represented the teaching performance aspect of the hypothesized model, they could not be clearly interpreted as instruction efficacy and group management efficacy factors. Finally, the hypothesized operative efficacy factor was not strongly represented, if at all, in this factor solution. 


\section{Factor Stability From Student Teacher Pretest}

\section{to Student Teacher Posttest Factor Analyses}

There was moderate stability of the factor structure from the student teacher pretest to posttest in that action efficacy, thought control efficacy, and two general teaching performance factors could be identified in both factor structures. In addition, two items loading on the action efficacy factor, two items loading on the thought control efficacy factor, and three items loading on each of the teaching performance factors remained the same.

However, the group relations efficacy factor derived from the student teacher pretest data was subsumed with the general teaching performance items in the student teacher posttest factor solution. This suggests that, perhaps, the underlying meaning of this factor more likely represents active teaching operations rather than teaching problems as suggested in the discussion related to the student teaching pretest.

Interestingly, one of the hypothesized impact efficacy items, "No matter how hard, I try I will not be able to get through to all students," loaded with a different item from pretest to posttest. In the pretest, the resiliencyprotection factor related to resolving discipline problems loaded with it; while in the posttest, the group relations item related to developing a rapport with students loaded with it. Prior to practicum, getting through to or influencing students was related to being able to control students; alternately, at the end of practicum, getting through to or influencing students was related to being able to develop positive relationships with them. 
Stability of the Student Teacher Posttest Factor Solution

Compared to the Teacher Pretest and Posttest Factor Solutions

While the nine-factor solution, derived using student teacher posttest data, differed in the number of factors from both the pretest and posttest factor solutions, there were some similarities in factors and factor loadings. Items Related to Impact Efficacy

The two items hypothesized to load on impact efficacy did so in the factor solutions for the teacher pretest and posttest; however, the number of items loading on impact efficacy expanded in the teacher posttest factor solution. Alternately, the two items loaded separately in the factor solutions for the student teacher pretest and posttest. However, the item "The students' home environment has more influence on their ability to achieve than I do as their teacher" loaded alone on the student teacher posttest. Items Related to Action Efficacy

The items loading on action efficacy are not the same in the factor solutions of the teacher pretest and the student teacher posttest. However, three items loading on action efficacy in the teacher posttest and student teacher posttest factor solutions are the same.

Items Related to

Thought Control Efficacy

Two items load together across the teacher pretest, teacher posttest, and student teacher posttest and represented thought control efficacy. Further, when only the teacher and student teacher posttest factor solutions are compared, three items loading on the thought control efficacy factor remained the same.

Items Related to Operative Efficacy

Of all the hypothesized factors, the operative efficacy factor was the most unstable in terms of common item loadings. It is represented best in the 
teacher pretest, where the hypothesized items load on two factors, each representing a predisposition of operative efficacy. That is, the predisposition to trust one's capabilities in dynamic situations is represented by one factor, and the predisposition for adaptive flexibility is represented by another.

In the teacher and student teacher posttests, the operative items most often load with action efficacy items, confounding an interpretation based on the hypothesized model.

Items Related to

\section{Group Relations Efficacy}

Three items, hypothesized as representing group relations efficacy, loaded together in the factor solutions of teacher pretest, teacher posttest, and student teacher posttest. However, while these items appear to represent a group relations efficacy factor in the teacher pretest and posttest, they are part of a broader unhypothesized factor, which might be called teaching operations efficacy in the student teacher posttest. In addition, two items loading on the group relations efficacy factor in the teacher posttest factor solution load on another unhypothesized factor, which might be called teaching preparation efficacy, in the student teacher posttest.

Items Related to

Student Influence Efficacy

Two items related to teachers' capabilities to influence student behavior and focused particularly on discipline load together as a student influence factor in the factor solutions of the teacher pretest and student teacher posttest. However, in the teacher posttest, other student influence items were subsumed under either the factor representing impact efficacy or the broader, unhypothesized teaching performarce factors. 
Items Related to

Instruction Efficacy

A clearly interpretable instruction efficacy factor was present in the teacher pretest factor solution only. In the factor solutions for the teacher posttest and student teacher pretest and posttest, this factor was replaced by one or two factors representing the more general teaching performance.

\section{Conclusion}

Chapter 4 has outlined the theory and the process underlying my attempt to reconceptualize the personal teaching efficacy construct. The final model hypothesizes that personal teaching efficacy is a multidimensional construct with motivational and volitional aspects, and the factor analyses somewhat confirm the validity of this hypothesis. The contribution of the theoretical aspect of this study to understanding teachers' sense of efficacy will be discussed in chapter 7.

Chapters 5 and 6 outline the empirical study conducted to test the utility of the model and scale. Chapter 5 presents the methodology used to test changes in teachers' and student teachers' sense of efficacy after participation in a reflective practitioner model practicum; chapter 6 reports the findings. 


\section{CHAPTER 5}

\section{METHODS}

\section{Overview}

The purposes of this study were to reconceptualize the personal teaching efficacy construct, to develop a model and scale based on the reconceptualization, and finally, to test the scale's utility in measuring teachers' and student teachers' sense of efficacy. Chapter 5 reports the methods used to fulfill this empirical aspect of the study.

Teachers and student teachers participating in the University of Alberta's final elementary student teaching experience were used as the sample groups. I reasoned that if teachers' and student teachers' sense of efficacy are affected by their experiences, then their participation in the University of Alberta's elementary term practicum, as school facilitators and student teachers, respectively, was also likely to affect their self-percepts of personal teaching efficacy.

The 12-week practicum offered through the University of Alberta was similar to the reflective practitioner model practicum offered through the University of Wisconsin (Zeichner, 1986). The literature on teaching and learning to teach and on reflective practice suggests that this program, with its focus on structured opportunities for collaboration and provisions for support, would provide an appropriate context for positive changes in teachers' and student teachers' sense of efficacy. 
The Study Population

The two populations of interest are teachers and student teachers participating in the final student teaching experience of the University of Alberta's teacher education program. At the beginning of this study, student teachers had completed all required course work, which focused on teaching in elementary schools, and had entered into the final term of a 4-year Bachelor of Education degree. Teachers who participate as school facilitators usually have a minimum of 5 years of experience.

Two hundred thirty-six student teachers, completing their practicum in 67 schools, represent the student teacher population of interest. In addition, 467 teachers played some role in the practicum (B. Skogen, personal communication, July 24,1998 ).

\section{Study Sample of Each Group: \\ Teachers and Student Teachers}

Voluntary samples from the teacher and student teacher populations were asked to complete the pretest and posttest forms of the Personal Teaching Efficacy Scale (see Table 7 in the previous chapter). As Table 7 demonstrates, the relatively large percentage (69.9\%) of student teachers completing the pretest suggests that the student teacher sample is representative of the population. In contrast, the teacher sample represents only $22.5 \%$ of the teacher population of interest. This percentage, however, may be somewhat misleading in that it represents all teachers who were paid for their participation: The actual participation of teachers could vary from 1 or 2 weeks to 12 weeks. It seems likely that most teachers who completed both the pretest and the posttest would be those with a substantial involvement in the practicum. Interestingly, a group of teachers at one school chose not to 
complete the survey because they did not believe that their perceptions of personal teaching efficacy would change in 12 weeks; a second group did not participate because they were concerned that they could be singled out as a group.

As might be expected, there was some attrition in the numbers of teachers and student teachers from pretest to posttest (see Table 7). The pretest was completed by 105 teachers and 165 student teachers; the posttest was completed by 93 teachers and 102 student teachers. This attrition in numbers, along with the fact that not all teachers and student teachers responded to all items in the scale, further reduced the number of matched teacher and student teacher cases ( 86 and 84 , respectively) that could be used in the subsequent statistical analyses (see Table 7).

The Setting

\section{The Geographical Area}

The University of Alberta offers student teachers the opportunity to complete their practicums in the greater Edmonton, Alberta, area, as well as in Regional Teacher Education Centres located in central and northern Alberta. Students completing the term practicums in elementary education in January, 1995, were assigned to elementary classrooms in both public and Catholic schools located within 60 miles of Edmonton and within 30 miles of Grande Prairie, Alberta. Thus, some student teachers completed their student teaching practicums in Edmonton schools, while others completed theirs in schools serving small cities, towns, and villages. 


\section{The Structure and Organization}

\section{of the Practicum}

The elementary term practicum is 12 weeks in length, with student teachers practicing in two classrooms over the 12-week period. One student teaching experience is completed in Division 1 (Grades 1 to 3 ) and the second is completed in Division 2 (Grades 4 to 6). In addition, students with a special education focus have the opportunity to complete one of their student teaching assignments working with special education students in either a pull-out program or an integrated setting.

The University of Alberta's elementary term practicum can be described as a reflective practitioner model practicum, with at least four characteristics separating it from traditional "apprenticeship" practicums. Opportunities for

Collaboration

The 12-week term practicum is specifically structured to encourage collaborative relationships. For example, more than one student teacher is assigned to a school. This encourages student teachers to talk together and share resources. In addition, many schools either provide time within the school day for students to meet together, or encourage student teachers to observe one another, or both.

Student teachers are also required to attend a weekly seminar. This not only provides them with alternate ways to collaborate with other student teachers, but also gives them an opportunity to share experiences with, and learn from, the seminar leader.

Having more than one student in the school also encourages participating teachers, called school facilitators, to work together. The university asks that teachers in the school team observe more than one student teacher on a regular basis, with each teacher observing all student 
teachers desirable. This gives teachers many opportunities to interact with each other and with the student teachers assigned to their school. In addition to these informal opportunities for collegial interaction, school facilitators are requested to find a common time when they can meet together with a member of the Faculty of Education, called a university facilitator. The university facilitator spends one-half day per week in the school, during which time he or she meets with school facilitators and student teachers, as well as observes student teachers in the classroom.

School facilitators can also communicate with seminar leaders through the university facilitator. Through their suggestions, school and university facilitators help each seminar leader to organize specific learning experiences for student teachers.

Opportunities for

Reflection

Many informal and formal opportunities for reflection are offered to student teachers. For example, all student teachers are encouraged to keep a personal journal to record their experiences and their reflections on them. Some school facilitators ask their student teachers to keep an interactive journal, whereby school facilitators can respond regularly to the student teachers' written thoughts and questions.

Shared reflection is also the foundation of the seminar and school-level opportunities for students to meet together. Teachers also have opportunities to reflect on their practice in their weekly meetings with the school facilitator.

Opportunities for Individual Development

The relatively long duration of the practicum (one academic semester) allows student teachers to be introduced to classroom teaching at variable 
rates. For example, some students quickly assume the responsibilities of fulltime teachers, while others--usually those with less experience working with children--are able to ease into full-time teaching by first working with small groups within the classroom, then taking responsibility for one subject, then two, and so on.

Allowing student teachers to assume responsibility for full-time teaching at their own rate helps them to maintain feelings of confidence and control over their learning and practice. However, all student teachers are required to assume full teaching duties for at least 1 week of their practice teaching experience.

Qpportunities for School-Level Participation

The focus of the 12-week practicum is full participation in the life of the school. Student teachers are encouraged to attend school meetings, share in recess and noon-hour supervision, and assume other school-level duties of practicing teachers. Student teachers are also encouraged to take part in special events and extracurricular activities. Many student teachers work together to complete a collaborative project of benefit to students and the schools.

\section{Research Methodology}

\section{Research Design}

This study can be classified as "survey research" (Borg \& Gall, 1989, p. 416), using a "one-group pretest-posttest design" (Borg \& Gall, 1989, p. 670). However, because there were two populations of interest, two separate studies were initiated. A new teaching efficacy scale, designed as part of the reconceptualization of the personal teaching efficacy construct, was 
administered to cross-sections (samples) of the two populations of interest in the first and last weeks of a 12-week reflective practitioner model practicum. Thus, the practicum experience acts as the intervening treatment. The relatively long interval between the pretest and posttest serves to reduce the threat of an interaction of time of measurement and treatment effect.

As with a one-group pretest-posttest design, the differences in teachers and student teachers' self-percepts of personal teaching efficacy were determined by comparing their pretest and posttest mean scores. In addition, the differences between pretest and posttest mean scores, or "gain scores" (Willett, 1994, cited in Chester \& Beaudin, 1996), were also used to determine differences among subgroups of teachers and student teachers.

\section{The Instrument: The Personal Teaching Efficacy Scale}

As chapter 3 outlines, the instrument used to measure personal teaching efficacy was developed by the researcher. The original scale contained 53 items: 46 items related to personal teaching efficacy and 7 items related to the context of teaching. However, as a result of decisions made during preliminary factor analyses, the scale used to determine underlying factors and to measure personal teaching efficacy was modified to include only 31 items.

\section{Underlying Factors}

Factor analyses of the 31-item scale failed to yield stable factors from pretest to posttest for either the teacher or the student teacher data. However, for some factors, there were two or three items which remained stable from pretest to posttest. The mean aggregate scores of the stable items loading on these factors were used to represent the factors in the statistical analyses for the study. 
Additional Scale Items

Pretest. In addition to the main scale items, items requesting demographic or descriptive data were added to the teacher and student teacher pretest forms of the scale. Four items were added to the teacher pretest form, requesting information related to gender, age, years of teaching experience, and previous participation in the practicum. Three items were added to the student teacher pretest form, requesting information related to gender, age, and amount of previous work with children. These data were used to describe the two samples and as independent variables in subsequent statistical analyses.

Posttest. Additional items were also added to the teacher and student teacher posttest forms of the scale. Both the teacher and student teacher posttests asked for information related to the size of their homeroom class, the number of students in the school, and the number of student teachers in the school cohort. The teacher posttest form also contained four items which polled teachers' perspectives on the practicum experience, while the student teacher posttest form contained eight similar items. These data (when valid) were used to describe the two samples.

\section{Content Validity}

The content validity of the Personal Teaching Efficacy Scale was affirmed in three ways: First, the items on the scale reflect theory and research on teacher efficacy and teacher effectiveness, as well as related theory and research on self-efficacy and volition. Second, the scale included the nonredundant items from the teacher efficacy scale accepted in the field (for example, Gibson \& Dembo, 1984; Woolfolk \& Hoy, 1990; Guskey \& Pasarro, 1993); however, items were all stated in the personal, "I." Third, the teachers in the pilot study confirmed that the items on the scale were representative of thoughts, feelings, and behavior of teachers. Interviews with teachers and 
student teachers in the later study reconfirmed the content validity of the scale. One teacher remarked, "You sure understand what teaching is all about."

\section{Scale Reliability}

Cronbach's alpha for the full scale (53-items) and for both the 46-item and the 31-item Personal Teaching Efficacy Scales of the four data sets are displayed in Table 25. The alpha values are all large, indicating that the Personal Teaching Efficacy Scale is quite reliable.

\section{Data Collection}

The university facilitators and seminar leaders involved in the wintersemester (January to April, 1995) practicum offered to help in the distribution, administration, and collection of the pretest and posttest forms of the Personal Teaching Efficacy Scale. I distributed the pretest scales to them prior to the practicum and the posttest scores 2 weeks prior to the end of the 12 weeks. Procedures for Collecting

Student Teacher Data

Pretest. In the first or second session of the seminar, the seminar leaders asked for student teacher volunteers to complete the Personal Teaching Efficacy Scale. Seminar leaders explained the pretest-posttest format of the study and emphasized that participation was voluntary and that confidentiality would be strictly maintained. Student teachers completed the survey in class and returned it to the seminar leader, who sent it to the Field Experience Office at the University of Alberta for me to pick up.

Confidentiality. Each pretest form of the scale was identified by a number. After student teachers had completed the scale, a record of the numbers and corresponding student teacher names, initials, or other 
Table 25

\section{Cronbach's Alpha Values}

\begin{tabular}{cccc}
\hline & \multicolumn{3}{c}{ Alpha Value } \\
\cline { 2 - 4 } $\begin{array}{c}\text { Scale } \\
\text { Form }\end{array}$ & $\begin{array}{c}\text { Full Scale } \\
\text { (53 Items) }\end{array}$ & $\begin{array}{c}\text { Personal Teaching } \\
\text { Efficacy Scale } \\
\text { (46 Items) }\end{array}$ & $\begin{array}{c}\text { Personal Teaching } \\
\text { Efficacy Scale } \\
\text { (31 Items) }\end{array}$ \\
\hline $\begin{array}{c}\text { Teacher Pretest } \\
\text { Teacher Posttest }\end{array}$ & .9185 & .9165 & .8765 \\
$\begin{array}{c}\text { Student Teacher } \\
\text { Pretest }\end{array}$ & .9395 & .9328 & .9040 \\
$\begin{array}{c}\text { Student Teacher } \\
\text { Posttest }\end{array}$ & .9233 & .8968 & .8589 \\
\hline
\end{tabular}


identifiers was made and sealed in an envelope. The envelope remained sealed until the posttest administration of the scale, when it was used to assure that a student teacher identified his or her posttest with the same number used in the pretest. The list of numbers and corresponding identifiers was then destroyed. Posttest. The posttest form of the scale was distributed in the 11 th or 12 th week of the seminar. Students completed the scale and affixed their pretest identification number to the first page. The seminar leader again collected the scales and returned them to the Field Experience Office.

Attrition. Attrition in the number of student teachers completing the scale from pretest to posttest occurred for a number of reasons: Some student teachers were absent from the seminar on the day the posttest was administered and could not be tracked down, some student teachers had dropped the practicum, and some students did not want to complete the posttest. In one instance, the seminar leader chose not to administer the posttest because several members of the seminar group had had a difficult time in the practicum.

Procedures for collecting Teacher Data

Pretest. The university facilitators asked for volunteers to complete the Personal Teaching Efficacy Scale from each of the school teams they were working with. University facilitators also explained the pretest-posttest format of the study and emphasized that participation was voluntary and that confidentiality would be strictly maintained. In many cases, the scale was not distributed until the second week of the practicum, as the first week was devoted to getting organized. In contrast to the student teachers, most school team members opted to take the scale with them to complete on their own time and return at the next seminar. This led to some scales being turned in as many as 4 weeks into the practicum. Once university facilitators had collected 
the scales, they turned them into the Field Experience Office at the University of Alberta for me to pick up.

Confidentiality. As with the student teacher scales, each pretest form of the scale was identified by a number, and a record of each number and the corresponding teacher name, initials, or other identifier was made and sealed in an envelope. The envelope remained sealed until the posttest administration of the scale, when it was used to assure that a teacher identified his or her posttest with the same number used in the pretest. The list of numbers and corresponding identifiers was then destroyed.

Posttest. The posttest form of the scale was distributed in the 11 th or 12 th week of the seminar. Teachers completed the scale and affixed their pretest identification number to the first page. The university facilitators collected the scales and again returned them to the Field Experience Office.

Attrition. Attrition in the number of teachers completing the scale from pretest to posttest also occurred: Some teachers found it difficult to find time to complete the scale with the extra time required to complete end-ofseminar commitments, while others chose not to. Interestingly, some teachers who had not completed the pretest chose to complete the posttest.

\section{Independent and Dependent Variables}

\section{Independent Variables}

The gender and age of both teachers and student teachers were used as independent variables. The number of years of teaching experience and previous participation in a practicum experience were also used as independent variables in the study of the teacher sample, while data related to previous work with children were used as an independent variable in the student teacher sample. 
Data related to class and school size, the number of student teachers in the school cohort, and student teachers' personal perspectives on the practicum were also collected, but were collected to describe the samples in this study.

\section{Dependent Variables}

Differences in teachers' self-percepts of personal teaching efficacy from the pretest to the posttest administration of the Personal Teaching Efficacy Scale were determined in a number of ways. Thus, each of the following was used as a dependent variable in one or more statistical analyses of the teacher and student teacher studies: (1) the pretest and posttest mean scores for each of the 46 scale items (variables); (2) the pretest and posttest mean aggregate score of the 31 items on the Personal Teaching Efficacy Scale; (3) the pretest and posttest mean aggregate score on selected variables, each representing an underlying factor of personal teaching efficacy; (4) the gain score representing the difference between the aggregate mean scores of the 31 items on the Personal Teaching Efficacy Scale from pretest to posttest; and (5) the gain score representing the difference between the aggregate mean scores of items representing selected factors.

Since only two or three items loading on a factor remained stable from pretest to posttest, a "factor" score is represented only by these stable items. In addition, because the stable items for each factor differ between the teacher and student teacher factor analyses, different items were used to represent the factors in the teacher and student teacher studies.

\section{Intervening Variable}

As stated previously, the practicum experience was the intervening variable in both the teacher and the student teacher study. Elements of the reflective practitioner model practicum were explained to all participants, and 
the university facilitator reinforced the guidelines through active participation as a member of the school team.

However, given the large number of schools and teachers participating in the practicum experience, the differing contexts across schools, and the variety of university facilitators working with school teams, these guidelines were not implemented uniformly across all schools. In addition, the reflective practitioner model itself encourages teachers to make decisions about how the practicum can best be modified to fit their particular school.

\section{Definitions of the Terms}

Used in the Practicum

\section{Term Practicum}

The term practicum is a full-time student teaching experience of 12 weeks, offered in the fourth and final year of a Bachelor of Education program in elementary education at the University of Alberta.

\section{Seminar}

The seminar is a three-credit course which is 13 weeks in length and runs concurrently with the practicum experience. Up to 34 student teachers attend the seminar one afternoon per week. Thus, students are in the schools only 4.5 days per week.

\section{Student Cohort}

A student cohort is a group of student teachers, usually two to six people, who complete a student teaching experience together in one school setting. Several student cohorts make up the seminar group.

School Team

A school team is a group of teachers at one school who have designed a school plan for the practicum experience and who work with a student cohort to fulfill that plan. 
University Secondment

University secondment is the "borrowing" of a staff member from a school district to work at the university for a predesignated period of time, usually 2 to 3 years. School staff members seconded to the university are paid the same salaries and benefits as in their regular jobs.

Practicum Associate

A practicum associate is a university faculty member or a "seconded" teacher who coordinates the practicums of a set of student teacher cohorts. The practicum associate is often a seminar leader, too.

\section{University Facilitator}

A university facilitator is a university faculty member, seconded teacher, or graduate student who works with the school team and student cohort at a particular school. The university facilitator spends one-half day per week in the school, observing student teachers and meeting with the school team and student teachers.

Seminar Leader

A seminar leader is a university faculty member or a practicum associate who conducts the weekly seminar.

Field Experience Office

The Field Experience Office is a department in the Faculty of Education, University of Alberta. The faculty and staff in the office arrange for practicum placements, organize the work of university facilitators, and oversee the general implementation of the practicum. Regional Teacher Education Centre

A Regional Teacher Education Centre (RTEC) is an administrative structure serving student teachers who want to complete their practicums outside the Edmonton area. RTECs are mainly responsible for organizing university facilitators to work with school teams and student teachers and for 
offering the seminar that runs concurrently with the practicum experience. Some RTECs also organize practicum placements.

\section{Operational Definitions: Dependent Variables}

\section{Personal Teaching Efficacy}

Personal teaching efficacy is operationally defined as the mean of the aggregated mean scores on the 31 items of the Personal Teaching Efficacy Scale.

Instructional Efficacy

Instructional efficacy is operationally defined as the mean of the aggregate mean scores on items loading on the instructional efficacy factor of both the pretest and posttest.

Teacher sample. Two items loading on the instruction efficacy factor were common to the teacher pretest and posttest:

1. I can plan instruction for students in my class who are at various levels of ability or stages of learning (Item 13).

2. I am able to accurately evaluate my students' progress (Item 17).

Student teacher sample. Three items loading on the instruction efficacy factor were common to the student teacher pretest and posttest:

1. I know how to create interesting learning activities for students to do (Item 12).

2. I know my subject matter well and am able to organize it for successful learning (Item 18).

3. I know how to get the resources I need to teach effectively (Item 46). Group Relations Efficacy

Group relations efficacy is operationally defined as the mean of the aggregate mean scores on items loading on the group relations efficacy factor of both the pretest and posttest. 
Teacher sample. Four items loading on the group relations efficacy factor were common to the teacher pretest and posttest:

1. I am able to develop a rapport with the students in my class(es) (Item 7).

2. I am able to implement routines for an orderly classroom (Item 8).

3. I can create an atmosphere so that students enjoy being in my class(es) (Item 10).

4. I am able to manage most problems in my classroom (Item 19).

Student teacher sample. Items 7,8 , and 10, above, loaded as a group relations efficacy factor in the factor analysis of student teacher pretest data, and Items 8 and 10 loaded together in the factor analysis of student teaching posttest data. However, in the posttest factor analysis, these items loaded on a new factor, and no group relations efficacy factor was present in the student teacher posttest factor analysis. Therefore, no index representing the group relations factor was created for analysis of the student teacher data.

\section{Impact Efficacy}

Impact efficacy is operationally defined as the mean of the aggregate mean scores on items loading on the impact efficacy factor of both the pretest and posttest.

Teacher sample. Two items loading on the impact efficacy factor were common to the teacher pretest and posttest:

1. No matter how hard I try, I will not be able to make a difference with some students (Item 23).

2. The students' home environment has more influence on their ability to achieve than I do as their teacher (Item 39).

Student teacher sample. None of the items representing impact efficacy loaded together in the factor analyses of the student teacher pretest and posttest. 
Thought Control Efficacy

Thought control efficacy is operationally defined as the mean of the aggregate mean scores on items loading on the thought control efficacy factor of both the pretest and posttest.

Teacher sample. Two items loading on the thought control efficacy factor were common to the teacher pretest and posttest:

1. I am often overwhelmed by the diversity of students in my classroom (Item 42).

2. I find it difficult to control feelings of tension or fearfulness that sometimes occur in a teaching situation (Item 43).

Student teacher sample. Two items loading on the thought control efficacy factor were common to the student teacher pretest and posttest: 1. I find it difficult to control feelings of tension or fearfulness that sometimes occur in a teaching situation (Item 43).

2. If a lesson is not going the way I would like, I find it difficult to change plans mid-stream (item 27).

Action Efficacy

Action efficacy is operationally defined as the mean of the aggregate mean scores on items loading on the action efficacy factor of both the pretest and posttest.

Teacher sample. Two items loading on the action efficacy factor were common to the teacher pretest and posttest:

1. When a particular lesson has gone badly, I spend time considering how I might improve it for the next time (Item 24).

2. When things are not going well in my classroom, I set out to learn new knowledge and skills that will improve the situation (Item 33).

Student teacher sample. Two items loading on the action efficacy factor were common to the student teacher pretest and posttest: 
1. I take advantage of opportunities to work with other teachers and staff in order to help my students learn (Item 48).

2. When things are not going well in my classroom, I set out to learn new knowledge and skills that will improve the situation (Item 33).

\section{Student Influence Efficacy}

While a student influence efficacy factor could be discerned in the teacher pretest and the student teacher posttest, no student influence efficacy factors were identified in the teacher posttest and the student teacher pretest. Thus, aggregated scores for a student influence efficacy factor could not be used in the statistical analyses of the teacher and student teacher data. Operative Efficacy

No clear operative efficacy factor could be discerned in the teacher pretest, the student teacher pretest, and the student teacher posttest; and only one item loaded on operative efficacy in the teacher posttest factor analysis. Thus, aggregated scores for an operative efficacy factor could not be used in the statistical analyses of the teacher and student teacher data. "Teaching Operations" Factor

As discussed in chapter 4, factor analyses of the student teacher pretest and posttest data revealed two new factors representing students' self-percepts of their capabilities to fulfill common teaching tasks. One factor represented teacher-planning activities, while the other represented tasks that were more operational in nature.

Two items loading on this teaching operations factor were common to the student teacher pretest and posttest:

1. I am able to manage most of the problems in my class (Item 19).

2. I am able to deal with the diversity of learners in my class (Item 20). 


\section{Operational Definitions: Independent Variables}

Specific groups within each sample were tested for their effect on changes in personal teaching efficacy. They acted as independent variables in subsequent analyses.

\section{Independent Variables in the}

\section{Teacher Sample}

Four independent variables were used to test for differences in the teacher sample: age group, gender, years of teaching experience, and previous participation in the practicum.

Age group. Teachers were categorized according to three age groups, and the mean score of each group was used in the analyses: "Young" teachers were 21 to 35 years of age, "middle-aged" teachers were 36 to 45 , and "mature" teachers were 46 to 59 .

Gender. Teachers were categorized according to whether they were male or female, and the mean score of each group was used in the analyses.

Years of teaching experience. Teachers were assigned to one of the three following groups: "neophyte teachers" had 3 to 10 years of teaching experience, "midcareer teachers" had 11 to 20 ears of experience, and "veteran teachers" had 21 to 39 years. The mean score of each group was used in the analyses.

Previous practicum experience. Teachers were assigned to one of two categories, those with previous practicum experience and those without, and the mean score of each group was used in the analyses.

Independent Variables in the Student Teacher Sample

Three independent variables were used to test for differences in the student teacher sample: age group, gender, and previous work with children. 
Age group. Student teachers were categorized according to four age groups, and the mean score of each group was used in the analyses. "Very young" student teachers were 20 to 22 years of age, "young" student teachers were 23 to25 years old, "middle-aged" student teachers were 26 to 35 years old, and finally, "mature" student teachers were 36 to 48 years old.

Gender. Student teachers were categorized according to whether they were male or female, and the mean score of each group was used in the analyses.

Work with children. Three categories of previous work with children distinguished student teachers: little or no previous work with children (Likert Values 1 and 2), moderate amounts (Likert Value 3), or a great deal of previous work with children (Likert Values 4 and 5). The mean score of each group was used in the analyses

\section{Study Questions, Hypotheses, and}

Methods of Interpreting Data

Two general questions, one for each of the two sample groups, shaped this study.

\section{General Questions}

1. Will teachers' self-percepts of personal teaching efficacy change after participation in a reflective practitioner model practicum?

2. Will student teachers' self-percepts of personal teaching efficacy change after participation in a reflective practitioner model practicum?

These two general questions were first answered at the level of the scale; that is, the differences in pretest and posttest mean aggregate scores of the 31 items representing personal teaching efficacy were tested. Then, mean differences at the factor level and the variable level were tested. The following 
null hypotheses were formulated for changes in teachers and student teachers' self-percepts of personal teaching efficacy.

Change in Teachers' Self-Percents of Personal Teaching Efficacy

Null Hypothesis 1 . There is no significant difference in the mean score of each of the 46 variables representing personal teaching efficacy from teacher pretest to posttest.

Null Hypothesis 2.- There is no significant difference in the aggregate mean score of the 31-item Personal Teaching Efficacy Scale from teacher pretest to posttest.

Null Hypothesis 3. There is no significant difference in the aggregate mean score of the two items representing instruction efficacy from teacher pretest to posttest.

Null Hypothesis 4. There is no significant difference in the aggregate mean score of the four items representing group relations efficacy from teacher pretest to posttest.

Null Hypothesis 5. There is no significant difference in the aggregate mean scores of the two items representing thought control efficacy from teacher pretest to posttest.

Null Hypothesis 6. There is no significant difference in the aggregate mean score of the two items representing impact efficacy from teacher pretest to posttest.

Null Hvoothesis 7. There is no significant difference in the aggregate mean scores of the two items representing action efficacy from teacher pretest to posttest. 
Change in Student Teachers' Self-Percepts

\section{of Personal Teaching Efficacy}

Null Hypothesis 1. There is no significant difference in the mean score of each of the 46 variables representing personal teaching efficacy from student teacher pretest to posttest.

Null Hypothesis 2.- There is no significant difference in the aggregate mean score of the 31-item Personal Teaching Efficacy Scale from student teacher pretest to posttest.

Null Hypothesis 3. There is no significant difference in the aggregate mean score of the three items representing instruction efficacy from student teacher pretest to posttest.

Null Hypothesis 4. There is no significant difference in the aggregate mean scores of the two items representing thought control efficacy from student teacher pretest to posttest.

Null Hypothesis 5 . There is no significant difference in the aggregate mean score of the two items representing action efficacy from student teacher pretest to posttest.

Null Hypothesis 6. There is no significant difference in the aggregate mean score of the two items representing the "teaching operations" factor from student teacher pretest to posttest.

Methods of Interpreting Data to

Answer the Two General Ouestions

The seven null hypotheses for teachers and the six null hypotheses for student teachers were tested using paired $\rfloor$ tests. Paired $\mathfrak{t}$ tests were conducted to determine the level of significance of differences between pretest and posttest scores for teachers and, again, for student teachers. According to Norusis (1996b), when $\underline{t}$ tests are conducted using pretest and posttest scores of the same subjects, a significant $I$ value represents change in persons. 
Comparison were made using aggregated scores of the 31-item scale, aggregated scores of variables representing the underlying factors, and single-variable scores. Paired $I$ tests at the single-variable and factor level responded to concerns voiced in the literature that important findings are lost when highly aggregated data are used (for example, see Greenwood, Olejnik \& Parkay, 1990; Ross, 1994; Woolfolk \& Hoy, 1993).

Methedological assumptions. While the paired I test assumes the populations of interest are normally distributed and have equal variances, assumptions of normality and homogeneity of variance have "almost no practical consequences in using the t-test" (Glass \& Hopkins, 1984, p. 237).

Eulfillment of the methodological requirements. A modified histogram of variable means showed that the distributions of teacher pretest and posttest data were negatively skewed, while the distributions of the student teacher pretest and posttest data were positively skewed and negatively skewed, respectively. Given this information, the paired $t$ test was a robust statistical test for these studies.

Handling missing cases. When conducting $t$ tests, the SPSS program's default for handling missing values is for an analysis-by-analysis deletion of any cases with missing values. At the variable level, the SPSS default was accepted. However, missing cases were handled differently in the $t$ tests for factor-level and full-scale differences: When aggregate scores were used at the factor level, cases were included if they had a score for at least one of the variables. The missing variables were not reassigned a score but simply dropped from the analysis. In 5 tests of the composite mean score of the 31 item scale, no cases were deleted because missing values would not appreciably affect the mean score. 


\section{Questions and Hypotheses}

\section{Related to Specific Subgroups}

In addition to the two general questions, this study also asked more specific questions about the subgroups in each sample.

Questions Related to

\section{the Teacher Sample}

1. Are changes in the personal teaching efficacy of teachers participating in a reflective practitioner model practicum affected by their gender, by their age, by the amount of teaching experience they have, or by whether or not they have participated in other practicum experiences?

2. Do interaction effects among age, gender, teaching experience, and previous practicum experience affect changes in teachers' sense of personal teaching efficacy from the beginning to the end of their participation in a reflective practitioner model practicum?

Questions Related to the Student Teacher Sample

1. Are changes in the personal teaching efficacy of student teachers participating in a reflective practitioner model practicum affected by their gender, by their age, or by their amount of previous work with children? 2. Do interaction effects among age, gender, and amount of previous work with children affect changes in student teachers' sense of personal teaching efficacy from the beginning to the end of their participation in a reflective practitioner model practicum?

Null hypotheses were formulated at the scale and factor level for each of the specific questions above. Data defining various subgroups of both the teacher and student teacher samples were used as independent variables, and the differences between pretest and posttest mean aggregate scores, expressed 
as gain scores, for the 31-item Personal Teaching Efficacy Scale and for several underlying factors were used as dependent variables.

Gain scores. Gain scores were derived by subtracting the appropriate posttest mean score from the pretest mean score for the same aggregated variables.

Null Hypotheses for the

Teacher Sample Groups

Table 26 provides an overview of the teacher subgroups acting as independent variables and the gain scores used as dependent variables in the analyses of the teacher data.

Null Hypothesis 1. There are no significant main or interaction effects for gender, age, teaching experience, and previous practicum participation on the mean gain score of personal teaching efficacy.

Null Hypothesis 2. There are no significant main or interaction effects for gender, age, teaching experience, and previous practicum participation on the mean gain scores of the instruction efficacy, group relations efficacy, impact efficacy, thought control efficacy, and action efficacy indices.

Null Hypotheses for the

\section{Student Teacher Sample Groups}

Table 27 provides an overview of the student teacher subgroups acting as independent variables and the gain scores used as dependent variables in the analyses of the student teacher data.

Null Hypothesis 1. There are no significant main or interaction effects for gender, age, and previous work with children on the mean gain score of personal teaching efficacy.

Null Hypothesis 2. There are no significant main or interaction effects for gender, age, and amount of previous work with children on the mean gain 
Independent and Dependent Variables Used in Statistical Analysis of the Teacher Sample ${ }^{b}$

\begin{tabular}{|c|c|c|c|c|c|c|}
\hline \multirow[b]{2}{*}{$\begin{array}{l}\text { Independent Variables } \\
\text { and Levels }\end{array}$} & \multicolumn{6}{|c|}{ Dependent Variables Expressed as Gain Scores } \\
\hline & $\begin{array}{c}\text { Personal } \\
\text { Teaching } \\
\text { Efficacy } \\
\text { (31-Item Scale) }\end{array}$ & $\begin{array}{l}\text { Instruction } \\
\text { Efficacy } \\
\text { (2 items) }\end{array}$ & $\begin{array}{l}\text { Thought } \\
\text { Control } \\
\text { Efficacy } \\
\text { (2 Items) }\end{array}$ & $\begin{array}{l}\text { Impact } \\
\text { Efficacy } \\
\text { (2 Items) }\end{array}$ & $\begin{array}{l}\text { Group } \\
\text { Relations } \\
\text { Efficacy } \\
\text { (4 Items) }\end{array}$ & $\begin{array}{l}\text { Action } \\
\text { Efficacy } \\
\text { (2 Items) }\end{array}$ \\
\hline $\begin{array}{l}\text { Gender } \\
\text { Male } \\
\text { Female }\end{array}$ & $\mathrm{x}^{\mathrm{a}}$ & $\mathrm{x}$ & $x$ & $x$ & $x$ & $x$ \\
\hline $\begin{array}{l}\text { Age } \\
\text { Young ( } 21-25 \text { years) } \\
\text { Middle-Aged ( } 36-45 \text { years) } \\
\text { Mature ( } 46-59 \text { years) }\end{array}$ & $\mathrm{x}$ & $\mathrm{x}$ & $x$ & $\mathbf{x}$ & $x$ & $\mathrm{x}$ \\
\hline $\begin{array}{l}\text { Teaching Experience } \\
\text { Neophyte ( } 3-10 \text { years) } \\
\text { Midcareer (11-20 years) } \\
\text { Veteran (21-39 years) }\end{array}$ & $\mathrm{x}$ & $\mathrm{x}$ & $\mathrm{x}$ & $\mathrm{x}$ & $x$ & $x$ \\
\hline $\begin{array}{l}\text { Previous Practicum } \\
\text { Experience } \\
\text { Yes } \\
\text { No }\end{array}$ & $\mathrm{x}$ & $x$ & $x$ & $x$ & $\mathrm{x}$ & $x$ \\
\hline
\end{tabular}

${ }^{a} \mathrm{x}=$ By b Four-way ANOVAs using a $2 \times 3 \times 3 \times 2$ factorial design were conducted for each dependent variable. 
Table 27

Independent and Dependent Variables Used

in Statistical Analysis of the Student Teacher Sample ${ }^{b}$

\begin{tabular}{|c|c|c|c|c|c|c|}
\hline \multirow[b]{2}{*}{$\begin{array}{l}\text { Independent Variables } \\
\text { and Levels }\end{array}$} & \multicolumn{6}{|c|}{ Dependent Variables Expressed as Gain Scores } \\
\hline & $\begin{array}{c}\text { Personal } \\
\text { Teaching } \\
\text { Efficacy } \\
\text { (31-Item Scale) }\end{array}$ & $\begin{array}{l}\text { Instruction } \\
\text { Efficacy } \\
\text { (3 items) }\end{array}$ & $\begin{array}{l}\text { Thought } \\
\text { Control } \\
\text { Efficacy } \\
\text { (2 Items) }\end{array}$ & $\begin{array}{l}\text { Teaching } \\
\text { Operations } \\
\text { Efficacy } \\
\text { (2 Items) }\end{array}$ & $\begin{array}{l}\text { Group } \\
\text { Relations } \\
\text { Efficacy } \\
\text { (4 Items) }\end{array}$ & $\begin{array}{l}\text { Action } \\
\text { Efficacy } \\
\text { (2 Items) }\end{array}$ \\
\hline $\begin{array}{l}\text { Gender } \\
\text { Male } \\
\text { Female }\end{array}$ & $\mathrm{x}^{\mathrm{a}}$ & $\mathrm{x}$ & $\mathrm{x}$ & $\mathrm{x}$ & $\mathrm{x}$ & $\mathrm{x}$ \\
\hline $\begin{array}{l}\text { Age } \\
\text { Very Young ( } 20-22 \text { years) } \\
\text { Young ( } 23-25 \text { years) } \\
\text { Middle-Aged ( } 26-35 \text { years) } \\
\text { Mature (36-48 years) }\end{array}$ & $\mathrm{x}$ & $\mathrm{x}$ & $\mathbf{x}$ & $\mathbf{x}$ & $\mathrm{x}$ & $\mathbf{x}$ \\
\hline $\begin{array}{l}\text { Work with Young Children } \\
\text { Small Amount (Likert 1-2) } \\
\text { Moderate Amount (Likert 3) } \\
\text { Large Amount (Likert 4-5) }\end{array}$ & $\mathrm{x}$ & $\mathrm{x}$ & $\mathrm{x}$ & $\mathrm{x}$ & $\mathrm{x}$ & $\mathbf{x}$ \\
\hline
\end{tabular}

$\mathrm{a} x=$ By $b$ Three-way ANOVAs using a 2 X 4 X 3 factorial design were conducted for each dependent variable. 
scores of the instruction efficacy, group relations efficacy, impact efficacy, thought control efficacy, and action efficacy indices.

Method of Interpreting Data to

Answer Questions About Specific Subgroups

Dependent variables in the teacher study were analyzed using four-way analyses of variance (ANOVAs) with a $2 \times 3 \times 3 \times 2$ factorial design, while the dependent variables in the student teacher study were analyzed using threeway ANOVAs with a $2 \times 4 \times 3$ factorial design. The use of ANOVA as an appropriate statistical method for the pretest-posttest studies of personal teaching efficacy is confirmed by Ross's (1994) review of the literature related to teacher efficacy: Of the six pretest-posttest studies Ross found, ANOVA was used in three.

Methodological assumptions. The ANOVA assumptions include normality, homogeneity of variance, and independence. However, Glass and Hopkins (1984) posit that "nonnormality has negligible consequences on typeI and type-II error probabilities unless populations are highly skewed, n's are small, and directional ('one-tailed') tests are employed" (p. 351, emphasis in original). In addition, when the ns of subgroups are equal, violation of the assumption of homogeneity of variance "has negligible consequences on probability statement (type-I error) or power" (p. 353). Finally, when the observation unit, defined as the "score on a trial or test or some other dependent measure" (p. 481), is individually administered, observations are considered to be independent.

The ANOVA procedure allows researchers to determine not only the main effects of independent variables on a dependent variable, but also the interaction effects of different levels of independent variables. For example, the researcher is able to determine not only if gender or age has a significant effect on the dependent variable, but also if gender and age are interacting to 
produce an effect and at what combination of levels. However, Glass and Hopkins (1984) point out that "if there is no interaction between the treatment factor and characteristics of the subjects, the findings can be generalized with greater confidence" (p. 404).

Eulfillment of methodological requirements. As the distributions of the two samples were not highly skewed, the $\underline{n}$ s were relatively large, and twotailed tests were employed, ANOVA appears to be a robust statistical test for the analysis of these data. Unfortunately, the teacher and student teacher samples, in similarity with the population from which they were drawn, exhibit highly unequal numbers of male and female teachers and student teachers. However, Bartlett's Box-F Tests show that there are no significant differences in the variation of mean gain scores for male and female teachers and student teachers on personal teaching efficacy and the factor indices tested, with two exceptions: The variation of mean gain scores was significantly different for male and female teachers on the group relations efficacy index $(\mathfrak{Q}=.035)$ and the action efficacy index. There were also significant differences in the responses of the three groups of student teachers with differing amounts of previous work with children on the instruction efficacy index $(\mathfrak{l}=.042)$ and the thought control efficacy index. In these cases, a threat to the assumption of homogeneity of variance may have consequences on the probability for Type I error when teachers' gender and students' previous work with children are used as independent variables in the statistical analyses of these factor indices (Glass \& Hopkins, 1984).

Handling missing cases. When conducting ANOVAs, the SPSS program's default for handling missing values is for listwise deletion of any cases with missing values--that is, a case that is missing for any variable in the analysis list is deleted for any analyses specified by that list. In the factor-level analyses, the SPSS default was accepted. However, missing cases were handled 
differently in the ANOVAs for the full-scale differences: Cases were included if they had scores on most variables., As in the $I$ tests, I determined that the composite mean score of the 31-item scale would not be appreciably affected by one or two missing values.

\section{Limitations of the Study Design}

\section{Threats to Internal Validity}

1. Since the conditions under which both teachers and student teachers participate in the practicum experience cannot be definitively controlled, the effect of the reflective practitioner model practicum as an intervening treatment may be confounded by extraneous variables (Borg \& Gall, 1989).

On the other hand, the relatively large samples of teachers and student teachers and the many school and practicum contexts not only make for a more representative research design, but also serve to make findings more generalizable (Borg \& Gall, 1989).

2. Attrition in the number of subjects participating in the studies can also be a threat to the internal validity of the study, through its potential to undermine the representativeness of the sample. This is of particular concern in the student teacher study, where it is known that student teacher attrition was due, to some extent, to negative experiences or failure to successfully complete the practicum.

3. The lack of a control group may also be a threat to the internal validity of the study. An ideal study design would have included control groups of teachers and student teachers participating in another type of practicum. The absence of control groups limits the researcher's ability to determine whether the change in teachers and student teachers' self-percepts of personal 
teaching efficacy was due specifically to the reflective practitioner model rather than just any practicum experience.

Similarly, without control groups representing teachers and student teachers not participating in a practicum experience, the researcher cannot conclude that changes in self-percepts of personal teaching efficacy would not have occurred as a result of normal teaching experiences. However, in this instance, research suggests that such changes do not occur.

\section{Threats to External Validity}

Because participation in the study was voluntary and, thus, randomized samples were not used, there may be a threat to external validity. The relatively large size of the student teacher sample diffuses some of the effects of nonrandom samples; nonetheless, findings from statistical analyses of both samples' data should be confirmed by additional research studies.

With the above constraint to the external validity of the data in mind, teacher educators at the University of Alberta, from similar-sized Faculties of Education, or from 4-year Bachelor of Education programs might find the data useful. 
CHAPTER 6

RESULTS, FINDINGS, AND ANALYSIS

Overview

As outlined in the Methods chapter, this study involved two samples, teachers and student teachers; each sample participated in a reflective practitioner model practicum offered by the University of Alberta. This chapter reports the results of the statistical analyses of data from the teacher and student teacher samples. It begins with a brief description of the school contexts in which the practicums took place, as reported by the teacher sample, and follows with a description of each sample. Then, the study's general question, which asks whether or not teachers and student teachers' sense of personal teaching efficacy would change as a result of participation in a reflective practitioner model practicum, is answered for each sample as a whole and, finally, for specific groups within each sample. 
The School-Practicum Context

Teachers report that the average school had 298.75 students, with the most often reported size (mode) between 300 and 400. Two schools had fewer than 100 students, while one school had over 700. Class sizes ranged from 8 students to 30 students, with the mean size being 23.04 and the mode, 26 .

According to the teacher responses, the average number of student teachers at any one school was 3.60. Only 1 student teacher was reported in one school; however, the most common number (mode) of student teachers in each school was 4 .

Demographic Data

The Teacher Sample

One hundred five teachers completed the Personal Teaching Efficacy Scale at the beginning of the study. They represent $22.5 \%$ of the 467 teachers participating in the practicum experience during the winter semester of 1995 (see Table 7 in chapter 4). Ninety-three teachers completed the Personal Teaching Efficacy Scale at the end of the practicum, representing $19.7 \%$ attrition. However, only 86 of these teachers had also completed the pretest (see Table 7).

Table 28 shows the teachers' mean age and years of teaching experience, while Tables 29 and 30 show the number and percentage of teachers by gender and previous practicum experience. The teacher sample appears to adequately represent the population of interest: Females outnumber males four to one, a typical distribution of males and females in elementary schools. Teachers' ages ranged from 21 years of age to 59, and the years of teaching experience of the sample ranged from 3 to 39 years; 
Table 28

Descriptive Statistics for the Teacher Sample:

Demographic Variables of Age and Teaching Experience

\begin{tabular}{ccccc}
\hline Variable & $\begin{array}{c}\text { Mean } \\
\text { (in Years) }\end{array}$ & $\begin{array}{c}\text { Median } \\
\text { (in Years) }\end{array}$ & $\begin{array}{c}\text { Mode } \\
\text { (in Years) }\end{array}$ & $\begin{array}{c}\text { Valid } \\
\text { Cases }\end{array}$ \\
\hline $\begin{array}{c}\text { Age } \\
\text { Teaching } \\
\text { Experience }\end{array}$ & 40.56 & 40.50 & 40.00 & 98 \\
\hline
\end{tabular}

Table 29

Descriptive Statistics for the Teacher Sample: Gender

\begin{tabular}{llcc}
\hline Variables & Response & Frequency & $\%$ \\
\hline \multirow{2}{*}{ Gender } & Male & 21 & 20.0 \\
& Female & 82 & 78.1 \\
& Missing & 2 & 1.9 \\
& n & 105 & 100.0 \\
\hline
\end{tabular}

Table 30

Descriptive Statistics for the Teacher Sample: Past Practicum Experience

\begin{tabular}{llcc}
\hline Past Practicum & "Yes" & 85 & 81.0 \\
Experience & "No" & 18 & 17.1 \\
& Missing & 2 & 1.9 \\
& $\underline{\mathrm{n}}$ & 105 & 100.0 \\
\hline
\end{tabular}


thus, the sample represents the wide range of ages and years of experience typically found across a number of schools.

Teachers' Perceptions

of the Practicum

At the end of the practicum, teachers were asked to respond to four statements related to their perceptions of the experience. Table 31 displays the mean, mode, and median for each of the four questions. The first two statements were related to practicum conditions and the last two, to teacher development as a result of the practicum.

Conditions of the practicum. Most teachers felt they had a real say in decisions related to the practicum, with $84.5 \%$ of teachers responding that they were part of practicum decisions either "a large amount" of the time (42.8\%) or "always" $(41.7 \%)$. In addition, over $91.6 \%$ of teachers reported that the school team and the university facilitator worked collaboratively "a large amount" of the time (30.1\%) or "always" (61.4\%).

Teacher development. Teacher responses to the last two questions were more varied. While $83.1 \%$ of teachers reported that the practicum experience had helped them develop as a teacher, $16.8 \%$ reported that they had developed as a teacher only "a little" (13.2\%) or "not at all" (3.6\%). Similarly, $72.3 \%$ of teachers felt that they had developed more confidence as a result of the practicum experience, but $27.7 \%$ saw little $(16.9 \%)$ or no change $(10.8 \%)$ in the degree of their confidence. The survey did not ask this question prior to the practicum, so there is no way to know how confident teachers felt before participation.

Teachers' Perceptions

of the School Context

As chapter 4 outlines, the original scale administered to teachers and student teachers contained 53 items, 7 of which were later deemed to 
Table 31

Teachers' Perceptions of Their Practicum

Experience and Its Value

\begin{tabular}{lcccc}
\hline \multicolumn{1}{c}{ Statement } & Mean & & & Valid \\
& Median & Mode & Cases \\
\hline $\begin{array}{l}\text { I felt I had a real say in the } \\
\text { decisions made related to the day- } \\
\text { to-day operation of the practicum. }\end{array}$ & 4.19 & 4.0 & 4.0 & 84 \\
$\begin{array}{l}\text { In my school, the school } \\
\text { facilitators and university faciliator } \\
\text { worked collaboratively. }\end{array}$ & 4.14 & 4.0 & 5.0 & 83 \\
$\begin{array}{l}\text { I have developed as a teacher as a } \\
\text { result of this practicum experience. }\end{array}$ & 3.57 & 3.0 & 4.0 & 83 \\
$\begin{array}{l}\text { I have more confidence as a teacher } \\
\text { as a result of this practicum } \\
\text { experience. }\end{array}$ & 3.24 & 3.0 & 4.0 & 83 \\
\hline
\end{tabular}

a Teachers responded to item statements using a 5-point Likert scale that ranged from "not at all" (1) to "always" (5). 
represent teachers' perceptions of the school context. Paired $\rfloor$ tests were conducted on each of these 7 items, using the teacher data.

Results show that teachers' perceptions of their school context changed over the course of the practicum (see Table 32 ). Teachers' responded more positively to five of the seven school context variables at the end of the practicum than at the beginning, with the mean difference in responses being statistically significant for three: Teachers were significantly more likely at the end of the practicum to believe that they were free to organize their classrooms in any way needed for effectiveness $(t=+3.14, \underline{D}=.002)$, suggesting that participation in the practicum helped them to recognize where they had autonomy. Further, teachers were significantly more likely to believe that others considered them a valued staff member $(t=+2.75, p=.007)$ and that they could count on others when they needed help $(\tau=+2.65, \mathfrak{R}=.010)$.

Alternately, teachers' perceptions changed negatively on two of the seven school context items, although neither change was statistically significant. First, teachers were less likely to feel that they had the resources to teach effectively $(t=-.62, \mathfrak{R}=.539)$. Second, teachers were also less likely to believe that the parents of their students really cared about their academic achievement $(t=-.96, \mathfrak{p}=.339)$.

\section{Analysis of the Demographic Data}

\section{From the Teacher Sample}

The data suggest that the practicum experience of most teachers was characterized by a high degree of collaboration and involvement in decision making related to the practicum. In accord with the literature related to mentoring (for example, see Crow \& Matthews, 1998), most teachers also reported feeling that they had grown from the experience and their sense of confidence as teachers had increased. 
Table 32

Results From t-tests: Change in Mean Teacher Responses from.

Pretest to Posttest by Context Variable

t-test Results

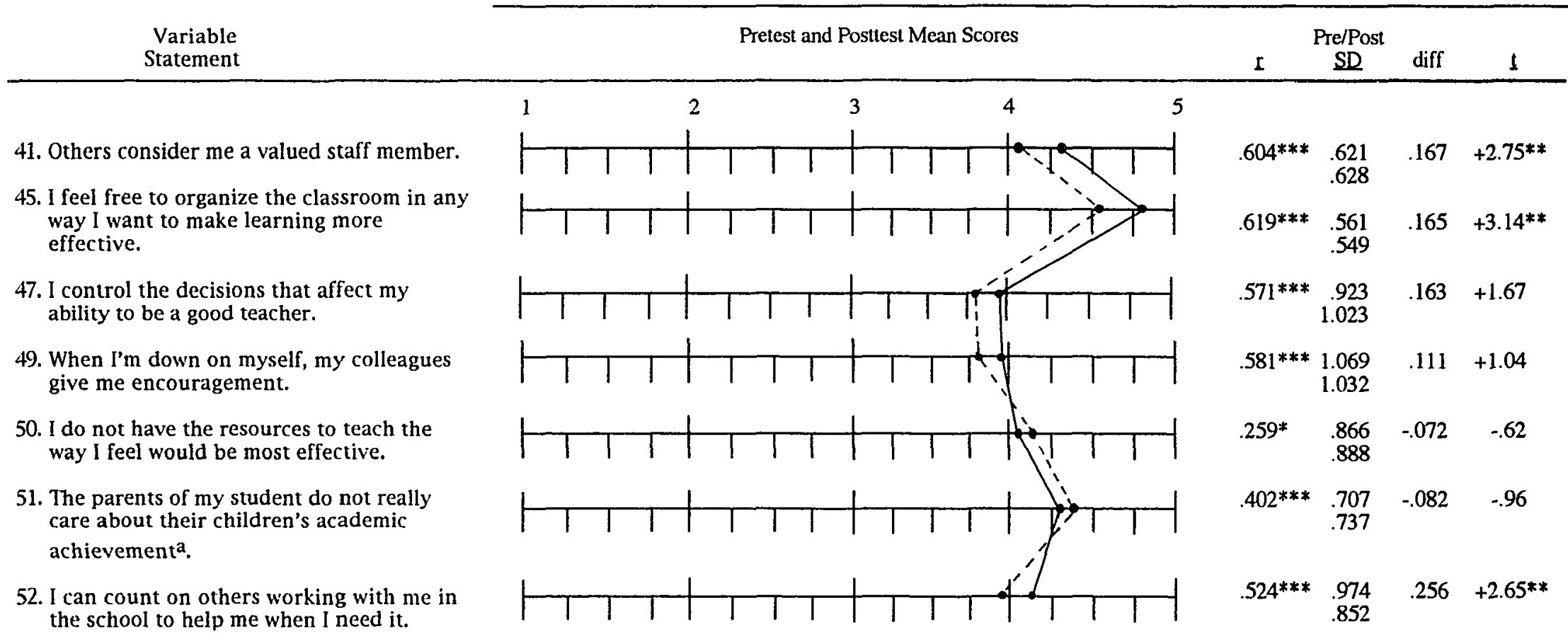

a Recoded before analysis.

Pretest

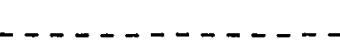

$\begin{array}{rl}* & \mathfrak{Q}=.05 \\ \star * & \underline{\mathfrak{n}}=.01 \\ * * & \underline{\mathfrak{n}}=.001\end{array}$

Posttest 
Interestingly, the results also showed that teachers' perceptions of their school context in general had also changed over the course of the practicum experience. Teachers significantly increased their feelings of autonomy over their classrooms and their perceptions that others valued them and were willing to offer help when needed. Perhaps, the collegial nature of the practicum (see Rosenholtz, 1985, cited in Cavers, 1988) changed teachers' perspectives of the interrelational nature of their role in the school and heightened their appreciation of their colleagues.

Also of interest was the negative change in teachers' perceptions related to their access to resources for effective teaching after the practicum and in their beliefs that parents cared about their children's academic achievement. It seems likely that after seeing the resources student teachers bring to the school from the Faculty of Education, teachers may have become more aware of gaps in their own resources. However, no definitive reason for teachers' lowering of expectations of parents comes to mind, other than that many teachers would have completed report cards and parent-teacher interviews for the spring reporting period prior to taking the pretest. Perhaps, the parents of students who did poorly did not attend the interviews and, hence, teachers' perceptions changed.

The overall positive change in teachers' perceptions of their schools suggests that participation in a reflective practitioner model is a valuable experience for improving school culture. However, the negative changes remind us that no intervention is without drawbacks.

\section{The Student Teacher Sample}

One hundred sixty-five student teachers completed the Personal Teaching Efficacy Scale at the beginning of the study. They represent $69.9 \%$ of the 236 student teachers participating in the practicum experience during 
the University of Alberta's 1995 winter semester (see Table 7). One hundred two student teachers completed the Personal Teaching Efficacy Scale at the end of the practicum, representing 38.2\% attrition. Furthermore, only 94 of these student teachers had also completed the pretest (see Table 7).

The disproportionate number of female to male elementary school teachers was also mirrored in the student teacher sample (see Table 33): Twenty-six males ( $15.8 \%$ of the sample) completed the pretest of the Personal Teaching Efficacy Scale compared to 138 females (83.6\%). The mean age of student teachers was 24.43 years (see Table 34 ), with $75.1 \%$ of the student teacher sample between 21 and 25 years of age. However, the range of student teachers' ages was from 20 years of age to 48 years. Most student teachers $(70.8 \%)$ reported they had either worked with children quite often $(37.4 \%)$ or a great deal (33.4\%).

\section{Student Teachers' Perceptions}

of the Practicum

At the end of the practicum, student teachers were asked to complete eight questions related to their perceptions of the experience and its value to their development (see Table 35). The first five questions addressed the conditions of the practicum, while the last three probed student teachers' perceptions of their development as teachers.

Conditions of the practicum. The highest mean response (4.18) among the first five questions was to the statement "The assistance of the school facilitators [teachers] helped me to develop as a teacher." The second highest mean score (3.14) was related to the value of the seminar in supporting learning to teach. The lowest mean response (3.06) was to the statement "The university facilitator helped me develop as a teacher."

Student teachers responded quite positively (mean $=3.82$ ) to the statement related to being able to use their own teaching style. Alternately, 
Table 33

Descriptive Statistics for Student Teacher Sample:

Demographic Variable of Gender

\begin{tabular}{llcc}
\hline Variables & Response & Frequency & $\%$ \\
\hline \multirow{2}{*}{ Gender } & Male & 26 & 15.8 \\
& Female & 138 & 83.6 \\
& Missing & 1 & .6 \\
& $\mathbb{n}$ & 165 & 100.0 \\
\hline
\end{tabular}

Table 34

Descriptive Statistics for the Student Teacher Sample:

Demographic Variables of Age and Previous Work With Children

\begin{tabular}{ccccc}
\hline Variable & $\begin{array}{c}\text { Mean } \\
\text { (in Years) }\end{array}$ & $\begin{array}{c}\text { Median } \\
\text { (in Years) }\end{array}$ & $\begin{array}{c}\text { Mode } \\
\text { (in Years) }\end{array}$ & $\begin{array}{c}\text { Valid } \\
\text { Cases }\end{array}$ \\
\hline Age & 24.43 & 23.00 & 21.00 & 162 \\
$\begin{array}{c}\text { Work With } \\
\text { Children }\end{array}$ & $3.558^{\mathrm{a}}$ & 4.00 & 4.00 & 163 \\
\hline
\end{tabular}

a Student teachers responded to a 4-point scale from "not at all" (1) to "a great deal" (4). 
Table 35

Student Teachers' Perceptions of

Their Practicum Experience and Its Value

\begin{tabular}{|c|c|c|c|c|}
\hline Statement & Mean ${ }^{2}$ & Median & Mode & $\begin{array}{l}\text { Valid } \\
\text { Cases }\end{array}$ \\
\hline $\begin{array}{l}\text { The student teachers at my } \\
\text { school worked together. }\end{array}$ & 3.09 & 3.00 & 4.00 & 101 \\
\hline $\begin{array}{l}\text { The assistance of the school } \\
\text { facilitators helped me } \\
\text { develop as a teacher. }\end{array}$ & 4.18 & 4.00 & 4.00 & 101 \\
\hline $\begin{array}{l}\text { The assistance of the university } \\
\text { facilitator helped me develop } \\
\text { as a teacher. }\end{array}$ & 3.06 & 3.00 & 3.00 & 101 \\
\hline $\begin{array}{l}\text { Participation in the seminar } \\
\text { supported my learning to teach. }\end{array}$ & 3.14 & 3.00 & 3.00 & 101 \\
\hline $\begin{array}{l}\text { I felt free to use my own } \\
\text { teaching style. }\end{array}$ & 3.82 & 4.00 & 4.00 & 101 \\
\hline $\begin{array}{l}\text { I have developed as a teacher } \\
\text { as a result of this practicum } \\
\text { experience. }\end{array}$ & 4.52 & 5.00 & 5.00 & 101 \\
\hline $\begin{array}{l}\text { I have more confidence as a } \\
\text { teacher as a result of this } \\
\text { practicum experience. }\end{array}$ & 4.15 & 5.00 & 5.00 & 101 \\
\hline $\begin{array}{l}\text { I feel ready to take on the } \\
\text { responsibilities of a } \\
\text { full-fledged teacher. }\end{array}$ & 4.31 & 4.000 & 5.000 & 101 \\
\hline
\end{tabular}

a Student teachers responded to a 5-point Likert scale from "not at all" (1) to "always" (5). 
student teachers perceived that they worked with other student teachers only "an average amount" (3.09), somewhat defeating the purpose of having more than one student teacher at a school.

The development of student teachers. The last three questions asked student teachers to rate their development as teachers. Here the responses were very strong (see Table 34 ). The mode responses were 5.00 for all three questions, affirming that most student teachers perceive the reflective practitioner model practicum not only as helping them to develop their skills as teachers and increase their feelings of confidence, but also as successfully preparing them for full-time teaching.

Analysis of the Demographic Data

From the Student Teacher Sample

As with the teacher sample, student teachers reported a high degree of satisfaction with their practicum. As other research suggests (for example, see Emmons, 1983, cited in Hoover, O'Shea, \& Carroll, 1988), student teachers in this study also placed the most value on their work with practicing teachers. In contrast, they gave relatively low scores for the learning they received from university facilitators. However, this is not too surprising, given that university facilitators play a more advisory role in the reflective practitioner model practicum and, typically, do far less supervision of student teachers than in the conventional student teaching model. In addition, this view is also similar to that of student teachers completing conventional student teaching programs (for example, see Benne, 1976, cited in Hoover, O'Shea, \& Carroll, 1988).

Somewhat surprising was the high mean response to the statement "I felt free to use my own teaching style." This is contrary to the research suggesting that student teachers feel compelled to follow the style of their teacher supervisors (for example, see MacKinnon, 1989). Somewhat 
disappointing was the low mean response to the item related to student teachers working together; however, this response may be more of a reflection of student teachers' heavy workload than of their lack of desire to work collaboratively with their student teaching colleagues.

\section{Research Question 1: Changes in Personal Teaching Efficacy}

The study first asked the general question Will teachers' and student teachers' self-percepts of personal teaching efficacy change after participation in a reflective practitioner model practicum?

Personal teaching efficacy was operationally defined as teachers' or student teachers' composite score on the 31-item Personal Teaching Efficacy Scale. However, because a composite score is likely to miss important information about changes in personal teaching efficacy, this study also examined changes in teachers and student teachers' self-percepts at the factor and variable level. Therefore, the first general research question was tested at three levels for each sample.

1. The difference in the mean composite scores for the pretest and posttest 31-item Personal Teaching Efficacy Scale was tested for statistical significance. 2. Factor-level differences were explored. Each factor was represented by an index of two or three items that loaded on the factor in both the pretest and posttest factor analyses. Since teacher and student teacher factors and factor loadings differed, the items representing the factors change across the factors from the teacher sample to the student teacher sample.

3. The differences in pretest and posttest mean scores of each of the 46 variables in the premodified Personal Teaching Efficacy Scale were also tested for statistical significance. 


\section{Changes in the Personal Teaching Efficacy \\ of the Teacher Sample}

\section{Null Hypothesis 1}

The first null hypothesis states: There is no significant difference in the mean composite scores of the 31-item Personal Teaching Efficacy Scale from teacher pretest to posttest.

Table 13 (chapter 5) lists the variables included in the 31-item Personal Teaching Efficacy Scale and Table 36 displays the mean, mode, median, and standard deviation of the teacher composite scores.

A paired $\rfloor$ test found that the difference in the mean composite score (.104) of the pretest and posttest was statistically significant, $\mathrm{I}=+3.42, \mathcal{D}=.001$ (see Table 37). It seems likely that the observed significance level represents a significant change in teachers' sense of personal teaching efficacy from the beginning to the end of the practicum. Therefore, the null hypothesis was rejected.

Null Hypotheses 2 Through 6

In order not to miss important information about pretest and posttest differences in teachers' sense of personal teaching efficacy, $t$ tests were also conducted at the factor level. Five null hypotheses were formed to test pretest to posttest differences in five of the seven hypothesized factors underlying personal teaching efficacy: the instruction efficacy factor, the thought control efficacy factor, the impact efficacy factor, the group relations efficacy factor, and the action efficacy factor.

Each factor was represented by an index of two to four items that loaded on the factor in both pretest and posttest factor analyses. Table 38 lists the item statements for each factor index, and Table 39 gives the mean, mode, median, and standard deviation for the pretest and posttest factor-index scores. 
Table 36

Descriptive Statistics for the Composite Scores

of the Teacher Samole on the Pretest and Posttest

31-Item Personal Teaching Efficacy Scale

\begin{tabular}{ccc}
\hline \multirow{2}{*}{ Descriptive } & 31-Item Personal Teaching Efficacy Scale \\
\cline { 2 - 3 } Statistics & Pretest & Posttest \\
Mean & 4.13 & 4.24 \\
Mode & 4.00 & 4.36 \\
Median & 4.13 & 4.30 \\
Standard Deviation & .378 & .373 \\
Valid Cases & 86 & 86 \\
\hline
\end{tabular}

$\mathrm{a} \underline{\mathrm{n}}=86$ 
Results of $t$-tests for Grouped Variables Using Data From the Teacher Sample

\begin{tabular}{|c|c|c|c|c|c|c|c|c|c|}
\hline \multirow{2}{*}{$\begin{array}{l}\text { Grouped } \\
\text { Variables }\end{array}$} & \multirow{2}{*}{$\begin{array}{l}\text { Number } \\
\text { Of Items }\end{array}$} & \multicolumn{2}{|c|}{ Mean } & \multicolumn{2}{|c|}{$\begin{array}{c}\text { Standard } \\
\text { Deviation }\end{array}$} & \multirow[b]{2}{*}{ Difference } & \multirow[b]{2}{*}{$\underline{\mathbf{r}}$} & \multirow[b]{2}{*}{$\underline{t}$} & \multirow[b]{2}{*}{$\underline{\mathrm{df}} \underline{\mathrm{a}}$} \\
\hline & & Pretest & Posttest & Pretest & Posttest & & & & \\
\hline Personal Teaching Efficacy & 31 & 4.1334 & 4.2372 & .378 & .373 & .1038 & $.720 * * *$ & $+3.42 * * *$ & 85 \\
\hline Instruction Efficacy Index & 2 & 4.1353 & 4.3176 & .683 & .571 & .1824 & $.636 * * *$ & $+3.09 * *$ & 84 \\
\hline Group Relations Efficacy Index & 4 & 4.6324 & 4.7176 & .413 & .359 & .0853 & $.576 * * *$ & $+2.19 *$ & 84 \\
\hline Impact Efficacy Index & 2 & 3.4643 & 3.5000 & .853 & .868 & .0357 & $.631 * * *$ & +.44 & 83 \\
\hline Thought Control Efficacy Index & 2 & 4.2025 & 4.1646 & .787 & .758 & -.0380 & $.669 * * *$ & -.54 & 78 \\
\hline Action Efficacy Index & 2 & 4.2048 & 4.2108 & .686 & .075 & .0060 & $.605^{* * *}$ & +.10 & 82 \\
\hline
\end{tabular}

$\mathrm{a}_{\mathrm{n}=86 * \mathrm{p}=.05 * * \mathrm{p}=.01 * * * \mathrm{p}=.001}$ 
Table 38

\section{Item Statements Representing Indices for Five Underlying Factors of}

Personal Teaching Efficacy in the Teacher Sample

\begin{tabular}{|c|c|c|}
\hline Factor & $\begin{array}{l}\text { Item } \\
\text { Number }\end{array}$ & Factor and Item Statement \\
\hline \multirow[t]{2}{*}{$\begin{array}{l}\text { Instruction } \\
\text { Efficacy }\end{array}$} & 13 & $\begin{array}{l}\text { I can plan instruction in my class for students at various levels } \\
\text { of ability or stages of learning. }\end{array}$ \\
\hline & 17 & I am able to accurately evaluate my students' progress. \\
\hline \multirow{3}{*}{$\begin{array}{l}\text { Group } \\
\text { Relations Efficacy }\end{array}$} & 7 & I am able to develop a rapport with students in my class(es). \\
\hline & 8 & I am able to implement routines for an orderly classroom. \\
\hline & 19 & I am able to manage most problems in my classroom. \\
\hline \multirow[t]{2}{*}{$\begin{array}{l}\text { Impact } \\
\text { Efficacy }\end{array}$} & $23^{a}$ & $\begin{array}{l}\text { No matter how hard I try, I will not be able to make a difference } \\
\text { with some students. }\end{array}$ \\
\hline & $39 a$ & $\begin{array}{l}\text { The students' home environment has more influence on their } \\
\text { ability to achieve than I do as their teacher. }\end{array}$ \\
\hline \multirow[t]{2}{*}{$\begin{array}{l}\text { Thought } \\
\text { Control Efficacy }\end{array}$} & $42^{\mathrm{a}}$ & $\begin{array}{l}\text { I am often overwhelmed by the diversity of students in my } \\
\text { classroom. }\end{array}$ \\
\hline & $43^{a}$ & $\begin{array}{l}\text { I find it difficult to control feelings of tension or fearfulness that } \\
\text { sometimes occur in a teaching situation. }\end{array}$ \\
\hline \multirow[t]{2}{*}{$\begin{array}{l}\text { Action } \\
\text { Efficacy }\end{array}$} & 24 & $\begin{array}{l}\text { When a particular lesson has gone badly, I spend time } \\
\text { considering how I might improve it for next time. }\end{array}$ \\
\hline & 33 & $\begin{array}{l}\text { When things are not going well in my classroom, I set out to } \\
\text { learn new knowledge and skills that will improve the situation. }\end{array}$ \\
\hline
\end{tabular}

a The item was recoded prior to statistical analysis 
Table 39

Descriptive Statistics for Each of the Pretest and Posttest

Factor-Index Scores Used in the Analysis of the Teacher Sample ${ }^{a}$

\begin{tabular}{|c|c|c|c|c|c|}
\hline $\begin{array}{l}\text { Factor } \\
\text { Index }\end{array}$ & Mean & Mode & Median & $\begin{array}{l}\text { Standard } \\
\text { Deviation }\end{array}$ & $\begin{array}{l}\text { Valid } \\
\text { Cases }^{a}\end{array}$ \\
\hline \multicolumn{6}{|l|}{$\begin{array}{l}\text { Instruction } \\
\text { Efficacy }\end{array}$} \\
\hline Pretest & 4.14 & 4.50 & 4.00 & .683 & 85 \\
\hline Posttest & 4.32 & 4.00 & 4.50 & .569 & 86 \\
\hline \multicolumn{6}{|c|}{ Impact Efficacy } \\
\hline Pretest & 3.46 & 4.00 & 3.50 & .853 & 84 \\
\hline Posttest & 3.51 & 4.00 & 3.50 & .864 & 86 \\
\hline \multicolumn{6}{|c|}{$\begin{array}{l}\text { Group Relations } \\
\text { Efficacy }\end{array}$} \\
\hline Pretest & 4.63 & 5.00 & 4.75 & .413 & 85 \\
\hline Posttest & 4.72 & 5.00 & 4.75 & .359 & 86 \\
\hline \multicolumn{6}{|c|}{$\begin{array}{l}\text { Thought Control } \\
\text { Efficacy }\end{array}$} \\
\hline Pretest & 4.20 & 4.50 & 4.50 & .787 & 79 \\
\hline Posttest & 4.19 & 4.00 & 4.50 & .752 & 85 \\
\hline \multicolumn{6}{|c|}{ Action Efficacy } \\
\hline Pretest & 4.20 & 4.50 & 4.50 & .591 & 86 \\
\hline Posttest & 4.21 & 4.00 & 4.00 & .679 & 85 \\
\hline
\end{tabular}


Teacher responses to the factor indices. An examination of Table 39 reveals interesting factor-level differences in teachers' perceptions of their sense of personal teaching efficacy, as indicated by the mean aggregate scores on the pretest and posttest factor indices.

For example, teachers' highest pretest mean score was on the group relations efficacy index, and this first-place ranking held from pretest (4.63) to posttest (4.72).

Alternately, the lowest pretest mean score was on the impact efficacy index (3.46), with over a full-point difference between that score and the group relations score (a 1.17 point difference). The mean score on the impact efficacy index retained its last-place ranking on the posttest (3.51) and the gap between mean scores for impact efficacy and group relations efficacy widened slightly from pretest to posttest (a 1.21-point difference).

Self-percepts of instruction efficacy increased more over the term of the practicum than any other self-percepts, from 4.14 to 4.32 . However, the pretest mean score was almost a half-point lower (.49) on the Likert scale than the pretest mean score for group relations efficacy, but only somewhat lower than the pretest mean scores of thought control efficacy (a difference of .06) or action efficacy (also a difference of .06).

Teachers' mean scores went down slightly for thought control efficacy ( a difference of -.01) and up slightly for action efficacy (a difference of +.01 ) from pretest to posttest. However, the median and mode for action efficacy dropped a half point, suggesting there were more posttest responses below 4.0 on the Likert scale than there were in the pretest. The median score for thought control efficacy remained the same, while the mode decrease by a half point. 
Null Hypothesis 2. Null Hypothesis 2 states: There is no significant difference from teacher pretest to posttest in the mean aggregate scores of the two items representing instruction efficacy.

Teachers' perceptions of instruction efficacy increased from the beginning of the practicum to the end (see Table 37). The mean difference between pretest and posttest mean aggregate scores yielded a statistically significant $I$ value of $+3.09(\mathfrak{l}=.003)$. Therefore, the null hypothesis of no difference was rejected.

Null Hypothesis 3. Null Hypothesis 3 states: There is no significant difference from teacher pretest to posttest in the mean aggregate scores of the four items representing group relations efficacy.

Teachers' mean aggregate score on the four items representing group relations efficacy increased from pretest to posttest (see Table 37 ). While the mean difference was small $(.085)$, the $I$ value $(+2.19)$ was significant $(\underline{Q}=.031)$. Therefore, the null hypotheses for this item was rejected, and it can be concluded that the sample teachers' self-percepts of group relations efficacy changed significantly and positively from pretest to posttest.

Null Hypothesis 4. Null Hypothesis 4 states: There is no significant difference in the mean aggregate scores of the two items representing impact efficacy from teacher pretest to posttest.

While teachers' sense of impact efficacy increased over the duration of the practicum (see Table 37), the mean difference was small (.036) and the 5 value $(+.44)$ was statistically nonsignificant $(\mathrm{D}=.659)$. There appears to be no difference in the sample teachers' pretest and posttest perception of impact efficacy, and the null hypothesis was retained.

Null Hypothesis 5 . Null Hypothesis 5 states: There is no significant difference from teacher pretest to posttest in the mean aggregate scores of the two items representing thought control efficacy. 
Teachers' feelings of thought control efficacy, as measured by the mean aggregate score of the two items representing thought control efficacy, actually decreased over the duration of the practicum (see Table 37). However, the mean difference was small and the observed significant level was high ( $D$ $=.593)$. It seems unlikely that the difference in sample means of the pretest and posttest thought control efficacy index represents a significant change in teachers' perceptions. Therefore, the null was retained.

Null Hypothesis 6. Null Hypothesis 6 states: There is no significant difference from teacher pretest to posttest in the mean aggregate scores of the two items representing action efficacy.

Teachers increased their sense of action efficacy as measured by the mean aggregate score on the two items representing action efficacy (see Table 37). However, the mean difference was small (.006) and the $I$ value $(I=+.10)$ was statistically nonsignificant $(\mathfrak{l}=.924)$. Therefore, the null of no difference in teachers' perceptions of their action efficacy was retained.

Null Hypothesis 7. To further sharpen the analysis of changes in teachers' sense of personal teaching efficacy, a paired t test was conducted for each of the 46 variables from the unmodified Personal Teaching Efficacy Scale. The seventh null hypothesis states: There is no significant difference in the mean scores of teacher pretest to posttest for each of the 46 variables representing personal teaching efficacy.

Table 40 plots the pretest and posttest mean scores and provides the $t$ value and observed significance level for each variable. The plotted mean scores clearly show that teachers' sense of their capabilities and volitional dispositions changed positively from the beginning of the practicum to the end, on all but four variables: The mean differences on three of these variables show a decrease in teachers' perceptions of their performance or 
Table 40

Results From 1 Tests: Change in Mean Teacher Responses From Pretest to Posttest by Variable

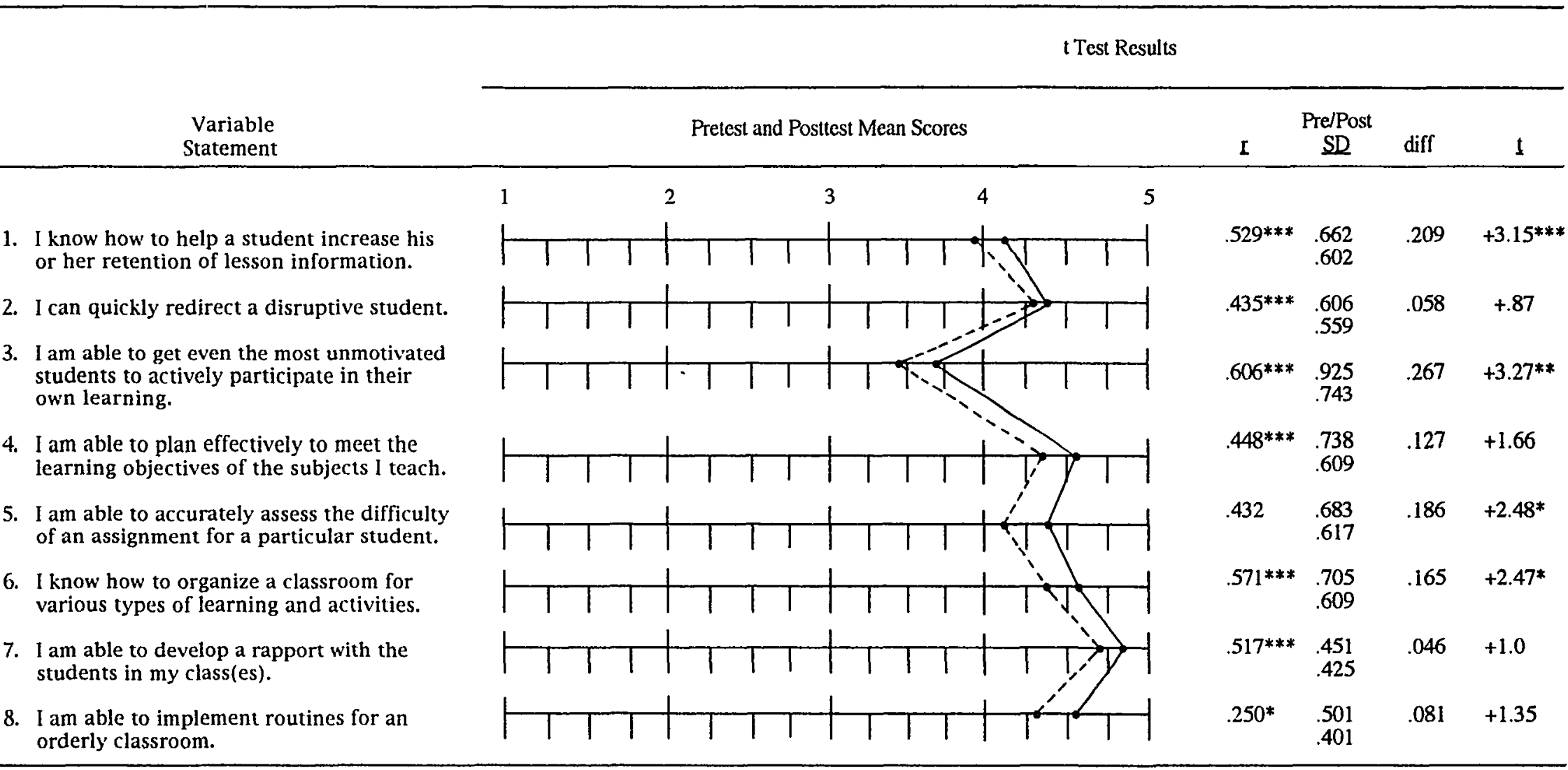

a Recoded before analysis.

\begin{tabular}{|c|c|c|}
\hline Pretest & $\cdots-------\ldots$ & $* \quad \mathfrak{p}=.05$ \\
\hline Posttest & & $\begin{array}{ll}* * * & \mathbf{D}=.01 \\
\mathbf{D} & =.001\end{array}$ \\
\hline
\end{tabular}


Table 40

\section{Results From t Tests: Change in Mean Teacher Responses From Pretest to Posttest by Variable}

t Test Results

\begin{tabular}{|c|c|c|c|c|c|}
\hline $\begin{array}{c}\text { Variable } \\
\text { Statement }\end{array}$ & Pretest and Posttest Mean Scores & $\underline{L}$ & $\begin{array}{c}\text { Pre/Post } \\
\text { SD }\end{array}$ & diff & 1 \\
\hline & 2 & & & & \\
\hline $\begin{array}{l}\text { 9. I am able to guide a student through the } \\
\text { necessary steps to master a new concept. }\end{array}$ & 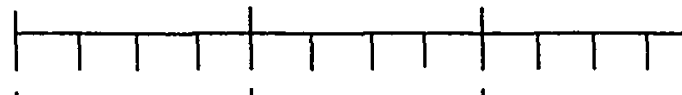 & $.305^{* *}$ & $\begin{array}{l}.605 \\
.548\end{array}$ & .188 & $+2.55^{*}$ \\
\hline $\begin{array}{l}\text { 10. I can create an atmosphere so that students } \\
\text { enjoy being in my classes. }\end{array}$ & \begin{tabular}{|l|l|l|} 
& 1 & 1
\end{tabular} & $.486 * * *$ & $\begin{array}{l}.586 \\
.545\end{array}$ & .105 & +1.69 \\
\hline $\begin{array}{l}\text { 11. I an able to adjust the difficulty of an } \\
\text { assignment to match the level of particular } \\
\text { students. }\end{array}$ & \begin{tabular}{l|l|l|l} 
& 1 & 1
\end{tabular} & $.439^{* * *}$ & $\begin{array}{l}.810 \\
.639\end{array}$ & .244 & $+2.90^{* *}$ \\
\hline $\begin{array}{l}\text { 12. I know how to create interesting learning } \\
\text { activities for students to do. }\end{array}$ & \begin{tabular}{|l|l|l|l|} 
& 1 & & 1
\end{tabular} & $.502 * * *$ & $\begin{array}{l}.631 \\
.606\end{array}$ & .081 & +1.22 \\
\hline $\begin{array}{l}\text { 13. I can plan instruction for students in my } \\
\text { class who are at various levels of ability or } \\
\text { stages of learning. }\end{array}$ & 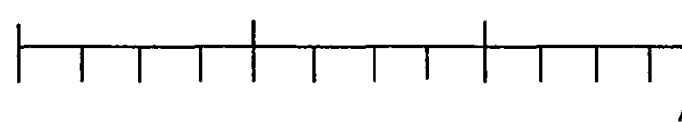 & $.582^{* * *}$ & $\begin{array}{l}.828 \\
.643\end{array}$ & .141 & +1.88 \\
\hline $\begin{array}{l}\text { 14. I know which teaching strategy is most } \\
\text { effective for different kinds of student } \\
\text { learning. }\end{array}$ & \begin{tabular}{|l|l}
1 \\
11
\end{tabular} & $.597^{* * *}$ & $\begin{array}{l}.695 \\
.694\end{array}$ & .186 & $+2.77^{* *}$ \\
\hline $\begin{array}{l}\text { 15. I am able to acquire new skills that are } \\
\text { necessary to teach effectively in particular } \\
\text { circumstances. }\end{array}$ & \begin{tabular}{|l|l|l|l|l|l|l|} 
& \multicolumn{1}{|l|l|}{$\mid$}
\end{tabular} & $.465^{* * *}$ & $\begin{array}{l}.726 \\
.583\end{array}$ & .209 & $+2.82 * *$ \\
\hline
\end{tabular}

a Recoded before analysis.

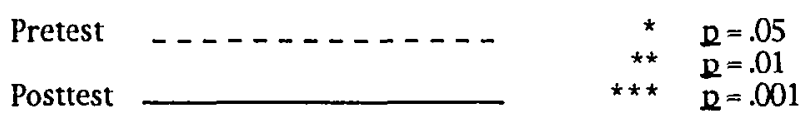


Table 40

Results Erom t Tests: Change in Mean Teacher Responses From Pretest to Posttest by Variable

t Test Results

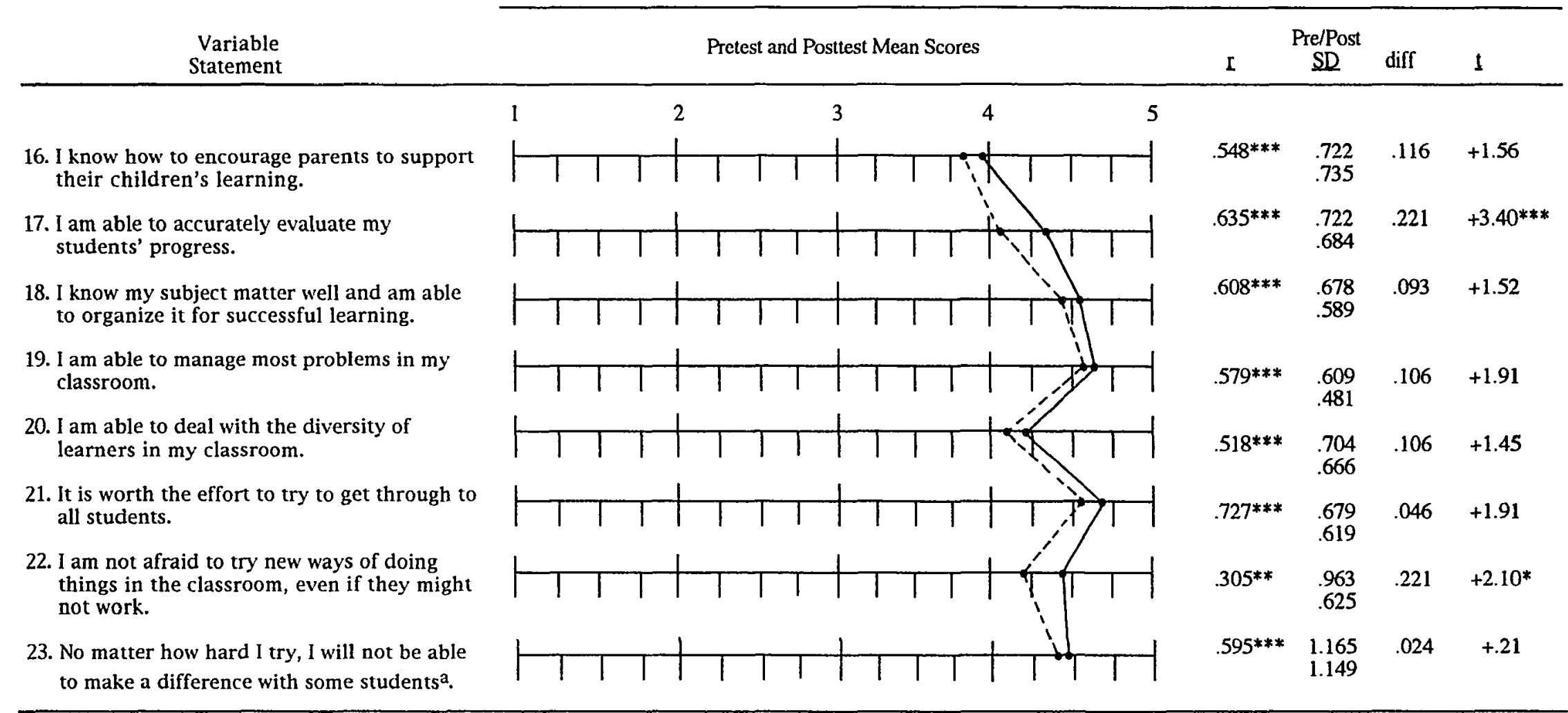

a Recoded before analysis.

Pretest -

Posttest 
Table 40

\section{Results From I Tests: Change in Mean Teacher Responses From Pretest to Posttest by Variable}

t Test Results

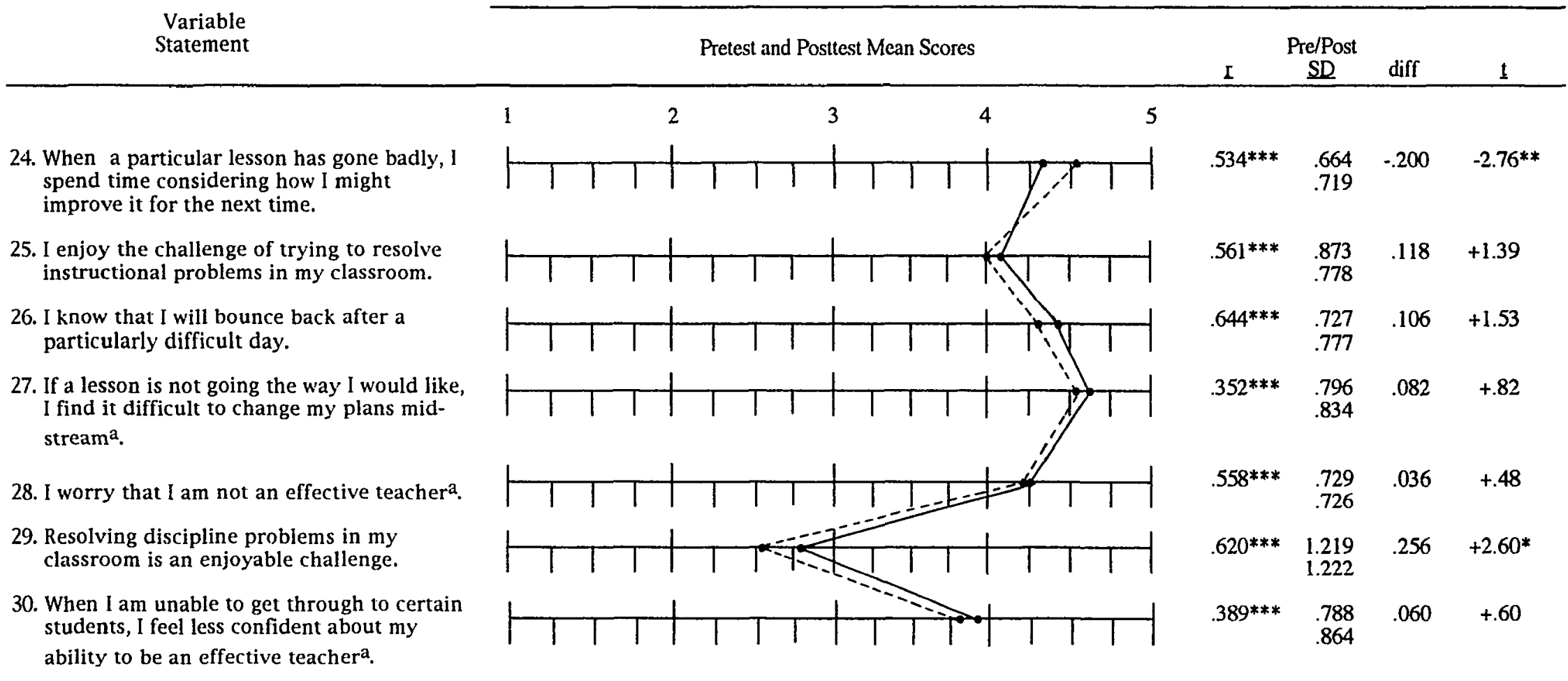

a Recoded before analysis.

\begin{tabular}{|c|c|}
\hline test & $\cdots-\ldots \ldots-\ldots$, \\
\hline
\end{tabular}


Table 40

\section{Results From t Tests: Change in Mean Teacher Responses From Pretest to Posttest by Variable}

\section{t Test Results}

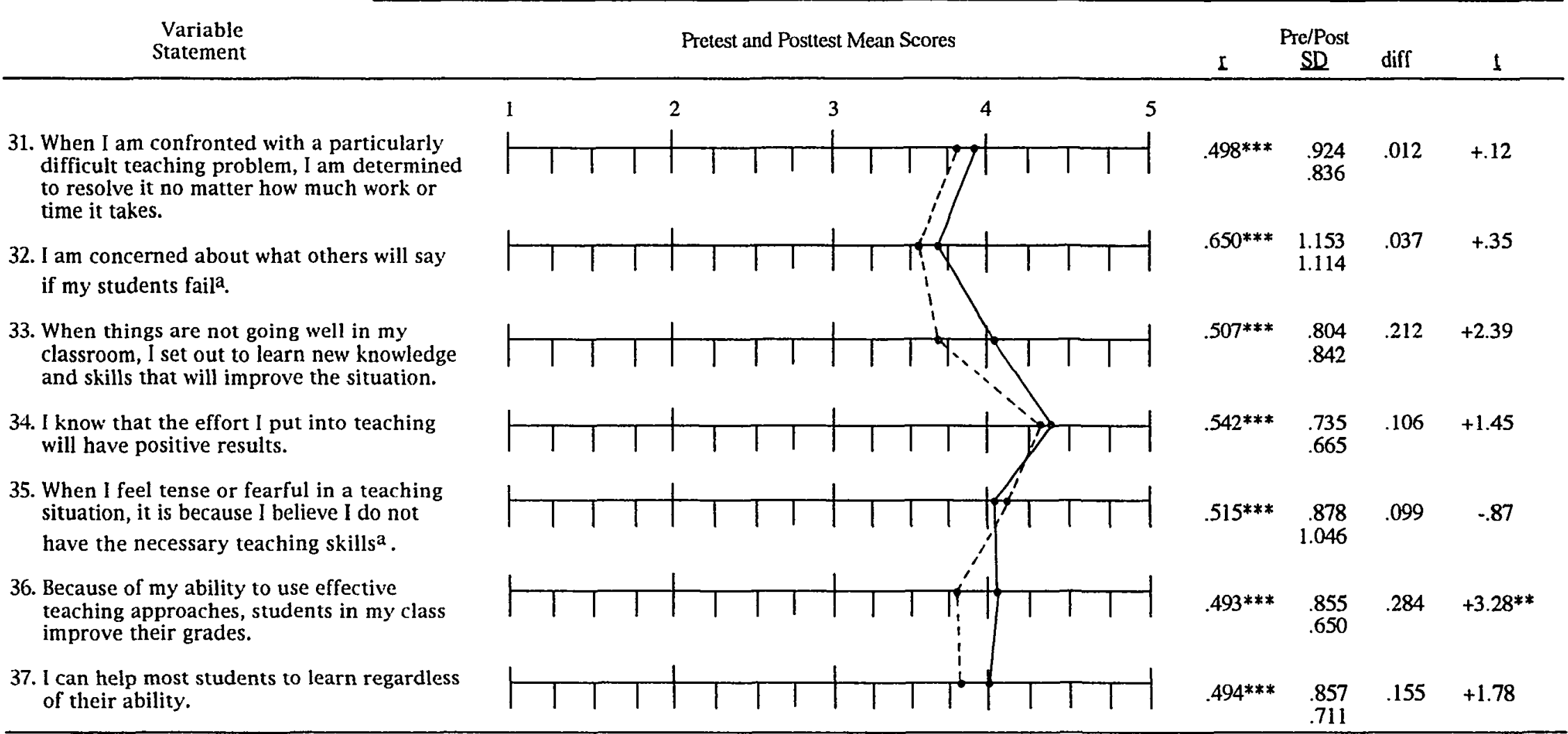

a Recoded before analysis.

Pretest

Posttest 


\section{Table 40}

\section{Results From t Tests: Change in Mean Teacher Responses Erom Pretest to Posttest by Variable}

\section{Test Results}

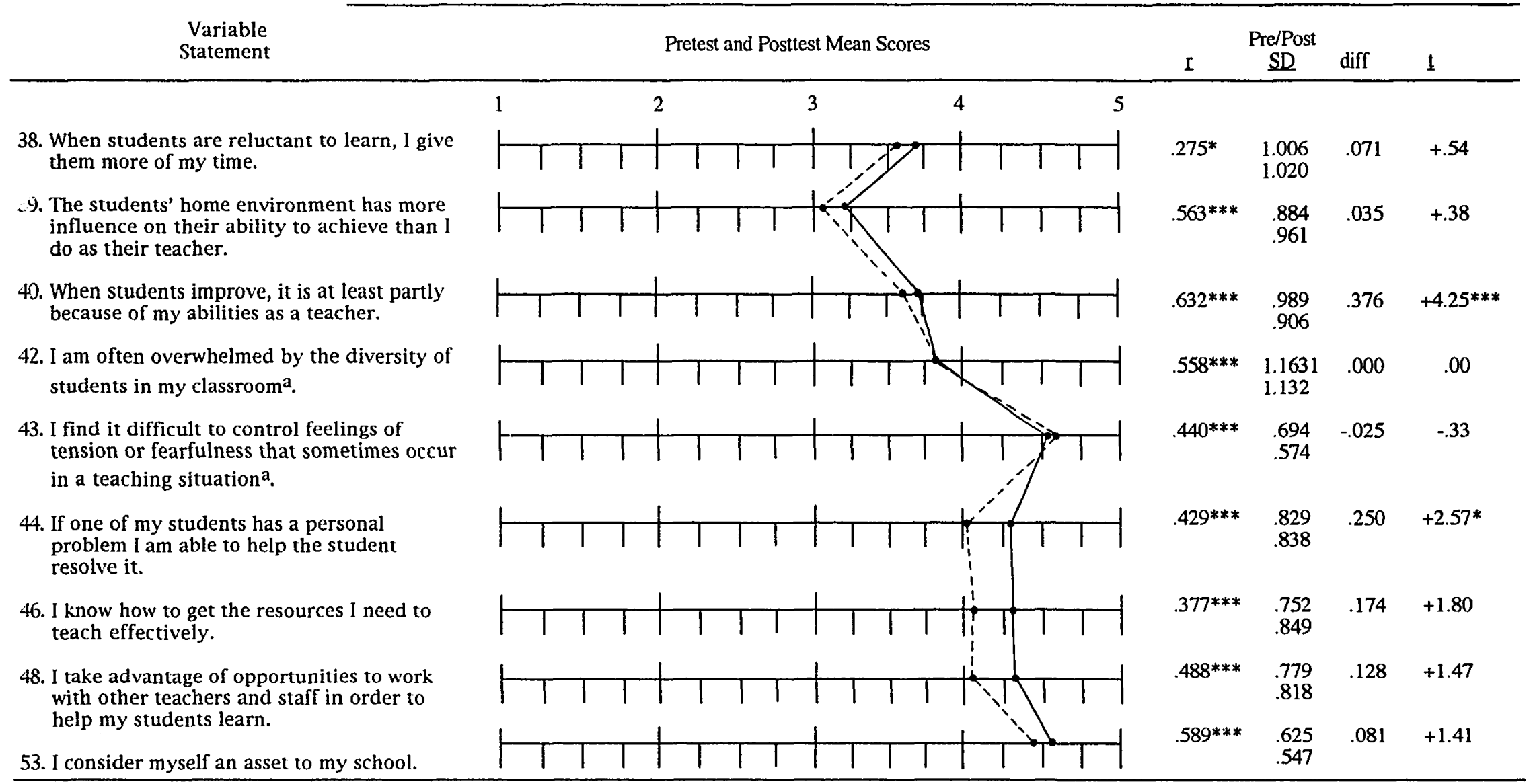

a Recoded before analysis. * $\mathfrak{D}=.05 * * \mathrm{D}=.011^{* * *} \mathrm{D}=.001 \quad$ Pretest 
volitional capabilities and dispositions, while the mean difference on one variable shows no change.

Negative changes in teachers' perceptions. Teachers' mean responses to Items 35 and 43 (both of which had been recoded prior to analysis) show that teachers were more likely at the end of the practicum than at the beginning to feel tense and fearful when they believe that they do not have necessary teaching skills $(t=-.87, \mathfrak{R}=.389)$ and to find it difficult to control feelings of tension or fearfulness $(\mathfrak{I}=-.33, \mathfrak{D}=.741)$. Both items are related to teachers' affective responses to difficult teaching situations, with Item 43--"I find it difficult to control feelings of tension or fearfulness that sometimes occur in teaching situations"--not only hypothesized to load on the thought control efficacy factor in the 31-item scale, but also used as an item in the thought control efficacy index of teachers.

As with the thought control efficacy index, the $t$ values for Items 35 and 43 were not statistically significant, and, therefore, the observed difference does not reflect a significant change in teachers' self-percepts of thought control efficacy. Thus, the null hypotheses for these two items were retained.

Teacher responses also show that they were less likely to spend time considering how they might improve their lessons after the practicum than they were at the beginning of it (Item 24). Further, the observed significance level $(t=-2.76, \underline{q}=.007)$ of the mean difference in pretest and posttest scores indicates a significant change in the sample teachers' predisposition to improve their lessons. Therefore, the null hypothesis was rejected for this item.

No change in teachers' perceptions. Teachers reported no change in their capability not to feel overwhelmed by the diversity of students in their classrooms $(t=.00)$; thus, the null hypothesis was retained for this item. 
Positive and significant differences in teacher perceptions. There were significant differences in the pretest and posttest mean scores of 14 of the 46 variables (30.4\%). Six of the 14 variables had been retained in the modified $31-$ item scale: 3 items (Items 6, 15, and 17) were hypothesized to load on the instruction efficacy factor, 1 (Item 3 ) to load on the student influence factor, and 1 (Item 22) on operative efficacy. The final item (Item 29) of the 6 had been hypothesized as a resiliency-protection factor.

Of the remaining 8 items, not used in the final 31-item scale, 4 were related to the instruction efficacy factor (Items 1, 5, 9, and 11), 1 was related to the student influence factor (Item 44), and 2 (Items 36 and 40) were more representative of resiliency-protection factors.

Instruction efficacy items. Teachers changed significantly from pretest to posttest in their response to 7 items (Items $6,15,17,1,9,5$, and 11), which were hypothesized to load on instruction efficacy in the unmodified 46item scale. Teachers were significantly more likely after the practicum to have higher perceptions of their capabilities to organize the class for various activities $(t=+2.47, \mathrm{D}=.015)$, to acquire new skills for effective teaching $(t=$ $+2.82, \mathfrak{D}=.006)$, and to accurately evaluate their students' progress $(\mathfrak{I}=+3.40, \mathfrak{D}=$ $.001)$. They were also more likely to perceive themselves as more able to help students retain lesson information $(t=+3.15, \underline{D}=.002)$, to guide students through the necessary steps to master a new concept $(t=+2.55, \mathfrak{D}=.013)$. Finally, teachers were significantly more likely to have higher perceptions of their capabilities to assess the difficulty of an assignment $(t=+2.48, \mathrm{R}=.015)$ and adjust it for particular students $(t=+2.90, \mathrm{R}=.005)$.

Student influence. Teachers also changed significantly from pretest to posttest in their response to 1 item (Item 3), which was hypothesized to load on student influence efficacy in the modified 31-item scale. They were significantly more likely at the end of the practicum to perceive themselves as 
more capable to get even the most unmotivated students to actively participate $(I=+3.27, \mathfrak{D}=.002)$ than they were at the beginning.

Teachers also changed significantly on three additional items (Items 44, 40, and 36) not retained in the modified scale. They were significantly more likely at the end of the practicum to hold higher perceptions of their capability to help students resolve personal problems $(t=+2.57, \mathrm{D}=.012)$ and to believe that students improved their grades because of their ability as a teacher $(t=4.25, \underline{D}=.000)$ and their teaching approaches $(t=3.28, \underline{D}=.002)$ than they were at the beginning of it.

Operative efficacy items. Teachers' perceptions of their willingness to try new things even if they might fail (Item 22) also changed over the length of the practicum. The mean difference of .221 yielded a statistically significant $t$ value $(t=+2.10, \mathfrak{D}=.039)$, which supports the conclusion that teachers significantly increased their willingness to try new things.

Items related to the resiliency-protection factors. One (Item 29) of the three items related to the resiliency-protection factors was retained in the modified Personal Teaching Efficacy Scale: Teachers were significantly more likely to enjoy resolving discipline challenges at the end of the practicum than they were at the beginning $(t=+2.18, \mathrm{D}=.032)$. Analysis of the $t$ Test Findings for the

\section{First Research Question of the Teacher Sample}

The positive value of teachers' participation in teacher education through a reflective practitioner model practicum appears to be supported by the statistically significant increase in their sense of personal teaching efficacy. This increase is largely due to significant and positive changes in instruction efficacy. Not only did teachers' mean aggregate score significantly increase on the factor index for instruction efficacy, but their mean scores on six additional variables, not represented on the instruction 
efficacy index but related to instruction efficacy, also significantly increased. In addition, teachers' mean scores on four variables related to student influence efficacy also increased significantly, as did their mean aggregate score on the group relations efficacy index. These represent teachers' perceptions of their teaching performance capabilities, and one can conclude that, for this sample, participation in the reflective practitioner model practicum enhanced teachers' feelings that they were competent classroom performers.

Teachers also significantly strengthened their predisposition to approach discipline problems as a challenge. This positive predisposition may protect the resiliency of teachers' overall sense of personal teaching efficacy.

Participation in a reflective practitioner model practicum did not have an effect on teachers' sense of impact efficacy or action efficacy. Are these volitional aspects of personal teaching efficacy less amenable to changes in the context? Further, teachers' sense of thought control efficacy decreased, as measured by the thought control efficacy index, and by an additional variable, which was part of the unmodified 46-item scale. While the decrease was not significant at the .05 level, it is somewhat surprising, given the increases on indices and variables of the teaching performance aspect. Perhaps, the increased observations by student teachers, the university facilitator, and other members of the school team heightened teachers' self-focus and increased their feelings of nervousness.

Also surprising was the significant decrease in teachers' predisposition to spend time considering how they might improve a lesson after it had gone badly. This item more closely represents teacher reflection than any other; and given the focus of the practicum, it seems unusual that this aspect of teacher volition would decrease. 


\section{Changes in the Personal Teaching Efficacy}

\section{of the Student Teacher Sample}

Changes in student teachers' sense of personal teaching efficacy were also tested using paired \pm tests. I began by conducting a paired $t$ test of the mean composite scores of the pretest and posttest 31-item Personal Teaching Efficacy Scale. Next, five paired I tests were conducted at the factor level. Finally, I again used paired 5 tests to examine changes in student teachers' perceptions at the variable level.

Changes at the Scale Level:

\section{Null Hyoothesis 1}

The first null hypothesis of the student teacher sample states: There is no significant difference in the mean composite score of the 31-item Personal Teaching Efficacy Scale from student teacher pretest to posttest.

Table 13 (see chapter 5) lists the variables included in the 31-item Personal Teaching Efficacy Scale, and Table 41 displays the mean, mode, median, and standard deviation for student teachers' mean composite scores on the pretest and posttest.

Results from a paired $t$ test indicate that it is highly likely that student teachers' sense of personal teaching efficacy significantly changed from the beginning to the end of the practicum. As Table 42 shows, the mean difference $(.570)$ between the student teachers' pretest and posttest $(\underline{n}=94)$ scores yielded a highly significant $t$ value of $+15.81(\underline{D}=.000)$. Therefore, the null hypothesis was rejected.

Changes at the Factor Level:

Null Hypotheses 2 Through 6

Differences in the pretest and posttest mean aggregate scores for four factors underlying personal teaching efficacy were examined using paired $\mathfrak{I}$ tests. Three of the four factors were hypothesized by the new model of 
Table 41

Descriptive Statistics for the Compesite Scores

of the Student Teacher Sample on the Pretest and Posttest

\section{1-Item Personal Teaching Efficacy Scale}

\begin{tabular}{ccc}
\hline \multirow{2}{*}{ Descriptive } & 31-Item Personal Teaching Efficacy Scale \\
\cline { 2 - 3 } Statistics & Pretest & Posttest \\
\hline Mean & 3.40 & 3.97 \\
Median & 3.43 & 4.02 \\
Mode & 3.48 & 4.13 \\
Standard Deviation & .367 & .393 \\
Valid Cases & & 94 \\
\hline
\end{tabular}

a $\underline{n}=94$ 
Table 42

Results of $t$ Tests for Grouped Variables Using Data From the Student Teacher Sample

\begin{tabular}{|c|c|c|c|c|c|c|c|c|c|}
\hline \multirow{2}{*}{$\begin{array}{l}\text { Grouped } \\
\text { Variables }\end{array}$} & \multirow{2}{*}{$\begin{array}{l}\text { Number } \\
\text { Of Items }\end{array}$} & \multicolumn{2}{|c|}{ Mean } & \multicolumn{2}{|c|}{$\begin{array}{l}\text { Standard } \\
\text { Deviation }\end{array}$} & \multirow[b]{2}{*}{ Difference } & \multirow[b]{2}{*}{$\underline{\mathbf{r}}$} & \multirow[b]{2}{*}{$\underline{t}$} & \multirow[b]{2}{*}{$\mathrm{df}^{\mathrm{a}}$} \\
\hline & & Pretest & Posttest & Pretest & Posttest & & & & \\
\hline Personal Teaching Efficacy & 31 & 3.3998 & 3.9694 & .367 & .393 & .5696 & $.579 * * *$ & $+15.81 * * *$ & 93 \\
\hline Instruction Efficacy Index & 3 & 3.0922 & 3.9787 & .607 & .598 & .8865 & $.347 * * *$ & $+12.48 * * *$ & 93 \\
\hline Thought Control Efficacy Index & 2 & 3.6593 & 4.1538 & .703 & .604 & .4945 & $.282 * *$ & $+5.99 * * *$ & 90 \\
\hline Action Efficacy Index & 2 & 3.7824 & 4.0824 & .713 & .663 & .3000 & $.548 * * *$ & $+4.22 * * *$ & 84 \\
\hline $\begin{array}{l}\text { Teacher Operations } \\
\text { Efficacy Index }\end{array}$ & 2 & 3.1489 & 3.9681 & .718 & .604 & .8191 & .284 & $+9.98 * * *$ & 93 \\
\hline
\end{tabular}

$\mathrm{a} \mathrm{n}=94 * \mathrm{p}=.05 * * \mathfrak{p}=.01 * * * \mathfrak{p}=.001$ 
personal teaching efficacy: instruction efficacy, thought control efficacy, and action efficacy. The fourth was a new factor unique to the student teacher sample that I refer to as "teaching operations" efficacy. Each factor was represented by an index of two -to three items that loaded on the factor in both the pretest and posttest factor analyses. Table 43 lists the items used in each factor index, while Table 44 provides the descriptive statistics for the student teachers' responses to them.

Student teacher responses to the factor indices. Table 44 shows that student teachers' mean scores on all the factor indices increased from pretest to posttest. The highest factor-level mean score for student teachers entering the practicum was on the thought control efficacy scale and the lowest mean score was on instruction efficacy. These rankings held from pretest to posttest, despite the largest gain being in instruction efficacy.

In addition to the large gain on instruction efficacy, student teachers also showed an almost equally large gain on the teaching operations factor-both of which represent the teaching performance aspect of personal teaching efficacy.

Of interest are the changes in the standard deviations of the factor indices, all of which narrowed from pretest to posttest. Thought control efficacy and teaching operations efficacy saw the most change in the variability of responses (see Table 44).

Null Hypothesis 2. The second null hypothesis states: There is no significant difference from student teacher pretest to posttest in the mean aggregate score of the three items representing instruction efficacy.

Results of a paired $t$ test of the mean aggregate scores of the three instruction efficacy variables show that student teachers' self-percepts of instruction efficacy changed significantly $(t=+12.48, \mathfrak{2}=.000)$ from the 
Table 43

\section{Items Statements of Indices Representing Five Underlying Factors of \\ Personal Teaching Efficacy in the Student Teacher Sample}

\begin{tabular}{ccc}
\hline Factor & $\begin{array}{c}\text { Item } \\
\text { Number }\end{array}$ & Factor and Item Statement \\
\hline $\begin{array}{c}\text { Instruction } \\
\text { Efficacy }\end{array}$ & 12 & $\begin{array}{l}\text { I know how to create interesting learning activities for students } \\
\text { to do. }\end{array}$ \\
& $18 \quad \begin{array}{l}\text { I know my subject matter well and am able to organize it for } \\
\text { successful learning. }\end{array}$ \\
\hline
\end{tabular}
Thought $\quad 43^{\mathrm{a}}$ I find it difficult to control feelings of tension or fearfulness that Control Efficacy sometimes occur in a teaching situation.
$27^{a}$ If a lesson is not going the way I would like, I find it difficult to change plans mid-stream.

Action

Efficacy

48 I take advantage of opportunities to work with other teachers and staff in order to help my students learn.

33 When things are not going well in my classroom, I set out to learn new knowledge and skills that will improve the situation.

Teaching $\mathrm{b}$

Operations

Efficacy
19 I am able to manage most of the problems in my class.

20 I am able to deal with the diversity of learners in my class.

a The item was recoded prior to statistical analysis. b This index represents an unhypothesized factor arising from the student teacher data only. 
Table 44

Descriptive Statistics for Each of the Pretest and Posttest Factor-Index

Scores Used in the Analvsis of the Student Teacher Sample

\begin{tabular}{|c|c|c|c|c|c|}
\hline $\begin{array}{l}\text { Factor } \\
\text { Index }\end{array}$ & Mean & Mode & Median & $\begin{array}{l}\text { Standard } \\
\text { Deviation }\end{array}$ & $\begin{array}{l}\text { Valid } \\
\text { Cases }^{a}\end{array}$ \\
\hline \multicolumn{6}{|l|}{$\begin{array}{l}\text { Instruction } \\
\text { Efficacy }\end{array}$} \\
\hline Pretest & 3.09 & 3.00 & 3.00 & .607 & 94 \\
\hline Posttest & 3.98 & 4.00 & 4.00 & .598 & 94 \\
\hline \multicolumn{6}{|c|}{$\begin{array}{l}\text { Thought Control } \\
\text { Efficacy }\end{array}$} \\
\hline Pretest & 3.66 & 4.00 & 3.75 & .700 & 92 \\
\hline Posttest & 4.16 & 4.00 & 4.00 & .599 & 93 \\
\hline \multicolumn{6}{|c|}{ Action Efficacy } \\
\hline Pretest & 3.78 & 3.50 & 4.00 & .710 & 86 \\
\hline Posttest & 4.10 & 4.00 & 4.00 & .659 & 91 \\
\hline \multicolumn{6}{|c|}{$\begin{array}{l}\text { Teaching } \\
\text { Operations Efficacy }\end{array}$} \\
\hline Pretest & 3.15 & 3.50 & 3.00 & .718 & 94 \\
\hline Posttest & 3.97 & 4.00 & 4.00 & .604 & 94 \\
\hline
\end{tabular}


beginning of the practicum to the end (see Table 42). Therefore, the null hypothesis can be rejected.

Null Hypothesis 3. The third null hypothesis states: There is no significant difference from student teacher pretest to posttest in the mean aggregate scores of the two items representing thought control efficacy.

Results of a paired $\rfloor$ test showed that student teachers were significantly more likely to have a higher sense of thought control efficacy after the practicum than before $(t=+5.99, \mathfrak{p}=.001)$. Therefore, the null hypothesis was rejected.

Null Hypothesis 4 . Null Hypothesis 4 states: There is no significant difference from student teacher pretest to posttest in the mean aggregate scores of the two items representing action efficacy.

The mean difference between student teachers' pretest and posttest mean scores on action efficacy yielded a significant $\rfloor$ value $(\underline{t}=+4.22, \mathfrak{I}=.001)$, suggesting that student teachers' self-percepts of action efficacy significantly and positively changed over the duration of the practicum (see Table 42). Therefore, the null was rejected.

Null Hypothesis 5. The final null hypothesis at the factor level states: There is no significant difference from student teacher pretest to posttest in the mean aggregate scores of the two items representing the unhypothesized factor, teaching operations efficacy.

A mean difference of .819 between student teachers' pretest and posttest mean scores on the teaching operations factor yielded a highly significant $I$ value $(t=+9.98, \mathfrak{D}=.000)$, confirming that student teachers' self-percepts of their capabilities to effectively fulfill common teaching operations positively and significantly increased over the term of the practicum (see Table 42). Therefore, the null hypothesis was rejected. 
Changes at the Variable Level:

\section{Null Hypothesis 6}

To further explore changes in student teachers' sense of personal teaching efficacy, a paired $\mathrm{I}$ test was conducted for each of the 46 variables from the unmodified Personal Teaching Efficacy Scale. Null Hypothesis 6 states: There is no significant difference in the mean scores of the student teacher pretest and posttest for each of the 46 variables on the unmodified Personal Teaching Efficacy Scale.

Table 45 plots the student teachers' mean scores of the 46 items on the pretest and posttest of the unmodified Personal Teaching Efficacy Scale and provides the $I$ value and observed significance level for each. The plotted mean scores clearly show that student teachers' sense of their capabilities and volitional dispositions changed positively from the beginning of the practicum to the end. The mean differences were positive for 44 of the 46 variables (95.7\%), with $43 \pm$ tests yielding significant $I$ values. The mean differences of only two variables were negative; however, the $t$ values for these two variables were nonsignificant.

Negative changes in student teachers' perceptions. Mean differences in student teachers' responses to Items 23 and 39 (both of which had been recoded prior to analysis) show that student teachers' beliefs that their effort will make a difference $(t=-.99, \mathbb{D}=.323)$ and that they have as much influence on students' ability to achieve as does students' home environment $(t=-1.40, \mathbb{D}$ $=.165$ ) decreased over the term of the practicum, although not significantly. The observed significance levels of the two variables was high; therefore, the null hypotheses for these two variables were retained.

Positive changes in student teachers' perceptions. The remaining 44 variables from the unmodified 46-item Personal Teaching Efficacy Scale showed that student teachers' perceptions of their performance and 
Table 45

Results Erom t Tests: Change in Mean Student Teacher Responses From Pretest to Posttest by Variable

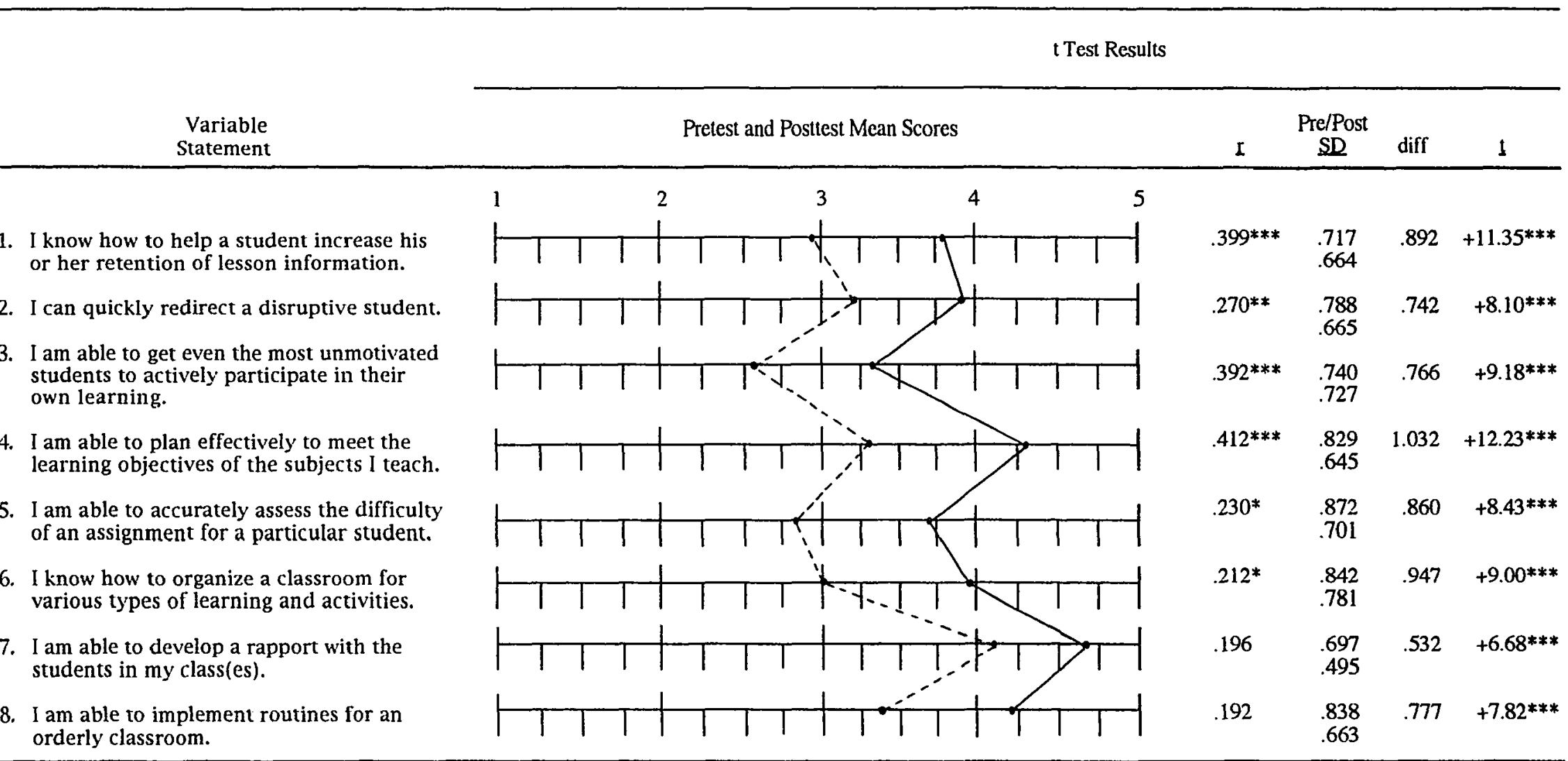

a Recoded before analysis.

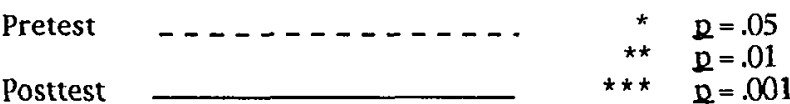


Table 45

Results From t Tests: Change in Mean Student Teacher Responses From Pretest to Posttest by Variable

t Test Results

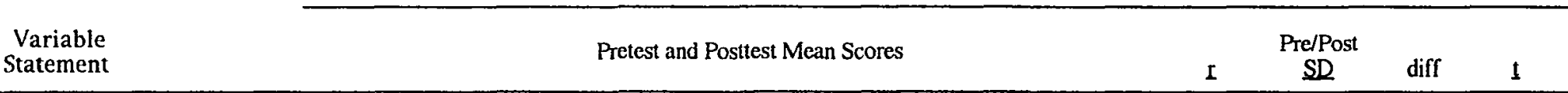

9. I am able to guide a student through the necessary steps to master a new concept.

10. I can create an atmosphere so that students enjoy being in my classes.

11. I am able to adjust the difficulty of an assignment to match the level of particular students.

12. I know how to create interesting learning activities for students to do.

13. I can plan instruction for students in my class who are at various levels of ability or stages of learning.

14. I know which teaching strategy is most effective for different kinds of student learning.

15. I am able to acquire new skills that are necessary to teach effectively in particular circumstances.

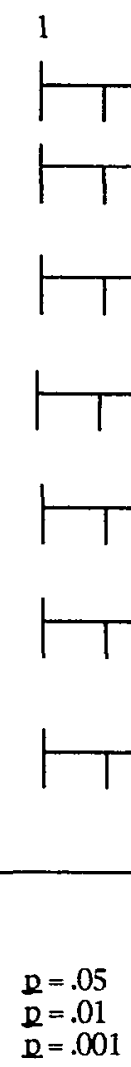

a Recoded before analysis.

\begin{tabular}{|c|c|}
\hline test & $\cdots-\cdots-\cdots-\cdots$ \\
\hline
\end{tabular}


Table 45

Results From t Tests: Change in Mean Student Teacher Responses From Pretest to Posttest by Variable

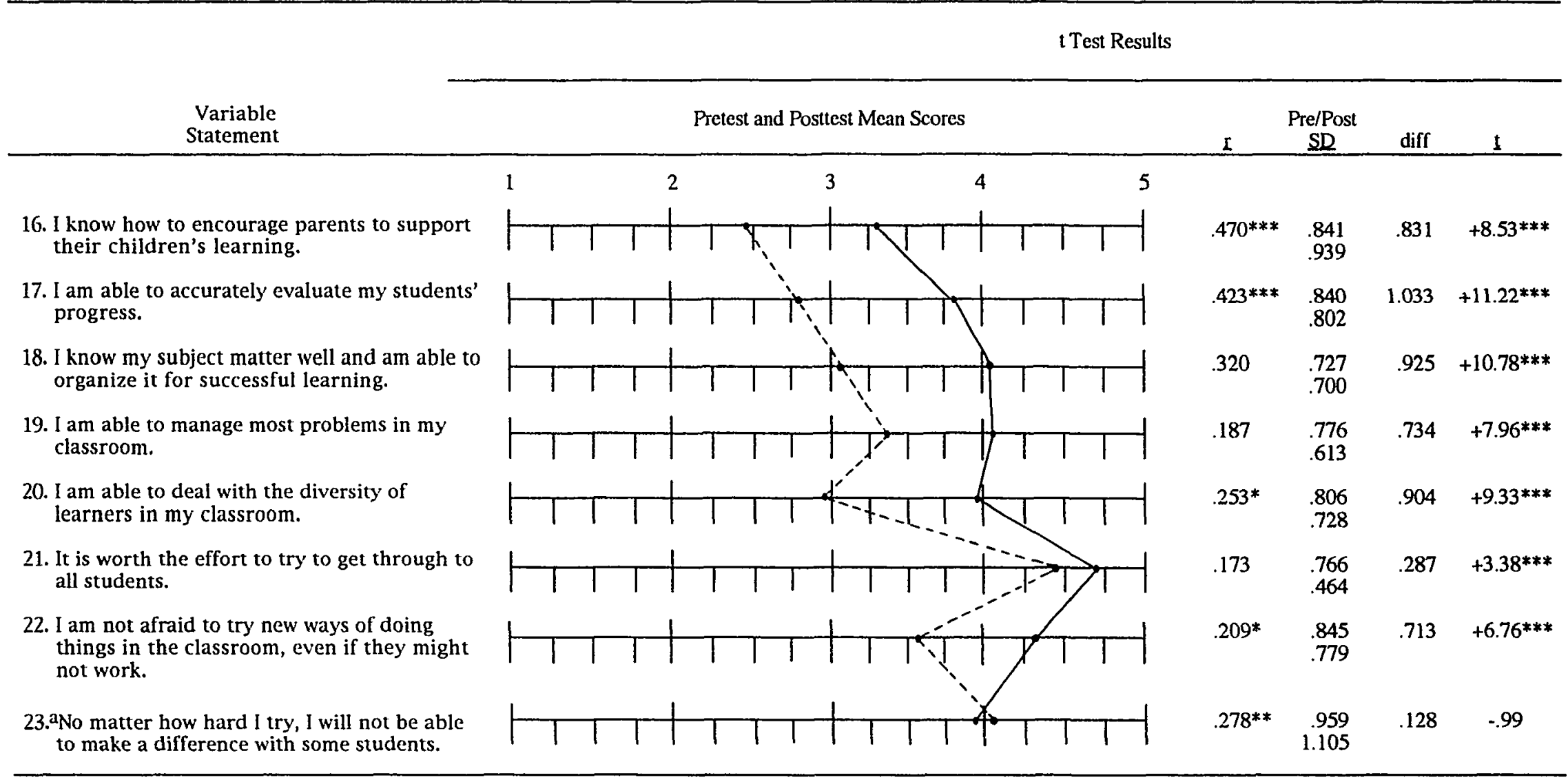

a Recoded before analysis.

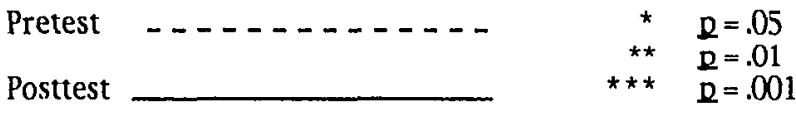


Table 45

Results From t Tests: Change in Mean Student Teacher Responses From Pretest to Posttest by Variable

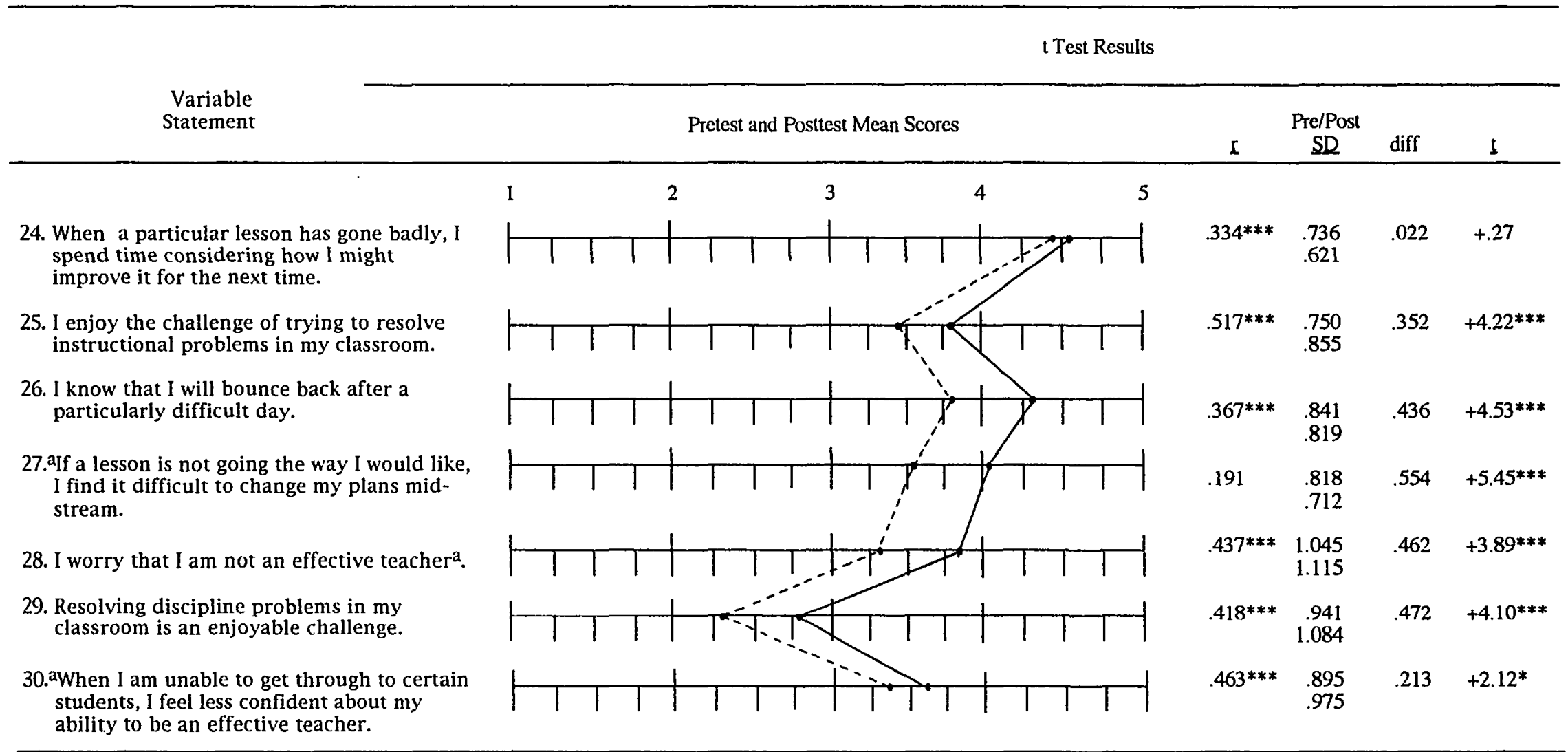

a Recoded before analysis.

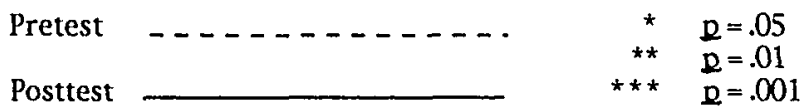


Table 45

Results From t Tests: Change in Mean Student Teacher Responses From Pretest to Posttest by Variable

\begin{tabular}{|c|c|c|c|c|c|}
\hline \multirow[b]{2}{*}{$\begin{array}{c}\text { Variable } \\
\text { Statement }\end{array}$} & \multicolumn{5}{|c|}{ t Test Results } \\
\hline & Pretest and Posttest Mean Scores & I & $\begin{array}{l}\text { Pre/Post } \\
\text { SD }\end{array}$ & diff & 1 \\
\hline & 2 & & & & \\
\hline $\begin{array}{l}\text { 31. When I am confronted with a particularly } \\
\text { difficult teaching problem, I am determined } \\
\text { to resolve it no matter how much work or } \\
\text { time it takes. }\end{array}$ & \begin{tabular}{|l|l|l|l|} 
& \multicolumn{3}{l|}{$\mid$}
\end{tabular} & $.279^{* *}$ & $\begin{array}{l}.930 \\
.930\end{array}$ & .418 & $+3.57 * * *$ \\
\hline $\begin{array}{l}\text { 32. I am concerned about what others will say } \\
\text { if my students faila. }\end{array}$ & 171 & $.383^{* * *}$ & $\begin{array}{l}1.045 \\
1.124\end{array}$ & .196 & +1.56 \\
\hline $\begin{array}{l}\text { 33. When things are not going well in my } \\
\text { classroom, I set out to learn new knowledge } \\
\text { and skills that will improve the situation. }\end{array}$ & \begin{tabular}{ll|}
11 \\
11
\end{tabular} & $.408 * * *$ & $\begin{array}{l}.815 \\
.757\end{array}$ & .247 & $+2.72^{* *}$ \\
\hline $\begin{array}{l}\text { 34. I know that the effort I put into teaching } \\
\text { will have positive results. }\end{array}$ & $T$ & $.423 * * *$ & $\begin{array}{l}.772 \\
.668\end{array}$ & .266 & $+3.31 * * *$ \\
\hline $\begin{array}{l}\text { 35. When I feel tense or fearful in a teaching } \\
\text { situation, it is because I believe I do not } \\
\text { have the necessary teaching skills. }\end{array}$ & \begin{tabular}{l|l|l} 
& 1
\end{tabular} & $.438^{* * *}$ & $\begin{array}{l}1.178 \\
1.221\end{array}$ & .344 & $+2.61^{*}$ \\
\hline $\begin{array}{l}\text { 36. Because of my ability to use effective } \\
\text { teaching approaches, students in my class } \\
\text { improve their grades. }\end{array}$ & $1 T$ & $.367^{* *}$ & $\begin{array}{l}.857 \\
.842\end{array}$ & .623 & $+5.41 * * *$ \\
\hline $\begin{array}{l}\text { 37. I can help most students to learn regardless } \\
\text { of their ability. }\end{array}$ & $T 1$ & $.354 * * *$ & $\begin{array}{r}1.052 \\
.886\end{array}$ & .494 & $+4.25^{* * *}$ \\
\hline
\end{tabular}

a Recoded before analysis.

Pretest $\quad * \ldots+\cdots \quad * \quad \begin{aligned} & \mathrm{D}=.05 \\ & \mathrm{D}=.01\end{aligned}$

Posttest $\quad * * * \quad \begin{aligned} & \mathrm{D}=.01 \\ & \mathrm{D}=.001\end{aligned}$ 
Table 45

\section{Results From t Tests: Change in Mean Student Teacher Responses Erom Pretest to Posttest by Variable}

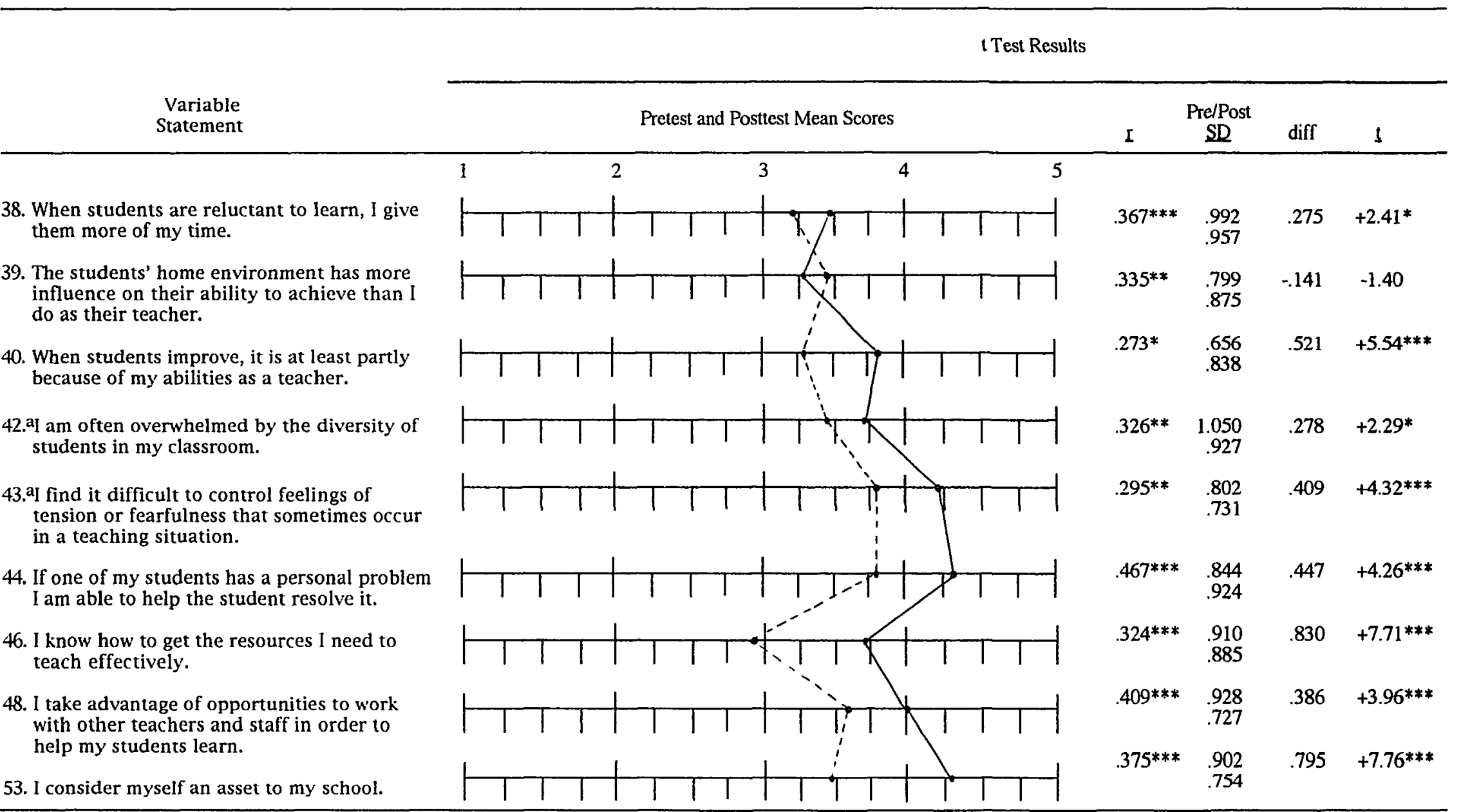

a Recoded before analysis. * $\mathrm{D}=.05 * * \mathrm{D}=.01 \quad * * * \mathrm{D}=.001$

Pretest ........... Posttest 
volitional capabilities and dispositions increased from the beginning of the practicum to the end. In addition, the mean difference of only 1 variable yielded a statistically nonsignificant $I$ value: Student teachers' predisposition to consider how they might improve lessons that had gone badly increased over the term of the practicum, but not significantly $(t=+.27, \mathfrak{R}=.791)$. Therefore, the null hypothesis for this variable was retained. Analvsis of the $t$ Test Findings for the First Research Ouestion of the Student Teacher Sample

Participation in a reflective practitioner model practicum appears to have high value for student teachers' development of a positive sense of personal teaching efficacy. In addition, this increase can be attributed to the variables representing all but one of the underlying factors of personal teaching efficacy. The differences in student teachers' mean aggregate scores on the instruction efficacy, thought control efficacy, action efficacy, and teaching operations efficacy indices were all significant, as were the difference in mean scores on 43 of the 46 variables.

As with the teacher sample, student teachers changed positively but nonsignificantly in their predisposition to consider how they might improve a lesson that has gone badly. Of particular interest, however, is the decrease in student teachers' mean scores on the two variables hypothesized to represent impact efficacy. While this decrease was nonsignificant, it does seem to support the concern of teacher educators that the student teaching experience negatively affects student teachers' beliefs in their ability to make a difference with most students, despite student ability or home environment. While the decline in feelings related to impact efficacy no doubt represents a decline in idealism, the decrease in scores also may represent a newfound realization of the reality that outside-class variables do have a strong influence on the children they teach. 
Research Question 2: The Effect of Personal Characteristics

on Changes in Personal Teaching Efficacy

The second general research question of the study asked: Will certain personal characteristics of teachers and student teachers have an effect on changes in their self-percepts of personal teaching efficacy after participation in a reflective practitioner model practicum? That is, will certain groups of teachers or student teachers change more or less than other groups, and will these differences in the rate of change be significantly different from other groups? The second research question was answered at the scale and factor levels.

\section{The Effect of Personal Characteristics on Changes in Personal Teaching Efficacy of the Teacher Sample}

The teacher study asked if four personal characteristics of teachers-gender, age group, teaching experience group, and previous practicum participation--would have main or interaction effects on teacher changes in personal teaching efficacy. Table 27 (chapter 5) outlines the levels for each of these independent variables; dependent variables were the gain scores derived from finding the difference between the pretest and posttest mean aggregate scores for the 31 items of the modified Personal Teaching Efficacy Scale and the gain scores for the factor indices used in the previous analyses. Four-way ANOVAs using a $2 \times 3 \times 3 \times 2$ factorial design were conducted to test the six null hypotheses at the scale and factor levels. 
Changes at the Scale Level:

\section{Null Hypothesis 1}

The first null hypothesis states: There will be no significant main or interaction effects for gender, age, teaching experience, and previous practicum participation on mean gain scores of personal teaching efficacy.

As in the previous analyses, personal teaching efficacy was operationally defined as the composite score on the 31-item Personal Teaching Efficacy Scale. A four-way ANOVA was conducted to determine differences in mean gain scores of personal teaching efficacy by gender, age, teaching experience, and previous practicum experience. An $\mathrm{E}$ test for differences shows no significant difference at the .05 level in changes in personal teaching efficacy for the main effects of the four personal characteristics of teachers (see Table 46).

However, as Table 46 shows, a main effect for teacher age group approached significance $(\mathrm{D}=.066)$ : An examination of the mean responses of teachers by age group shows that the mean gain scores were .22 for "young" teachers (ages 21-35), .06 for "middle-aged" teachers (ages 36-45), and .07 for "mature" teachers (ages 46-59), indicating that the youngster group experienced a higher rate of change in composite personal teaching efficacy than the other two groups.

Two-way ANOVAs. Interaction effects were suppressed in the four-way ANOVAs due to empty cells. Therefore, to assure that no important interaction effects were missed, two-way ANOVAs were conducted for the group combinations with no empty cells: gender and age group, gender and teaching experience, gender and previous practicum experience, age group and previous practicum experience, and teaching experience and previous practicum experience. The main effect for age group on the personal teaching efficacy index approached a .05 significance level on the two-way 
Table 46

Analysis of Variance Table: The Main Effects of Four Independent Variables

on Teacher Gain Scores for the 31-Item Personal Teaching Efficacy Scale ${ }^{\text {ab }}$

\begin{tabular}{|c|c|c|c|c|c|}
\hline Source of & Sum of & & Mean & & Sig of \\
\hline Variation & Squares & df & Square & $E$ & $\mathrm{E}$ \\
\hline Main Effects & .525 & 6 & .087 & 1.133 & .352 \\
\hline Gender & .008 & 1 & .008 & .105 & .747 \\
\hline Age Group & .436 & 2 & .218 & 2.823 & .066 \\
\hline $\begin{array}{l}\text { Teaching } \\
\text { Experience } \\
\text { Group }\end{array}$ & .161 & 2 & .081 & 1.045 & .357 \\
\hline $\begin{array}{l}\text { Practicum } \\
\text { Experience }\end{array}$ & .020 & 1 & .020 & .256 & .614 \\
\hline Explained & .525 & 6 & .087 & 1.133 & .352 \\
\hline Residual & 5.559 & 72 & .077 & & \\
\hline Total & 6.084 & 78 & .078 & & \\
\hline
\end{tabular}


ANOVAs for gender and age group $(\underline{R}=.076)$ and approached a .10 significance level on the two-way ANOVA for age group and previous practicum experience $(\mathbb{D}=.106)$, with the gain scores of young teachers positively influencing the main effect. However, no statistically significant interaction effects were found.

Changes at the Factor Level:

Null Hypotheses 2 to 6

The second through sixth null hypotheses presume the following: There will be no significant main or interaction effects for gender, age, teaching experience, and previous practicum participation on the mean gain scores of instruction efficacy, group relations efficacy, impact efficacy, thought control efficacy, and action efficacy. Four-way ANOVAs, using a $2 \times 3$ X 3 X 2 design, were conducted for each of the mean factor gain scores.

No main effects were found for gender, age, teaching experience, or previous practicum experience on the instruction efficacy, group relations efficacy, impact efficacy, thought control efficacy, and action efficacy mean factor gain scores.

The effect of gender on group relations efficacy. However, a main effect for gender approached the .05 significance level on the group relations efficacy gain score $(\underline{D}=.088$; see Table 47$)$. An examination of cell means for the two levels of gender indicates that the mean gain score of female teachers (.10) on the group relations efficacy index was positive and higher than the negative score of male teachers (-.07), although not significantly.

The effect of teaching experience on group relations efficacy. In addition, a main effect for teaching experience $(\mathrm{Q}=.111)$ approached a .10 significance level (see Table 47), which is often considered an appropriate alpha level in exploratory work (Huberty, 1987, cited in Reiman \& TheisSprinthall, 1993). The cell means for the three levels of teaching experience 
Table 47

Analysis of Variance Table: The Main Effects of Four Independent Variables

on Teacher Gain Scores for the Group Relations Efficacy Index ${ }^{\text {ab }}$

\begin{tabular}{|c|c|c|c|c|c|}
\hline Source of & Sum of & & Mean & & Sig of \\
\hline Variation & Squares & df & Square & $E$ & $E$ \\
\hline Main Effects & 1.059 & 6 & .177 & 1.365 & .240 \\
\hline Gender & .386 & 1 & .386 & 2.983 & .088 \\
\hline Age Group & .385 & 2 & .192 & 1.489 & .233 \\
\hline $\begin{array}{l}\text { Teaching } \\
\text { Experience } \\
\text { Group }\end{array}$ & .585 & 2 & .293 & 2.265 & .111 \\
\hline $\begin{array}{l}\text { Practicum } \\
\text { Experience }\end{array}$ & .080 & 1 & .080 & .618 & .434 \\
\hline Explained & 1.059 & 6 & .177 & 1.365 & .240 \\
\hline Residual & 9.178 & 71 & .129 & & \\
\hline Total & 10.237 & 77 & .133 & & \\
\hline
\end{tabular}


were $.04, .03$, and .15 for "neophyte" teachers (3-10 years of teaching experience), "midcareer" teachers (11-20 years), and "veteran" teachers (2139 years), respectively. Thus, veteran teachers increased their feelings of group relations efficacy more than did either neophyte or midcareer teachers, although not significantly.

Two-way ANOVAs. Interaction effects were again suppressed because of empty cells, and two-way ANOVAs were conducted for each of the factor indices to assure that no important interaction effects were missed. While there were no interaction effects found for the impact efficacy, group relations efficacy, and thought control efficacy indices, there were noteworthy interaction effects on the instruction efficacy and action efficacy indices.

Interaction effects on the instruction efficacy index. There were two interaction effects on the instruction efficacy index that approached statistical significance at the .05 level. First, a significant interaction effect at the .05 level for age group and practicum experience $(\mathfrak{L}=.027$; see Table 48 ). Second, there was an interaction effect between teaching experience and previous practicum experience that approached significance $(\mathcal{L}=.055$; see Table 49).

The interaction effect of age group and previous practicum experience on instruction efficacy. Figure 8 show the cell means and plots the two-factor interaction. As the graph shows, in Age Groups 1 and 2 (young and middleaged), teachers without previous practicum experience had larger gains in self-percepts of instruction efficacy than teachers with previous practicum experience. However, teachers in Age Group 3 (mature) with no previous practicum experience lowered their sense of instruction efficacy over the course of the practicum. Teachers in all three age groups who had previous practicum experience modestly increased their sense of instruction 
Table 48

Two-Way ANOVA Table: The Main and Interaction Effects

of Age Group and Previous Practicum Participation

on Teacher Gain Scores for the Instruction Efficacy Index ${ }^{a}$

\begin{tabular}{lccccc}
\hline Source of & Sum of & & Mean & & Sig of \\
Variation & Squares & df & Square & E & E \\
\hline Main Effects & .750 & 3 & .250 & .860 & .466 \\
Age Group & .448 & 2 & .224 & .771 & .466 \\
$\begin{array}{l}\text { Practicum } \\
\text { Experience }\end{array}$ & .138 & 1 & .138 & .476 & .493 \\
2-Way Interactions & 2.202 & 2 & 1.101 & 3.792 & .027 \\
$\quad \begin{array}{l}\text { Age Group/ } \\
\text { Practicum }\end{array}$ & 2.202 & 2 & 1.101 & 3.792 & .027 \\
Experience & & & & & \\
Explained & & 5 & .590 & 2.033 & \\
Residual & 2.952 & 73 & .290 & & \\
Total & 21.200 & 78 & .310 & & \\
\hline
\end{tabular}

a $\mathfrak{n}=85 ; 6$ cases were missing. 
Table 49

Two-Way ANOVA Table: The Main and Interaction Effects

of Teaching Experience and Previous Practicum Participation

on Teacher Gain Scores for the Instruction Efficacy Index ${ }^{a}$

\begin{tabular}{lccccc}
\hline $\begin{array}{l}\text { Source of } \\
\text { Variation }\end{array}$ & $\begin{array}{c}\text { Sum of } \\
\text { Squares }\end{array}$ & df & Square & E & E \\
\hline $\begin{array}{l}\text { Main Effects } \\
\text { Teaching } \\
\text { Experience }\end{array}$ & .446 & 3 & .149 & .521 & .669 \\
$\begin{array}{l}\text { Practicum } \\
\text { Experience }\end{array}$ & .036 & 2 & .018 & .063 & .939 \\
$\begin{array}{l}\text { 2-Way Interactions } \\
\text { Teaching and }\end{array}$ & 1.720 & 1 & .294 & 1.030 & .313 \\
$\begin{array}{l}\text { Practicum } \\
\text { Experience }\end{array}$ & 1.720 & 2 & .860 & 3.014 & .055 \\
& & 2 & .860 & 3.014 & .055 \\
Explained & & & & & \\
Residual & 2.166 & 5 & .433 & 1.518 & .194 \\
Total & 21.972 & 77 & .285 & & \\
\hline
\end{tabular}

${ }^{a} \underline{n}=85 ; 2$ cases were missing. 


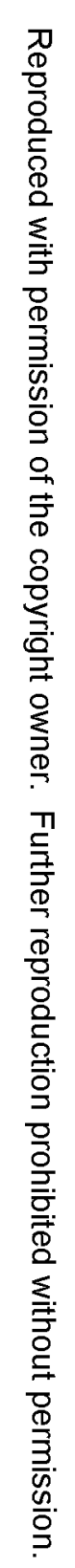

Figure 8

Interaction Effects of Age Group and Previous Practicum Experience on

Teachers' Change in Instruction Efficacy ${ }^{a}$

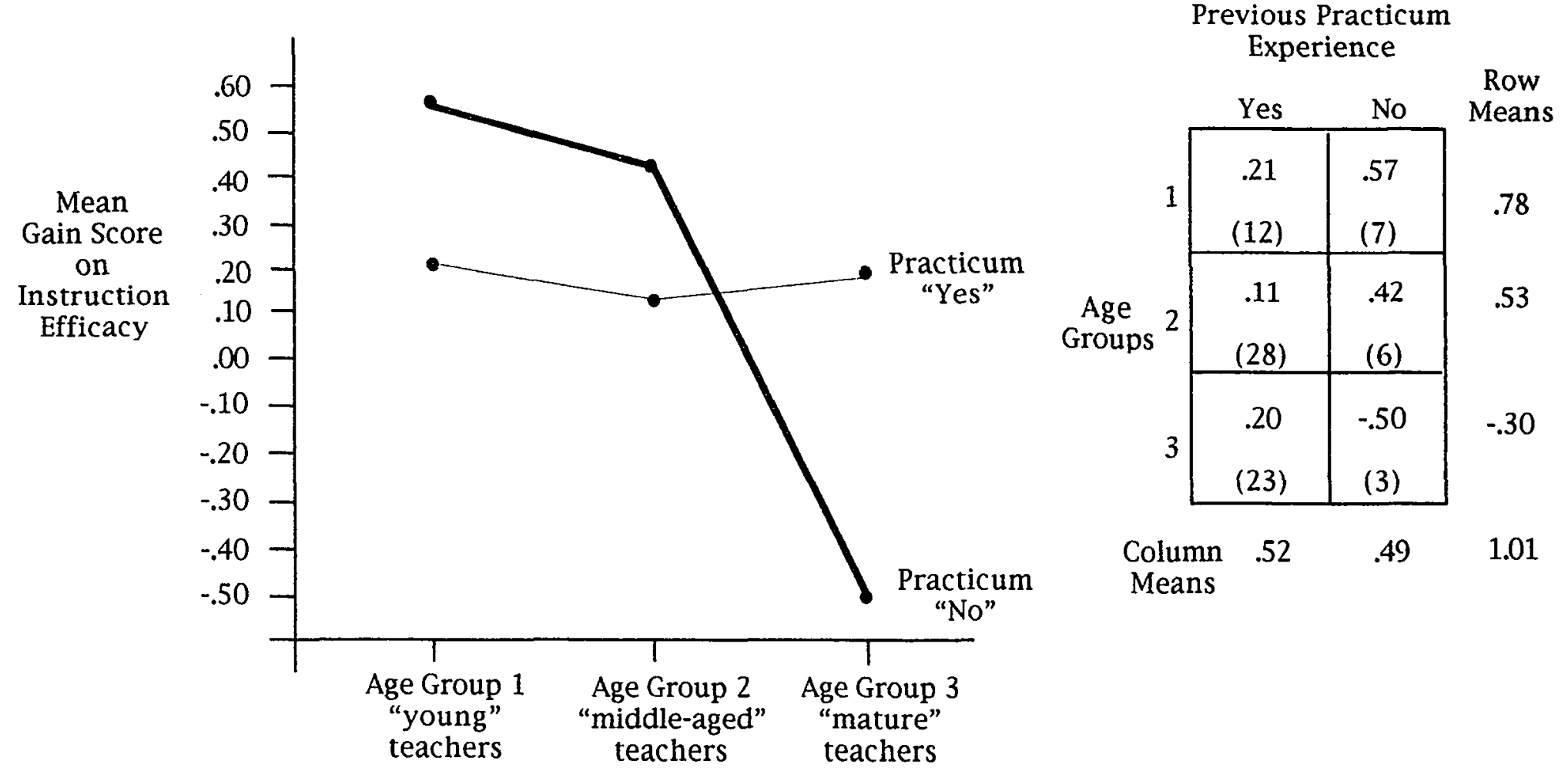

a By Plotting of Cell Means 
efficacy over the term of the practicum, with Age Group 2 increasing slightly less.

It seems likely that a teacher's age and whether or not he or she has participated in previous practicum experiences have an effect on increased feelings of instruction efficacy. Young (21-35 years old) and middle-aged (3645 years old) teachers with no previous practicum experience had relatively large gains in their sense of instruction efficacy, while mature teachers (4659 years old) with no previous practicum experience had a relatively large decrease in feelings of efficaciousness for instruction. However, these findings should be viewed with caution, given the unequal cell sizes and the threat of a Type I error.

The interaction effect of teaching experience and previous practicum experience on instruction efficacy. There was also a differential interaction effect for teachers at different levels of teaching experience with previous practicum experience, although the interaction effect approached significance only at the .05 level ( $\mathrm{L}=.055$; see Table 49). Neophyte, midcareer, and veteran teachers with previous practicum experience had modest increases in feelings of instruction efficacy, with midcareer teachers having the smallest gain (see Figure 9). However, neophyte and midcareer teachers with ne previous practicum experience had larger gains than all teachers with previous practicum experience. Alternately, veteran teachers with no previous practicum experience experienced a marked decline in self-percepts of instruction efficacy over the period of the practicum. While the column means suggest that having participated in previous practicum experiences enhances the likelihood that teachers will experience a positive change in their sense of efficacy, such a conclusion would be simplistic. First-time participants who had taught for over 20 years experienced a loss in selfpercepts of instruction efficacy over the term of the reflective practitioner 
Figure 9

Interaction Effects of Teaching Experience and Previous Practicum

Experience on Teachers' Change in Instruction Efficacy ${ }^{a}$

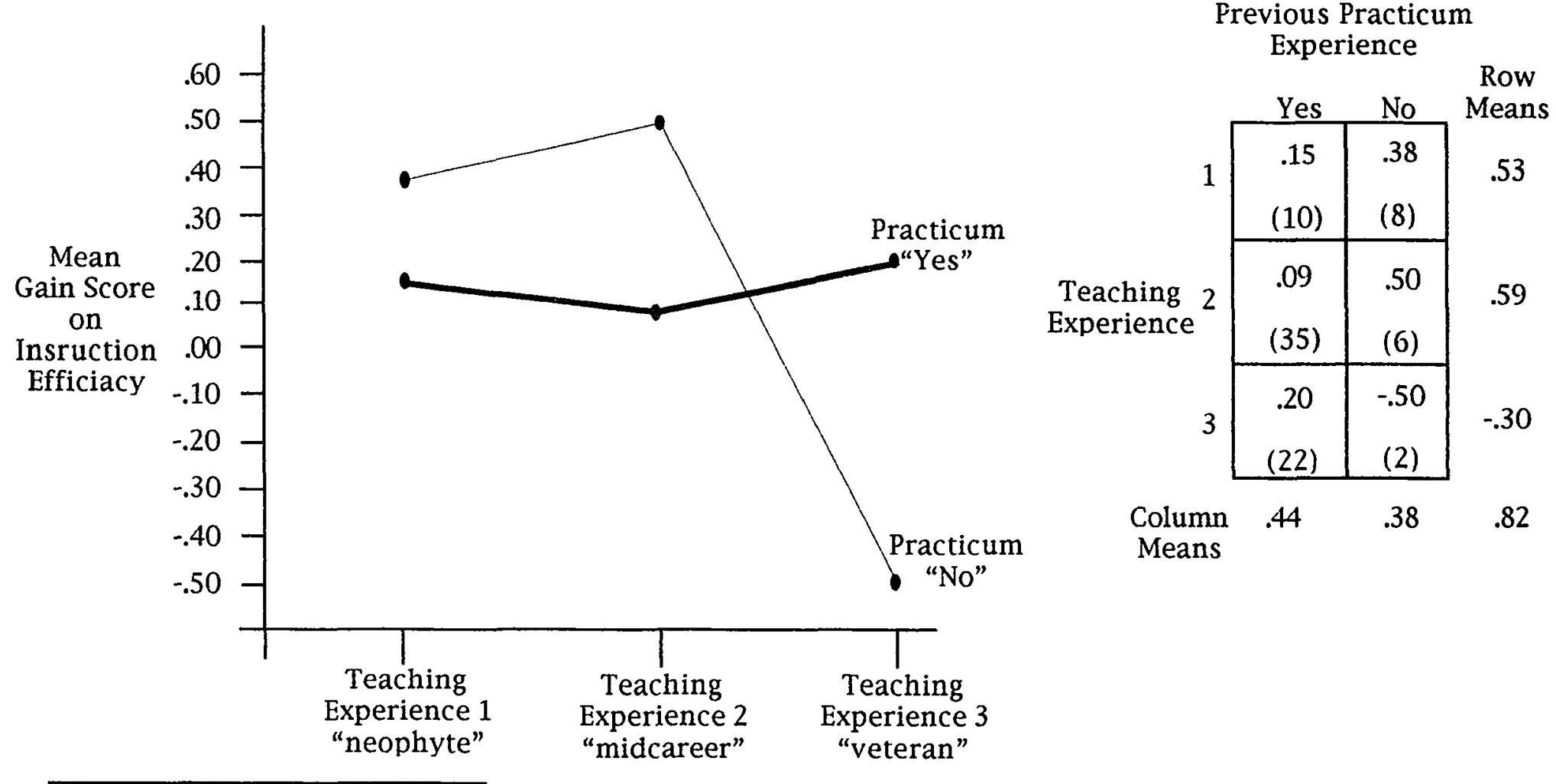

a By Plotting of Cell Means 
model practicum, while others, with less teaching experience, increased their feelings of instruction efficacy, albeit modestly.

It is not surprising that the interaction effect of age and previous practicum experience and the interaction effect between teaching experience and previous practicum experience form similar patterns--age and amount of teaching experience are highly related, especially for veteran teachers.

However, in both cases, previous practicum experience produced mild gains in instruction efficacy across the three groups, while no previous practicum experience positively affected changes in instruction efficacy for young and middle-aged teachers and neophyte and midcareer teachers. Only mature and veteran teachers experienced a decline in self-percepts of efficacy, suggesting that older teachers with more experience have a more negative first-time practicum experience than teachers in younger age groups with less experience. This finding needs to be accepted with caution, however: The large differences in cell size across groups make it possible for a Type I error to occur when variance between groups is also dissimilar.

Interaction effects on changes in action efficacy. As with instruction efficacy, interaction effects between age group and previous practicum experience and between teaching experience and previous practicum experience produced differences in the teacher gain scores on action efficacy, indexed by two items related to improving teaching and the teaching situation through reflection and learning new knowledge and skills.

The interaction effect of teaching experience and previous practicum experience on action efficacy. There was a significant interaction effect $(\mathbb{R}=$ .031 ) between teaching experience and previous practicum experience on teachers' sense of action efficacy (see Table 50). Neophyte teachers with previous practicum experience experienced a modest increase in their sense of action efficacy from the beginning to the end of the practicum, while 
Table 50

Two-Way ANOVA Table: The Main and Interaction Effects

of Teaching Experience and Previous Practicum Participation

on Teacher Gain Scores for the Action Efficacy Index ${ }^{2}$

\begin{tabular}{lccccc}
\hline $\begin{array}{l}\text { Source of } \\
\text { Variation }\end{array}$ & $\begin{array}{c}\text { Sum of } \\
\text { Squares }\end{array}$ & df & Square & E & E \\
\hline $\begin{array}{l}\text { Main Effects } \\
\text { Teaching }\end{array}$ & .168 & 3 & .056 & .171 & .916 \\
$\begin{array}{l}\text { Experience } \\
\begin{array}{l}\text { Practicum } \\
\text { Experience }\end{array}\end{array}$ & .168 & 2 & .084 & .255 & .776 \\
$\begin{array}{l}\text { 2-Way Interactions } \\
\text { Teaching }\end{array}$ & .008 & 1 & .008 & .026 & .873 \\
$\begin{array}{l}\text { Experience/ } \\
\text { Eracticum }\end{array}$ & 2.402 & 2 & 1.201 & 3.651 & .031 \\
$\begin{array}{l}\text { Experience } \\
\text { Explained }\end{array}$ & & 2 & 1.201 & 3.651 & .031 \\
Residual & 2.571 & 5 & & & \\
Total & 24.676 & 75 & .329 & & \\
\hline
\end{tabular}

a $\underline{\underline{n}}=83 ; 2$ cases were missing. 
midcareer teachers experienced a small decline, and veteran teachers stayed the same (see Figure 10). Alternately, midcareer teachers with no previous practicum experience increased their feelings of action efficacy more than any of the teachers with previous practicum experience.

Of particular interest is the effect of first-time participation in a practicum experience on neophyte and veteran teachers. Neophyte and veteran teachers experienced more of a decline in self-percepts of action efficacy than any other group, with or without previous practicum experience. This decline was in sharp contrast to the gains in action efficacy of midcareer teachers with no practicum experience. Again the unequal cell sizes suggest the possibility of a Type I error when the variability of the groups is unequal.

The interaction effect of age group and previous practicum experience on action efficacy. The interaction effect between age group and previous practicum experience on teachers' sense of action efficacy approached significance at the .10 level $(\mathfrak{R}=.135$; see Table 51$)$. Figure 11 reveals a pattern of change between teachers with and without practicum experience in the three age groups similar to that of teachers with and without practicum experience in the three teaching experience groups. However, closer inspection of the graph and cell means shows that the self-percepts of action efficacy of middle-aged teachers with practicum experience actually declined over the term of the practicum, while self-percepts of action efficacy of middle-aged teachers with no previous practicum experience modestly increased. Further, first-time participation in a practicum experience had the most negative effect on young teachers' sense of action efficacy, while mature teachers, with or without practicum experience, experienced little or no change in their self-percepts of action efficacy. Again, the threat of a Type I error is likely due to the unequal cell sizes. 


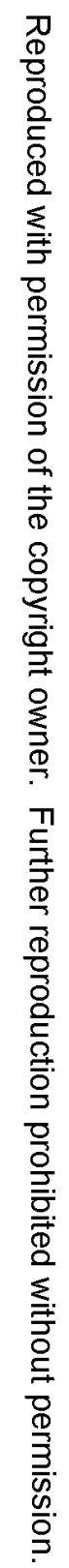

Figure 10

Interaction Effects of Teaching Experience and Previous Practicum

Experience on Teachers' Change in Action Efficacy ${ }^{a}$
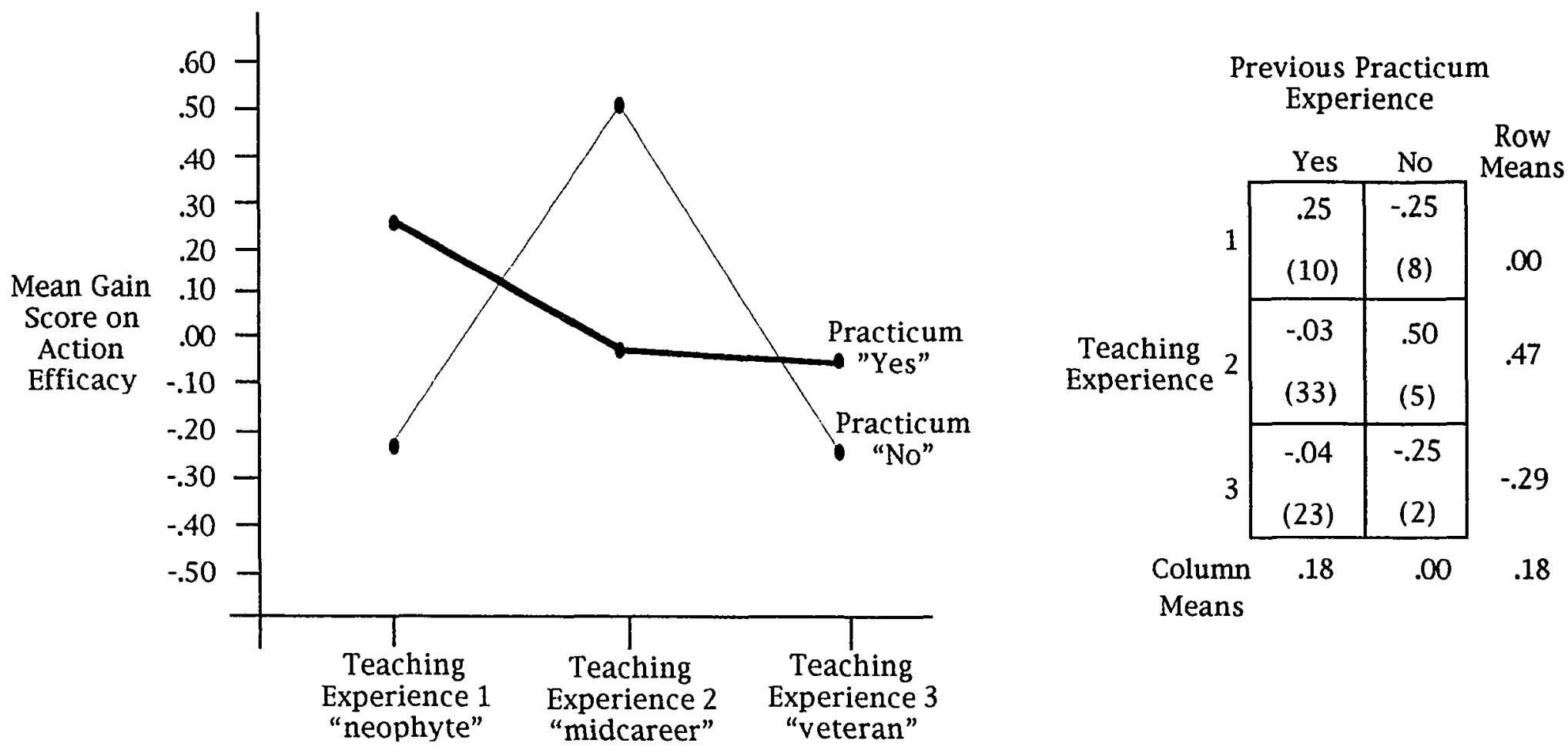

a By Plotting of Cell Means 
Table 51

Two-Way ANOVA Table: The Main and Interaction Effects

of Age Group and Previous Practicum Participation

on Teacher Gain Scores for the Action Efficacy Index ${ }^{a}$

\begin{tabular}{lccccc}
\hline Source of & Sum of & & Mean & & Sig of \\
Variation & Squares & df & Square & E & E \\
\hline Main Effects & .524 & 3 & .175 & .587 & .626 \\
Age Group & .505 & 2 & .252 & .848 & .432 \\
$\begin{array}{l}\text { Practicum } \\
\text { Experience }\end{array}$ & .090 & 1 & .090 & .304 & .583 \\
2-Way Interactions & 1.226 & 2 & .613 & 2.060 & .135 \\
$\begin{array}{l}\text { Age Group } \\
\text { Practicum }\end{array}$ & 1.226 & 2 & .613 & 2.060 & .135 \\
Experience & & & & & \\
Explained & & 5 & .350 & 1.176 & .329 \\
Residual & 1.750 & 72 & .298 & & \\
Total & 21.420 & 77 & .301 & & \\
\hline
\end{tabular}

a $\underline{\underline{n}}=83 ; 5$ cases were missing. 


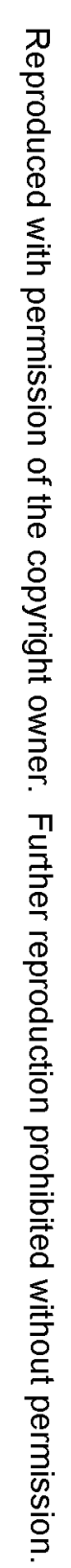

Figure 11

Interaction Effects of Age Group and Previous Practicum Experience on

Teachers' Change in Action Efficacy ${ }^{a}$
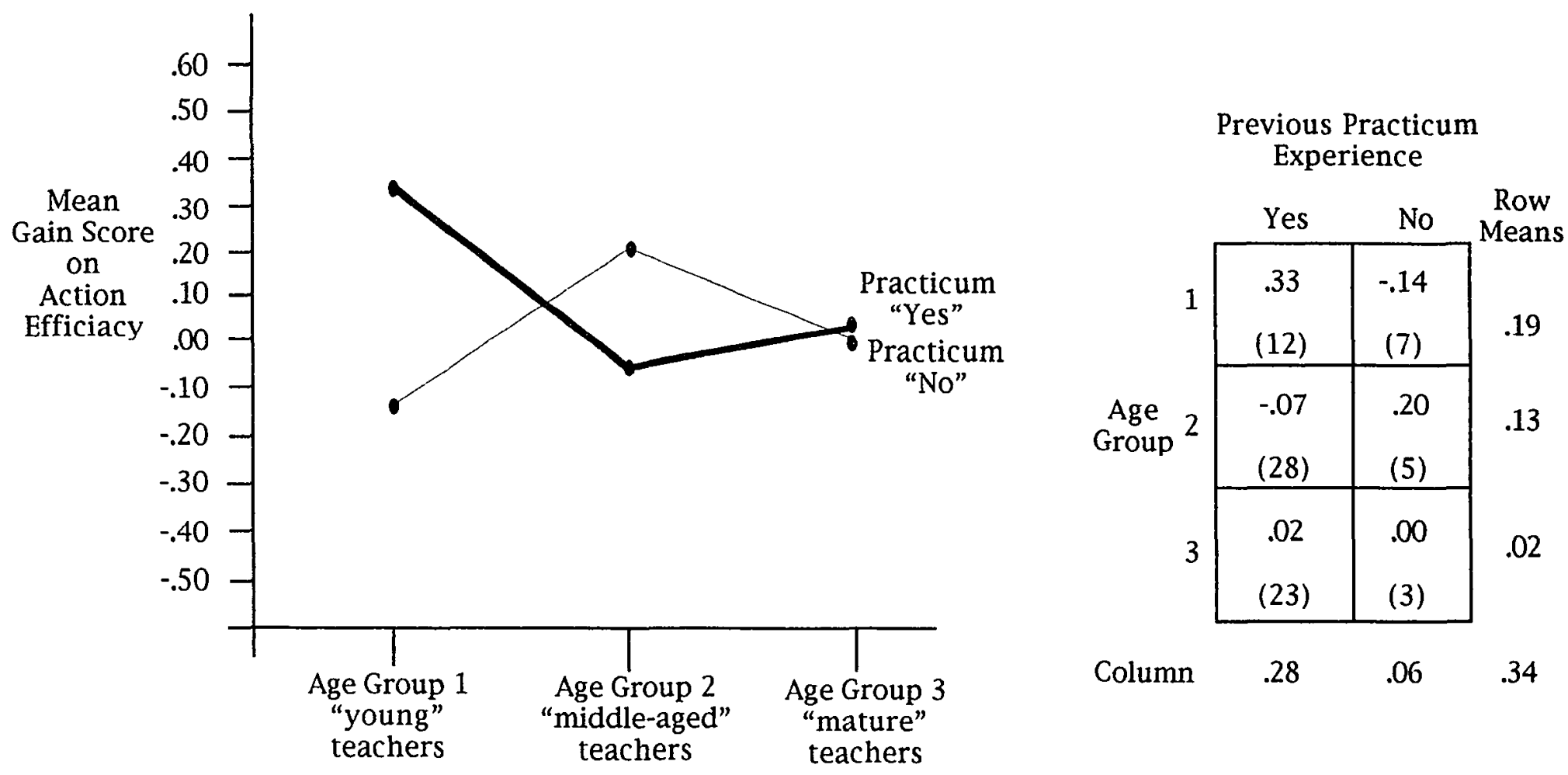

$\begin{array}{llll}\text { Column } & .28 & .06 & .34\end{array}$

a By Plotting of Cell Means 
Analysis of ANOVA Findings for the

\section{Second Research Question of the Teacher Sample}

The 1 test results had shown positive changes on teachers' sense of personal teaching efficacy and on all but one of the underlying factors, as measured by the scale and factor indices, respectively. Specifically, teachers' sense of personal teaching efficacy, instruction efficacy, and group relations efficacy had significantly increased, and their sense of impact and action efficacy had positively but nonsignificantly increased. Only teachers' sense of thought control efficacy had negatively decreased, although nonsignificantly.

However, the findings from the ANOVA tests suggest that participation in the reflective practitioner model practicum was not a uniform developmental opportunity for teachers with different personal characteristics: While teachers' personal characteristics did not appear to affect their sense of impact efficacy and thought control efficacy, they did affect their sense of personal teaching efficacy, group relations efficacy, instruction efficacy, and action efficacy.

Personal teaching efficacy. Young teachers gained more than others in their overall feelings of personal teaching efficacy, although the gain was nonsignificant. This finding was confirmed by both four-way $(\mathfrak{R}=.066)$ and two-way (.088) ANOVA results. Since young teachers often have fewer years of experience, this result is not surprising: Participation in the reflective practitioner model practicum may have been young teachers' first real opportunity to compare their teaching capabilities and dispositions with those of student teachers and, thus, to realize that they had made gains in expertise. However, this explanation does not account for middle-aged or mature teachers who had recently entered the profession. One wonders what other variables played a part in their less noticeable gains in personal teaching efficacy. 
Group relations efficacy. Female teachers also made nonsignificant but positive gains in their self-percepts of group relations efficacy, while the group relations efficacy of male teachers declined. Further, veteran teachers increased their sense of group relations efficacy more than neophyte or midcareer teachers. In general, it makes sense that working with student teachers would boost one's self-percepts of group relations efficacy, given that student teachers are often not able to manage groups of students and develop rapport with the same ease as more experienced practicing teachers. However, this does not account for the decrease in self-percepts of group relations efficacy experienced by male teachers, nor the relative small gains made by neophyte and midcareer teachers.

Instruction efficacy. While there were no significant main effects on the three-way and two-way ANOVAs with instruction efficacy as the dependent variable, previous participation in a practicum and age group and previous participation in a practicum and teaching experience had interaction effects on instruction efficacy.

There was a significant interaction effect $(\underline{D}=.027)$ for previous participation and age group of teachers on instruction efficacy. All teachers with previous practicum experience, but only young and middle-aged teachers without previous practicum experience, increased their feelings of instruction efficacy over the practicum term. In addition, the sense of instruction efficacy of mature teachers without previous practicum experience decreased over the practicum. It may be that young and middleaged teachers are more resilient than mature teachers and, therefore, are more likely to change as a result of first-time participation in the reflective practitioner model practicum.

There was also a nonsignificant interaction effect $(\mathfrak{R}=.055)$ on instruction efficacy for previous practicum experience and teaching 
experience. Veteran teachers did not fare well when they had not previously participated in a practicum experience: Their feelings of instruction efficacy declined over the period of the practicum, although not significantly. Relatedly, mature teachers without previous practicum experience also suffered nonsignificant losses in feelings of instruction efficacy from the beginning to the end of the practicum.

For others at different stages of their careers, first-time participation in a practicum experience boosted their feelings of instruction efficacy. Perhaps the increased conversation with other teachers about their practice and the chance to view student teachers learning--and often struggling--to teach made neophyte and midcareer teachers more consciously aware of their expertise. Alternately, veteran teachers with no previous practicum experience may have felt less comfortable with their own teaching methods, in contrast to the new teaching methods brought by student teachers from the University.

The fact that mature teachers and veteran teachers with previous practicum experience made modest gains in instruction efficacy suggests that early involvement in practicum experiences--in terms of both age and years of teaching experience--may be an important factor in assuring positive change in self-percepts of instruction efficacy.

Action efficacy. As with instruction efficacy, there were interaction effects on action efficacy for previous participation in a practicum and age group and for previous participation in a practicum and teaching experience.

There was a significant interaction effect on action efficacy for previous practicum experience and teaching experience. The action efficacy of neophyte teachers with previous practicum experience and midcareer teachers with no previous practicum experience increased over the practicum. The sense of action efficacy of teachers in all other teaching 
experience groups decreased, with the action efficacy of neophyte and veteran teachers declining most markedly.

While there was no significant interaction effect on action efficacy for age group and previous practicum experience, the significance level approached .10 and, therefore, was worth examining in this exploratory study. In contrast to the significant interaction effect of teaching experience and previous practicum experience, the interaction effect of age group and previous practicum experience showed that only middle-aged teachers with no practicum experience and young teachers with no practicum experience suffered declines in action efficacy. Most teachers either maintained or increased their sense of action efficacy, with young teachers with previous practicum experience experiencing the most gain.

Since action efficacy is described as teachers' predisposition to protect their teaching intentions and was indexed by two items related to teachers' propensity to consider how they might improve a lesson gone badly or learn new knowledge and skills in order to improve their teaching, the decline-albeit relatively small--in a sense of action efficacy for some teachers is perplexing. One would presume that the daily conversations with other teachers and the ongoing observations of student teachers learning to teach would reinforce the value of these two activities for all teachers, and therefore, teachers would be more likely to participate in them.

The overall gains in teachers' sense of efficacy suggest that participation in a reflective practitioner model practicum is an opportunity for teachers to strengthen their feelings of personal teaching efficacy. However, the main and interaction effects of personal characteristics on teachers' sense of overall personal teaching efficacy, as well as of group relations efficacy, instruction efficacy, and action efficacy, suggest that the 
practicum experience can affect different groups of teachers in different ways.

\section{The Effect of Personal Characteristics}

on Changes in Personal Teaching Efficacy

of the Student Teacher Sample

The student teacher study asked if three personal characteristics of student teachers--gender, age, and previous work with children--would have main or interaction effects on changes in their personal teaching efficacy. Table 28 outlines the levels for each of these independent variables; the dependent variables were the gain scores representing the difference between student teachers' pretest and posttest mean aggregate scores for the 31-item Personal Teaching Efficacy Scale measuring personal teaching efficacy and for the factor indices measuring instruction, thought control, action, and teaching operations efficacy. Three-way ANOVAs using a $2 \times 4 \times 3$ factorial design were conducted to test five null hypotheses.

Changes at the Scale Level:

\section{Null Hypothesis 1}

The first null hypothesis states: There are no significant main or interaction effects for gender, age, and previous work with children on student teachers' mean gain score on personal teaching efficacy.

A three-way ANOVA was conducted to determine difference in the mean gain score of personal teaching efficacy by gender, age, and previous work with children. An $\mathrm{E}$ test for differences found no significant difference at the .05 level in changes in personal teaching efficacy for the main effects of the three personal characteristics of student teachers (see Table 52). 
Table 52

Analysis of Variance Table: The Main Effects of

Three Independent Variables on Student Teacher

Gain Scores for the 31-Item Personal Teaching Efficacy Scale ${ }^{a b}$

\begin{tabular}{|c|c|c|c|c|c|}
\hline Source of & Sum of & & Mean & & Sig of \\
\hline Variation & Squares & df & Square & $E$ & $E$ \\
\hline Main Effects & 1.145 & 6 & .191 & 1.592 & .159 \\
\hline Gender & .250 & 1 & .250 & 2.082 & .153 \\
\hline Age Group & .518 & 3 & .173 & 1.439 & .237 \\
\hline $\begin{array}{l}\text { Previous Work } \\
\text { With Children }\end{array}$ & .158 & 2 & .079 & .657 & .521 \\
\hline Explained & 1.145 & 6 & .191 & 1.592 & .159 \\
\hline Residual & 10.189 & 85 & .120 & & \\
\hline Total & 11.334 & 91 & .125 & & \\
\hline
\end{tabular}


Interaction effects were suppressed due to empty cells. However, as with the teacher sample, two-way ANOVAs were conducted for the group combinations with no empty cells: (a) gender and previous work with children and (b) age group and previous work with children.

Two-way ANOVAs. No interaction effects were found when two-way ANOVAs were conducted, but a main effect for gender on the gain score of personal teaching efficacy now approached significance $(\mathfrak{R}=.058$; see Table 53 ) in the two-way ANOVA for gender and previous work with children (see Table 49). An examination of the cell means revealed that the mean gain score on personal teaching efficacy for male student teachers was $.42(\underline{n}=16)$, compared to $.60(n=77)$ for female student teachers. These mean gain scores suggest that female student teachers increased their feelings of personal teaching efficacy more than male student teachers. However, the differences were nonsignificant at the .05 level, and the large difference in cell sizes also makes the threat to the assumption of homogeneity of variance and a Type I error possible.

A main effect for previous work with children also approached the .10 significance level on personal teaching efficacy, using age group and previous work with children as the independent variables in the two-way ANOVA (see Table 54). Student teachers' mean gain scores varied depending on their age. "Mature" (ages 36 to 59) student teachers made a mean gain in their sense of personal teaching efficacy of $.80(\underline{n}=6)$, compared to "very young" (ages 20-22), “young" (ages 23-25), and "middle-aged” (ages 26-35) student teachers, who had mean gains of $.60(\underline{n}=47), .47(\underline{n}=31)$, and $.56(\underline{n}=$ 11), respectively. While not statistically significant, these differences do suggest some variance in change of personal teaching efficacy across age groups. 
Table 53

Two-Way Analysis of Variance: The Main and Interaction Effects for

Gender and Previous Work With Children on Student Teacher

Personal Teaching Efficacy Gain Scores ${ }^{a}$

\begin{tabular}{|c|c|c|c|c|c|}
\hline Source of & Sum of & & Mean & & Sig of \\
\hline Variation & Squares & df & Square & $\underline{E}$ & $E$ \\
\hline Main Effects & .626 & 3 & .209 & 1.703 & .172 \\
\hline Gender & .452 & 1 & .452 & 3.695 & .058 \\
\hline $\begin{array}{l}\text { Previous Work } \\
\text { With Children }\end{array}$ & .198 & 2 & .099 & .807 & .449 \\
\hline 2-Way Interactions & .058 & 2 & .029 & .236 & .791 \\
\hline $\begin{array}{l}\text { Gender and Previous } \\
\text { Work With Children }\end{array}$ & s .058 & 2 & .029 & .236 & .791 \\
\hline Explained & .683 & 5 & .137 & 1.116 & .358 \\
\hline Residual & 10.654 & 87 & .122 & & \\
\hline Total & 11.337 & 92 & .123 & & \\
\hline
\end{tabular}

a $\underline{\underline{n}}=94 ; 1$ case was missing. 
Table 54

Two-Way Analysis of Variance: The Main and Interaction Effects for

Age Group and Previous Work With Children on Student Teacher

Personal Teaching Efficacy Gain Scores ${ }^{a}$

\begin{tabular}{lccccc}
\hline Source of & Sum of & & Mean & & Sig of \\
Variation & Squares & df & Square & E & E \\
\hline Main Effects & .896 & 5 & .179 & 1.435 & .221 \\
Age Group & .723 & 3 & .241 & 1.930 & .131 \\
$\begin{array}{l}\text { Previous Work } \\
\text { With Children }\end{array}$ & .143 & 2 & .071 & .571 & .567 \\
2-Way Interactions & .451 & 6 & .075 & .601 & .728 \\
$\quad \begin{array}{l}\text { Gender/Previous } \\
\text { Work With Children }\end{array}$ & .451 & 6 & .075 & .601 & .728 \\
Explained & 1.346 & 11 & .122 & .980 & .471 \\
Residual & 9.988 & 80 & .125 & & \\
Total & 11.334 & 91 & .125 & & \\
\hline
\end{tabular}

a $\underline{n}=94 ; 2$ cases were missing. 
Changes at the Factor Level:

\section{Null Hypotheses 2 to 5}

The second through fifth null hypotheses presume the following: There are no significant main or interaction effects for gender, age, and previous work with children on the mean gain scores for the factor indices of instruction efficacy, thought control efficacy, action efficacy, and teaching operations efficacy. Three-way ANOVAs, using a $2 \times 4 \times 3$ factorial design, were conducted with each of the mean factor gain scores as the dependent variable.

No main effects were found for gender, age group, or previous work with children on the mean factor gain scores for instruction efficacy, thought control efficacy, action efficacy, and teaching operations efficacy.

The effect of gender on changes in teaching operations efficacy. Results from a three-way ANOVA show a main effect for gender that approached an alpha of .05 on the teaching operations efficacy gain score $(\mathfrak{L}=$ .076; see Table 55). Teaching operations efficacy was indexed by two items related to managing class problems and dealing effectively with the diversity among students.

A closer examination of the cell means for teaching operations efficacy, with gender as the independent variable, revealed that male student teachers had a mean gain score of $.47(\underline{n}=16)$, while female students teachers had a mean score of $89(\underline{n}=76)$. Thus, female student teachers increased their feelings of teaching operations efficacy more than males, although not significantly. However, the results should be viewed with caution as the large difference in cell size between males and females makes the threat of a Type I error probable when the variance of the two groups is unequal. 
Table 55

Analysis of Variance Table: The Main Effects of

Three Independent Variables On Student Teacher

Gain Scores for the Teaching Operations Efficacy Index ${ }^{a b}$

\begin{tabular}{lccccc}
\hline $\begin{array}{l}\text { Source of } \\
\text { Variation }\end{array}$ & $\begin{array}{c}\text { Sum of } \\
\text { Squares }\end{array}$ & df & Square & E & E \\
\hline Main Effects & 7.247 & 6 & 1.208 & 1.992 & .076 \\
$\quad$ Gender & 1.953 & 1 & 1.953 & 3.221 & .076 \\
$\quad$ Age Group & 1.465 & 3 & .488 & .806 & .494 \\
$\quad \begin{array}{l}\text { Previous Work } \\
\text { With Children }\end{array}$ & 3.121 & 2 & 1.561 & 2.574 & .082 \\
Explained & 7.247 & 6 & 1.208 & 1.992 & .076 \\
Residual & 51.543 & 85 & .606 & & \\
Total & 58.791 & 91 & .646 & & \\
\hline
\end{tabular}

$a \underline{n}=94 ; 2$ cases were missing. $b$ Interaction effects were suppressed due to empty cells. 
The effect of previous work with children on changes in teaching

operations efficacy. In addition, a three-way ANOVA resulted in a main effect for previous work with children which also approached an alpha of .05 on the teaching operations efficacy gain score $(\mathfrak{R}=.082$; see Table 55). A closer examination of the cell means for teaching operations efficacy, with previous work with children as the independent variable, revealed that student teachers with little or no previous work with children had a mean gain score of $1.13(\underline{n}=23)$ on the teaching operations efficacy index. Student teachers with moderate amounts of previous work with children had a mean gain score of $.73(\underline{n}=35)$ and student teachers with a great deal of previous work with children had a mean gain score of $.71(n=34)$. Thus, student teachers with little or no previous wcrk with children increased their self-percepts of teaching operations efficacy more than did those with either moderate amounts or a great deal of previous work with children. While these findings were not significant, a gain of over 1 Likert point is important and suggests that the practicum experience had a relatively strong effect on the sense of teaching operations efficacy for students with little or no previous experience working with children.

Two-way ANOVAs. Statistics related to the interaction effects of student teachers' age, gender, and previous work with children on the factor indices were suppressed because of empty cells. Therefore, two-way ANOVAs were conducted on the mean gain score of each factor index, using two combinations of groups with no empty cells: (a) gender and previous work with children and (b) age group and previous work with children. There were no significant main effects for either of the two combinations of groups on the factor indices of instruction efficacy, thought control efficacy, and action efficacy. 
Results of a two-way ANOVA on teaching operations efficacy. There was a significant main effect for gender $(\underline{R}=.034)$ on teaching operations efficacy in the two-way ANOVA using gender and previous work with children as independent variables (see Table 56). An examination of cell means revealed a mean gain score of $.47(n=16)$ for male student teachers and $.89(n=77)$ for female student teachers. The overall mean gain score was $.82(\underline{n}=92)$, showing that change in self-percepts of teaching operations efficacy of the student teacher sample was significantly influenced by the gain scores of female student teachers. While it is apparent that female student teachers increased their sense of teaching operations efficacy more than male student teachers, this finding should be accepted with caution due to the threat of a Type I error when cell sizes and variance between the two groups are unequal.

In addition, a main effect for previous work with children on teaching operations efficacy also approached significance $(\mathrm{R}=.061)$. Student teachers with little or no previous work with children increased their self-percepts of teaching operations efficacy by more than 1 Likert point $(1.13, \underline{n}=23)$, compared to student teachers with moderate amounts and a great deal of previous work with children, whose mean increase was $.73(\underline{n}=35)$ and $.70(\underline{n}=$ $35)$, respectively.

Two-way ANOVA interaction effects on factor indices. There were no significant interaction effects for any of the factor indices. However, an interaction between age group and previous work with children approached significance on action efficacy ( $\mathfrak{l}=.064$; see Table 57). Action efficacy was indexed by two items related to propensity to work with other staff to help children learn and to learn new knowledge and skills to improve classroom situations. 
Table 56

Two-Way Analysis of Variance: The Main and Interaction Effects for

Gender and Previous Work With Children on Student Teacher

Teaching Operations Efficacy Gain Scores ${ }^{a}$

\begin{tabular}{lccccc}
\hline Source of & Sum of & & Mean & & Sig of \\
Variation & Squares & df & Square & E & E \\
\hline Main Effects & 5.818 & 3 & 1.939 & 3.223 & .027 \\
$\quad$ Gender & 2.806 & 1 & 2.806 & 4.662 & .034 \\
$\begin{array}{l}\text { Previous Work } \\
\text { With Children }\end{array}$ & 3.471 & 2 & 1.736 & 2.885 & .061 \\
& & & & & .601 \\
2-Way Interactions & .723 & 2 & .362 & .551 \\
$\quad \begin{array}{l}\text { Gender/Previous } \\
\text { Work With Children }\end{array}$ & .723 & 2 & .362 & .601 & .551 \\
& & & & & \\
Explained & 6.541 & 5 & 1.308 & 2.174 & .064 \\
Residual & 52.351 & 87 & .602 & & \\
Total & 58.892 & 92 & .640 &
\end{tabular}

a $\underline{\underline{n}}=94 ; 1$ case was missing. 
Table 57

Two-Way Analysis of Variance: The Main and Interaction Effects for

Age Group and Previous Work With Children on Student Teacher

Action Efficacy Gain Scores ${ }^{a}$

\begin{tabular}{lccccc}
\hline $\begin{array}{l}\text { Source of } \\
\text { Variation }\end{array}$ & $\begin{array}{c}\text { Sum of } \\
\text { Squares }\end{array}$ & df & Square & E & E \\
\hline Main Effects & 1.644 & 5 & .329 & .801 & .553 \\
\multicolumn{1}{c}{ Age Group } & 1.530 & 3 & .510 & 1.242 & .301 \\
$\begin{array}{l}\text { Previous Work } \\
\text { With Children }\end{array}$ & .085 & 2 & .042 & .103 & .902 \\
$\begin{array}{l}\text { 2-Way Interactions } \\
\text { Age Group/Work }\end{array}$ & 5.163 & 6 & .861 & 2.095 & .064 \\
With Children & 5.163 & 6 & .861 & 2.095 & .064 \\
Explained & & & & & \\
Residual & 6.808 & 11 & .619 & 1.507 & .148 \\
Total & 29.162 & 71 & .411 & & \\
\hline
\end{tabular}

a $\underline{n}=85 ; 2$ cases were missing. 
Interaction effect of age group and previous work with children on action efficacy. Figure 12 displays the cross-tabulation table and plots the cell means for each student teacher age group and level of previous work with children. The graph shows an interesting pattern of differences in the change in self-percepts of action efficacy among the four age groups.

While the self-percepts of action efficacy of all student teachers either stayed the same or increased, the amount of previous work with children affected the amount of change they experienced depending on their age.

Most student teachers with little or no previous work with children maintained the same level of action efficacy over the term of the practicum; however, the mean gain score of young student teachers with no previous practicum experience increased by .75 of a Likert point. There was almost a reverse effect for student teachers with moderate amounts of previous work with children: In this group, very young, middle-aged, and mature student teachers experienced a positive change in their sense of action efficacy, while young student teachers' scores stayed the same.

Student teachers with a great deal of previous work with children also differed by age group. Middle-aged student teachers with a great deal of previous work with children experienced no change in their sense of action efficacy, while the self-percepts of action efficacy of very young, young, and mature student teachers increased over the length of the practicum, with mature teachers experiencing the most change.

Thus, for mature student teachers, the more previous work with children they had, the larger and more positive the change in their selfpercepts of action efficacy. This pattern is similar to that of very young student teachers: While all very young student teachers experienced an 
Figure 12

Interaction Effects of Age Group and Previous Work With Children on

Student Teachers' Change in Action Efficacy ${ }^{\mathrm{a}}$

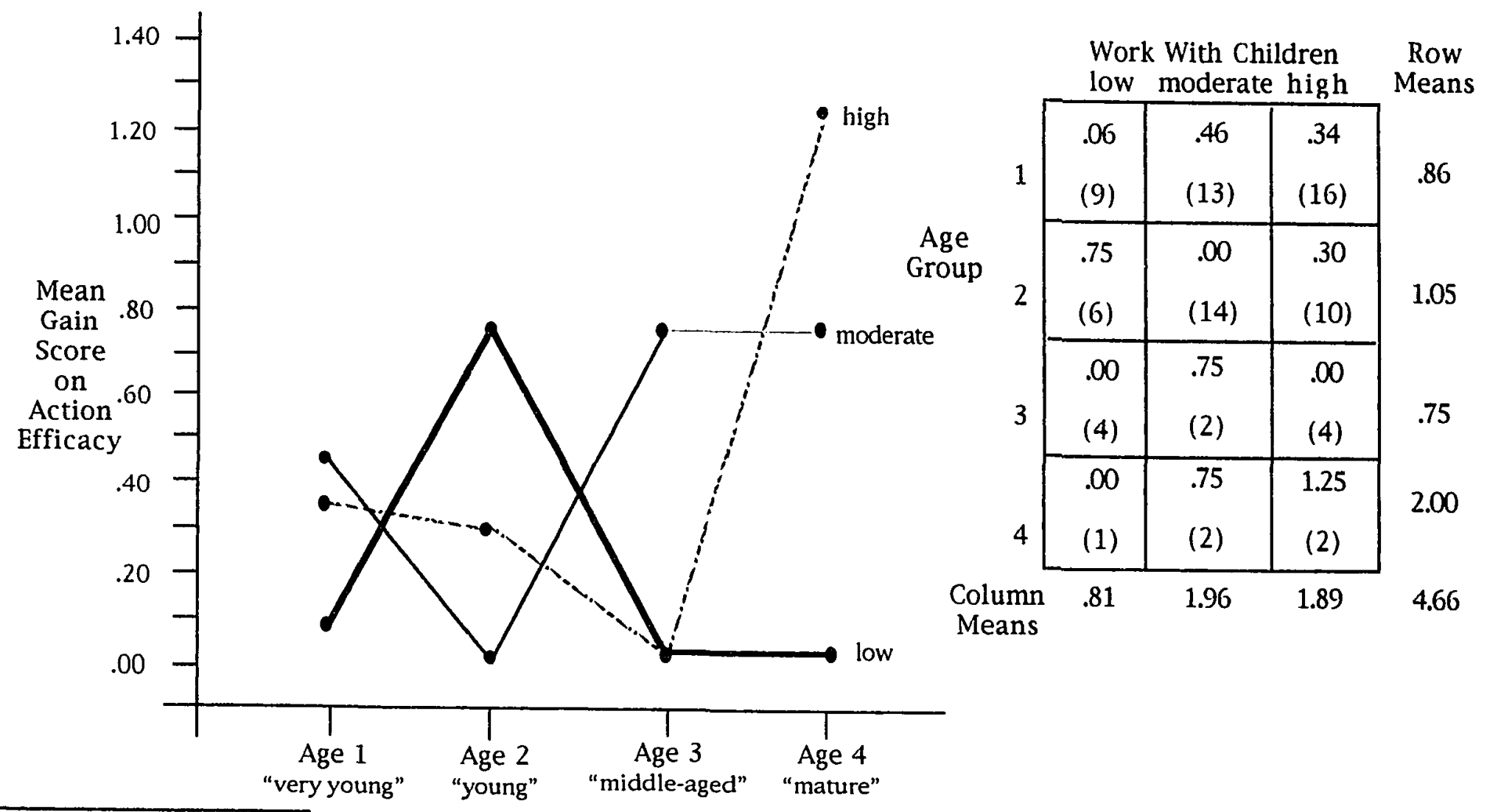

a By plotting cell means 
increased sense of action efficacy, those with moderate amounts or a great deal of previous work with children increased more.

Alternately, middle-aged student teachers with either a great deal of or little previous work with children maintained their feelings of action efficacy, while those with moderate amounts of previous work with children increased their sense of action efficacy over the course of the practicum. Finally, of the four age groups, only young student teachers experienced more change in their sense of efficacy when they had little or no previous work with children.

\section{Analysis of the ANOVA Findings of the}

\section{Second Question of the Student Teacher Sample}

The significant gains in student teachers' self-percepts of efficacy at the scale and factor level of personal teaching efficacy appear to be influenced by three personal characteristics, although most often not significantly.

Gender. Gender affected the amount of change in student teachers' general feelings of personal teaching efficacy, measured as the difference in pretest and posttest composite scores: Female student teachers increased their feelings of personal teaching efficacy more than male student teachers over the term of the practicum, although the difference in the amount of change was nonsignificant. Change in student teachers' sense of teaching operations efficacy is also affected by gender. Again, female student teachers increased their self-percepts of their capabilities to manage classroom situations and deal with diversity more than did male student teachers. This difference approached significance in the four-way ANOVA and was a significant main effect in the two-way ANOVA. Interestingly, there were no statistically significant differences between male and female student teachers on the other 
two underlying factors of personal teaching efficacy, instruction efficacy and thought control efficacy.

Age group. Student teachers' age affected the amount of change in their feelings of personal teaching efficacy, approaching significance at the .10 level. Both mature and very young student teachers had larger gains in their sense of personal teaching efficacy than young and middle-aged student teachers. Mature students usually come to teaching with a wide range of past life experiences, including being parents, and with a strong commitment to their later-than-usual career choice. Perhaps, these characteristics also make them more determined to become effective teachers and, hence, more likely to achieve real and perceived effectiveness. On the other hand, very young student teachers may have entered the practicum with more uncertainty about their teaching capabilities and, hence, the change in their perceptions of personal teaching efficacy is larger.

previous work with children. Common sense suggests that student teachers with previous work with children would have already developed capabilities that would support their efforts in learning to teach and would have more beginning confidence in their capabilities to become effective teachers. Thus, student teachers with no previous work with children could experience more gain than those with moderate amounts or a great deal of practicum experience because they would have more capabilities to develop and would have a wider range in the amount of confidence they could develop. This assumption is supported by the relatively large gains in teaching operations efficacy of student teachers with little or no previous work with children, which suggest that these students probably began their practicum with lower self-percepts of efficacy for teaching than their counterparts with moderate amounts or a great deal of previous work with children and, therefore, made larger gains over the term of the practicum. 
However, the interaction effect of age group and previous work with children on action efficacy, which approached the 05 significance level, suggests that, for this underlying factor of personal teaching efficacy, the effect of previous work with children may be more complex. Changes in the sense of action efficacy appear to be facilitated by previous work with children for mature student teachers with a great deal of previous work with children and for middle-aged student teachers with moderate amounts. Alternately, no previous work with children was an impetus for change only for young student teachers with little or no previous work with children.

\section{Conclusion}

Chapter 6 demonstrates that the newly conceptualized model and the attendant scale are effective in measuring teachers' and student teachers' self-percepts of personal teaching efficacy, at the composite scale level, at the factor level, and at the variable level. Chapter 7 summarizes the findings presented in this chapter and their implications. As well, it summarizes the results of the conceptual analysis of personal teaching efficacy and provides conclusions and recommendations. 


\section{CHAPTER 7}

SUMMARY, CONCLUSIONS, AND RECOMMENDATIONS

\section{Overview of the Study}

Teachers' sense of efficacy for teaching has been shown to influence teaching effectiveness and student learning and to be influenced by the contexts in which teachers teach. However, while the results have been interpreted mostly using Gibson and Dembo's (1984) two-factor model of teacher efficacy, researchers are in general agreement that teachers' sense of efficacy is a multidimensional construct with many underlying factors. This general agreement, along with the uncertainty of meaning of Gibson and Dembo's second factor, teaching efficacy, which they define as a "belief that any teacher's ability to bring about change is significantly limited by factors external to the teacher, such as home environment, family background, and parental influence" (p. 574), served as the impetus behind this dissertation.

Thus, this study sought to fulfill two main purposes: The first purpose was to introduce a new theory of personal teaching efficacy. Using social cognitive theory and research, including theories of self-efficacy and related constructs and, later, theories of volitional psychology and related constructs, I conducted a conceptual analysis of teachers' sense of efficacy which led to 
the development of a model and scale. The model and scale reflected the wide range of thoughts, feelings, and behaviors associated with the teaching role and clarified the interpretative meaning underlying Gibson and Dembo's (1984) second factor, teaching efficacy.

The second purpose of the study was to test the model and scale for their utility in measuring and explaining personal teaching efficacy. Changes in the self-perceptions of personal teaching efficacy of teachers and student teachers participating in the final elementary student teaching experience through the University of Alberta were measured and analyzed using the new model and scale.

\section{Background and}

\section{Review of the Theory and Research}

\section{Underlving the Study}

Statement of the Problem

Chapter 1established the importance of teachers' sense of efficacy to their effectiveness as teachers and outlined the current social, economic, and cultural conditions and the endemic school conditions that constrain teachers' effectiveness and negatively influence the development of a strong sense of efficacy for teaching. Low public opinion of schools and teachers, changing conditions in schools and school communities, and increased legislative and school board demands for accountability were cited. These factors, along with teacher isolation and the uncertainty and unpredictability of teachers' work, constitute the range of environmental conditions which negatively influence teachers' effectiveness and sense of efficacy for teaching.

Chapter 1 also introduced the current model of teachers' sense of efficacy and outlined concerns with the current models of teacher efficacy, particularly those related to the definition of Gibson and Dembo's (1984) second factor, teaching efficacy, and to problems with the interpretation of 
findings. It was suggested that the multiple meanings assigned to the construct of teacher efficacy across research studies undermined the interpretation of results, while the use of aggregate scores--as opposed to variable or factor scores--resulted in the inability to discern underlying patterns in self-perceptions of teacher efficacy and subtle differences in teachers' self-beliefs. In addition, the paucity of research studies focusing on changes in teacher efficacy over time limited not only other researchers' understanding of the dynamic nature of teachers' perceptions of efficacy for teaching, but also their ability to identify contextual variables that enhance or constrain teachers' sense of efficacy.

Teachers' Sense of Efficacy

Chapter 2 reviewed the theory and research underlying the construct of teacher efficacy. It enumerated several common definitions of teacher efficacy and introduced three models of teacher efficacy. The conception of teacher efficacy as a two-factor construct, with one factor representing teachers' feelings of their own efficacy of teaching and the other representing their perceptions of either the ideal teacher or teachers in general, was demonstrated as common across the three models. Current methods for measuring teacher efficacy were also outlined, and the Gibson and Dembo (1984) Teacher Efficacy Scale was established as the scale most often used by researchers.

A synthesis of the research on teacher efficacy showed that teachers' sense of efficacy was positively correlated with teachers' internal locus of control, high professional esteem, and self-concept, as well as with teacher reasoning and thinking styles (see Ross, 1994a). The synthesis also revealed that teachers' sense of personal teaching efficacy could differ from their more generalized perceptions of teaching efficacy; however, teachers' scores 
on the two underlying factors were often aggregated when results were reported (for example, see Hoy \& Woolfolk, 1993).

Of particular salience to this study are the reported findings related to changes in teachers' sense of efficacy and the effects of demographic variables and experiential factors on these changes. For example, gender was shown to have an effect on self-percepts of efficacy for teaching, with female preservice students having stronger perceptions of teaching efficacy than their male counterparts (Evans \& Tribble, 1986).

The effect of teaching experience on teachers' sense of efficacy was also explored: Prospective teachers were found to begin teacher education programs with a low sense of personal teaching efficacy and a high sense of teaching efficacy; however, their self-percepts of personal teaching efficacy grew as they gained more experience, but their self-percepts of teaching efficacy declined (Gibson \& Brown, 1982, cited in Dembo \& Gibson, 1985; Housego, 1982; Hoy \& Woolfolk, 1993). Similarly, Hoy and Woolfolk (1993) found that teaching efficacy declined over time, while personal teaching efficacy increased over the first 5 years of teaching. Another study, conducted by Pigge and Marso (1993), found no significant differences between teachers at four career stages (preservice, early career, midcareer, and late career) but did find significant differences among career-stage groups on three of nine personal teaching efficacy items and two of the seven teaching efficacy items.

Finally, studies were cited that showed teaching efficacy to be positively affected by feedback and by collaboration with other teachers in instructional matters (Rosenholtz, 1989, cited in Smylie, 1990) and by opportunities to participate in school decision making (Ashton \& Webb, 1986). Alternately, personal teaching efficacy was positively affected by general communication among teachers (Cavers, 1988), while overall sense of efficacy for teaching 
was positively influenced by coaching and being coached by other teachers (McDaniel \& Dibella-McCarthy, 1989, cited in Miller, 1991).

Concerns related to the conceptualization and measurement of teacher efficacy were also enumerated (for example, see Ross, 1994a). It was argued that the two-factor model proposed by current theory and used in research on teacher efficacy did not adequately represent the multivariate nature of teachers' sense of efficacy and that differences in interpretations of the meaning of Gibson and Dembo's (1984) teaching efficacy factor further constrained understanding of the construct. In addition, arguments were made that one-time measurements obscured the effect of experience on teachers' sense of efficacy and that the use of aggregate scores, rather than factor- or variable-level scores, missed important patterns underlying teachers' sense of efficacy (see Ross, 1994a). Researchers' call for further research on the efficacy construct was recorded. For example, Smylie (1990) suggested the possibility that teachers "possess different senses of efficacy that operate in different ways in relation to different dimensions of their work" (p. 62), while Fuller, Wood, Rapoport, and Dornbusch (1982) suggested that research on specific organization variables influencing teachers' sense of efficacy should be continued.

\section{Self-Efficacy}

Next, definitions of self-efficacy were discussed, followed by a summary of the ways in which self-efficacy is measured, the effects of self-efficacy on behavior, and the types of self-efficacy. This section reiterated Bandura's position that self-efficacy perceptions vary according to the level, generality, strength, and magnitude of one's perceived capabilities to be efficacious in particular situations or domains of functioning and, thus, are subject to change. 
Bandura's (1986) differentiation between self-efficacy and responseoutcome expectancies was then explored. Bandura considers self-efficacy expectancies to be related to one's perceived capabilities to act in given situations, with response-outcome expectancies defined as the resultant consequences and rewards of one's actions, whether completed or uncompleted. This section showed that researchers use the terms "outcome" and "outcome expectancies" in multiple ways and suggested that these multiple meanings impede our progress in understanding how and what selfperceptions affect teachers' sense of efficacy. It was argued that a more careful delineation of the types of expectancies and their definitions is needed. Heckhausen's (1991) situation-outcome expectancy, action-outcome expectancy, and action-by-situation-outcome expectancy were cited as a move in this direction. A discussion of the types of efficacy followed, ending with the introduction of occupation efficacy as a self-schema of efficacy that develops over time and across situations.

\section{Constructs Related to Self-Efficacy}

Several constructs related to self-efficacy, including locus of control, perceived personal control, achievement motivation, personal causation, and learned helplessness, were also examined for their theorized contingencies between action and outcomes and for their explanatory theories of motivation. The constructs were then compared to Bandura's construct of self-efficacy. These constructs (including self-efficacy) were classified as self-referent thought and posited as intermediaries between thought and action. In addition, all concede the presence of internal means such as ability and effort and internal mechanisms such as causal attributions and expectancies as mediators of one's sense of control.

It was argued that when ability is conceived as an acquirable condition, both effort and ability are viewed as valued means of attaining effective 
performances and desired outcomes. The abilities to learn and to deploy effort for learning are also conceived of as important capabilities within one's selfschema of efficacy. This section posited that one's self-schema of efficacy is strengthened by beliefs that the environment is controllable and that one has the capabilities and opportunities to influence environmental variables. Volition Theory and Research

Chapter 3 began with a review of volition theory and research. A summary of volition theory, which emphasized volitional control capabilities and an action orientation, introduced this section, and the implications of looking at self-efficacy and the role of teaching from a volitional perspective were examined. This section showed that volitional control processes work in tandem with task-or role-related capabilities and that volitional control is the foundation of the coping response. It further argued that one's sense of volitional control would naturally be taken into consideration as part of selfassessments of one's efficacy. This section also showed that, in occupations such as teaching where competence is developed over time and through practice, feelings of efficacy are tied to one's capability to protect one's intentions by setting short-term task, learning, or mastery goals.

Further, it was argued that one's feelings of volitional control are inextricably linked to one's willingness and capability to deploy effort, particularly in the face of distractions, obstacles, and impending failure; the deployment of effort was then presented as a set of capabilities related to the management of internal and external resources. Finally, because one's capabilities and continued efforts result in the formation of habits and predispositions to act in certain ways, dispositions were also argued to play a role in one's real and perceived volitional control and, hence, in one's selfassessments of efficacy. 
Resiliency and Emotional Intelligence

Chapter 3 then turned to emerging perspectives on effectiveness offered by the theories of resiliency and emotional intelligence. Resiliency theory was shown to contribute to self-efficacy theory through its delineation of protective factors that reduce the potential that individuals' vulnerabilities, along with the challenges and risks in the environment, will negatively influence their effectiveness and sense of efficacy. Emotional intelligence was then discussed as a corollary theory of volition. It was argued that being able to manage one's emotions and being able to influence the feelings of others are volitional capabilities that give one an "added edge in the workplace" (Goleman, 1995, p. 36) and, thus, also contribute to one's sense of efficacy.

This section of chapter 3 also argued that a sense of efficacy depended on one taking responsibility for being and feeling efficacious by recognizing that the opportunity to choose how to respond is inherent in every situation, regardless of the conditions. By choosing to be proactive and finding a way to be "response-able" (Covey, 1990, p. 75), individuals are also able to make a difference. Last, the importance of continued effort and learning was reiterated through Gallwey's (1981) conception that effectiveness is reinforced by relaxed concentration, mindful effort, and interest in and responsiveness to the environment.

\section{Contexts of Teaching and Learning to Teach}

Chapter 3 ended with background of theory and research related to the contextual conditions affecting teaching and learning to teach, as well as the theory and research related to reflective practice. The research showed the importance of collaboration, decision making, and supportive school culture in enhancing teacher engagement, satisfaction, effectiveness, and sense of efficacy. 
After describing the context in which prospective teachers learn to teach and are socialized into the profession, this section proposed that involvement in school-based components of teacher education programs structured for increased collaboration would help teachers and student teachers enhance their feelings of personal teaching efficacy.

Next, an historical perspective on what constitutes effective teaching and an overview of the theory and research underlying reflective practice were presented. Various types of reflective practice and student teaching models that focus on reflective practice were surveyed. The important roles that teacher thinking and reflection play in the improvement of teaching practice were also introduced, including Dewey's $(1906,1966)$ belief that thinking should assist one not only in responding effectively to present stimuli, but also in forming "an end in view" (p. 146) or creating a preferred future (Noordhoff \& Kleinfeld, 1990). This section of chapter 3 argued that, through reflection, teachers develop the capabilities to teach with skill and artistry (Schon, 1983), to improvise their knowledge and skills in the moment (Yinger, 1990), to respond to children in a caring way (van Manen, 1995), and to create positive and supportive learning communities (Valli, 1990).

\section{Discussion Related to the Reconceptualization of Personal Teaching Efficacy}

The review of the literature had not only confirmed the importance of teachers' sense of efficacy, but also presented several limitations of Gibson and Dembo's (1984) model and scale, including the uncertain meaning of the underlying factor of teaching efficacy and the fact that most researchers considered teachers' sense of efficacy to be a multidimensional construct with many underlying factors. 
Review of the Theoretical Aspect

of the Study

One purpose of this dissertation was to reexamine teachers' sense of efficacy from efficacy construct from the broader theoretical perspective of social cognitive theory, focusing on teachers' perceptions of their own teaching efficacy--that is, personal teaching efficacy. As a result of the review, an initial model and scale of personal teaching efficacy were developed.

The initial model hypothesized five underlying factors of personal teaching efficacy. The first two, instruction efficacy and classroom management efficacy, retained the essence of Gibson and Dembo's first factor. Using Bandura's conception of self-efficacy, I viewed these two factors as representing teachers' perceptions of their classroom capabilities related to student learning and behavior and grouped them under a more general heading of teaching performance efficacy.

The other three factors of influence efficacy, behavioral coping efficacy, and thought control efficacy drew not only on the self-efficacy theory and research of Bandura (1986), but also on other theories that proposed a mediator between thought and action, particularly those of Skinner (1992) and McCarthy and Newcomb (1992). Following Skinner, these three factors were grouped under teacher control efficacy in the first model.

The development of the new model and scale also involved conducting exploratory factor analyses using data from teachers and student teachers participating in a reflective practitioner model practicum at the University of Alberta. It was hoped that these factor analyses would either confirm the model and scale or provide information for further modifications to one or the other. However, the initial round of factor analyses produced several more 
factors than had been hypothesized-13 factors each from the teacher pretest and posttest and 14 factors each from the student teacher pretest and posttest.

The analysis of the factor solutions across the teacher and student teacher pretests and posttests revealed that the instruction efficacy factor was most clearly discernible and the most stable of the hypothesized factors. In addition, the classroom management efficacy and thought control efficacy factors were also somewhat discernible, but less stable from pretest to posttest. However, influence efficacy and behavioral coping efficacy were less discernible, and as the large number of factors suggests, there were also many factors whose substantive meaning could not be discerned at all.

Thus, I returned once again to the literature in search of better explanations for these factors. This led me to volitional theory and other more mainstream theories such as resilience and emotional intelligence. These theories, along with continued emphasis on personal teaching efficacy as a self-schema of occupational efficacy, were the foundation of the final model that conceptualizes personal teaching efficacy from a volitional perspective. This seven-factor model explained more factors and did so more adequately; however, there were still more factors produced by the factor analyses than there were hypothesized factors (see Table 9 in chapter 4), and the factor loadings across the four administrations of the scale were still unstable.

Therefore, in an attempt to reduce the large number of factors and to increase the stability of the factor loadings, I conducted new factor analyses using matched cases only. When this move resulted in only a small reduction in the number of factors, I then reduced the items in the scale in hopes of achieving a more parsimonious factor solution. Factor analyses using the 31item Personal Teaching Efficacy Scale resulted in 10 factors from the teacher pretest factors, 8 factors from the teacher posttest, and 9 factors each from the student teacher pretest and posttest. 
Teacher factor analyses. The factor structures derived from the factor analyses of the teacher pretest and posttest using the 31-item scale both moderately supported the hypothesized model of personal teaching efficacy. Factor solutions of the teacher data showed that group relations efficacy remained the most stable of the factors from pretest and posttest, with thought control efficacy and impact efficacy remaining reasonably stable. Of most interest was the first factor of the teacher pretest and posttest factor solutions. While the percentages of variance of the pretest and posttest initial factor remained almost the same (27.3\% in the pretest and $31.3 \%$ in the posttest), the factors themselves were not the same. In the teacher pretest, the first factor represented instruction efficacy, while in the teacher posttest, the first factor represented action efficacy. Thus, perceptions of what is of primary importance to teachers' sense of personal teaching efficacy appeared to have shifted over the 12 weeks of the practicum.

Student teacher factor analyses. Factor solutions using the 31 -item scale and student teacher data also showed moderate stability of the factors representing action efficacy and thought control efficacy from pretest and posttest. That is, each had two of three items loading in common from pretest to posttest. Of most interest here was the emergence of two unhypothesized factors which appeared to take the place of the instruction efficacy and the group relations efficacy factors. One factor could be interpreted as a student influence efficacy factor, in that it included student teachers' perceptions of their capabilities to overcome common teaching problems, including disruptive or unmotivated students and a diversity of learners. However, it also contained an item related to acquiring new skills. The other factor related to the teaching performance aspect appeared to represent student teachers' perceptions of their capabilities to organize or access "technical resources" such as organized subject matter, curriculum materials, and interesting 
learning activities--and parents. It contained items hypothesized to represent action efficacy, impact efficacy, and operative efficacy.

\section{The Importance of the Theoretical Study}

The failure of the final factor analyses to fully confirm the hypothesized volitional model of personal teaching efficacy and to produce stable factors from pretest to posttest of the teacher and student teacher data was disappointing. However, the research does contribute substantially to the conversation on the personal teaching efficacy construct:

1. The hypothesized model and the results of factor analyses oresent personal teaching efficacy as a complex, multidimensional construct with at least seven factors.

The study first provides a prospective model in response to other researchers' (Dembo \& Gibson, 1984; Good \& Tom, 1985; Guskey \& Passaro, 1993; Smylie, 1990) call for a broader, more detailed conceptualization of the underlying factors of personal teaching efficacy. In addition, it proposes an alternate interpretation of Gibson and Dembo's (1984) second factor, teaching efficacy, conceptualizing it as another aspect of personal teaching efficacy.

Second, exploratory factor analyses of the 46-item and 31-item Personal Teaching Efficacy Scale confirmed the multidimensionality of personal teaching efficacy. Depending on the number of scale items used and whether all cases or matched-cases data were used, factor solutions produced anywhere from 8 to 14 factors. While additional research is needed to fully understand the underlying factors of personal teaching efficacy, the study points out the limitations of the current two-factor design proposed by Gibson and Dembo (1984). 
2. The hypothesized model and the results of factor analyses begin to

integrate the theory and research on other cognitive mediators between thought and action. which Bandura (1986) and Skinner (1992) have advocated.

This model continues to conceptualize personal teaching efficacy as one type of self-efficacy, albeit from a volitional perspective. Self-perceptions of one's capabilities to teach effectively, represented by the factors related to the teaching performance aspect of the model, align most closely with Bandura's (1986) definition of self-efficacy. In addition, those factors related to the teacher volition aspect reaffirm Bandura's (1986) conception of triadic reciprocal causation, which stresses the reciprocal influence among one's perceptions, one's behavior, and the context in which one is acting, and Skinner's (1992) concept of personal control as effective engagement with the environment. However, they are placed within a framework of volitional theory (Heckhausen, 1991).

3. The hypothesized model and the results of factor analyses support a volitional perspective of personal teaching efficacy which further places Dersonal teaching efficacy within occupational and self-schema frameworks, consisting of a number of interrelated perceptions, values, and beliefs.

The volitional perspective fits well with the real nature of the teaching role: After the first day of a new year or a new semester, teachers have crossed Heckhausen's (1991) "Rubicon" (p. 175). That is, they have chosen to act, and now they must continue to act in the situation presented to them or disengage (Skinner, 1992), by leaving the profession (Rosenholtz, 1989), by retreating to an attitude of just "going through the motions" (Ashton \& Webb, 1986), by changing their focus away from the teaching of children (Ross, 1994a), or by becoming stressed or burning out (Greenwood, Olejnik, \& Parkey, 1990). The volitional perspective looks at how effective teachers follow 
through and accounts for their proactive responses to the dynamic and often difficult situations with which they must deal.

Second, by defining teachers' self-percepts of efficacy from an occupational perspective, the model takes into account the social nature of the school context; the ongoing, dynamic nature of teachers' tasks; and the longterm nature of teachers' goals. This emphasis on the ongoing nature of the teachers' role is supported by Schon's conception (1983) of a "situation" and Heckhausen's (1991) conception of "action," which are both considered as the totality of behaviors directed towards a distal goal.

Third, the volitional perspective on personal teaching efficacy reaffirms the multidimensional nature of the construct in its recognition not only of teachers' role capabilities, but also of their volitional capabilities. Teachers' positive perceptions of their volitional capabilities to act--or to continue acting--reinforce their continuing predispositions to respond flexibly to dynamic situations, to be nonvulnerable to stress, and to protect their teaching intentions, particularly in the face of obstacles and aversive situations. Further, a volitional perspective also accounts for the underlying values and beliefs that affect not only teachers' performance attainments, but also their sense of personal teaching efficacy.

Finally, the multiple capabilities, beliefs, and predispositions presented in the model suggest that personal teaching efficacy is a self-schema of interrelated self-referent thoughts, while the factor analyses suggest that this self-schema is a dynamic fluid representation of self-percepts of personal teaching efficacy that is changeable. 
The Effectiveness of the Scale in Delineating the

\section{Hypothesized Factors Underlying Personal Teaching Efficacy}

In developing a new scale of personal teaching efficacy, I attempted to select items that would represent a wide range of thoughts, feelings, and behaviors related to the teaching role. I hypothesized that if I could capture these, the factor analyses would represent personal teaching efficacy as a multidimensional construct with more than two underlying factors. This general hypothesis was supported by the resultant factor analyses. If the scale items are representative of teachers' thoughts, feelings, and behaviors related to personal teaching efficacy, then the factor analyses show that personal teaching efficacy is a multidimensional construct.

However, the factor solutions proposed between 8 and 14 factors, depending on the data used; the first model proposed 5 factors, while the final model proposed 7 . The 5 -factor model, thus, left many unexplained factors, and while the 7-factor model helped to identify more of the underlying factors, it did not account for all of the factors derived from the factor solutions.

In the factor solutions using the 46-item scale and the volitional model, thought control efficacy, action efficacy, and impact efficacy remained the most stable across the four administrations of the scale. The remaining factors and factor loadings were less stable. In addition, the factor loadings continued to remain unstable even when matched cases data were used and when the scale was reduced to 31 items. While one definitive reason for this instability cannot be given, there are several reasons that can be conjectured. proposed Reasons for the Instability of the Factors

1. The instability of the underlving factors of personal teaching efficacy may be an effect of the modest correlations among some variables and between some factors. 
The factor correlation matrices derived from the factor analyses of teacher and student teacher pretests and posttests show that, with the exception of impact efficacy, the underlying factors are somewhat correlated. Thus, the differences in the number of factors and the factor loadings among the factor solutions of the teacher and student teacher pretests and posttests may be an effect of the correlations among factors. Alternately, a reduction in the number of factors and a small increase in the stability of factor loadings occurred as a result of reducing the number of items in the Personal Teaching Efficacy Scale, suggesting that stability may be achieved by limiting the semantic space covered by scale items.

However, the exploratory factor analyses of the present study may likewise indicate that the factors underlying teachers and student teachers' sense of personal teaching efficacy are simply less stable over time than has been previously presumed by other researchers using Gibson and Dembo's (1984) two-factor model.

2. The scale does not cover the "semantic space" required to adequately represent the hypothesized model.

The scale items were developed using the first tentative model as a guide and great care was taken to cover the semantic space of the teaching role. However, the subsequent return to the literature provided a new perspective. The appeal of this perspective was that it seemed to more adequately fit not only teachers' real-life experience, but also the first round of factor analyses results. Despite this, the new model was designed after the scale had been administered, and it is, therefore, reasonable to presume that the items do not perfectly reflect the volitional perspective on personal teaching efficacy. 3. The model does not adequately represent the factors underlving teachers' sense of efficacy.

Given that the model specifies only 7 underlying factors and the factor 
solutions of the 31-item scale derive between 8 and 10, depending on the data used, it is obvious that the model does not yet completely explain the underlying dimensions of personal teaching efficacy. Kim and Mueller (1985) suggest that "after proper rotation" some minor factors may be ignored "on substantive grounds" (p. 42). However, while ignoring some factors does improve the alignment between the factor solutions and the hypothesized model, it is more likely that either the model or the scale items (or both) do not yet completely capture what it means for teachers and student teachers to be efficacious.

4. Student teachers and teachers have different conceptions of what constitutes personal teaching efficacy.

A "subproblem" underlying the instability issue was the fact that the factor solutions representing teacher data and student teacher data did not align. Not only do scale items load differently when teacher and student teacher data are used, but interpretations of the meanings of the factors change. This is evidenced by the emergence of a "teaching operations efficacy" factor that was not present in the teacher factor solutions. Thus, the results from factor analyses conducted in the present study strongly suggest that student teachers perceive the teaching role differently than teachers, and they may have different perceptions of what constitutes personal teaching efficacy.

5. Along with changing their self-perceptions of personal teaching efficacy over the term of the practicum, both teachers and student teachers may have also changed their conception of what constitutes personal teaching efficacy.

Teachers. Changes in teachers' conception of the teaching role and in their perceptions of the relationships among variables constituting personal teaching efficacy seem unlikely to occur in the short period of 12 weeks. 
There is, however, some evidence that some change did occur. For example, the first factors in the teacher pretest and posttest were substantively different. In the factor analyses of the teacher pretest, the first factor was represented by instruction efficacy; in the factor analyses of the teacher posttest, the first factor was represented by action efficacy. Since this first factor had a higher eigenvalue and represented a higher proportion of total variance explained by the factor solution, a shift from instruction efficacy to action efficacy appears to represent a substantive change.

Perhaps self-percepts of personal teaching efficacy are as dynamic as the situations in which they are assessed, suggesting that not only does teachers' sense of personal teaching efficacy change as a result of their experiences, but the relationship among variables remains fluid and dynamic as well.

However, if teachers' conceptualization of the teaching role and of what constitutes personal teaching efficacy have changed, as the factor solution suggests, it may also be reasonable to presume that their experience in the practicum was an important intervening variable. Additionally, it seems reasonable to further presume that the special conditions of the reflective practitioner model practicum have affected this change.

Student teachers. As stated previously, given student teachers' lack of experience in classroom teaching, it is not unlikely that their perceptions of the role of the teacher--and, hence, their perceptions of what constitutes personal teaching efficacy--would change after participation in the practicum experience. However, this presumption and the fact that the factor solutions using student teacher data remain substantively different from the factor solutions using teacher data--even after the practicum--move away from previous research. For example, in previous research by Woolfolk and Hoy (1990), the factors and factor loadings derived from factor analysis of 
student teacher data were posited to be so similar to those derived using teacher data that the data were merged.

\section{Conclusion}

Despite the uncertainties arising from the new model and scale, it may be more important to determine whether or not the reconceptualization of personal teaching efficacy is moving in the right direction. This can be answered affirmatively, in light of the evidence from the factor analyses already reported. Factors for thought control efficacy and action efficacy, part of the volitional aspect of personal teaching efficacy, are represented in all factor solutions. In addition, the teaching performance aspect is also present in the four factor solutions, despite changes in the individual factors represented. The weakness of the operative efficacy factor and the instability of factor loadings related to it point to the need for a more careful delineation of the factors, with more carefully worded items to represent them.

\section{Discussion Related to the Empirical Study}

Using the New Personal Teaching Efficacy Model and Scale

The second purpose of this dissertation was to test the model and scale for their utility in explaining and measuring changes in teachers' and student teachers' personal teaching efficacy over the term of a 12-week reflective practitioner model practicum. In addition, this study attempted to address the known limitations of current research on teachers' sense of efficacy by designing a research methodology which not only explored changes in personal teaching efficacy at the item, factor, and full-scale level, but also analyzed differences among teachers and student teachers with different personal characteristics and experiences. 


\section{Summary of Findings}

\section{Teachers' and Student Teachers'}

\section{Perceptions of the Practicum Context}

The statistical analyses of the data derived from the teacher and student teacher pretests and posttests show both the teacher and student teacher samples viewed the practicum experience as a positive one. Teachers perceived the practicum as a collaborative venture, with opportunities to work together and to participate in making decisions related to the day-to-day operation of the practicum. Student teachers felt that their school facilitators were very helpful in their development as teachers, rating this relationship as a stronger influence on their development as teachers than either their relationship with their university facilitator or their experiences in the seminar.

Not surprisingly, while teachers reported that they had developed as teachers as a result of the practicum, student teachers' mean score on perceptions of their development was higher than teachers' mean score. Further, student teachers felt they not only had developed as teachers, but had also gained confidence in their capability to teach and in their feelings of readiness to take on full-time teaching responsibilities.

The findings also confirm that teachers' and student teachers' perceptions of personal teaching efficacy did change after participation in a reflective practitioner model practicum offered through the University of Alberta.

Teacher Change in

\section{Perceptions of the Context}

Of interest are the changes in teachers' perceptions of various context variables. The results of $t$ tests show that teachers significantly increased their perceptions that they were considered to be valued staff members and 
that they could count on others to help them when they needed help. These feelings of support by others were balanced by a significant increase in their feelings of autonomy to organize their class in effective ways. Teachers also increased self-perceptions that they controlled decisions related to teaching and that others would encourage them when they were down, although the increases were nonsignificant. These positive changes suggest that participation in the reflective practitioner model practicum may have a positive influence on teachers' perceptions of their school context and may be one way to improve school culture, especially if many teachers in the school participate.

Teachers' Perceptions and

Sense of Personal Teaching Efficacy

Teachers began and ended the practicum with a strong and positive sense of their capabilities and dispositions to act effectively. This is reflected in high pretest scores and the significant increase in their composite personal teaching efficacy score from pretest to posttest.

Teacher Change at the Variable Level

of Personal Teaching Efficacy

A review of the results of $t$ tests for the individual variables shows that only 15 of teachers' mean pretest scores were below 4.0, with 1 mean pretest score below 3.0, indicating that, by and large, teachers had highly positive perceptions of their capabilities and dispositions to act effectively upon entry into the practicum. However, the teachers' posttest mean scores increased on all 15 variables, with 5 posttest mean scores greater than 4.0. In fact, teachers' mean scores on all but 4 of the 46 variables increased over the term of the practicum, with a significant and positive change on 14 variables.

Negative changes in teachers' perceptions were nonsignificant and small on three of the remaining four variables. However, teachers were significantly 
less predisposed to consider how they might improve a lesson gone badly after the practicum than they were before. While the mean posttest score was significantly lower than the mean pretest score on this item, both scores were over 4.25 on the 5-point Likert scale.

\section{Teacher Change at the Composite}

\section{Scale Level and the Factor Level}

The $t$ test results also showed a significant increase in teachers' overall sense of personal teaching efficacy from pretest to posttest, measured as the mean composite score of the 31 items, suggesting that participation in the reflective practitioner model practicum positively influenced teachers' sense of personal teaching efficacy.

However, the results of $\mathrm{t}$ tests conducted using the factor indices more clearly delineate what effected this significant increase in personal teaching efficacy: The significant increase in an overall sense of personal teaching efficacy was most probably due to significant increases in feelings of instruction efficacy and group relations efficacy and further supported by positive but nonsignificant changes in impact and action efficacy. Alternately, perceptions of thought control efficacy decreased over the period of the practicum, although not significantly.

Effects of Personal Characteristics on Teachers' Sense of Personal Teaching Efficacy

Further analyses using ANOVAs revealed that teachers' sense of personal teaching efficacy changed differentially over the period of the practicum, depending on certain personal characteristics. Analyses using four-way ANOVAs found that age group influenced changes in teachers' overall sense of personal teaching efficacy, with "young" teachers (ages 2125) experiencing the most gain. Gender was also found to influence changes in group relations efficacy, with females experiencing a gain in their sense of 
group relations efficacy and males experiencing a decline. While both these findings were nonsignificant, they reflect similar findings by Evans and Tribble (1986) that female teachers have stronger self-percepts of personal teaching efficacy than males.

In addition, two-way ANOVAs show interaction effects for age group and past practicum experience and for teaching experience and past practicum experience on changes in teachers' sense of instruction efficacy, with the former having a significant effect and the latter approaching significance.

The self-percepts of instruction efficacy of mature teachers with ne past practicum experiences declined over the practicum, but their selfpercepts of instruction efficacy increased more than those of young and middle-aged teachers when they did have previous practicum experience. Young and middle-aged teachers' sense of instruction efficacy increased regardless of whether or not they had previous practicum experience.

Similarly, veteran teachers with no past practicum experience suffered a marked decline in self-percepts of instruction efficacy over the course of the practicum, and neophyte and midcareer teachers with no previous practicum experience increased their self-percepts of instruction efficacy. Their increases were higher than those of any group with previous practicum experience. Teachers with past practicum experience in all three age groups experienced an increase in their sense of instruction efficacy.

The interaction effect between teaching experience and previous practicum experience suggests that early participation in practicum experiences supports positive changes in instruction efficacy. This conclusion is reinforced by the finding that veteran teachers with previous practicum experience experienced a slightly greater change in their feelings of instruction efficacy than neophyte and midcareer teachers. In contrast, Pigge and Marso (1993) found no difference in overall sense of teacher 
efficacy as a result of career level; however, they did find differences on some variables.

Teaching experience and previous practicum experience also have a significant effect on teachers' sense of action efficacy. In this instance, when teachers had no previous practicum experience, young teachers' sense of action efficacy declined, veteran teachers experienced no change, and midcareer teachers had modest gains. With previous practicum experience, young and veteran teachers experienced an increase in action efficacy, while midcareer teachers experienced a decrease. However, the small number of teachers in many of the groups suggests that further research is needed to confirm this finding.

\section{Student Teachers' Perceptions and}

\section{Sense of Personal Teaching Efficacy}

The statistical analyses of the student teacher pretest and posttest data show that the student teachers entered the practicum with a lower sense of efficacy than did teachers but experienced a higher rate of change over more variables than did teachers after participation in the reflective practitioner model practicum. This fits with the commonsense notions that, prior to real experience in the classroom, student teachers' sense of personal teaching efficacy would be lower than that of experienced teachers, but that this sense of efficacy would grow quickly as experience was gained.

Student Teacher Change at the Variable Level of Personal Teaching Efficacy

Student teachers' mean pretest scores were over 4.0 on only 5 of the variables, while teachers had pretest mean scores over 4.0 on 31 variables. However, student teachers entered the practicum with strong beliefs in their ability to establish rapport with their pupils and in the efficacy of effort in influencing student learning. 
Also in contrast with the teacher results, $t$ tests show that student teachers significantly increased their perceptions of their capabilities on all but 4 of the 46 variables. The mean scores on 2 of these 4 variables increased nonsignificantly, and 2 mean scores decreased nonsignificantly.

Although the change was not statistically significant, student teachers were more likely to consider how to improve a lesson gone badly at the end of the practicum than they were before and less likely to be concerned about what others would say if they failed. Alternately, they were less likely to believe they could make a difference with students and to believe that they had more influence than students' home environment.

The significant increases on most of the 46 variables suggest that participation in the reflective practitioner model practicum had a positive influence on student teachers' sense of personal teaching efficacy. Student Teacher Change at the Composite Scale Level and at the Factor Level

The variable results were further confirmed by results from $₫$ tests measuring differences in pretest and posttest scores: Student teachers experienced significant and positive changes in overall personal teaching efficacy and in self-percepts of instruction efficacy, thought control efficacy, action efficacy, and teaching operations efficacy, as measured by indices of two to three variables. Similar to the teacher results, the greatest mean score difference was on the instruction efficacy index. Effects of Personal Characteristics on Student Teachers' Sense of Personal Teaching Efficacy

Gender had a significant effect on student teachers' self-percepts of "teaching operations" efficacy, with females increasing their sense of teaching operations efficacy more than male teachers. No other personal characteristic had a main or interaction effect on student teachers' overall 
sense of personal teaching efficacy or their self-percepts of instruction, thought control, or action efficacy.

There was an interesting interaction effect for age group and previous work with children on action efficacy, although it was not statistically significant. At least one age group experienced little or no change in action efficacy depending on the amount of previous work with children: "Very young," "middle-aged," and "mature" student teachers experienced a small positive change or no change in action efficacy when they had little previous work with children. Alternately, “young" student teachers with moderate amounts of previous work with children and middle-aged student teachers with high amounts experienced a moderate and positive change. Only middleaged student teachers with moderate amounts of previous work with children had positive gains in action efficacy.

The general lack of significant main and interaction effects suggests that the reflective practitioner model practicum may be a good model to produce diffuse positive changes in the sense of efficacy of most student teachers at the scale and the factor level.

\section{Conclusions Related to the Emoirical Study}

1. The new scale of personal teaching efficacy was able to discern changes in teachers' and student teachers' sense of personal teaching efficacy at the variable level, the composite-scale level, and the factor level.

2. Changes in teachers' and student teachers' sense of personal teaching efficacy are influenced both negatively and positively by demographic variables and personal experiences.

3. Participation in the practicum appeared to effect changes in both teachers' and student teachers' sense of efficacy. 
Teachers experienced significant gains in their overall sense of personal teaching efficacy, their instruction efficacy, and their group relations efficacy. No significant gains were made in impact efficacy or action efficacy, and thought control efficacy declined slightly.

Alternately, student teachers not only experienced significant gains in all aspects of personal teaching efficacy, but they also had larger gains than the teachers.

4. While this study did not have a control group of nonparticipating teachers, it seems likely that the reflective practitioner model practicum, with its demand for increased interaction among teachers and its emphasis on collegial decision making, may be an important vehicle for enhancing teachers' and student teachers' self-percepts of personal teaching efficacy.

Teachers' perceptions of their school context changed positively on all but one variable, and significantly on two. This conclusion is at least partly confirmed by the positive change in teachers' perceptions of their school environment over the 12-week period.

The 12-week practicum also led to increases in student teachers' selfpercepts of personal teaching efficacy. Confirming other research findings (for example, see Housego, 1992), this study shows that student teachers significantly increased self-perceptions that they had the capabilities required for effective teaching performance. In addition, the significant increases in thought control efficacy and action efficacy suggest that the reflective practitioner model practicum may also have reinforced important volitional capabilities and dispositions required for ongoing teaching effectiveness.

The findings of this study support other research which indicates that some aspects of student teachers' sense of efficacy increased over their 
student teaching experience while other aspects decreased (for example, see Evans \& Tribble, 1986).

\section{Overview of the Study's \\ Main Conclusions}

Based on results from factor analyses and findings from other research studies, the following conclusions can be sustained:

1. Personal teaching efficacy is a vastly more complex phenomenon than has been previously hypothesized.

2. The construct of personal teaching efficacy is a multidimensional, as opposed to a one- or two-dimensional, phenomenon.

3. Personal teaching efficacy is an unstable construct, affected by experiences over time.

4. Self-perceptions of personal teaching efficacy do change over time as a result of experiences and changes in contextual conditions.

5. Over the course of a practicum experience, the personal teaching efficacy of both teachers and student teachers is subject to change.

6. Gains in composite-scale-, factor-, and variable-level scores of personal teaching efficacy are generally greater for student teachers than for teachers.

7. Demographic variables such as age, gender, and previous experience and their interaction effects do impact the potential for changes in the personal teaching efficacy of some teachers and student teachers. 
Recommendations for Further Study and Research

\section{Recommendations Related to \\ the Revision of the Scale}

1. Given that a new model of personal teaching efficacy was derived after data were collected, the Personal Teaching Efficacy Scale should be carefully examined and revisions made to assure that the model is appropriately represented and the semantic space adequately covered.

2. Given the instability in the number of factors and the factor loadings between teacher and student teacher and from pretest to posttest, the scale items need to be carefully scrutinized for possible modifications.

3. The directions given to teachers and student teachers, indicating how they should respond to item statements, should be changed to make responses more representative of continuous data and, thus, increase the ways in which the data could be analyzed.

For example, teachers and student teachers could assess the strength of their efficacy or indicate the degree of their agreement by using a point from 1 to 100 to respond to each item statement. Further, the volitional aspects of personal teaching efficacy could use a percentage scale indicating how often teachers act in certain ways or how strong their beliefs are.

\section{Recommendations Related to the Contexts of Teaching and Learning to Teach}

1. Ongoing research should continue to discern the effects of various models of practicum on teachers' and student teachers' sense of personal teaching efficacy.

However, the characteristics of the University of Alberta's reflective practitioner model practicum appear to have had a positive effect of both 
teachers' and student teachers' sense of personal teaching efficacy and should be replicated in the student teaching experiences offered by other teacher education programs.

2. Further study and research should continue to delineate those aspects of the school context that not only protect but also enhance teachers' sense of personal teaching efficacy.

\section{Recommendations for Further Analysis of the Personal Teaching Efficacy Construct}

1. Further study and research should continue to consider both performance and volitional aspects of the personal teaching efficacy construct.

2. The preteaching perceptions of personal teaching efficacy of student teachers are worthy of further research.

Understanding of how student teachers perceive personal teaching efficacy and what aspects of their thoughts, feelings, and behavior confirm or disconfirm their feelings of personal teaching efficacy would inform teacher educators' understanding of how student teachers develop and what constitutes their preparedness to teach, as well as help teacher educators to predict student teachers' eventual success or failure as practicing teachers. 3. Further exploration (perhaps using more qualitative research. designs) is needed to further delineate those aspects of teaching that teachers use when assessing their sense of personal teaching efficacy. 


\section{REFERENCES}

Reproduced with permission of the copyright owner. Further reproduction prohibited without permission. 
Alberta Education. (1996). An integrated framework to enhance the quality of teaching in Alberta (pp. 24-26). Edmonton, AB: Queen's Printer. Alberta Teachers' Association. (1993, January). Trying to teach. An interim report of the Committee on Public Education and Professional Practice as approved by the Provincial Executive Council of the ATA for discussion at the 1993 Annual Representative Assembly of the ATA.

Applegate, J. H., \& Lasley, T. J. (1986). Early field experience: A synthesis cf role perspective studies. ED 320065.

Ashton, P. T., \& Webb, R. B. (1986). Making a difference: Teachers' sense of efficacy and student achievement. New York: Longman, Inc.

Bacharach, S. B., Bamberger, P., Conley, S. C., \& Bauer, S. (1990, May). The dimensionality of decision practicipation in educational organizations: The value of a multi-domain evaluative approach. Educational Administration Quarterly, 26 (2), 126-167.

Bamburg, J. D. (1994). Raising expectations to improve student learning. Oak Brook, IL: North Central Regional Educational Lab. ED 378290.

Bandura, A. (1982). Self-efficacy mechanism in human agency. American Psychologist, $37(2), 122-147$.

Bandura, A. (1986). Social foundations of thought and action: A social cognitive theory. Englewood Cliffs, NJ: Prentice-Hall Inc.

Bandura, A. (1989, October). Perceived self-efficacy in the exercise of personal agency. The Psychologist Bulletin of the British Psychological Society, 2, 411-424.

Bandura, A. (1992). Exercise of personal agency through the self-efficacy mechanism. In R. Schwarzer (Ed.) Self-efficacy: Thought control of action (pp. 3-37). Washington, DC: Hemisphere Publishing Corporation. 
Bandura, A., \& Jourden, F. J. (1991). Self-regulatory mechanisms governing the impact of social comparison on complex decision making. Journal of Personality and Social Psychology, 60(6), 941-951.

Bandura, A., \& Wood, R. (1989). Effect of perceived controllability and performance standards on self-regulation of complex decision making. Journal of Personality and Social Psychology, 56(5), 805-814.

Barfield, V., \& Burlingame, M. (1974). The pupil control ideology of teachers in selected schools. The Journal of Experimental Education, 42(4), 8-11.

Berman, P., \& McLaughlin, M. (1977). Federal programs supporting educational change (Vol. II): Factors affecting implementation and continuation (Report No R-1589/7-HEW). Santa Monica, CA: Rand Corporation.

Berry, J. M., \& West, R. L. (1993). Cognitive self-efficacy in relation to personal mastery and goal setting across the life span. International Lournal of Behavioral Development, 16(2), 351-379.

Blumberg, A. (1974). Supervisors and teachers: A private cold war. Berkeley, CA: McCutchan Publishers, Corp.

Bolin, F. S. (1988). Helping student teachers think about teaching. Journal of Teacher Education, 39(2), 48-52.

Borg, W. R., \& Gall, M. D. (1989). Educational research: An introduction (5th edition). New York: Longman, Inc.

Borton, W. M. (1991). Empowering teachers and students in a restructuring school: A teacher efficacy interaction model and the effet on reading outcomes. Paper presented at the Annual Meeting of the American Educational Research Association (Chicago, IL, April 3-7), pp. 3-24. ED 335341. 
Bouffard-Bouchard, T., Parent, S., \& Larivee, S. (1991). Influence of selfefficacy on self-regulation and performance among junior and senior high-school age students, International Journal of Behavioral Development, 14(2), 153-164.

Boydell, D. (1986). Issues in teaching practice supervision research: A review of the literature. Teaching and Teacher Education, 2(2) 115-125.

Bronfenbrenner, U. (1977, July). Toward an experimental ecology of human development. American Psychologist, 513-531.

Cavers, L. (1988). Teacher efficacy: Its relationship to school level organizational conditions and teacher demographic characteristics. Dissertation. Vancouver, BC: University of British Columbia.

Cherniss, C. (1998). Social and emotional learning for leaders. Educational Leadership, 55(7), 26-28.

Chester, M. D., \& Beaudin, B. Q (1996, Spring). Efficacy beliefs of newly hired teachers in urban schools. American Educational Research Journal, $\underline{33}(1), 233-257$.

Clifton, R. A., \& Covert, J. R. (1980). Two experimental programs and the professional dispositions of student teachers. The Morning Watch, $7(3-$ 4), 35-42.

Coladarci, T., \& Breton, W. A. (1991). Teacher efficacy, supervision, and the special education resource-room teacher. Paper presented at the AERA (Chicago, IL, April 2-6, 1991) 30p.

Cone, W. H., \& Hudgins, J. M. (1989, November). Supervising effective teaching: Conceptual tools for getting started. The Clearing House, $\underline{63}$, $118-121$.

Cornbleth, C. (1986, April). Ritual and rationality in teacher education reform. Educational Researcher, 15(4), 5-14. 
Corno, L. (1993). The best-laid plans: Modern conceptions of volition and educational research. Educational Researcher, 22(2), 14-22.

Corno, L. (1994). Student volition and education: Outcomes, influences, and practices. In, D. H. Schunk, \& B. Zimmerman (Eds.), Self-regulation of learning and performance: Issues and educational applications (pp. 229251). Hillsdale, NJ: Lawrence Erlbaum Associates, Inc., Publishers.

Corno, L., \& Kanfer, R. (1993). The role of volition in learning and performance. Review of Research in Education, 19, 301-341.

Court, D. (1989, February). "Skills" in education: The perils of a frequent misnomer. The Clearing House, 63,225-226.

Covey, S. R. (1990). The seven habits of highly effective people. New York: Fireside Books.

Crow, G. M., \& Matthews, L. J. (1998). Finding one's way: How mentoring can lead to dynamic leadership. Thousand Oaks, CA: Corwin Press, Inc.

Dembo, M., \& Gibson, S. (1985). Teachers' sense of efficacy: An important factor in school improvement. The Elementary School Journal, 86(2), 173-184.

Denham, C. H., \& Michael, J. J. (1981). Teacher sense of efficacy: A definition of the construct and a model for further consideration. Educational Research Quarterly, $\underline{5}, 39-63$.

Dewey, J. (1966). Democracy and education. Toronto, Canada: CollierMacmillan Canada, Limited.

Elam. S. M., Rose. L.C., \& Gallup, A. M. (1994). The 26th annual Phi Delta Kappa/Gallup poll of the public's attitudes toward public schools. Phi Delta Kappan. 78 $(1), 41-56$.

Evans, E. D., \& Tribble, M. (1986). Perceived teaching problems, self-efficacy, and commitment to teaching among preservice teachers. Journal of Educational Research, $80(2), 81-85$. 
Freiberg, H. J., \& Waxman, H. C. (1990). Reflection and the acquisition of technical teaching skills. In R. T. Clift, \& W .R. Houston (Eds.). Encouraging reflective practice in education: An analysis of issues and programs (pp. 119-138). New York: Teachers College Press.

Friend, M., \& Cook, L. (1990). Collaboration as a predictor for success in school reform. Journal of Educational and Psychological Consultation. 1(1), 69-86.

Fritz, J. J., Miller-Heyl, J., Kreutzer, J. C., \& McPhee, D. (1995). Fostering personal teaching efficacy through staff development and classroom activities. Journal of Educational Research, 88(4), 200-208.

Fullan, M. \& Steigelbauer, C. (1991). The new meaning of educational change. Toronto: OISE Press.

Fuller, B., Wood, K., Rapoport, T., \& Dornbusch, S. M. (1982, Spring). The organizational context of individual efficacy. Review of Educational Research, $\underline{52}(1), 7-30$.

Funk \& Wagnalls standard dictionary. (1983). New York: Harper \& Row, Publishers, Inc.

Gallwey, (1981). Inner game of golf. New York: Randon House, Inc.

Garcia, T., \& Pintrich, P. R. (1991, August). The effects of autonomy on motivation, use of learning strategies, and performance in the college classroom. Paper presented at the Annual Convention of the American Psychological Association (99th, San Francisco, CA).

Garcia, T., \& Pintrich, P. R. (1994). Regulating motivation and cognition in the classroom: The role of self-schemas and self-regulatory strategies. In D. H. Schunk \& B. Zimmerman (Eds.), Self-regulation of learning and performance: Issues and educational applications (pp. 127-153). Hillsdale, NJ: Lawrence Erlbaum Associates, Inc., Publishers. 
Gardner, H. (1993). Multiple intelligences: The theory in practice. New York: Basic Books, Inc.

Garmston, R. J. (1998). Becoming expert teachers. Iournal of Staff Development, $19(1), 60-63$.

Germyn, C. (1992). Teacher as leader. In C. F. Webber, L. Bosetti, \& F. T. Johnson (Eds.) Trends in educational leadership (pp. 43-53). Calgary, AB: University of Calgary.

Gibson, S. \& Dembo, M. H. (1984). Teacher efficacy: A construct validation. Journal of Educational Psychology, 76(4), 560-582.

Glass, G. V., \& Hopkins, K. D. (1984). Statistical methods in education and psychology. Needham Heights, MA: Allyn and Bacon.

Goleman, D. (1995). Emotional intelligence. New York: Bantam Books.

Goodlad, J. I. (1984). A place called school. New York: McGraw-Hill.

Government of Alberta. (1994, January 18). News release.

Gozali, H., Cleary, T. A., Walster, W. M., \& Gozali, J. (1973). Relationship between the internal-external control construct and achievement. Journal of Educational Psychology, 64(1), 9-14.

Graham, S., \& Harris, K. R. (1994). The role of development of self-regulation in the writing process. In D. H. Schunk, \& B. Zimmerman (Eds.), Selfregulation of learning and performance: Issues and educational applications (pp. 203-228). Hillsdale, NJ: Lawrence Erlbaum Associates, Inc., Publishers.

Greenwood, G. E., Olejnik, S. F., \& Parkay, F. W. (1990). Relationships between four teacher efficacy belief patterns and selected teacher characteristics. Journal of Research and Development in Education, 23(2), 102-106. 
Grimmet, P. T., \& Ratzlaff, H. C. (1986, November-December). Expectations for the cooperating teacher role. Journal of Teacher Education, 37(6), 4150.

Grimmet, P. T., MacKinnon, A. M., Erickson, G. L., \& Riecken, T. J. (1990). Reflective practice in teacher education. In R. T. Clift, \& W. R. Houston (Eds.). Encouraging reflective practice in education: An analysis of issues and programs (pp. 20-38). New York: Teachers College Press.

Guba, E. G., \& Lincoln, Y. S. (1989). Fourth generation evaluation. Newbury Park, CA: Sage Publications.

Guskey, T. R. (1987, September/October). Context variables that affect measures of teacher efficacy. Iournal of Educational Research, $81(1)$, $41-47$.

Guskey, T. R., \& Passaro, P. (1993). Teacher efficacy: A study of construct dimensions. A paper presented at the annual meeting of the American Educational Research Association, Atlanta, GA. [ED 359202]

Guyton, E. (1994). Relationship among economic diversity and context of stuent teaching placements and educational attitudes and performance of pre-service teachers. Paper presented at the Annual Meeting of the American Educational Research Association (New Orleans, LA, April 4-8, 1994). ED 369754

Hall, B. W., Hines, C. V., Bacon, T. P., \& Koulianos, G. M. (1992). Attributions that teachers hold to account for student success and failure and their relationship to teaching level and teacher efficacy beliefs. A Paper presented at the Annual Meeting of the AERA (San Francisco, CA, April 20-24, 1992). 24p. ED 349280.

Harter, S. (1978). Effectance motivation reconsiderd: Toward a developmental model. Lournal of Human Development, 21, 34-64. 
Heckhausen, H. (1991). Motivation and action. New York: Spinger-Verlag. (translation by Peter K. Leppman)

Henderson, N., \& Milstein, M. M. (1996). Resiliency in schools: Making it happen for students and educators. Thousand Oaks, CA: Corwin Press, Inc.

Hersom, N., Birch, D., Gaskell, J., Horowitz, M., \& Plante, J. (1981, November). Teacher education. In J. H. M. Andrews, \& W. T. Rogers (Eds.), Canadian research in education: A state of the art review (pp. 12-1-12-18). Vancouver, BC: University of British Columbia.

Hoover, N. L., O'Shea, L J., \& Carroll, R. G. (1988). The supervisor-intern relationship and effective interpersonal communication skills. Journal of Teacher Education, 39 (2), 22-27.

Housego, B. E. J. (1987). Critical incidents in the supervision of student teaching in an extended practicum. The Alberta Journal of Educational Research, $\underline{\operatorname{XXIII}(4), 247-259 .}$

Housego, B. (1992). Monitoring student teachers; feelings of preparedness to teach and teacher efficacy in a new elementary teacher education program. Journal of Education for Teaching, 18(3), 259-272.

Hoy, W. K., \& Woolfolk, A. E. (1993). Teachers' sense of efficacy and the organizational health of schools. The Elementary School Journal, 23(4), 355-372.

Huberman, M. (1989). The professional life cycle of teachers. Teachers College Record, $91(1), 31-57$.

Idol, L., \& West, J. F. (1991). Educational collaboration: A catalyst for effective schooling. Interventions in School and Clinic, 27(2), pp. 70-80, 125.

Johnson, D. W., \& Johnson, R. T. (1987). Research show benefits of adult cooperation. Educational Leadership, 45(3), 27-30. 
Kagan, D. M. (1992). Implications of research on teacher beliefs. Educational Psychologist, 27(1), 65-90.

Kennedy, M. (1991). Some surprising findings on how teachers learn to teach. Educational Leadership, 49(3), 14-17.

Killion, J., \& Todnem, G. (1991). A process for personal theory building. Educational Leadership, 48(6), 14-16.

Kim, J., \& Mueller, C. W. (1985). Factor analysis: Statistical methods and practical issues. Sage University Paper series on Quantitative Applications in the Social Sciences, 07-001. Beverly Hills, CA: Sage Publications.

Kirchhoff, S. (1989, November). Collaborative university/school district approaches for student teaching supervision. A paper presented at the the Annual Conference of the National Council of States on Inservice Education (San Antonio TX, November 17-21).

Kottcamp, R. B. (1990). Teacher attitudes about work. In P. Reyes (Ed.). Teachers and their workplace: Commitment, performance, and productivity. Newbury Park, CA: Sage Publications, Inc.

Kushman, J. W. (1992). The organizational dynamics of teacher workplace commitment: A study of urban elementary and middle schools. Educational Administration Quarterly, 28 (1), 5-42.

Kushner, S. N. (1993). Teacher efficacy and preservice teachers: A construct validation. Paper presented at the Annual Meeting of the Eastern Educational Research Association. (Clearwater Beach FL, February 1722, 1993) $10 \mathrm{p}$.

Lanier, J. E., \& Little, J. W. (1986). Research on teacher education. Handbook for research on teaching (3rd ed.), pp. 527-569. 
Levine, D. U., \& Stark, J. (1982, December). Instructional and organizational arrangements that improve achievement in inner-city schools. Educational Leadership, 40, 41-46.

Lewington, J., \& Orpwood, G. (1993). Overdue assignment: Taking responsibility for Canada's schools. Rexdale, OT: John Wiley \& Sons Canada Limited.

Lieberman, A., \& Miller. L. (1978). The social realities of teaching. Teachers' College Record, 20(1), 54-68.

Little, J. W. (1982). Norms of collegiality and experimentation: Workplace conditions of school success. American Educational Research Journal, 19, 325-340.

Locke, E. A., Frederick, E., Lee, C., \& Bobko, P. (1984). Effects of self-efficacy, goals, and task strategies on task performance. Journal of Applied Psychology, 69(2), 241-251.

Lortie, D. S. (1975). Schoolteacher: A sociological study. Chicago, IL: University of Chicago Press.

Louis, K. S., \& Smith, B. (1990). Teacher working conditions. In P. Reyes (Ed.) Teachers and their workplace: commitment, performance, and productivity (pp. 23-47). Newbury Park, CA: Sage.

Mackenzie, D. E. (1983, April). Research for school improvement: An appraisal of some recent trends. Educational Researcher, pp. 5-16.

MacKinnon, J. D. (1989). Living with conformity in student teaching. The Alberta Journal of Educational Research, $\underline{X X V}(1), 2-19$

Maddux, J. E., Sherer, M., \& Rogers, R. W. (1982). Self-efficacy expectancy and outcome expectancy: Their relationship and their effects on behavioral intentions. Cognitive Therapy and Research, $6(2), 207-211$. 
Marradi, A. (1981). Factor Analysis as an aid in the formation and refinement of empirically useful concepts. In Factor analysis in sociological research (pp. 11-49). Sage studies in international sociology: 21 . Beverly Hills, CA: Sage Publications.

Masten, A. S. (1989). Resilience in development: Implications of the study of successful adaptation for developmental psychology. In D. Cicchetti (Ed.), The emergence of a discipline: Rochester symposium on developmental psychopathology: Vol. 1 (pp. 261-294). Hillsdale, NJ: Lawrence Erlbaum Associates, Publishers.

McCarthy, W. J., \& Newcomb, M. D. (1992). Two dimensions of perceived selfefficacy: Cognitive control and behavioral coping ability. In R. Schwarzer (Ed.), Self-efficacy: Thought control of action (pp. 39-64). Washington, DC: Hemisphere Publishing Corporation.

McLaughlin, M. W. \& Marsh, D. D. (1978). Staff development and school change. Teachers College Record, 80,70-94.

Meece, J. L. (1994). The role of motivation in self-regulated learning. In D. H. Schunk, \& B. Zimmerman (Eds.), Self-regulation of learning and performance: Issues and educational applications (pp. 25-44). Hillsdale, NJ: Lawrence Erlbaum Associates, Inc., Publishers.

Miller, P. S. (1991, Fall). Increasing teacher efficacy with at-risk students: The sine qua non of school restructuring. Equity \& Excellence, 25(1), 30-35.

Moore, W. P., \& Esselman, M. E. (1992). Teacher efficacy: Empowerment, and a focused instructional climate: Does student achievement benefit? Paper presented at the Annual Conference of the American Research Association, San Francisco, CA, April 20-24. pp. 3-59. ED 350252. 
Moore, W. P., \& Esselman, M. E. (1994). Exploring the context of teacher efficacy: The role of achievement and climate. Paper presented at the Annual Meeting of the American Educational Research Association, New Orleans, LA, April 4-8, 1994).

Noordhoff, K., \& Kleinfeld, J. (1990). Shaping the rhetoric of reflection for multicultural settings. In R. T. Clift, \& W .R. Houston (Eds.), Encouraging reflective practice in education: An analysis of issues and programs (pp. 163-185). New York: Teachers College Press.

Norusis, M. J. (1990a). SPSS base system user's guide. Chicago, IL: SPSS Inc. Norusis, M. J. (1990b). The SPSS guide to data analysis for release 4. Chicago, IL: SPSS Inc.

Pajares, M. F. (1992, Fall). Teachers' beliefs and educational research: Cleaning up a messy construct. Review of Educational Research, 62(3), 307-332.

Pigge, F. L., \& Marso, R. N. (1993). Outstanding teachers' sense of teacher efficacy at four stages of career development. Paper presented at the Annual Meeting of the Association of Teacher Educators, Los Angeles, CA, February 13-17. ED 35206.

Pintrich, P. R., Marx, R. W., \& Boyle, R. A. (1993). Beyond cold conceptual change: The role of motivational beliefs and classroom contextual factors in the process of conceptual change. Review of Educational Research, 63(2), 167-199.

Pugach, M. C., \& Johnson, L. J. (1990). Developing reflective practice through structured dialogue. In R. T. Clift, \& W .R. Houston (Eds.), Encouraging reflective practice in education: An analysis of issues and programs (pp. 186-207). New York: Teachers College Press. 
Raudenbush, S. W., Rowan, B., \& Cheong, Y. F. (1992). Contextual effects on the self-efficacy of high school teachers. Sociology of Education, 65 , 150-167.

Reagan, T. (1993). Educating the "reflective practitioner": The contribution of philosophy of education. Journal of Research and Development in Education, $\underline{26}(4), 189-196$.

Reid, D. W., \& Ziegler, M. (1981). The desired control measure and adjustment among the elderly: Advances and innovations in locus of control research. Ontario: Academic Press.

Reiman, A. J., \& Thies-Sprinthall, L. (1993). Promoting the development of mentor teachers: Theory and research programs using guided reflection. Journal of Research and Development in Education, 26 (4), $179-185$.

Reyes, P. (1990). Linking commitment, performance, and productivity. In P. Reyes (Ed.), Teachers and their workplace: Commitment, performance, and productivity (pp. 299-311). Newbury Park, CA: Sage.

Richardson-Koehler, V. (1988). Barriers to the effective supervision of student teaching: A field study. Journal of Teacher Education, 39(2), 28-34.

Rosenholtz, S. J. (1989). Workplace conditions that affect teacher quality and commitment: Implications for teacher induction programs. The Elementary School Journal, 89(4), 421-439.

Ross, J. A. (1992, Winter). Teacher efficacy and the effects of coaching on student achievement. Canadian Journal of Education, 17(1), 51-65.

Ross, J. A. (1994a). Beliefs that make a difference: The origins and impacts of teacher efficacy. Paper presented at the Annual Meeting of the Canadian Association for Curriculum Studies, Calgary AB, Canada, June 1994. ED 379216. 
Ross, J. A. (1994b). The impact of an inservice to promote cooperative learning on the stability fo teacher efficacy. Teaching and Teacher Education, 10(4), 381-394.

Rotter, J. B. (1966). Generalized expectancies for internal versus external control of reinforcement. Psychological Monographs, 80, 1-28.

Sarason, S. B. (1993). You Are Thinking of Teaching? Opportunities, problems, realities. San Franscisco, CA: Jossey-Bass Inc., Publishers.

Schon, D. (1983). The reflective practitioner: How professionals think in action. New York: Basic Books.

Schaller, K. A., \& DeWine, S. (1993). The development of a communicationbased model of teacher efficacy. Paper presented at the Annual Meeting of the Speech Communication Association (79th, Miami, FL, November 18-21, 1993). ED 362928.

Schonwetter, D. J., Perry, R. P., \& Struthers, C. W. (1992). Students' perceptions of control and success in the college classroom: Affects and achievement under different instructional conditions. Journal of Experimental Education, 61(3), 227-246.

Schunk, D. H. (1994). Self-regulation of self-efficacy and attributions in academic settings. In D. H. Schunk, \& B. Zimmerman (Eds.), Selfregulation of learning and performance: Issues and educational applications (pp. 3-21). Hillsdale, NJ: Lawrence Erlbaum Associates, Inc., Publishers.

Schunk, D. H. (1996). Learning theories: An educational perspective (2nd Edition). Englewood Cliffs, NJ: Prentice Hall, Inc.

Scott, J. J., \& Smith, S. C. (1987). From isolation to collaboration: Improving the work environment of teaching (pp. 3-91). Eugene, OR: ERIC Clearinghouse on Educational Management, University of Oregon.

Seligman, M. E. P. (1991). Learned optimism. New York: Alfred Knopf. 
Sexton, T. L., \& Tuckman, B. W. (1991). Self-beliefs and behavior: The role of self-efficacy and outcome expectation over time. Personality and Individual Differences, 12(7), 725-736.

Simmons, J. M., \& Schuette, M. K. (1988, Summer). Strengthening teachers' reflective decision making. Journal of Staff Development, 2(3), 18-27.

Simpson, G. W. (1990, May). Keeping it alive: Elements of school culture that sustain innovation. Eduational Leadership, 34-37.

Sizer, T. (1984). Horace's compromise: The dilemma of the American high school. Boston, MA: Houghton Mifflin.

Skinner, E. A. (1992). Perceived control: motivation, coping and development. In R. Schwarzer (Ed.) Self-efficacy: Thought control of action (pp. 3964). Washington, DC: Hemisphere Publishing Corporation.

Smylie, M. A. (1990). Teacher efficacy at work. In P. Reyes (Ed.), Teachers and their workplace: Commitment, performance, and productivity (pp. 4866). Newbury Park, CA: Sage Publications, Inc.

Soodak, L. C., \& Podell, D. M. (1993). Teacher efficacy and student problem as factors in special education referral. The Journal of Special Education $\underline{27}(1), 66-81$.

Sparks, D. (1993, November). Team Building empowers teachers in change efforts. School Team Innovator, p. 2.

Sternberg, R. J. (1985). Beyond I. Q.: A triarchic theory of human intelligence. Cambridge: Cambridge University Press.

Stipek, D. J., \& Weisz, J. R. (1981). Perceived personal control and academic achievement. Review of Educational Research, 51(1), 101-137.

Stock, J. \& Cervone, D. (1990). Proximal goal-setting and self-regulatory processes. Cognitive Therapy and Research, 14(5) 483-498.

Su, J. Z. X. (1992). Sources of influence in preservice teacher socialization. Journal of Education for Teaching, 18(3), 239-258. 
Sullivan, K. (1996a, April). Collaborative culture supports improvement. School Team Innovator, pp. 1,5. National Staff Development Council. Sullivan, K. (1996b, May). Teaming contributes to professional community. School Team Innovator, pp. 1, 5. National Staff Development Council. Swanson, J. (1995, September). Systemic reform in the professionalism of educators. Phi Delta Kappan, $77(1), 36-39$.

Tinsley, E. A., \& Tinsley, D. J. (1987). Uses of factor analysis in counseling psychology research. Journal of Counseling Psychology 14(3), 414-424. Tipton, R. M., \& Worthington, E. L. (1984). The measurement of generalized self-efficacy: A study of construct validity. Iournal of Personality Assessment, $48(5), 545-548$.

Tom, A. R. (1984). Teaching as a moral craft. New York : Longman.

Tuckman, B. W., \& Sexton, T. L. (1989). The relation between beliefs and selfregulated performance. Paper presented at the Annual Conference of AERA (San Francisco, CA, March 27-31, 1989). ED 305514.

Valli, L. (1990). Moral approaches to reflective practice R. T. Clift, \& W .R. Houston (Eds.). Encouraging reflective practice in education: An analysis of issues and programs (pp. 39-56). New York: Teachers College Press.

van Manen, M. (1977). Linking ways of knowing with ways of being practical. Curriculum Inquiry, $6(3), 205-228$.

van Manen, M. (1991). Reflectivity and the pedagogical moment: The normativity of pedagogical thinking and acting. Journal of Curriculum Studies, $\underline{23}(6), 507-536$.

van Manen, M. (1995). On the epistemology of reflective practice. Teachers and Teaching: Theory into Practice 1(1), 33-50.

Van Wagenen, R. K. (1991). Writing a thesis: Substance and style. Englewood Cliffs, NJ: Prentice Hall Inc. 
Volkman, B. K., Scheffler, A. J., \& Dana, M. E. (1992). Enhancing Preservice teachers' self-efficacy through a field-based aprogram of reflective practice. A paper presented at the 1992 Meeting of the Mid-South Educational Research Association, Knoxville, Tennessee. ED 354232. Walker, L. (1992). Perceptions of preservice teacher efficacy. Paper presented at the Annual Meeting of the Mid-South Educational Research Association (Knoxville,TN, November 11-13, 1992). pp. 1-46. ED 354230.

Walker, C. A., \& Cousins, J. B. (1994). Influences on teachers' attitudes toward applied educational research. Toronto, Canada: Ontario Institute for Studies in Education, pp. 1-30. ED 378155.

Wang, A. Y., \& Richarde, R. S. (1988). Global versus task-specific measures of self-efficacy. The Psychological Report, $\underline{38}, 533-541$.

Wedman, J. M., \& Martin, M. W. (1991). The influence of a reflective student teaching program: An evaluation study. Journal of Research and Development in Education, 24(2), 31-40.

Weiner, B. (1994). Ability versus effort revisited: The moral determinants of achievement evaluation and achievement as a moral system. Educational Psychologist, 29(3), 163-172.

Wildman, T. M., \& Niles, J. A. (1987, February). Essentials of professional growth. Educational Leadership, 44(5), 4-10.

Wildman, T. M., Niles, J. A., Magliaro, S. G., \& McLaughlin, R. A. (1990). Promoting reflective practice among beginning and experienced teachers. In R. T. Clift, \& W .R. Houston (Eds.), Encouraging reflective practice in education: An analysis of issues and programs (pp. 139-162). New York: Teachers College Press. 
Wilson, J. D. (1994). An evaluation of field experiences fro the preparation of elementary teachers for science, mathematics, and technology. Paper presented at the Annual Meeting of the Mid-South Educational Research Association (Nashville, TN, November 9-11). ED 383656.

Wilson, S. M., \& Coolican, M. J. (1996, August). How high and low selfempowered teachers work with colleagues and school principals. Journal of Educational Thought, 30(2), 99-117.

Wong F. K. Y., Kember, D., Chung, L. Y. F., \& Yan, L. (1995). Assessing the level of student reflection from reflective journals. Journal of Advanced Nursing, 22, 48-57.

Wood, R., \& Bandura, A. (1989a). Impact of conceptions of ability on selfregulatory mechanisms and complex decision making. Journal of Personality and Social Psychology, 56(3), 407-415.

Wood, R., \& Bandura, A. (1989b). Social cognitive theory of organizational management. Academy of Management Review, 14(3), 361-384.

Woolfolk, A. E., Rosoff, B., \& Hoy, W. K. (1990). Teachers' sense of efficacy and their beliefs about managing students. Teaching and Teacher Education, $6(2), 137-148$.

Woolfolk, A. E., \& Hoy, W. K. (1990). Prospective teachers' sense of efficacy and beliefs about control. Journal of Educational Psychology, 82(1), 8191.

Yinger, R. J. (1990). The conversation of practice. In R. T. Clift, \& W .R. Houston (Eds.), Encouraging reflective practice in education: An analysis of issues and programs (pp. 73-94). New York: Teachers College Press.

Zahorik, J. A. (1988, March-April). The observing-conferencing role of university supervisors. Journal of Teacher Education, 39(2), 9-16. 
Zeichner, K. M. (1986). Preparing reflective teachers: An overview of instructional strategies which have been employed in preservice teacher education. International Journal of Educational Research, $\underline{11}(5), 565-575$.

Zeichner, K., \& Liston, D. (1987). Teaching student teachers to reflect. Harvard Educational Review, 57(1), 23-48.

Zimmerman, B. J. (1994). Dimensions of academic self-regulation: A conceptual framework for education. In D. H. Schunk, \& B. Zimmerman (Eds.), Self-regulation of learning and performance: Issues and educational applications (pp. 3-21). Hillsdale, NJ: Lawrence Erlbaum Associates, Inc., Publishers. 


\section{A P P E DIX A \\ Personal Teaching Efficacy Scale: \\ Teacher Pretest}




\title{
Personal Teaching Efficacy Scale
}

Our beliefs about our teaching effectiveness often vary depending upon the students we are teaching, the daily situations in our classrooms and schools, and other influences inside and outside the school.

This scale is a snap-shot of teachers' perceptions of their capability to teach well, given their current knowledge, skills, and particular teaching context.

TO ASSURE ANONYMITY, PLEASE DO NOT PUT YOUR NAME ON ANY OF THE PAGES OF THIS SCALE.

\author{
Jan Shields \\ Doctoral Candidate \\ University of San Diego
}




\section{PART ONE}

Consider your CURRENT teaching assignment and your teaching activities over the last week. With these thoughts in mind, please assess your present CONFIDENCE in your ability to do the following teaching tasks, using the scale below.

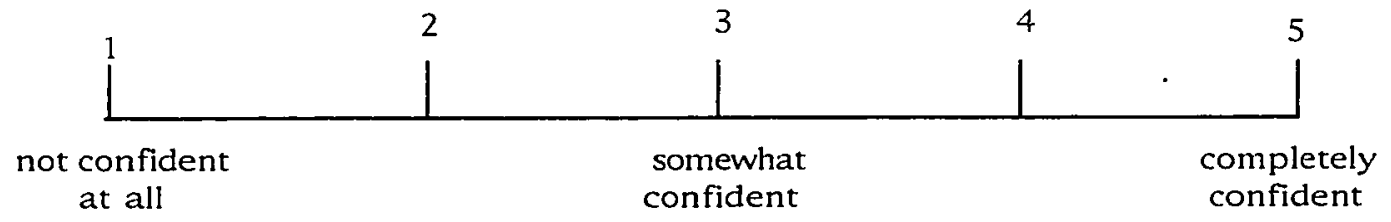

1. I know how to help a student increase his or her retention of lesson information.

2. I can quickly redirect a disruptive student.

3. I am able to get even the most unmotivated students to actively participate in their own learning.

4. I am able to plan effectively to meet the learning objectives of the subjects I teach.

5. I am able to accurately assess the difficulty of an assignment for a particular student.

6. I know how to organize a classroom for various types of learning and activities.

7. I am able to develop a rapport with the students in my class(es).

8. I am able to implement routines for an orderly classroom.

9. I am able to guide a student through the necessary steps to master a new concept.

10. I can create an atmosphere so that students enjoy being in my classes.

11. I am able to adjust the difficulty of an assignment to match the level of particular students.

12. I know how to create interesting learning activities for students to do.

13. I can plan instruction for students in my class who are at various levels of ability or stages of learning. 


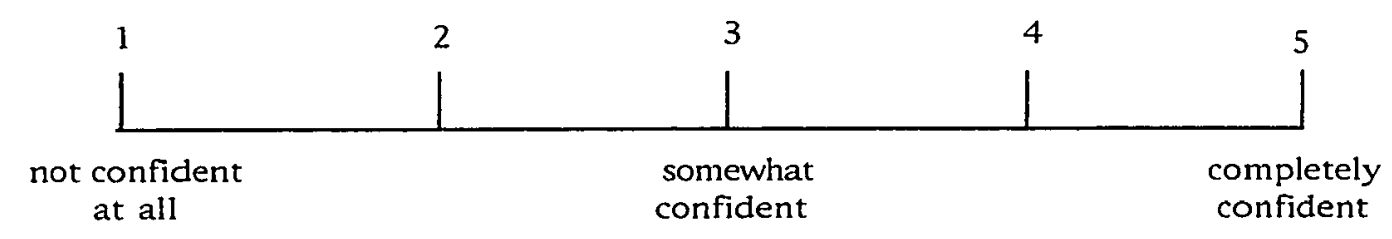

14. I know which teaching strategy is most effective for different kinds of student learning.

15. I am able to acquire new skills that are necessary to teach effectively in particular circumstances.

16. I know how to encourage parents to support their children's learning.

17. I am able to accurately evaluate my students progress.

18. I know my subject matter well and am able to organize it for successful learning.

19. I am able to manage most problems in my classroom.

20. I am able to deal with the diversity of learners in my classroom.

\section{PART TWO}

Again, consider your CURRENT situation and assess your agreement with each of the following statements, using the scale below. If you cannot respond to a particular statement, write NA for not applicable.

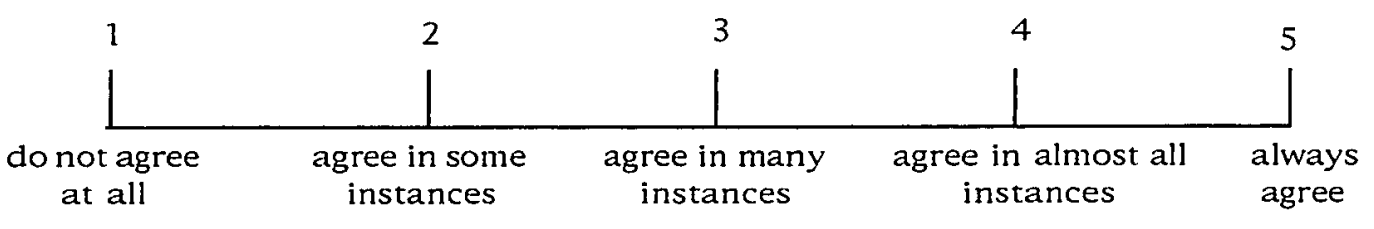

21. It is worth the effort to try to get through to all students.

22. I am not afraid to try new ways of doing things in the classroom, even if they might not work.

23. No matter how hard I try, I will not be able to make a difference with some students. 


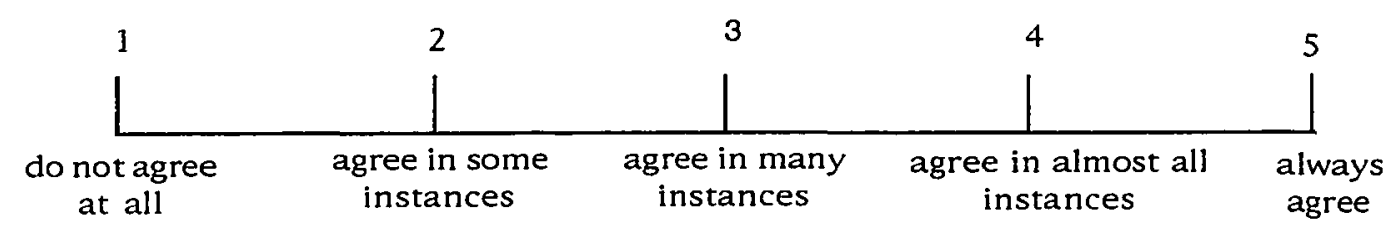

24. When a particular lesson has gone badly, I spend time considering how I might improve it for the next time.

25. I enjoy the challenge of trying to resolve instructional problems in my classroom.

26. I know that I will bounce back after a particularly difficult day.

27. If a lesson is not going the way I would like, I find it difficult to change my plans mid-stream.

28. I worry that I am not an effective teacher.

29. Resolving discipline problems in my classroom is an enjoyable challenge.

30. When I am unable to get through to certain students, I feel less confident about my ability to be an effective teacher.

31. When I am confronted with a particularly difficult teaching problem, I am determined to resolve it no matter how much work or time it takes.

32. I am concerned about what others will say if my students fail.

33. When things are not going well in my classroom, I set out to learn new knowledge and skills that will improve the situation.

34. I know that the effort I put into teaching will have positive results.

35. When I feel tense or fearful in a teaching situation, it is because I believe I do not have the necessary teaching skills.

36. Because of my ability to use effective teaching approaches, students in my class improve their grades.

37. I can help most students to learn regardless of their ability.

38. When students are reluctant to learn, I give them more of my time. 


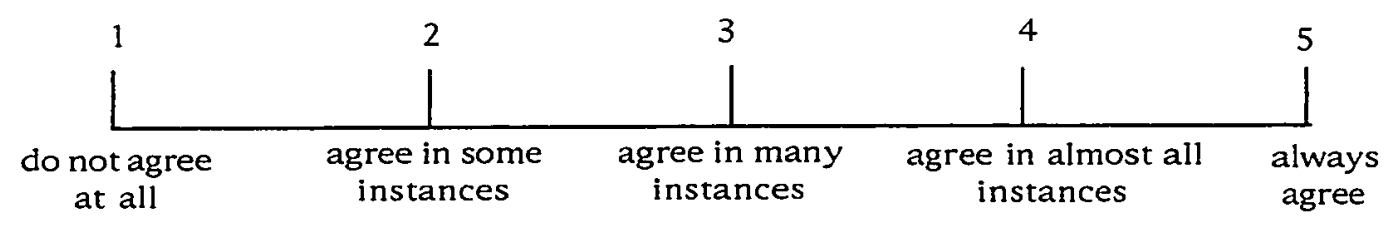

39. The students' home environment has more influence on their ability to achieve than I do as their teacher.

40. When students improve, it is at least partly because of my abilities as a teacher.

41. Others consider me a valued staff member.

42. I am often overwhelmed by the diversity of students in my classroom.

43. I find it difficult to control feelings of tension or fearfulness that sometimes occur in a teaching situation.

44. If one of my students has a personal problem I am able to help the student resolve it.

45. I feel free to organize the classroom in any way I want to make learning more effective.

46. I know how to get the resources I need to teach effectively.

47. I control the decisions that affect my ability to be a good teacher.

48. I take advantage of opportunities to work with other teachers and staff in order to help my students learn.

49. When I'm down on myself, my colleagues give me encouragement.

50. I do not have the resources to teach the way I feel would be most effective.

51. The parents of my student do not really care about their children's academic achievement.

52. I can count on others working with me in the school to help me when I need it.

53. I consider myself an asset to my school. 
PART THREE Demographic Information

Please complete the following by filling in the blanks or checking the appropriate box.

54. Male $\square$ Female $\square$

55. Age:

56. Number of years of teaching experience:

57. I have previously participated in the practicum experience.

Yes $\square$ No $\square$

THANK YOU

FOR COMPLETING

THE TEACHER EFFICACY SCALE 
APPENDIX B

Personal Teaching Efficacy Scale:

Student Teacher Pretest

Reproduced with permission of the copyright owner. Further reproduction prohibited without permission. 


\section{Personal Teaching Efficacy Scale}

Our beliefs about our teaching effectiveness often vary depending upon the students we are teaching, the daily situations in our classrooms and schools, and other influences inside and outside the school.

This scale is a snap-shot of student teachers' perceptions of their capability to teach well, given their current knowledge, skills, and particular teaching contexts.

TO ASSURE ANONYMITY, PLEASE DO NOT PUT YOUR NAME ON ANY OF THE PAGES OF THIS SCALE.

Jan Shields Doctoral Candidate

University of San Diego

0 


\section{PART ONE}

Consider your CURRENT student teaching assignment and your teaching activities over the last week. With these thoughts in mind, please assess your present CONFIDENCE in your ability to do the following teaching tasks, using the scale below.

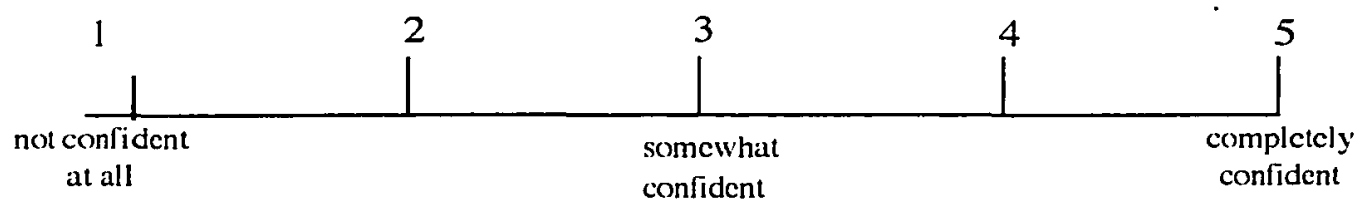

1. I know how to help a student increase his or her retention of lesson information.

2. I can quickly redirect a disruptive student.

3. I am able to get even the most unmotivated students to actively participate in their own learning.

4. I am able to plan effectively to meet the learning objectives of the subjects I teach.

5. I am able to accurately assess the difficulty of an assignment for a particular student.

6. I know how to organize a classroom for various types of learning and activities.

7. I am able to develop a rapport with the students in my class(es).

8. I am able to implement routines for an orderly classroom.

9. I am able to guide a student through the necessary steps to master a new concept.

10. I can create an atmosphere so that students enjoy being in my classes.

11. I am able to adjust the difficulty of an assignment to match the level of particular students.

12. I know how to create interesting learning activities for students to do.

13. I can plan instruction for students in my class who are at various levels of ability or stages of learning. 


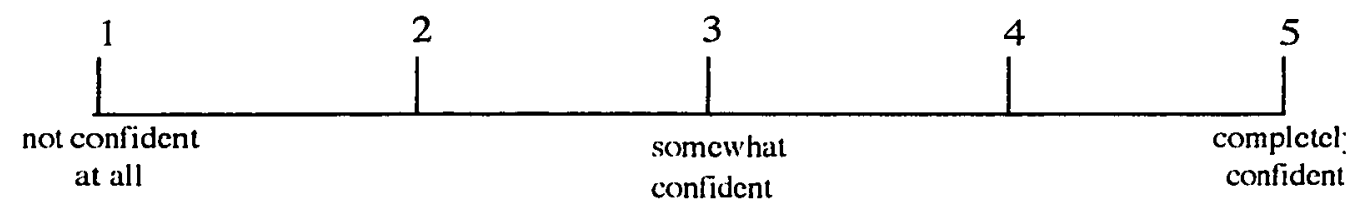

14. I know which teaching strategy is most effective for different kinds of student learning.

15. I am able to acquire new skills that are necessary to teach effectively in particular circumstances.

16. I know how to encourage parents to support their children's learning.

17. I am able to accurately evaluate my students progress.

18. I know my subject matter well and am able to organize it for successful learning.

19. I am able to manage most problems in my classroom.

20. I am able to deal with the diversity of learners in my classroom.

\section{PARTTWO}

Again, consider your CURRENT situation and assess your agreement with each of the following statements, using the scale below. Some statements may apply to situations you have not encountered before. In those cases, respond with your currents beliefs about the way things probably are. If you cannot respond to a particular statement, write NA for not applicable.

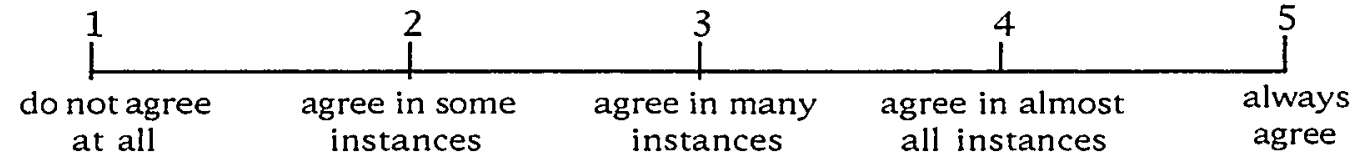

21. It is worth the effort to try to get through to all students.

22. I am not afraid to try new ways of doing things in the classroom, even if they might not work.

23. No matter how hard I try, I will not be able to make a difference with some students. 


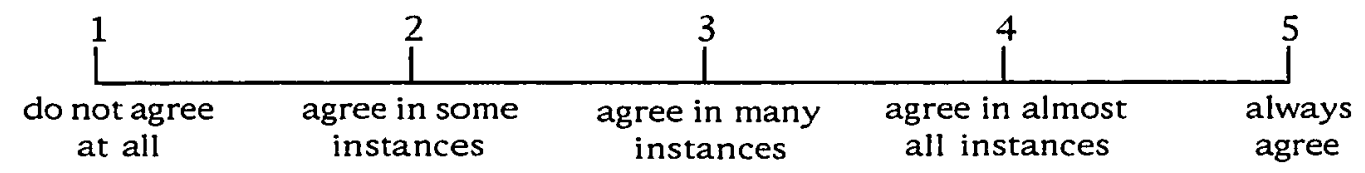

24. When a particular lesson has gone badly, I spend time considering how I might improve it for the next time.

25. I enjoy the challenge of trying to resolve instructional problems in my classroom.

26. I know that I will bounce back after a particularly difficult day.

27. If a lesson is not going the way I would like, I find it difficult to change my plans mid-stream.

28. I worry that I am not an effective teacher.

29. Resolving discipline problems in my classroom is an enjoyable challenge.

30. When I am unable to get through to certain students, I feel less confident about my ability to be an effective teacher.

31. When I am confronted with a particularly difficult teaching problem, 1 am determined to resolve it no matter how much work or time it takes.

32. I am concerned about what others will say if my students fail.

33. When things are not going well in my classroom, I set out to learn new knowledge and skills that will improve the situation.

34. I know that the effort I put into teaching will have positive results.

35. When I feel tense or fearful in a teaching situation, it is because I believe I do not have the necessary teaching skills .

36. Because of my ability to use effective teaching approaches, students in my class improve their grades.

37. I can help most students to learn regardless of their ability.

38. When students are reluctant to learn, I give them more of my time. 


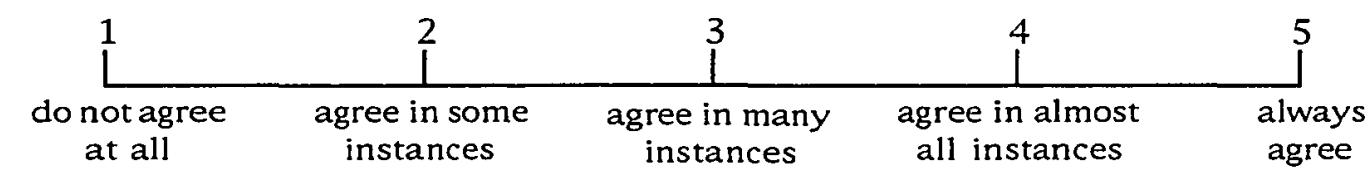

39. The students' home environment has more influence on their ability to achieve than I do as their teacher.

40. When students improve, it is at least partly because of my abilities as a teacher.

41. Others consider me a valued staff member.

42. I am often overwhelmed by the diversity of students in my classroom.

43. I find it difficult to control feelings of tension or fearfulness that sometimes occur in a teaching situation.

44. If one of my students has a personal problem I am able to help the student resolve it.

45. I feel free to organize the classroom in any way I want to make learning more effective.

46. I know how to get the resources I need to teach effectively.

47. I control the decisions that affect my ability to be a good teacher.

48. I take advantage of opportunities to work with other teachers and staff in order to help my students learn.

49. When I'm down on myself, my colleagues give me encouragement.

50. I do not have the resources to teach the way I feel would be most effective.

51. The parents of my student do not really care about their children's academic achievement.

52. I can count on others working with me in the school to help me when I need it.

53. I consider myself an asset to my school. 
PART THREE Demographic Information

Please complete the following by filling in the blanks or checking the appropriate box.

54. Male $\square$ Female $\square$

55. Age:

56. Number of years of teaching experience:

57. I have previously participated in the practicum experience.

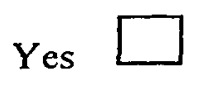

No $\square$

58. I have worked with children:

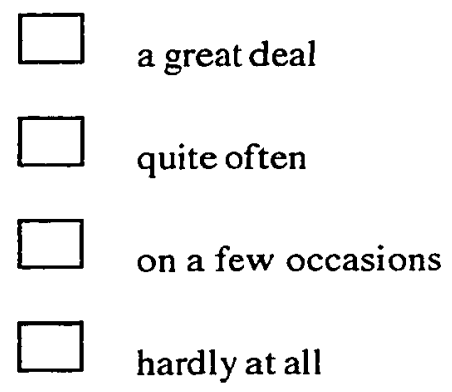

THANK YOU

FOR COMPLETING

THE PERSONAL TEACHING EFFICACY SCALE 


\section{APPENDICES C - F \\ Factor Loadings of Teacher and Student Teacher Pretest and Posttest Data \\ Using the 46-Item Scale and a Varimax Rotation ${ }^{a}$}


Appendix C.1

Teacher Pretest Factors Using the 46-Item Scale

and a Varimax Rotation ${ }^{a}$

Item

Number

FACTORONE

13. I can plan instruction for students in my class who are at various levels of ability or stages of learning.

20. I am able to deal with the diversity of learners in my classroom.

9. I am able to guide a student through the necessary steps to master a new concept.

11. I am able to adjust the difficulty of an assignment to match the level of particular students.

5. I am able to accurately assess the difficulty of an assignment for a particular student.

4 I am able to plan effectively to meet the learning objectives of the

6. I know how to organize a classroom for various types of learning and activities.

12. I know how to create interesting learning activities for students to do.

25. I enjoy the challenge of trying to resolve instructional problems in my classroom.

14. I know which teaching strategy is most effective for different kinds of student learning.

18. I know my subject matter well and am able to organize it for successful learning.

1. I know how to help a student increase his or her retention of lesson information.

17. I am able to accurately evaluate my students progress.

continued on the next page

a Items are presented in the order of factor-loading. 
Appendix C.2

Item

Number

FACTOR ONE (continued)

3. I am able to get even the most unmotivated students to actively participate in their own learning.

15. I am able to acquire new skills that are necessary to teach effectively in particular circumstances.

8. I am able to implement routines for an orderly classroom.

16. I know how to encourage parents to support their children's learning.

Item

Number

\section{FACTORTWO}

7. I am able to develop a rapport with the students in my class(es).

10. I can create an atmosphere so that students enjoy being in my classes.

53. I consider myself an asset to my school.

26. I know that I will bounce back after a particularly difficult day.

19. I am able to manage most problems in my classroom.

Item

Number

FACTOR THREE

37. I can help most students to learn regardless of their ability.

31. When I am confronted with a particularly difficult teaching problem, I am determined to resolve it no matter how much work or time it takes.

36. Because of my ability to use effective teaching approaches, students in my class improve their grades.

40. When students improve, it is at least partly because of my abilities as a teacher.

21. It is worth the effort to try to get through to all students.

continued on the next page 
Appendix C.3

Item

Number

FACTOR FOUR

27. If a lesson is not going the way I would like, I find it difficult to change my plans mid-stream.

48. I take advantage of opportunities to work with other teachers and staff in order to help my students learn.

46. I know how to get the resources I need to teach effectively.

Item

Number

FACTOR FIVE

35. When I feel tense or fearful in a teaching situation, it is because I believe I do not have the necessary teaching skills .

42. I am often overwhelmed by the diversity of students in my classroom.

Item

Number

FACTOR SIX

39. The students' home environment has more influence on their ability to achieve than I do as their teacher.

Item

Number

FACTOR SEVEN

30. When I am unable to get through to certain students, I feel less confident about my ability to be an effective teacher.

34. I know that the effort I put into teaching will have positive results.

Item

Number

FACTOR EIGHT

22. I am not afraid to try new ways of doing things in the classroom, even if they might not work.

38. When students are reluctant to learn, I give them more of my time.

continued on the next page 
Appendix C.4

Item

Number

FACTOR NINE

28. I worry that I am not an effective teacher.

Item

Number

FACTOR TEN

43. I find it difficult to control feelings of tension or fearfulness that sometimes occur in a teaching situation.

32. I am concerned about what others will say if my students fail.

Item

Number

FACTOR ELEVEN

44. If one of my students has a personal problem I am able to help the student resolve it.

2. I can quickly redirect a disruptive student.

Item

Number

FACTOR TWELVE

23. No matter how hard I try, I will not be able to make a difference with some students.

33. When things are not going well in my classroom, I set out to learn new knowledge and skills that will improve the situation.

24. When a particular lesson has gone badly, I spend time considering how I might improve it for the next time.

Item

Number

FACTOR THIRTEEN

29. Resolving discipline problems in my classroom is an enjoyable challenge. 
Appendix D.1

Teacher Posttest Using 46-Item Scale

and a Varimax Rotation ${ }^{a}$

Item

Number

FACTORONE

4. I am able to plan effectively to meet the learning objectives of the subjects I teach.

5. I am able to accurately assess the difficulty of an assignment for a particular student.

9. I am able to guide a student through the necessary steps to master a new concept.

13. I can plan instruction for students in my class who are at various levels of ability or stages of learning.

11. I am able to adjust the difficulty of an assignment to match the level of particular students.

18. I know my subject matter well and am able to organize it for successful learning.

1. I know how to help a student increase his or her retention of lesson information.

17. I am able to accurately evaluate my students progress.

14. I know which teaching strategy is most effective for different kinds of student learning.

20. I am able to deal with the diversity of learners in my classroom.

3. I am able to get even the most unmotivated students to actively participate in their own learning.

12. I know how to create interesting learning activities for students to do.

2. I can quickly redirect a disruptive student.

continued on the next page

a Items are presented in the order of factor-loading. 
Appendix D.2

Item

Number

\section{FACTORTWO}

33. When things are not going well in my classroom, I set out to learn new knowledge and skills that will improve the situation.

48. I take advantage of opportunities to work with other teachers and staff in order to help my students learn.

24. When a particular lesson has gone badly, I spend time considering how I might improve it for the next time.

34. I know that the effort I put into teaching will have positive results.

31. When I am confronted with a particularly difficult teaching problem, I am determined to resolve it no matter how much work or time it takes.

10. I can create an atmosphere so that students enjoy being in my classes.

15. I am able to acquire new skills that are necessary to teach effectively in particular circumstances.

Item

Number FACTOR THREE

6. I know how to organize a classroom for various types of learning and activities.

22. I am not afraid to try new ways of doing things in the classroom, even if they might not work.

25. I enjoy the challenge of trying to resolve instructional problems in my classroom.

19. I am able to manage most problems in my classroom.

Item

Number

FACTOR FOUR

53. I consider myself an asset to my school.

40. When students improve, it is at least partly because of my abilities as a teacher.

26. I know that I will bounce back after a particularly difficult day.

continued on the next page 


\section{Appendix D.3}

Item

Number

FACTOR FIVE

43. I find it difficult to control feelings of tension or fearfulness that sometimes occur in a teaching situation.

42. I am often overwhelmed by the diversity of students in my classroom.

Item

Number

FACTOR SIX

35. When I feel tense or fearful in a teaching situation, it is because I believe I do not have the necessary teaching skills.

44. If one of my students has a personal problem I am able to help the student resolve it.

23. No matter how hard I try, I will not be able to make a difference with some students.

16. I know how to encourage parents to support their children's learning.

Item

Number

FACTOR SEVEN

21. It is worth the effort to try to get through to all students.

46. I know how to get the resources I need to teach effectively.

Item

Number

FACTOR EIGHT

39. The students' home environment has more influence on their ability to achieve than I do as their teacher.

continued on the next page 
Appendix D.4

Item

Number

FACTOR NINE

29. Resolving discipline problems in my classroom is an enjoyable challenge.

37. I can help most students to learn regardless of their ability.

36. Because of my ability to use effective teaching approaches, students in my class improve their grades.

Item

Number

\section{FACTOR TEN}

28. I worry that I am not an effective teacher.

30. When I am unable to get through to certain students, I feel less confident about my ability to be an effective teacher.

7. I am able to develop a rapport with the students in my class(es).

8. I am able to implement routines for an orderly classroom.

Item

Number

FACTOR ELEVEN

38. When students are reluctant to learn, I give them more of my time.

Item

Number

FACTOR TWELVE

27. If a lesson is not going the way I would like, I find it difficult to change my plans mid-stream.

Item

Number

FACTOR THIRTEEN

32. I am concerned about what others will say if my students fail. 
Appendix E.1

\title{
Student Teacher Pretest Using 46-Item Scale \\ and a Varimax Rotation ${ }^{a}$
}

Item

Number

\author{
FACTORONE
}

13. I can plan instruction for students in my class who are at various levels of ability or stages of learning.

11. I am able to adjust the difficulty of an assignment to match the level of particular students.

14. I know which teaching strategy is most effective for different kinds of student learning.

12. I know how to create interesting learning activities for students to do.

16. I know how to encourage parents to support their children's learning.

5. I am able to accurately assess the difficulty of an assignment for a particular student.

17. I am able to accurately evaluate my students progress.

10. I can create an atmosphere so that students enjoy being in my classes.

9. I am able to guide a student through the necessary steps to master a new concept.

1. I know how to help a student increase his or her retention of lesson information.

4 I am able to plan effectively to meet the learning objectives of the subjects I teach.

continued on the next page

a Items are presented in the order of factor-loading. 
Appendix E.2

Item

Number

FACTORTWO

2. I can quickly redirect a disruptive student.

19. I am able to manage most problems in my classroom.

8. I am able to implement routines for an orderly classroom.

7. I am able to develop a rapport with the students in my class(es).

20. I am able to deal with the diversity of learners in my classroom.

15. I am able to acquire new skills that are necessary to teach effectively in particular circumstances.

Item

Number

\section{FACTOR THREE}

24. When a particular lesson has gone badly, I spend time considering how I might improve it for the next time.

33. When things are not going well in my classroom, I set out to learn new knowledge and skills that will improve the situation.

48. I take advantage of opportunities to work with other teachers and staff in order to help my students learn.

25. I enjoy the challenge of trying to resolve instructional problems in my classroom.

31. When I am confronted with a particularly difficult teaching problem, I am determined to resolve it no matter how much work or time it takes.

53. I consider myself an asset to my school. 
Appendix E.3

Item

Number

FACTOR FOUR

43. I find it difficult to control feelings of tension or fearfulness that sometimes occur in a teaching situation.

27. If a lesson is not going the way I would like, I find it difficult to change my plans mid-stream.

32. I am concerned about what others will say if my students fail.

30. When I am unable to get through to certain students, I feel less confident about my ability to be an effective teacher.

Item

Number

FACTOR FIVE

21. It is worth the effort to try to get through to all students.

38. When students are reluctant to learn, I give them more of my time.

37. I can help most students to learn regardless of their ability.

40. When students improve, it is at least partly because of my abilities as a teacher.

Item

Number

FACTOR SIX

36. Because of my ability to use effective teaching approaches, students in my class improve their grades.

44. If one of my students has a personal problem I am able to help the student resolve it.

Item

Number

FACTOR SEVEN

39. The students' home environment has more influence on their ability to achieve than I do as their teacher.

46. I know how to get the resources I need to teach effectively.

continued on the next page 
Appendix E.4

Item

Number

FACTOR EIGHT

28. I worry that I am not an effective teacher.

6. I know how to organize a classroom for various types of learning and activities.

Item

Number

FACTOR NINE

23. No matter how hard I try, I will not be able to make a difference with some students.

42. I am often overwhelmed by the diversity of students in my classroom.

Item

Number

FACTOR TEN

26. I know that I will bounce back after a particularly difficult day.

18. I know my subject matter well and am able to organize it for successful learning.

3. I am able to get even the most unmotivated students to actively participate in their own learning.

Item

Number

FACTOR ELEVEN

29. Resolving discipline problems in my classroom is an enjoyable challenge

Item

Number

FACTOR TWELVE

22. I am not afraid to try new ways of doing things in the classroom, even if they might not work.

Item

Number

FACTOR THIRTEEN

35. When I feel tense or fearful in a teaching situation, it is because I believe I do not have the necessary teaching skills .

Item

Number

FACTOR FOURTEEN

34. I know that the effort I put into teaching will have positive results. 
Appendix F. 1

\section{Student Teacher Posttest Using the 46-Item Scale \\ and a Varimax Rotation ${ }^{a}$}

Item

Number

FACTORONE

18. I know my subject matter well and am able to organize it for successful learning.

5. I am able to accurately assess the difficulty of an assignment for a particular student.

4. I am able to plan effectively to meet the learning objectives of the subjects I teach.

11. I am able to adjust the difficulty of an assignment to match the level of particular students.

46. I know how to get the resources I need to teach effectively.

9. I am able to guide a student through the necessary steps to master a new concept.

12. I know how to create interesting learning activities for students to do.

6. I know how to organize a classroom for various types of learning and activities.

20. I am able to deal with the diversity of learners in my classroom.

Item

Number

\section{FACTORTWO}

8. I am able to implement routines for an orderly classroom.

19. I am able to manage most problems in my classroom.

16. I know how to encourage parents to support their children's learning.

continued on the next page

a Items are presented in the order of factor-loading. 
Appendix F.2

Item

Number

FACTOR TWO (continued)

17. I am able to accurately evaluate my students progress.

14. I know which teaching strategy is most effective for different kinds of student learning.

10. I can create an atmosphere so that students enjoy being in my classes.

Item

Number

FACTOR THREE

30. When I am unable to get through to certain students, I feel less confident about my ability to be an effective teacher.

28. I worry that I am not an effective teacher.

35. When I feel tense or fearful in a teaching situation, it is because I believe I do not have the necessary teaching skills .

32. I am concerned about what others will say if my students fail.

27. If a lesson is not going the way I would like, I find it difficult to change my plans mid-stream.

Item

Number

FACTOR FOUR

37. I can help most students to learn regardless of their ability.

33. When things are not going well in my classroom, I set out to learn new knowledge and skills that will improve the situation.

48. I take advantage of opportunities to work with other teachers and staff in order to help my students learn.

13. I can plan instruction for students in my class who are at various levels of ability or stages of learning.

36. Because of my ability to use effective teaching approaches, students in my class improve their grades.

Continued on the next page 


\section{Appendix F.3}

Item

Number

FACTOR FIVE

42. I am often overwhelmed by the diversity of students in my classroom.

39. The students' home environment has more influence on their ability to achieve than I do as their teacher.

43. I find it difficult to control feelings of tension or fearfulness that sometimes occur in a teaching situation.

Item

Number

FACTOR6

34. I know that the effort I put into teaching will have positive results.

26. I know that I will bounce back after a particularly difficult day.

44. If one of my students has a personal problem I am able to help the student resolve it.

25. I enjoy the challenge of trying to resolve instructional problems in my classroom.

Item

Number

FACTOR 7

2. I can quickly redirect a disruptive student.

3. I am able to get even the most unmotivated students to actively participate in their own learning.

21. It is worth the effort to try to get through to all students.

Item

Number

FACTOR 8

23. No matter how hard I try, I will not be able to make a difference with some students.

7. I am able to develop a rapport with the students in my class(es).

Continued on the next page 
Appendix F.4

Item

Number

FACTOR 9

31. When I am confronted with a particularly difficult teaching problem, I am determined to resolve it no matter how much work or time it takes.

38. When students are reluctant to learn, I give them more of my time.

22. I am not afraid to try new ways of doing things in the classroom, even if they might not work.

Item

Number

FACTOR 10

40. When students improve, it is at least partly because of my abilities as a teacher.

29. Resolving discipline problems in my classroom is an enjoyable challenge.

Item

Number

FACTOR 11

24. When a particular lesson has gone badly, I spend time considering how I might improve it for the next time.

15. I am able to acquire new skills that are necessary to teach effectively in particular circumstances.

1. I know how to help a student increase his or her retention of lesson information.

53. I consider myself an asset to my school. 